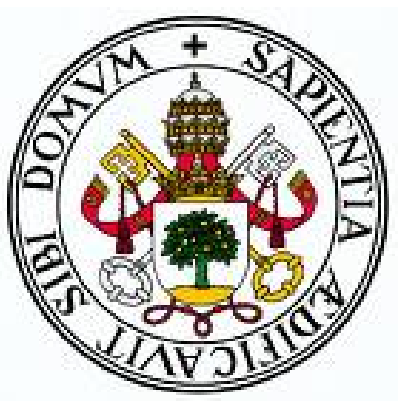

UNIVERSIDAD DE VALLADOLID

Departamento de Didáctica de las CCSS y de las CCEE

\title{
PROPORCIONALIDAD ARITMÉTICA: UNA PROPUESTA DIDÁCTICA PARA ALUMNOS DE SECUNDARIA
}

TESIS DOCTORAL

Antonio M. Oller Marcén

Valladolid, marzo de 2012 

Memoria presentada para optar al grado de Doctor por la Universidad de Valladolid por el licenciado en la Universidad de Zaragoza, D. Antonio M. Oller Marcén, en el Programa de Doctorado: Investigación en Didáctica de las Ciencias Sociales, Experimentales, y de la Matemática.

Directores de la Tesis:

Dr. José María Gairín Sallán. Departamento de Matemáticas. Universidad de Zaragoza.

Dr. Tomás Ortega del Rincón. Departamento de Didáctica de las CCSS y de las CCEE. Universidad de Valladolid. 
Esta tesis ha sido desarrollada en el marco del proyecto $\mathrm{I}+\mathrm{D}+\mathrm{i}$, EDU2009-12063, del Ministerio de Ciencia e Innovación. 
TOMÁS ORTEGA DEL RINCÓN, CAUN de Didáctica de la Matemática de la Universidad de Valladolid,

\section{CERTIFICA:}

Que la presente memoria, Proporcionalidad aritmética: una propuesta didáctica para alumnos de Secundaria, ha sido realizada por Don Antonio M. Oller Marcén bajo la dirección de José María Gairín Sallán y de Tomás Ortega del Rincón en la Universidad de Zaragoza y la Universidad de Valladolid, respectivamente.

Valladolid, marzo de 2012.

Fdo.: Tomás Ortega del Rincón 

Para Ruth 

Veritatis simplex oratio est.

(Séneca)

La frase de Séneca que hemos situado en el encabezamiento motiva gran parte del trabajo que hemos realizado. Si la Matemática encierra - o pretende encerrar aquello que de verdadero tiene nuestro cambiante mundo, no vemos el motivo para que el lenguaje que utilice sea complicado y difícil de entender. Sin embargo, a menudo, encontramos que los textos de Matemáticas, incluso los escolares, parecen perseguir un objetivo distinto; añadiendo a la relativa dificultad de los conceptos que se manejan, la necesidad de memorizar nombres, técnicas y procedimientos que para los alumnos son poco menos que trucos de magia.

Estamos convencidos de que esto no debe ser así. Pensamos que gran parte de la Matemática escolar puede fundamentarse en base a ideas claras y sencillas. En el caso de la Proporcionalidad aritmética esas ideas son las estructuras multiplicativas de los naturales y racionales positivos y el manejo de las magnitudes. A partir de ahí podremos construir todos los conceptos importantes relativos a la Proporcionalidad. Esta es, concretamente, la tarea que pretendemos iniciar con este trabajo.

Hay muchas personas que merecen nuestro agradecimiento. El Departamento de Matemáticas del I.E.S. Avempace de Zaragoza por su colaboración durante la implementación de la propuesta didáctica diseñada. Tomás Ortega, por prestarse a codirigir este trabajo y posibilitar su defensa en la Universidad de Valladolid. José María Gairín por su apoyo y motivación, por “acogerme” en un momento complicado y por haberme brindado la posibilidad de desarrollar esta investigación. También quiero agradecer a José María Muñoz su apoyo y las muchas conversaciones (matemáticas, didácticas y “profanas”) que hemos mantenido a lo largo de los años.

No puedo ni quiero olvidar tampoco a mi familia, los que están y los que ya no están, porque sin lo que me han enseñado (más importante que cualquier cosa que haya leído en un libro) no podría haber alcanzado las metas que me he ido proponiendo.

Y por supuesto, aunque ya le haya sido dedicado este trabajo, las últimas líneas son para Ruth. Gracias por acompañarme - espero - todos los días de mi vida. 



\section{ÍNDICE GENERAL}

\section{Capítulo I: El problema de investigación}

I.1. Introducción 1

I.2. Problemas y dificultades en el manejo de la proporcionalidad 3

I.3. Algunas deficiencias de la práctica educativa habitual 5

I.4. Aspectos metodológicos de la investigación 9

I.4.1. Fases de la investigación-Acción $\quad 10$

I.4.1.1. Fase de planificación $\quad 11$

I.4.1.2. Fase de acción 12

I.4.1.3. Fase de observación 13

I.4.1.4. Fase de reflexión 13

I.4.1.5. Fases de la Investigación-Acción y Análisis Didáctico 14

I.4.2. Focos de investigación 14

I.4.2.1. Primer foco de investigación: razón y condición de regularidad 14

I.4.2.2. Segundo foco de investigación: proporcionalidad

$\begin{array}{ll}\text { I.4.2.3. Tercer foco de investigación: proporcionalidad } & \\ \text { inversa } & 14\end{array}$

I.4.3. El análisis de errores 15

$\begin{array}{lll}\text { I.5. } & \text { Revisión bibliográfica } & 16\end{array}$

$\begin{array}{lll}\text { I.6. } & \text { Objetivos del trabajo } & 20\end{array}$

$\begin{array}{lll}\text { I.7. } & \text { Plan de la obra } & 21\end{array}$

I.7.1. Capítulo II: Estudio histórico sobre la Proporcionalidad aritmética 22

I.7.2. Capítulo III: Características de la enseñanza tradicional 22

I.7.3 Capítulos IV, V y VI: Diseño y experimentación de la propuesta

I.7.4. Capítulo VII: Conclusiones 23 


\section{Capítulo II: Fenomenología y epistemología de la Proporcionalidad aritmética desde un punto de vista histórico}

II.1. Introducción $\quad 25$

II.2. Marco espacio-temporal y fuentes revisadas 25

II.3. Sobre aspectos conceptuales $\quad 29$

II.3.1. Razón y proporción en los Elementos $\quad 30$

II.3.2 Proporcionalidad en el Jiu Zhang suan shu 33

II.3.3. Comparando ambos enfoques 36

II.3.4. La aritmetización de las razones 37

II.3.4.1 Los comentarios de Ommar al-Khayyam a los Elementos de Euclides 38

II.3.4.2 Campano y la denominación de una razón 39

II.3.5 La fundamentación y el simbolismo 40

II.4. Sobre la tipología de problemas $\quad 42$

II.4.1. Problemas relacionados con intercambios 44

II.4.1.1. Intercambios de mercancías $\quad 44$

II.4.1.2. Compra-venta $\quad 45$

II.4.1.3. Cambio de divisas $\quad 46$

II.4.2. Problemas relacionados con repartos 47

II.4.3. Problemas relacionados con préstamos 50

II.4.4. Problemas relacionados con mezclas y aleaciones 51

II.4.5. Problemas en otras situaciones 52

II.5. Sobre técnicas de resolución $\quad 54$

II.5.1. Devenir histórico de la Regla de tres 54

II.5.2. El uso de la regla de tres simple directa 57

II.5.3. Técnicas para la proporcionalidad inversa $\quad 60$

II.5.4. Técnicas para la proporcionalidad compuesta 62

II.5.5. Las reglas de falsa posición $\quad 64$

II.6. Implicaciones para la enseñanza de la Proporcionalidad aritmética 66

\section{Capítulo III: Tratamiento educativo de la Proporcionalidad aritmética}

III.1. Introducción $\quad 69$

III.2. S Significados sobre Proporcionalidad aritmética desde 1850 hasta la actualidad 
$\begin{array}{lll}\text { III.2.1. } & \text { Método } & 70\end{array}$

$\begin{array}{lll}\text { III.2.2. } & \text { Resultados } & 72\end{array}$

$\begin{array}{lll}\text { III.2.2.1. } & \text { Razón y proporción } & 72\end{array}$

$\begin{array}{lll}\text { III.2.2.2. } & \text { Proporcionalidad directa } & 75\end{array}$

$\begin{array}{lll}\text { III.2.2.3. } & \text { Proporcionalidad inversa }\end{array}$

III.2.2.4. Búsqueda de cantidades desconocidas en proporcionalidad simple $\quad 82$

III.2.2.5. Proporcionalidad compuesta 86

III.2.2.6. Búsqueda de cantidades desconocidas en situaciones de proporcionalidad compuesta $\quad 87$

$\begin{array}{lll}\text { III.2.2.7. Aplicaciones } & 89\end{array}$

$\begin{array}{lll}\text { III.2.3. Reflexiones } & 96\end{array}$

III.3. Análisis de la enseñanza actual de la proporcionalidad $\quad 97$

III.3.1. Secuenciación de los contenidos y espacio dedicado 98

$\begin{array}{lll}\text { III.3.2. Metodología } & 104\end{array}$

$\begin{array}{ll}\text { III.3.3. } & \text { Modelos de aprendizaje } \\ \end{array}$

$\begin{array}{ll}\text { III.3.4. Sistemas de representación } & 108\end{array}$

$\begin{array}{ll}\text { III.3.5. Significados que se construyen } & 109\end{array}$

\begin{tabular}{ll} 
III.3.6. & Resolución de problemas \\
\hline
\end{tabular}

$\begin{array}{lll}\text { III.3.7. } & \text { Reflexiones } & 122\end{array}$

\section{Capítulo IV: Fase de planificación}

$\begin{array}{lll}\text { IV.1. Introducción } & 125\end{array}$

IV.2. Ideas en las que se sustenta la propuesta $\quad 126$

$\begin{array}{ll}\text { IV.2.1. Ideas relativas a aspectos conceptuales } & 126\end{array}$

$\begin{array}{ll}\text { IV.2.2. Ideas relativas a aplicaciones prácticas } & 129\end{array}$

IV.3. La propuesta didáctica $\quad 131$

IV.3.1. La razón 132

IV.3.1.1. Aspectos matemáticos y de la enseñanza tradicional 132

$\begin{array}{lll}\text { IV.3.1.2. Propuesta alternativa } & 133\end{array}$

IV.3.2. Magnitudes directamente proporcionales 141

IV.3.2.1. Aspectos matemáticos y de la enseñanza tradicional 141

$\begin{array}{lll}\text { IV.3.2.2. Propuesta alternativa } & 143\end{array}$

$\begin{array}{lll}\text { IV.3.3. Porcentajes } & 148\end{array}$ 
IV.3.3.1. Aspectos matemáticos y de la enseñanza tradicional 148

$\begin{array}{lll}\text { IV.3.3.2 Propuesta alternativa } & 148\end{array}$

IV.3.4. Repartos respecto a una única magnitud 155

IV.3.4.1. Aspectos matemáticos y de la enseñanza tradicional 155

$\begin{array}{lll}\text { IV.3.4.2. Propuesta alternativa } & 157\end{array}$

$\begin{array}{lll}\text { IV.3.5. } & \text { Magnitudes inversamente proporcionales } & 160\end{array}$

IV.3.5.1. Aspectos matemáticos y de la enseñanza tradicional 160

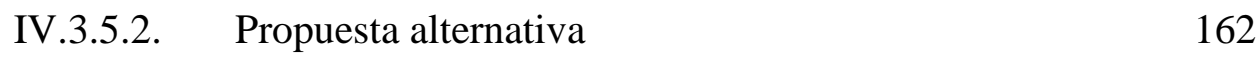

$\begin{array}{lll}\text { IV.3.6. } & \text { Mezclas y aleaciones } & 167\end{array}$

IV.3.6.1. Aspectos matemáticos y de la enseñanza tradicional 167

$\begin{array}{lll}\text { IV.3.6.2. } & \text { Propuesta alternativa } & 167\end{array}$

$\begin{array}{lll}\text { IV.3.7. } & \text { Proporcionalidad compuesta } & 168\end{array}$

IV.3.7.1. Aspectos matemáticos y de la enseñanza tradicional 168

$\begin{array}{lll}\text { IV.3.7.2. } & \text { Propuesta alternativa } & 169\end{array}$

$\begin{array}{lll}\text { IV.3.8. } & \text { Regla de interés } & 171\end{array}$

IV.3.8.1. Aspectos matemáticos y de la enseñanza tradicional $\quad 171$

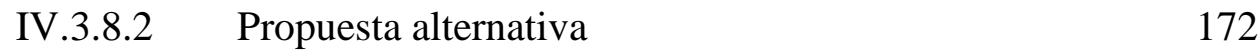

$\begin{array}{lll}\text { IV.3.9. } & \text { Repartos respecto a varias magnitudes } & 174\end{array}$

IV.3.9.1. Aspectos matemáticos y de la enseñanza tradicional 174

IV.3.9.2. Propuesta alternativa $\quad 174$

\section{Capítulo V: Fase de acción}

$\begin{array}{lll}\text { V.1. Introducción } & 177\end{array}$

$\begin{array}{lll}\text { V.2. } & \text { Planificación de la fase de acción } & 177\end{array}$

$\begin{array}{lll}\text { V.2.1. Participantes } & 178\end{array}$

$\begin{array}{ll}\text { V.2.2. Temporalización } & 178\end{array}$

$\begin{array}{ll}\text { V.2.3. Secuenciación } & 179\end{array}$

V.3. Actividades y tareas diseñadas para el trabajo de los alumnos 183

V.3.1. Actividad de aula 1: Introducción del concepto de razón 183

V.3.1.1. Objetivos 183

V.3.1.2. Contenidos 183

V.3.1.3 Metodología 183

$\begin{array}{lll}\text { V.3.1.4. Evaluación } & 185\end{array}$

V.3.2. Tarea de casa 1: Intercambio en la otra dirección 185 
$\begin{array}{lll}\text { V.3.2.1. Objetivos } & 186\end{array}$

$\begin{array}{lll}\text { V.3.2.2. Contenidos } & 187\end{array}$

$\begin{array}{lll}\text { V.3.2.3 Metodología } & 187\end{array}$

$\begin{array}{lll}\text { V.3.2.4. Evaluación } & 187\end{array}$

$\begin{array}{lll}\text { V.3.3. Actividad de aula 2: La condición de regularidad } & 187\end{array}$

$\begin{array}{lll}\text { V.3.3.1. Objetivos } & 188\end{array}$

$\begin{array}{lll}\text { V.3.3.2. Contenidos } & 188\end{array}$

$\begin{array}{lll}\text { V.3.3.3 Metodología } & 189\end{array}$

$\begin{array}{lll}\text { V.3.3.4. Evaluación } & 190\end{array}$

V.3.4. Actividad de aula 3: Comparar razones en situaciones de $\begin{array}{ll}\text { intercambio } & 190\end{array}$

$\begin{array}{lll}\text { V.3.4.1. Objetivos } & 191\end{array}$

$\begin{array}{lll}\text { V.3.4.2. Contenidos } & 191\end{array}$

$\begin{array}{lll}\text { V.3.4.3 Metodología } & 191\end{array}$

$\begin{array}{lll}\text { V.3.4.4. Evaluación } & 192\end{array}$

V.3.5. Tarea de casa 2: Reconocimiento de condiciones de regularidad y razones 182

$\begin{array}{lll}\text { V.3.5.1. Objetivos } & 193\end{array}$

V.3.5.2. Contenidos 193

$\begin{array}{lll}\text { V.3.5.3 Metodología } & 194\end{array}$

$\begin{array}{lll}\text { V.3.5.4. Evaluación } & 195\end{array}$

V.3.6. Actividad de aula 4: Reconocer magnitudes directamente $\begin{array}{ll}\text { proporcionales } & 195\end{array}$

$\begin{array}{lll}\text { V.3.6.1. Objetivos } & 196\end{array}$

$\begin{array}{lll}\text { V.3.6.2. Contenidos } & 196\end{array}$

$\begin{array}{lll}\text { V.3.6.3 Metodología } & 196\end{array}$

$\begin{array}{lll}\text { V.3.6.4. } & \text { Evaluación } & 198\end{array}$

V.3.7. Tarea de casa 3: Comparación de razones en situaciones
cualesquiera

V.3.7.1. Objetivos 199

$\begin{array}{lll}\text { V.3.7.2. Contenidos } & 199\end{array}$

$\begin{array}{lll}\text { V.3.7.3 Metodología } & 19\end{array}$

$\begin{array}{ll}\text { V.3.7.4. Evaluación } & 201\end{array}$

V.3.8. Actividad de aula 5: búsqueda de cantidades desconocidas en
situaciones de proporcionalidad directa 
$\begin{array}{lll}\text { V.3.8.1. Objetivos } & 202\end{array}$

$\begin{array}{lll}\text { V.3.8.2. Contenidos } & 202\end{array}$

V.3.8.3 Metodología 202

$\begin{array}{lll}\text { V.3.8.4. Evaluación } & 204\end{array}$

V.3.9. Tarea de casa 4: búsqueda de cantidades desconocidas en situaciones de proporcionalidad directa 204

V.3.9.1. Objetivos 205

V.3.9.2. Contenidos 205

$\begin{array}{lll}\text { V.3.9.3 Metodología } 205 & 205\end{array}$

$\begin{array}{lll}\text { V.3.9.4. Evaluación } & 207\end{array}$

V.3.10. Actividad de aula 6: Porcentajes 207

$\begin{array}{lll}\text { V.3.10.1. Objetivos } & 208\end{array}$

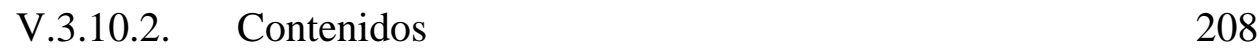

$\begin{array}{lll}\text { V.3.10.3 Metodología } 208 & 208\end{array}$

$\begin{array}{lll}\text { V.3.10.4. Evaluación } & 210\end{array}$

$\begin{array}{lll}\text { V.3.11. Tarea de casa 5: Porcentajes } & 210\end{array}$

$\begin{array}{lll}\text { V.3.11.1. Objetivos } & 211\end{array}$

$\begin{array}{lll}\text { V.3.11.2. Contenidos } & 211\end{array}$

$\begin{array}{lll}\text { V.3.11.3 Metodología } & 211\end{array}$

$\begin{array}{lll}\text { V.3.11.4. Evaluación } & 213\end{array}$

V.3.12. Tarea de casa 6: Reconocimiento de condiciones de regularidad y razones II 213

$\begin{array}{lll}\text { V.3.12.1. Objetivos } & 214\end{array}$

$\begin{array}{lll}\text { V.3.12.2. Contenidos } & 215\end{array}$

$\begin{array}{lll}\text { V.3.12.3 Metodología } & 215\end{array}$

$\begin{array}{lll}\text { V.3.12.4. Evaluación } & 216\end{array}$

V.3.13. Actividad de aula 7: Reconocer magnitudes inversamente $\begin{array}{ll}\text { proporcionales } & 217\end{array}$

$\begin{array}{lll}\text { V.3.13.1. Objetivos } & 217\end{array}$

$\begin{array}{lll}\text { V.3.13.2. Contenidos } & 217\end{array}$

$\begin{array}{lll}\text { V.3.13.3 Metodología } & 218\end{array}$

$\begin{array}{lll}\text { V.3.13.4. Evaluación } & 219\end{array}$ $\begin{array}{ll}\text { V.3.14. } & \text { Actividad de aula 8: Búsqueda de cantidades desconocidas en } \\ \text { situaciones de proporcionalidad inversa } & 219\end{array}$

$\begin{array}{lll}\text { V.3.14.1. Objetivos } & 220\end{array}$ 
V.3.14.2. Contenidos 220

$\begin{array}{lll}\text { V.3.14.3 Metodología } & 221\end{array}$

$\begin{array}{lll}\text { V.3.14.4. Evaluación } & 222\end{array}$

V.3.15. Tarea de casa 7: Búsqueda de cantidades desconocidas en situaciones de proporcionalidad inversa 222

V.3.15.1. Objetivos 223

V.3.15.2. Contenidos 223

V.3.15.3 Metodología 223

V.3.15.4. Evaluación 225

V.4. Desarrollo de las sesiones 225

$\begin{array}{lll}\text { V.4.1. Sesión } 1 & 225\end{array}$

V.4.2. Sesión $2 \quad 226$

$\begin{array}{lll}\text { V.4.3. Sesión } 3 & 226\end{array}$

$\begin{array}{lll}\text { V.4.4. Sesión } 4 & 227\end{array}$

$\begin{array}{lll}\text { V.4.5. Sesión } 5 & 227\end{array}$

$\begin{array}{lll}\text { V.4.6. Sesión } 6 & 228\end{array}$

$\begin{array}{lll}\text { V.4.7. Sesión } 7 & 228\end{array}$

$\begin{array}{lll}\text { V.4.8. Sesión } 8 & 229\end{array}$

$\begin{array}{lll}\text { V.4.9. Sesión } 9 & 229\end{array}$

$\begin{array}{lll}\text { V.4.10. Sesión } 10 & 229\end{array}$

$\begin{array}{lll}\text { V.4.11. Sesión } 11 & 230\end{array}$

\section{Capítulo VI: Observación y reflexión}

VI.1. Introducción 231

VI.1.1. Unidades de análisis 232

VI.1.1.1. Unidades para el primer foco de investigación 232

VI.1.1.2. Unidades para el segundo foco de investigación 236

VI.1.1.3. Unidades para el tercer foco de investigación 238

VI.1.2. Errores de los alumnos en la prueba final 241

VI.2. Observación y reflexión del primer foco de investigación 243

VI.2.1. Punto 1: El concepto de razón 243

VI.2.1.1. Análisis y valoración de la Actividad de aula $1 \quad 243$

VI.2.1.2. Análisis y valoración de la Tarea de casa 1

VI.2.1.3. Reflexiones relativas al punto $1 \quad 270$ 
$\begin{array}{lll}\text { VI.2.2. } & \text { Punto 2: La condición de regularidad } & 274\end{array}$

VI.2.2.1. Análisis y valoración de la Actividad de aula 2

$\begin{array}{lll}\text { VI.2.2.2. } & \text { Reflexiones relativas al punto } 2 & 284\end{array}$

VI.2.3. Punto 3: Comparar razones 285

VI.2.3.1 Análisis y valoración de la Actividad de aula $3 \quad 285$

VI.2.3.2 Análisis y valoración de la Tarea de casa 3

VI.2.3.3. Reflexiones relativas al punto $3 \quad 308$

VI.2.4. Punto 4: Análisis de situaciones 309

VI.2.4.1. Análisis y valoración de la Tarea de casa 2

$\begin{array}{lll}\text { VI.2.4.2. } & \text { Reflexiones relativas al punto } 4 & 324\end{array}$

VI.3. Observación y reflexión del segundo foco de investigación 325

VI.3.1. Punto 1: Reconocimiento y distinción de magnitudes directamente $\begin{array}{ll}\text { proporcionales } & 326\end{array}$

VI.3.1.1. Análisis y valoración de la Actividad de aula $4 \quad 326$

VI.3.1.2. Reflexiones relativas al punto $1 \quad 336$

VI.3.2. Punto 2: Búsqueda de cantidades desconocidas 337

VI.3.2.1. Análisis y valoración de la Actividad de aula 5

VI.3.2.2. $\quad$ Análisis y valoración de la Tarea de casa 4

VI.3.2.3 Reflexiones relativas al punto 2

$\begin{array}{lll}\text { VI.3.3. } & \text { Punto 3: Porcentajes } & 364\end{array}$

VI.3.3.1. Análisis y valoración de la Actividad de aula $6 \quad 364$

VI.3.3.2. $\quad$ Análisis y valoración de la Tarea de casa 5

VI.3.3.3. Reflexiones relativas al punto $3 \quad 402$

VI.4. Observación y reflexión del tercer foco de investigación 403

VI.4.1. Punto 1: Análisis de situaciones 403

VI.4.1.1. Análisis y valoración de la Tarea de casa $6 \quad 404$

VI.4.1.2. Reflexiones relativas al punto $1 \quad 416$

VI.4.2. Punto 3: Búsqueda de cantidades desconocidas 417

VI.4.2.1. Análisis y valoración de la Actividad de aula $8 \quad 417$

VI.4.2.2. Análisis y valoración de la Tarea de casa $7 \quad 426$

VI.4.2.3. Reflexiones relativas al punto $3 \quad 440$

VI.5. Observación y reflexión de la prueba final $\quad 441$ 


\section{Capítulo VII: Conclusiones}

VII.1. Introducción 477

VII.2. Conclusiones sobre la comprensión de los contenidos 478

VII.2.1. Uso significativo de las estructuras multiplicativas 478

VII.2.2. Aprehensión de aspectos conceptuales 480

VII.2.2.1. Las ideas de ‘razón’ y de ‘condición de regularidad’ 481

VII.2.2.2. El porcentaje 483

VII.2.2.3. El concepto de magnitudes proporcionales 483

VII.2.2.4. Conclusiones sobre la propuesta 485

VII.2.3. Resolución de problemas 486

VII.2.3.1. Problemas relativos a porcentajes 486

VII.2.3.2. Búsqueda de cantidades desconocidas $\quad 487$

VII.3. Herencias e influencias 488

VII.4. Encuesta final plateada a los alumnos 491

VII.4.1. Análisis de las preguntas orientadas a conocer la opinión del alumno sobre el desarrollo de las clases y la forma de trabajar 492

VII.4.2. Análisis de las preguntas orientadas a conocer la opinión del alumno acerca del interés y la utilidad de los contenidos trabajados

VII.4.3. Análisis de las preguntas orientadas a conocer la actitud del alumno hacia la asignatura de matemáticas

VII.4.4. Análisis de las preguntas orientadas a descubrir la ayuda externa recibida por los alumnos

$\begin{array}{ll}\text { VII.5. } & \text { Perspectivas de futuro }\end{array}$

$\begin{array}{ll}\text { Referencias Bibliográficas } & 501\end{array}$

Anexo I: Diario de clase 515

Anexo II: Material para los alumnos 


\section{CAPÍTULO I:}

\section{EL PROBLEMA DE INVESTIGACIÓN.}

\section{I.1. INTRODUCCIÓN}

Nos proponemos realizar una investigación en Didáctica de la Matemática, en el ámbito de la innovación y el desarrollo curricular en Educación Secundaria, sobre un tópico concreto: la proporcionalidad aritmética.

La enseñanza actual de la proporcionalidad aritmética, como gran parte de la instrucción, se basa en la adquisición de una serie de destrezas y técnicas de resolución de problemas que, en gran medida, culminan con la llamada Regla de Tres. Esta técnica, en cierto modo, supone el punto álgido de la aritmética escolar y será una de las ideasfuerza que los alumnos, futuros ciudadanos, asimilarán tras su formación aritmética.

Sin embargo, existen multitud de estudios que demuestran que esta enseñanza basada en destrezas y técnicas aplicadas acríticamente conduce a resultados indeseados, como la llamada “ilusión de linealidad” o el uso indiscriminado de la Regla de Tres. Constamos, no obstante, que son escasos los trabajos que critican el estado actual de la enseñanza de la proporcionalidad aritmética, y menos aún los que ofrecen propuestas didácticas alternativas que abarquen la totalidad del currículum relacionado con la proporcionalidad: concepto de razón, magnitudes directa e inversamente proporcionales, porcentajes, proporcionalidad compuesta, repartos, mezclas, etc... Esta realidad nos impulsa a considerar el objetivo fundamental de nuestra investigación: investigar las dificultades de comprensión del concepto y, basándonos en ellas, realizar una propuesta curricular que ayude a superar dichas dificultades. 
Por tanto, emprendemos un trabajo de investigación en Didáctica de la Matemática situado dentro de la línea de investigación denominada Pensamiento Numérico y Algebraico, puesto que trata fenómenos de enseñanza, aprendizaje y comunicación de aspectos puramente aritméticos en el Sistema Educativo y en el medio social. El marco conceptual del Pensamiento Numérico y Algebraico nos permite asumir en nuestra investigación los siguientes principios: la construcción del conocimiento matemático es un fenómeno social y cultural; la educación matemática desempeña un papel relevante en la transmisión de los significados y valores compartidos en nuestra sociedad; y la investigación tiene una orientación esencialmente curricular, en la que ocupa un lugar central el estudio de los errores y las dificultades de compresión de los alumnos.

A la hora de llevar a cabo nuestra investigación hemos tenido en cuenta el procedimiento denominado Análisis Didáctico (Gómez, 2002) que se preocupa especialmente "del procedimiento en virtud del cual el profesor planifica, lleva a la práctica y evalúa una unidad didáctica, una hora de clase o una porción de una hora de clase” (Gómez, 2002, pág. 257). Este marco de investigación ha sido utilizado en diversos trabajos por el propio Gómez (2004), por Lupiáñez y Rico (2008) o por Rico, Marín, Lupiáñez y Gómez (2008); por citar sólo algunos ejemplos.

En el cuadro siguiente, tomado de Gómez (2002, pág. 258), se presenta el ciclo del análisis didáctico tal y como lo concibe el citado autor:

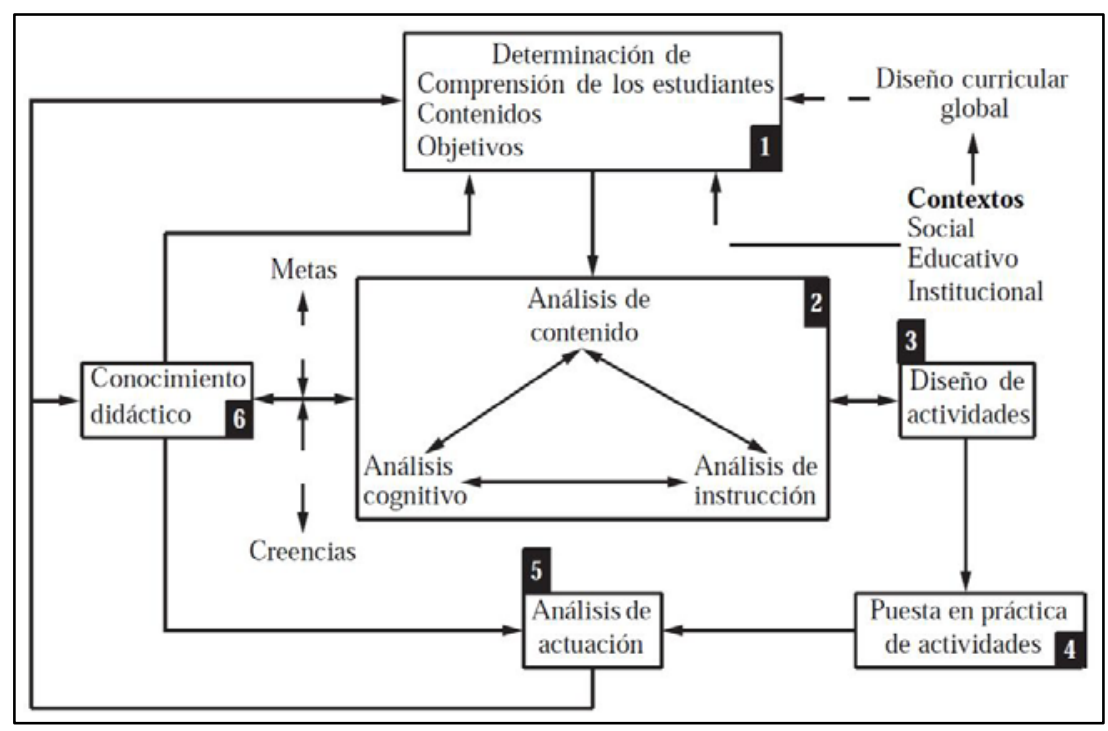

Figura I.1. Ciclo del Análisis Didáctico según Gómez (2002). 
Pensamos que este marco de investigación se adapta bien tanto a la filosofía del trabajo que pretendemos realizar como a la metodología de investigación elegida para llevarlo a cabo, metodología que será descrita algo más adelante.

\section{I.2. PROBLEMAS Y DifiCULTADES EN EL MANEJO DE LA PROPORCIONALIDAD}

Un aspecto que contribuye a la importancia de la proporcionalidad aritmética como contenido curricular, es que ésta supone en gran medida la culminación de toda la aritmética escolar. Los números naturales y racionales, las magnitudes, las operaciones e interrelaciones entre estos objetos, así como su significado, entran en juego (o deberían hacerlo) a la hora de afrontar situaciones que hoy llamamos "de proporcionalidad”.

Sin embargo, pese al largo devenir histórico (ver Capítulo II) y pese a la gran importancia que posee este contenido en el sistema educativo (ver Capítulo III), son múltiples las evidencias que muestran problemas de comprensión por parte de los alumnos. En este sentido, una valiosa fuente de información la constituye el Proyecto TIMSS (Trends in International Mathematics and Science Study). Se trata de un estudio que pretende mostrar el rendimiento de los alumnos entre $4^{\circ}$ de primaria y $2^{\circ}$ de E.S.O. de países de la O.C.D.E. La diferencia fundamental con los estudios PISA es que no se centra en las competencias, sino en los contenidos y en el currículum. España, desafortunadamente, se presentó por primera y última vez en 1995 (López y Moreno, 1997).

En el citado estudio aparecían 11 preguntas, sobre un total de 130, relacionadas con la proporcionalidad aritmética. Estas preguntas se plantearon a alumnos de $7^{\circ}$ y $8^{\circ}$ grados (equivalentes a $1^{\circ}$ y $2^{\circ}$ curso de E.S.O.). A continuación vamos a analizar algunas de las 6 preguntas del bloque de proporcionalidad que se han hecho públicas; aquellas que nos parecen de especial relevancia para nuestros intereses.

\section{Pregunta V-03:}

"Para fabricar una cierta clase de pintura, Alana mezcla 5litros de pintura roja con 2 litros de pintura azul y otros 2 litros de pintura amarilla. ¿Cuál es la razón entre la pintura roja y la cantidad total de pintura?”
A) $5 / 2$
B) $9 / 4$
C) $5 / 4$
D) $5 / 9$ 
Tan sólo un 23’9\% de los alumnos de $7^{\circ}$ grado y un 34’1\% de los de $8^{\circ}$ indica la respuesta correcta (la opción D).

Para resolver este ejercicio, es necesario conocer y comprender únicamente el significado del concepto de razón. Sin embargo, como pondremos en evidencia más adelante en nuestro trabajo, el concepto de razón suele presentarse de forma puramente numérica sin hacer apenas referencia alguna a su significado.

\section{Pregunta L-14:}

"La siguiente tabla muestra los valores de x e y, donde x es proporcional a y:

\begin{tabular}{|l|l|l|l|}
\hline$x$ & 3 & 6 & $P$ \\
\hline$y$ & 7 & $Q$ & 35 \\
\hline
\end{tabular}

Encuentra los valores de P y Q."
A) $P=14$ y $Q=31$
B) $P=10$ y $Q=14$
C) $P=10$ y $Q=31$
D) $P=14$ y $Q=15$
E) $P=15$ y $Q=14$

Tan sólo un 16 ' $1 \%$ de los alumnos de $7^{\circ}$ grado y un 10 ’3\% de los de $8^{\circ}$ indica la respuesta correcta (la opción E).

Este tipo de ejercicios suelen plantearse habitualmente a los alumnos al introducir las magnitudes directa e inversamente proporcionales. Se trata de un ejercicio puramente rutinario $y$ que, al encontrarse completamente descontextualizado, no permite al alumno comprender la situación. Los alumnos, por tanto, terminan por buscar relaciones puramente numéricas entre las cantidades implicadas, lo que explica que la opción preferida por los alumnos, con un 31\%, sea la C; que es “correcta” (si intercambiamos los valores de $P$ y $Q$ ) con una relación “aditiva”, lo que se traduce en la función afín $y=x+4$.

3. Pregunta M-06:

“Una clase tiene 28 estudiantes. La razón entre las chicas y los chicos es 4:3. Se pregunta cuántas chicas hay en clase.”

En este caso únicamente un $14 \%$ de los alumnos de $7^{\circ}$ grado y un $23 \% 8 \%$ de los de $8^{\circ}$ responden acertadamente (16 chicas y 12 chicos). 
En este caso, para resolver el ejercicio, además de conocer y comprender el significado del concepto de razón es necesario que los alumnos sean capaces de utilizarlo en una situación problemática. Sin embargo habitualmente los problemas relacionados con la proporcionalidad se resuelven sin recurrir en absoluto al concepto de razón y haciendo uso de técnicas en gran medida carentes de sentido.

Pensamos que los resultados que acabamos de exponer y comentar justifican plenamente uno de los objetivos principales de este trabajo, que es desarrollar una propuesta curricular de la Proporcionalidad aritmética que contribuya específica y esencialmente a:

1. Ayudar a superar las dificultades de los alumnos.

2. Fortalecer la comprensión que los mismos tienen respecto a la proporcionalidad.

\section{I.3. AlgunAS DEFICIENCIAS DE LA PRÁCTICA EDUCATIVA HABITUAL}

En principio pensamos que los problemas y dificultades de comprensión por parte de los alumnos que se han ilustrado en el apartado anterior pueden tener un triple origen. En concreto existen dificultades:

1. Procedentes de la propia dificultad de los conceptos involucrados.

2. Procedentes de deficiencias cognitivas de los propios alumnos.

3. Procedentes de la práctica educativa.

De estas tres opciones, nuestra investigación se va a centrar en la última de ellas, puesto que una mejora de la práctica educativa necesariamente debería tener como objetivo evitar o suavizar la dificultad de los conceptos matemáticos implicados; y también debería tratar de solventar las deficiencias cognitivas de los alumnos. No obstante encontramos que la mayor parte de los trabajos dedicados a la didáctica de la Proporcionalidad Aritmética se centran principalmente en las dos primeras posibilidades, sin entrar a analizar la práctica educativa tradicional y, mucho menos, a proponer posibles alternativas. 
En el apartado anterior hemos comentado brevemente los escasos porcentajes de acierto de los alumnos en las preguntas sobre proporcionalidad del estudio TIMSS 95, indicando cómo una posible causa puede rastrearse hasta el modo tradicional de presentar los contenidos relativos a la proporcionalidad. A continuación vamos a abundar en esta idea y, a modo de ejemplo, presentamos algunos aspectos de la práctica educativa tradicional; ejemplos que en nuestra opinión, dan lugar a importantes dificultades por parte de los alumnos:

1. Desaparece el significado de las operaciones aritméticas, se sustituye por la utilización de una técnica. En la figura siguiente, se presenta un ejemplo sacado de Álvarez et al. (2003, pág. 160):

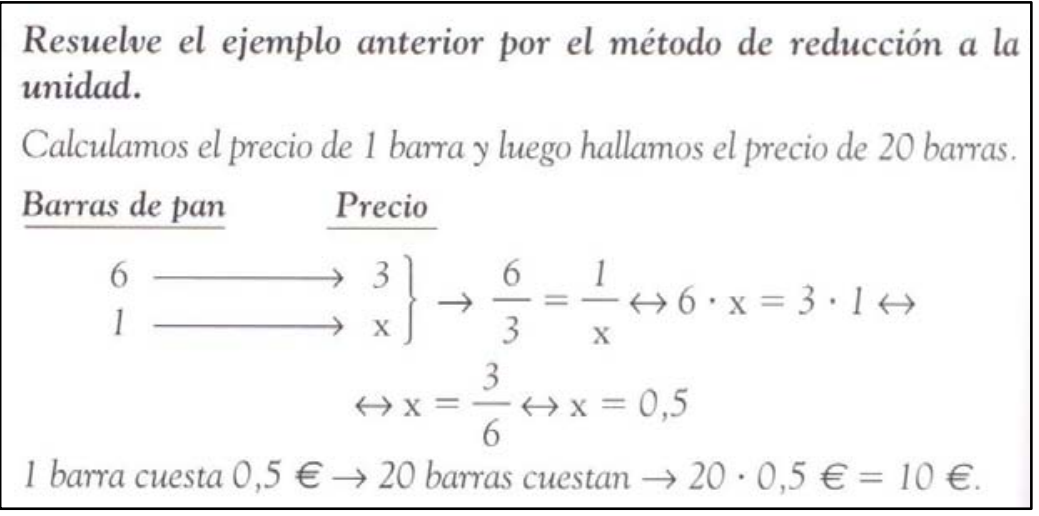

Figura I.2. Desaparición del significado de las operaciones.

En el ejemplo se muestra un procedimiento para calcular el precio de una barra de pan a partir del precio de seis barras. En lugar de recurrir al significado de la división pertinente en este contexto, se plantea una técnica similar a la de la Regla de Tres (pese a que el procedimiento mostrado pretende evitarla). Es interesante observar, además, el abuso de conectores lógicos que el alumno no entiende.

Lo grave, más allá de las conclusiones que podrían sacarse respecto a los autores del texto, son las consecuencias que este tipo de argumentos tienen sobre el alumnado. Así, en la figura siguiente se muestra el razonamiento de un alumno de la Licenciatura en Matemáticas ante la necesidad de comparar la tasa de cambio Euro-Dólar en dos bancos diferentes: 


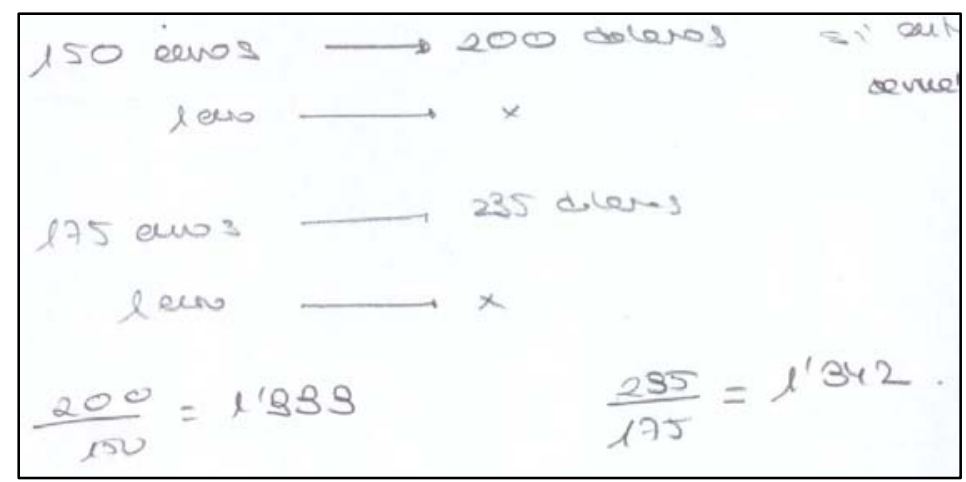

Figura I.3. Consecuencias de la desaparición de los significados.

El resultado de dividir los dólares que se obtienen entre los euros entregados no se hace para calcular los dólares que se obtienen a cambio de un euro, sino que simplemente es uno de los pasos necesarios para completar el algoritmo de la Regla de Tres.

2. Como consecuencia directa y natural de este abandono del uso de los significados de las manipulaciones numéricas y con magnitudes se plantea la resolución de problemas como la aplicación de destrezas carentes de significado e incluso, a veces, de lógica. En la figura siguiente se presenta un ejemplo extraído de Cólera y Gaztelu (2008a, pág. 165):

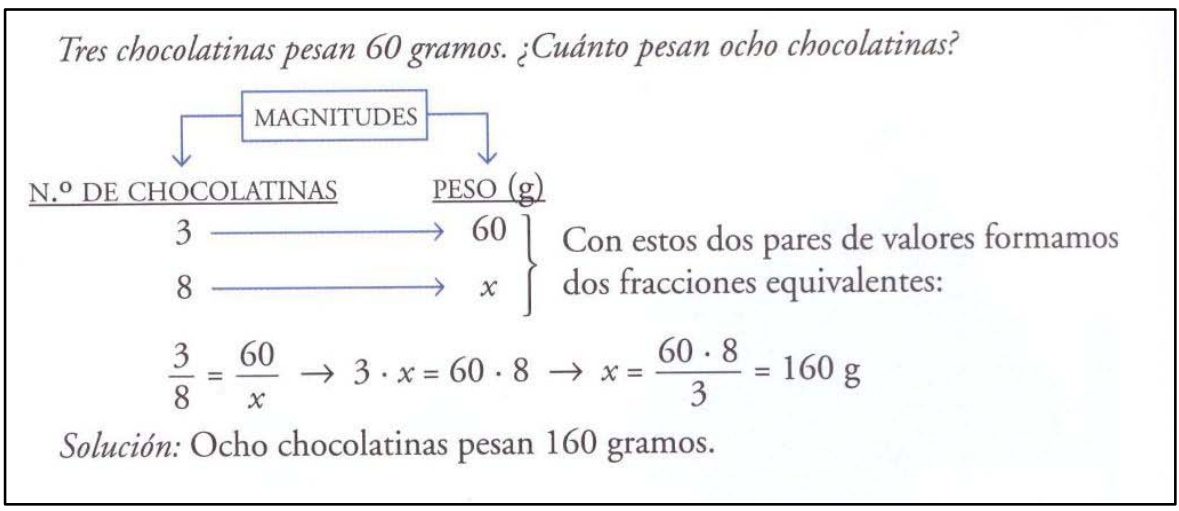

Figura I.4. Destrezas carentes de sentido.

La resolución del problema es una mera sucesión de pasos cuya motivación o significado están ausentes. Al final, mágicamente, se da un sentido al número obtenido pero no como consecuencia de las operaciones realizadas, sino porque eso es "lo que nos están pidiendo". Este texto, como el anterior, muestra gran preocupación por los aspectos matemáticos pero ningún razonamiento didáctico. Este tipo de enseñanza produce consecuencias muy claras. Por ejemplo, en la 
figura siguiente, ver (Gairín y Escolano, 2009), se muestra el intento de resolución de un alumno de $2^{\circ}$ de E.S.O. del problema “Cuatro vacas negras $y$ tres vacas marrones dan tanta leche en cinco días como tres vacas negras y cinco marrones en cuatro días. ¿Qué clase de vaca es mejor lechera?”:

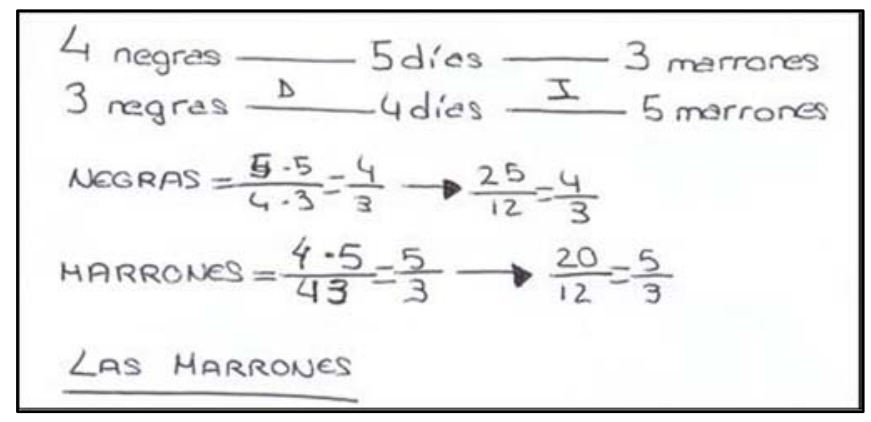

Figura I.5. Consecuencias de la aplicación de destrezas sin sentido.

Ante un enunciado que claramente evoca los problemas "de proporcionalidad compuesta” el alumno trata de reproducir las técnicas aprendidas. El éxito es imposible, pero el alumno persevera y termina por llevar a cabo una serie de operaciones que también evocan la aplicación de la Regla de Tres. El objetivo de aplicar de algún modo el algoritmo aprendido está cumplido aunque los números obtenidos carezcan de sentido.

3. En último lugar encontramos que se produce un abuso de técnicas utilizadas en situaciones inapropiadas. Nótese que este hecho no deja de ser nuevamente una consecuencia de los dos puntos mencionados anteriormente. En la figura siguiente, sacada del texto de Becerra et al. (1997, pág. 95), vemos un ejemplo de este hecho:

La prensa informa que a los cuatro acertantes aparecidos, cuando se lleva realizado la mitad del escrutinio de los boletos del sorteo de Bonoloto, les corresponden 75 millones de pesetas. Al terminar el escrutinio, los acertantes son 6. ¿Qué premio le corresponde ahora a cada uno?

Al aumentar el número de acertantes, disminuye la cantidad que le corresponde a cada uno, por tanto, estas magnitudes están en proporcionalidad inversa.

Figura I.6. Uso de técnicas en situaciones inadecuadas.

Se ha enmarcado la típica caracterización incompleta y, por tanto, incorrecta de la proporcionalidad inversa. La consecuencia inevitable es el uso de técnicas relacionadas con la proporcionalidad no ya en situaciones donde no son útiles 
(como sucedía en el punto anterior), sino en situaciones en las que no tiene sentido hacerlo. Como ejemplo valga la siguiente producción de un alumno de $1^{\circ}$ de E.S.O.:

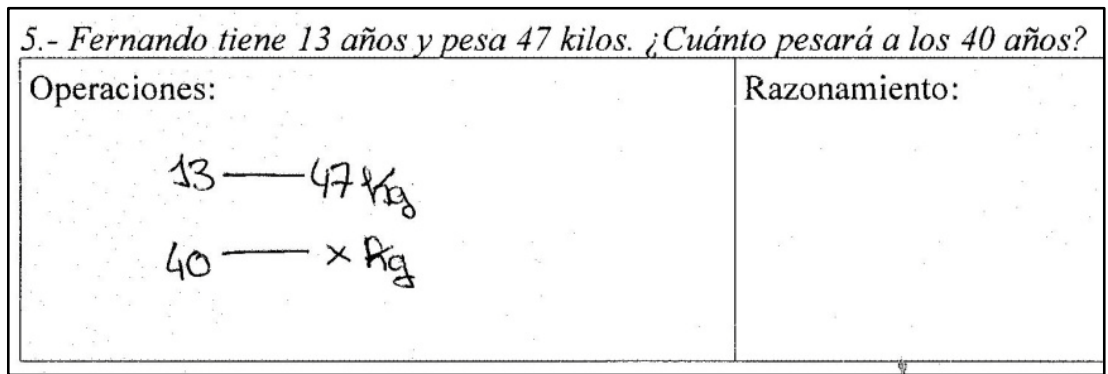

Figura I.7. Consecuencias del uso de técnicas en situaciones inadecuadas.

Este panorama que acabamos de presentar justifica sobradamente la pertinencia de una actuación sobre la práctica educativa tradicional en lo que la Proporcionalidad Aritmética se refiere.

\section{I.4 ASPECTOS METODOLÓGICOS DE LA INVESTIGACIÓN}

El trabajo que emprendemos, que sigue las líneas generales del modelo de investigación ya desarrollado con anterioridad por Castro (1994), Romero (1995), Gairín (1999) y Escolano (2007), ha sido concebido dentro de la metodología denominada Investigación-Acción. La idea fundamental de este método de investigación es reflexionar sobre la práctica en general (la práctica educativa en particular), con la intención fundamental de mejorar la calidad de dicha práctica educativa (McNiff, 1992) a través de una indagación introspectiva colectiva (Kemmis y McTaggart, 1988). De este modo el campo de actuación de esta metodología se limita a entornos reducidos que permitan la introducción de modificaciones y el análisis de las consecuencias de dichas modificaciones por un pequeño grupo de investigadores.

En este método de trabajo se da la particularidad de que el investigador actúa también como profesor de aula, haciendo que la división entre prácticos e investigadores se desvanezca (Lewin, citado por Elliot, 1990).

A la hora de detallar con mayor precisión la metodología que utilizaremos podemos recurrir a diversos autores. Así, atendiendo a la clasificación de Arnal et al. 
(1992) podemos decir que nuestro trabajo se halla en la intersección de dos de las categorías de la escuela lewiniana:

- Lo consideramos dentro de la categoría de investigación-acción diagnóstica puesto que está enfocado hacia la recogida de datos y su interpretación realizando un diagnóstico y enunciando medidas de acción.

- Lo consideramos dentro de la categoría de investigación-acción empírica ya que se estudia un problema social mediante una acción que supone un cambio tratando de valorar sistemáticamente los efectos que tal cambio produce.

Si acudimos a la tipología planteada por Stake (1994) podemos calificar nuestra investigación como estudio de caso instrumental puesto que se trata de una experiencia curricular. Por último, volviendo al trabajo de Arnal et al. (1992), delimitamos nuestro trabajo en los términos siguientes:

- Es una investigación aplicada en cuanto a su finalidad, ya que se trata de mejorar la calidad educativa mediante una modificación de las condiciones de enseñanza.

- Es un estudio longitudinal en su alcance temporal, puesto que se recaban datos de dos grupos a lo largo de un periodo de sesiones.

- Respecto a su objeto, se trata de una investigación de tipo descriptivo, pues hay interés hacia el descubrimiento y la interpretación de fenómenos que se dan en el aula.

- Por el marco, la investigación desarrollada es de campo al trabajar en el aula con grupos naturales de alumnos.

- Es una investigación evaluativa por cuanto se pretende introducir un cambio en el currículo y valorar los efectos que se producen.

\section{I.4.1 Fases de la Investigación-Acción}

El método de trabajo en esta línea de investigación se articula en torno a las cuatro fases siguientes:

1. Fase de planificación. 
2. Fase de acción.

3. Fase de observación.

4. Fase de reflexión.

Estas fases se suceden de forma cíclica, formando distintas etapas de manera que las conclusiones obtenidas en la fase de reflexión de una de las etapas sirven de punto de partida a la hora de planificar la siguiente (Kemmis y McTaggart, 1998; Elliot, 1990; Castro, 1994).

En el caso de nuestro estudio nos centramos en la primera de dichas etapas. En particular implementamos y evaluamos una propuesta curricular sobre la proporcionalidad aritmética con dos grupos naturales de $1^{\circ}$ de E.S.O. Las cuatro fases antes reseñadas se concretan del siguiente modo:

\section{I.4.1.1. Fase de planificación:}

- Se realiza un estudio epistemológico e histórico de la proporcionalidad aritmética. Este estudio se completa con una revisión de textos escolares de los últimos 150 años así como con el análisis de una propuesta didáctica actual.

- A partir de los datos obtenidos en el punto anterior se elabora una propuesta curricular novedosa para la proporcionalidad aritmética en secundaria cuyos aspectos fundamentales son:

- La utilización de un modelo estable basado en las situaciones de intercambio sobre el que construir el concepto de razón entre dos magnitudes e introducir las ideas básicas relacionadas con el mismo.

- La extensión del concepto de razón a situaciones no de intercambio, caracterizando así las magnitudes directamente proporcionales.

- El uso de la razón como "tanto por uno" a la hora de resolver situaciones de búsqueda de cantidades desconocidas, de porcentajes y de repartos respecto de una magnitud.

- El tratamiento diferenciado de la proporcionalidad inversa, definida en base a los conceptos de razón y de constante de proporcionalidad. 
- El uso de los conceptos anteriores para resolver situaciones de búsqueda de cantidades desconocidas.

- La traducción de las situaciones de proporcionalidad compuesta en otras de proporcionalidad simple teniendo en cuenta el significado de las operaciones entre magnitudes.

- De acuerdo a los aspectos anteriores se diseña la programación de las sesiones de clase que se llevarán a cabo en la siguiente fase. Para el diseño de dichas sesiones se han tomado en consideración únicamente los contenidos correspondientes a $1^{\circ}$ de E.S.O. por ser en dicho curso en el que se llevará a cabo la experimentación. Del mismo modo se diseñan las tareas de refuerzo que los alumnos llevarán a cabo en su propia casa. Para cada una de las sesiones y tareas la programación se organiza en torno a cuatro componentes curriculares: objetivos, contenidos, metodología y evaluación.

\section{I.4.1.2. Fase de acción:}

En esta fase se lleva a cabo la programación diseñada en la fase anterior. Los alumnos han de enfrentarse a dos tipos de trabajo:

- Actividades de aula.

Estas actividades tienen el objetivo de servir de introducción o presentación de aspectos tanto conceptuales como procedimentales. Se llevan a cabo en parejas (y algún grupo de tres, según la paridad del número total de alumnos) y siempre de manera previa a la exposición del profesor.

Esta exposición tiene como punto de partida las aportaciones de los alumnos y permite la institucionalización de las ideas matemáticas en juego.

- Tareas para casa:

Estas tareas se plantean con una doble finalidad:

- Reforzar los contenidos introducidos y trabajados en las actividades de aula precedentes.

- En ocasiones, servir de punto de partida para introducir ideas que se trabajan en la actividad de aula siguiente. 
Las sesiones de clase suelen comenzar ( $\mathrm{si}$ es el caso) con una puesta en común de parte del trabajo realizado por los alumnos en la tarea de casa. Con esta puesta en común se pretenden cumplir los dos fines que acabamos de reseñar.

La planificación inicial de la propuesta contempla que, a lo largo de 11 sesiones, los alumnos lleven a cabo 8 actividades de aula y 7 tareas de casa. Además se reservan 2 sesiones de trabajo en las que realizar una recapitulación de los contenidos trabajados hasta ese momento. Finalmente, la última sesión se dedicará a la realización de una prueba final de evaluación.

\section{I.4.1.3. Fase de observación:}

Una vez completadas las dos fases anteriores se dispone de datos respecto a la puesta en práctica de los contenidos y sobre la comprensión de los estudiantes sobre dichos contenidos. El objetivo principal de esta fase no es otro que recopilar y organizar toda esta información.

Las principales fuentes de datos en el estudio realizado son:

- Las producciones escritas de los alumnos.

- El diario de clase del profesor, donde se recogen las incidencias de cada una de las sesiones de clase.

\section{I.4.1.4. Fase de reflexión:}

Tras recopilar y organizar todos los datos disponibles en la fase anterior el trabajo consistirá en realizar un análisis y valoración de dichos datos que permita extraer conclusiones y tomar las decisiones que se deriven. En concreto la reflexión debe encaminarse a:

- Determinar los aspectos relacionados con la organización del contenido que deben mejorarse.

- Determinar el grado de comprensión alcanzado por los alumnos, así como las formas de mejorarlo.

- Determinar los aspectos de la metodología que deben mantenerse o modificarse; y si es así, en qué sentido. 


\section{I.4.1.5. Fases de la Investigación-Acción y Análisis Didáctico}

En la introducción hemos hecho mención del marco de investigación denominado Análisis Didáctico, presentado en la Figura I.1. el ciclo del mismo con sus diversas etapas. Parece interesante indicar aquí cómo dichas etapas encuentran acomodo en las distintas fases de la metodología elegida.

En concreto, las etapas 1, 2 y 3 de la citada figura se desarrollan durante la Fase de planificación. La etapa número 4 se lleva a cabo durante la Fase de acción y, por último, las etapas 5 y 6 se completan en las Fases de observación y reflexión.

\section{I.4.2. Focos de investigación}

La finalidad principal del trabajo que estamos llevando a cabo es formativa. Pretendemos mejorar la comprensión de los alumnos en tres campos fundamentalmente:

- En el uso significativo de las estructuras multiplicativas que han estudiado con anterioridad.

- En la aprehensión de los aspectos conceptuales relacionados con la proporcionalidad.

- En la aplicación de dichos aspectos a la hora de resolver situaciones problemáticas relacionadas con la proporcionalidad.

Para ello la propuesta didáctica que experimentamos en el aula se articula en torno a tres núcleos de contenido o focos de investigación que detallamos a continuación.

\section{I.4.2.1. Primer foco de investigación: razón y condición de regularidad.}

Para introducir el concepto de razón (central en toda la propuesta), se diseña un modelo estable basado en los intercambios. A partir del trabajo sobre este modelo se introducen las condiciones necesarias para la existencia de la razón, así como el uso de la razón a la hora de comparar situaciones.

En este núcleo de contenido se busca que los alumnos construyan las ideas anteriores a partir de su trabajo y reflexión sobre el modelo diseñado. 


\section{I.4.2.2. Segundo foco de investigación: proporcionalidad directa y porcentajes.}

Los conceptos introducidos en el foco anterior pueden extenderse a situaciones más generales que las de intercambio. Esta idea sirve como caracterización de las magnitudes directamente proporcionales. El concepto de porcentaje se presenta íntimamente relacionado con el de razón y se hace especial énfasis en las relaciones entre ellos.

Se pretende que los alumnos sean capaces de identificar magnitudes directamente proporcionales y distinguir aquellas que no lo son. También se persigue que apliquen el concepto de razón y los significados de las operaciones entre magnitudes a la hora de resolver problemas de búsqueda de cantidades desconocidas y, en particular, en problemas de porcentajes.

\section{I.4.2.3. Tercer foco de investigación: proporcionalidad inversa.}

Tras el foco anterior los alumnos distinguen magnitudes directamente proporcionales de las que no lo son. En este bloque se presenta un segundo tipo de relación entre magnitudes: la proporcionalidad inversa. Las magnitudes inversamente proporcionales se caracterizan nuevamente haciendo uso del concepto de razón, aunque en este caso entra en juego una idea nueva: la constante de proporcionalidad.

Además del análisis de situaciones de un modo más profundo (considerando magnitudes que varían o que permanecen constantes), y del reconocimiento y la distinción de las magnitudes inversamente proporcionales, en este núcleo se pretende que los alumnos hagan uso de las ideas de razón y constante de proporcionalidad y de los significados de las operaciones entre magnitudes a la hora de resolver problemas de búsqueda de cantidades desconocidas.

\section{I.4.3. El análisis de errores.}

El estudio de los errores cometidos por los alumnos a la hora de resolver una tarea debe ser (Rico, 1998) “un objeto de estudio para la Educación Matemática”. En nuestro caso el análisis de los errores cometidos por los alumnos a la hora de afrontar las tareas que se les proponen debe servir para evaluar y, en su caso, mejorar la propuesta didáctica que hemos diseñado. 
Puesto que este análisis de errores va a ser utilizado principalmente como indicador del buen o mal funcionamiento de nuestra propuesta, sólo realizaremos un estudio detallado de dichos errores a la hora de analizar las respuestas de los alumnos en la prueba final. Es evidente que los alumnos cometerán errores a lo largo de todo el proceso de aprendizaje, pero estos errores pueden atribuirse al propio proceso. Nuestro interés se centrará, por tanto, en observar qué errores cometen los alumnos una vez que han completado el proceso de instrucción de acuerdo a la propuesta diseñada.

\section{I.5. REVISIÓN BIBLIOGRÁFICA}

La importancia de la Proporcionalidad aritmética como contenido curricular, junto con las múltiples dificultades que, siquiera brevemente, hemos visto que conlleva su aprendizaje, hacen que exista un gran número de trabajos en Didáctica de la Matemática dedicados a este tema.

Esta abundancia de trabajos hace que sea también muy variado el enfoque de los mismos. Sin ánimo de pretender ser exhaustivos podríamos distinguir trabajos de los siguientes tipos:

a) Trabajos de tipo teórico que reflexionan sobre los conceptos matemáticos involucrados.

b) Trabajos de campo que muestran repuestas de alumnos ante tareas relacionadas con la Proporcionalidad.

c) Trabajos que tratan de estudiar parámetros de los problemas relacionados con la Proporcionalidad que influyen en las dificultades que encuentran los alumnos a la hora de resolverlos.

d) Trabajos que pretenden proponer un modelo para el desarrollo del razonamiento proporcional.

e) Trabajos que reflexionan sobre el método habitual de enseñanza y/o proponen alternativas al mismo.

En lo que sigue haremos algunos comentarios más detallados sobre cada uno de estos tipos de trabajos y presentaremos algunos ejemplos concretos. 


\section{a) Trabajos de tipo teórico:}

Consideramos bajo este epígrafe aquellos trabajos que se centran en estudiar diversos aspectos del aparato matemático relativo a la Proporcionalidad aritmética, ya sean los conceptos implicados o los métodos de resolución de problemas.

Clark, Berenson y Cavey (2003) presentan los posibles enfoques existentes a la hora de considerar la relación entre los conceptos de ‘fracción’ y 'razón’ (las razones como un subconjunto de las fracciones, las fracciones como un subconjunto de las razones, ambos conjuntos disjuntos, conjuntos distintos con intersección no vacía o conjuntos idénticos), y buscan evidencias de estas concepciones en respuestas de alumnos, profesores y analizando libros de texto. Person, Berenson y Greenspon (2004) han analizado estas ideas a través de un estudio con profesores de Secundaria en formación.

Otro tipo de estudio es el realizado por Fernández y Puig (2002), que presentan el análisis fenomenológico de la Proporcionalidad presentado por Freudenthal (1983) que distingue entre “exposiciones”, “composiciones” y “constructos” a la hora de presentar situaciones que dotan de sentido a la razón, y recurre a parejas de las anteriores para presentar la idea de proporcionalidad.

Finalmente, Gómez (1999, 2006) analiza desde un punto de vista histórico la evolución en los métodos de resolución de los problemas de compañías (en su trabajo de 1999) y de los métodos de aplicación de la Regla de tres (en el de 2006).

Los Capítulos II y III de esta memoria recogen en cierto modo el espíritu de los trabajos de Gómez, si bien pretenden ser mucho más exhaustivos. La finalidad general de nuestra investigación hace que hayamos evitado discusiones de tipo más teórico, como las de los trabajos de Clark, Berenson y Cavey (2003) o de Fernández y Puig (2002).

\section{b) Trabajos de campo:}

Aunque gran parte de los trabajos que comentaremos en epígrafes posteriores incluyen en mayor o menor medida el análisis de las producciones de los alumnos ante un cuestionario relativo a la Proporcionalidad, consideraremos en este epígrafe a 
aquellos que no van mucho más allá de la mera descripción y categorización de las respuestas.

Los trabajos de este tipo varían mucho en cuanto al contexto en que se presentan los estudios. Así, Benchaim et al. (1998) muestran diversas estrategias utilizadas por alumnos de $7^{\circ}$ grado (12-13 años) con experiencias curriculares diversas. Por su parte Nabors (2003) estudia las respuestas de cuatro alumnos de $7^{\circ}$ grado en un entorno informático. Aún más restringido resulta el trabajo de Singh (2000) que se centra en dos alumnos de $6^{\circ}$ grado, analizando especialmente el uso de estrategias multiplicativas.

Algo más amplio es el estudio realizado por Solar y Zamorano (2005) en Santiago de Chile. En concreto, los autores analizan respuestas de 80 alumnas (de un nivel equivalente al de $4^{\circ}$ de E.S.O. y $1^{\circ}$ de Bachillerato españoles), a la hora de distinguir relaciones de proporcionalidad entre magnitudes. También se estudian las técnicas de resolución de problemas utilizadas por parte de 8 de las anteriores alumnas.

Algunos trabajos se centran en aspectos geométricos de la proporcionalidad entendiendo que la idea de figuras semejantes es un buen punto de partida. Ejemplos de esto son el trabajo de Psycharis y Kynigos (2004) en el que se analizan las actuaciones de alumnos de 13 años en un entorno informático, o el trabajo de Sophian (2000) que compara la capacidad de identificar la semejanza de figuras en diversas situaciones entre alumnos de 4-5 años y adultos. También en un contexto geométrico, pero más centrado en aspectos métricos (áreas, volúmenes, etc.), se enmarca en trabajo de Modestou et al. (2007) que ilustran la tendencia de los alumnos a pensar que "todo es lineal”.

Ya con alumnos españoles Fernández y Llinares (2010) presentan la evolución de las respuestas de alumnos de entre 9 y 16 años a la hora de resolver problemas lineales y no lineales, y Fernández (2009) en su tesis doctoral analiza las respuestas de alumnos de segundo y tercer ciclo de Primaria (8-12 años) con el ánimo de comprobar la posibilidad de introducir los conceptos de razón y proporción en dicho nivel educativo.

En el Capítulo VI de esta memoria se presenta la fase de observación de nuestra investigación que, en gran medida, supone un trabajo de este tipo. 


\section{c) Trabajos centrados en la dificultad de los problemas:}

Gran parte de los trabajos de campo disponibles en la literatura ponen de manifiesto, como también hemos hecho nosotros en los apartados I.2. y I.3., las dificultades que los alumnos encuentran a la hora de afrontar situaciones relativas a la proporcionalidad. Una línea de investigación natural consiste en tratar de establecer qué aspectos de los problemas de proporcionalidad tienen una influencia directa sobre tales dificultades.

Rapetti (2003), por ejemplo, estudia la influencia que tiene sobre el éxito de los alumnos el que los problemas involucren razones internas o externas en el sentido apuntado por Freudenthal (1983).

Steinthorsdottir (2006) estudia la influencia de diversos factores, como la categoría semántica de los problemas según la clasificación de Lamon (1993) o el carácter entero de las razones y la respuesta, sobre las estrategias utilizadas por 53 alumnos islandeses de $8^{\circ}$ grado y sobre su tasa de éxito. En la misma línea va el trabajo de Van Dooren et al. (2006) que defienden la hipótesis de que una razón entera entre los datos de un problema verbal estimula a los alumnos a utilizar métodos proporcionales aún siendo estos inapropiados.

\section{d) Trabajos que presentan modelos para el desarrollo del razonamiento proporcional:}

Los estudios de campo también plantean como línea de trabajo interesante el tratar de diseñar un modelo de desarrollo para el razonamiento proporcional. Es decir, tratar de comprender si dicho desarrollo es jerárquico y, caso de serlo, averiguar qué mecanismos intervienen en el proceso.

Uno de los trabajos más importantes en este sentido es el de Noelting (1980a, 1980b) que se centra tanto en determinar las etapas del desarrollo del razonamiento proporcional, como en analizar las estrategias de resolución de problemas propias de cada etapa.

Trabajos en una dirección similar son los de Alatorre y Figueras (2004, 2005) en los que se utiliza una tipología de problemas más variada que en los de Noelting antes citados. 


\section{e) Trabajos centrados en modificar el método de enseñanza:}

Todos los trabajos anteriores ponían su foco bien en los conceptos relacionados con la proporcionalidad, bien en el alumno. Evidentemente quedan por mencionar aquellos trabajos que se centran en el tercer vértice del triángulo didáctico: el método de enseñanza.

En algunos casos, como en el trabajo de Miyakawa y Winslow (2009) se comparan dos diseños didácticos (uno francés y otro japonés), orientados a introducir el razonamiento proporcional en alumnos de 11-12 años en un contexto geométrico (nuevamente apelando a la idea de "tener igual forma”).

Adjiage y Pluvinage (2007) comparan, en $6^{\circ}$ y $7^{\circ}$ grados, los resultados obtenidos por alumnos en un contexto tradicional, frente a los obtenidos por alumnos que han recibido instrucción en un contexto informático utilizando un software específico.

Van Dooren et al. (2004) diseñan un entorno de aprendizaje orientado a evitar la “ilusión de linearidad” de los alumnos especialmente en contextos de geometría métrica (áreas, volúmenes, etc.).

Abrahamson y Cigan (2003) y el propio Abrahamson (2004) en su tesis doctoral presentan un método para introducir los conceptos de razón y proporción a alumnos de $5^{\circ}$ grado. Su idea se basa en el uso de la tabla de multiplicar como herramienta.

Los trabajos anteriores se centran en aspectos muy restringidos o bien, como en el caso de estos últimos, presentan situaciones que realmente no dotan de significado a los conceptos de razón y proporción. Gairín y Escolano (2009), sin embargo, presentan ideas generales y significativas que han influido en gran medida a la hora de diseñar la propuesta didáctica completa para la Proporcionalidad aritmética en Secundaria que presentamos en el Capítulo IV de esta memoria.

\section{I.6. OBJETIVOS DEL TRABAJO}

El trabajo que planteamos pretende, en cierto modo, llenar el vacío indicado en el apartado I.1., aumentando la atención de los alumnos hacia el contexto de los problemas y mejorando su manejo de las magnitudes y su comprensión de las operaciones entre 
ellas (entendida la razón como una de dichas operaciones). Más en concreto los objetivos principales de esta investigación son los siguientes:

1. Elaborar una propuesta didáctica para alumnos de secundaria que abandone la enseñanza tradicional (basada en las operaciones descontextualizadas y la Regla de Tres) y que se caracterice por:

- Separar completamente el estudio de la proporcionalidad directa del de la proporcionalidad inversa.

- Prestar especial atención al uso y manejo de las magnitudes y al significado de las operaciones entre ellas.

- Hacer especial énfasis en las condiciones necesarias para la existencia de la razón entre dos magnitudes.

- Utilizar el significado de razón como "tanto por uno”, como cantidad de una magnitud que se corresponde con una unidad de otra magnitud, en situaciones de proporcionalidad directa.

- Concebir la constante de proporcionalidad como una cantidad de magnitud que se mantiene constante en situaciones de proporcionalidad inversa.

- Transformar las situaciones de proporcionalidad compuesta en situaciones de proporcionalidad simple, realizando las adecuadas operaciones entre las cantidades de magnitud implicadas en la situación inicial.

2. Concretar esta propuesta al tiempo, espacio, contenido y necesidades concretas de un grupo natural de alumnos de $1^{\circ}$ de E.S.O. e implementarla.

3. En base a la implementación anterior, evaluar las potencialidades y limitaciones de la propuesta inicial.

\section{I.7. PLAN DE LA OBRA}

El trabajo realizado se organiza en base a dos ámbitos: teórico (capítulos II y III) y de aplicación (capítulos IV, V y VI). El capítulo VII, con el que se cierra este trabajo, 
está dedicado a presentar las conclusiones principales de nuestra investigación así como a presentar algunas ideas para futuras investigaciones. Los aspectos principales de cada uno de los capítulos centrales son los siguientes:

\section{I.7.1 Capítulo II: Estudio histórico sobre la Proporcionalidad aritmética.}

El uso de la Proporcionalidad aparece reflejado ya en los primeros textos matemáticos que se conservan y ha sido una constante a lo largo de la historia. En este capítulo se realiza un detallado estudio, tanto epistemológico como fenomenológico, de la Proporcionalidad aritmética desde un punto de vista histórico.

El estudio histórico realizado se estructura en torno a tres grandes bloques de contenido:

- Aspectos conceptuales de la Proporcionalidad.

- Tipología de problemas.

- Técnicas de resolución de los citados problemas.

El capítulo concluye con una serie de conclusiones extraídas de la investigación realizada y que serán tenidas en cuenta a la hora de diseñar una propuesta didáctica en capítulos posteriores.

\section{I.7.2. Capítulo III: Características de la enseñanza tradicional.}

La Proporcionalidad ha sido tema de estudio en la Matemática escolar desde el surgimiento de los primeros planes de estudios reglados en España hacia mediados del siglo XIX. Consecuentemente se trata de un contenido que aparece reflejado en los libros de texto y manuales escolares desde ese momento hasta la actualidad.

En este capítulo, mediante el análisis de textos escolares de distintas épocas, perseguimos los dos objetivos parciales siguientes:

1. Caracterizar los significados que se utilizan en la enseñanza de la proporcionalidad aritmética desde 1850 hasta la vigente ley de educación.

2. Analizar la enseñanza actual de la proporcionalidad.

Las conclusiones obtenidas serán nuevamente de utilidad a la hora de diseñar una propuesta didáctica. 


\section{I.7.3. Capítulos IV, V y VI: Diseño y experimentación de la propuesta didáctica.}

La metodología de Investigación-Acción que se ha elegido a la hora de desarrollar nuestro trabajo se articula, como hemos dicho más arriba, en cuatro fases. Estas cuatro fases aparecen recogidas en estos tres capítulos. En concreto:

- El Capítulo IV se dedica a la Fase de Planificación. En particular se recogen las conclusiones de los dos capítulos anteriores y se diseña la propuesta didáctica completa para la enseñanza de la Proporcionalidad en Secundaria; sin duda uno de los principales aportes de esta investigación.

- En el Capítulo V se desarrolla la Fase de Acción, es decir, se describe la particularización de la propuesta anterior en una secuencia de sesiones para alumnos de primer curso de E.S.O. También se recogen las incidencias más importantes sucedidas en el transcurso de la experimentación.

- El Capítulo VI está dedicado a las Fases de Observación y Reflexión. En él se completa un análisis detallado de la información obtenida durante la Fase de Acción.

\section{I.7.4. Capítulos VII: Conclusiones.}

En este último capítulo se recogerán las principales conclusiones que se obtengan a partir del análisis de los datos obtenidos en la Fase de acción, relativas tanto a la comprensión de los alumnos como a la propia propuesta didáctica. También se dedicará espacio a apuntar posibles líneas de trabajo futuro. 


\title{
CAPÍtUlo II:
}

\section{FENOMENOLOGÍA Y EPISTEMOLOGÍA}

\author{
DE \\ LA \\ PROPORCIONALIDAD
}

\section{ARITMÉTICA DESDE UN PUNTO DE}

\section{VISTA HISTÓRICO.}

\section{II.1. INTRODUCCIÓN}

En este capítulo nos proponemos emprender un estudio fenomenológico histórico sobre la proporcionalidad aritmética y su epistemología en el sentido que señala Freudenthal (1983, pp. 28-29). Este estudio es interesante no sólo por su importancia académica, sino también por que las conclusiones a las que conduce tendrán una influencia muy significativa sobre la propuesta didáctica para la proporcionalidad aritmética que hemos diseñado y que presentaremos en siguientes capítulos.

En las siguientes secciones vamos a estudiar los distintos enfoques y el devenir en el tiempo de tres aspectos fundamentales relativos a la proporcionalidad aritmética: los conceptos involucrados, la tipología de problemas en que aparecen estos conceptos, y las técnicas y métodos de resolución de dichos problemas. 


\section{II.2. MARCO ESPACIO-TEMPORAL Y FUENTES REVISADAS}

A la hora de afrontar este estudio se ha marcado como límite temporal más cercano la época de publicación del Liber Abaci de Leonardo de Pisa; es decir, los inicios del siglo XIII. Esta decisión se basa en la evidencia de que, en esa época, los conceptos y técnicas de la proporcionalidad aritmética están ya plenamente establecidos. A partir de este momento comienza a extenderse y generalizarse el uso del Álgebra y de sus técnicas propias. Estas técnicas, que encontrarán gran aplicación en el campo de los problemas tradicionales sobre proporcionalidad, quedan fuera de este estudio pese a su evidente interés.

Se ha mencionado con anterioridad la gran importancia práctica cotidiana del razonamiento proporcional. Esta importancia se hace patente, por ejemplo, en el hecho de que podemos encontrar vestigios de su uso en los más antiguos textos matemáticos conservados. Por ejemplo en el Papiro de Rhind encontramos, entre otros muchos problemas, el siguiente (Robins y Shute, 1987, p. 51):

“Si 10 hekat ${ }^{1}$ de grasa deben durar un año, ¿cuánta grasa puede usarse en un día?”

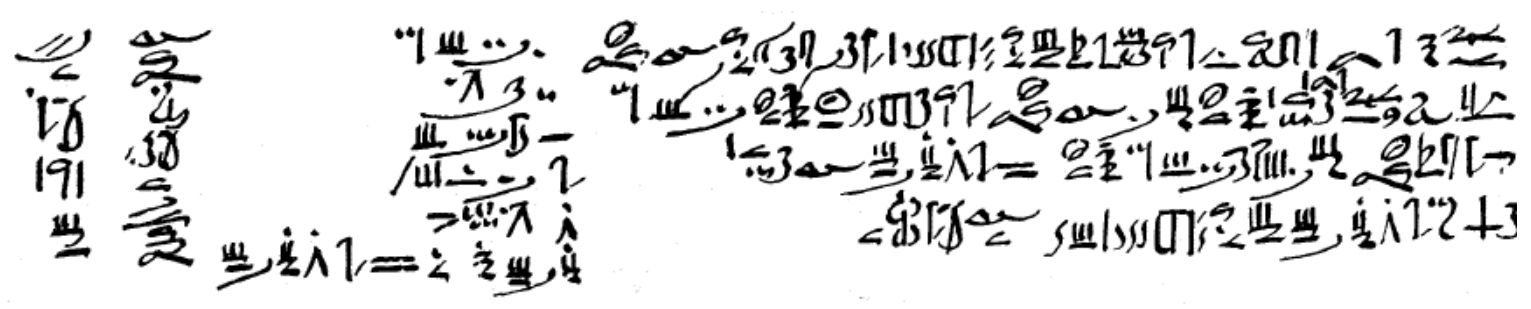

Figura II.1. El problema 66 del Papiro de Rhind.

En ese mismo texto aparecen problemas referentes a intercambios de mercancías o a repartos proporcionales. También aparecen estos tipos de problemas, junto con otros muchos, en textos chinos desde el siglo II a.n.e. (Cullen , 2007) y en textos hindúes que, aunque cronológicamente mucho más tardíos, recogen tradiciones anteriores; como el Lilavati (Patwardan et al., 2001). Es remarcable el hecho de que las técnicas de resolución y los algoritmos utilizados son ya similares a los actuales pese a que surgen en contextos alejados del paradigma griego (Crespo et al., 2009).

1 Unidad de volumen aproximadamente igual a 4.8 litros (Robins y Shute, 1987, p. 14). 
Por otra parte, en los Elementos de Euclides ya se encuentra un tratamiento teórico de los conceptos de razón y proporción relativamente próximo al actual; si bien es cierto que dicho tratamiento se trata de una versión ya refinada de teorías anteriores (Fowler, 1979, 1980, 1981, 1982; Thorup, 1992). Curiosamente no se conservan textos griegos en los que la teoría de las proporciones se utilice en aplicaciones prácticas al estilo oriental; sin embargo, si hay aplicaciones por ejemplo en la Física de Aristóteles (Caveing, 1994). En la Edad Media se unificarán en cierto sentido las dos corrientes anteriores, utilizando y ampliando (aunque, como veremos, no de forma completamente correcta desde un punto de vista matemático), el marco teórico griego para justificar los algoritmos y técnicas orientales; así lo harán Al-Khwarizmi (Rosen, 1986), Al-Biruni (Bag, 1975) u Omar Khayyam (Rashed y Vahabzadeh, 1999). También se avanzará en la progresiva aritmetización del concepto de razón, que originariamente es un concepto no numérico, por parte de Omar Khayyam (Rashed y Vahabzadeh, 1999, p. 279) o Campano (Rommevaux, 1999, pp. 104-106), por ejemplo. Por otro lado, y en esta misma época, aparecen nuevos problemas; asociados a los repartos de herencias en el mundo árabe (Laabid, 1990, 1999), (Meusnier, 2007) y a los intercambios de divisas y la acuñación de moneda en el cristiano (Cassinet, 1999; Spiesser, 1999; Williams, 1995). Como ejemplo paradigmático de la fusión acaecida durante la Edad Media se puede tomar el Liber Abaci de Leonardo de Pisa (Sigler, 2002).

Estas consideraciones justifican la elección de las culturas objeto de este estudio y cuya relación se refleja de manera esquemática en el siguiente gráfico ${ }^{2}$ :

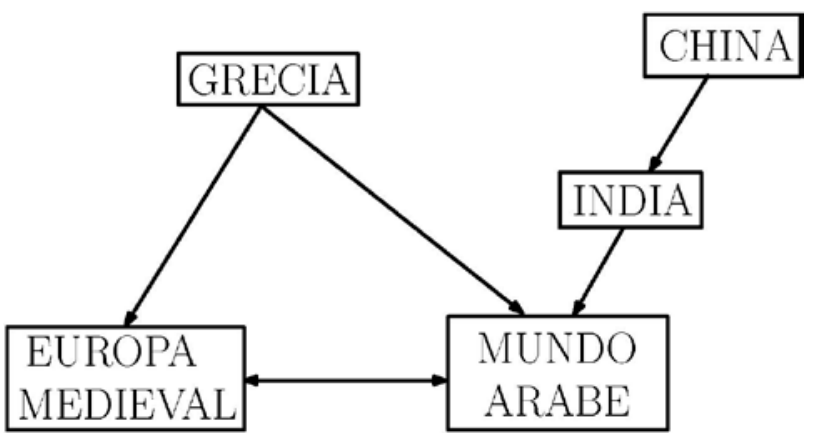

Figura II.2. Influencia y transmisión entre culturas antiguas.

2 En la Figura II.2. se muestra un esquema de la influencia y transmisión de conocimientos sobre la proporcionalidad aritmética entre algunas de las culturas estudiadas. Hemos dejado al margen la civilización egipcia debido a su excesiva distancia en el tiempo. 
Además de la revisión de gran cantidad de bibliografía secundaria, se ha hecho imprescindible recurrir al análisis de fuentes directas o, al menos, de traducciones lo más directas posible. En nuestro caso las fuentes primarias estudiadas han sido las siguientes:

- $\quad$ El Papiro de Rhind (Egipto, siglo XVII a.n.e.):

Se ha manejado el texto de Robins y Shute (1987). No se trata de una traducción completa, sino más bien de un comentario crítico que, en ocasiones, omite los enunciados de los problemas.

- Suan shu shu (China, siglo II a.n.e.):

Se ha empleado el texto de Cullen (2004). Se trata de una traducción completa al inglés, acompañada de comentarios.

- Jiu zhang suan shu. (China, siglo III, aunque el contenido es varios siglos anterior):

Se ha manejado el texto de Kangshen et al. (1999). Se trata de una traducción crítica completa al inglés del texto original y de los comentarios de Liu Hui (el “editor” de la obra original).

- Los Elementos (Grecia, siglo III a.n.e.):

Se ha utilizado edición crítica en castellano de la editorial Gredos (Euclides, 1994).

- $\quad$ Lilavati (India, siglo XII):

El texto utilizado ha sido el de Patwardan et al. (2001). Se trata de una edición crítica en inglés acompañada de comentarios.

- Comentarios de Omar Khayyam a los Elementos (Mundo árabe, siglo XI):

Se ha empleado la traducción completa al francés, con comentarios, que puede encontrarse en Rashed y Vahabzadeh (1999).

- El Álgebra de Al-Khwarizmi (Mundo árabe, siglo IX):

Se ha empleado la traducción íntegra al inglés de Rosen (1986).

- $\quad$ Propositiones ad acuendos juvenes (Europa medieval, siglo VIII): 
Se ha trabajado con la traducción al inglés y comentarios de Hadley y Singmaster (1992).

- $\quad$ El Liber abaci (Europa medieval, siglo XIII):

El texto empleado ha sido la traducción íntegra al inglés de Sigler (2002).

\section{II.3. SOBRE ASPECTOS CONCEPTUALES}

A la hora de estudiar el tratamiento que los aspectos puramente conceptuales relacionados con la proporcionalidad han recibido a lo largo de la historia, surgen algunas dificultades que, por otra parte, son inherentes a la propia investigación histórica:

1. Las teorías matemáticas siempre aparecen ante la necesidad de resolver problemas prácticos concretos. Incluso desde la rama más abstracta de la matemática actual puede rastrearse el camino que lleva a las raíces del árbol hundidas en la tierra. Esto hace que el modo de manipular los conceptos abstractos esté influido por los usos prácticos que se vayan a dar a esos conceptos. En otros términos, hay que ser conscientes y tener en cuenta que la realidad modelada influye de manera decisiva en el modelo de la misma.

2. El modo en que concebimos los conceptos sometidos a estudio influye en cómo los buscamos al analizar un texto antiguo. No buscamos el concepto en la forma en que se concibe hoy en día, pues nuestra concepción actual es fruto de una evolución que pretendemos rastrear y de una cultura que no necesariamente era la imperante en el momento o el lugar en que se escribió la obra que se analiza.

En esta sección abordamos tres aspectos principalmente:

1. En primer lugar, estudiaremos el texto de los Elementos de Euclides, donde los conceptos clave de ‘razón’ y ‘proporción’ aparecen por vez primera y donde el tratamiento que estos conceptos reciben, en esencia, es similar al actual.

2. En segundo lugar, analizaremos y comentaremos el intento de fundamentación teórica de los fenómenos asociados a la proporcionalidad que se encuentra en un 
texto chino cuyo origen e inspiración son radicalmente diferentes a los del anterior: el Jiu zhang suan shu.

3. En tercer lugar, presentaremos el proceso de aritmetización, entendida como la identificación de las razones con entes numéricos que se inicia en la Edad Media y que llega hasta nuestros días.

\section{II.3.1. Razón y proporción en los Elementos}

De los trece libros que conforman la obra de Euclides, dos son los dedicados a la temática que nos ocupa: el libro V, dedicado a las magnitudes y el libro VII, dedicado a la aritmética ${ }^{3}$.

El primer inconveniente importante del texto es que el concepto 'razón' no está definido. En el libro VII, este término apenas aparece mientras que en el libro V todo lo que se dice es que "una razón es determinada relación con respecto a su tamaño entre dos magnitudes homogéneas” (V, Def. 3) y que “guardan razón entre sí las magnitudes que, al multiplicarse, pueden exceder una a otra” (V, Def. 4). Lo que parece quedar claro a la luz de la primera de estas dos definiciones es que la razón no es, en modo alguno, un número. Este carácter no numérico de las razones en los Elementos está reforzado por el hecho de que no se haga ningún intento de definir sistemáticamente operaciones entre razones ${ }^{4}$; además, nunca se habla de igualdad de razones, sino de “guardar la misma razón” (V, Def. 5) o de “guardar una razón mayor” (V, Def. 7).

Parece comúnmente aceptado el hecho de que antes del desarrollo de la teoría de proporciones de Eudoxo, presentada por Euclides en el libro VII de sus Elementos, la razón entre dos números ${ }^{5}$ o magnitudes homogéneas venía dada por un proceso llamado antifairesis o antanairesis ${ }^{6}$. Este proceso se lleva a cabo del siguiente modo: dados dos números o magnitudes homogéneas, se resta el menor al mayor tantas veces como se pueda hasta que quede un resto menor que el menor de los números de partida. Entonces se repite el proceso tomando como partida el menor de los números iniciales y el resto

3 Si bien en el texto los números aparecen representados como segmentos.

4 Tan sólo se admite la composición de dos razones de la forma $a: b$ y $b: c$ para obtener $a: c$. GrattanGuinness (1996, pp. 367-368) ve en esto un cierto trasfondo musical reforzado por el paralelismo entre las ternas número-magnitud-razón y aritmética-geometría-música.

5 Entendidos como números sólo los enteros positivos.

6 Hoy lo denominamos Algoritmo de Euclides. 
obtenido; y así sucesivamente. Lo importante aquí es el proceso en sí y no los números que aparecen durante el mismo; es decir, llevamos la cuenta sólo de las longitudes de las series de restas que efectuamos antes de cambiar los papeles. Por ejemplo:

$$
\begin{aligned}
(14,6) \rightarrow(8,6) \rightarrow & (2,6) \\
& (6,2) \rightarrow(4,2) \rightarrow(2,2) \rightarrow(2,0)
\end{aligned}
$$

y así, puesto que hemos hecho primero dos restas y luego tres, la antifairesis de 14 y 6 sería la sucesión (finita) $\{2,3\}$.

Esta definición de razón mediante la antifairesis refuerza claramente el carácter no numérico del concepto junto con su íntima relación con un proceso de medida, a la vez que aclara el motivo por el cual sólo se consideran razones entre magnitudes homogéneas. En el caso de números, además, es importante indicar que el proceso siempre termina en un número finito de pasos debido a la existencia del máximo común divisor. Sin embargo, al aplicar el proceso a magnitudes esto no tiene por qué suceder ${ }^{7}$; por ejemplo, si $d$ y $l$ denotan respectivamente la diagonal y el lado de un cuadrado se tiene $^{8}$ :

$$
\begin{aligned}
(d, l) \rightarrow & (d-l, l) \\
& (l, d-l) \rightarrow(2 l-d, d-l)=(D, L) \rightarrow(D-L, L)
\end{aligned}
$$

y el proceso se repetiría a partir de aquí indefinida, pero periódicamente, puesto que $D=2 l-d$ y $L=d-l$ son nuevamente diagonal y lado de un cuadrado ${ }^{9}$. En definitiva, se tiene que la razón $d: l$ vendría dada por la sucesión ${ }^{10}$ (infinita y periódica) $\{1,2,2, \ldots\}$. Debe resaltarse el hecho de que todas las operaciones realizadas durante este proceso de antifairesis pueden llevarse a cabo con regla y compás al estilo de la época. Más aún, según Fowler (1980) el Libro II sería un compendio de las herramientas básicas necesarias para profundizar en el estudio de la antifairesis.

7 Sólo sucederá en el caso de magnitudes conmensurables.

8 Ver (Fowler, 1979) para una demostración geométrica.

9 Esto ya era conocido en la época. De hecho este sería el estilo de la primera demostración de inconmensurabilidad.

10 En el primer paso se ha efectuado una sola resta, en el segundo paso dos y a partir de ese momento se repite el proceso con dos restas en cada iteración. 
Aunque en trabajos como los de Fowler $(1980,1982)$ o Thorup (1992) se muestra cómo esta definición de razón permite construir toda la teoría de proporciones del Libro VII, lo cierto es que las dificultades en el manejo ${ }^{11}$ superan con mucho las potencialidades de la definición. De este modo, la teoría original quedó relegada al ámbito de la aritmética y del Libro V, mientras que para el caso de magnitudes hubo de idearse una nueva teoría. En concreto fue Eudoxo $^{12}$ el que dio con una solución satisfactoria que pasó por dejar indefinido el concepto de razón y definir únicamente aquello que importaba desde un punto de vista puramente geométrico; es decir, definir lo que significa ‘guardar la misma razón’ y 'guardar una razón mayor'. En concreto “una primera magnitud guarda la misma razón con una segunda que una tercera con una cuarta, cuando cualesquiera equimúltiplos de la primera y la tercera excedan a la par, sean iguales a la par o resulten inferiores a la par, que cualesquiera equimúltiplos de la segunda y la cuarta, respectivamente y tomados en el orden correspondiente” (V, Def. 5) y una definición análoga se da para el caso de 'guardar una razón mayor' en (V, Def. 7). Estas definiciones tienen la virtud de que son válidas para cualquier tipo de magnitudes, conmensurables o inconmensurables, dejando de lado la necesidad de calcular la sucesión definida por la antifairesis de dichas magnitudes.

Sin embargo surge un problema al tener dos teorías, una para números y otra para magnitudes, y es que hay que probar resultados similares dos veces. Esto es así por la forma en la que los griegos concebían las magnitudes. Para ellos no tenía sentido considerar el producto de dos magnitudes ${ }^{13}$ y así resultados como "si cuatro números son proporcionales, el producto del primero y el cuarto será igual al del segundo y el tercero" (VII, Prop. 19) y “si cuatro rectas son proporcionales, el rectángulo comprendido por las extremas es igual ${ }^{14}$ al rectángulo comprendido por las medias” (VI, Prop. 16) requieren de tratamientos radicalmente diferentes ${ }^{15}$. No obstante estos tratamientos se reconciliarán en el Libro X cuando se pruebe que dos magnitudes son

11 De hecho, según Fowler (1979, p. 829) toda una rama del saber de la época, la logística, estaría dedicada al estudio de las razones.

12 Véase (Filep, 2003) para la reconstrucción del posible razonamiento original de Eudoxo y (Rusnock y Thagard, 1995) para un análisis del proceso de cambio conceptual que tuvo lugar.

13 El producto de dos longitudes no es una superficie, por ejemplo.

14 Se entiende que de igual área.

15 Aun cuando para nosotros son equivalentes. 
conmensurables si y sólo si guardan entre sí la misma razón que un número con otro número (X, Prop. 5-8).

Otro aspecto problemático interesante surge a la hora de aplicar en situaciones prácticas concretas toda la teoría desarrollada. La razón tenía sentido únicamente entre magnitudes homogéneas, el producto de magnitudes carecía de sentido. Estos dos hechos hacen prácticamente inaplicable la teoría a las situaciones prácticas en las que debería aplicarse, que tan profusamente aparecen en los textos orientales, y que evidentemente debían ser situaciones cotidianas también en la Grecia clásica. Esta imposibilidad de aplicar rigurosamente la teoría quizás sea una explicación de porqué no hemos sido capaces de encontrar textos griegos clásicos sobre, digamos, aritmética práctica mientras que sí es posible encontrar aplicaciones al mundo de la Física, como el siguiente texto extraído de la Física de Aristóteles (Caveing, 1994):

"Supongamos que A es el moviente, B la cosa movida, C la distancia súg la cual es movida y T el tiempo en el cual es movida. Entonces, en el tiempo T una fuerza igual a A hará que algo que es la mitad deB se mueva sobre el doble de la distancia $C$, y lo hará mover sobre la distancia $C$ en la mitad del tiempo $T$, pues de esta manera se mantendrá la proporción. Y si la fuerza de A hace mover a $B$ sobre la distancia $C$ en el tiempo $T$, también hará mover a B sobre la mitad de $C$ en la mitad del tiempo T, y una fuerza igual a la mitad de A moverá a la mitad de B sobre la distancia C en el tiempo T.” (VII, 249b31-250a7)

Nótese que las razones son siempre entre tiempos o entre distancias y nunca entre distancias y tiempos; en otras palabras, sólo se consideran razones internas y no externas. Como veremos más adelante, el enfoque chino será mucho más apropiado para las aplicaciones “comerciales”.

\section{II.3.2. Proporcionalidad en el Jiu zhang suan shu}

Pese a ciertos prejuicios, no es la griega la única cultura en la que pueden encontrarse algunos intentos de fundamentación teórica. Aunque es cierto que no puede encontrarse un texto puramente teórico como son los Elementos, no debe creerse que no existiera una preocupación por la búsqueda de métodos generales o por la 
justificación ${ }^{16}$ de dichos métodos. Así, aunque algunos análisis psicolingüísticos del chino, como los citados por Dauben (1998), dan cuenta de las dificultades que esta cultura pudiera encontrar a la hora de intentar desarrollar un rigor lógico, digamos, “a la griega”; no es menos cierto que en la medida de sus posibilidades los matemáticos ${ }^{17}$ chinos se preocupaban por algo más que por la mera aplicación de métodos. En este sentido Cullen (2007, pág. 39) traduce las palabras de un maestro chino del siglo I de nuestra era:

"La dificultad en cuanto a la comprensión del Camino es que, cuando uno lo ha estudiado, debe preocuparse por aplicarlo ampliamente. Una vez que ha sido ampliamente aplicado, uno se preocupa de ponerlo en práctica. Cuando ha sido puesto en práctica, surge la preocupación de no ser capaz de comprenderlo. Así, métodos similares se estudian comparativamente y problemas similares son comparativamente considerados. Esto distingue al estudiante inteligente del estúpido y al valioso del que no vale. La capacidad de clasificar para unificar categorías: esa es la esencia de cómo el valioso se dedica a refinar la práctica y la comprensión.”

Los textos antiguos orientales y los chinos en particular, por más que escondan como ya se ha dicho - una cierta búsqueda de métodos generales, poseen un eminente enfoque práctico. Se trata de colecciones de problemas acompañados de una solución numérica o de una mera descripción del método de resolución aplicado a los datos concretos del problema presentado. Esta presentación, que choca radicalmente con el paradigma griego (que de hecho constituye la excepción en el mundo antiguo) se prolongará mucho en el tiempo y puede observarse aún su influencia en textos muy posteriores como el Liber Abaci, por ejemplo.

El Jiu zhang suan shu no pasaría de ser uno de tales repertorios de problemas si no fuera por los comentarios con los que un matemático chino del siglo III llamado Liu Hui acompañó a su edición del libro. En sus comentarios, además de relacionar unos problemas con otros o de aclarar los métodos del texto original, también aparecen

16 Decimos justificación y no demostración por la carga de lógica que posee dicha palabra. La distinción entre justificación y demostración es muy fina y, desde luego, la segunda no existe sin la primera.

17 Aunque no tenga sentido hablar de matemáticos (como profesión) hasta épocas muy recientes. Entenderemos que matemático, incluso actualmente, son aquellos que hacen o utilizan matemáticas. 
algunos indicios de lo que, salvando las distancias, podríamos llamar una cierta fundamentación teórica.

Dada la naturaleza de la obra, los aspectos relacionados con la proporcionalidad no podían faltar. El concepto central en el tratamiento que Liu Hui hace de la proporcionalidad es el de $l \ddot{u}^{18}$. Liu Hui define lü como un "conjunto de números correlacionados" y enumera algunas propiedades y operaciones entre ellas. En concreto: "Las lü pueden convertirse unas en otras. Si hay fracciones en una lü, ésta puede convertirse en otra en enteros multiplicando por un número adecuado. Las lü se pueden simplificar reduciéndolas usando el común denominador” (Kangshen et al., 1999, p. 80).

La interpretación de este concepto es sencilla. Se dispone de varias magnitudes directamente proporcionales ${ }^{19}$ y una lü no es más que un conjunto de valores de dichas magnitudes. Las propiedades y operaciones descritas se siguen de la proporcionalidad directa entre las magnitudes consideradas. Kangshen et al. (1999, p. 81), en este contexto, interpretan la razón entre dos magnitudes como su lü cuando una de ellas toma el valor 1 . No obstante no hay nada parecido a la definición euclídea de razón ni a la razón por antifairesis, aunque el proceso de simplificación de fracciones descrito en el Jiu zhang suan shu es idéntico al Algoritmo de Euclides. Este concepto de lü, decimos, es fundamental para Liu Hui y nos permitirá comprender perfectamente, como veremos más adelante, el tipo de razonamiento detrás de la génesis de la Regla de Tres.

El motivo por el que esta concepción de la proporcionalidad se adapta mejor a las aplicaciones mercantiles salta a la vista. En este contexto no hay problemas a la hora de relacionar directamente dos magnitudes distintas; de hecho, se consideran simultáneamente pares de magnitudes diferentes. Es más, esta forma de enfocar la situación está mucho más cerca de una concepción funcional puesto que mientras en el enfoque griego se relacionan por separado cada una de las magnitudes y después se comparan dichas relaciones, en el chino se entra directamente a analizar la relación

18 La traducción de este término parece problemática. En el capítulo XIV - en francés - de (Benoit et al., 1992) se deja sin traducir. En (Kangshen et al., 1999) se traduce al inglés como rate. En (Lam, 1994) la traducción es proportional value. Nosotros optaremos por no traducir, las traducciones inglesas dan una idea aproximada de lo que se quiere decir.

19 La idea de magnitudes directamente proporcionales se da por supuesta en Los nueve capítulos. 
existente entre ambas magnitudes. Aquí predomina la idea de razón externa frente a la interna.

\section{II.3.3. Comparando ambos enfoques}

Consideremos el siguiente enunciado extraído de un manual escolar cualquiera: “Una fuente arroja 42 litros de agua en 6 minutos. ¿Cuántos litros arrojará en 15 minutos?”.

Bajo un punto de vista griego debe tenerse en cuenta que los litros arrojados guardan la misma razón que los tiempos necesarios para arrojarlos. Es decir, se busca un número de forma que dicho número guarde con 42 la misma razón que 15 con 6 . En términos modernos y empleando el lenguaje algebraico, plantearíamos la proporción:

$$
\frac{x}{42}=\frac{15}{6}
$$

Bajo un punto de vista chino, consideraríamos el par $(6,42)$ y estaríamos interesados en encontrar un par correspondiente a la misma situación bajo la restricción de que el primer elemento ha de ser 15. De nuevo empleando un lenguaje algebraico plantearíamos la proporción:

$$
\frac{6}{42}=\frac{15}{x}
$$

Consideradas desde un punto de vista puramente numérico y descontextualizado ambas situaciones son equivalentes. Sin embargo el significado es bien distinto. El primer enfoque carecería de sentido para un resolutor chino puesto que si el problema muestra claramente que la relación es entre litros arrojados y tiempo necesario para hacerlo ¿por qué relacionar tiempos y litros separadamente? Para un griego es el segundo enfoque el carente de sentido puesto que no concibe “dividir” o "repartir” litros entre tiempo.

Es muy interesante observar como al plantear situaciones de este tipo a alumnos que no están familiarizados con las técnicas de la proporcionalidad y, dejando de lado estrategias aditivas o argumentos incorrectos, la dialéctica entre estos dos enfoques permanece viva (ver Capítulo VI). Por supuesto, lo deseable es conseguir ambas visiones en los alumnos, pero no podemos evitar señalar el mayor sentido que 
proporciona a las operaciones y la mejor comprensión de la situación que, a nuestro juicio, se obtiene pensando “a lo chino” antes que “a lo griego”.

\section{II.3.4. La aritmetización de las razones}

De los dos enfoques posibles que acabamos de presentar y comparar, fue la potente teoría griega de la proporcionalidad la que permaneció a lo largo de los siglos; primero en el propio mundo griego y, después, adoptada por la cultura árabe, en la Europa medieval. Sin embargo, pese a su potencia, existían algunos defectos o inconvenientes en la teoría. Los principales eran:

1. El concepto de razón no estaba definido en los Elementos y la idea de razón por antifairesis no aparece sino insinuada en el algoritmo de la división. También subyace la problemática respecto a la naturaleza - numérica o no - de dichos entes.

2. En los Elementos, Euclides sólo admite la composición de dos razones de la forma $a: b$ y $b: c$ para obtener $a: c$. En algunas traducciones aparece una definición interpolada de composición de dos razones cualesquiera, que falla para el caso de magnitudes ${ }^{20}$.

El primero de estos problemas es de carácter puramente teórico. La necesidad de solucionarlo surge únicamente del deseo de que la teoría esté completa desde un punto de vista lógico. El segundo de los problemas es quizás más interesante puesto que surge - a nuestro juicio - ante la necesidad de dar un fundamento teórico a las técnicas orientales (Regla de Tres, de Cinco y superiores) que los árabes recogen de las tradiciones orientales y que no podían ser justificadas estrictamente por la teoría griega de las proporciones.

Es natural, pues, que fuera la Baja Edad Media, época en la que proliferaron las traducciones, copias y comentarios a los Elementos de Euclides, cuando surgieran algunas respuestas a los problemas anteriores. El problema de la definición y la naturaleza de las razones surge en las dos culturas más importantes del momento: la cristiana y la árabe. El problema de la composición de razones, por su origen práctico

20 La composición de $a: b$ y $c: d$ sería $a c: b d$; pero recuérdese que para Euclides no tenía sentido el producto de magnitudes. 
recogido de la tradición oriental, sólo apareció en el seno de la cultura árabe. Aquí vamos a presentar los principales avances en la respuesta a las cuestiones anteriores: el comentario de Omar al-Khayyam (s. XI) a los Elementos y la traducción de la misma obra por parte de Giovanni Campano (s. XIII). Resulta curioso observar que, mientras en el caso de al-Khayyam se trabajará siempre en el ámbito de las magnitudes, Campano se centrará únicamente en las razones numéricas. Además, ninguna de las soluciones aportadas en uno de los ámbitos es exportable al otro y, de hecho, pensamos que cada una de las propuestas que vamos a presentar es la más natural (si es que tal apelativo tiene sentido) en el ámbito en que se dio.

\section{II.3.4.1. Los comentarios de Ommar al-Khayyam a los Elementos de Euclides}

Los comentarios de Omar al-Khayyam a los Elementos han sido traducidos por Rashed et al. (1999). En este texto se plantean, y hasta cierto punto se resuelven, las dos cuestiones presentadas anteriormente, pero sólo en el ámbito de las magnitudes (entendidas en el sentido griego, es decir, como magnitudes geométricas). Esto es así porque al-Khayyam utilizará de modo esencial la posibilidad de dividir una cantidad de magnitud hasta el infinito, algo imposible de hacer en el ámbito numérico de los Elementos que se limita a los enteros positivos que, obviamente, no permiten su subdivisión más allá de la unidad (aunque la dialéctica discreto-continuo fuera el centro de ricas disputas. Recuérdense, por ejemplo, las paradojas de Zenón de Elea)

Al-Khayyam, igual que algunos de sus predecesores, redescubre la definición de razón como antifairesis; es decir, como proveniente de un proceso de medida por conmensuración íntimamente ligado a lo que hoy llamamos Algoritmo de Euclides. Así, dos razones son iguales si ambos pares de magnitudes dan lugar a la misma sucesión de enteros tras el proceso de antifairesis. A esta nueva ${ }^{21}$ definición de igualdad (y desigualdad) de razones la llama al-Khayyam - no sin cierta inmodestia - "la verdadera" mientras que la de Euclides es para él "la usual”. Todo el Libro II del comentario de al-Khayyam a los elementos está dedicado a demostrar la equivalencia entre esta noción “verdadera” y la “usual”. Es importante indicar que para hacerlo utilizará constantemente la existencia de una cuarta proporcional a tres magnitudes dadas; para lo cual admitirá que las magnitudes son divisibles hasta el infinito. 
En el Libro III de su comentario, al-Khayyam se dedica a la composición de razones $^{22}$. Al-Khayyam, en particular, demostrará que dadas tres magnitudes $a, b$ y $c$ la razón $a: c$ es la composición de las razones $a: b$ y $b: c$. Para ello al-Khayyam procede del siguiente modo: dadas las magnitudes $a$ y $b$ se fija una unidad $u$ y, entonces, por la existencia de la cuarta proporcional existe otra magnitud $g$ tal que $g: u:: a: b$. Ahora, como $u$ es la unidad, al-Khayyam considera $g$ como un número que representa la razón $a: b^{23}$; es decir, identifica en cierto modo las razones con números y así puede identificar la composición de razones con la multiplicación numérica. Además este argumento permite, como así hace al-Khayyam, extende este resultado para una cantidad cualquiera de magnitudes ${ }^{24}$. Esta visión es de vital importancia y aparece aquí por primera vez en la historia; aunque bien es cierto que al-Khayyam no entrará en una discusión sobre la naturaleza numérica o no de las razones.

\section{II.3.4.2. Campano y la denominación de una razón}

Una de las traducciones ${ }^{25}$ de los Elementos que más éxito tuvieron en la Europa cristiana medieval fue la llevada a cabo a mediados del siglo XIII por Giovanni Campano. El aspecto más importante que queremos destacar de esta obra es la introducción del concepto de 'denominación de una razón'. En concreto Campano define este concepto del siguiente modo (Rommevaux, 1999, pág. 97):

“Se dice denominación de una razón, de un número más pequeño en relación a uno más grande, a la parte o las partes que ese número menor está en el más grande. $Y$ de un número más grande a otro más pequeño, al múltiplo o al múltiplo y la parte o las partes según las cuales el mayor lo es.”

Pese a lo relativamente oscuro de esta definición, se observa que lo perseguido por Campano al introducirla es aritmetizar en cierto modo el concepto de razón. Debe recordarse que en Euclides la razón es más bien una relación entre magnitudes (o entre números en este caso). Campano está asignando un número a cada razón. El problema de la inconmensurabilidad no surge aquí puesto que se restringe al caso de razones

22 Este tema será también recurrente en los comentadores árabes de Euclides, como por ejemplo Ibn Sartaq (s. XIII), mencionado por Djebbar (1997).

$23 \mathrm{O}$ mejor aún, la medida de $a$ al tomar $b$ como unidad.

24 El modo es obvio, si $a 1, \ldots$, an son magnitudes, la razón a1:an es el resultado de componer a1:a2, a2:a3,...,an-1:an.

25 Aunque, como afirma Rommevaux (1999), se trata más bien de una recensión. 
numéricas (Libro VII). Sin embargo, la herencia euclidea se hace patente cuando, como aplicación de esta definición, Campano define la semejanza (y no la igualdad) de dos razones (Rommevaux, op. cit., pág. 98):

"Se dicen semejantes a las razones que reciben la misma denominación, y más grande a la que recibe una más grande, y más pequeña a aquella que recibe una menor."

Así pues, se observa una práctica parecida a la actual. Se asocia ${ }^{26}$ la razón con un número racional y la igualdad o la relación de orden entre razones con los respectivos conceptos numéricos. Es importante hacer énfasis, no obstante, en que se trata de una asociación más que una identificación. La razón no es aún un número sino que es nombrada mediante un número. La diferencia, aunque de índole casi filosófica, es importante.

\section{II.3.5. La fundamentación y el simbolismo}

Como hemos visto, el lenguaje de las proporciones sirvió a los matemáticos árabes para analizar algunos métodos, como el de falsa posición, y darles el rigor del que carecían. Lo mismo sucede en el ámbito de los repartos proporcionales o las Reglas de compañía. Los cálculos más o menos arbitrarios que se efectuaban en los textos de China e India encontraron en manos de unos matemáticos poseedores de la potencia del lenguaje euclídeo su justificación final. En el caso de la Regla de Tres aún podemos decir más, puesto que la Teoría de las Proporciones sólo podía justificar aquellas situaciones en las que intervenía una única proporción; los casos en los que los hindúes utilizaban sus Reglas de cinco, siete, etc... requerían de la composición de razones y esta teoría no aparecía en los elementos. Así pues, bien pudo ser la necesidad de justificar estas reglas (más que la necesidad puramente matemática de completar una teoría) lo que llevara a desarrollar el aparato matemático necesario ${ }^{27}$.

El siguiente ejemplo muestra de forma nítida la fusión entre práctica y teoría llevada a cabo por los árabes. Se trata de un fragmento del Liber Ysagogarum Alchorismi tal y como aparece traducido por Allard (1992, p. 50). En él se trata un

26 Hoy en día, más que asociar, se identifica la razón con el número racional. Campano aún no ha llegado a ese punto.

27 Pero esto es una mera hipótesis. 
problema típico de textos muy antiguos (el de dos viajeros que marchan al encuentro), que en dichos textos se resuelve utilizando sin justificación argumentos de proporcionalidad, mientras que en este caso se nos remite a un resultado de los Elementos como justificación:

\section{“[...] La distancia está en relación con su movimiento diario [...] En el caso en} que los viajeros caminan hacia un mismo punto, tenemos que descomponer la cantidad, es decir, el valor relativo de cada uno, en dos fracciones. Por el $19^{\circ}$ teorema del $7^{\circ}$ libro de Euclides sobre las proporciones, sabemos que el producto de los extremos es igual al producto de los medios. Por ejemplo. Un viajero recorre 2000 pasos al día, otro 4000. La ruta es de 30000 pasos. ... . Los viajeros se encontrarán en el punto 20 y 10; el número de días hasta su reunión está en función del movimiento del primero con respecto al lugar del encuentro.”

El ejemplo concreto ya no es el único apoyo que el lector tenía para comprender el texto. No debe creer ciegamente en un procedimiento más o menos oscuro. La proposición 19 del Libro VII de los Elementos ya no es un frío enunciado sobre cuatro números que cumplen una determinada condición. La práctica se fundamenta en la teoría y ésta, en cierto modo, se justifica y reivindica en la primera.

La misma fusión incipiente entre ambas formas de pensar se observa claramente en el Liber Abaci donde, como veremos, comienzan a aparecer entremezclados problemas puramente prácticos con otros problemas numéricos concretos pero descontextualizados y con bosquejos de demostraciones. Por ejemplo, la fundamentación teórica de la Regla de Tres compuesta que presenta Fibonacci (y que veremos más adelante en II.5.4.) es fundamentada por el autor en base a la teoría de las razones compuestas y cita el Almagesto de Ptolomeo (s. II), así como un tratado de Ahmed ibn Yusuf (s. IX) sobre proporciones.

Por último, con la llegada y generalización del álgebra, muchos de los problemas puramente aritméticos trasmitidos de generación en generación sufrirán una progresiva algebrización en sus modos de resolución ${ }^{28}$. Esto se aprecia, por ejemplo, en el tercer

28 En este sentido son muy interesantes las comparaciones que hace Djebbar (1999) entre los métodos de resolución de diversos problemas por parte de los “calculadores” y de los “algebristas”. 
capítulo del Álgebra de al-Khwarizmi donde todos los problemas planteados acaban siendo traducidos a ecuaciones. En cualquier caso la manipulación de proporciones seguía jugando un papel importante como muestra un tratado sobre herencias de alHububi (un matemático de los siglos X y XI), que comienza con la definición de proporcionalidad entre cuatro números y algunas de sus propiedades (Laabid, 1990, p. 160-162). Más tarde, ya en el siglo XV, al-Kasi proporciona cincuenta reglas de manipulación y transformación de proporciones para poder “determinar los números desconocidos” (Souissi, 1999, p. 306). El uso del simbolismo al que todos estamos ya completamente acostumbrados fue el último de los ingredientes que nos permite comprender la forma en que hoy en día se enfoca la enseñanza y el uso de la proporcionalidad aritmética.

\section{II.4. SOBRE LA TIPOLOGÍA DE PROBLEMAS}

En el papiro de Rhind, obra fechada por el propio copista Ahmose en torno al siglo XVI a.n.e. y en la que reconoce estar copiando textos anteriores datados en torno al siglo XIX a.n.e. (Robins y Shute, 1987, pág. 11), encontramos ya problemas como el siguiente:

"Si 10 hekat de grasa deben durar un año, ¿cuánta grasa puede usarse en un día?’. (Robins y Shute, 1987, p. 51)

La cotidianidad de este problema - planteado en el más antiguo texto de contenido matemático conocido - muestra claramente la importante aplicación práctica que tuvo y tiene el razonamiento proporcional en múltiples situaciones relacionadas con aspectos productivos, comerciales o administrativos. De hecho, la situación que sirve como introducción a la materia en aquellos libros que aspiran a ser compendios del saber de su época, como el Jiu zhang suan shu o el Liber Abaci, es la del intercambio comercial o trueque.

Un aspecto importante respecto de los problemas que se resuelven mediante técnicas relacionadas con la proporcionalidad es su persistencia en el tiempo y su presencia en obras de distintas culturas. Todos los tipos de problemas, con escasísimas excepciones, que aparecen en los textos más antiguos siguen apareciendo en los textos posteriores y de otras culturas. Tan sólo en el caso de los problemas de reparto de 
herencias, que aparecen en la cultura árabe musulmana y en el caso de los problemas de cambio de divisas y de acuñación de moneda, que surgen en la Europa medieval occidental, puede hablarse de problemas nuevos.

Debido a la gran variedad de problemas que se resuelven mediante técnicas relacionadas con la proporcionalidad resulta complicado establecer una clasificación exhaustiva de los mismos. De hecho, no pensamos que sea posible diseñar una clasificación en función de las técnicas de resolución utilizadas, puesto que éstas no son demasiado variadas. Así pues el esquema de la clasificación que vamos a seguir se basa en el contexto en que se presentan los problemas.

No pretendemos que la siguiente lista sea exhaustiva, eso sería imposible. Nos conformamos con ilustrar la gran variedad de situaciones en las que aparece la proporcionalidad y mostrar algunos ejemplos interesantes. Los principales tipos de problemas que vamos a presentar son los siguientes:

1. Problemas relacionados con intercambios.

a. Intercambios de mercancías.

b. Compra-ventas.

c. Cambio de divisas

2. Problemas relacionados con repartos.

3. Problemas relacionados con préstamos.

4. Problemas relacionados con mezclas y aleaciones.

5. Problemas en otros contextos.

De esta clasificación, los cuatro primeros tipos son los más importantes tanto por el número de problemas que aparecen como por su antigüedad y persistencia en el tiempo, pues llegan hasta la actualidad. En el último apartado recogeremos algunos ejemplo que no pueden situarse bajo ninguno de los descriptores anteriores pero que consideramos lo suficientemente importantes como para presentarlos aquí (valgan como ejemplo los típicos problemas de grifos). 


\section{II.4.1. Problemas relacionados con intercambios}

Es muy probable que fueran las situaciones de intercambio de mercancías (o trueque), junto quizás a las de reparto de bienes, las que hicieron surgir el razonamiento proporcional. De hecho, en textos como el Jiu zhang suan shu o el Liber Abaci son las situaciones de trueque las que se presentan como introducción al tema. En economías en las que existía una moneda (todas las estudiadas salvo la egipcia), tenía sentido ya la compra-venta de bienes; aunque dicha situación puede entenderse como un intercambio de mercancías por dinero. Finalmente, al ponerse en contacto distintas culturas o países surge la necesidad de comparar e intercambiar las monedas de cada uno de ellos. También esto lo entendemos como un intercambio.

En este contexto, hemos encontrado principalmente problemas de proporcionalidad simple directa y de proporcionalidad compuesta; en mucha menor medida aparece la proporcionalidad inversa. Es curioso ver que en muchas situaciones de este tipo en las que podría entrar en juego la proporcionalidad inversa, como por ejemplo el intercambio de mercancías en las que se dispone de una unidad que mide la calidad de las mismas, lo que se mide es la falta de calidad y así se evita la proporcionalidad inversa. Tan sólo en el Lilavati hemos encontrado problemas de intercambios, en concreto de compra-venta, en los que se maneja la proporcionalidad inversa.

\section{II.4.1.1. Intercambios de mercancías}

Para poder realizar el intercambio debe existir un criterio que garantice que dicho intercambio es justo. En nuestro estudio hemos encontrado distintos criterios que presentamos a continuación junto con algunos enunciados de problemas:

1. El criterio puede ser una tabla ${ }^{29}$ o una información adicional que indique la cantidad de una determinada mercancía que se obtiene a cambio de una determinada cantidad de la otra:

- "Ahora, se quieren cambiar 5 dou 2/3 sheng ${ }^{30}$ de mijo por semillas de sésamo. Di: ¿Cuánto se obtiene?” (Kangshen et al, 1999, p. 146).

29 Esto es así, por ejemplo, en Jiu zhang suan shu donde uno de los capítulos comienza con una tabla que indica los “tipos de cambio” de diversos cereales. Ver (Kangshen et al, 1999, p. 141). 
- "Cerca de Bugia o Ceuta, alguien transporta en un barco 31 quintales y 64 rollos ${ }^{31}$ de piel de cabra que quiere intercambiar por cuero. Se sabe que 2 quintales de piel de cabra equivalen a 3 de cuero”. (Sigler, 2002, p. 177).

2. También pueden conocerse los precios de ambas mercancías y utilizar dicha información para deducir la forma justa de intercambiarlas ${ }^{32}$ :

- “100 libras (peso) de pimienta cuestan 13 libras (moneda), mientras que un quintal de canela cuesta 3 libras, se desea saber cuántos rollos de canela se obtienen a cambio de 342 libras (peso) de pimienta”. (Sigler, 2002, p. 181).

3. Incluso puede disponerse de una unidad que mida de algún modo la "calidad" de las mercancías intercambiadas ${ }^{33}$ :

- “Cuántas barras de pan de pesu 44 deben intercambiarse por 100 barras de pesu 10?” (Robins y Shute, 1987, p. 52)

\section{II.4.1.2. Compra-venta.}

Los procesos de compra-venta pueden dar lugar a muy diversas situaciones problemáticas. Algunas de las que hemos encontrado son las siguientes:

1. A menudo surge la necesidad de conocer el precio de determinada cantidad de mercancía. Para ello suele conocerse el precio de otra cantidad y se utiliza dicha información para obtener el precio buscado:

- “Un dou de laca cuesta 35 monedas. Ahora hay 5/40 dou. Pregunta: ¿Cuántas monedas se obtienen?” (Cullen, 2007, p. 56).

- “Se pagan 13500 monedas en la compra de 2350 bambúes. Di: ¿Cuánto cuesta cada uno?” (Kangshen et al., 1999, p. 150).

- "Si el precio de una esclava de 16 años es de 32 niskas, encuentra el precio de una de 21 años. Si un buey con dos años de trabajo cuesta 4 niskas,

301 dou = 10 sheng son unidades de capacidad. 1 sheng rondaba los 200 ml. (Kangshen et al., 1999, pp. 9-10).

311 quintal $=100$ rollos.

32 Esto puede observarse en el Liber abaci. Ver Sigler (2002, pp. 188 y ss.).

33 Esto sucede, por ejemplo, en el Papiro de Rhind. Ver (Robins y Shute, 1987, p.51).

34 Esta unidad medía la falta de calidad de las barras de pan, indicando la cantidad de barras obtenidas a partir de 1 hekat de harina (Robins y Shute, 1987, p. 51). 
¿cuánto costará un buey que ha trabajado durante 6 años?” (Patwardan et al., 2001, p. 78).

- “Un quintal de cierta mercancía cuesta 14 libras y 7 sueldos $^{35}$, ¿cuánto cuestan 37 rollos de la misma mercancía?” (Sigler, 2002, p. 134).

2. En otras ocasiones, partiendo de la misma información inicial, lo que interesará es conocer la cantidad de mercancía que puede comprarse con una cierta cantidad de dinero:

- "Si 3/2 pala de azafrán cuestan 3/7 niskas ${ }^{36}$ ¡oh! experto hombre de negocios, responde rápidamente que cantidad de azafrán puede comprarse con 9 niskas” (Patwardan et al., 2001, p. 82).

- "Por 1 niska puede comprarse un 'gadyanaka de oro de 10 quilates. ¿Cuánto oro de 15 quilates puede comprarse por el mismo precio?” (Patwardan et al., 2001, p. 78).

\section{II.4.1.3. Cambio de divisas}

El cambio de divisas es un fenómeno comercial relativamente reciente. Entre los textos estudiados este tipo de problemas únicamente aparece en el Liber abaci; claro que esto no es sorprendente si tenemos en cuenta el contexto en que fue escrito. Este tipo de problemas se hará muy popular en las aritméticas comerciales escritas a partir del renacimiento, dado el abundante intercambio comercial en toda la zona del Mediterráneo (Cassinet, 1999; Labarthe, 1999; Spiesser, 1999).

A la hora de proceder al intercambio puede disponerse de diversa información lo que, por supuesto, dará lugar a situaciones problemáticas diferentes. Algunos ejemplos de estas posibilidades son los siguientes:

1. Puede saberse la cantidad de una de las divisas que se obtiene a cambio de una determinada cantidad de la otra: 
- "Un sueldo de Génova se vende a cambio de 211/2 denario de Pisa, se pretende saber por cuánto se venderán 7 sueldos y 5 denarios $^{37}$ de Génova”. (Sigler, 2002, p. 157)

2. Puede conocerse el valor de las dos monedas a intercambiar respecto de una tercera:

- "Un sueldo imperial vale tanto como 31 denarios de Pisa y un sueldo genovés tanto como 22 denarios de Pisa; se pretende saber cuántos denarios genoveses valen tanto como 7 denarios imperiales”. (Sigler, 2002, p. 186)

3. También puede conocerse toda una cadena de equivalencias entre diversas divisas que “conecten” las dos que quieren cambiarse:

- "Dos denarios imperiales valen tanto como 31 denarios de Pisa, un sueldo genovés tanto como 23 denarios de Pisa, un sueldo de Turín vale lo mismo que 13 denarios de Génova y un sueldo de Barcelona lo mismo que 11 denarios turineses; se pretende saber a cuántos denarios de Barcelona equivalen 15 denarios imperiales”. (Sigler, 2002, p. 195)

4. Por último, puede hacerse el intercambio en base al valor de las mismas determinado por la cantidad de plata (o del metal correspondiente) que contienen:

- “Alguien posee 8 2/3 libras de una determinada moneda de la que cada libra contiene $2 \frac{1 / 4}{\text { onzas }^{38}}$ de plata, además una onza de plata cuesta 7 9/20 libras de Pisa. Se pretende saber cuántas libras de Pisa se obtendrán a cambio de las monedas”. (Sigler, 2002, p. 199)

\section{II.4.2. Problemas relacionados con repartos}

Como ya hemos dicho, los repartos son también una de las situaciones más antiguas en las que aparece el razonamiento proporcional. En el Papiro de Rhind los primeros problemas relacionados con la proporcionalidad aparecen en este contexto. 
Los contextos en los que se hace necesario efectuar un reparto, así como aquello que se ha de repartir, son muy variados. Generalmente, es el contexto el que marca la forma más “justa” de efectuar el reparto; en algunas ocasiones el reparto será directo y, en otras, inverso. Por ejemplo:

1. Se puede repartir un cierto beneficio, ya sea fruto de un trabajo o de una inversión de forma directamente proporcional a la aportación de cada persona:

- “Cuatro capataces reciben 100 hekat cuádruples de grano. Sus cuadrillas están formadas, respectivamente, por 12, 8, 6 y 4 hombres. ¿Cuánto debe recibir cada capataz para distribuir entre sus hombres?”. (Robins y Shute, 1987, p. 42)

- “Un hombre que construía una casa contrató a 6 albañiles, cinco de los cuales eran maestros y uno era aprendiz. Acordó pagarles 25 peniques al día, de modo que el aprendiz recibiera la mitad de lo que recibiera un maestro. ¿Cuánto recibe cada uno de ellos al día?”. (Hadley y Singmaster, 1992, p. 119)

- "Tres hombres hicieron compañía de modo que el primero puso 17 libras, el segundo 29 libras, el tercero 42 libras y el beneficio total fue de 100 libras”. (Sigler, 2002, p. 220)

2. Se puede repartir una pérdida (el pago de un impuesto, por ejemplo) de forma inversamente proporcional al "rango" (militar o social) de cada persona:

- "Hay cinco oficiales de distintos rangos: Dafu, Bugeng, Zanniao, Shangzao y Gongshi. Deben pagar un total de 100 monedas. Si el pago debe compartirse de acuerdo con sus rangos, el de mayor rango paga menos y el de rango más bajo paga más, Di: ¿cuánto debe pagar cada uno?’. (Kangshen et al, 1999, p. 166)

3. Pueden intervenir varios factores a la hora de efectuar el reparto:

- "Sea el siguiente problema de distribución del impuesto sobre el mijo. La oficina de recaudación está en la provincia A, en la que habitan 20520 familias y donde el mijo cuesta 20 monedas cada hu. La provincia B está a 200 li de distancia de la oficina, en ella viven 12312 familias y el mijo cuesta 
10 monedas cada hu. La provincia C está a 150 li de la oficina, allí viven 7182 familias y el mijo cuesta 12 monedas cada lu. La provincia $D$ se encuentra a 250 li, consta de 13338 familias y el precio del mijo es de 17 monedas cada lu. La provincia E, a 150 li de distancia, en ella viven 5130 familias y el mijo cuesta 13 monedas cada lu. El impuesto que deben pagar entre las cinco provincias es de $10000 \mathrm{hu}$. Un carro tiene una capacidad de 25 hu y el transporte cuesta 1 moneda por li. Supongamos que cada familia ha de aportar lo mismo tanto en dinero como en trabajo. Di: ¿cuánto mijo ha de pagar cada provincia?”. (Kangshen et al, 1999, p. 315)

Este tipo de problemas persistirá en el tiempo de forma muy importante, dando lugar a los llamados problemas de "compañías” que recibieron gran atención y muy diverso tratamiento en las aritméticas desde el siglo XIII en adelante, comenzando por el Liber Abaci donde ya se emplea incluso esa denominación. Ver (Gómez, 1999) o (Lamassé, 1999).

Otro contexto muy importante en el que aparecen problemas relacionados con los repartos es el de las herencias. Esto sucede de forma muy particular en el mundo árabe musulmán debido a las estrictas - y a veces enrevesadas - normas que fija el Islam a la hora de efectuar dichos repartos. De hecho, todo el tercer capítulo del Álgebra de alKhwarizmi (Rosen, 1986) está dedicado - si bien desde un punto de vista más algebraico - a problemas de herencias. Un ejemplo típico puede ser el siguiente enunciado extraído de una obra del matemático sevillano del siglo XII al-Hufi (Laabid, 1999, p.321):

“Una mujer deja al morir marido, madre, una hermana, una hermana de padre y una hermana de madre. Su herencia consta de un esclavo y 15 dinares. La hermana ha tomado como herencia el esclavo y ha abonado 5 dinares al resto de herederos. Se trata de calcular el valor total de la herencia y la parte de cada uno.”

Para comprender que se trata de un problema de repartos, hay que tener en cuenta que la ley musulmana (Laabid, 1999) fija que, en este caso, el marido y la hermana deben recibir la mitad de la herencia y el resto un sexto de la misma. En los países regidos aún por esta ley, este tipo de cálculos siguen siendo necesarios (Laabid, 1990). 


\section{II.4.3. Problemas relacionados con préstamos.}

En muchas culturas el préstamo de dinero estuvo mal visto. La ley islámica prohíbe aún hoy los préstamos con interés y en el mundo occidental hubo de ser el calvinismo quien lo justificara desde un punto de vista ético. Sin embargo, el préstamo de dinero a cambio de un cierto interés parece, a juzgar por los testimonios encontrados, una práctica bastante antigua.

El interés simple sigue mereciendo aún hoy la atención de los libros de texto en los temas dedicados a la proporcionalidad, aunque la justificación a este hecho haya que buscarla más en la tradición que en la practicidad o la importancia conceptual. En esencia hemos encontrado dos tipos de problemas que involucran de algún modo el préstamo de dinero:

1. Problemas que se corresponden con lo que hoy llamaríamos proporcionalidad compuesta:

- 'Si el capital es de 100 monedas, el interés es de 3 al mes. Ahora el capital es de 60 monedas y se devuelve cuando han pasado 16 días. Calcula cuánto es el interés”. (Cullen, 2007, p. 58)

- "Si se prestan 1000 monedas se recibe un interés mensual de 30 monedas. Si se prestan 750 monedas durante 9 días ¿cuál es el interés?’. (Kangshen et al, 1999, p. 172)

- “Si el interés por 100 durante 4/3 de mes es $5 \frac{1}{5}$, ¿cuál será el interés por 62 $\frac{1}{2}$ durante $3 \frac{1}{5}$ de mes?”. (Patwardan et al., 2001, p. 84)

2. Problemas en el contexto de los préstamos pero que no se corresponden directamente con la situación típica de calcular el interés proporcionado por un capital invertido un tiempo concreto

- “Cierto hombre depositó 100 libras en cierto banco a un interés de 4 denarios por libra y mes y además cada año recibe un pago de 30 libras. Se debe averiguar durante cuántos años meses, días y horas ese hombre tendrá dinero en ese banco”. (Sigler, 2002, p. 384) 


\section{II.4.4. Problemas relacionados con mezclas y aleaciones}

Al trabajar con materias primas es natural la idea de mezclar productos de diversas calidades - y por lo tanto precios - para poder obtener un producto de un precio determinado o para “diluir” o “rebajar” la calidad del producto. Un caso muy particular de lo anterior es el de los metales preciosos o el de las aleaciones en general. Este último tipo de problema cobró gran importancia en Europa desde el siglo XIII (Williams, 1995), hasta tal punto que un texto de la inspiración del Liber Abaci le dedica todo su capítulo 11 (Sigler, 2002, pp. 227-257).

Nuevamente resulta de interés mostrar algunos ejemplos ilustrativos de la variedad de situaciones diferentes que pueden agruparse bajo este epígrafe:

1. Cuando se trata de mezclas puede buscarse el peso o la pureza de la mezcla, conocidos los de los “ingredientes":

- "En 1 dou de laca se vierten 3 dou de agua. Un cazo tiene una capacidad de 2 dou 7 sheng. Pregunta: ¿cuánta laca y cuánta agua sobran?”. (Cullen, 2007, p. 59)

- “Oh dorado matemático, cuatro clases de oro: 10 masas de 13 quilates, 4 masas de 12 quilates, 2 masas de 11 quilates y 4 masas de 10 quilates se funden juntos para formar uno nuevo. Halla su calidad. Si se purifica para obtener 16 masas de oro, cuál es su calidad. Si una vez purificado el oro es de 16 quilates, ¿cuál es su peso?”. (Patwardan et al., 2001, p. 98)

2. También se puede requerir la cantidad o calidad de uno o varios de los “ingredientes” conociendo los de la mezcla y los del resto de ellos:

- "3 masas de 10 quilates y 1 masa de 14 quilates se mezclan con cierta cantidad de 16 quilates. Si la calidad de la mezcla es de 12 quilates, encuentra el peso del oro de 16 quilates”. (Patwardan et al., 2001, p. 100)

- “Cierto hombre posee 7 libras de plata con las cuales quiere hacer moneda con 2 onzas de plata por libra y quiere saber cuál será el peso total de la aleación, así como la cantidad de cobre que debe añadir”. (Sigler, 2002, p. 228) 
- “Cierto hombre desea fabricar una campana usando una aleación de cinco metales. Un quintal de uno de esos metales cuesta 16 libras, de otro 18 libras, del tercero, 20 libras; del cuarto, 27 y del quinto, 31 libras. La campana ha de pesar 775 rollos y costar $162 \frac{3}{4}$ libras y se pretende averiguar qué cantidad de cada metal ha de utilizar”. (Sigler, 2002, p. 255)

3. En ocasiones, y aquí se muestra claramente la influencia oriental en algunos textos europeos medievales, el contexto del problema está aparentemente muy alejado del de las mezclas y debe ser el que resuelve el problema quien observe las similitudes:

- “Un mercader quiere comprar 100 cerdos por 100 peniques. Por un macho pagará 10 peniques, por una hembra 5 peniques y 1 penique por un par de lechones. ¿Cuántos machos, hembreas y lechones debe comprar para pagar exactamente 100 peniques por 100 animales?”. (Hadley y Singmaster, 1992, p. 106)

\section{II.4.5. Problemas en otras situaciones}

En los apartados anteriores hemos mostrado los contextos más importantes en los que aparece la proporcionalidad. Sin embargo, éstos están lejos de agotar la riqueza de situaciones que pueden ser afrontadas con ayuda de dichas técnicas. Como se observa los problemas siempre aparecen en un contexto más o menos realista pese a que al resolverlos se observa claramente que son problemas “preparados” en el sentido que los datos numéricos que se proporcionan están generalmente adaptados para que las operaciones no sean demasiado complejas (ejemplos 1, 2, 3, 4 y 5). Sin embargo, en el Liber Abaci aparecen por primera vez (en lo que a la proporcionalidad se refiere) problemas totalmente descontextualizados, sin referencia a situación real alguna, a medio camino entre la aritmética práctica y la especulativa: en los que que trata de aplicar reglas generales a situaciones numéricas concretas pero que no provienen, a priori, de ninguna necesidad práctica real (ejemplos 6 y 7). Algunos ejemplos son los siguientes: 
1. Problemas “de grifos”:

- "Ahora tenemos una cisterna que se llena a través de cinco canales. Abre el primero y la cisterna se llenará en 1/3 de día; con el segundo, se llenará en 1 día; con el tercero, en 2 días y medio; con el cuarto en 3 días, con el quinto en 5 días. Supón que se abren los cinco. Di: ¿cuántos días serán necesarios para llenar la cisterna?’. (Kangshen et al, 1999, p. 343)

2. Problemas de persecuciones:

- “Tenemos un campo que mide 150 pies de largo. En un extremo hay un perro y en el otro una liebre. El perro persigue a la liebre cuando esta se echa a correr. El perro recorre 9 pies a cada salto mientras la liebre recorre 7 pies. ¿Cuántos pies habrán recorrido el perro persiguiendo y la liebre huyendo antes de que la liebre sea atrapada?”. (Hadley y Singmaster, 1992, p. 106)

3. Problemas “de adivinación”:

- "Tres hombre portan denarios, uno de ellos dice a los otros, si me dais 7 de vuestros denarios, entonces tendré cinco veces lo mismo que vosotros. El segundo dice a los otros, si me dais 9 denarios yo tendré seis veces lo mismo que vosotros; el tercero, cogiendo 11 denarios, dice tener 7 veces lo mismo que los otros dos. Se pretende averiguar cuánto tiene cada uno”. (Sigler, 2002, p. 300)

4. Descomposición de un número en partes que cumplan ciertas restricciones:

- "Se propone descomponer 10 en cuatro partes distintas y proporcionales, es decir, de forma que el producto de la primera y la cuarta sea igual al producto de la segunda y la tercera”. (Sigler, 2002, p. 265)

- "Descompón 11 en dos partes de manera que una parte multiplicada por 9 es tanto como la otra parte multiplicada por 10”. (Sigler, 2002, p. 310)

5. Problemas diversos de proporcionalidad compuesta:

- “30 planchas de madera, cada una de dimensiones 14 cúbitos por 16 dedos por 12 dedos cuestan 100 niskas. Encuentra, oh amigo, el precio de 14 
planchas cuyas dimensiones son menores a las de las anteriores en 4 unidades”. (Patwardan et al., 2001, p. 86)

- "Cinco caballos comen 6 sestarios de cebada en 9 días; se pretende averiguar cuántos días tardarán 10 caballos en comer 16 sestarios”. (Sigler, 2002, p. 206)

\section{II.5. SOBRE TÉCNICAS DE RESOLUCIÓN}

Existe un gran contraste entre la variedad de problemas considerados de los que la sección anterior, pese a su extensión, es sólo un breve muestrario, y la escasez de técnicas de resolución esencialmente diferentes que se han podido encontrar. A esto hemos de añadir el hecho de que lo habitual en los textos matemáticos antiguos era indicar tan sólo el valor numérico de la solución o, quizás, indicar ordenadamente las operaciones aritméticas a realizar. A veces, extraer de esa secuencia de operaciones la idea de una técnica general exige esfuerzo y, por qué no decirlo, voluntad.

En el campo de la proporcionalidad está claro que la técnica por antonomasia es la Regla de Tres (simple directa). No obstante debe quedar claro que la Regla de Tres se concibe como un algoritmo que, dados tres números, permite obtener un cuarto número que cumple ciertas condiciones. Así pues, a menudo, lo importante a la hora de resolver un problema no será el hecho de aplicar dicho algoritmo, sino ver las manipulaciones que se llevan a cabo con los datos del problema antes de aplicarlo. No obstante, desde una visión actual, la Regla de Tres simple directa sólo es válida en situaciones de proporcionalidad directa. La proporcionalidad inversa y la proporcionalidad compuesta quedarían en principio fuera de su ámbito de aplicación. Por tanto, veremos algunas técnicas específicas que se han utilizado a lo largo del tiempo para resolver dichas situaciones. También dedicaremos espacio a dos técnicas muy importantes basadas en la Regla de Tres: las Reglas de falsa posición.

\section{II.5.1. Devenir histórico de la Regla de Tres}

Aunque en el Papiro de Rhind ya aparecen problemas resueltos mediante la aplicación de una serie de operaciones que obedecerían a la aplicación de una Regla de 
Tres, es en el texto chino Jiu zhang suan shu donde aparece la primera descripción explícita de la Regla de Tres (Kangshen et al, 1999, p. 141):

“Toma el número dado y multiplícalo por la lü [apartado II.3.2] de lo que buscas. El producto es el dividendo. La lü de lo que tienes es el divisor. Divide."

Recordando lo que era una lü es fácil interpretar el texto. Dada una pareja de magnitudes, por ejemplo $\left(M_{1}, M_{2}\right)$, una lü es un par de valores correspondientes de dichas magnitudes, por ejemplo $\left(m_{1}, m_{2}\right)$. Así, si se nos da un valor $m_{1}{ }_{1}$ de la primera magnitud y se nos pide el valor $m_{2}{ }_{2}$ correspondiente, la aplicación del algoritmo descrito implicaría multiplicar $m_{1}{ }_{1}$ (el número dado) por $m_{2}$ (la lü conocida de lo que busco) y dividir entre $m_{1}$ (la lü conocida de lo que tengo). En notación actual se obtiene la conocida expresión:

$$
m_{2}^{\prime}=\frac{m_{1}^{\prime} m_{2}}{m_{1}}
$$

Aunque en el Jiu Zhang suan shu esta regla aparece en un contexto muy determinado (el de intercambiar unos tipos de grano por otros), el comentador de la obra, Liu Hui, observa la generalidad de la Regla de Tres y advierte al lector con unas interesantes palabras (Kangshen et al, 1999, p. 142):

"Esta es una regla general. [El concepto de] lü puede aplicarse en muchos problemas. Como señala el dicho: «Conociendo el pasado puede predecirse el futuro. Muestra la esquina [de un cuadrado] y podrás imaginar las otras tres.» Esta regla puede resolver complicados y engañosos problemas y superar las barreras entre distintas cantidades [de distintos objetos]. Extrae las lü de la situación dada, distinguiendo claramente su lugar en la matriz...”

Para aquellos que estamos familiarizados con la disposición tradicional de los datos a la hora de aplicar la Regla de Tres la expresión "su lugar en la matriz” tiene un significado muy claro. En la época de Liu Hui el significado era aún más claro debido al modo en que los maestros efectuaban sus cálculos, disponiendo una cuadrícula sobre la que efectuaban los cálculos mediante unas barras (Kanghsen et al, 1999, pp. 11-17). 


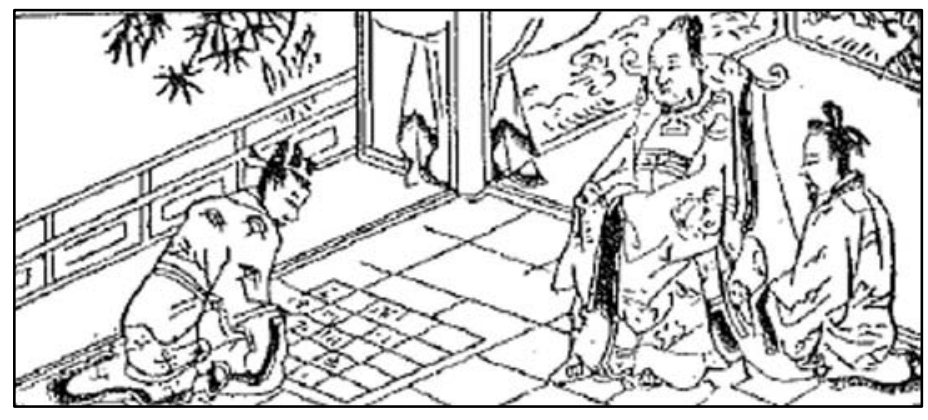

Figura II.3. Cálculos con barras (ilustración japonesa del s. XVIII).

Además de estas palabras, la Regla de Tres parece tener la importancia suficiente como para ser el tema único del capítulo más extenso de la obra, con 46 problemas. En capítulos posteriores, una vez adquirida la destreza necesaria en la aplicación directa de la regla, aparecerán los problemas “engañosos”.

Desde China parece bastante claro y natural que la Regla de Tres se propagara (o quizás fuera también conocida) a la India. Brahmagupta (siglo VII) describe la regla:

“En la Regla de Tres, pramana, phala e iccha son los nombres de los términos. Iccha multiplicado por phala y dividido por pramana es la respuesta, si iccha y pramana son similares”. (Smith, 1953, p. 483)

En obras posteriores de Mahavira (siglo IX) o en el Lilavati aparecen descripciones similares de esta regla, junto con diversos problemas de aplicación directa.

Posteriormente, siguiendo su camino hacia occidente, fue la cultura árabe la que recogió la técnica como parece dejar claro al-Biruni (siglo X) dedicando un texto a la Regla de Tres (Bag, 1975; Youschkevitch, 1976), titulado La Regla de Tres de los hindúes en el que incluso afirma haber visto problemas sobre proporcionalidad que involucraban más de once magnitudes distintas. Esto puede parecer excesivo, pero en el Lilavati (algo posterior) se encuentra un problema en el que aparecen seis magnitudes (Patwardan et al., 2001, p. 86).

El mundo árabe adoptó sin problemas el algoritmo de la Regla de Tres como una herramienta útil a la hora de resolver problemas. Ya el segundo capítulo del Álgebra de al-Khwarizmi (siglos VIII-IX), titulado Sobre transacciones mercantiles presenta una descripción de la Regla de Tres simple directa, afirmando a la conclusión de dicho capítulo que: 
"Este es el procedimiento mediante el que se acuerdan todas las transacciones que involucran intercambios o medidas o pesos”. (Rosen, 1986, p. 70)

El viaje de la Regla de Tres, como técnica bien establecida y descrita metódicamente concluye su periplo hacia occidente en la Plena Edad Media y seguramente como fruto de la interacción entre el mundo árabe y el europeo occidental. En el Liber Abaci leemos:

“En la parte superior derecha de la tabla pon el primer número (la mercancía), después en la misma línea el valor de la mercancía (segundo número). El tercero, si es mercancía, colócalo bajo la mercancía y, si es precio, bajo el precio [...] Como hay cuatro cantidades proporcionales, el producto del segundo por el tercero ha de ser igual al producto del primero por el cuarto”. (Sigler, 2002, p. 127-128)

En este texto llama la atención no sólo el énfasis en el lugar de la colocación de cada valor (como se hace hoy en día en la práctica educativa), sino el hecho de que ya se observa el intento de dar una justificación teórica al método. Aquí se habla explícitamente de cantidades proporcionales y de la propiedad que caracteriza la proporcionalidad de dichas cantidades.

\section{II.5.2. El uso de la Regla de Tres simple directa}

Hemos señalado que el origen de la Regla de Tres como técnica se encuentra en situaciones de intercambio (ver apartado 3.1.). Este origen se hace patente en el hecho de que en los textos consultados la situación introductoria de la regla se da siempre en ese contexto: intercambio de tipos de cereal en el Jiu Zhang suan shu, transacciones e intercambios en el Álgebra de al-Khwarizmi o hallar el valor de mercancías en el Liber Abaci. Sin embargo, la regla resultaría de un interés menor si no pudiera "exportarse” a otras situaciones (como ya indicó Liu Hui). Ahora bien, hay que observar que existen contextos en los que dicha aplicación es más natural que en otros. No obstante, conforme se avanza en el tiempo se observa que aumenta el número de reglas específicas para distintas situaciones, lo que lleva a una menor manipulación previa de los datos pero a un mayor esfuerzo memorístico por parte de un hipotético aprendiz. 
En el Jiu zhang suan shu la totalidad de los problemas relacionados con la proporcionalidad (excepto un único problemas de proporcionalidad inversa), son traducidos por Liu Hui en términos de la Regla de Tres simple directa; incluso aquellos en los que el texto da una regla específica - como es el caso de la Regla de Compañías, por ejemplo - la nueva regla se justifica en base a la Regla de Tres. Veamos el problema siguiente:

“A tiene 560 monedas, B tiene 350 y C tiene 180 monedas. Tienen que pagar un impuesto de 100 monedas para pasar una aduana. Di: ¿cuánto paga cada uno si se reparte de acuerdo con las monedas que cada uno tiene?”. (Kangshen et al., 1999, p. 162)

Para resolverlo, lo que se hace es una Regla de Tres donde los datos son la lü $(1090,100)$ y lo que se busca es completar otras lü de las formas $(560, x)$, $(350, y)$ y $(180, z)$.

Evidentemente, en otras situaciones resulta más complicado, sobre todo, si dichas situaciones están relacionadas con aspectos de proporcionalidad inversa o compuesta. El caso más claro respecto a la proporcionalidad inversa se da en los repartos. Así, cuando el reparto ha de hacerse de forma directamente proporcional a algunos valores e inversamente proporcional a otros el proceso consiste en manipular esos valores para obtener un nuevo valor, de modo que el reparto se hace de forma directamente proporcional respecto de dicho valor. Por ejemplo:

“En la provincia A, a 8 días de la oficina de impuestos viven 10000 familias; en la provincia B a 10 días de distancia viven 9500 familias; en la C, a 13 días, viven 12350. En la provincia D, a 20 días, viven 12200 familias. El impuesto a pagar es de 250000 hu de mijo para los que se necesitarán 10000 carretas. Di: ¿cuánto mijo ha de aportar cada provincia?, ¿cuántos carros usará cada provincia?”. (Kangshen et al., 1999, p. 310)

En esta situación, el reparto ha de hacerse de forma directamente proporcional al número de familias que viven en cada provincia, pero también de forma inversamente proporcional a la distancia que media entre la provincia y la oficina de impuestos. El procedimiento, pues, consiste en fabricar un nuevo indicador (dividiendo el número de familias por la distancia para cada provincia) y repartir de forma directamente 
proporcional a esos valores (en este caso 125 para $A$, 95 para $B, 95$ para $C$ y 61 para $D$ ). De este modo el problema vuelve a consistir es varias Reglas de Tres simples directas sucesivas.

Con respecto a la proporcionalidad compuesta, el artificio es aún más interesante y consiste nuevamente en manipular las magnitudes implicadas, como se pone de manifiesto en el problema siguiente:

"Si se prestan 1000 monedas se recibe un interés mensual de 30 monedas. Si se prestan 750 monedas durante 9 días ¿cuál es el interés?’. (Kangshen et al, 1999, p. 172)

En este caso se dan hasta dos métodos de resolución:

En el primero, el dato en la Regla de Tres a resolver es el par $(30000,30)$ y se busca otro par de la forma $(6750, x)$. La justificación que se da es que la situación es equivalente a que si prestas 30000 (1000 monedas diarias) obtienes 30 monedas y pretendes averiguar lo que se obtiene por 6750 monedas.

En el segundo, el dato es el par $(1000,1)$ y se busca otro de la forma $(6750, x)$. La justificación ahora se basa en que 1000 monedas dan un interés diario de 1 moneda y se pretende averiguar el interés en 9 días de 750 monedas (que se afirma que coincide con el interés diario de 6750 monedas). Nótese que en ambos casos el tiempo pasa a jugar un papel implícito y las magnitudes se manipulan (con pleno sentido) para resolver únicamente una Regla de Tres simple directa.

Con el uso extensivo de la Regla de Compañías, de la Regla de Tres Compuesta y de otras similares, las manipulaciones anteriores quedaron relegadas por la evidente maestría en el manejo de las magnitudes que se requería. Sin embargo, en situaciones en las que no existía una regla concreta el ingenio de los autores seguía siendo necesario para poder aplicar la Regla de Tres. Por ejemplo (Sigler, 2002, p. 275):

"Un hombre compra 7 huevos por un denario y vende 5 huevos por un denario y su beneficio es de 19 denarios; se pretende averiguar cuánto invierte en huevos." 


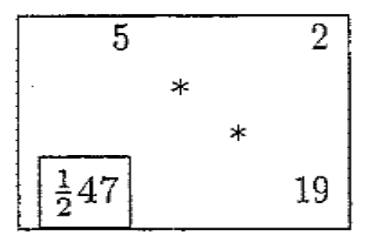

Figura II.4. Regla de Tres para el problema de los huevos.

Como se aprecia en la figura adjunta, Fibonacci observa que si se invierten 5 denarios, entonces el hombre compra 35 huevos que venderá por 7 y el beneficio será de 2 denarios (pudo elegir otra cantidad, pero esta es la más sencilla, el mínimo común múltiplo de 5 y 7). Así que todo se reduce a, sabiendo esto, hallar los denarios invertidos para que el beneficio sean los 19 denarios buscados.

Los ejemplos se podrían multiplicar hasta el infinito; no es ese el objetivo. Lo que ha de quedar claro es que, además de en las situaciones obvias en las que la Regla de Tres tiene aplicación inmediata, también se ha utilizado esta técnica en la resolución de problemas de proporcionalidad compuesta, incluso en aquellos en los que alguna de las variables era inversamente proporcional a otra. Las únicas situaciones en las que no hemos hallado atisbo de uso de esta regla son, evidentemente, aquellas en las que sólo aparecían involucradas dos magnitudes inversamente proporcionales.

\section{II.5.3. Técnicas para la proporcionalidad inversa}

Son escasísimos los problemas de proporcionalidad inversa "pura” (en el sentido de que sólo aparecen dos magnitudes inversamente proporcionales) que se han encontrado. En esos casos, como es natural, no se puede aplicar la Regla de Tres simple directa ni siquiera manipulando los datos del problema. La única posibilidad pasaría por considerar como nueva magnitud la inversa de una de las iniciales, pero a menudo es difícil asignar un significado razonable a la inversa de una magnitud dada.

En los casos en los que no se enuncia una Regla de Tres inversa, como sucede en el Jiu zhang suan shu, la resolución del problema pasa principalmente por tener bien claro el significado de las operaciones con magnitudes, como se ilustra en el siguiente ejemplo: 
“Ahora, alguien con una carga de 1 dan 17 jin realiza 50 trayectos de 76 bu de distancia. Otra persona con una carga de 1 dan realiza trayectos de 100 bu.

Di: ¿cuántos trayectos es capaz de realizar?”. (Kangshen et al., 1999, p. 323)

El método de resolución es el siguiente: “toma el producto de la longitud del nuevo trayecto por la carga de ese trayecto como divisor. Toma el producto de la carga original por la longitud de trayecto y por el número de trayectos como dividendo. Divide para obtener el número de trayectos”. Liu Hui comenta el significado de las operaciones efectuadas: "el divisor es la distancia que puede cubrirse por trayecto llevando la unidad de carga. El dividendo es la distancia que se puede recorrer cargando la unidad de carga. Así al dividir la distancia total entre la distancia por trayecto se obtiene el número de trayectos”. Como se observa el argumento es impecable.

En una anotación de otro comentarista posterior (siglo VII) de la obra se puede leer: “Aquí el número de trayectos disminuye conforme aumenta la distancia y viceversa. Así, la distancia del recorrido original es la lü para en número de trayectos actual y viceversa...” En definitiva, está planteando la idea de una Regla de Tres simple directa, pero intercambiando los lugares de algunos datos; es decir, se está "invirtiendo" la Regla de Tres. No obstante, esta “inversión” no aparece planteada como regla ni se utiliza en la obra original.

En textos posteriores, como en el Lilavati, ya hay mención explícita a una Regla de Tres “invertida” (Patwardan et al., 2001, p. 81):

"Si, en una situación dada, la respuesta buscada disminuye (resp. aumenta) al aumentar (resp. disminuir) iccha entonces la regla de tres invertida será aplicada por el matemático experto.”

Los problemas se resuelven algorítmicamente empleando esta técnica, sin más discusión.

En cualquier caso, como hemos dicho, son muy escasos los problemas antiguos en los que la proporcionalidad inversa juega un papel crucial. El contexto más importante en el que interviene esencialmente la proporcionalidad inversa es el de las mezclas y aleaciones. Esto es así porque cuando se desea mezclar dos calidades de una cierta mercancía para obtener una de una calidad intermedia, las cantidades que se han de 
coger de cada una de ellas son inversamente proporcionales a las diferencias en la calidad (precio, ley, etc...). En términos modernos: si tenemos dos clases de un determinado bien, una de ellas con un precio unitario $p_{1}$ y la otra con un precio unitario $p_{2}$, si tomamos $x$ unidades de la primera e y unidades de la segunda y pretendemos obtener una mezcla de precio unitario $p_{3}$ con $p_{1}<p_{3}<p_{2}$, entonces se tiene que:

$$
p_{1} x+p_{2} y=p_{3}(x+y) \Rightarrow \frac{x}{y}=\frac{p_{2}-p_{3}}{p_{3}-p_{1}}
$$

La justificación, sin recurrir al álgebra, es simple. Lo que gano de más al vender una cantidad del bien más barato a un precio superior ha de ser exactamente lo mismo que lo que dejo de ganar al vender una cantidad del bien más caro a un precio inferior. Esta regla aparece ya en el Lilavati y se utilizó profusamente hasta bien entrado el siglo $\mathrm{XX}$.

\section{II.5.4. Técnicas para la proporcionalidad compuesta}

Es natural que en las situaciones problemáticas planteadas aparezcan más de dos magnitudes, sobre todo si se quiere dar a los problemas visos de realidad. Aparecen así lo que hoy en día denominaríamos problemas de proporcionalidad compuesta.

Ya hemos comentado que en el Jiu zhang suan shu se resuelven estos problemas manipulando las magnitudes implicadas de modo que al final se reduzca el problema a uno que involucre sólo dos magnitudes. En párrafos anteriores se presentó ya un ejemplo.

En la India surgen extensiones de la Regla de Tres simple directa diseñadas para resolver este tipo de problemas. En concreto encontramos (Patwardan et al., 2001, p. 83):

"En el caso de ejemplos sobre las reglas de cinco, siete, nueve, etc... has de mantener los antecedentes en el numerador. Todos los demás términos, excepto el resultado buscado deben estar en el denominador. El producto de los numerados dividido por el producto de los denominadores es la solución buscada."

Esta regla se utiliza en problemas que involucran hasta seis magnitudes. En más complejo es el siguiente: 
“Transportar 30 planchas de madera de dimensiones 14 cúbitos por 16 dedos por 12 dedos a lo largo de una distancia de 1 kosa cuesta 8 drammas, encuentra los gastos por transportar 14 planchas cuyas dimensiones son menores a las de las anteriores en 4 unidades a lo largo de una distancia de 6 kosas”. (Patwardan et al., op. cit., p.86)

El método de resolución no tiene mayor interés puesto que se limita a operar según la regla anterior.

La regla descrita es esencialmente la que se ha utilizado hasta nuestros días, a este respecto merece la pena comparar la regla anterior con la presentada en el capítulo noveno del Liber Abaci. Es interesante indicar que el primer contexto en el que se presenta es también el de transacciones comerciales, en este caso el de intercambio de mercancías de las que se conoce su precio con respecto a una misma moneda. El método general que se propone es (Sigler, op. cit., pág. 179-180):

"Pon una de las mercancías en la parte superior derecha de la tabla. Hacia la izquierda, en la misma fila, su precio. Ahora en la fila inferior y debajo del precio anterior coloca el precio de la otra mercancía y, más hacia la izquierda, la cantidad de dicha mercancía que vale ese precio. Ahora coloca la cantidad de mercancía que quieres cambiar en el lugar correspondiente. Así que hay cinco números, multiplica el último por su diagonalmente opuesto y el resultado por el otro opuesto; divide eso por los dos números restantes.”

Sin embargo es este mismo texto se encuentra una forma alternativa y mucho más interesante de resolver problemas de este tipo, como sucede en el siguiente ejemplo:

“Cinco caballos se comen seis sestarios de cebada en nueve días, ¿cuántos días tardan diez caballos en comer 16 sestarios?’. (Sigler, op. cit., pág. 206)

El primer procedimiento de resolución consiste en aplicar mecánicamente el algoritmo de la Regla de Tres compuesta. Pero justo después el problema se resuelve "paso a paso" diciendo:

"Si cinco caballos comen seis sestarios en nueve días, entonces diez caballo se comerán el doble de seis sestarios en nueve días, puesto que diez caballos son el doble que cinco caballos. De nuevo, como diez caballos comen doce 
sestarios en nueve días, entonces comerán dieciséis sestarios en doce días, lo cual resulta de multiplicar el dieciséis por nueve y dividirlo entre doce."

Este método, además de evitar el uso de la Regla de Tres compuesta, es también esencialmente diferente de las técnicas encontradas en textos anteriores.

\section{II.5.5. Las reglas de falsa posición}

Además de su facilidad para aplicarla directamente, la Regla de Tres simple directa es la base de dos muy importantes técnicas utilizadas para resolver problemas lineales: la Reglas de falsa posición simple y la Regla de doble falsa posición. Estas técnicas son útiles para la resolución de problemas que pueden modelizarse, respectivamente, mediante ecuaciones del tipo $a x=b$ y $a x+b=c$. Su importancia se hace patente en el hecho de que estas reglas, como otras muchas basadas en la proporcionalidad, aparecen en libros de texto hasta bien entrado el siglo XX.

La Regla de falsa posición simple se utiliza para resolver problemas que se modelizan mediante una ecuación de la forma $a x=b$. La idea consiste en dar un valor arbitrario $c$ a la cantidad desconocida, observar el resultado que se obtendría con dicha cantidad (pongamos $b_{1}$ ) y plantear una Regla de Tres simple directa donde los datos son el par $\left(c, b_{1}\right)$ y buscamos otro par de valores correspondientes de la forma $(x, b)$. Desde un punto de vista moderno esto se basa en que, debido a la relación que liga a las magnitudes implicadas, se cumple que:

$$
\frac{c}{b_{1}}=\frac{x}{b}
$$

Los ejemplos más antiguos de este tipo de razonamiento se encuentran, nuevamente, en el Papiro de Rhind. De acuerdo con Robins y Shute (1987) al menos 14 problemas se resuelven mediante técnicas que pueden interpretarse como una aplicación de la idea anterior. El último problema reseñado en el apartado II.5.2. anterior muestra un ejemplo de resolución mediante este método en el Liber Abaci.

No obstante es la Regla de doble falsa posición, quizás por la mayor dificultad de la ecuación $a x+b=c$, la que parece haber recibido más atención por parte de los matemáticos de la antigüedad. La mayor complejidad se basa, con una visión actual, en que la función implicada ya no es lineal, sino que es afín. Como consecuencia, para 
poder aplicar criterios de proporcionalidad hay que involucrar diferencias entre valores y de ahí que sea necesaria una doble suposición. En el Jiu zhang suan shu la regla aparece motivada por problemas como el siguiente:

"Un bien se compra de manera conjunta; si todos contribuyen con 8 sobran 3; si todos contribuyen con 7, faltan 4. Di: ¿Cuál es el número de personas y el precio del bien?”. (Kangshen et al., op. cit., p. 358)

El método de resolución pasa por la aplicación de la siguiente regla:

“Combina el exceso y el defecto como dividendo. Toma las contribuciones y resta la menor de la mayor, la diferencia es el divisor. Divide para obtener el número de personas. Multiplica este número por la contribución y resta el exceso o suma el defecto para obtener el precio.”

En este caso una de las aproximaciones falla por exceso y la otra por defecto, pero para el resto de casos se dan reglas similares en el texto.

En obras hindúes o árabes también hay vestigios de la Regla de doble falsa posición y en el Liber Abaci el capítulo 13 está dedicado a este método bajo el muy elocuente título de "Sobre el Método Elchataym y cómo con él casi todos los problemas de matemáticas pueden ser resueltos” Al inicio del capítulo Fibonacci dice (Sigler, op. cit., p. 447):

"El valor real se encuentra de acuerdo [...] a lo que ocurre en el método de cuatro proporcionales en el que tres números son conocidos y el cuarto desconocido [...]: el primer número es la diferencia entre una falsa posición y la otra. El segundo es la diferencia entre las aproximaciones al verdadero valor. El tercero es la diferencia entre la segunda aproximación y el valor verdadero."

Es decir, que si $p_{\mathrm{i}}$ son las posiciones que proporcionan unos errores respectivos $e_{\mathrm{i}}$ (y se cumple que $p_{1}<p_{2}$ y que $\left.e_{1}<e_{2}<c\right)$, entonces se plantea la proporción:

$$
\frac{p_{2}-p_{1}}{e_{2}-e_{1}}=\frac{x-p_{2}}{c-e_{2}}
$$

En el Liber Abaci se ilustra esta regla y las análogas para otras situaciones relativas de los errores respecto al valor verdadero con múltiples ejemplos. 
Con la llegada del álgebra simbólica y el abandono de las soluciones retóricas estas reglas fueron perdiendo importancia, si bien pueden encontrarse en tratados de aritmética elemental hasta bien entrado el siglo XX. (Meavilla 2005).

\section{II.6. IMPLICACIONES PARA LA ENSEÑANZA DE LA PROPORCIONALIDAD ARITMÉTICA}

Del estudio pormenorizado que acabamos de presentar se desprende una serie de reflexiones que pensamos que deberán ser tenidas en cuenta a la hora de diseñar una propuesta didáctica y de planificar el proceso de enseñanza-aprendizaje de la proporcionalidad aritmética. Algunas de las más importantes son las siguientes:

1. Aparentemente hay en el ser humano una cierta predisposición a razonar proporcionalmente. Esta predisposición a utilizar la proporcionalidad se hace patente en el hecho de que hay problemas muy antiguos (problema 40 del Papiro de Rhind, por ejemplo ${ }^{39}$ ) en los que el uso de la proporcionalidad como técnica de resolución no está ni mucho menos justificado en base al soporte matemático que se poseía en la época.

2. Existen dos modos de concebir la proporción. Bien como la igualdad de dos razones (o fracciones) o bien desde un punto de vista funcional. Este segundo punto de vista sólo se encuentra sugerido en el comentario de Liu Hui al Jiu zhang suan shu y no fue recogido por ninguna cultura posterior.

3. La proporcionalidad inversa parece ser fuente de errores. De hecho, los únicos errores graves encontrados involucran proporcionalidad inversa. En el Jiu Zhang suan shu (donde se considera que la distancia que puede andar un hombre es inversamente proporcional a la carga que lleva) y en el Lilavati (donde el precio de una esclava se toma como inversamente proporcional a su edad). La proporcionalidad directa es, sin embargo, mucho más comprensible. Esto puede deberse a que la proporcionalidad directa es más fácilmente manejable con una visión de proporción como igualdad de razones, mientras que la proporcionalidad inversa se aborda mejor con una visión funcional, más compleja.

39 Repartir 100 hogazas de pan entre 5 hombres de modo que las cantidades recibidas por cada uno estén en progresión aritmética y 1/7 de la suma de lo que reciben los 3 que más reciben es igual a la suma de lo que reciben los dos que menos. 
4. La proporcionalidad directa y la proporcionalidad inversa están muy alejadas, tanto desde un punto de vista matemático como cognitivo. Históricamente esta separación queda reflejada en el desequilibrio que se observa - a favor de la proporcionalidad directa - en cuanto al número de situaciones y problemas que se estudian.

5. Históricamente la génesis de los conceptos relacionados con la proporcionalidad directa se encuentra en las situaciones de intercambio o trueque.

6. Históricamente, el manejo sistemático de la proporcionalidad inversa, sobre todo, surge en contextos que involucran una magnitud que actúa como medida de la “calidad” de algún bien ${ }^{40}$. Como por ejemplo en el caso de mezclas y aleaciones metálicas donde se puede tomar la cantidad de oro por unidad de peso como indicador de la calidad de una aleación.

7. Respecto a la proporcionalidad compuesta; es decir, situaciones en las que aparecen involucradas más de dos magnitudes de forma que consideradas por parejas pueden suponerse proporcionales, existe evidencia de que no es necesario un tratamiento específico del tema. Así, en el Jiu zhang suan shu, observamos que ante una de tales situaciones la técnica utilizada pasa por traducirla a una situación que involucre sólo dos magnitudes mediante una transformación adecuada del problema. A partir de ahí se pueden aplicar las ideas conocidas para proporcionalidad simple.

40 Aunque ya hemos mencionado que en los textos antiguos existe muy poca querencia por la proporcionalidad inversa. Tanto es así que, en algunas ocasiones, lo que se mide es la falta de calidad del bien para así trabajar con magnitudes directamente proporcionales. Ver, por ejemplo, (Robins y Shute, op. cit., p. 51) para el caso egipcio. 


\section{CAPÍTULO III:}

\section{Tratamiento EdUCATIVo DE LA PROPORCIONALIDAD ARITMÉTICA.}

\section{III.1. INTRODUCCIÓN}

El análisis de libros de texto es una importante herramienta a la hora de estudiar los procesos de enseñanza-aprendizaje. Esto es así, entre otros motivos, porque: “observar el proceso de aprendizaje de la humanidad requiere dirigir la atención a la historia de las ideas matemáticas, a través del único registro disponible de las mismas. Esto es, a través de textos y manuales escolares y mediante un análisis de los mismos” (Gómez, 2011, p. 50). Existen variados trabajos al respecto en diferentes sentidos.

La orientación de los trabajos respecto al análisis de textos puede ser variada. En concreto podemos encontrar:

- Trabajos sobre el propio concepto del análisis de textos, como los de Dormolen (1986) o Schubring (1987).

- Estudios comparativos o que analizan la evolución de los propios textos a lo largo del tiempo. Como ejemplos cabe citar Dhombres (1984), Cantoral (1997), Howson (1995) o Pepin et al. (2001).

- Estudios en los que se analiza el tratamiento que distintos conceptos matemáticos han recibido en los textos a lo largo del tiempo. Por ejemplo Maz (2000) respecto a los números negativos, Sierra, González y López (1999, 2003) sobre de los límites y la continuidad de funciones González y Sierra (2004) sobre los puntos críticos de funciones, Escolano (2007) respecto a los 
significados del número racional positivo o Picado y Rico (2009) sobre el sistema métrico decimal.

La primera parte de este capítulo se enmarca en el tercero de los tipos anteriores. Puesto que la proporcionalidad aritmética aparece en los currícula oficiales de los últimos 150 años, parece plenamente justificado emprender un estudio sobre los significados que se otorgan a los contenidos involucrados en la proporcionalidad aritmética desde mediados del siglo XIX hasta la actualidad.

La segunda parte se dedicará a estudiar la propuesta didáctica completa que una editorial propone para la proporcionalidad aritmética. Pensamos que, como dice Schubring (1987); citado por González y Sierra (2004, pág. 390): “los libros de texto determinan la enseñanza en la práctica más que los decretos de los diferentes gobiernos”. En consecuencia el estudio que se realice nos permitirá obtener una visión bastante detallada y real del estado actual de la enseñanza de la proporcionalidad.

En definitiva, mediante el análisis de textos escolares de distintas épocas, perseguimos los dos objetivos parciales siguientes:

1. Caracterizar los significados de la proporcionalidad aritmética presentes en la enseñanza española desde 1850 hasta la vigente ley de educación.

2. Analizar la enseñanza actual de la proporcionalidad.

III.2. SIGNIFICADOS SOBRE PROPORCIONALIDAD ARITMÉTICA DESDE 1850 HASTA LA ACTUALIDAD

\section{III.2.1. Método}

El estudio que hemos llevado a cabo se sustenta, en cuanto al primero de los objetivos parciales que se persiguen, en los tres puntos siguientes:

1. Se toma como eje vertebrador los bloques de contenido en que, tradicionalmente, se ha organizado la enseñanza de la proporcionalidad. A saber:

i. Razón y proporción.

ii. Proporcionalidad directa. 
iii. Proporcionalidad inversa.

iv. Búsqueda de cantidades desconocidas en situaciones de proporcionalidad simple.

v. Proporcionalidad compuesta.

vi. Búsqueda de cantidades desconocidas en situaciones de proporcionalidad compuesta.

vii. Aplicaciones de la proporcionalidad.

2. Se analiza la enseñanza en cinco periodos caracterizados por la existencia de leyes educativas. Estos periodos son los siguientes (Escolano, 2007):

i. 1850-1900: Se generaliza y se extiende la enseñanza obligatoria.

ii. 1900-1950: Se producen importantes cambios políticos y sociales en el país.

iii. 1950-1970: Se producen avances en educación como consecuencia de la apertura al exterior. Estos avances culminarán con la Ley General de Educación que extendió la enseñanza obligatoria hasta los 14 años.

iv. 1970-1980: Este periodo de caracteriza por el auge de la llamada "Matemática Moderna”.

v. 1980-1990: Se abandona el movimiento anterior y se produce un cierto "retorno a lo básico" en cuanto a la enseñanza de las Matemáticas se refiere.

vi. 1990-2010: En este periodo se conjuga una inestabilidad en el marco legal; tres leyes en menos de 20 años (LOGSE de 1990, LOCE de 2002 y LODE de 2006), con una escasa variación tanto en el paradigma de aprendizaje como en el contenido curricular relativo a la proporcionalidad. Se extiende la enseñanza obligatoria hasta los 16 años.

3. Se realiza una búsqueda en libros de texto de cada uno de los periodos establecidos en el punto 2. Se pretende describir las ideas, conceptos y técnicas que figuran en los textos estudiados relativas a los bloques descritos en el punto 1. En un primer momento no entraremos a valorar qué ideas de las que aparecen 
en una determinada época son las predominantes; nos limitaremos a indicar si aparecen o no en los textos objeto de estudio.

Los textos consultados, que aparecen reseñados en la bibliografía de esta memoria, pertenecen al fondo bibliográfico de la Universidad de Zaragoza, a la biblioteca del Instituto de Educación Secundaria Goya de Zaragoza y a la colección privada del propio autor.

\section{III.2.2. Resultados}

A la hora de presentar los resultados obtenidos a partir de nuestro estudio seguiremos el esquema presentado en II.2.1. (apartado 1).

\section{III.2.2.1 Razón y proporción}

a. Significado de la razón.

En los textos estudiados se ha encontrado que la razón puede definirse tanto entre dos números, como entre dos cantidades homogéneas (de la misma magnitud). En ningún caso se asigna significado a la razón entre cantidades de magnitudes distintas.

En la siguiente tabla se recoge la aparición de la razón entre números o entre cantidades en las distintas épocas analizadas.

\begin{tabular}{|c|c|c|c|c|c|c|}
\hline Razón entre & $\mathbf{1 8 5 0 - 1 9 0 0}$ & $\mathbf{1 9 0 0 - 1 9 5 0}$ & $\mathbf{1 9 5 0 - 1 9 7 0}$ & $\mathbf{1 9 7 0 - 1 9 8 0}$ & $\mathbf{1 9 8 0 - 1 9 9 0}$ & $\mathbf{1 9 9 0 - 2 0 1 0}$ \\
\hline Números & SÍ & SÍ & SÍ & SÍ & SÍ & SÍ \\
\hline Cantidades & SÍ & SÍ & SÍ & SÍ & SÍ & NO \\
\hline
\end{tabular}

Más interesante aún que los objetos entre los que se define la razón es la interpretación que se da a dicho objeto.

a1. Interpretaciones de la razón entre dos números:

Cuando el autor de un texto escolar considera la razón entre dos números encontramos los siguientes significados:

1. Su cociente exacto. 
302. El cociente de dos números recibe también los nombres de relación ó razón. Asi, la relación de 8 á 4 es $\frac{8}{4}$, ó en otra forma, $8: 4$ y es $2 ;$ la de 3 á 5 queda indicada, y es $\frac{3}{5}$.

\section{Sanjurjo, 1884, pág. 119.}

2. El resultado de compararlos a través de la división.

664. Llámase razón ó relación el resultado de la compatación de dos cantidades de una misma especie.

665. Dos cantidades pueden compararse entre si por Jiferencia ó por cociente, de donde resultan dos clases de razones : las aritméticas y las gcometricas.

Bruño, 1912, pág. 221.

3. El número por el que se ha de multiplicar el segundo para obtener el primero.

XIV-1. Razón de dos números. - Se denomina razón de dos núme. ros, al cociente exacto de esos números o, lo que es igual, el número por el que se ha de multiplicar el segundo para obtener el primero.

Baratech, 1966b, pág. 89.

Aunque los dos primeros ejemplos son muy similares, el segundo incluye la importante idea de comparación; dando a entender que la razón es algo más que el mero valor numérico, es un proceso de comparación. El tercer ejemplo, que también incluye la idea de cociente (presente en los tres casos), está muy cercano a una idea funcional y resulta de utilidad a la hora de resolver problemas de cantidades desconocidas. No obstante, el que se presenta es el único caso de este tipo de definición.

En la tabla siguiente se recoge la presencia de los significados anteriores en cada una de las épocas analizadas.

\begin{tabular}{|c|c|c|c|c|c|c|}
\hline $\begin{array}{c}\text { Significado entre } \\
\text { números }\end{array}$ & $1850-1900$ & $1900-1950$ & $1950-1970$ & $1970-1980$ & 1980-1990 & $1990-2010$ \\
\hline Cociente exacto & SÍ & SÍ & SÍ & SÍ & SÍ & SÍ \\
\hline $\begin{array}{c}\text { Resultado de } \\
\text { compararlos } \\
\text { dividiendo }\end{array}$ & SÍ & SÍ & NO & $\mathrm{NO}$ & NO & NO \\
\hline $\begin{array}{l}\text { Número por el que } \\
\text { se multiplica uno } \\
\text { para obtener otro }\end{array}$ & NO & $\mathrm{NO}$ & Sí & $\mathrm{NO}$ & NO & NO \\
\hline
\end{tabular}


a2. La razón entre dos cantidades homogéneas aparece definida como:

En el caso de magnitudes homogéneas los significados asociados al concepto de razón que se encuentran son los siguientes:

1. El número que indica la medida de la primera cuando se toma la segunda como unidad.

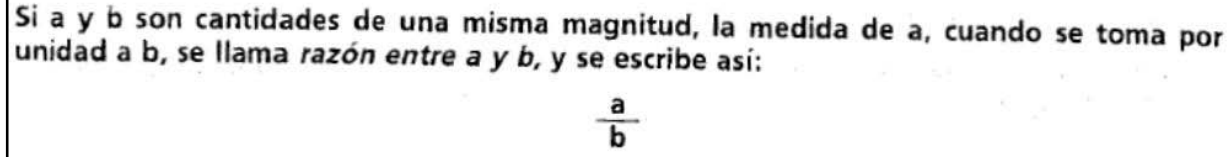

2. El cociente de sus medidas [respecto a otra unidad].

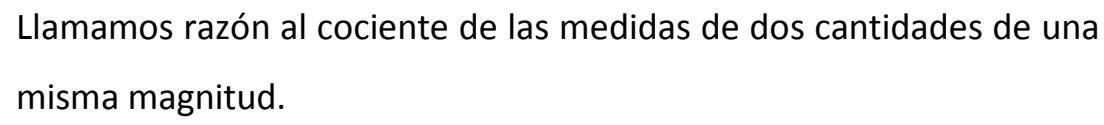

Rico et al., 1977, pág. 191.

3. El número por el que se ha de multiplicar la segunda para obtener la primera.

203. Llámase razón de dos cantidades homogíncas d mímiro por el cual debe multiplicarse la segunda para obterier la primera.

Ruíz, 1931, pág. 129.

En los tres casos, por más que los dos primeros hablen de medir, se acaba definiendo la razón entre magnitudes como un número. La razón nunca es una magnitud. Obsérvese que, excepto en la primera definición, la imposición de que las cantidades sean homogéneas es arbitraria.

En la tabla siguiente se recoge la presencia de los significados anteriores en cada una de las épocas analizadas.

\begin{tabular}{|c|c|c|c|c|c|c|}
\hline $\begin{array}{c}\text { Significado entre } \\
\text { cantidades }\end{array}$ & $\mathbf{1 8 5 0 - 1 9 0 0}$ & $\mathbf{1 9 0 0 - 1 9 5 0}$ & $\mathbf{1 9 5 0 - 1 9 7 0}$ & $\mathbf{1 9 7 0 - 1 9 8 0}$ & $\mathbf{1 9 8 0 - 1 9 9 0}$ & $\mathbf{1 9 9 0 - 2 0 1 0}$ \\
\hline $\begin{array}{c}\text { Medida de la primera } \\
\text { tomando la segunda } \\
\text { como unidad }\end{array}$ & SÍ & SÍ & SÍ & NO & SÍ & NO \\
\hline Cociente de las medidas & NO & SÍ & NO & SÍ & NO & NO \\
\hline $\begin{array}{c}\text { Factor por el que se } \\
\text { multiplica la primera } \\
\text { para obtener la segunda }\end{array}$ & NO & SÍ & SÍ & NO & NO & NO \\
\hline
\end{tabular}


b. El concepto de proporción y aspectos afines:

Frente a la riqueza y variabilidad que se han puesto de manifiesto al hablar del concepto de razón, encontramos que la idea de proporción permanece invariante a lo largo del tiempo. Todos los autores entienden una proporción como la igualdad de dos razones y asignan gran importancia a su propiedad fundamental, que se presenta frecuentemente apelando a la idea análoga en el caso de fracciones. Por ejemplo, en Hurtado (1932, p. 158) leemos:

"Si las dos razones que forman una proporción tienen que ser iguales, fácilmente se comprende que «el producto de los términos extremos será igual al producto de los términos medios».”

También se presta atención, algo menos con el paso del tiempo, a las manipulaciones que permiten obtener nuevas proporciones a partir de otras conocidas: Intercambiar medios, intercambiar extremos, invertir etc...

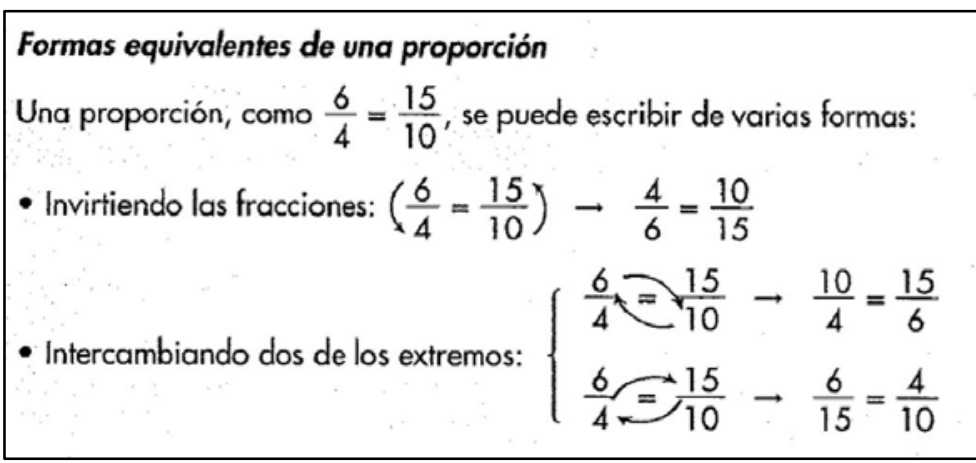

Álvarez et al., 1999b, pág. 78.

Otro aspecto relacionado que aparece repetidamente a lo largo del tiempo es la siguiente propiedad de las proporciones y que fácilmente se extiende a series de razones iguales:

$$
\frac{a}{b}=\frac{c}{d}=\frac{a \pm c}{b \pm d}
$$

Esta propiedad servirá como base para una de las posibles formas de tratar los problemas de repartos directamente proporcionales.

\section{III.2.2.2 Proporcionalidad directa}

Como se puede observar, la riqueza del concepto en cuestión queda ilustrada por la gran variedad de distintas caracterizaciones equivalentes encontradas. Esta riqueza 
hace que, en la mayoría de los textos consultados, aparezca más de una caracterización de la proporcionalidad directa. En esos casos hemos optado por considerar únicamente la que se presenta en primer lugar, entendiendo que dicho lugar es indicativo de la preferencia del autor hacia esa definición. En concreto las caracterizaciones encontradas son las siguientes:

1. Caracterización por razones internas:

Dos magnitudes son directamente proporcionales si la razón entre dos cantidades de una de ellas es la misma que la razón entre las dos cantidades correspondientes de la otra.

I. Se dice que dos cantidades variables, dependientes entre si, son directamente proporcionales, ó simplemente proporcionales, ó que cada una es proporcional á la otra, ó que varia en rasón directa de esta otra, cuando la razón de dos valores arbitrarios de la primera; es igual á la razón de los dos valores correspondientes de la segumda. Por ejemplo, una cantidad

Bartrina, 1910, pág. 264.

2. Caracterización por conservación de un cociente (o por razones externas):

Dos magnitudes son directamente proporcionales si el cociente entre pares de cantidades correspondientes se mantiene constante.

Para generalizar, llamaremos a los valores de una primera magnitud (a prima $=a^{\prime}$ ), (a segunda $\left.=a^{\prime \prime}\right),\left(a\right.$ tercera $\left.=a^{\prime \prime \prime}\right)$, etc., y $\left(\right.$ b prima $\left.=b^{\prime}\right),\left(\right.$ b segunda $=b^{\prime \prime}$ ), etcétera, a los valores correspondientes de la segunda magnitud, y tendremos:

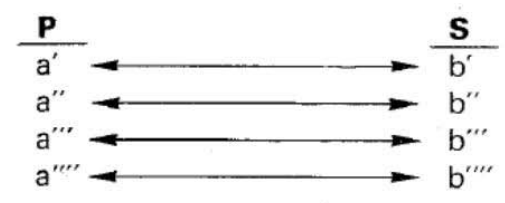

- En correspondencia biunívoca

$$
\text { siendo } \frac{\mathrm{a}^{\prime}}{\mathrm{b}^{\prime}}=\frac{\mathrm{a}^{\prime \prime}}{\mathrm{b}^{\prime \prime}}=\frac{\mathrm{a}^{\prime \prime \prime}}{\mathrm{b}^{\prime \prime \prime}}=\frac{\mathrm{a}^{\prime \prime \prime \prime}}{\mathrm{b}^{\prime \prime \prime \prime}}=\mathrm{K}
$$

Con estas dos condiciones las magnitudes $\mathrm{P}$ y $\mathrm{S}$ son directamente proporcionales, y K su constante de proporcionalidad.

González y Cappa, 1971, pág. 99.

En este caso, teniendo en cuenta que todos los textos presentan la razón bien entre números o bien entre cantidades homogéneas, los autores deben, o bien omitir por completo las magnitudes implicadas, o bien no hablar de razón. En el 
ejemplo mostrado parece optarse por la primera opción, habida cuenta que la constante $K$ es adimensional.

3. Caracterización multiplicativa:

Dos magnitudes son directamente proporcionales cuando al multiplicar (dividir) una cantidad de la primera magnitud por dos, tres, etc..., la cantidad correspondiente de la segunda magnitud queda multiplicada (dividida) por dos, tres, etc...

\section{Dos magnitudes son directamente proporcionales cuando:}

- Al multiplicar una (doble, triple, ...), la otra se multiplica de la misma manera (doble, triple, ...).

- Al dividir una (mitad, tercio, ...), la otra se divide de la misma forma (mitad, tercio,....).

Cólera y Gaztelu, 2008a, pág 162.

Esta caracterización supone un inicio de aproximación hacia un enfoque más funcional; es interesante compararla con la caracterización implícitamente funcional (versión a.) que se presenta más adelante. En ocasiones aparece esta caracterización sólo con el caso del doble y la mitad.

4. Caracterización por aumentos y disminuciones:

Dos magnitudes son directamente proporcionales si al aumentar o disminuir una de ellas, la otra también aumenta o disminuye respectivamente.

223. División de las reglas de tres simples. - Las reglas de tres simples se dividen en directas e inversas. Son directas cuando van de más a más o de menos a menos, e inversas, cuando van de más a menos o de menos a más.

Dalmau, 1930, pág. 213.

Esta caracterización, obviamente incorrecta, aparece ante el deseo de proporcionar a los alumnos un criterio “sencillo” para decidir el tipo de relación de proporcionalidad ante el que se encuentran. Evidentemente, comprobar este criterio resulta mucho más sencillo para el alumno que cualquiera de los otros. En particular, evita tener que realizar consideraciones cuantitativas, centrándose en las puramente cualitativas. Muchos autores, conscientes de su incorrección, omiten este criterio a la hora de caracterizar la proporcionalidad directa. Sin 
embargo, a la hora de resolver los problemas, sucumben ante su sencillez y acaban presentándolo como regla práctica.

Quede dicho que si nos restringimos a las magnitudes proporcionales, el criterio anterior es cierto (salvo que admitamos cantidades negativas). Pero la experiencia diaria nos muestra que existen multitud de magnitudes relacionadas entre sí mediante relaciones que no son de proporcionalidad.

5. Caracterización explícitamente funcional:

Dos magnitudes son directamente proporcionales si están relacionadas mediante una función lineal $y=k x$ (o análoga).

\section{Llamamos magnitudes directamente proporcionales a aquellas que están relacionadas mediante una función lineal: $a x=y$.}

Rico et al., 1977, pág. 186.

Podemos pensar que esta caracterización es una versión funcional y, por tanto, más abstracta, de la caracterización por conservación que hemos presentado más arriba. Sin embargo, presenta grandes inconvenientes desde un punto de vista práctico, por lo que los autores que utilizan esta definición terminan por presentar alguna otra (en especial la caracterización por razones o la implícitamente funcional (en su versión a.) para poder afrontar los problemas.

6. Caracterización implícitamente funcional:

Empleamos el término 'implícitamente' en el sentido de que, si bien las caracterizaciones a las que vamos a hacer referencia no hablan explícitamente de funciones o aplicaciones, sí que nos parece que sus enunciados tienen una fuerte componente funcional.

a. Dos magnitudes son directamente proporcionales si están relacionadas mediante una función $y=f(x)$ tal que $f(a x)=a f(x)$.

Dos magnitudes son directamente proporcionales si al multiplicar (o dividir) una de ellas por un número, la otra queda multiplicada (o dividida) por ese mismo número.

Álvarez el at., 2003a, pág. 132. 
Esta caracterización es la generalización de la que hemos llamado caracterización multiplicativa. De hecho, en algunos textos (Cólera y Gaztelu, 2008a, 2008b) se presenta la caracterización multiplicativa en $1^{\text {o }}$ de E.S.O. y la caracterización implícitamente funcional en $2^{\circ}$ de E.S.O.

b. Dos magnitudes son directamente proporcionales si se corresponden en igualdad y en suma. Es decir, si están relacionadas mediante una función $y=f(x)$ tal que $f(a+b)=f(a)+f(b)$.

DEFINICIÓN.-Dos magnitudes se llaman directamente proporcionales cuando hay una correspondencia entre cada cantidad de una y cada cantidad de la otra, de tal modo que a una cantidad suma de dos cantidades de una magnitud corresponde una cantidad que es la suma de las cantidades correspondientes a aquéllas.

Rey y Puig, 1935, pág. 115.

Esta caracterización, bastante poco extendida, es sólo parcialmente correcta por cuanto se necesita la hipótesis (asumida por los autores sin decirlo) de la continuidad de la relación que liga ambas magnitudes.

Para concluir con esta sección recogemos en la siguiente tabla la presencia de cada una de las caracterizaciones anteriores según las épocas estudiadas:

\begin{tabular}{|c|c|c|c|c|c|c|}
\hline Caracterización & $\mathbf{1 8 5 0 - 1 9 0 0}$ & $\mathbf{1 9 0 0 - 1 9 5 0}$ & $\mathbf{1 9 5 0 - 1 9 7 0}$ & $\mathbf{1 9 7 0 - 1 9 8 0}$ & $\mathbf{1 9 8 0 - 1 9 9 0}$ & $\mathbf{1 9 9 0 - 2 0 1 0}$ \\
\hline Razones internas & NO & SÍ & SÍ & NO & SÍ & NO \\
\hline Razones externas & NO & SÍ & NO & SÍ & SÍ & SÍ \\
\hline Multiplicativa & SÍ & SÍ & SÍ & NO & NO & SÍ \\
\hline $\begin{array}{c}\text { Aumentos } y \\
\text { disminuciones }\end{array}$ & NO & SÍ & SÍ & NO & NO & SÍ \\
\hline Exp. funcional & NO & NO & NO & SÍ & SÍ & NO \\
\hline Imp. funcional $a$. & SÍ & SÍ & SÍ & SÍ & SÍ & SÍ \\
\hline Imp.funcional $b$. & NO & SÍ & SÍ & NO & NO & NO \\
\hline
\end{tabular}

\section{III.2.2.3 Proporcionalidad inversa}

Como no puede ser de otro modo, el análisis de las caracterizaciones encontradas para la proporcionalidad inversa ha de ser muy similar al efectuado en el apartado anterior y muchos de los comentarios que allí se hicieron siguen siendo válidos aquí. Todas las caracterizaciones de la proporcionalidad directa (excepto la denominada implícitamente funcional b.) tienen su "reflejo" en el caso de la proporcionalidad 
inversa. De hecho, es muy frecuente que las caracterizaciones de uno y otro tipo de proporcionalidad se den siempre emparejadas del mismo modo. Se han encontrado las siguientes caracterizaciones para la proporcionalidad inversa:

1. Caracterización por razones internas:

Dos magnitudes son inversamente proporcionales si la razón entre dos cantidades de una de ellas es la razón inversa de la razón entre las dos cantidades correspondientes de la otra.

24. Cantidades inversamente proporcionales son dos cantidades relativas tales, que la razón de dos valores cualesquiera de una de ellas sea constantemente inversa de la razón de los valores correspondientes de la otra. De modo que, con la misma notación anterior, se pueda formar la proporción $\frac{a}{a^{\prime}}=\frac{b^{\prime}}{b}$.

Moya, 1897, pág. 156.

2. Caracterización por conservación de un producto:

Dos magnitudes son inversamente proporcionales si los productos de cantidades correspondientes de ambas magnitudes son constantes.

\begin{tabular}{|c|c|c|c|c|}
\hline \multicolumn{5}{|c|}{ Dos magnitudes cuyas cantidades se corresponden con esta tabla: } \\
\hline Magnitud 1.: & $a$ & $b$ & c & $\ldots$ \\
\hline Magnitud 2," & $a^{\prime}$ & $b^{\prime}$ & $c^{\prime}$ & $\cdots$ \\
\hline \multicolumn{5}{|c|}{ son inversamente proporcionales si se verifica que: } \\
\hline \multicolumn{5}{|c|}{$a \cdot a^{\prime}=b \cdot b^{\prime}=c \cdot c^{\prime}=\ldots=k$} \\
\hline \multicolumn{5}{|c|}{ siendo $k$ la constante de proporcionalidad inversa. } \\
\hline
\end{tabular}

S.M., 2009b, pág. 130.

Ante este tipo de caracterización, el mayor problema surge a la hora de tratar de asignar un significado a esos productos constantes; sobre todo, porque se omiten por completo las magnitudes implicadas, centrándose el análisis sólo en los valores numéricos de las cantidades.

3. Caracterización multiplicativa:

Dos magnitudes son directamente proporcionales cuando al multiplicar (dividir) una cantidad de la primera magnitud por números enteros, la 
cantidad correspondiente de la segunda magnitud queda dividida (multiplicada) por dichos números.

317. Dos cantidades son inversamente proporcionales cuando multiplicando el valor de la primera por $2,3,4$, etc., el de la segunda queda dividido por el mismo número.

Edelvives, 1951, pág. 192.

4. Caracterización por aumentos y disminuciones:

Dos magnitudes son inversamente proporcionales si al aumentar o disminuir una de ellas, la otra también disminuye o aumenta respectivamente.

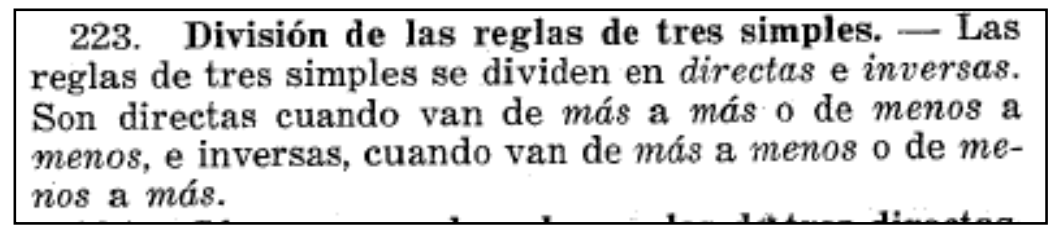

Dalmau, 1930, pág. 213.

5. Caracterización explícitamente funcional:

Dos magnitudes son inversamente proporcionales si están relacionadas mediante una función $y=k / x$.

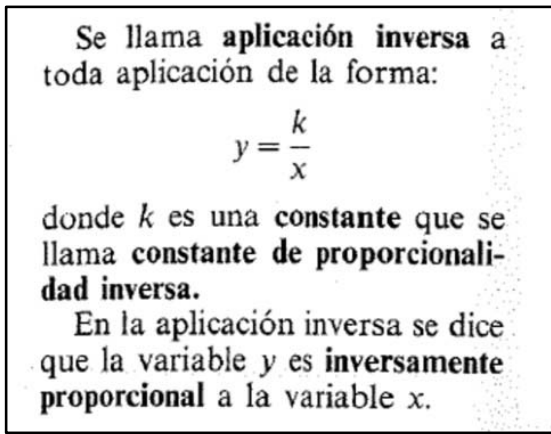

Signo, 1983, pág. 141.

6. Caracterización implícitamente funcional:

Dos magnitudes son inversamente proporcionales si al multiplicar una cantidad de la primera por un número, la cantidad correspondiente de la segunda queda dividida por el mismo número. Es decir, si están relacionadas mediante una función $y=f(x)$ tal que $f(a x)=f(x) / a$. 
Se dice que dos magnitudes relacionadas son inversamente proporcionales cuando al multiplicar un valor de una de ellas por un número, el valor correspondiente de la otra queda dividido por el mismo número.

Rodríguez, 1965, pág. 75.

En la tabla siguiente se refleja la aparición de estas caracterizaciones en cada una de las épocas analizadas.

\begin{tabular}{|c|c|c|c|c|c|c|}
\hline Caracterización & $\mathbf{1 8 5 0 - 1 9 0 0}$ & $\mathbf{1 9 0 0 - 1 9 5 0}$ & $\mathbf{1 9 5 0 - 1 9 7 0}$ & $\mathbf{1 9 7 0 - 1 9 8 0}$ & $\mathbf{1 9 8 0 - 1 9 9 0}$ & $\mathbf{1 9 9 0 - 2 0 1 0}$ \\
\hline Razones internas & NO & SÍ & SÍ & NO & SÍ & NO \\
\hline $\begin{array}{c}\text { Conservación } \\
\text { producto }\end{array}$ & NO & Sí & NO & SÍ & Sí & SÍ \\
\hline $\begin{array}{c}\text { Multiplicativa } \\
\begin{array}{c}\text { Aumentos } y \\
\text { disminuciones }\end{array}\end{array}$ & SII & SÍ & SÍ & NO & NO & SÍ \\
\hline Exp. funcional & NO & NO & NÓ́ & NO & NO & SÍ \\
\hline Imp. funcional & SÍ & SÍ & SÍ & SÍ & SÍ & NO \\
\hline
\end{tabular}

\section{III.2.2.4 Búsqueda de cantidades desconocidas en proporcionalidad simple}

En la práctica, el esfuerzo dedicado a la caracterización de las magnitudes directa e inversamente proporcionales se refleja en los problemas de búsqueda de cantidades desconocidas. En ellos se conocen dos cantidades relacionadas de sendas magnitudes y se hace necesario encontrar la cantidad de una de ellas relacionada con una cantidad dada de la otra.

Cabría esperar una mayor relación entre la caracterización elegida por el autor para cada uno de los tipos de magnitudes proporcionales y los métodos de resolución utilizados, pero lo cierto es que, como se observará a continuación, hay dos métodos de resolución que permanecen inalterables a lo largo del tiempo. También es muy habitual que, aunque en el texto se presente un método justificado, se de a los alumnos un algoritmo supuestamente fácil de memorizar y que les alivie el trabajo. Huelga decir que, como en tantas situaciones, el algoritmo acaba suplantando a la idea.

En los diferentes textos analizados se han encontrado las siguientes técnicas de resolución: 
1. Regla de tres tradicional:

Se disponen los datos en forma tabular de un modo más o menos “canónico” y se aplica un algoritmo más o menos injustificado en función de si se trata de proporcionalidad directa o inversa.

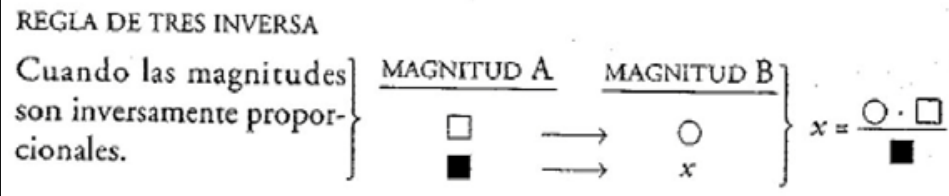

Cólera y Gaztelu, 2008c, pág. 65.

El anterior es uno de los ejemplos más claros de cómo se presenta un algoritmo con el único afán de su memorización. Hay otras versiones menos extravagantes, que incluyen el uso del lenguaje algebraico, pero que comparten el espíritu de este ejemplo.

2. Por proporciones:

Se basa en la caracterización de la proporcionalidad (directa o inversa) por razones internas o por conservación y en la propiedad fundamental de las proporciones. A partir de los datos se plantea una proporción y se reduce el problema a encontrar el cuarto proporcional de los tres valores dados.

II. Con una cantidad de metal se han obtenido $576 \mathrm{mc}$ tros de alambre de $2 \mathrm{~mm}{ }^{2}$ de sección; đcuántos metros de alambre se obtendrán con la misma cantidad de metal, si la sección fuese de 1 '5 mm.2?

Las variables son: longitud y sección; si se dobla la seccion, la longitud queda reducida a la mitad; luego, la proporcionalidad es inversa. Se tendrá, pues,

$576: x=1 ` 5: 2, \quad$ de donde, $\quad x=576 \times 2: 1 ‘ 5=768$ mts.

Crusat, 1941, pág. 227.

El método anterior es el que aparece con más profusión en los textos analizados. Esto tiene pleno sentido, pues es el método que utiliza de manera directa las ideas centrales de razón y proporción tal y como se presentan en el discurso teórico. 
3. Por reducción a la unidad:

Se trabaja en dos pasos, primero se obtiene la cantidad de la magnitud buscada que se corresponde con una unidad de la otra magnitud y con ese dato se obtiene la cantidad desconocida. El "paso a la unidad” se realiza en los textos de dos formas:

a. Mediante el significado de las operaciones con números decimales.

2.0 Si 23 libros de igual precio han costado 1242 pesetas. ¿Cuánto Hibro hubiéramos adquirido con 918 pesetas, en las mismas condiciones'

El precio de un libro será 1242 ptas. : $23=54$ pesetas.

por lo que el número de libros comprados con 918 ptas., será el cocientı $918: 54=17$

Baratech, 1966a, pág. 89.

Este método tiene ciertos inconvenientes a la hora de ser aplicado en el caso de la proporcionalidad inversa puesto que el "paso a la unidad” es difícil (a veces casi imposible) de justificar basándose únicamente en el significado de las operaciones.

b. Aplicando la caracterización multiplicativa o la implícitamente funcional.

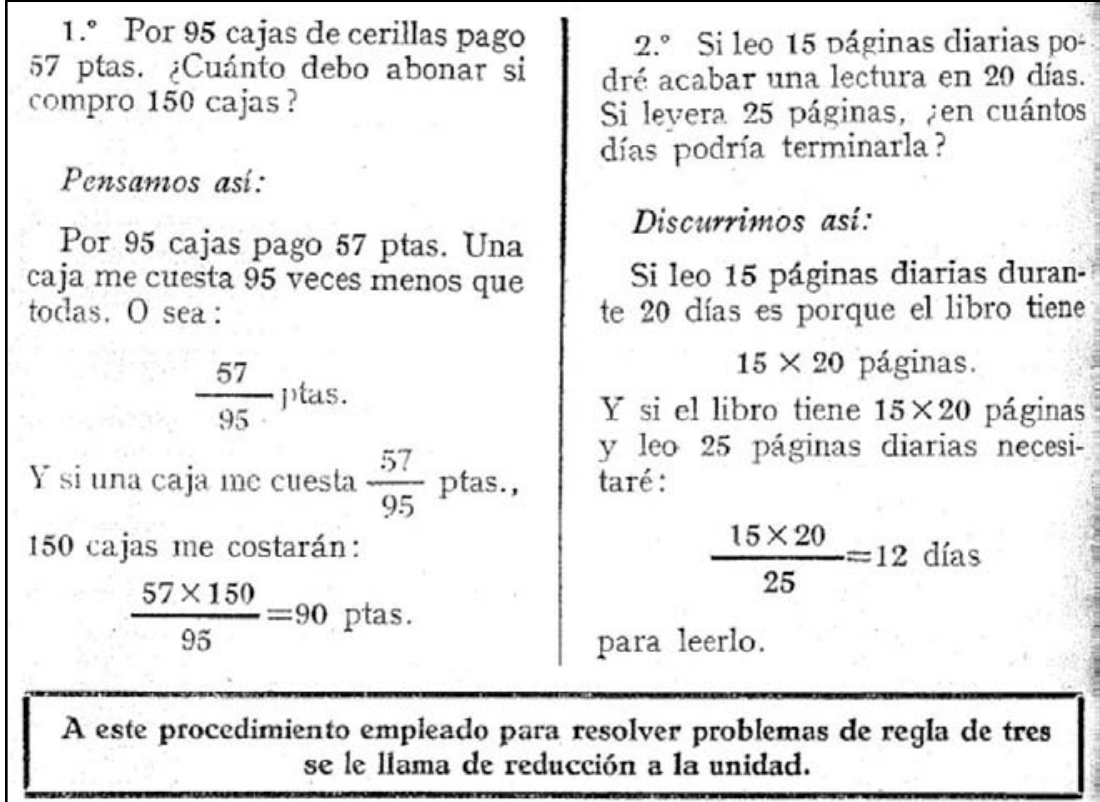

Ortega, 1963, pág. 112. 
La diferencia entre las dos variantes anteriores puede parecer sutil, pero pensamos que es de suma importancia. Si se observa el ejemplo $1^{\circ}$ anterior de Ortega (1963) es interesante ver que si por 95 cajas se pagan 57 pesetas, el motivo de que para encontrar el precio de una caja haya que dividir 57/95 no se justifica en que el precio total se reparte por igual entre todas las cajas que se compran, sino en que 1 caja cuesta 95 veces menos que 95 cajas. Estos diferentes modos de pensar, a nuestro entender, reflejan formas radicalmente diferentes de concebir la idea de razón y, por ende, la de proporcionalidad.

c. Recurriendo a la Regla de tres tradicional.

Calculamos el precio de 1 barra y luego hallamos el precio de 20 barras.

Barras de pan Precio

$$
\begin{aligned}
& \left.\begin{array}{ll}
6 \longrightarrow \\
1 \longrightarrow x
\end{array}\right\} \rightarrow \frac{6}{3}=\frac{1}{x} \leftrightarrow 6 \cdot x=3 \cdot 1 \leftrightarrow \\
& \leftrightarrow \mathrm{x}=\frac{3}{6} \leftrightarrow \mathrm{x}=0,5
\end{aligned}
$$

1 barra cuesta $0,5 € \rightarrow 20$ barras cuestan $\rightarrow 20 \cdot 0,5 €=10 €$.

Álvarez et al., 2003, pág. 160.

Este método de resolución resulta sorprendente. Si bien la idea está clara y es la misma que en los casos anteriores, en este caso, el valor unitario de obtiene de una forma totalmente mecánica. En el ejemplo mostrado se recurre al método de las proporciones para encontrar dicho valor unitario.

A continuación recogemos la aparición de los anteriores métodos en los periodos de tiempo estudiados:

\begin{tabular}{|c|c|c|c|c|c|c|}
\hline Técnica & $\mathbf{1 8 5 0 - 1 9 0 0}$ & $\mathbf{1 9 0 0 - 1 9 5 0}$ & $\mathbf{1 9 5 0 - 1 9 7 0}$ & $\mathbf{1 9 7 0 - 1 9 8 0}$ & $\mathbf{1 9 8 0 - 1 9 9 0}$ & $\mathbf{1 9 9 0 - 2 0 1 0}$ \\
\hline Algoritmo & SÍ & SÍ & SÍ & NO & NO & SÍ \\
\hline Proporciones & SÍ & SÍ & SÍ & SÍ & SÍ & SÍ \\
\hline Red. Unidad $a$. & NO & NO & SÍ & NO & NO & SÍ \\
\hline Red. Unidad $b$. & SÍ & SÍ & SÍ & SÍ & SÍ & SÍ \\
\hline Red. Unidad $c$. & NO & NO & NO & NO & NO & SÍ \\
\hline
\end{tabular}




\section{III.2.2.5 Proporcionalidad compuesta}

1. Definición de proporcionalidad compuesta.

El concepto de proporcionalidad compuesta permanece casi inalterado a lo largo del tiempo. En todos los textos en los que se trata este tema se presenta una definición muy similar a la siguiente: Una magnitud es proporcional (de forma compuesta) a otras varias cuando es proporcional (directa o inversamente) a cada una de ellas al permanecer fijas las restantes. Sirvan como ilustración los siguientes ejemplos, separados entre sí más de un siglo:

253. REgla de tres Compuesta.-El carácter general de todas las cuestiones á que puede aplicarse esta regla es: que comprendan un. número par de cantidades, inclusa la incógnita; que sean homogéneas dos á dos, y que estén ligadas entre sí por una proporcionalidad. Su

Moya, 1897, pág. 160.

En la regla de tres compuesta intervienen más de dos magnitudes, con distintas relaciones de proporcionalidad entre ellas

De la Haza et al., 2003, pág. 83.

2. Propiedad fundamental de las magnitudes en proporción compuesta:

De cara a la resolución de problemas de búsqueda de cantidades desconocidas en situaciones de proporcionalidad compuesta (apartado 1.2.6.) encontramos textos que presentan una propiedad que les permite construir una proporción y así resolver el problema:

Por tanto, cuando las relaciones entre las magnitudes son de tipo directo, podemos decir que:

«La razón de las dos cantidades de la primera magnitud por la razón de las dos cantidades de la segunda magnitud es igual a la razón de las dos cantidades de la tercera magnitud."

Rico et al., 1977, pág. 216.

Como es evidente, cuando las relaciones no son todas de proporcionalidad directa se enuncian las propiedades análogas. Esta propiedad dará lugar, como veremos, a un método para resolver problemas de proporcionalidad compuesta. 


\section{III.2.2.6 Búsqueda de cantidades desconocidas en situaciones de proporcionalidad compuesta}

$\mathrm{Al}$ igual que sucedía en el caso de la proporcionalidad simple (directa o inversa), el énfasis se hace más en la resolución de problemas que en el reconocimiento o caracterización de las situaciones (con los problemas que ello conlleva).

A la hora de resolver problemas de búsqueda de cantidades desconocidas en situaciones de proporcionalidad compuesta se han encontrado esencialmente tres posibilidades. La primera de ellas es la mera presentación de un algoritmo, mientras que las otras dos surgen de la definición de proporcionalidad compuesta o de la propiedad fundamental presentada en el apartado anterior. Son las siguientes:

1. Regla de tres compuesta tradicional:

Se disponen los datos en forma tabular de un modo más o menos “canónico” y se aplica un algoritmo injustificado en función de las relaciones que ligan cada pareja de magnitudes.

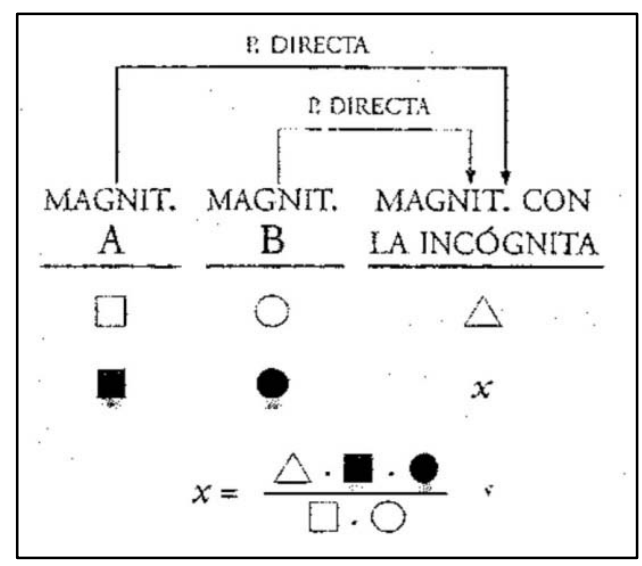

Cólera y Gaztelu, 2008c, pág. 66.

Además de ser sólo aplicable en el caso de tres magnitudes (de hecho en los problemas apenas aparecen situaciones con mayor número de ellas) el esfuerzo memorístico es notable e inútil.

2. Por proporciones:

Se construye una proporción con los datos del problema (haciendo uso de la propiedad fundamental de la proporcionalidad compuesta) y se reduce a encontrar un cuarto proporcional. 


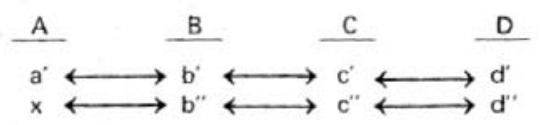

Ahora vamos a suponer que la magnitud $\mathrm{A}$ es directamente proporcional con $\mathrm{B}$ e inversamente proporcional con las magnitudes $\mathrm{C}$ y $\mathrm{D}$; podemos establecer la siguiente igualdad:

$$
\frac{a^{\prime}}{x}=\frac{b^{\prime}}{b^{\prime \prime}} \cdot \frac{c^{\prime \prime}}{c^{\prime}} \cdot \frac{d^{\prime \prime}}{d^{\prime}}
$$

por subsistir la proporcionalidad, porque si una magnitud depende de otras varias, la relación de dos valores de la primera es igual al producto de las relaciones directas o inversas de los valores correspondientes de las otras magnitudes, según que sean directa o inversamente proporcionales con la primera.

Si despejamos x en la anterior proporción, nos dará:

$$
x=a^{\prime} \cdot \frac{b^{\prime \prime} \cdot c^{\prime} \cdot d^{\prime}}{b^{\prime} \cdot c^{\prime \prime} \cdot d^{\prime \prime}}
$$

\section{González y Cappa, 1971, pág. 113.}

Este método no posee ventajas esenciales respecto al anterior puesto que en vez de memorizar la disposición de cada una de las cantidades en la fórmula, lo que debe recordarse es la citada propiedad fundamental. Se observa la tendencia a la algebrización y hacia el uso de lenguaje simbólico.

\section{Paso a paso:}

Se pasa de los datos iniciales a la situación incógnita paso a paso, fijando en cada uno de ellos todas las magnitudes involucradas, salvo la magnitud que se pide y otra más. Así, cada paso no es más que una regla de tres simple.

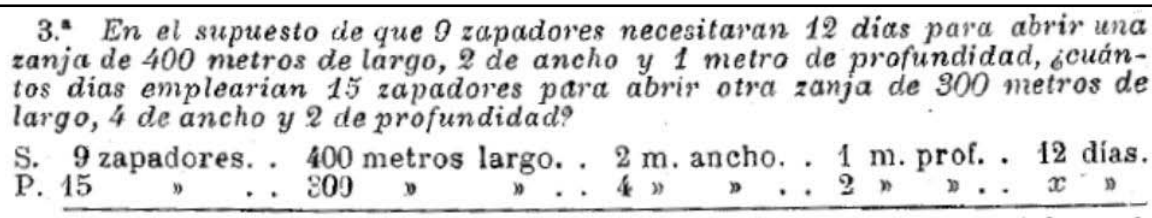

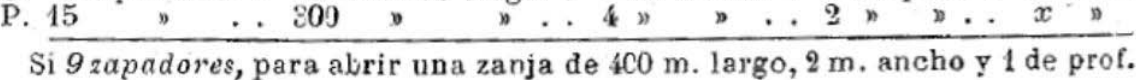
están. . . . 12 días,

un zapador, para hacer 10 mismo, empleará Ø̃ veces más dias.

esto es, $12 \times 9$, dias.

Si un zapador emplea $12 \times 9$, dias,

15 zapadores, para hacer el mismo trabajo, emplearán 15 veces menos días, esto es, $\frac{12 \times 9}{15}$ dias.

Si 15 zapadores, para hacer una zanja de 400 metros largo, $2 \mathrm{~m}$. a. y $1 \mathrm{~m}$. profundidad, están $\frac{12 \times 9}{15}$ dias,

los mismos zapadores, para abrir una zanja de 1 metro largo, el mismo ancho é igual prof, emplearian 400 veces menos dias, esto es, $\frac{12 \times 9}{15 \times 400}$ dias,

Dalmáu, 1898, pág. 172. 
Por su extensión, no se ha reproducido la resolución completa, pero la idea queda bien clara en el fragmento expuesto. Desde un punto de vista conceptual, este procedimiento de resolución es mucho más rico que los otros dos pues implica una buena comprensión de la relación entre cada par de magnitudes. No obstante, se produce un abuso de la idea de "tantas veces más” o “tantas veces menos” frente al recurso a la idea de razón.

En la siguiente tabla se recoge la aparición de los anteriores métodos en los periodos de tiempo estudiados:

\begin{tabular}{|c|c|c|c|c|c|c|}
\hline Técnica & $\mathbf{1 8 5 0 - 1 9 0 0}$ & $\mathbf{1 9 0 0 - 1 9 5 0}$ & $\mathbf{1 9 5 0 - 1 9 7 0}$ & $\mathbf{1 9 7 0 - 1 9 8 0}$ & $\mathbf{1 9 8 0 - 1 9 9 0}$ & $\mathbf{1 9 9 0 - 2 0 1 0}$ \\
\hline Algoritmo & SÍ & SÍ & SÍ & NO & SÍ & SÍ \\
\hline Proporciones & SÍ & SÍ & SÍ & SÍ & SÍ & NO \\
\hline Paso a paso & SÍ & SÍ & SÍ & NO & SÍ & SÍ \\
\hline
\end{tabular}

\section{III.2.2.7 Aplicaciones}

Tradicionalmente los temas relacionados con la proporcionalidad que venimos de presentar desembocan en una serie de aplicaciones cuyo origen se remonta en ocasiones aún más en el tiempo. A continuación vamos a desgranar las aplicaciones más importantes que hemos identificado.

1. Porcentajes:

Se han hallado tres formas de enfocar y resolver los problemas de porcentajes:

a. Teniendo en cuenta el significado del concepto "porcentaje” y de las operaciones con números decimales.

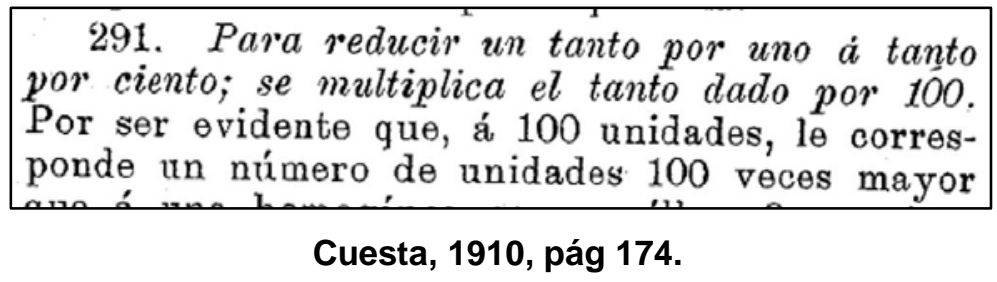

b. Aplicando la regla de tres simple.

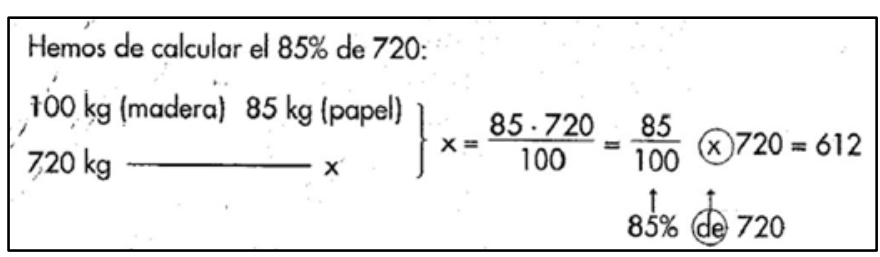

Álvarez et al., 1999, pág. 82. 
c. Describiendo un proceso algorítmico para el cálculo del porcentaje.

- Para calcular un determinado tanto por ciento de una cantidad, dividimos la cantidad entre 100 y multiplicamos por el tanto

Cólera y Gaztelu, 2008a, pág. 168.

El menos común de estos tres enfoques es el primero. En los otros, especialmente en el tercero, el procedimiento suplanta al concepto.

2. Regla de interés:

Los métodos de resolución pasan por utilizar fórmulas. Hay dos opciones:

a. Usar una única fórmula (la del interés) y despejar según el valor que se busque. Esto implica la realización de manipulaciones algebraicas.

b. Emplear fórmulas distintas para cada una de las variables involucradas (interés, capital, rédito y tiempo).

También son varios los modos de deducir dichas fórmulas:

a. Mediante el significado de las variables involucradas y de las operaciones entre ellas.

b. Aplicando la regla de tres compuesta.

c. Presentar las fórmulas sin justificación alguna.

Asociadas a la Regla de interés aparecen en ciertos textos, sobre todo hasta la década de los 70, aplicaciones como la Regla de descuento y particularizaciones a pagarés y letras de cambio. No obstante, no vamos a dedicar tiempo a estas aplicaciones pues entendemos que su utilidad práctica es muy escasa y que dichas situaciones pueden afrontarse sin grandes complicaciones haciendo uso de las ideas presentadas con anterioridad.

3. Repartos proporcionales:

a. Repartos directamente proporcionales.

Se han encontrado cuatro métodos de resolución: 
- Teniendo en cuenta el significado de las operaciones y de lo que significa repartir.

Tres socios invierten 1 millón, 2 millones y 5 millones de euros, respectivamente, en un negocio que al cabo de un año rinde un beneficio de $600000 €$ ¿QQué cantidad de los beneficios corresponde a cada uno?

Podemos considerar el negocio dividido en $1+2+5=8$ partes. Ahora no tenemos más que dividir los beneficios en otras ocho partes, de las que el primer socio se llevará una; el segundo, dos; y el tercero, cinco.

El beneficio correspondiente a cada parte es $600000: 8=75000 €$.

El reparto será: $\left\{\begin{array}{l}1 .^{\text {er }} \text { socio: } 75000 € \cdot 1=75000 € \\ 2 .^{\circ} \text { socio: } 75000 € \cdot 2=150000 € \\ 3 .^{\text {er }} \text { soclo: } 75000 € \cdot 5=375000 €\end{array}\right.$

Cólera y Gaztelu, 2008c, pág. 67.

- Reduciendo el problema a varias reglas de tres.

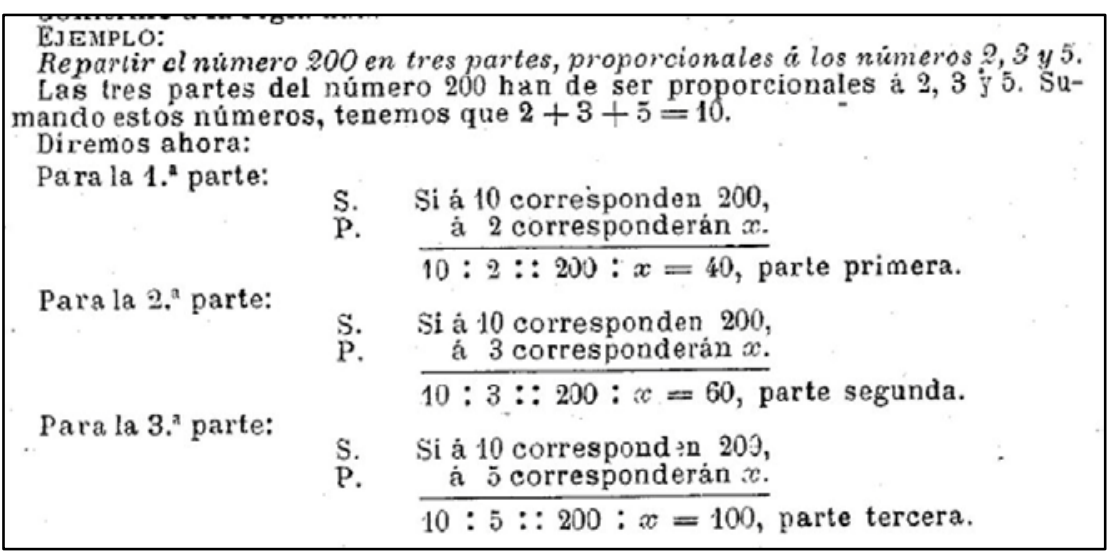

Dalmáu, 1898, pág. 187.

- Haciendo uso de la propiedad fundamental de las series de razones iguales.

I54. InVESTIGACión DE LA REgLA PRÁCtiCA.-Segín lo demostrado (I3I) la serie de razones iguales anterior nos da:

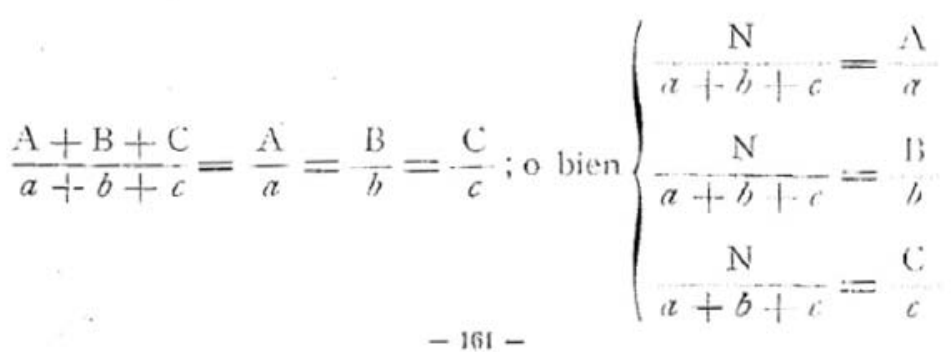

Xiberta, 1928, pág. 161. 
- Se describe una regla algorítmica.

Para dividir un número en partes proporcionales a otros, se le multiplica por cada uno de éstos y los productos se dividen por la

Ruiz, 1931, pág. 141.

Como ya hemos indicado en otras situaciones, pese a la diversidad de enfoques que acabamos de presentar, muchos de los textos terminan por presentar fórmulas cerradas que “faciliten” el aprendizaje del alumno. Generalmente las fórmulas se dan para el caso de repartos entre tres partes y se ajustan a los dos esquemas siguientes:

$$
\begin{aligned}
& \text { - } p_{i}=\frac{n a_{i}}{a_{1}+a_{2}+a_{3}} \\
& \text { - } \quad p_{i}=\frac{a_{i}}{a_{1}+a_{2}+a_{3}} n .
\end{aligned}
$$

Donde $p_{i}$ es la parte $i$-ésima, $a_{i}$ es el número al que dicha parte debe ser proporcional y $n$ es el total a repartir. Si bien ambas expresiones son equivalentes, pensamos que no es arbitrario inclinarse por una o por otra. De hecho, la segunda refleja con mucha mayor claridad el significado de las operaciones implicadas.

b. Repartos inversamente proporcionales.

Se hacen directamente proporcionales a los inversos.

c. Repartos directamente proporcionales a algunas magnitudes e inversamente a otras.

Se multiplican las cantidades respecto de las que el reparto es directo, se divide por las cantidades respecto a las que el reparto es inverso y se realiza un reparto directamente proporcional respecto de las cantidades así construidas.

4. Regla de compañía:

Se reduce a un problema de repartos. Se trata del caso particular en que se debe repartir una ganancia o pérdida entre varios socios en función del capital 
invertido y, eventualmente, del tiempo durante el que se mantuvo invertido dicho capital

5. Mezclas y aleaciones:

Hay dos tipos de problemas:

a. Hallar el precio de una mezcla conocidos los precios y cantidades de los componentes. Este tipo se resuelve mediante el uso de una fórmula justificada en base a la definición de precio y a la aditividad de las cantidades y los precios.

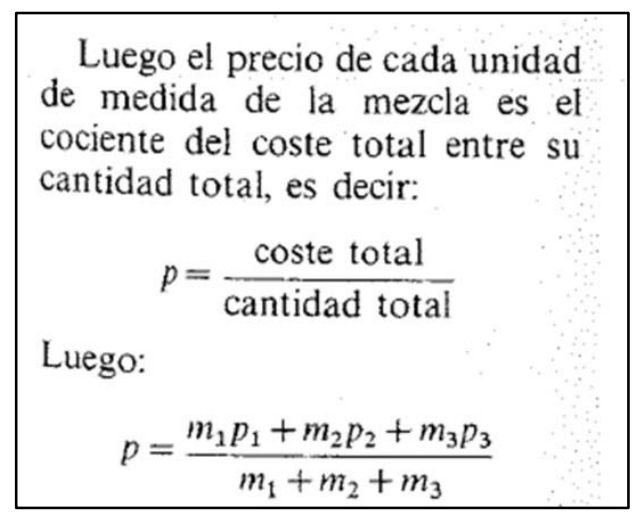

Signo, 1983, pág. 167.

b. Hallar las cantidades necesarias de los componentes de la mezcla sabiendo sus precios y el precio que se desea que tenga la mezcla. Aquí hay dos posibilidades:

- Dar una regla algorítmica sin justificar.

RFGLA.-Las cantidades que deben mezclatse para obtener una mezcla de precio prefijado, son inversamente proporcionales a las diferencias entre sus precios y el precio intermedio prefijado.

Rey y Puig, 1935, pág. 161.

- Justificar que las cantidades son inversamente proporcionales a la diferencia del precio de dicho componente con el precio medio en el caso de dos componentes. Esta justificación puede ser:

- Algebraica. 
En efecto: si suponemos, por ejemplo, $l>l_{m}>l^{\prime}$, y establecemos la igualdad evidente

$$
l_{m} \cdot\left(\mathrm{P}+\mathrm{P}^{\prime}\right)=l \cdot \mathrm{P}+l^{\prime} \cdot \mathrm{P}^{\prime}
$$

entre el peso de metal fino que ha de contener la aleación y la suma de los pesos de metal fino de los lingotes que se alean, tendremos:

$$
\mathrm{P}^{\prime}\left(l_{m}-l^{\prime}\right)=\mathrm{P}\left(l-l_{m}\right)
$$

Parellada, 1943, pág. 232.

- Mediante el significado de las operaciones.

Primer caso. Siendo dos las especies que se han de mezclar cuyos precios respectivos son $p$ y $p^{\prime}, m$ el precio medio comprendido entre $p$ y $p^{\prime}$, y $x$ é $y$ las unidades que de cada especie se han de mezclar, se tendrá, que por cada unidad de la especie superior cuyo precio supondremos sea $p$, que se venda al precio medio $m$, habrá una pérdida igual á la diferencia de ámbos precios; es decir, de $p-m$ unidades de dinero. $\mathrm{Al}$ contrario, por cada unidad de la especie inferior cuyo precio es $p^{\prime}$, que se venda al precio $m$, se tendrá una ganancia marcada por la diferencia $m-p^{\prime}$ de dichos precios; por consiguiente en $x$ unidades de la primera especie habrá una pérdida de $x(p-m)$, y en $y$ de la segunda, una ganancia representada por $y\left(m-p^{\prime}\right)$; y como entre estas dos cantidades ha de haber compensacion, se deberá tener

Sánchez, 1866, pág. 335.

El método presentado se adapta perfectamente al caso en que la mezcla consta sólo de dos componentes. Para más de dos componentes se suele recurrir a mezclas parciales; es decir, se mezcla un componente de precio superior al precio medio con uno de precio inferior reiteradamente.

En este tipo de problemas se observa que, incluso cuando los argumentos utilizados son de carácter aritmético, hay una tendencia muy clara a la algebrización (ver por ejemplo el caso de (Signo, 1983) en el apartado a. anterior).

6. Regla conjunta:

Se trata de aplicar la proporcionalidad en situaciones de cambio de unidades cuando aparecen más de dos unidades distintas. Como datos se dan una serie de equivalencias entre diversas unidades "enlazadas"; por ejemplo, $5 u=6 v, 7 v=4 w$, 
$3 w=10 z$. El objetivo es encontrar una equivalencia entre la primera y la última unidad. En este caso, por ejemplo, $21 u=48 z$.

Se acostumbra a dar una regla similar a la siguiente (Tuñon de Lara, 1908, pág. 175):

"Si se multiplican ordenadamente varias equivalencias tales, que el primer miembro de cada una de sea de la misma especie que el segundo de la anterior, resultará otra equivalencia cuyo primer miembro será de la misma especie que el primer miembro de la primera, y el segundo de la del segundo de la última.”

7. Reglas de falsa posición y de doble falsa posición:

Se trata de aplicar la proporcionalidad para resolver ecuaciones de primer grado con una incógnita (la simple), y sistemas de dos ecuaciones de primer grado con dos incógnitas (la doble).

Si la ecuación es de la forma $a x=b$, el método de falsa posición se basa en suponer que la solución es $x=c$, en ese caso $a c=b^{\jmath} \neq b$; y la verdadera solución se obtiene planteando la proporción $\frac{c}{b^{\prime}}=\frac{x}{b}$.

Si lo que se tiene es un sistema de dos ecuaciones de primer grado con dos incógnitas $\left\{\begin{array}{l}a_{1} x+b_{1} y=c_{1} \\ a_{2} x+b_{2} y=c_{2}\end{array}\right.$, se toman dos valores arbitrarios para una de las variables; por ejemplo $x_{1}$ y $x_{2}$. Sustituimos estos dos valores en la primera ecuación para obtener $y_{1}$ e $y_{2}$ y sustituimos los pares $\left(x_{1}, y_{1}\right)$ y $\left(x_{2}, y_{2}\right)$ en la segunda ecuación. Llamamos $e_{1} \mathrm{y} e_{2}$ a los errores cometidos al efectuar dichas sustituciones. Es decir, $e_{i}=a_{2} x_{i}+b_{2} y_{i}-c_{2}$. Entonces $\frac{e_{1}}{e_{2}}=\frac{x_{1}-x}{x_{2}-x}$ y de aquí se obtiene que $x=\frac{x_{2} e_{1}-x_{1} e_{2}}{e_{1}-e_{2}}$.

En ambos casos existen tres posibilidades a la hora de plantear las reglas:

a. Se presentan sin justificación.

b. Se justifican en mediante argumentos aritméticos de proporcionalidad. 
c. Se justifican algebraicamente.

En la tabla siguiente se recoge la aparición de las aplicaciones anteriores en los distintos periodos de tiempo analizados.

\begin{tabular}{|c|c|c|c|c|c|c|}
\hline Aplicación & $\mathbf{1 8 5 0 - 1 9 0 0}$ & $\mathbf{1 9 0 0 - 1 9 5 0}$ & $\mathbf{1 9 5 0 - 1 9 7 0}$ & $\mathbf{1 9 7 0 - 1 9 8 0}$ & $\mathbf{1 9 8 0 - 1 9 9 0}$ & $\mathbf{1 9 9 0 - 2 0 1 0}$ \\
\hline Porcentajes & SÍ & SÍ & SÍ & SÍ & SÍ & SÍ \\
\hline Interés & SÍ & SÍ & SÍ & SÍ & SÍ & SÍ \\
\hline Repartos & SÍ & SÍ & SÍ & SÍ & SÍ & SÍ \\
\hline Compañías & SÍ & SÍ & SÍ & NO & NO & NO \\
\hline Mezclas & SÍ & SÍ & SÍ & SÍ & SÍ & SÍ \\
\hline Conjunta & SÍ & SÍ & NO & NO & NO & NO \\
\hline Falsa Posición & SÍ & SÍ & NO & NO & NO & NO \\
\hline
\end{tabular}

\section{III.2.3. Reflexiones}

Terminamos el análisis de los significados de la proporcionalidad desde 1850 hasta la actualidad con unas breves reflexiones:

1. Con el paso del tiempo se ha abandonado por completo la idea de razón entre cantidades y sólo ha permanecido la razón entre números, identificada, además, con su cociente.

2. La proporción como igualdad de razones y la propiedad fundamental de las proporciones se mantienen como un contenido destacado en todas las épocas estudiadas.

3. Desaparecen casi totalmente las manipulaciones para obtener nuevas proporciones a partir de una dada; tan sólo en algunos casos sigue presentándose la propiedad de las series de razones iguales, con la idea de justificar los repartos directamente proporcionales.

4. Hay gran variedad en las caracterizaciones de la proporcionalidad simple. Sin embargo, aún cuando en los textos se utilice otra, siempre suele presentarse la caracterización por razones internas o por conservación, pues estas caracterizaciones permiten introducir la técnica de búsqueda de cantidades desconocidas por proporciones.

5. La proporcionalidad compuesta recibe un tratamiento similar, en cuanto a su definición, a lo largo del tiempo. 
6. Los problemas de búsqueda de cantidades desconocidas en situaciones de proporcionalidad simple también reciben un tratamiento muy homogéneo en el tiempo. En el método de reducción a la unidad se observa una escasa tendencia a justificarlo en base al significado de las operaciones (desproveyéndolo así de su esencia).

7. Aunque se presente el método de las proporciones, muchos textos terminan por presentar el algoritmo descontextualizado como método para resolver los problemas.

8. En las situaciones de proporcionalidad compuesta se ha impuesto el método de resolución paso a paso. El método por proporciones desaparece casi completamente, al igual que las reglas algorítmicas (muy complejas).

9. El número de aplicaciones de la proporcionalidad que se tratan desciende drásticamente: sólo sobreviven con un estatus importante los porcentajes y la regla de interés. En algunos casos se tratan de forma casi anecdótica los repartos (sólo directamente proporcionales) y las mezclas (sólo en el caso de la búsqueda del precio medio o similares).

10. El estudio de los porcentajes ha ganado en importancia con el paso del tiempo, pero se ha producido un abandono de su significado en pos de los métodos algorítmicos para su cálculo y resolviendo los problemas mediante proporciones.

11. Se observa una progresiva y creciente algebrización en la forma de presentar y resolver los problemas de interés, repartos y mezclas.

\section{III.3. ANÁLISIS DE LA ENSEÑANZA ACTUAL DE LA PROPORCIONALIDAD}

En la sección anterior hemos revisado los significados asociados con la proporcionalidad en textos escolares españoles de los últimos 160 años. En esta vamos a estudiar con mayor detenimiento la enseñanza actual de la proporcionalidad.

Para llevar a cabo este estudio se ha analizado una propuesta completa de la Editorial Anaya (Cólera y Gaztelu, 2008a, 2008b, 2008c). Estos textos, debidamente autorizados por el Ministerio de Educación, han sido elegidos por dos razones principalmente: 
1. Gozan de amplia implantación en la Comunidad Autónoma de Aragón y en buena parte de España.

2. Son los textos elegidos por el Departamento de Matemáticas del I.E.S. Avempace de Zaragoza, centro en el que se ha realizado la fase de experimentación de esta investigación.

La propuesta didáctica analizada se desarrolla a lo largo de los cursos $1^{\circ}$ y $2^{\circ}$ de Educación Secundaria Obligatoria, así como en la opción A de $4^{\circ}$ curso. Las variables en torno a las que vamos a organizar nuestro estudio son las siguientes:

i. Secuenciación de los contenidos y espacio dedicado a los mismos.

ii. Metodología.

iii. Modelos de aprendizaje.

iv. Sistemas de representación.

v. Significados que se construyen.

vi. Resolución de problemas.

\section{III.3.1. Secuenciación de los contenidos y espacio dedicado}

En este apartado vamos a presentar el orden en que se presentan los contenidos relativos a la proporcionalidad en cada uno de los cursos en los que dicho tema aparece, así como el espacio (en número de páginas) dedicado a cada uno de los epígrafes que estructuran los temas. Además de presentar el título del epígrafe y su extensión, señalaremos las ideas principales que se desarrollan en el mismo.

En $1^{\circ}$ de E.S.O. se dedica un tema a aspectos relacionados con la proporcionalidad. En concreto, se trata del noveno tema (de un total de catorce) titulado “Proporcionalidad y porcentajes”. Este tema se inserta justo tras los temas dedicados a las fracciones e inmediatamente antes que los dedicados a la introducción al lenguaje algebraico. Los contenidos tratados en este tema (y el espacio dedicado a ellos) son los siguientes:

- Relación de proporcionalidad entre magnitudes (2 páginas).

o Relación de proporcionalidad directa.

o Relación de proporcionalidad inversa.

- Problemas de proporcionalidad directa (2 páginas). 
o Método de reducción a la unidad.

o Fracciones equivalentes en las tablas de valores directamente proporcionales.

o Regla de tres directa.

- Problemas de proporcionalidad inversa (2 páginas).

o Método de reducción a la unidad.

o Fracciones equivalentes en tablas de proporcionalidad inversa.

o Regla de tres inversa.

- Porcentajes (4 páginas).

o Concepto de tanto por ciento.

o Un porcentaje es una fracción.

o Porcentajes y números decimales.

o Algunos porcentajes especiales.

- Un porcentaje es una proporción (2 páginas).

o El porcentaje como proporción.

o Cálculo de la parte.

o Cálculo del total.

o Cálculo del tanto por ciento.

- Aumentos y disminuciones porcentuales (1 página).

o Aumentos porcentuales.

o Disminuciones porcentuales.

En $2^{\circ}$ curso nuevamente se dedica un tema a aspectos relacionados con la proporcionalidad. En este caso, es el cuarto de un total de doce y se titula también “Proporcionalidad y porcentajes”. Su ubicación en el desarrollo del curso es similar: tras las fracciones y justo antes del álgebra. Los contenidos presentados son los siguientes:

- Razones y proporciones (1 página). 
o Conceptos de razón y proporción.

o Cálculo del término desconocido de una proporción.

- Magnitudes directamente proporcionales (3 páginas).

o Caracterización de magnitudes directamente proporcionales.

o Resolución de problemas: método de reducción a la unidad.

o Otras relaciones en las tablas de proporcionalidad directa.

o Resolución de problemas: regla de tres.

o La constante de proporcionalidad.

o Resolución de problemas con la constante de proporcionalidad.

- Magnitudes inversamente proporcionales (2 páginas).

o Caracterización de magnitudes inversamente proporcionales.

o Resolución de problemas: método de reducción a la unidad.

o Proporciones en las tablas de proporcionalidad directa.

o Resolución de problemas: Regla de tres inversa.

- Problemas de proporcionalidad compuesta (2 páginas).

- Los porcentajes (2 páginas).

o Un porcentaje indica una proporción.

o Un porcentaje es una fracción.

o Un porcentaje se asocia a un número decimal.

o Cálculo rápido de algunos porcentajes.

- Problemas con porcentajes (4 páginas).

o Cálculo del total, conocidos el tanto por ciento y la parte.

o Cálculo del tanto por ciento, conocidos el total y la parte.

o Aumentos porcentuales.

o Disminuciones porcentuales. 
- Interés bancario (1 página)

En $4^{\circ}$ curso, opción A, el tema dedicado a la proporcionalidad es el cuarto de un total de 14. Se inserta tras los temas dedicados al número real y, de nuevo, justo antes de los dedicados al álgebra. Su título es "Problemas aritméticos" y los aspectos que se tratan son los siguientes:

- Problemas de proporcionalidad simple (1 página).

o Proporcionalidad directa.

o Proporcionalidad inversa.

- Proporcionalidad compuesta (1 página).

o Proporcionalidad directa-directa.

o Proporcionalidad directa-inversa.

- Repartos proporcionales (1 página).

- Problemas de mezclas (1 página).

- Problemas de móviles (1 página).

o Encuentros.

o Alcances.

- Cálculos con porcentajes (3 páginas).

o Cálculo de un tanto por ciento de una cantidad.

o Porcentaje correspondiente a una proporción.

o Cálculo de aumentos porcentuales.

o Cálculo de disminuciones porcentuales.

o Encadenamiento de variaciones porcentuales.

- Depósitos y préstamos (2 páginas).

o Interés simple.

o Interés compuesto. 
Tras la descripción explícita de la secuenciación de los contenidos y del espacio dedicado a cada uno de ellos presentamos algunos comentarios al respecto:

1. Los contenidos comunes de los dos primeros cursos siguen una secuenciación similar. La diferencia entre dichos cursos radica únicamente en la inclusión de aspectos nuevos como la idea de razón, la proporcionalidad compuesta o el interés bancario.

2. En estos dos primeros cursos también coincide el lugar que ocupa el tema dedicado a la proporcionalidad dentro del marco general del texto: tras el número racional (a cuyo manejo se recurre una y otra vez en el contexto de la proporcionalidad), y justo antes del álgebra (cuyo lenguaje se utiliza a veces prematura e injustificadamente en la presentación de los contenidos). Esta última observación es especialmente relevante en primer curso, pues en segundo los alumnos ya han tenido contacto con el lenguaje algebraico.

3. Respecto al espacio dedicado a los contenidos, se observa que en los dos primeros cursos los porcentajes son el tópico al que se dedica un mayor espacio: 7 páginas de 13 en primero y 7 de 15 en segundo (ver figura adjunta).

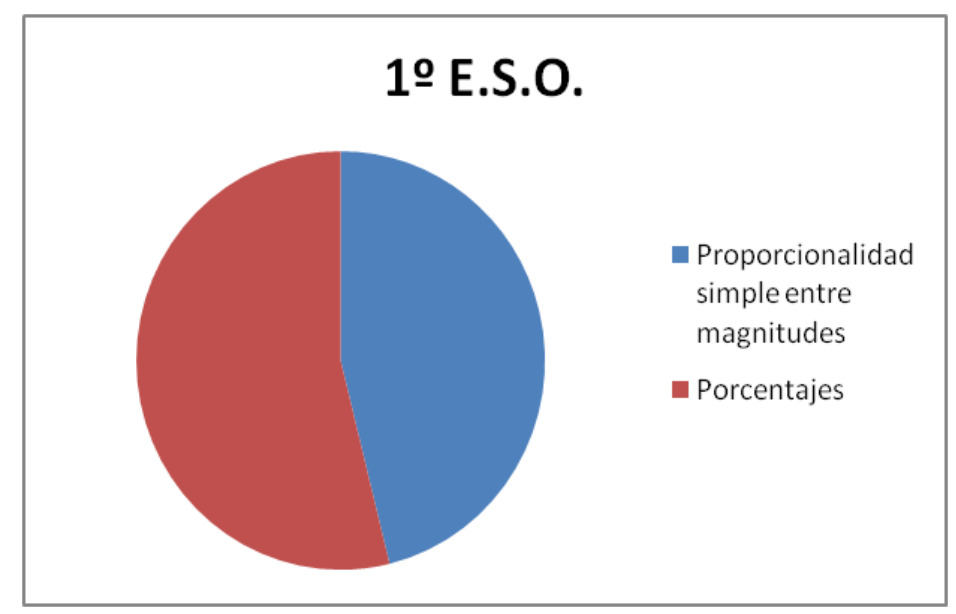

Figura III.1. Reparto de los contenidos en $1^{\circ}$ de E.S.O. 


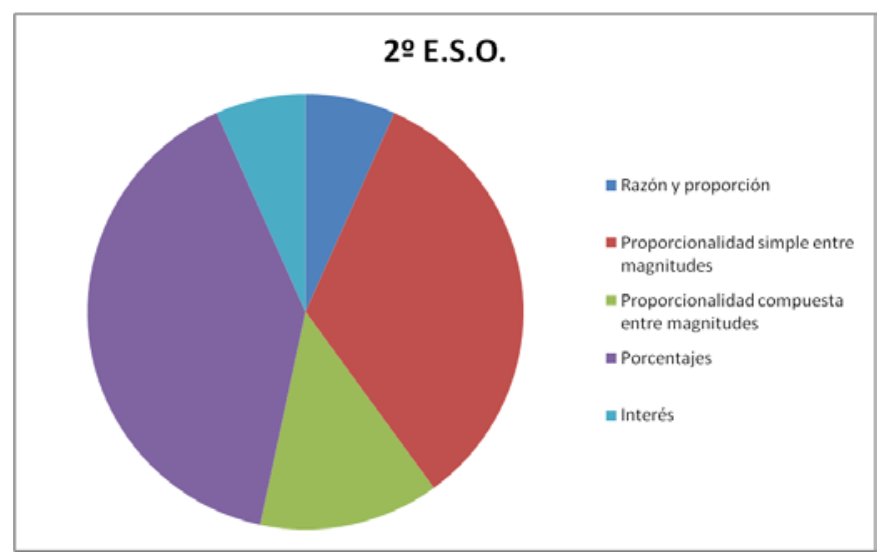

Figura III.2. Reparto de los contenidos en $2^{\circ}$ de E.S.O.

4. Los contenidos de $4^{\circ}$ curso son: un repaso de lo presentado en los dos primeros cursos, por una parte, y una presentación de situaciones en las que puede aplicarse la proporcionalidad de forma significativa y que, sorprendentemente, no se habían tratado con anterioridad, por otra. Igualmente, resulta sorprendente el hecho de que estas aplicaciones no aparezcan en la opción B de $4^{\circ}$ curso.

5. En relación al espacio dedicado a cada apartado, se observa una mayor homogeneidad en la distribución (debido seguramente a que el tema se concibe como un "contenedor" de técnicas y procedimientos más, que sirve de recordatorio más que de presentación). No obstante, nuevamente el porcentaje es el concepto que más atención recibe con 3 páginas de un total de 10 (ver figura).

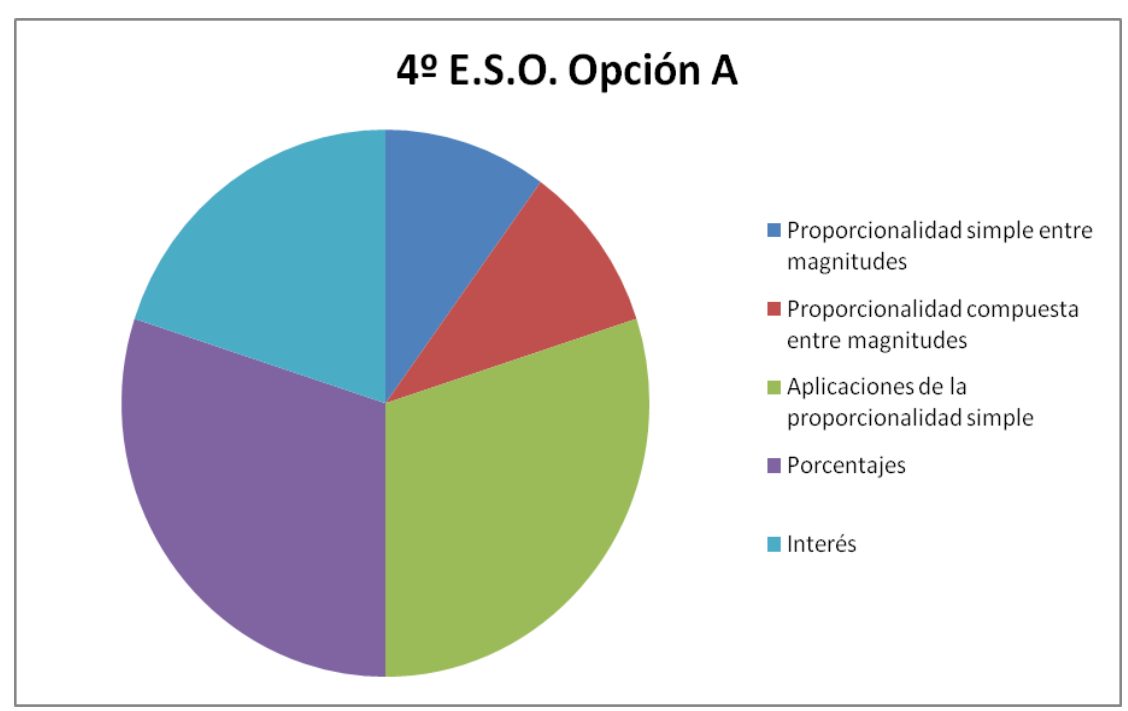

Figura III.3. Reparto de los contenidos en $4^{\circ}$ de E.S.O. Opción A 


\section{III.3.2. Metodología}

En este apartado vamos a analizar la metodología seguida por los autores a la hora de presentar los contenidos. Para ello nos centraremos en primer lugar en cómo se organizan dichos contenidos - desde un punto de vista estructural - dentro de cada uno de los temas por cuanto creemos que la organización espacial de los mismos influye en gran medida sobre los alumnos. También presentaremos algunos comentarios más generales sobre el modo en que los autores presentan el material.

Los textos analizados mantienen un formato uniforme en los tres cursos estudiados. Más aún, la estructura general de los temas es también invariante, salvo un pequeño detalle que comentaremos más adelante. La organización general de los temas es la siguiente:

1. La primera página presenta un pequeño párrafo en el que se trata de explicar a los alumnos la idea general de lo que se les va a presentar. También aparece una situación problemática introductoria basada en la ilustración que abre el tema (ver Figura III.4.).

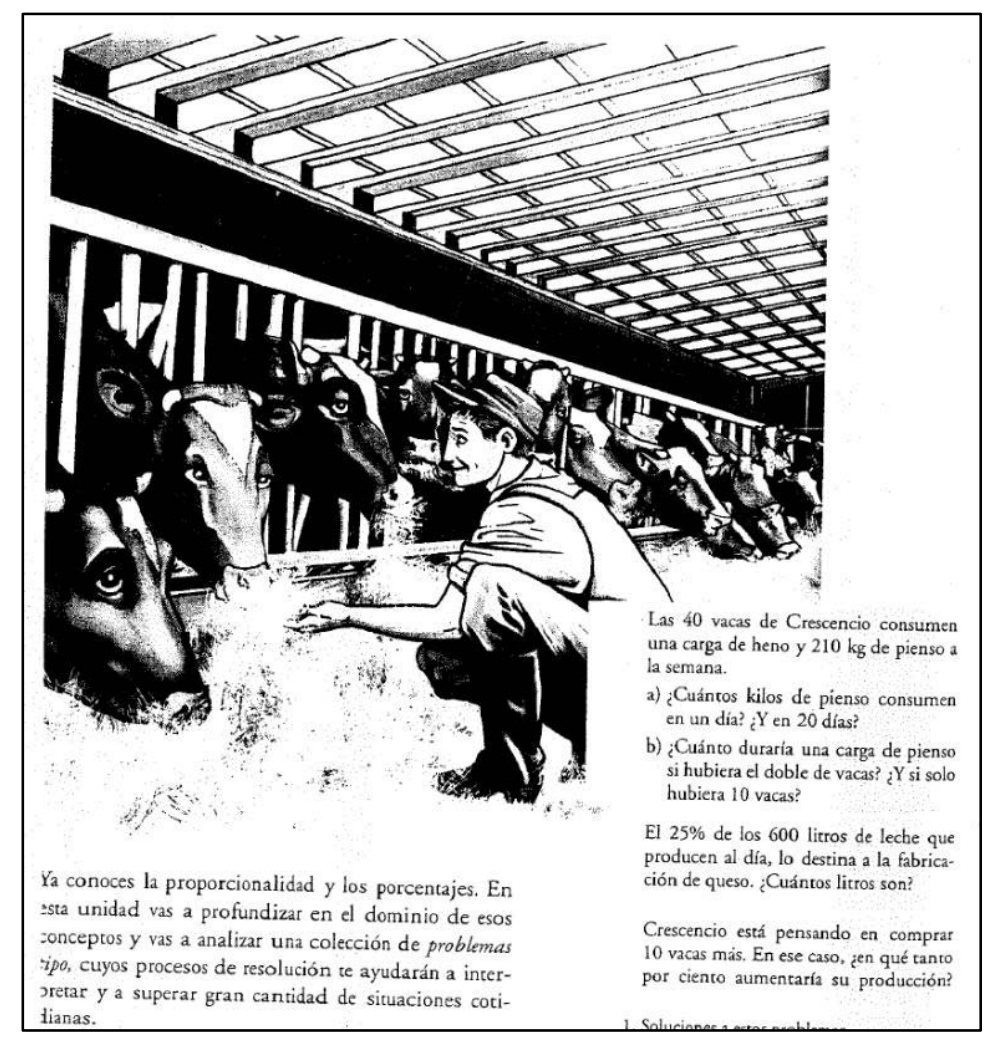

Figura III.4. Primera página del tema "Proporcionalidad y porcentajes". $2^{\circ}$ E.S.O., pág. 82. 
2. En los dos primeros cursos (no en cuarto) aparece una página titulada: “Antes de comenzar, recuerda”. Como su nombre indica, en ella se presentan algunas ideas y técnicas que los autores consideran claves para que el alumno sea capaz de seguir el contenido del tema. La página se distribuye en dos columnas; la izquierda tiene la mitad de anchura que la de la derecha. En la columna izquierda se presenta de manera formal la idea o técnica (generalmente esto último) que el alumno debe conocer; a la derecha se ponen 1 ó 2 ejemplos y se plantean ejercicios de repaso (ver figura III.5.).

Cómo se multiplica y se divide Dor 100

Bastará con que desplaces

la coma hacia la derecha

o la izquierda.

\section{kemplos}

$5,3 \cdot 100=530 \leftarrow$ La coma se ha desplazado dos lugares a la derecha.

$2,7: 100=0,027 \leftarrow$ La coma se ha desplazado dos lugares a la izquierda.
6 Opera:
a) $35 \cdot 100$
b) $0,4 \cdot 100$
c) $143: 100$
d) $1,7: 100$

Figura III.5. Apartado típico de la sección “Antes de comenzar”. $1^{\circ}$ E.S.O., pág. 161.

3. La división en dos columnas se mantiene durante todo el tema. En la columna de mayor anchura, a la derecha, se inserta el discurso principal, con las presentaciones ostensivas de los conceptos y, en ocasiones, algunos ejemplos. En la columna izquierda, de menor anchura, se presentan ilustraciones que apoyan el discurso: ejercicios resueltos, cuadros resumen con ideas clave (a menudo en forma de "recetas" para memorizar procedimientos). Estos últimos cuadros aparecen frecuentemente, aunque no siempre, titulados como "Ten en cuenta”.

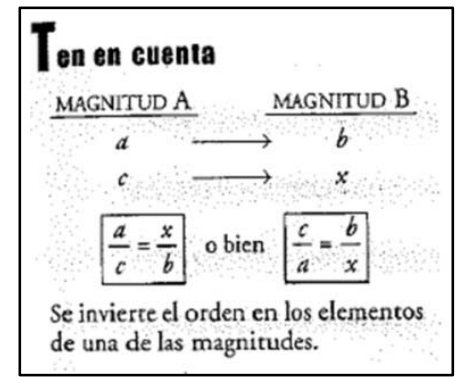

Figura III. 6. Ejemplo del cuadro "Ten en cuenta". $2^{\circ}$ E.S.O., pág. 89. 
4. Cada uno de los epígrafes en torno a los que se organiza el tema (ver 2.1.) concluye con una serie de actividades de refuerzo en las que se trabajan los conceptos presentados.

5. Al final de cada tema, se presentan una serie de ejercicios clasificados según los contenidos trabajados. Los enunciados de los ejercicios se acompañan de un indicador de su dificultad, graduada de 1 a 3 y los ejercicios aparecen en orden creciente de dificultad para cada uno de los contenidos.

6. Los temas se cierran con un apartado titulado "Desarrolla tus competencias" en el que se presentan actividades más abiertas que podríamos calificar de problemas y que, en mayor o menor medida, guardan relación con los contenidos tratados. Dentro de este apartado, aparece un epígrafe que, bajo el título “Autoevaluación”, vuelve a plantear el tipo de ejercicios que los autores consideran más importantes.

Una vez descrita la estructura general bajo la que se organizan los temas relativos a la proporcionalidad, cabe también hacer algunos comentarios más generales sobre la metodología seguida por los autores a la hora de presentar los contenidos a los alumnos:

1. Cada nuevo concepto se presenta siempre ostensivamente a partir de un ejemplo que, sin embargo, suele resultar artificial y que, en gran medida, suplanta la labor que debería hacer el alumno al “descubrir” o “construir” el concepto por sí mismo.

2. No parece darse gran importancia a los aspectos conceptuales. En algunas ocasiones los conceptos aparecen referidos someramente, sin resaltar su importancia.

3. En contraste con lo anterior, los aspectos procedimentales reciben una gran atención. Abundan los cuadros en los que se presentan métodos, fórmulas, procedimientos de resolución paso a paso, etc...

4. En relación con el punto anterior, existe una gran preocupación por presentar métodos de resolución para el mayor número de situaciones problemáticas distintas. De este modo se transmite la idea de que cada problema diferente tiene su procedimiento prescrito. Esto se afianza en la forma de presentar los 
problemas al final de cada tema, que aparecen clasificados según tipología y, por tanto, según procedimiento de resolución.

\section{III.3.3. Modelos de aprendizaje}

Un modelo de aprendizaje es un entorno físico creado por el profesor con el objetivo de que sea el propio alumno quien construya los conceptos matemáticos en juego a partir de las reflexiones que le suscite la manipulación de los objetos del modelo.

Con la definición anterior en mente, encontramos que la propuesta didáctica analizada no muestra preocupación alguna por el uso de los modelos de aprendizaje y ello, entre otras razones, es debido a las siguientes razones:

1. Existe una gran variación en los contextos en los que se presentan los ejercicios de modo que el esfuerzo y la reflexión que pueda realizar un alumno al resolver uno de ellos, en principio, le es inservible para los inmediatamente posteriores.

2. Incluso cuando se plantean situaciones problemáticas para un supuesto análisis por parte del alumno los autores suplantan dicho trabajo indicando al alumno lo que debe observar. En la figura III.7. se ilustra esto muy claramente: Los autores comienzan la situación pidiendo al alumno que reflexione sobre la situación presentada, pero sin solución de continuidad le indica también lo que debe observar. Con esa indicación se está impidiendo al alumno que pueda extraer otra información (que puede ser tanto o más relevante que la elegida por los autores) y, sobre todo, está transformando su papel de actor principal en el de mero espectador. 


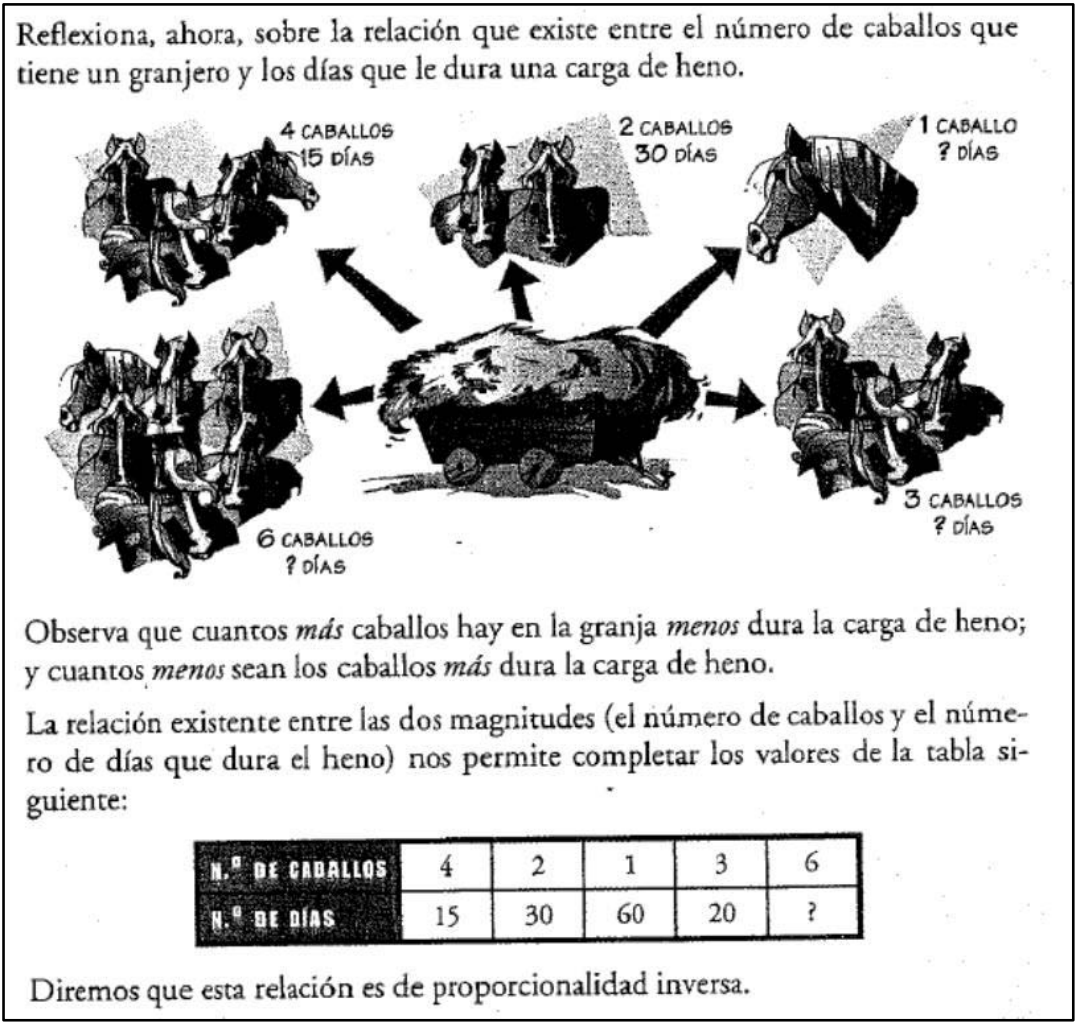

Figura III.7. $1^{\circ}$ E.S.O., pág. 163.

\section{III.3.4. Sistemas de representación}

Pese a la antigua concepción de los conceptos matemáticos como ideas hasta cierto punto inmutables a las que se accede por medio del intelecto, lo cierto es que en realidad se accede a ellas - como a cualquier otro conocimiento - por medio del lenguaje. En consecuencia la forma en la que se representan dichos conceptos influye radicalmente en las concepciones que los alumnos tendrán sobre ellos, así como en el modo en que los abordarán y manipularán.

En el caso de la proporcionalidad aritmética esto es especialmente notorio en el caso del porcentaje. Asociadas a este concepto encontramos hasta cuatro formas de representación diferentes:

1. El porcentaje representado con el símbolo usual '\%’.

2. El porcentaje como una fracción de denominador 100.

3. El porcentaje como un número decimal.

4. El porcentaje como una proporción. 
Cabe indicar que en el texto cada una de estas cuatro posibles representaciones juega un papel claro y diferenciado con respecto a las demás. A saber:

1. El símbolo usual se utiliza casi exclusivamente como una notación. Se enseña a los alumnos a leer el símbolo mediante la indicación: “el símbolo \% se lee por ciento: $20 \% \rightarrow$ veinte por ciento" (1 E.S.O., p.: 168$)$.

2. El porcentaje como fracción de denominador 100 se introduce para justificar el algoritmo para calcular los porcentajes: "para calcular un determinado tanto por ciento de una cantidad, se multiplica la cantidad por el tanto y se divide entre 100” (2 E.S.O., p.: 92).

3. Puesto que los alumnos han aprendido a convertir fracciones en decimales, se introduce la notación decimal para los porcentajes: "para calcular un porcentaje, se multiplica el total por el tanto por ciento expresado en forma decimal” (2 E.S.O., p.: 92). Además esto proporciona un nuevo método de cálculo.

4. El porcentaje como proporción: "cada cantidad es directamente proporcional a su porcentaje correspondiente" ( $1^{\circ}$ E.S.O., p.: 172). Esta idea abre la puerta al uso de las reglas de tres en la resolución de problemas de porcentajes.

Las representaciones anteriores apenas aparecen relacionadas entre sí, excepto en el caso de la segunda y tercer por razones obvias. La última es la idea que los autores parecen considerar clave y, de hecho, se acaba reemplazando (Figura III.8.) cualquier método para el cálculo de un porcentaje por el uso de las reglas de tres:

$\left.\begin{array}{|l}\frac{\text { POTAL }}{100} \longrightarrow 20 \\ 400 \longrightarrow x\end{array}\right\} \quad \frac{100}{400}=\frac{20}{x} \rightarrow x=\frac{20 \cdot 400}{100}=80$

Figura III.8. $1^{\circ}$ E.S.O., pág. 172

\section{III.3.5. Significados que se construyen}

En la sección III.2 hemos realizado un estudio de los significados relativos a la proporcionalidad que aparecen en los textos escolares desde mediados del siglo XIX. 
Aquí vamos a indicar cuáles son los que aparecen en la propuesta didáctica estudiada. Para ello analizaremos los bloques de contenido señalados en III.2.1. (apartado 1).

1. Razón y proporción.

El concepto de razón se introduce en segundo curso. Sólo se considera la razón entre números y se identifica con una fracción. La proporción se presenta como igualdad de dos razones (por tanto, de dos fracciones) y de ahí la propiedad fundamental de las proporciones (Figura III.9.):

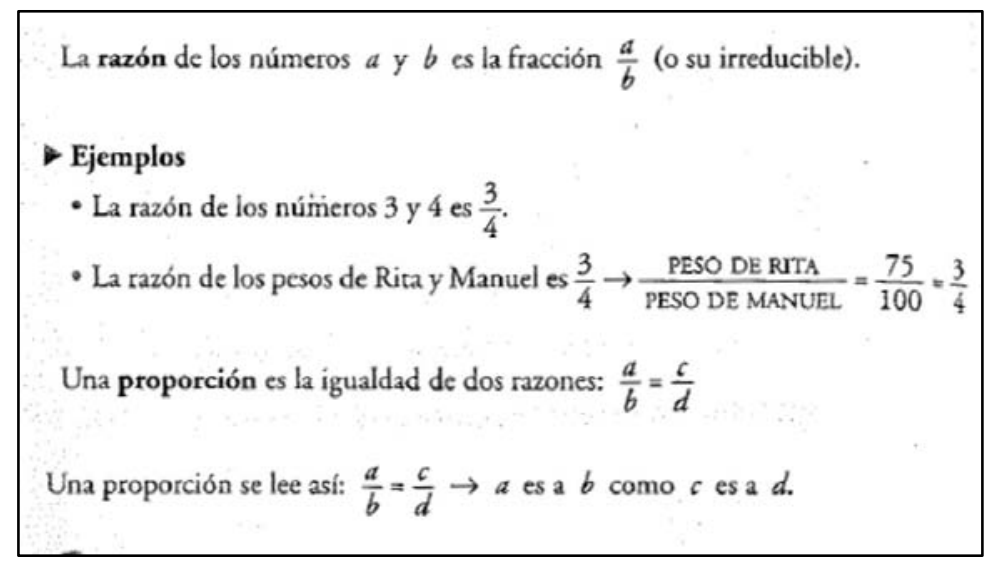

Figura III.9. $2^{\circ}$ E.S.O., pág. 84.

Cabe señalar que la identificación entre razón y fracción es incorrecta desde un punto de vista matemático por cuanto dicha identificación asume que las cantidades implicadas son siempre enteros positivos.

Se presta gran atención (Figura III.10.) al cálculo de términos desconocidos en una proporción, llegando a dar una expresión simbólica para ello:

$$
\frac{a}{b}=\frac{c}{x} \rightarrow a \cdot x=b \cdot c \rightarrow x=\frac{b \cdot c}{a}
$$

Figura III.10. $2^{\circ}$ E.S.O., pág. 84.

2. Proporcionalidad directa.

A la hora de caracterizar la proporcionalidad directa se observa un fenómeno reseñable:

a. $1^{\circ}$ E.S.O., pág. 162: “Dos magnitudes son directamente proporcionales cuando al multiplicar una (doble, triple,...) la otra se multiplica de la 
misma manera (doble, triple,...) y al dividir una (mitad, tercio,...) la otra se divide de la misma forma (mitad, tercio,...)”. Es decir, lo que denominamos como caracterización “multiplicativa”.

b. $2^{\circ}$ E.S.O., pág 85: “En las magnitudes directamente proporcionales, multiplicando (dividiendo) por el mismo número dos valores correspondientes se obtiene otro par de valores correspondientes”. Es decir, caracterización “implícitamente funcional”.

c. $4^{0}$ E.S.O., pág 65: No aparece una caracterización enunciada en forma general. Sin embargo en un ejemplo vemos: “A más metros, más dinero. A menos metros, menos dinero. El coste es directamente proporcional a la longitud”. Es decir, caracterización “por aumentos y disminuciones”.

Mientras que en el paso de $1^{\circ}$ a $2^{\circ}$ se observa un avance en la abstracción del significado, pasando de hablar de doble, triple, mitad o tercio a hablar de "un mismo número", en $4^{\circ}$ encontramos un retroceso radical. Allí parece que lo importante no es ya entender lo que significa que dos magnitudes sean directamente proporcionales, sino que lo interesante es una receta rápida y sencilla (sin importar su incorrección) que permita a los alumnos resolver problemas.

Aunque las caracterizaciones de la proporcionalidad directa son las presentadas anteriormente, hay que señalar que también aparecen mencionadas la caracterización “por razones internas” y “por conservación” (razones externas). Estas dos ideas surgen a partir del estudio de tablas de valores de magnitudes directamente proporcionales, tema que recibe gran atención en los dos primeros cursos.

3. Proporcionalidad inversa.

Se da exactamente la misma situación que en el caso de la proporcionalidad directa. Se pasa de una caracterización "multiplicativa” en $1^{\circ}$ a una caracterización "implícitamente funcional” en $2^{\circ}$, y a una "por aumentos y disminuciones” en $4^{\circ}$. También se presenta la caracterización por “razones internas” y por “conservación de un producto” a partir de las tablas. 
4. Búsqueda de cantidades desconocidas en situaciones de proporcionalidad simple.

En este apartado se refleja perfectamente lo sucedido en los dos anteriores:

a. $1^{\circ}$ E.S.O.: Aparece el método de reducción a la unidad (Figura III.11.) realizado mediante una aplicación de la caracterización multiplicativa de la proporcionalidad directa o inversa.

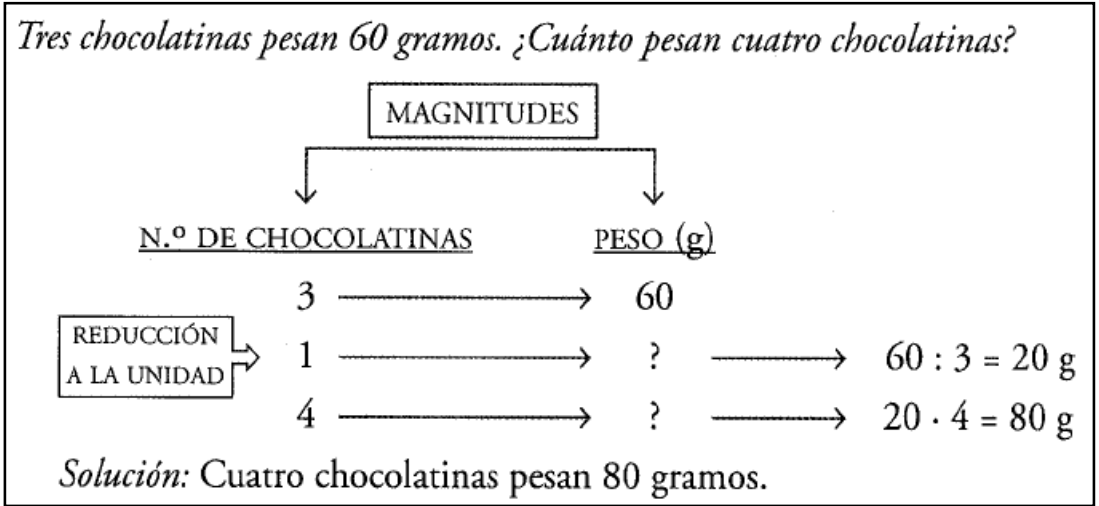

Figura III.11. $1^{\circ}$ E.S.O., pág. 164.

Sin embargo el método principal de resolución (Figura III.12.) es el de las proporciones.

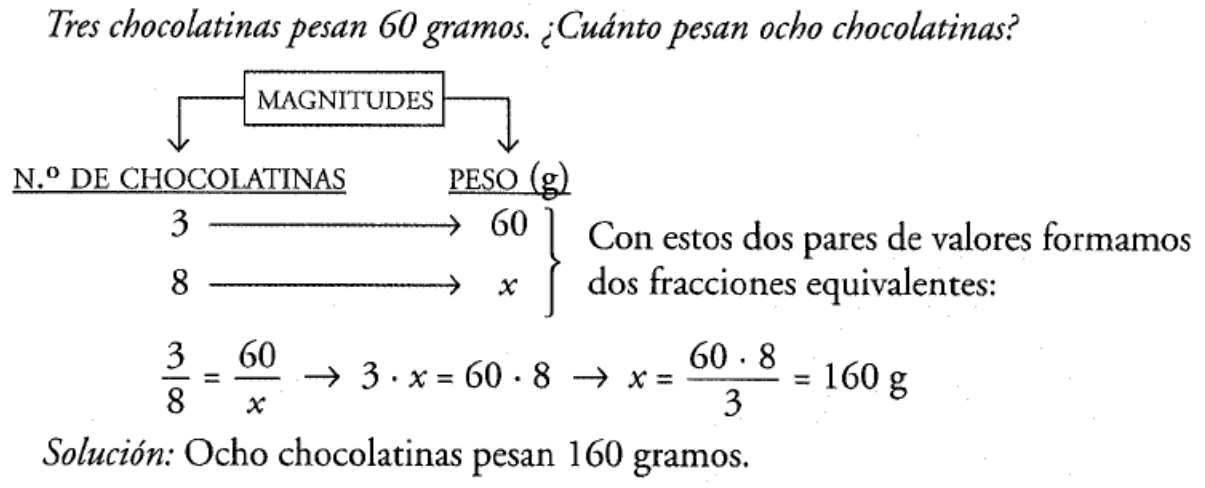

Solución: Ocho chocolatinas pesan 160 gramos.

Figura III.12. 1 E.S.O., pág. 165.

También se presenta una regla algorítmica (Figura III.13.) utilizando lenguaje algebraico (pese a que el álgebra aún no se ha introducido). 


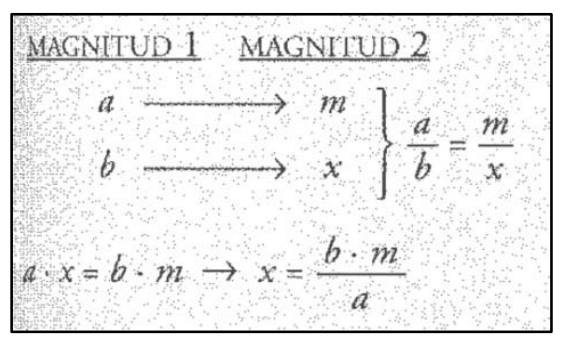

Figura III.13. $1^{\circ}$ E.S.O., pág. 165

b. $2^{\circ}$ E.S.O.: Siguen apareciendo los dos métodos anteriores, aunque en este curso al haber introducido la caracterización “por conservación” (Figura III.14.) también se utiliza esta idea a la hora de aplicar el método de las proporciones.

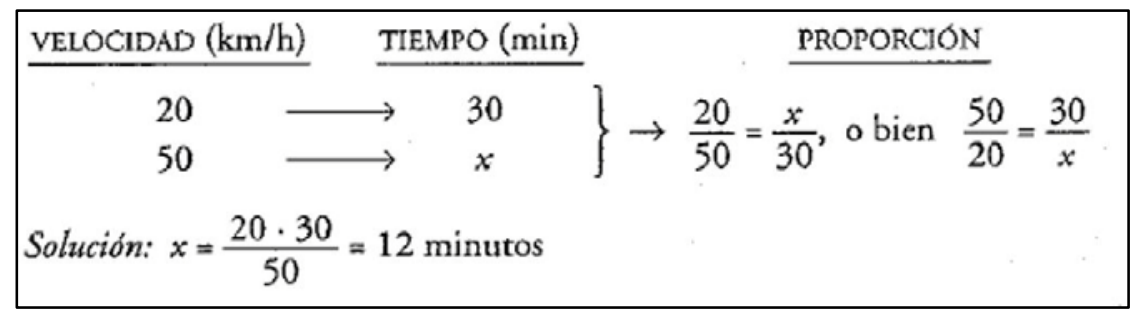

Figura III.14. $2^{\circ}$ E.S.O., pág. 89.

También se presentan fórmulas utilizando lenguaje algebraico, similares a las del curso anterior.

c. $4^{\circ}$ E.S.O.: En este curso tan sólo se presenta un método algorítmico (Figura III.15.) que ni siquiera hace uso de lenguaje algebraico.

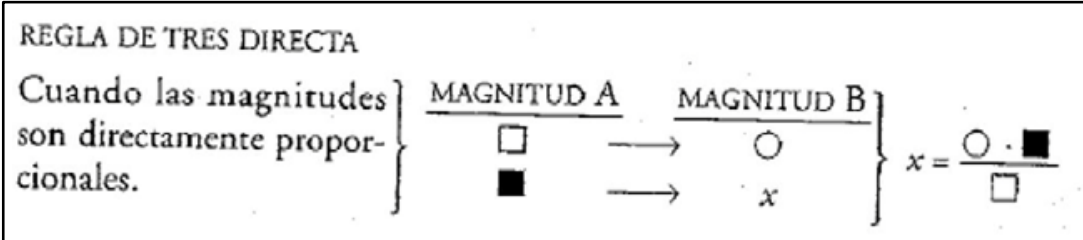

Figura III.15. $4^{\circ}$ E.S.O., pág. 65.

5. Proporcionalidad compuesta.

La proporcionalidad compuesta se introduce en segundo curso y solamente con 3 magnitudes implicadas. De este modo, tan sólo se presentan dos casos al fijar una de las tres magnitudes: que las otras dos sean directamente proporcionales a la fijada o que una lo sea directamente y la otra inversamente. Así, se presenta una visión muy sesgada y simplificada del fenómeno, y se observa claramente 
que lo que buscan los autores, más que la comprensión del alumno, es que memorice los procedimientos. Que la “definición” de proporcionalidad compuesta (Figura III.16.) quede relegada a dos pequeñas líneas justo antes de dos largos problemas resueltos y que no esté remarcada en absoluto contribuye a afianzar esta idea.

Llamamos de proporcionalidad compuesta a aquellas situaciones en las que intervienen más de dos magnitudes ligadas por la relación de proporcionalidad

Figura III.16. $2^{\circ}$ E.S.O., pág. 90.

En cuarto curso no se habla de proporcionalidad compuesta como concepto más allá de la resolución de problemas que comentaremos en el apartado siguiente.

6. Búsqueda de cantidades desconocidas en situaciones de proporcionalidad compuesta.

Este aspecto se aborda tanto en segundo curso como en cuarto curso. En segundo curso se presenta en primer lugar un proceso de resolución "paso a paso” (Figura III.17.)

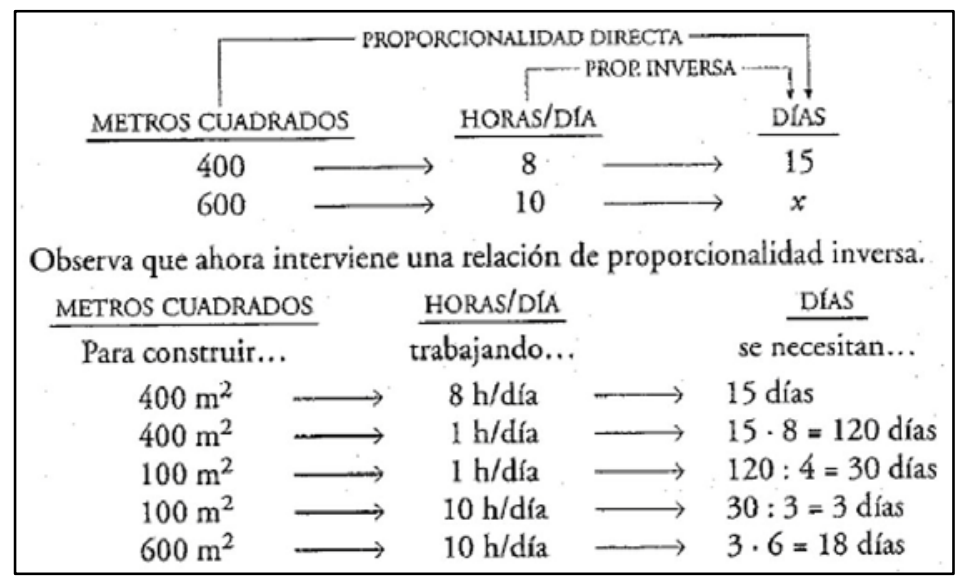

Figura III.17. $2^{\circ}$ E.S.O., pág. 91.

Pero inmediatamente después, bajo el encabezamiento “Automatiza el proceso” (Figura III.18.), se presenta la resolución por el método de las proporciones. 


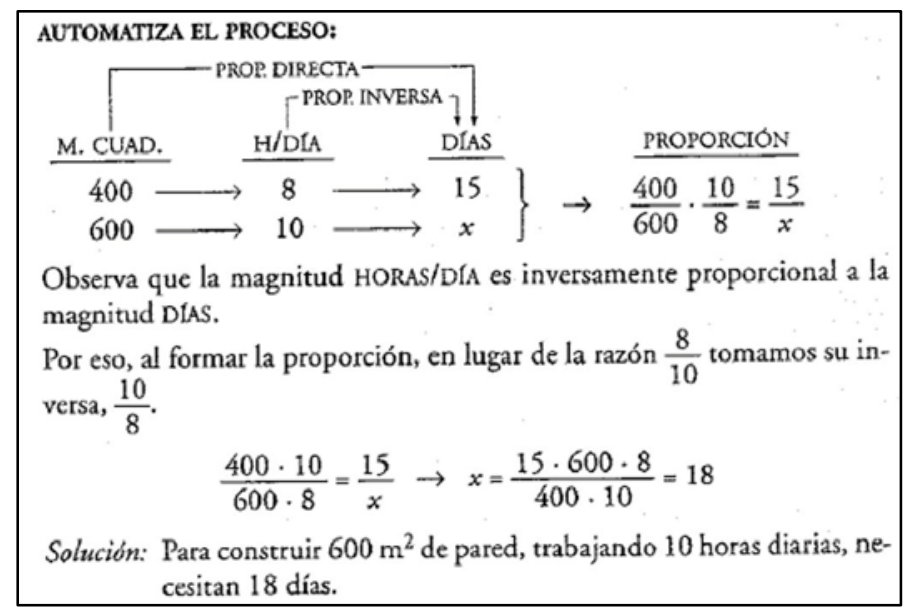

Figura III.18. $2^{\circ}$ E.S.O., pág. 91.

Esto es bastante sorprendente puesto que no se ha introducido la propiedad fundamental de la proporcionalidad compuesta ni ningún ejemplo que permita justificar este procedimiento (y por consiguiente no se da justificación alguna). Sin embargo, la necesidad de automatizar y mecanizar prima sobre los contenidos conceptuales. No obstante, no se da ninguna fórmula algebraica ni algoritmo memorístico de resolución de forma explícita.

En cuarto curso (Figura III.19.) la situación es justamente la contraria. No aparece el procedimiento de resolución "paso a paso”, sino tan solo el de las proporciones (sin justificación ni explicación alguna).

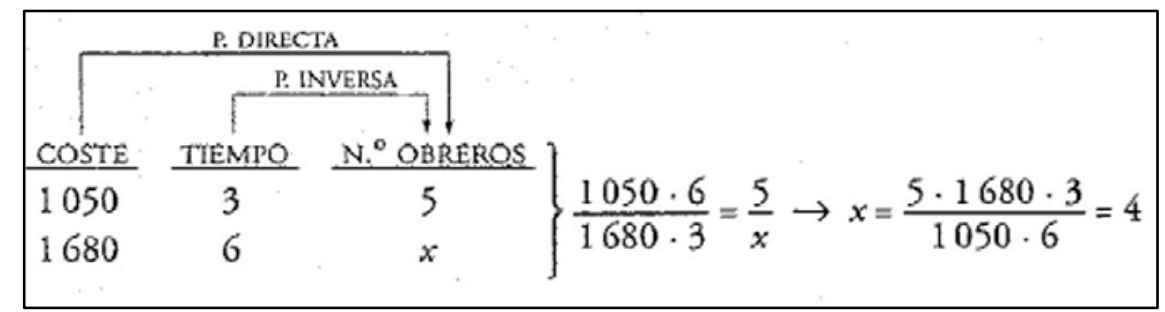

Figura III.19. $4^{\circ}$ E.S.O., pág. 66.

Al margen (Figura III.20.), aparece una regla con la que resolver automáticamente los problemas planteados. 


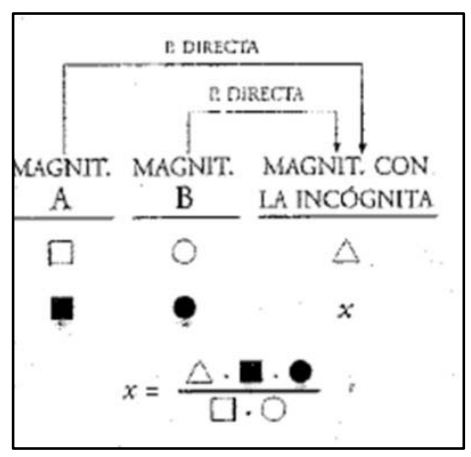

Figura III.20. $4^{\circ}$ E.S.O., pág. 66.

7. Aplicaciones de la proporcionalidad.

De las aplicaciones de la proporcionalidad que hemos recogido en los epígrafes del apartado 1.2.7., en la propuesta analizada aparecen las siguientes:

a. $1^{\circ}$ E.S.O.: Porcentajes.

b. $2^{\circ}$ E.S.O.: Porcentajes y Regla de interés.

c. $4^{\circ}$ E.S.O.: Porcentajes, Regla de interés, repartos proporcionales y mezclas.

Veamos el tratamiento que recibe cada uno de estos temas.

a. Porcentajes.

Tanto en $1^{\circ}$ y $2^{\circ}$ el tratamiento de los porcentajes es similar. Se comenta muy de pasada el concepto de tanto por ciento. En concreto, en primer curso, se lee: “Tomar un determinado tanto por ciento equivale a partir el total en porciones de cien unidades y tomar de cada porción el tanto indicado". Lo realmente importante y que aparece en un cuadro sombreado (Figura III.21.) es la forma de calcular el porcentaje:

El símbolo \% se lee por ciento: $20 \% \rightarrow$ veinte por ciento.

Para calcular un determinado tanto por ciento de una cantidad, dividimos

Figura III.21. $1^{\circ}$ E.S.O., pág. 168.

Se presta especial atención a la notación fraccionaria y decimal de los porcentajes y, sobre todo, a identificar un porcentaje con una proporción 
puesto que, de este modo, los autores resuelven cualquier problema relacionado con porcentajes mediante reglas de tres (Figura III.22.):

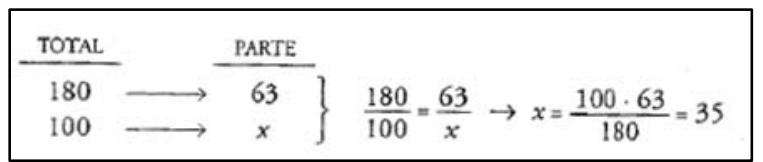

Figura III.22. $2^{\circ}$ E.S.O., pág. 95.

En segundo curso, la única aportación se da precisamente en el marco de los aumentos y disminuciones porcentuales (Figura III.23.), donde se presenta una "forma rápida", considerando el porcentaje que la nueva cantidad supone respecto de la inicial y reduciendo el problema al mero cálculo de un porcentaje.

Aumentar una cantidad en un $a \%$ equivale a calcular el $(100+a) \%$ de dicha cantidad

Figura III.23. $2^{\circ}$ E.S.O., pág. 95.

En cuarto curso no se introduce ninguna idea nueva. Tan sólo se repasan con ejemplos los tipos de problemas ya introducidos en cursos anteriores.

b. Regla de interés:

El interés bancario se introduce a través de un ejemplo resuelto (Figura III.24.) mediante el procedimiento "paso a paso", puesto que se trata como un problema de proporcionalidad compuesta.

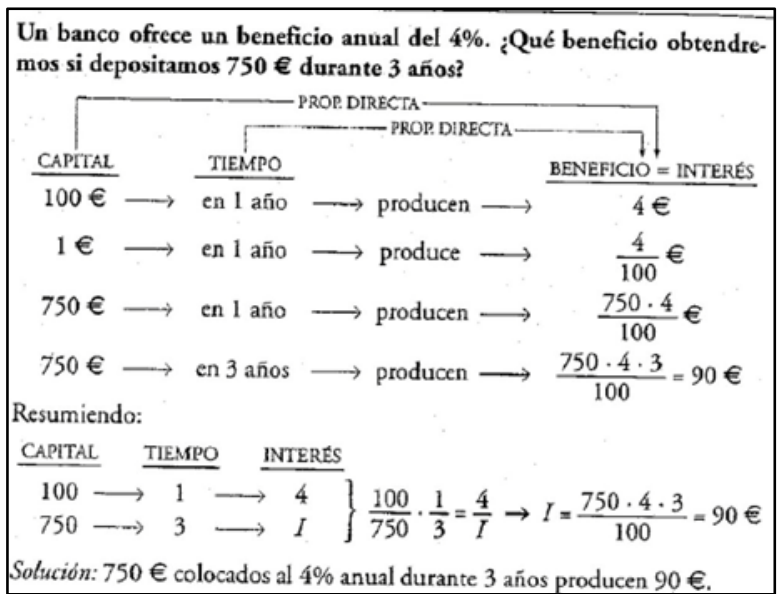

Figura III.24. $2^{\circ}$ E.S.O., pág. 98. 
Sin embargo, acto seguido se presenta (Figura III.25.) una fórmula general para el interés.

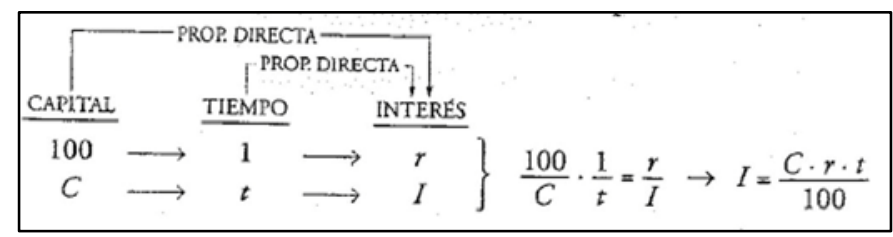

Figura III.25. $2^{\circ}$ E.S.O., pág. 98.

Si en los problemas se solicita otra de las magnitudes implicadas el alumno debe manipular la fórmula algebraicamente.

En cuarto curso, paradójicamente, no se presenta fórmula alguna ni se razona como en la proporcionalidad compuesta. En su lugar (Figura III.26.) se recurre al significado de obtener un tanto por ciento de interés en un tiempo concreto y se resuelven los problemas empleando aumentos porcentuales:
3. ¿Cuánto producen $10000 € \quad 3.6$ meses es medio año. Un $5 \%$ anual significa un $2,5 \%$ semestral. durante 6 meses al $5 \%$ anual?$$
10000 \stackrel{+2,5 \%}{\longrightarrow} 10000 \cdot 1,025=10250 €
$$

Figura III.26. $4^{\circ}$ E.S.O., pág. 73.

c. Repartos proporcionales:

Se tratan únicamente en cuarto curso y sólo se consideran repartos directamente proporcionales. Esto hace que para resolver los problemas pueda recurrirse al significado de repartir (Figura III.27.) teniendo en cuenta la importancia de saber en cuántas partes iguales debe descomponerse la cantidad en cuestión:

\footnotetext{
Tres socios invierten 1 millón, 2 millones y 5 millones de euros, respectivamente, en un negocio que al cabo de un año rinde un beneficio de $600000 €$ ¿Qué cantidad de los beneficios corresponde a cada uno?

Podemos considerar el negocio dividido en $1+2+5=8$ partes. Ahora no tenemos más que dividir los beneficios en otras ocho partes, de las que el primer socio se llevará una; el segundo, dos; y el tercero, cinco.

El beneficio correspondiente a cada parte es $600000: 8=75000 €$.

El reparto será: $\left\{\begin{array}{l}1{ }^{\text {er }} \text { SOCIO: } 75000 € \cdot 1=75000 € \\ 2 .^{\circ} \text { socio: } 75000 € \cdot 2=150000 € \\ 3 .^{\text {er }} \text { SOCIO: } 75000 € \cdot 5=375000 €\end{array}\right.$
}

Figura III.27. $4^{\circ}$ E.S.O., pág. 67. 
d. Mezclas:

Los problemas de mezclas que se trabajan en cuarto curso (Figura III.28.) se limitan al cálculo de, digamos, medias ponderadas:

\begin{tabular}{|c|c|c|c|}
\hline \multirow{2}{*}{\multicolumn{4}{|c|}{$\begin{array}{l}\text { Se muelen conjuntamente } 50 \mathrm{~kg} \text { de café de } 8,80 € / \mathrm{k} \\
\text { calidad, de } 6,40 € / \mathrm{kg} \text {. ¿A cómo resulta el kilo de la } \\
\text { Para resolverlo, situamos los datos en una tabla: }\end{array}$}} \\
\hline & & & \\
\hline & GAKTIDAO & PAtc10 & Cosin \\
\hline Cart SUPtBion & $50 \mathrm{~kg}$ & $8,80 € / \mathrm{kg}$ & $50 \cdot 8,80=440 €$ \\
\hline CARE WFERHOR & $30 \mathrm{~kg}$ & $6,40 € / \mathrm{kg}$ & $30 \cdot 6,40=192 €$ \\
\hline MELEL' & $80 \mathrm{~kg}$ & & $632 €$ \\
\hline \multicolumn{4}{|c|}{ Precio de la mezcla $=\frac{\text { Coste total }}{\text { Peso total }}=\frac{632 €}{80 \mathrm{~kg}}=7,90 € / \mathrm{kg}$} \\
\hline \multicolumn{4}{|c|}{ Solución: El kilo de la mezcla obtenida costará 7,90€. } \\
\hline
\end{tabular}

Figura III.28. $4^{\circ}$ E.S.O., pág. 68.

\section{III.3.6. Resolución de problemas}

La resolución de problemas juega un doble papel en la instrucción matemática. Por un lado pueden plantearse situaciones problemáticas que, a partir de la reflexión del alumno, permitan construir nuevos conocimientos. Por otro lado, sirven para que el alumno ponga en juego conocimientos adquiridos, tanto conceptuales como procedimentales. En resumen, pensamos que la resolución de problemas puede servir tanto para introducir como para afianzar.

En primer lugar hablaremos sobre el primero de los aspectos anteriores. En la propuesta didáctica analizada todos los apartados (ver III.3.1.) se inician con una situación problemática que debe servir de introducción. Sin embargo, este enfoque resulta fallido en, al menos, dos sentidos:

1. Son problemas que aparecen siempre completamente resueltos. De este modo el alumno no participa activamente en la construcción de los conceptos o procedimientos que se pretenden introducir, sino que es un mero receptor pasivo y, además, solitario.

2. El modo de presentar la resolución de los problemas hace que el proceso de resolución parezca algo que debe ser obvio e instantáneo. De este modo la única dificultad a la hora de resolver un problema radica en decidir el tipo de problema 
ante el que uno se encuentra y elegir el proceso de resolución adecuado de entre los que se han presentado.

Con respecto al uso de los problemas para afianzar los conocimientos adquiridos, encontramos que los textos analizados dan una gran importancia a la ejercitación de los alumnos. De hecho, tras cada apartado del texto (ver III.3.1.) se incluye siempre un repertorio de actividades destinadas a poner en juego los conocimientos presentados en ese apartado. Esta importancia queda de manifiesto aún más si consideramos que, dejando de lado ejercicios resueltos y ejemplos, el número de actividades propuestas a los alumnos es de 101 en primer curso, 139 en segundo y 109 en cuarto (algunas de ellas con múltiples apartados). Sin embargo, pese al indudable valor de estas actividades para la instrucción del alumno, encontramos algunos inconvenientes:

1. Las actividades aparecen siempre agrupadas en función de los conocimientos que se han de poner en juego para resolverlas. Esto, que es inevitable en las actividades que se presentan tras cada apartado del texto, no lo es tanto en las actividades que se presentan al final de cada tema. Con esta práctica se abunda en el segundo punto anterior, haciendo que el alumno identifique la resolución de problemas con la elección de técnicas.

2. Los problemas están acompañados de una indicación de su dificultad, de 1 a 3. Desconocemos los criterios seguidos por los autores a la hora de efectuar tal graduación, ni si la dificultad de un problema es susceptible de ser cuantificada, pero pensamos que esta práctica puede provocar:

a. Que ciertos alumnos no se atrevan a enfrentarse a determinados problemas considerados "difíciles", o que si lo hacen sea con la convicción de no ser capaces de resolverlos.

b. La frustración de un alumno que falla a la hora de resolver un problema "fácil" que, por tanto, se supone que debe ser capaz de resolver.

3. Al presentar una graduación en la dificultad de las actividades los autores están en cierto modo asumiendo el trabajo del profesor, que debe graduar las actividades en función del nivel de los alumnos con los que esté trabajando. 
Es frecuente la distinción entre ejercicios y problemas a la hora de analizar las actividades propuestas a los alumnos. Posiblemente el tema relativo a la proporcionalidad aritmética sea de los más proclives a que el número de problemas sea mayor que el de ejercicios (al contrario de lo que sucede en un gran número de ocasiones). En la propuesta analizada hemos encontrado los siguientes datos:

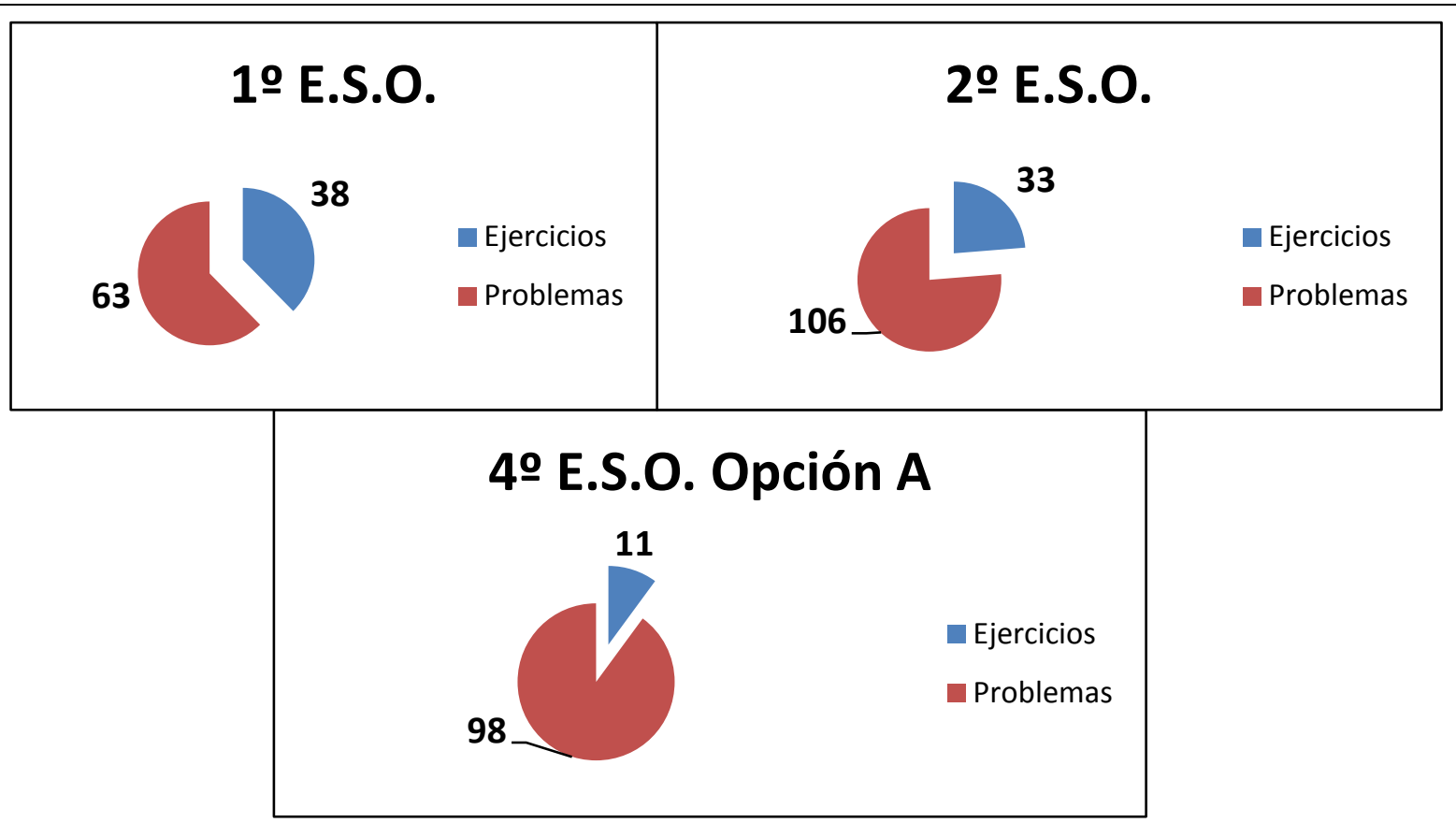

Figura III.29. Ejercicios y problemas en los distintos cursos.

Como se esperaba, en los temas relativos a la proporcionalidad hay un mayor número de problemas que de ejercicios. En primer curso encontramos 38 ejercicios frente a 63 problemas, en segundo la diferencia es bastante mayor (33 ejercicios frente a 106 problemas) y en cuarto es abrumadora diferencia a favor de los problemas (98 frente a 11 ejercicios). Sin embargo, si se analizan los problemas con más detenimiento, se observa que los datos son relativamente engañosos por cuanto gran parte de los problemas que se plantean se reducen a una aplicación mecánica de los algoritmos que los autores han introducido durante el desarrollo del tema. Esto se pone especialmente de manifiesto en enunciados como el siguiente: 


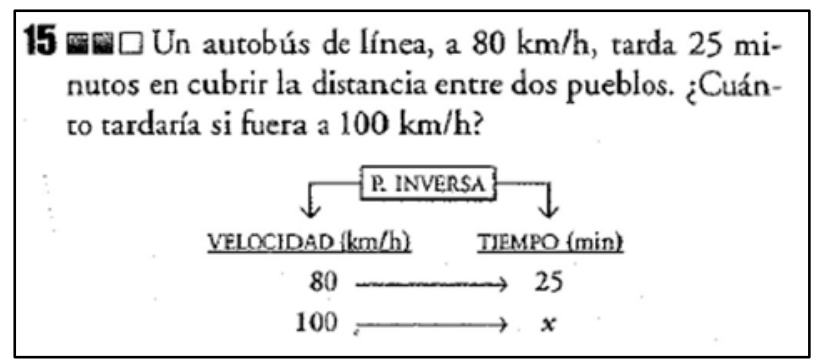

Figura III.30. 1º E.S.O., pág. 176

Donde se indica sin más a los alumnos el tipo de proporcionalidad entre las magnitudes implicadas para que apliquen (pues eso es lo que importa) el algoritmo correspondiente. En este caso se pierde una gran ocasión de poder discutir la relación entre velocidad y tiempo, magnitudes que en la experimentación que se ha llevado a cabo han demostrado ocasionar bastantes problemas a los alumnos de $1^{\circ}$ de E.S.O.

\section{III.3.7. Reflexiones}

Una vez revisada la propuesta didáctica, podemos extraer algunas reflexiones sobre la práctica docente actual relativa a la proporcionalidad aritmética:

1. Pese a que desde la aplicación de la LOGSE (y en leyes posteriores) las autoridades educativas proponen un aprendizaje basado en los presupuestos del constructivismo, encontramos que la metodología utilizada en los textos analizados se encuentra completamente alejada de dichos presupuestos.

2. No aparece una adaptación que tenga en cuenta la educación matemática atendiendo a la diversidad, que es uno de los pilares de currículo.

3. En la propuesta estudiada se muestra un gran desequilibrio entre los conocimientos de tipo conceptual y los de tipo procedimental, a favor de estos últimos. De hecho, se observa que:

a. Los procedimientos de cálculo llegan en ocasiones a suplantar a los propios conceptos (caso del porcentaje, por ejemplo).

b. Los conocimientos relevantes para los alumnos son los procedimentales (despreocupación por la identificación de magnitudes proporcionales, por ejemplo). 
4. En $4^{\circ}$ curso de E.S.O. tan sólo aparece la proporcionalidad en la opción A. Además se observa una cierta “involución” en la presentación de los contenidos. En concreto en este curso es cuando más claramente se observa el énfasis en las destrezas y los procedimientos.

5. Sólo se considera la razón entre números y, además, identificada con su cociente. Más aún, se identifica la idea de razón con la de fracción, lo que es matemáticamente incorrecto. Los autores parecen preferir dicha incorrección en base a las ventajas que produce a la hora de presentar las proporciones por analogía a la equivalencia de fracciones.

6. Se observa una total despreocupación en el manejo de las magnitudes; en parte como consecuencia del punto anterior. A la hora de resolver problemas todas las manipulaciones se llevan a cabo tan sólo desde un punto de vista numérico y la magnitud aparece sólo al final de un modo casi mágico.

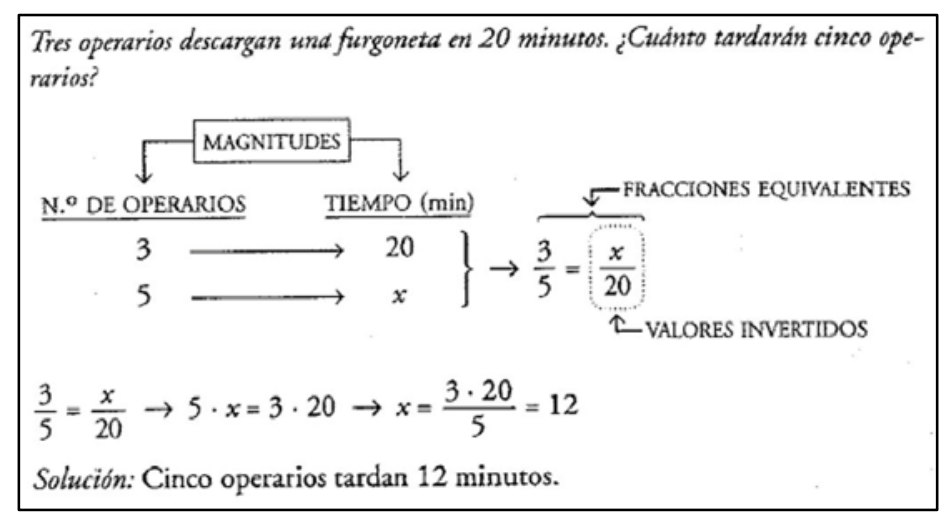

Figura III.31. $1^{\circ}$ E.S.O., pág. 167.

7. La proporcionalidad entre magnitudes es algo que se da casi por supuesto, reduciéndose los problemas a decidir si la proporcionalidad es directa o inversa. De las 349 actividades que se proponen entre los tres cursos analizados, sólo en 4 se pueden ver ejemplos de magnitudes que no guardan relación de proporcionalidad.

8. A la hora de resolver problemas de cantidades desconocidas (tanto en el caso de proporcionalidad simple como de compuesta) hay una gran tendencia a presentar técnicas de resolución que podríamos definir como “memorísticas”. Esto es especialmente claro en el caso de la proporcionalidad compuesta donde, tras un 
procedimiento de resolución basado en el concepto de proporcionalidad compuesta y en los conocimientos del alumno sobre proporcionalidad simple, se presenta un método de resolución que carece de justificación alguna en base a la instrucción recibida por el alumno.

9. Como consecuencia del punto anterior y pese a la elevada proporción que suponen los problemas, frente a los ejercicios, en el total de actividades propuestas al alumno; se produce el fenómeno de que los problemas propuestos se convierten en ejercicios de aplicación mecánica "en serie" de las destrezas adquiridas.

10. Se observa una gran tendencia a la algebrización y hacia el uso de lenguaje simbólico. Esto es especialmente grave en el caso de $1^{\circ}$ de E.S.O. si tenemos en cuenta que el tema dedicado a la proporcionalidad se encuentra situado antes que los dedicados al lenguaje algebraico.

11. El concepto de porcentaje está completamente oculto tras el método de cálculo. Más aún, los problemas de porcentajes acaban resolviéndose mediante reglas de tres, ocultando todavía más el sentido de lo que se está haciendo a favor de cómo se hace.

12. La Regla de interés se acaba presentando como una fórmula, acrecentando una vez más la importancia de la memoria frente a la comprensión.

13. Los repartos proporcionales y las mezclas se abordan de forma muy parcial y casi anecdótica. Además, estas aplicaciones sólo aparecen en el texto de $4^{\circ}$ de E.S.O. opción A. 


\section{CAPÍTULO IV:}

\section{FASE DE PLANIFICACIÓN.}

\section{IV.1. INTRODUCCIÓN}

En los capítulos anteriores hemos realizado un profundo análisis fenomenológico, histórico y epistemológico de la proporcionalidad aritmética. Observamos que, tradicionalmente, la enseñanza de la proporcionalidad se organiza en torno a los siguientes contenidos: razón, proporción, magnitudes directa e inversamente proporcionales, regla de tres (con sus variantes) y aplicaciones (porcentajes, repartos, regla de interés, mezclas y aleaciones...).

En este capítulo nos proponemos dar una alternativa justificada a la enseñanza de cada uno de estos contenidos. Los ejes principales en torno a los que va a girar nuestra propuesta son los siguientes:

1. La razón como "tanto por uno" es el concepto central en torno a la que se construyen otras ideas relevantes relacionadas con la proporcionalidad.

2. La condición de regularidad como elemento clave para discernir las situaciones en las que resulta pertinente aplicar ideas de proporcionalidad.

3. Separar las situaciones de proporcionalidad directa e inversa.

4. Potenciar la estructura multiplicativa de los números racionales positivos dando significado a las operaciones con cantidades de magnitud.

5. Definir las técnicas adecuadas adaptadas a las ideas de proporcionalidad que se ponen en juego. 


\section{IV.2. IDEAS EN LAS QUE SE SUSTENTA LA PROPUESTA}

Como ya hemos indicado un poco más arriba, las ideas que vamos a presentar surgen del exhaustivo análisis fenomenológico, histórico y epistemológico de los conceptos y procedimientos ligados a la proporcionalidad que se ha llevado a cabo; además de tener en cuenta las características cognitivas de los alumnos.

Pensamos que el objetivo principal que ha de tener la propuesta curricular a la que den lugar estas ideas es el de incrementar la comprensión de los alumnos en tres campos fundamentalmente:

- En el uso significativo de las estructuras multiplicativas que han estudiado con anterioridad.

- En la aprehensión de los aspectos conceptuales relacionados con la proporcionalidad.

- En la aplicación de dichos aspectos a la hora de resolver situaciones problemáticas relacionadas con la proporcionalidad.

En lo que sigue vamos a distinguir entre ideas relativas a aspectos conceptuales (aunque algunas irán orientadas a la resolución de problemas) e ideas relativas a aplicaciones prácticas.

\section{IV.2.1 Ideas relativas a aspectos conceptuales}

En este apartado vamos a agrupar las ideas fundamentales que se refieren a aspectos conceptuales de la proporcionalidad; ya sea de forma directa o bien al modo en que dichos conceptos se manejan a la hora de afrontar una situación problemática:

1. La primera observación que queremos hacer es que la proporcionalidad directa y la proporcionalidad inversa están muy alejadas, tanto desde un punto de vista matemático como cognitivo. Históricamente, esta separación queda reflejada en el desequilibrio que se observa - a favor de la proporcionalidad directa - en cuanto al número de situaciones y problemas que se estudian. Además, es interesante observar que los errores que se localizan siempre se dan en situaciones de proporcionalidad inversa. 
Matemáticamente, si observamos la Figura IV.1, que muestra las gráficas de las típicas funciones de proporcionalidad, vemos su naturaleza esencialmente distinta: una recta y una hipérbola. Incluso si pensamos en una definición más habitual surgen las diferencias. En la proporcionalidad directa se conserva la razón entre pares de valores correspondientes, en la inversa se conserva el producto.

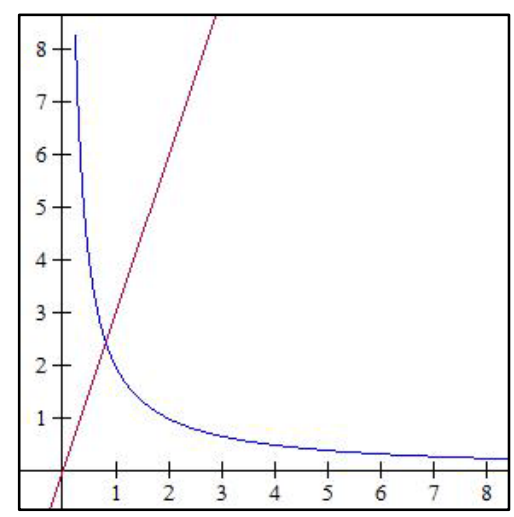

Figura IV.1. Distintas naturalezas

Así pues, ¿por qué deberían tratarse ambas situaciones de forma conjunta como tradicionalmente se viene haciendo? Pensamos que sería mucho más interesante y ventajoso para los alumnos presentar y desarrollar completamente el concepto de magnitudes directamente proporcionales para después, de forma separada, hacer lo propio con las magnitudes inversamente proporcionales.

2. La segunda observación tiene que ver con la caracterización de las situaciones de proporcionalidad. El enunciado "la magnitud $A$ es directamente (o inversamente) proporcional a $B$ ” es incompleto y sólo tiene sentido dentro del contexto en el que ambas magnitudes se relacionan. Para solventar este hecho hemos de salir del mundo puramente aritmético para introducir un concepto de carácter funcional que hemos dado en llamar condición de regularidad. La condición de regularidad es un hecho, dependiente de la situación concreta en la que se de una relación entre dos magnitudes, que nos permitirá (si se dan el resto de condiciones necesarias) hacer una afirmación del tipo “ $A$ es proporcional a $B$ ” con pleno sentido. Por ejemplo, ante el problema “4 vacas comen 500 kilos de alfalfa en 15 días, ¿cuánta alfalfa comerán 7 vacas en 25 días?” para poder afirmar que la cantidad de alfalfa es directamente proporcional al número de días 
y al número de vacas es necesario que se cumpla la condición de regularidad "todas las vacas comen diariamente la misma cantidad de alfalfa". Una vez hecho esto ya tiene sentido el cálculo de las razones que resuelven el problema: la cantidad de alfalfa que una vaca come al día o bien los días que una vaca puede subsistir con un kilo de alfalfa.

3. Históricamente la génesis de los conceptos relacionados con la proporcionalidad aritmética se encuentra en las situaciones de intercambio o trueque. En consecuencia, a la hora de diseñar una propuesta didáctica se ha creado un modelo de aprendizaje que incluye las variables: magnitudes (continuas), acción (intercambiar) y técnica (búsqueda de la cantidad correspondiente a la unidad).

4. A partir de la actividad de intercambio surge de forma natural la idea de razón como "tanto por uno", es decir, entendida como la cantidad de una de las magnitudes que se corresponde con una unidad de la otra. Este concepto constituye el núcleo central en torno al que construir ideas cognitivamente significativas sobre proporcionalidad directa.

5. La resolución de problemas de búsqueda de cantidades desconocidas en situaciones de proporcionalidad directa se sustenta en la conjugación de:

- La idea de razón como tanto por uno.

- El significado de las operaciones básicas entre cantidades de magnitud.

6. Históricamente el manejo sistemático de la proporcionalidad inversa surge sobre todo en contextos que involucran una magnitud que actúa como medida de la "calidad" de algún bien; como por ejemplo en el caso de mezclas y aleaciones metálicas donde se puede tomar la cantidad de oro por unidad de peso como indicador de la calidad de una aleación. Sin embargo, al contrario de lo que sucedía en el caso de la proporcionalidad directa y de los repartos, este tipo de situación no es tan apropiada para su utilización en el aula. En su lugar se plantea un modelo de aprendizaje basado en el embotellado de una cantidad fija de líquido en botellas de diferentes tamaños, donde las magnitudes relevantes son: magnitudes (continuas), acción (embotellar) y técnica (reparto en partes iguales). 
7. En esta situación surge de forma natural la idea de constante de proporcionalidad. El concepto de constante de proporcionalidad es el núcleo central en torno al que construir ideas cognitivamente significativas sobre proporcionalidad inversa. Sin embargo, en este caso, existen muchas situaciones en las que la constante de proporcionalidad no resulta tan fácilmente accesible y en las que resulta más interesante recurrir únicamente al significado de las operaciones y al manejo de las magnitudes.

8. La resolución de problemas de búsqueda de cantidades desconocidas en situaciones de proporcionalidad inversa se sustenta en la conjugación de:

- La idea de constante de proporcionalidad.

- El significado de las operaciones entre cantidades de magnitud.

9. Respecto a la proporcionalidad compuesta; es decir, situaciones en las que aparecen involucradas más de dos magnitudes de forma que consideradas por parejas pueden suponerse proporcionales, pensamos que no merece la pena un tratamiento específico del tema. Esto es así porque siempre que se nos plantea una de tales situaciones es posible traducirla a una situación que involucre sólo a dos magnitudes mediante una transformación adecuada del problema. Por ejemplo, el enunciado "una lavadora industrial trabajando 8 horas diarias durante 5 días ha lavado 1000 kilos de ropa. ¿Cuántos kilos de ropa lavará en 12 días trabajando 10 horas diarias?” (Cólera y Gaztelu, 2008b) puede traducirse en el enunciado equivalente: "una lavadora tarda 40 horas en lavar 1000 kilos de ropa. ¿Cuántos kilos de ropa lavará en 120 horas?’.

A este último enunciado el alumno puede enfrentarse con las herramientas que tiene a su disposición. Este procedimiento, además, hace que el alumno deba adquirir una comprensión muy fina de la situación problemática así como del significado de las operaciones que efectúa durante el proceso de traducción.

\section{IV.2.2 Ideas relativas a aplicaciones prácticas}

En el apartado anterior hemos comentado algunas ideas sobre cómo manejar los principales conceptos involucrados a la hora de afrontar una situación problemática en un contexto de proporcionalidad. En este apartado vamos a centrarnos en lo que 
tradicionalmente se ha venido llamando “aplicaciones de la proporcionalidad”. Estas aplicaciones han variado ligeramente a lo largo del tiempo y actualmente se suelen presentar las siguientes:

- Porcentajes.

- Regla de interés.

- Repartos proporcionales (Reglas de compañía).

- Mezclas (Reglas de aligación).

Esta lista, que permanece principalmente por tradición, se veía incrementada en el pasado con otras aplicaciones como, por ejemplo, la Regla conjunta (que no consistía más que en una concatenación de intercambios), o las Reglas de falsa posición y de doble falsa posición que resultaban útiles a la hora de resolver ciertos problemas sin recurrir al lenguaje del álgebra. Es notorio el hecho de que en la única de estas aplicaciones en la que el papel de la proporcionalidad inversa es sustancial es el caso de las mezclas.

Del anterior listado optamos por trabajar específicamente los porcentajes y los repartos. Respecto a la Regla de interés, además de por su escasa aplicación práctica, no le dedicamos atención por cuanto se trata de una relación entre magnitudes difícilmente justificable más allá de la convención y, por tanto, su manejo reside en la aceptación tácita del hecho de que el interés es directamente proporcional al capital, al rédito y al tiempo. En cuanto a las Reglas de aligación, que pudieron tener su interés y aplicación en el pasado, ya no se justifica su presentación en el aula de no ser por tradición. Si se quieren presentar situaciones relacionadas con mezclas es mucho más interesante observar la aditividad de los pesos y deducir cómo se obtiene el precio de una mezcla.

Las ideas principales que guiarán nuestra propuesta a la hora de trabajar con estas aplicaciones son las siguientes:

1. El porcentaje se presenta como "tanto por cien” en analogía a la idea de razón como “tanto por uno". El principal problema a tener en cuenta es evitar la identificación entre el concepto y el algoritmo, sobre todo en alumnos que, al llegar de la Primaria, tienen asimilado el algoritmo pero no entienden claramente el significado. 
2. A la hora de efectuar un reparto se considerarán como datos los “índices” respecto a los cuáles se va a efectuar el reparto. El modo de obtener dichos índices es donde entra en juego la proporcionalidad y se distinguirá según el reparto sea respecto de una o varias magnitudes. Los puntos clave a la hora de trabajar los repartos son:

- Enfatizar el significado de las razones entre los índices dados: que alguien reciba el doble o el triple que otro, que por cada 3 unidades que uno recibe el otro recibe 2 , etc.

- Ver que, siempre que nos movamos en el ámbito del número racional, dichos índices pueden convertirse en enteros sin que el efecto del reparto varíe.

- Una vez que los índices son enteros, ha de identificarse la importancia y el significado de la suma de dichos índices: el número de partes en los que ha de dividirse el objeto del reparto.

\section{IV.3. LA PROPUESTA DIDÁCTICA}

La propuesta didáctica que vamos a presentar se organiza en torno a los siguientes epígrafes:

i. La razón.

ii. Magnitudes directamente proporcionales.

iii. Porcentajes.

iv. Repartos respecto a una magnitud.

v. Magnitudes inversamente proporcionales.

vi. Proporcionalidad compuesta.

vii. Repartos respecto a varias magnitudes.

Aunque estos son los aspectos que se trabajan específicamente, también se mencionan tópicos que tradicionalmente se relacionan con la proporcionalidad, como la Regla de Interés o las mezclas y aleaciones. Sin embargo, estos dos temas no reciben 
atención específica porque entendemos que con el trabajo de los siete apartados anteriores el alumno dispone de las herramientas suficientes para enfrentarse a estas situaciones concretas sin necesidad de introducir tipologías de problemas adicionales.

De hecho, está en la base de la propuesta tratar de reducir al mínimo las tipologías y clasificaciones de problemas y situaciones, así como las técnicas de resolución de problemas. Pensamos que es más importante dotar al alumno de un aparato conceptual potente (idea de razón y de porcentaje, manejo de las magnitudes, significado de las operaciones con cantidades de las mismas) que, ante un problema concreto, le permita comprender profundamente la situación y así poder resolverla haciendo uso de las ideas (herramientas) que se le han proporcionado.

Así, la filosofía anterior se refleja especialmente en el tratamiento recibido por parte de lo que habitualmente se llaman “aplicaciones de la proporcionalidad”.

\section{IV.3.1. La razón}

\section{IV.3.1.1. Aspectos matemáticos y de la enseñanza tradicional}

En el ámbito puramente matemático la razón no tiene un tratamiento específico. Aunque en un primer momento el concepto de razón por antifairesis sí recibió la atención de los matemáticos griegos, su complejidad hizo que fuera abandonado en favor del concepto “estar en la misma razón” mucho más operativo desde un punto de vista práctico. Posteriormente se produjo una aritmetización del concepto de razón que ha llegado hasta nuestros días.

Tradicionalmente, en el ámbito aritmético, se presenta la razón como una relación ordenada entre dos cantidades de magnitud. Cuando se utiliza la notación fraccionaria $a / b$ se interpreta no como un único valor numérico, sino como dos valores separados. En concreto se interpreta el numerador como la cantidad de la magnitud citada en primer lugar y el denominador como la cantidad de la magnitud citada en el segundo lugar. Así, al decir que la razón entre harina y aceite en una determinada receta es de 3/4, se interpreta como que 3 unidades de harina se relacionan con 4 unidades de aceite. En ciertas ocasiones se produce una aritmetización total del concepto de razón que se llega a identificar, simplemente, con un cociente o con una fracción. En estos casos suele omitirse cualquier tipo de significado. 
La razón también hace su aparición en el ámbito funcional asociada a las funciones de proporcionalidad directa $f(x)=k x$. En este contexto, sin embargo, el significado que se asigna a la razón es bien diferente al anterior. Aquí la razón se presenta como el cociente (que se mantiene constante) $f(x) / x=k$. De hecho, en este ámbito se habla más comúnmente de razón de proporcionalidad o de constante de proporcionalidad.

Así pues, se podría decir que, salvo casos excepcionales, la razón se presenta de tres formas:

- Como una relación ordenada entre dos cantidades de magnitud (en un contexto aritmético).

- Como el cociente entre dos números.

- Como el cociente (constante) entre dos variables (en un contexto funcional).

Asociado al concepto de razón en el ámbito aritmético aparece inmediatamente el de proporción. Se define una proporción como la igualdad de dos razones. Para evaluar la igualdad o no de dos razones dadas se recurre a la notación fraccionaria, obviando el significando de la razón como relación entre cantidades de magnitud y aplicando el conocido criterio de igualdad (semejanza) de fracciones: "producto de medios igual a producto de extremos” aun cuando, sensu stricto, las cantidades $a$ y $b$ que aparecen en la notación $a / b$ no tendrían por qué ser enteros.

Otro aspecto que refleja claramente la aritmetización del concepto de razón, el énfasis que se hace en los aspectos meramente numéricos frente a los relacionales, es el hecho de que no aparece de forma explícita en la enseñanza tradicional una discusión sobre las condiciones necesarias para poder hablar de la razón entre dos magnitudes. Evidentemente, si se concibe la razón como un cociente, nunca habrá problemas para definirla. Sin embargo si se concibe desde un punto de vista relacional, es necesario establecer en qué términos se da la relación entre las magnitudes implicadas. Esto no aparece en los textos escolares y, en caso de hacerlo, está asumido de forma implícita o enmascarado en los discursos de presentación del tema.

\section{IV.3.1.2. Propuesta alternativa}

Frente a las interpretaciones anteriores del concepto de razón, nosotros 
consideramos la razón con un significado de "tanto por uno", entendida como la cantidad de una magnitud que se relaciona con una unidad de la otra. Así, al emplear la notación $a / b$ no vemos ya dos números separados $a$ y $b$, sino que se considera como un único número que nos indica la cantidad de la primera magnitud que se relaciona con la unidad de la magnitud citada en segundo lugar. En torno a este significado se construirá la propuesta completa.

Para introducir el concepto de razón recurriremos a la situación que, históricamente, entendemos que dio lugar a este tipo de razonamientos: las situaciones de intercambio. La extensión de las ideas que surgen en estas situaciones a otras más generales no es difícil y se abordará más adelante.

Además de introducir el concepto de razón, pensamos que existen otros aspectos esenciales asociados de forma directa a esta idea. En consecuencia, los apartados en torno a los que se vertebra nuestra propuesta a la hora de desarrollar y transmitir el concepto de razón y sus ideas asociadas son los siguientes:

a) El concepto de razón.

b) La existencia de dos razones en toda situación de intercambio.

c) La condición de regularidad, o condiciones que deben darse para que tenga sentido hablar de razón.

d) Comparación de razones.

e) Composición de razones.

\section{a) El concepto de razón.}

Para introducir la idea de razón como "tanto por uno" recurrimos a situaciones de intercambio entre dos magnitudes. En concreto, se pretende introducir la siguiente definición de razón entre dos magnitudes:

Supongamos que se produce el intercambio de dos magnitudes A y B (cuyas unidades de medida están fijadas de antemano), de forma que a unidades de A se intercambian por b unidades de B. En esta situación llamaremos razón entre A y $B$ a la cantidad de la magnitud A que se obtiene a cambio de una unidad de la magnitud $B$. 
Es importante indicar que el concepto de razón que presentamos no es puramente numérico. También incluye información sobre las magnitudes implicadas y sobre el sentido del intercambio.

\section{Ejemplo:}

En una situación en la que se cambian 3 litros de leche por 2 kilos de carne la razón entre los kilos de carne y los litros de leche será:

2/3 de kilo de carne por cada litro de leche.

Esquemáticamente, simbolizaremos estas situaciones mediante un diagrama como el siguiente:

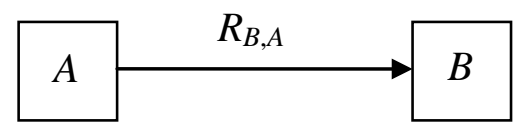

Esta notación pretende indicar que la razón, en cierto modo, es el concepto que nos permite comprender el funcionamiento interno de la situación de intercambio que estemos analizando. Más en concreto, si $a$ y $b$ son las cantidades de $A$ y $B$, respectivamente, que se relacionan en el intercambio considerado, y teniendo en cuenta el significado de la razón como “tanto por uno”, es evidente que:

$$
R_{B, A}=b / a \text {. }
$$

Como el conocimiento de la cantidad de $B$ que se obtiene a cambio de una unidad de $A$ nos permite calcular fácilmente la cantidad de $B$ que se obtiene a cambio de cualquier otra cantidad de $A$ (sin más que multiplicar), está claro que conocer la razón como dijimos - proporciona una comprensión completa de la situación.

\section{Ejemplo:}

En el ejemplo anterior, en el que se obtenían 2/3 de kilo de carne por cada litro de leche (A sería la magnitud “litros de leche” y $B$ la magnitud “kilos de carne”). Si queremos saber cuánta carne se recibirá a cambio de 7 litros de leche basta con multiplicar esta cantidad por los kilos de carne que se obtienen a cambio de 1 litro para obtener el resultado: 14/3 de kilo de carne.

\section{b) La existencia de dos razones en toda situación de intercambio.}

Cuando se plantea una situación en la que se intercambian dos mercancías está claro que ambas juegan un papel simétrico. Así pues se puede plantear lo siguiente: 
Supongamos que se produce el intercambio de dos magnitudes A y B (cuyas unidades de medida están fijadas de antemano,) de forma que a unidades de A se intercambian por b unidades de B. Llamaremos:

1. Razón entre $A$ y $B$, a la cantidad de la magnitud $A$ que se obtiene a cambio de una unidad de la magnitud $B$.

2. Razón entre $B$ y A, a la cantidad de la magnitud $B$ que se obtiene a cambio de una unidad de la magnitud $B$.

\section{Ejemplo:}

En la misma situación que en los ejemplos anteriores, si ponemos en paralelo ambas razones se tiene algo como lo siguiente:

2/3 de kilo de carne por cada litro de leche (razón entre kilos de carne y litros de leche).

3/2 de litro de leche por cada kilo de carne (razón entre litros de leche y kilos de carne).

Resulta bastante natural dar a la razón entre $B$ y $A$ el nombre de razón inversa de la razón entre $A$ y $B$. Además, si nos fijamos sólo en el valor numérico de la razón, se obtienen fracciones inversas.

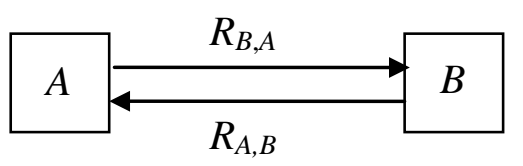

Como antes, si a y b son cantidades de $A$ y $B$ que se relacionan mediante el intercambio, sabemos que $R_{A, B}=a / b$ y que $R_{B, A}=b / a$. De aquí se obtiene inmediatamente que:

$$
R_{A, B}=1 / R_{B, A} .
$$

Esta relación admite la justificación intuitiva de que si intercambiamos una cierta cantidad de $A$ por otra determinada cantidad de $B$, lo lógico es que si queremos cambiar esa cantidad de $B$ obtengamos exactamente la cantidad de $A$ inicial.

Naturalmente, en una situación concreta la información que proporcionan ambas razones es la misma. Tan sólo cambia el modo de ver el intercambio; es decir, cuando se da un intercambio entre las dos magnitudes $A$ y $B$ podemos pensar que tenemos $A$ y queremos obtener $B$ o, simétricamente, que tenemos $B$ y queremos obtener $A$.

\section{c) La condición de regularidad.}

En los dos apartados anteriores hemos introducido el concepto de razón a partir de 
situaciones de intercambio. Sin embargo, parece que hemos asumido tácitamente su existencia cuando, de hecho, no es así. No podremos hablar de razón en cualquier situación en la que se produce un intercambio entre dos magnitudes. Para que se pueda hablar de razón en una situación concreta, deberán cumplirse una o varias condiciones. Estas condiciones recibirán el nombre de condiciones de regularidad.

\section{Ejemplo:}

Volviendo sobre la situación anterior, para que en ella tenga sentido hablar de la razón entre kilos de carne y litros de leche o de la razón entre litros de leche y kilos de carne deberá cumplirse, respectivamente, que:

Por cada litro de leche se obtiene siempre la misma cantidad de carne.

Por cada kilo de carne se obtiene siempre la misma cantidad de leche.

Veamos un ejemplo sencillo en el que no se dan las condiciones de regularidad necesarias para hablar de razón.

\section{Ejemplo:}

Supongamos que dos niños intercambian cromos por canicas. Si siempre se obtiene el mismo número de canicas por cada cromo no habrá problema en hablar de la razón entre canicas y cromos. Si, por el contrario, por los cromos más difíciles de conseguir se piden más canicas no podremos hablar de la citada razón.

Es decir:

La condición de regularidad supone asumir que todos los objetos involucrados en el intercambio son “iguales” y que el intercambio se hace siempre "de la misma forma”.

\section{d) Comparación de razones.}

Hasta ahora hemos definido las razones que surgen en una situación de intercambio, así como las condiciones que deben cumplirse para garantizar la existencia de dichas razones. La utilidad de este concepto quedará muy clara en las secciones siguientes, pero una primera aplicación práctica es la de comparar diversas situaciones en las que se intercambian las mismas magnitudes. 
Supongamos que tenemos dos situaciones en las que se intercambian las magnitudes $A$ y $B$ (medidas en ambas situaciones mediante las mismas unidades respectivas) de manera que:

1. En la situación 1 se obtiene una cantidad $a_{1}$ de $A$ a cambio de una cantidad $b_{1}$ de $B$.

2. En la situación 2 se obtiene una cantidad $a_{2}$ de $A$ a cambio de una cantidad $b_{2}$ de $B$.

Puesto que hemos definido la razón entre $A$ y $B$ (si se dan las condiciones de regularidad necesarias), como la cantidad de la magnitud $A$ que se obtiene a cambio de una unidad de $B$, tenemos:

1. La razón entre $A$ y $B$ en la situación 1 es: “una cantidad $a_{1} / b_{1}$ de $A$ a cambio de una unidad de $B$ ”.

2. La razón entre $A$ y $B$ en la situación 2 es: "una cantidad $a_{2} / b_{2}$ de $A$ a cambio de una unidad de $B$ ”.

Así pues, si queremos comparar ambas situaciones desde el punto de vista de en cuál obtenemos más o menos a cambio de una misma cantidad de $B$, es evidente que lo podremos hacer comparando los valores numéricos de ambas razones. Lo mismo sucedería si pensásemos en el intercambio inverso, sólo que las razones que se compararían serían las inversas de las consideradas más arriba.

\section{Ejemplo:}

Supongamos que nos encontramos ante las dos situaciones siguientes:

1. En el banco A se obtienen 175 dólares a cambio de 129 euros.

2. En el banco B se obtienen 200 dólares a cambio de 145 euros.

Si queremos obtener dólares a cambio de nuestros euros nos fijamos en la razón entre dólares y euros en cada situación (suponiendo que el cambio se hace siempre del mismo modo):

1. En el banco A la razón entre dólares y euros es “1’36 dólares por cada euro”.

2. En el banco B la razón entre dólares y euros es “1’38 dólares por cada euro”. 
Por tanto, resulta más interesante acudir al banco $B$ para efectuar el cambio

Como comentario, parece interesante indicar que debido a que los valores numéricos de las razones inversas son inversos el uno del otro, entonces si comparamos dos situaciones, la que sea más ventajosa considerando el intercambio en uno de los dos sentidos posibles, será la menos ventajosa considerando el intercambio inverso; y viceversa.

\section{Ejemplo:}

En el ejemplo anterior, si quisiéramos obtener euros a cambio de dólares resulta más ventajoso hacerlo en el banco $A$, que es precisamente el menos ventajoso para el cambio anterior.

\section{e) Composición de razones.}

Hasta ahora sólo se han considerado situaciones en las que aparecían involucradas dos magnitudes. Sin embargo parece natural considerar una situación en la que producen varios intercambios sucesivos. Por ejemplo, en un primer momento se puede cambiar la magnitud $A$ por la magnitud $B$ y, a continuación la magnitud $B$ por la $C$. En tal caso se puede plantear la idea de que, en realidad, se intercambia la magnitud $A$ por la $C$.

En la situación anterior (asumiendo las condiciones de regularidad necesarias) se pueden considerar - por ejemplo - las tres razones siguientes:

1. La razón entre $B$ y $A$ : cantidad de $B$ que se obtiene a cambio de una unidad de $A$.

2. La razón entre $C$ y $B$ : cantidad de $C$ que se obtiene a cambio de una unidad de $B$.

3. La razón entre $C$ y $A$ : cantidad de $C$ que se obtiene a cambio de una unidad de $A$.

La cuestión, pues, es encontrar la relación existente entre las tres razones anteriores. Evidentemente, para saber la cantidad de $C$ que se obtiene a cambio de una unidad de $A$, primero calculamos la cantidad de $B$ que se obtiene a cambio de dicha unidad. Después, basta multiplicar esta cantidad por la razón entre $C$ y $B$ para encontrar lo buscado. Es decir: 
El valor numérico de la razón entre C y A es el producto del valor numérico de la razón entre $B$ y A y la razón entre $C$ y $B$.

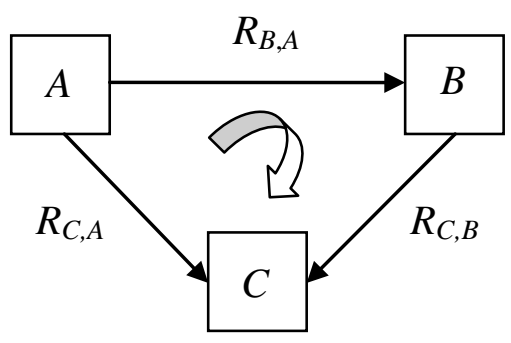

A la vista del diagrama anterior, sean $a, b, c$ y $d$ cantidades respectivas de cada una de las magnitudes que se relacionan mediante los intercambios considerados; es decir, se obtienen $b$ unidades de $B$ a cambio de $a$ unidades de $A$ y $d$ unidades de $C$ a cambio de $c$ unidades de $B$. Sabemos que $R_{B, A}=b / a$, que $R_{C, B}=d / c$. Por tanto, es fácil ver que a cambio de una unidad de $A$ se obtienen $b d / a c$ unidades de C. Es decir, $R_{C, A}=b d / a c$ y, por lo tanto:

$$
R_{C, A}=R_{C, B} R_{B, A}
$$

Es fácil imaginar que esta idea se puede reproducir cuando se considera un número arbitrario de magnitudes implicadas.

\section{Ejemplo:}

Supongamos que estamos ante las dos situaciones siguientes:

1. En la situación 1 se cambian 3 litros de leche por 2 kilos de carne.

Razón entre kilos de carne y litros de leche: "2/3 de kilo de carne por cada litro de leche”.

2. En la situación 2 se cambian 3 kilos de carne por 4 litros de vino.

Razón entre litros de vino y kilos de carne: “4/3 de litro de vino por cada kilo de carne”.

Siempre que, como es lógico, se cumplan las condiciones de regularidad necesarias. Ahora, queremos averiguar cómo se produce el intercambio entre vino y leche. Para ello, haciendo uso de la razón entre litros de vino y kilos de carne, es fácil ver que a cambio de los 3 litros de leche iniciales se obtienen 2 kilos de carne y, por tanto, 8/3 de litro de vino. Así pues, tenemos una tercera situación resultado de “componer” las dos 
anteriores:

3. En la situación 3 se cambian 3 litros de leche por 8/3 de litro de vino.

Razón entre litros de vino y litros de leche: "8/9 de litro de vino por cada litro de leche”.

Se observa, como ya dijimos antes, que:

$$
\frac{8}{9}=\frac{4}{3} \times \frac{2}{3}
$$

relación que ha surgido de forma natural a partir de los significados de cada una de las razones implicadas.

\section{IV.3.2. Magnitudes directamente proporcionales}

\section{IV.3.2.1. Aspectos matemáticos y de la enseñanza tradicional}

Desde un punto de vista matemático se puede definir el concepto de proporcionalidad directa, al menos, de las siguientes formas:

1. Definición por razones: Dos magnitudes son directamente proporcionales si y sólo si se cumple que el cociente $y / x$ entre pares de cantidades relacionadas es constante. Ya indicamos que, en este caso, este cociente constante recibe el nombre de razón (o constante) de proporcionalidad.

2. Definición implícitamente funcional: Dos magnitudes son directamente proporcionales si y sólo si la función que las relaciona $y=f(x)$ cumple que $f(a x)=a f(x)$ para todo $a$.

3. Definición explícitamente funcional: Dos magnitudes son directamente proporcionales si y sólo si la función que las relaciona es de la forma $y=f(x)=k x$.

De estas tres caracterizaciones, la última sólo cobra sentido en un contexto funcional. Sin embargo, las otras dos, y especialmente la primera, se suelen dar en un contexto aritmético. De hecho, la segunda caracterización se suele traducir en un enunciado del tipo:

Dos magnitudes son directamente proporcionales cuando al multiplicar (dividir) una cantidad de la primera magnitud por dos, tres, etc..., la cantidad 
correspondiente de la segunda magnitud queda multiplicada (dividida) por dos, tres, etc...

Esta caracterización es correcta salvo consideraciones relacionadas con la continuidad, pero da lugar al error habitual de pensar que dos magnitudes son directamente proporcionales siempre que si una aumenta o disminuye, la otra hace lo mismo.

En la práctica educativa habitual se utiliza generalmente la segunda caracterización (especialmente su versión en cursiva), para comprobar si dos magnitudes son directamente proporcionales. La primera suele ser la elegida a la hora de resolver problemas, aunque también la segunda sirve como fundamento para algunos de los métodos de resolución habituales.

Caracterizar en el aula las magnitudes directamente proporcionales de acuerdo al enunciado en cursiva anterior presenta el problema de que presupone el hecho de que a cada unidad de la primera magnitud se corresponde siempre la misma cantidad de la segunda (o vicecersa). Esta presunción, que no es sino lo que llamábamos antes condición de regularidad, casi siempre se omite. Además nunca se indica la importancia del contexto a la hora de hablar de proporcionalidad directa. Se presentan ejemplos típicos de magnitudes que son o no son directamente proporcionales, pero nunca contextos en los que la misma pareja de magnitudes lo sean o no.

Aparte de la caracterización de magnitudes directamente proporcionales, el otro eje en torno al que gira la enseñanza tradicional es el de la búsqueda de cantidades desconocidas en situaciones de proporcionalidad directa. En esencia, se presenta una situación en la que conocemos un par de cantidades relacionadas de dos magnitudes directamente proporcionales y otra cantidad de una de ellas. A partir de estos datos se solicita la cantidad correspondiente de la otra magnitud.

Para afrontar este tipo de problemas el esquema que se suele presentar es el siguiente: Primero comprobar que las dos magnitudes son directamente proporcionales (aquí es donde suele aparecer la segunda de las caracterizaciones anteriores y, en ocasiones, su versión incorrecta). Después aplicar alguno de los siguientes procedimientos:

- Regla de tres: se disponen los datos al modo "tradicional" y se aplica, o bien un algoritmo memorizado, o bien la igualdad de razones (externas) que se 
desprende de la caracterización 1.

- Reducción a la unidad: se calcula, a partir de las dos cantidades conocidas, la cantidad de la segunda que corresponde a una unidad de la primera y después se utiliza este valor para resolver el problema. Para hallar el valor unitario se recurre al significado de las operaciones (poco corriente), a la igualdad de razones (en este caso internas) que se desprende de la caracterización 2, o bien se aplica (sorprendentemente) la Regla de tres.

Es muy destacable el hecho de que en este punto se suele introducir el lenguaje algebraico (utilización de la letra $x$ para denotar la cantidad desconocida), e incluso se realizan algunas manipulaciones formales.

También es interesante observar que el concepto de razón juega un papel principalmente instrumental a la hora de resolver problemas y muy secundario, o casi inexistente, a la hora de caracterizar las magnitudes directamente proporcionales.

\section{IV.3.2.2. Propuesta alternativa}

Frente a lo señalado en el párrafo anterior, proponemos que la idea de razón como “tanto por uno”, a la que se ha dedicado ya una atención especial, juegue un papel central no sólo a la hora de resolver problemas sino también, y especialmente, a la hora de caracterizar las magnitudes que son directamente proporcionales.

Puesto que la idea de razón va a ser fundamental, también hará su aparición la idea de condición de regularidad. Además, al no estar ya sólo ante situaciones de intercambio, habrá que modificar ligeramente el lenguaje, que no las ideas, para adaptarlo a situaciones más generales. En consecuencia los apartados en torno a los que se vertebra nuestra propuesta a la hora de introducir las magnitudes directamente proporcionales son los siguientes:

a) El concepto de magnitudes directamente proporcionales.

b) Razones que se definen en situaciones de proporcionalidad directa. La condición de regularidad.

c) Búsqueda de cantidades desconocidas en situaciones de proporcionalidad directa. 


\section{a) El concepto de magnitudes directamente proporcionales.}

Más allá de situaciones en las que se produce un intercambio entre ellas, existen muchos contextos en los que dos magnitudes pueden estar relacionadas. Es decir, contextos en los que conociendo la cantidad de una de las magnitudes es posible conocer la cantidad correspondiente de la otra magnitud.

Una pareja de magnitudes relacionadas puede estarlo de muy diversas formas. Una de estas formas es la que llamaremos proporcionalidad directa. En concreto:

Dos magnitudes relacionadas en un contexto determinado son directamente proporcionales siempre que tenga sentido definir la razón entre ambas magnitudes.

Evidentemente, para poder definir la razón deberán cumplirse ciertas condiciones de regularidad que dependerán fuertemente del contexto en el que aparecen las magnitudes estudiadas. De este modo, se captura en la definición la importancia que pensamos debe tener dicho contexto.

Está claro que cuando se produce un intercambio, si se cumplen las condiciones de regularidad necesarias, nos encontramos ante dos magnitudes relacionadas de tal modo que son directamente proporcionales. Para las situaciones que no son estrictamente de intercambio habrá que “extender” la idea de razón que se introdujo anteriormente así como la de condición de regularidad.

\section{b) Razones que se definen en situaciones de proporcionalidad directa. La condición de regularidad.}

Anteriormente se definió la razón entre $A$ y $B$ en una situación de intercambio concreta como la cantidad de la magnitud A que se obtenía a cambio de una unidad de la magnitud $B$. Para poder extender esta definición sólo hay que considerar que si dos magnitudes están relacionadas, en cierto modo se puede pensar que se produce un intercambio entre ellas. Así, si dos magnitudes $A$ y $B$ son directamente proporcionales en un contexto determinado:

La razón entre A y B es la cantidad de la magnitud A que se corresponde con la unidad de la magnitud $B$.

La razón entre $B$ y A es la cantidad de la magnitud B que se corresponde con la 
unidad de la magnitud A.

Al igual que sucedía en las situaciones de intercambio, se pueden definir dos razones debido a la simetría existente. Ahora bien, para que se puedan definir estas razones es crucial estudiar el modo en que las magnitudes consideradas se relacionan. Recordemos que las condiciones que deben cumplirse para definir la razón reciben el nombre de condiciones de regularidad. En una situación general, no de intercambio, podemos afirmar que:

La condición de regularidad supone que la relación entre las dos magnitudes consideradas es siempre la misma, y que a cada unidad de una de ellas le corresponde siempre la misma cantidad de la otra.

\section{Ejemplo:}

Veamos algunos ejemplos de diversas situaciones posibles:

1. En una clase consideramos las magnitudes “altura” y "nota en el último examen de matemáticas”. Evidentemente estas dos magnitudes no están relacionadas, así que mucho menos pueden ser directamente proporcionales.

2. En la misma clase consideramos ahora las magnitudes “altura” y "edad”. Puede admitirse que existe una cierta relación entre ambas. Sin embargo, para poder hablar de razón debería cumplirse que a cada año de vida le correspondiese siempre el mismo incremento de altura; lo que no es cierto puesto que el primer año de vida lleva incluida la altura con la que se nace. Así pues, aunque estén relacionadas (puede que ni siquiera lo estén), estas magnitudes no son directamente proporcionales.

3. Consideremos una taza de leche caliente y fijémonos en las magnitudes “tiempo" y “temperatura de la leche”. Ambas magnitudes están claramente relacionadas pues con el paso del tiempo la leche se enfría. Sin embargo, cuanto más caliente está la leche más rápido se enfría, así que no se cumple ningún tipo de condición de regularidad y estas magnitudes no son directamente proporcionales.

4. Supongamos que tenemos una mascota. Nos fijamos en las magnitudes "tiempo" 


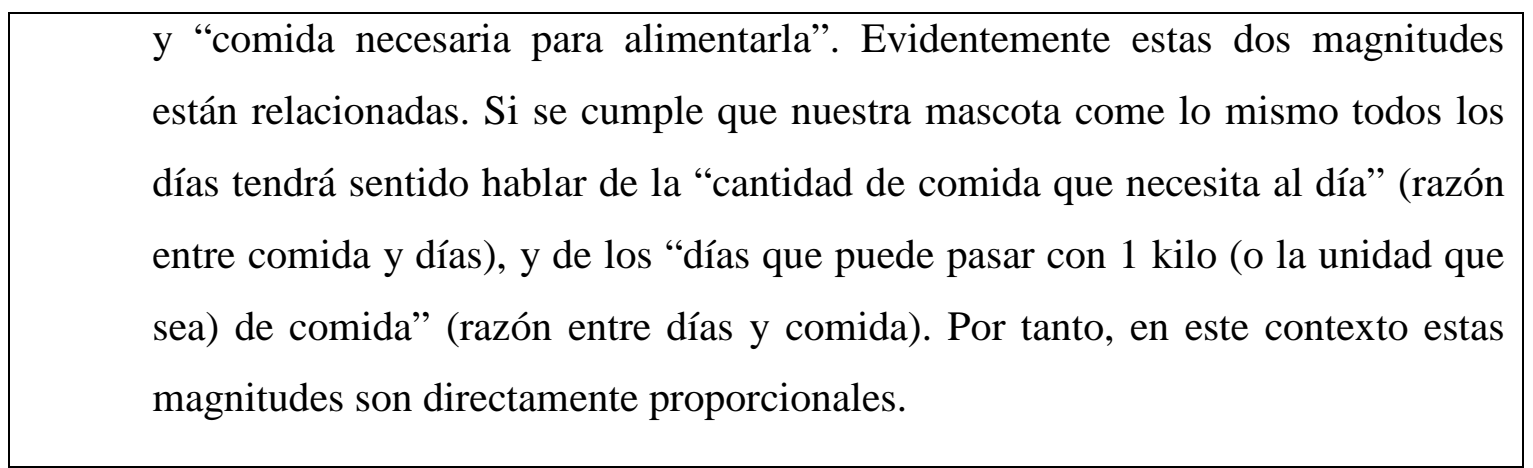

El último ejemplo anterior nos sirve para enfatizar el hecho de que la relación de proporcionalidad (o no) entre dos magnitudes es algo que depende completamente del contexto en que se relacionan ambas magnitudes. Si por alguna razón la mascota no comiera lo mismo diariamente (o no pudiera suponerse este hecho) ambas magnitudes dejarían de ser directamente proporcionales.

\section{c) Búsqueda de cantidades desconocidas en situaciones de proporcionalidad directa.}

Cuando dos magnitudes están relacionadas, de la forma que sea, si conocemos exactamente la naturaleza de la relación y la cantidad de una de ellas podemos encontrar la cantidad correspondiente de la otra.

Supongamos que tenemos dos magnitudes directamente proporcionales $A$ y $B$ en un contexto determinado y que, además, sabemos que a una cierta cantidad $a$ de la magnitud $A$ le corresponde una cantidad $b$ de la magnitud $B$.

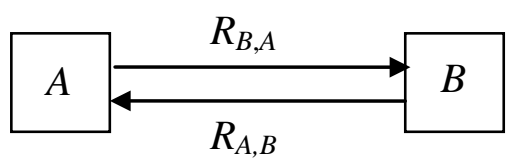

Sabemos que, en esta situación, se cumple que $R_{A, B}=a / b$ y que $R_{B, A}=b / a$. Ahora, supongamos que, por ejemplo, queremos averiguar la cantidad de la magnitud $B$ que se corresponde con una cantidad $c$ de la magnitud $A$. Si llamamos $d$ a esta cantidad desconocida tenemos que $d=R_{B, A} C$ y que $d=C / R_{A, B}$. Por tanto, es posible encontrar la cantidad desconocida de dos formas posibles atendiendo únicamente al significado de la razón como "tanto por uno", así como a los significados del producto y el cociente de cantidades de magnitud. En concreto:

1. Si sabemos que a una unidad de la magnitud $A$ le corresponde una cantidad $R_{B, A}$ (razón entre $B$ y $A$ ) de la magnitud $B$, a una cantidad $c$ de la magnitud $A$ debe 
corresponderle una cantidad $R_{B, A} \times C$ de la magnitud $B$.

2. Si sabemos que a una unidad de la magnitud $B$ se corresponde con una cantidad $R_{A, B}$ (razón entre $A$ y $B$ ) de la magnitud $A$, entonces una cantidad $c$ de la magnitud $A$ corresponderá a una cantidad $c / R_{A, B}$ de la magnitud $B$.

Ambas formas de razonamiento son perfectamente correctas. En consecuencia, el problema puede resolverse haciendo uso de cualquiera de las dos razones que se definen en la situación de proporcionalidad directa considerada. Sin embargo entendemos que una de ellas, la primera en este caso, resulta más natural por cuanto supone razonar en el sentido de la transformación. Es decir, en el problema planteado se conocía la cantidad de la magnitud $A$ y se pedía la de $B$; para ello consideramos $B$ dependiendo de $A$ y utilizamos $R_{B, A}$. En el caso simétrico en el que conociésemos la cantidad de $B$ y nos pidiesen la correspondiente de $A$, podríamos ver $A$ dependiendo de $B$ y utilizar la razón inversa.

\section{Ejemplo:}

Consideremos el siguiente enunciado:

“Las cáscaras que se obtienen al pelar $20 \mathrm{Kg}$. de nueces pesan $4 \mathrm{~kg}$. Elena quiere conseguir $15 \mathrm{~kg}$ de nueces peladas. ¿Cuántos kilos de nueces tiene que pelar?”

Las magnitudes implicadas serán "kilos de nueces peladas" $(A)$ y "kilos de nueces sin pelar” (B); que evidentemente están relacionadas Las razones que se podrían considerar son "kilos de nueces peladas que se obtienen a partir de 1 kilo de nueces sin pelar" (razón entre $A$ y $B$ ), o bien "kilos de nueces sin pelar necesarios para obtener 1 kilo de nueces peladas” (razón entre $B$ y $A$ ). Para que estas razones tengan sentido y, por tanto, se pueda afirmar que en este contexto $A$ y $B$ son directamente proporcionales, se deberá cumplir la condición de regularidad: “de cada kilo de nueces sin pelar se obtiene siempre la misma cantidad de nueces peladas”. Como es razonable suponer esto, concluimos que $A$ y $B$ son directamente proporcionales. Ahora, sabemos que de 20 kilos de nueces sin pelar se obtienen 16 kilos de nueces peladas. Tenemos dos caminos:

1. Para obtener 1 kilo de nueces peladas son necesarios 5/4 de kilo de nueces sin pelar (razón entre $B$ y $A$ ). En consecuencia, para obtener 15 kilos de nueces peladas harán 
falta $\frac{5}{4} \times 15=\frac{75}{4} \mathrm{Kg}$. de nueces sin pelar.

2. Se obtienen $4 / 5$ de kilo de nueces peladas a partir de 1 kilo de nueces sin pelar (razón entre $A$ y $B$ ) y, por tanto, para obtener 15 kilos de nueces peladas se necesitarán $\frac{15}{4 / 5}=\frac{75}{4}$ kg de nueces sin pelar.

\section{IV.3.3. Porcentajes}

\section{IV.3.3.1. Aspectos matemáticos y de la enseñanza tradicional}

En la mayor parte de los textos escolares no aparece definición alguna del concepto de porcentaje. En el mejor de los casos aparecen frases explicativas como "al decir que el 30\% de los jóvenes chatea estamos diciendo que 30 de cada 100 lo hace”. En su lugar, el peso de la exposición se pone en los distintos modos de representación:

- Un porcentaje expresa una proporción.

- Un porcentaje es una fracción de una cantidad.

Y, sobre todo, en los distintos métodos para calcular porcentajes:

- Se multiplica la cantidad por el tanto y se divide por 100.

- Se multiplica el total por el tanto por ciento expresado en forma decimal.

Apenas se encuentran referencias explícitas a la idea de "tanto por ciento", es decir, de indicar la cantidad de una magnitud correspondiente a 100 unidades de la otra.

Para resolver problemas que no sea simplemente el cálculo de un porcentaje de una cantidad (por ejemplo, calcular la cantidad inicial a partir del porcentaje o los aumentos y disminuciones porcentuales), se recurre generalmente a las reglas de tres o incluso al álgebra. Casi nunca se recurre al significado del porcentaje ni al de las operaciones con magnitudes.

\section{IV.3.3.2. Propuesta alternativa}

Nuestra propuesta a la hora de presentar los porcentajes se basa fundamentalmente en la introducción de la idea de "tanto por ciento" cuya analogía con la razón como “tanto por uno” es evidente. Además, esta analogía va más allá y permite relacionar 
ambos conceptos y definir varias razones a partir del porcentaje, cada una de las cuales permitirá resolver diferentes tipos de problemas. Los apartados en torno a los que se organiza nuestra propuesta a la hora de introducir el porcentaje y sus ideas asociadas son los siguientes:

a) El concepto de porcentaje. Relación con la razón.

b) La resolución de problemas directos e inversos.

c) La resolución de problemas relacionados con aumentos y disminuciones porcentuales.

\section{a) El concepto de porcentaje. Relación con la razón.}

Presentaremos el concepto de porcentaje siguiendo una cierta analogía con el de razón como "tanto por uno". Recordemos que, dadas dos magnitudes $A$ y $B$, en un contexto en el que son directamente proporcionales, se define la razón entre $A$ y $B$ como la cantidad de la magnitud A que se corresponde con la unidad de la magnitud B (de igual forma se podría haber definido la razón entre $B$ y $A$ ).

Ahora bien, en ciertas situaciones, sobre todo cuando ambas magnitudes son la misma, puede resultar interesante averiguar la cantidad de la primera magnitud que se corresponde con cien unidades de la segunda. Esto recibirá el nombre de porcentaje de $A$ respecto de $B$. Es decir:

Supongamos que dos magnitudes A y B son directamente proporcionales en un determinado contexto. Entonces el porcentaje que la magnitud A representa respecto de la magnitud $B$ es la cantidad de A que se corresponde con cien unidades de B. Para representarlo se utiliza el símbolo \%, que se lee "por ciento".

\section{Ejemplo:}

Supongamos que en una determinada receta de refresco tenemos que mezclar 1 litro de zumo con 2 litros de agua. Consideramos las magnitudes "litros de zumo" (A) y "litros totales de refresco" $(B)$. Suponiendo que para seguir la receta siempre se mezclan los ingredientes del mismo modo (condición de regularidad), podemos afirmar en este contexto que ambas magnitudes son directamente proporcionales. Por tanto, tiene pleno 
sentido definir, por ejemplo, la razón entre litros de zumo y litros de refresco:

“1/3 de litro de zumo por cada litro de refresco”.

También se puede definir el porcentaje que representan los litros de zumo respecto de los litros de refresco:

“100/3 de litro de zumo por cada 100 litros de refresco, o bien, el 33’3\% del refresco corresponde a zumo”.

A la vista de esta definición, y como se aprecia en el ejemplo, el concepto de razón entre dos magnitudes y el de porcentaje que una representa respecto la otra están íntimamente relacionados. Debido a esta relación, emplearemos un diagrama similar al utilizado al hablar de magnitudes directamente proporcionales:

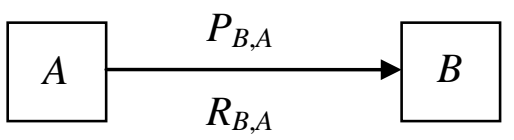

Podemos hacer esta relación aún más explícita del siguiente modo. Si $A$ y $B$ son las magnitudes involucradas y en la situación considerada se relacionan $a$ unidades de $A$ con $b$ unidades de $B$, se tiene que $R_{B, A}=b / a$ es la razón entre $B$ y $A$; es decir, la cantidad de $B$ que se corresponde con una unidad de $A$. Como el porcentaje $P_{B, A}$ es por definición la cantidad de $B$ que se corresponde con 100 unidades de $A$; debe ser $P_{B, A}=b / a \times 100$. Así pues, dado el porcentaje $P_{B, A}$ se pueden definir, al menos, las siguientes razones:

\begin{tabular}{|l|l|}
\hline$R_{B, A}=P_{B, A} / 100$ & $R_{A, B}=100 / P_{B, A}$ \\
\hline$\left(100+P_{B, A}\right) / 100$ & $100 /\left(100+P_{B, A}\right)$ \\
\hline$\left(100-P_{B, A}\right) / 100$ & $100 /\left(100-P_{B, A}\right)$ \\
\hline
\end{tabular}

Las razones anteriores aparecen agrupadas en pares de razones inversas. Las dos primeras corresponden exactamente a las razones que se pueden definir entre las dos magnitudes directamente proporcionales de las que se conoce el porcentaje que una representa respecto de la otra. Las otras dos parejas no tienen aún un significado asignado, pero pronto les asignaremos uno de forma que cada una de estas tres parejas de razones permitirá resolver los distintos tipos de problemas que veremos a continuación, en base a su significado. 


\section{Ejemplo:}

En el ejemplo anterior se consideraron las magnitudes "litros de zumo" (A) y "litros de refresco” (B). Se indicó que los litros de zumo representaban un 33’3\% respecto de los litros totales de refresco. En esta situación se tienen las siguientes razones:

Razón entre $A$ y $B$ : “1/3 de litro de zumo por cada litro de refresco”.

Razón entre B y A: “3 litros de refresco por cada litro de zumo”.

$$
\begin{aligned}
& \left(100+P_{B, A}\right) / 100=4 / 3 \text { у } 100 /\left(100+P_{B, A}\right)=3 / 4 \\
& \left(100-P_{B, A}\right) / 100=2 / 3 \text { у } 100 /\left(100-P_{B, A}\right)=3 / 2
\end{aligned}
$$

\section{b) La resolución de problemas directos e inversos.}

Entenderemos por problemas directos e inversos, al hablar de porcentajes, los siguientes:

1. El problema directo consiste en calcular un cierto porcentaje de una cantidad conocida. Es decir, cualquier situación que se traduzca a una pregunta similar a ¿cuál es la cantidad que representa el $c \%$ de una cantidad $a$ ?

2. El problema inverso consiste en calcular la cantidad respecto de la cuál otra cantidad supone un porcentaje conocido. Es decir, cualquier situación que se traduzca a una pregunta como ¿respecto de qué cantidad la cantidad $b$ representa el $c \%$ ?

En el fondo, teniendo en cuenta la relación entre la razón y el porcentaje, está claro que no se trata más que de dos casos particulares de búsqueda de cantidades desconocidas en situaciones de proporcionalidad directa y que, por lo tanto, se resuelven haciendo uno del significado del porcentaje como "tanto por ciento" y de los significados del producto y del cociente entre magnitudes.

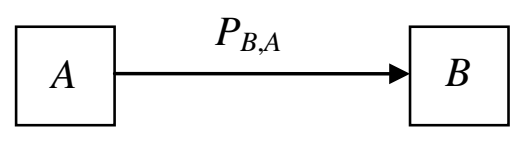

Así pues, los problemas anteriores pueden enfocarse del siguiente modo:

1. En el problema directo queremos encontrar una cantidad $b$ que represente el $c \%$ 
de una cantidad $a$. Hemos visto que la razón $R_{B, A}$ es justamente $P_{B, A} / 100$, por lo que:

$$
b=\frac{P_{B, A}}{100} a=\frac{c}{100} a
$$

2. En el problema inverso queremos encontrar la cantidad $a$ de la que sabemos que la cantidad $b$ representa un $c \%$. En este caso sabemos que $R_{A, B}=100 / P_{B, A} \mathrm{y}$, por lo tanto:

$$
a=\frac{100}{P_{B, A}} b=\frac{100}{c} b .
$$

Ambos problemas se han resuelto haciendo uso del significado de la razón como "tanto por uno" y de la forma de obtener la razón a partir del porcentaje pensado como "tanto por ciento”.

A la vista del diagrama anterior y de los procedimientos numéricos de resolución, queda bastante claro el porqué de la terminología “directo” e “inverso”. Sin embargo, si pensamos que la situación en realidad está dada por un diagrama como el que sigue:

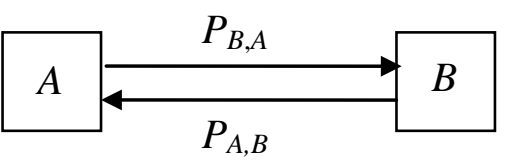

Podemos pensar que, en realidad, ambas situaciones son idénticas y sólo se diferencian en el papel que juegan ambas magnitudes. Con todo, en las situaciones reales siempre suele haber una forma "natural” en la que pensar.

\section{Ejemplo:}

1. En un colegio el $56 \%$ de los estudiantes son chicas. Si en total van a ese colegio 2300 alumnos, ¿¿cuál es el número de chicas?

Estamos claramente ante un problema directo. La razón relevante en este contexto (en el que las magnitudes "número de alumnos” y “número de chicas” pueden suponerse directamente proporcionales), es la razón entre el número de chicas y el de alumnos: “56/100 chicas por cada alumno”. Con esta razón se 
obtiene que el número de chicas es: $56 / 100 \times 2300=1456$.

2. Sabemos que en un determinado colegio el $43 \%$ de los alumnos son chicas. Si hay 1075 chicas, ¿¿cuántos alumnos tiene el colegio?

En este caso se trata de un problema inverso. Las magnitudes son las mismas que en la situación anterior, pero la razón relevante en este caso es la razón entre alumnos y chicas: “100/43 alumnos por cada chica”. Con esta razón se obtiene que el número de alumnos es: 100/43 × $1075=2500$.

c) La resolución de problemas relacionados con aumentos y disminuciones porcentuales.

A menudo nos encontramos ante situaciones en las que no sólo se ha de calcular un porcentaje de una determinada cantidad (problema directo), sino que dicho porcentaje ha de sumarse (o restarse) a la cantidad inicial. Estas situaciones son las que reciben el nombre de aumentos y disminuciones porcentuales. Esencialmente son dos las posibilidades que surgen en este contexto:

1. Se conoce la cantidad inicial y el porcentaje de aumento (o disminución), y se pide la cantidad final.

2. Se conoce la cantidad final y el porcentaje de aumento (o disminución), y se pide la cantidad inicial.

La primera de estas situaciones no presenta ninguna dificultad añadida con respecto al apartado anterior puesto que supone resolver el problema directo (calcular la cantidad que se representa el porcentaje dado) y sumarla o restarla (según convenga) a la cantidad inicial.

Pese a que el anterior es el enfoque más simple, también puede atacarse esa situación haciendo uso de las razones $\left(100+P_{B, A}\right) / 100$ ó $\left(100-P_{B, A}\right) / 100$, según se trate de aumentos o disminuciones. Esto es así porque la razón $\left(100+P_{B, A}\right) / 100$, por ejemplo, representa la cantidad tras el aumento que se corresponde con una unidad de la cantidad sin aumentar. Así, si se aplica un aumento del $c$ \% a una cantidad $a$, la razón considerada será $(100+c) / 100$ y por tanto la cantidad final será: 


$$
\frac{100+c}{100} a
$$

Igualmente se razonaría en el caso de disminuciones, pero con la otra razón indicada.

\section{Ejemplo:}

Debido al encarecimiento del precio del petróleo se espera que el precio de un billete de autobús de la línea Zaragoza-Madrid aumente un 2,5\%. Si ahora ese billete cuesta 12 euros, ¿cuánto costará tras la subida?

Se trata de un problema de aumentos porcentuales. Hay, en principio dos enfoques:

1. Se calcula la cantidad correspondiente a la magnitud "aumento de precio" que representa el 2’5\% de la magnitud “precio inicial del billete” obteniendo 0’3 euros y se le suma esta cantidad al precio original para obtener la cantidad correspondiente de la magnitud “precio final del billete”, que es de 12’3 euros.

2. La razón entre las magnitudes “precio final” y “precio inicial” es 102’5/100 euros de precio final por cada euro de precio inicial; de este modo, el precio final correspondiente a un precio inicial de 12 euros será: 102'5/100 $\times 12=12^{\prime} 3$ euros.

La segunda situación, en cierto modo, es la inversa de la anterior. Es decir, se conoce el resultado de aplicar el aumento o la disminución así como el porcentaje correspondiente y se pide encontrar la cantidad inicial. En este caso, pues, se hará necesario utilizar las inversas de las razones anteriores. Por ejemplo, si sabemos que tras un descuento del $c \%$ una determinada cantidad se ha convertido en $a$, la razón entre la cantidad inicial y la final (es decir, la cantidad inicial a partir de la cual se obtiene 1 unidad de la cantidad final) será 100/(100-c) y por lo tanto la cantidad inicial buscada es:

$$
\frac{100}{100-c} a
$$

\section{Ejemplo:}

Durante las rebajas de una tienda de informática se oferta un descuento del 20\%. Si compras un ordenador por 450 euros, ¿¿cuál habría sido su precio antes de las rebajas? 
Si consideramos las magnitudes "precio anterior" y "precio actual” tenemos que la razón entre el precio anterior y el precio actual es: “100/80 euros de precio anterior por cada euro de precio actual”. En consecuencia, el precio anterior correspondiente a un precio actual de 450 euros es $100 / 80 \times 450=562$ ' 5 euros.

\section{IV.3.4. Repartos respecto a una única magnitud}

\section{IV.3.4.1. Aspectos matemáticos y de la enseñanza tradicional}

Junto con las situaciones de intercambio, los repartos son los contextos más antiguos en los que surge la idea de proporcionalidad. En principio, existen diversas formas de repartir una determinada cantidad entre un grupo de personas. La más simple, obviamente, es el reparto equitativo. Es decir, repartir a todos por igual. Sin embargo, esto no siempre es justo y se hace necesario encontrar otras formas de resolver el problema.

La idea más sencilla después de repartir a todos por igual (y que la generaliza) consiste en asignar de determinada manera (en función de cómo se desee realizar el reparto) un número, que llamaremos índice, y asignar a cada persona una cantidad de forma que las razones entre las cantidades de cada persona sean exactamente las mismas que las razones entre sus índices. Sin embargo, incluso una consideración tan sencilla como la anterior está completamente ausente en la enseñanza tradicional de estos conceptos.

Desde un punto de vista matemático, y así lo refleja la práctica educativa habitual, se presta atención en primer lugar a los repartos que se realizan de forma que las cantidades que obtiene cada persona (aunque no tiene por qué tratarse de personas nos referiremos a los "receptores" del reparto de este modo), son directamente proporcionales a las cantidades de una determinada magnitud que cada persona “posee”.

En general, se dispone de una cantidad $C$ a repartir entre varias personas $P_{1}, \ldots, P_{n}$ de tal modo que la cantidad $c_{i}$ que reciba cada persona debe ser directamente proporcional a un valor $p_{i}$ que le es asignado (por el medio que sea) a dicha persona. Se pueden encontrar hasta tres enfoques a la hora de resolver este tipo de problemas en el aula: 
1. Un enfoque puramente algebraico, recurriendo en muchos casos a la resolución de sistemas de ecuaciones, sobre todo cuando se introducen estos problemas en el segundo ciclo de la secundaria. En este caso debería resolverse el sistema:

$$
\left\{\begin{array}{c}
c_{1}+\cdots+c_{n}=C \\
\frac{p_{i}}{c_{i}}=\frac{p_{j}}{c_{j}}
\end{array}\right.
$$

2. Cuando es demasiado pronto para hablar de sistemas de ecuaciones se suele utilizar la propiedad siguiente para una serie de razones iguales:

$$
\frac{a}{b}=\frac{c}{d}=\frac{a \pm c}{b \pm d}
$$

que se extiende fácilmente en el caso de más de dos razones iguales y que permite, reducir el problema a una serie de reglas de tres sucesivas puesto que una de las sumas es la cantidad (conocida) a repartir. Esto implica también, como ya se comentó anteriormente, la introducción de lenguaje algebraico. Cada una de las reglas de tres a resolver toma la forma:

$$
\frac{p_{i}}{p_{1}+\cdots+p_{n}}=\frac{x}{C}
$$

3. Una tercera posibilidad que se encuentra a menudo en los textos consiste simplemente en presentar fórmulas con un leguaje más o menos algebraico que, en definitiva, no suponen más que dar al alumno el resultado de aplicar las reglas de tres del apartado anterior.

Una vez presentado y resuelto el problema en el caso directamente proporcional, se plantea el caso análogo en el que las cantidades que recibe cada persona son inversamente proporcionales (ver más adelante) a las cantidades de una determinada magnitud que esas personas poseen. El método que se propone es siempre el mismo y adopta la forma del siguiente principio:

Repartir de forma inversamente proporcional respecto a ciertas cantidades es lo mismo que repartir de forma directamente proporcional respecto a los inversos de esas cantidades.

De este modo se repite el mismo esquema de resolución pero intercambiando cada $p_{i}$ por $1 / p_{i}$. 
En resumen, de nuevo un enfoque algorítmico que, en el mejor de los casos, utiliza la proporcionalidad sólo de una forma instrumental y que apenas presta atención a los significados de los conceptos o las manipulaciones involucrados.

\section{IV.3.4.2. Propuesta alternativa}

Nuestra propuesta se basa en la idea de que al efectuar un reparto se produce la comparación entre dos situaciones. En la primera situación cada persona posee una cantidad de una cierta magnitud, en función de la cual se efectuará el reparto,. En la segunda situación cada persona deberá poseer una cierta parte de la cantidad a repartir. El reparto deberá bien reflejar (si es que se trata de un reparto directamente proporcional), bien equilibrar (si se trata de un reparto inversamente proporcional) la situación inicial. Si se debe reflejar o equilibrar; es decir, si el reparto debe ser directa o inversamente proporcional, es algo que el alumno debe decidir en función del contexto en que se presenta el problema.

Conviene aclarar qué se entenderá por reflejar una situación. En la situación inicial, cada persona tiene asignada una cierta cantidad de una magnitud. Por tanto, podemos considerar las razones entre dichas cantidades. Entenderemos que la situación tras el reparto refleja la situación inicial si las razones entre las cantidades recibidas coinciden con las razones entre las cantidades que tenían asignadas.

Del mismo modo, cuando hablamos de equilibrar una situación entendemos que las razones entre las cantidades recibidas por cada persona son las inversas de las razones entre las cantidades que tenían asignadas.

\section{Ejemplo:}

1. Supongamos que varias personas han realizado un trabajo a cambio del que reciben cierta cantidad de dinero. Si sabemos las horas que ha trabajado cada persona parece lógico repartir en función de dichas horas y, además, el reparto deberá reflejar la situación inicial (por ejemplo, si una persona ha trabajado el doble que otra, también deberá recibir el doble de dinero).

2. Supongamos que varias personas se van a repartir un premio que han ganado a la lotería. Para ser justos deciden que van a repartir el premio en función del 


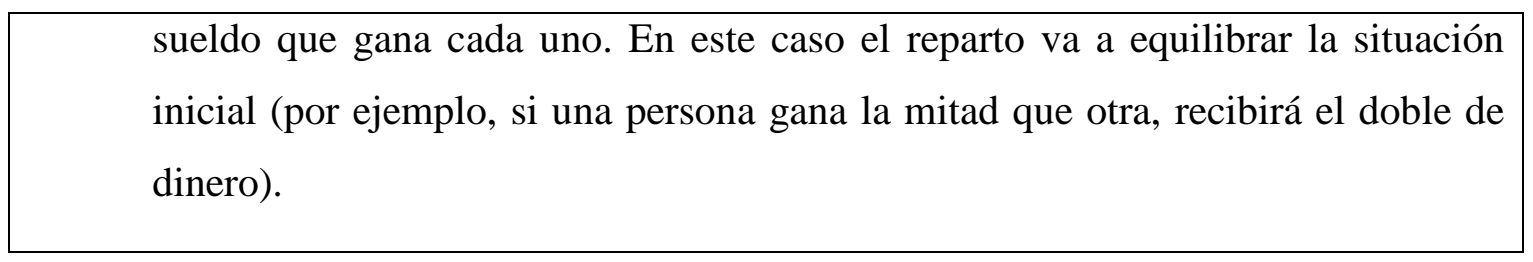

No obstante, si se reflexiona un poco ante los dos tipos de situaciones descritas, es fácil observar que reflejar o equilibrar la situación inicial pasa en primer lugar por asignar un número, que llamaremos índice, a cada una de las personas implicadas en el reparto. Si se pretende reflejar la situación inicial, se asignarán los índices de modo que las razones entre ellos sean las mismas que las razones entre las cantidades de la magnitud en función de la que se efectúa el reparto, si se pretende equilibrar las razones serán las inversas.

El procedimiento de resolución que se propone consta de los siguientes pasos:

1. Decidir si se desea reflejar o equilibrar la situación inicial.

2. Asignación de los índices: Se elige una persona concreta que se usará de base. A esa persona se le asignará el índice 1. Después se irán formando todas las posibles parejas con esa persona y se irán asignando índices a cada una de las otras personas del modo que corresponda (según se quiera reflejar o equilibrar la situación). Los índices asignados pueden ser naturales o racionales positivos.

3. Conversión de los índices en enteros: Como lo que nos interesa sólo es la razón entre los índices no hay ningún problema es conseguir que todos sean naturales (multiplicando por alguna cantidad adecuada).

4. Suma de los índices: Una vez que tenemos los índices enteros de todas las personas, pongamos $p_{1}, p_{2}, \ldots, p_{n}$ cabe preguntarse por el significado que posee la suma $S=p_{1}+p_{2}+\ldots+p_{n}$. Si la cantidad a repartir entre las personas fuese justamente $S$ se tendría que cada persona debería recibir justamente la cantidad que señala el índice que le corresponde.

5. Cálculo de la parte de cada persona: Una vez interpretada la suma de los índices, la razón entre la cantidad que recibirá cada persona y el total a repartir es justamente $\frac{p_{i}}{p_{1}+\cdots+p_{n}}$.

En conclusión, si $c_{1}, \ldots, c_{n}$ son las cantidades que debe recibir cada persona y $C$ es 
la cantidad total a repartir, hemos visto que $R_{c_{i}, C}=\frac{p_{i}}{p_{1}+\cdots+p_{n}}$ y por lo tanto:

$$
c_{i}=\frac{p_{i}}{p_{1}+\cdots+p_{n}} C
$$

\section{Ejemplo:}

Se asocian tres personas en un negocio de forma que la primera aporta 5000 euros, la segunda 7500 y la tercera 9000. Si al cabo de un año han tenido un beneficio de 6450 euros, ¿¿cómo deben repartir dicho beneficio?

Veamos cómo resolver este problema siguiendo los pasos anteriores:

1. En este contexto parece razonable pensar que se desea reflejar la situación inicial.

2. Elegimos como base la primera persona. A ella se asignamos el índice 1. Ahora, la razón entre lo que recibe la segunda persona y lo que recibe la primera es 7500/5000 por lo que si la primera recibe el índice 1, a la segunda habrá que asignarle el índice 7500/5000 $=3 / 2$. La razón entre lo que recibe la tercera persona y lo que recibe la segunda es 9000/5000 por lo que el índice de la tercera persona será 9/5.

3. Para convertir los índices en enteros basta multiplicarlos por 10. Así a la primera le corresponde el índice 10, a la segunda 15 y a la tercera 18.

4. La suma de los índices es 43. Así que si se repartieran 43 euros recibirían 10, 15 y 18 euros, respectivamente.

5. La razón entre lo que recibe la primera persona y la cantidad total es "10/43 de euro por cada euro del total”. Por tanto, para un total de 6450 euros la primera persona recibirá $10 / 43 \times 6450=1500$ euros.

La razón entre lo que recibe la segunda persona y la cantidad total es "15/43 de euro por cada euro del total”. Por tanto, para un total de 6450 euros la primera persona recibirá $15 / 43 \times 6450=2250$ euros.

La razón entre lo que recibe la tercera persona y la cantidad total es “18/43 de 
euro por cada euro del total” por lo tanto para un total de 6450 euros la primera persona recibirá $18 / 43 \times 6450=2700$ euros.

\section{IV.3.5. Magnitudes inversamente proporcionales}

\section{IV.3.5.1. Aspectos matemáticos y de la enseñanza tradicional}

El tratamiento que se suele dar a la proporcionalidad inversa discurre de un modo completamente paralelo al de la proporcionalidad directa. Sin embargo este tratamiento en paralelo no siempre es perfecto dada la distinta naturaleza de ambas relaciones.

Desde un punto de vista matemático se puede definir el concepto de proporcionalidad inversa, al menos, de las siguientes formas:

1. Definición por razones: Dos magnitudes son inversamente proporcionales si y sólo si se cumple que la razón entre dos cantidades cualesquiera de una de las magnitudes es la inversa de la razón entre las cantidades correspondientes de la otra magnitud.

2. Definición por producto: Dos magnitudes son inversamente proporcionales si y sólo si los productos $x y$ de pares de cantidades relacionadas son constantes. En tal caso dicho producto recibe el nombre de constante de proporcionalidad.

3. Definición implícitamente funcional: Dos magnitudes son inversamente proporcionales si y sólo si la función que las relaciona $y=f(x)$ cumple que $f(a x)=f(x) / a$ para todo $a$.

4. Definición explícitamente funcional: Dos magnitudes son inversamente proporcionales si y sólo si la función que las relaciona es de la forma $y=f(x)=k / x$.

De estas cuatro caracterizaciones, la última sólo cobra sentido en un contexto funcional. Sin embargo, las otras tres, y especialmente las dos primeras, se suelen dar en un contexto aritmético. De hecho, la segunda caracterización se suele traducir en un enunciado del tipo:

Dos magnitudes son inversamente proporcionales cuando al multiplicar (dividir) una cantidad de la primera magnitud por dos, tres, etc..., la cantidad correspondiente de la segunda magnitud queda dividida (multiplicada) por dos, 
tres, etc...

Caracterización que (salvo consideraciones relacionadas con la continuidad) es correcta, pero que da lugar al error habitual de que dos magnitudes son inversamente proporcionales siempre que si una aumenta o disminuye, la otra hace lo contrario.

En la práctica educativa habitual se utiliza generalmente la segunda caracterización (especialmente su versión en cursiva) para comprobar si dos magnitudes son inversamente proporcionales. Las dos primeras son las preferidas a la hora de resolver problemas.

La primera caracterización, que surge del deseo de tratar unificadamente la proporcionalidad directa y la inversa, suele ser una fuente de errores debido al esfuerzo memorístico que implica recordar que debe invertirse una de las razones (además de que las razones que aparecen carecen de significado como magnitudes). En cuanto a la segunda caracterización, la constante de proporcionalidad es de gran importancia en el ámbito de la proporcionalidad inversa. Sin embargo, no suele atribuírsele significado alguno más allá de su cálculo numérico.

Además de la caracterización de magnitudes inversamente proporcionales, el otro eje en torno al que gira la enseñanza tradicional es el de la búsqueda de cantidades desconocidas en situaciones de proporcionalidad inversa. En esencia se presenta una situación en la que conocemos un par de cantidades relacionadas de dos magnitudes inversamente proporcionales y otra cantidad de una de ellas. A partir de estos datos se solicita la cantidad correspondiente de la otra magnitud.

Para afrontar este tipo de problemas el esquema que se suele presentar es el siguiente: Primero, comprobar que las dos magnitudes son inversamente proporcionales (aquí es donde suele aparecer la caracterización anterior y, en ocasiones, su versión incorrecta). Después, aplicar alguno de los siguientes procedimientos:

- Regla de tres: se disponen los datos al modo "tradicional” y se aplica, o bien un algoritmo memorizado, o bien la igualdad de razones (internas invertidas) que se desprende de la caracterización 1.

- Reducción a la unidad: se calcula, a partir de las dos cantidades conocidas, la cantidad de la segunda que corresponde a una unidad de la primera y después se 
utiliza este valor para resolver el problema. Para hallar el valor unitario se recurre al significado de las operaciones (poco corriente), al valor constante de los productos entre pares de cantidades relacionadas (caracterización 2), o bien se aplica la Regla de tres.

Nuevamente en este punto se suele introducir el lenguaje algebraico (utilización de la letra $x$ para denotar la cantidad desconocida) e incluso se realizan algunas manipulaciones formales. Tampoco en el caso de la proporcionalidad inversa la razón juega un papel más allá del meramente instrumental a la hora de resolver problemas o distinguir magnitudes inversamente proporcionales. Además las razones que aparecen son casi siempre internas, es decir, entre cantidades de la misma magnitud y por lo tanto no se interpretan como una nueva magnitud.

\section{IV.3.5.2. Propuesta alternativa}

Pretendemos que las ideas fundamentales sean nuevamente la idea de razón como “tanto por uno” y la de constante de proporcionalidad, pero dotando a ambos conceptos de significado concreto en cada situación. En torno a estas dos ideas girará no sólo la caracterización de las magnitudes inversamente proporcionales, sino la resolución de problemas.

En consecuencia, los apartados en torno a los que se vertebra nuestra propuesta a la hora de introducir la razón y sus ideas asociadas son los siguientes:

a) El concepto de magnitudes inversamente proporcionales.

b) La constante de proporcionalidad, razones y condiciones de regularidad.

c) Búsqueda de cantidades desconocidas en situaciones de proporcionalidad inversa.

\section{a) El concepto de magnitudes inversamente proporcionales.}

Esta segunda forma en la que dos magnitudes pueden estar relacionadas sin ser directamente proporcionales recibe el nombre de proporcionalidad inversa. Entre dos magnitudes inversamente proporcionales no tiene sentido definir la razón (pues en ese caso serían directamente proporcionales). Sin embargo la idea de razón también jugará un papel en estas situaciones. La definición es la siguiente: 
Dos magnitudes relacionadas $A$ y $B$ en un determinado contexto se dicen inversamente proporcionales cuando no se puede definir la razón entre ellas, pero existe una tercera magnitud $C$, que se mantiene constante, de forma que sí tiene sentido definir la razón entre esta tercera magnitud y las dos que varían y además la razón entre C y cada una de las magnitudes es justamente la otra magnitud implicada.

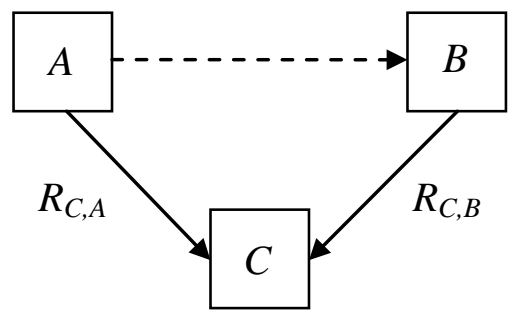

Según el diagrama anterior, supongamos que $a$ y $b$ son cantidades relacionadas de $A$ y $B$ respectivamente. La magnitud $C$ es constante y se tiene que:

$$
R_{C, A}=b \text { y } R_{C, B}=a .
$$

En este caso, el valor numérico de las razones que aparecen no es constante, sino que depende de las cantidades de $A$ y $B$ que estemos considerando en cada caso (recordar que $C$ es constante).

\section{b) La constante de proporcionalidad, razones y condiciones de regularidad.}

Acabamos de ver que en la definición de magnitudes inversamente proporcionales se hace intervenir una tercera magnitud que permanece constante y que, en cierto modo, sirve para “enlazar” ambas magnitudes. Esta magnitud que se mantiene constante recibe el nombre de constante de proporcionalidad. Es decir:

En una situación en la que dos magnitudes A y B son inversamente proporcionales, se llama constante de proporcionalidad a una tercera magnitud $C$ que se mantiene constante y tal que tiene sentido definir la razón de esta magnitud con las dos iniciales.

Así pues, entre dos magnitudes inversamente proporcionales no tiene sentido definir la razón, pero al hacer intervenir la constante de proporcionalidad sí que aparecen en escena dos razones (y sus inversas):

1. La razón entre C y A; es decir, la cantidad de C que se corresponde con una unidad de A que, por definición, es justamente la cantidad de $B$ que se 
corresponde con la cantidad de A considerada.

2. La razón entre C y B; es decir, la cantidad de C que se corresponde con una unidad de $B$ que, por definición, es justamente la cantidad de $A$ que se corresponde con la cantidad de B considerada.

En consecuencia, también en estas situaciones de proporcionalidad inversa será necesario introducir condiciones de regularidad que permitan definir estas dos razones.

Respecto a la constante de proporcionalidad, es importante señalar que es muy importante tener en cuenta la unidad de medida que se utiliza. En ocasiones esta unidad de medida será evidente a partir de los datos del problema (ver ejemplo siguiente), pero en otros casos será necesario elegir cuidadosamente dicha unidad para que los cálculos cobren sentido (ver ejemplo de la sección siguiente)

\section{Ejemplo:}

Supongamos que hemos comprado una televisión y que la compramos a plazos. Nos fijamos en las magnitudes “número de plazos" e “importe de cada plazo". Evidentemente estas magnitudes están relacionadas pero no tiene sentido tratar de definir las razones entre ellas puesto que el importe de cada plazo no puede "repartirse" entre el número de plazos. Sin embargo, si consideramos la magnitud constante (constante de proporcionalidad) “precio de la televisión” (cuya unidad de medida será el euro), sí que tiene sentido calcular la razón entre el precio de la televisión y el número de plazos (y se obtiene justamente el importe de cada plazo), así como la razón entre el precio de la televisión y el importe de cada plazo (y se obtiene el número de plazos). Así pues, las dos magnitudes consideradas inicialmente son inversamente proporcionales siempre y cuando se cumplan las condiciones de regularidad necesarias que, en este caso, son siempre se pague lo mismo en cada plazo y que la duración de los plazos sea la misma.

Una vez que ya hemos presentado el concepto de magnitudes inversamente proporcionales, ya podemos presentar la tipología de situaciones que podemos encontrar:

- Magnitudes no relacionadas en absoluto. 
- Magnitudes relacionadas pero que no son ni directa ni inversamente proporcionales.

- Magnitudes que son (o pueden suponerse) directamente proporcionales.

- Magnitudes que son (o pueden suponerse) inversamente proporcionales.

\section{Búsqueda de cantidades desconocidas en situaciones de proporcionalidad inversa.}

Supongamos que nos encontramos ante dos magnitudes inversamente proporcionales $A$ y $B$ de forma que, además, sabemos que a una cierta cantidad $a$ de la magnitud $A$ le corresponde una cantidad $b$ de la magnitud $B$.

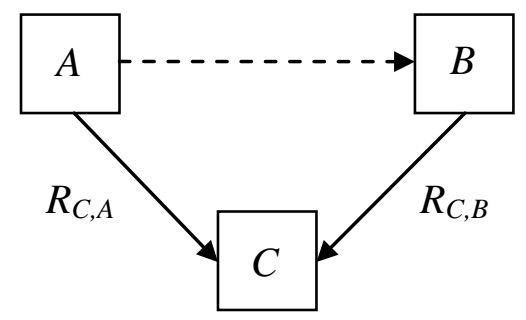

Sabemos que, en esta situación $R_{C, A}=b$ por lo que se obtiene (recordando la idea de razón como "tanto por uno" y que $C$ es constante), que $C=a b$ es el valor numérico de la magnitud constante $C$. Ahora, supongamos que, por ejemplo, queremos averiguar la cantidad de la magnitud $B$ que se corresponde con una cantidad $e$ de la magnitud $A$. Si llamamos $f$ a dicha cantidad, se tiene que, en este caso, $R_{C, B}=e$. Así pues, puesto que $C=a b$ llegamos a que:

$$
f=\frac{a b}{e}
$$

Toda esta argumentación se ha llevado a cabo recurriendo únicamente a los significados de razón como "tanto por uno" y al de constante de proporcionalidad, teniendo en cuenta que nos hallamos en una situación de proporcionalidad inversa. En concreto se puede razonar de la siguiente forma:

Sabemos que la razón entre la constante de proporcionalidad y la cantidad de la magnitud $A$ nos proporciona la cantidad de la magnitud $B$ por lo que como a una cantidad $a$ de $A$ le corresponde una cantidad $b$ de $B$, sabemos que $b$ es la cantidad de $C$ que se corresponde con una unidad de $A$; por tanto, con una cantidad $a$ de $A$ el valor numérico de $C$ ha de ser $a b$. Por otro lado, sabemos que $e$ es la cantidad de $C$ que se 
corresponde con una unidad de $B$; por tanto, para saber la cantidad de $B$ basta con dividir $C=a b$ entre $e$.

Al igual que en el caso de la proporcionalidad directa, al haber aquí diversas razones (y sus inversas) implicadas existen distintas formas equivalentes de razonar. La mayor sencillez de unas y otras depende de las magnitudes implicadas y de la forma de pensar la relación entre ellas.

\section{Ejemplo:}

Nueve amigos tienen en su nevera refrescos para 8 días. Si fueran 24 amigos, ¿para cuántos días tendrían?

Las magnitudes implicadas son "número de amigos" $(A)$ y "número de días para los que tienen bebida” $(B)$. Evidentemente ambas magnitudes están relacionadas, pero no tiene sentido hablar de razón entre $A$ y $B$, por ejemplo, puesto que no hay un cierto número de amigos por día. Sin embargo, si consideramos la magnitud “cantidad de refresco” $(C)$ que permanece constante (y cuya unidad de medida será la cantidad de refresco que consume cada amigo en un día, llamémosla $u$ ), podemos definir sin problema las razones "cantidad de refresco que se consume en un día" (razón entre $C$ y $B$ ) y “cantidad de refresco que consume cada amigo” (razón entre $C$ y $A$ ) siempre que se cumplan las condiciones de regularidad: "todos los amigos toman el mismo número de refrescos” y “todos los días se consume el mismo número de refrescos”; las cuales son perfectamente razonables. Así pues, las magnitudes A y B son inversamente proporcionales. A partir de aquí hay dos caminos:

1. Sabemos que si hay 9 amigos, la cantidad de refresco que consume cada uno es $8 u$. Así pues la cantidad total de refresco es $72 u$. Si hay 24 amigos, la razón entre la cantidad de refresco y el número de amigos da el número de días; es decir, hay refresco para $72 / 24=3$ días.

2. Sabemos que si están 8 días la cantidad de refresco que se consume al día es $9 u$. En consecuencia la cantidad total de refresco es $72 u$. A partir de aquí se procede como en el caso anterior.

En los ejemplos más sencillos en los que sí es conocida la unidad en la que se mide la magnitud constante $C$ el proceso de resolución sería exactamente el mismo. 


\section{IV.3.6. Mezclas y aleaciones}

\section{IV.3.6.1. Aspectos matemáticos y de la enseñanza tradicional}

Para poder hablar de mezclas o aleaciones, en primer lugar, es necesario disponer de una medida de la "calidad" o el "valor" de los productos implicados (a la que llamaremos precio, para simplificar). Históricamente este tipo de situaciones se dan en un contexto de mezcla de metales (especialmente preciosos).

En general en una situación de mezclas se juntan cantidades $c_{1}, \ldots, c_{n}$ de unos ciertos productos de precios $p_{1}, \ldots, p_{n}$ respectivamente. Otras variables relevante en la situación serán el precio final de la mezcla $(P)$ y la cantidad total $\left(C=C_{1}+\ldots+c_{n}\right)$. Las dos situaciones problemáticas que se suelen plantear en estos contextos son:

1. Calcular el precio final de la mezcla conociendo las cantidades de cada producto y sus precios (este problema tiene solución única).

2. Calcular las cantidades de cada producto sabiendo sus precios y el precio final (este problema no tiene solución única aún incluso si se añade como dato la cantidad total.

En el caso en que se consideran sólo dos productos es fácil ver que las cantidades de cada producto son inversamente proporcionales a la diferencia entre sus precios y el precio final. Este hecho es el que justifica su tradicional inclusión en los temas dedicados a la proporcionalidad. También esta idea daba lugar a complicados algoritmos de resolución para los problemas anteriores. Sin embargo, en la actualidad, debido al número de variables implicadas y a la no unicidad de solución, el enfoque que se da a este tipo de problemas es muy marginal y siempre de tipo algebraico.

\section{IV.3.6.2. Propuesta alternativa}

En la actualidad, este tipo de situaciones apenas poseen el interés que, desde un punto de vista práctico, tuvieron en su momento. Además, pensamos que teniendo en cuenta conceptos sencillos como:

1. La idea de mezcla.

2. La aditividad de las cantidades.

3. El concepto de precio medio. 
Junto con los significados de las operaciones con cantidades de magnitud, es posible enfrentarse al problema 1 descrito en la sección anterior. El problema de tipo 2, habida cuenta que no suele poseer solución única, puede posponerse hasta la introducción del lenguaje algebraico necesario.

\section{Ejemplo:}

Se funden juntos 10 gramos de oro, cuyo precio es de 250 euros con 60 gramos de plata, cuyo precio es de 70 euros. ¿Cuál es el precio de 40 gramos de la aleación resultante?

Como se juntan 10 gramos de oro y 60 de plata, la aleación resultante pesará 70 gramos y su precio será de 320 euros. Ahora, se consideran las magnitudes "precio” (A) y “peso” (B). Como cada gramo de la aleación tiene el mismo valor (condición de regularidad), se sigue que A y B son directamente proporcionales y la razón entre A y B es “4’6 euros por cada gramo de aleación”. Conocido el valor de esta razón es fácil ver que el precio de 40 gramos será: 4'6 × $40=184$ euros.

\section{IV.3.7. Proporcionalidad compuesta}

\section{IV.3.7.1. Aspectos matemáticos y de la enseñanza tradicional}

El concepto de proporcionalidad compuesta surge ante la aparición de situaciones en las que una magnitud depende no sólo de otra, sino de otras varias de tal forma que cada relación “parcial”, entendida ésta como la que se da entre la magnitud dependiente y una de las demás al suponer que el resto permanecen constantes, es de proporcionalidad directa o inversa. Desde un punto de vista funcional esto se traduce en que la relación entre las magnitudes involucradas es de la forma:

$$
y=f\left(x_{1}, \ldots, x_{s}\right)=k \frac{x_{1} \ldots x_{r}}{x_{r+1} \ldots x_{s}} .
$$

De tal modo que si todas las magnitudes $x_{i}$, excepto una, son contantes la relación funcional entre las dos magnitudes no constantes es de proporcionalidad directa o inversa.

Tradicionalmente el modo de reconocer este tipo de situaciones consiste en ir analizando las magnitudes consideradas por parejas mientras se aplica cualquiera de los criterios presentados al caracterizar las magnitudes directa e inversamente 
proporcionales.

No obstante, este tipo de situaciones siempre aparecen en el contexto de problemas en los que se busca una cantidad desconocida; es decir, si apenas se ejercita la distinción de magnitudes directa o inversamente proporcionales, mucho menos se hace en el caso de la proporcionalidad compuesta.

En el caso de la proporcionalidad compuesta, las situaciones de búsqueda de cantidades desconocidas se pueden plantear del siguiente modo: Se dan magnitudes $A_{1}, \ldots, A_{n}$ junto con una serie de cantidades relacionadas de dichas magnitudes $a_{1}, \ldots, a_{n} \mathrm{y}$ se pide calcular la cantidad de $A_{n}$ que se corresponde con las cantidades dadas $b_{1}, \ldots b_{n-1}$ de las otras magnitudes. En general se suelen plantear a los alumnos dos modos de resolución:

- Un método mecánico que supone introducir simbolismo algebraico, y memorizar una fórmula en la que la disposición de los datos depende de si cada relación “parcial” es inversa o directa. Este procedimiento suele recibir el nombre de Regla de tres compuesta.

- Un método algorítmico que supone transformar la tupla $a_{1}, \ldots, a_{n}$ en otra $b_{1}, \ldots b_{n-}$ ${ }_{1}, \beta$ de manera que, en cada paso, se fijan todas las magnitudes salvo dos y se utiliza el hecho de que esas dos son directa o inversamente proporcionales. Al final $\beta$ es la cantidad buscada.

Es interesante observar que, en ambos casos, el proceso de resolución implica llevar a cabo una serie de pasos y, sobre todo, memorizar un procedimiento.

\section{IV.3.7.2. Propuesta alternativa}

La alternativa que proponemos supone dar un tratamiento mucho más similar al que recibe la proporcionalidad simple frente a los procedimientos complicados y “artificiosos” de la práctica habitual.

La clave para poder abordar estas situaciones es considerar la relación existente entre una magnitud y cada una de las otras magnitudes involucradas, de tal modo que sólo seremos capaces de enfrentarnos a situaciones en las que cada magnitud es, bien directa, bien inversamente proporcional a cada una de las demás. Para distinguirlas haremos uso de las caracterizaciones que ya hemos presentado con anterioridad 
(existencia de la razón en el caso de la proporcionalidad directa y de la constante de proporcionalidad en el de la inversa, junto con las condiciones de regularidad necesarias)

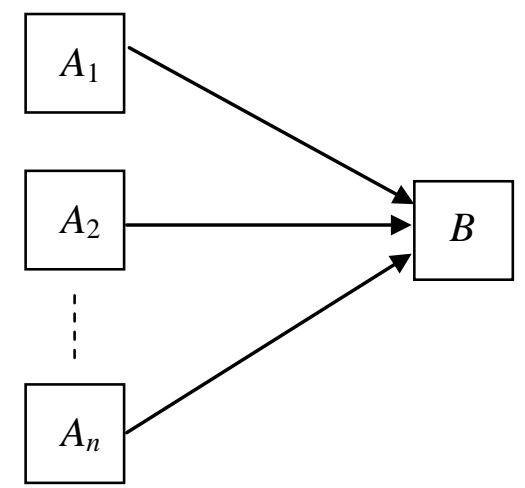

En este tipo de situaciones siempre es posible "fabricar" una nueva magnitud $A$ a partir de las magnitudes $A_{1}, \ldots, A_{n}$ de tal forma que la dependencia de $B$ respecto de estas magnitudes se traduce en una dependencia, que será de proporcionalidad directa generalmente, con la nueva magnitud $A$. Para efectuar esta traducción basta con apelar al significado de las operaciones entre magnitudes y con interpretar adecuadamente los resultados.

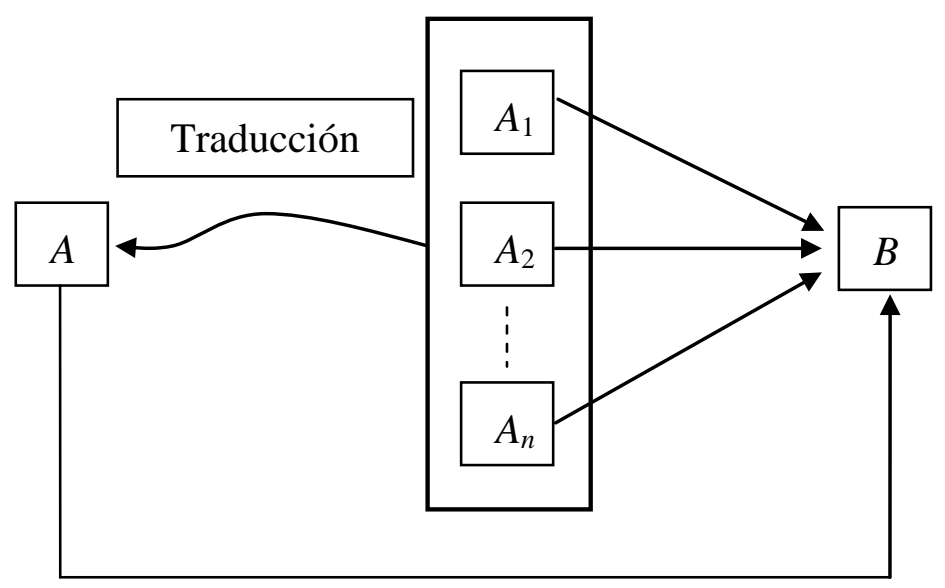

Una vez que se ha efectuado la traducción, la situación se reduce a alguno de los casos estudiados con anterioridad, con lo que basta aplicar las ideas antes expuestas y desandar el camino a la hora de completar el análisis. 


\section{Ejemplo:}

Una lavadora industrial, trabajando 8 horas diarias durante 5 días, ha lavado 1000 kilos de ropa. ¿Cuántos kilos de ropa lavará en 12 días, trabajando 10 horas diarias?”

En esta situación, las magnitudes relevantes son "horas diarias de trabajo", "días de trabajo" y "kilos de ropa”. Por la pregunta del problema nos interesa pensar en los "kilos de ropa" (B) como dependientes de las otras dos magnitudes $\left(\begin{array}{lll}A_{1} & \text { y } & A_{2}\end{array}\right.$ respectivamente). Podemos fabricar una nueva magnitud "horas totales de trabajo" $(A)$ que surge como el producto de $A_{1}$ y $A_{2}$. De esta forma el enunciado del problema queda traducido del siguiente modo:

“Una lavadora industrial trabajando 40 horas ha lavado 1000 kilos de ropa. ¿Cuántos kilos de ropa lavará en 120 horas?”

En este caso las magnitudes $A$ y $B$ son directamente proporcionales puesto que las razones entre ambas tienen sentido (los kilos de ropa que se lavan por hora o bien las horas de trabajo necesarias para lavar un kilo de ropa) siempre y cuando se consideren las condiciones de regularidad necesarias, en este caso únicamente que todos los kilos requieran el mismo tiempo de lavado puesto que el peso de un kilo y la duración de una hora son obviamente constantes.

Así, el problema se puede resolver multiplicando los 25 kilos que se lavan en una hora por las 120 horas de trabajo o bien dividiendo las 120 horas de trabajo entre los 2/50 de hora necesarios para lavar un kilo de ropa, dependiendo de la razón que se desee utilizar.

\section{IV.3.8. Regla de interés}

\section{IV.3.8.1. Aspectos matemáticos y de la enseñanza tradicional}

La llamada Regla de Interés se utiliza en contextos de préstamo de dinero cuando se supone que los intereses devengados por la cantidad prestada (denominada capital) son directamente proporcionales al citado capital, a la duración del préstamo (tiempo) y al tanto por ciento de interés al que se efectúa el préstamo (rédito). Además se da una suposición extremadamente importante (y arbitraria) que consiste 
en asumir que los intereses producidos no se añaden al capital para calcular los intereses del siguiente periodo de tiempo (este tipo de interés se denomina interés simple, frente a la posibilidad contraria que recibe el nombre de interés compuesto y en el que ya no existe proporcionalidad).

A la hora de plantear estas situaciones en el aula se recurre a diversas soluciones, las más habituales son las siguientes:

1. Se presenta simplemente la fórmula $I=C \times r \times t$ (el interés resulta de multiplicar el capital, el rédito y el tiempo) de acuerdo a la idea funcional relacionada con la proporcionalidad compuesta (ver 7.2.). A partir de esta fórmula, si se ha trabajado el lenguaje y las manipulaciones algebraicas, se puede resolver cualquier problema de este tipo.

2. Si no se ha trabajado el álgebra a veces se recurre a presentar 4 fórmulas diferentes, en cada una de las cuales se halla despejada una de las variables que intervienen. De este modo, el alumno ha de utilizar la que necesite en función de los datos del problema.

3. Se resuelve el problema, considerándolo como una situación de proporcionalidad compuesta, utilizando alguna de las técnicas descritas en 7.1.

En cualquier caso, se observa que, independientemente de la técnica de resolución utilizada, no se recurre a los significados de las magnitudes implicadas. Además, incluso cuando se emplean métodos aritméticos de resolución (apartado 3 anterior) se aprecia un proceso de inducción que termina planteando una fórmula como la del apartado 1.

\section{IV.3.8.2. Propuesta alternativa}

No encontramos sentido a presentar la Regla de Interés como un contenido independiente por varias razones:

1. Su utilidad práctica es reducida por cuanto en la vida real apenas se encuentran situaciones en las que se preste o reciba dinero a interés simple.

2. Con los aspectos trabajados previamente: significado del porcentaje, manejo de situaciones de proporcionalidad compuesta o sentido de las operaciones 
con cantidades de magnitud, el alumno puede resolver problemas relacionados con la Regla de Interés sin necesidad de indicarle que estos problemas reciben un nombre concreto.

Así pues pensamos que si se desea introducir problemas de este tipo en el aula resulta suficiente con presentar el significado del término interés y recurrir a ideas ya trabajadas con anterioridad por parte del alumno.

\section{Ejemplo:}

Calcular el interés que produce en 5 meses un capital de 9000 euros colocado al 4\% anual.

En primer lugar, nos fijamos en las magnitudes “capital” $(A)$ e "interés al cabo de un año” $(B)$. Se nos dice que $B$ representa el $4 \%$ de $A$ por lo que nos encontramos entre un problema directo (ver 3.2.). Aplicando las ideas descritas en esa sección se obtiene que los intereses que se obtiene al cabo de un año correspondiente a un capital de 9000 euros son de 360 euros.

Ahora nos fijamos en las magnitudes "interés" $(C)$ y "tiempo transcurrido en meses" (D). Ambas magnitudes pueden suponerse directamente proporcionales si se cumple la condición "cada mes se genera la misma cantidad de intereses" (cosa que puede ser razonable, aunque no deja de ser arbitraria). En cualquier caso, asumiendo dicha condición de regularidad se tiene que los intereses generados en un mes (razón entre $C$ y $D$ ) son “30 euros de intereses por cada mes”. Finalmente, con el dato anterior se obtienen con facilidad los intereses producidos al cabo de 5 meses, que son: $30 \times$ $5=150$ euros.

En el ejemplo anterior se ha hecho uso únicamente de los conceptos de porcentaje y de razón. El resto del razonamiento se basa simplemente en una comprensión profunda de la situación problemática concreta. 


\section{IV.3.9. Repartos respecto a varias magnitudes}

\section{IV.3.9.1. Aspectos matemáticos y de la enseñanza tradicional}

Los repartos ya se trataron en la sección 4, allí nos centramos únicamente en repartos respecto una magnitud, pero la extensión natural consiste en repartir una determinada cantidad de forma que la cantidad que recibe cada persona es directamente proporcional a las cantidades de varias magnitudes que posee cada persona e inversamente proporcional a otras.

Es decir, se dispone de una cantidad $C$ a repartir entre varias personas $P_{1}, \ldots, P_{n}$ de tal modo que la cantidad $c_{i}$ que reciba cada persona debe ser directamente proporcional a unos valores $p_{i}^{j}$ e inversamente proporcional a unos valores $q_{i}^{j}$ que le son asignados (por el medio que sea) a dicha persona.

Del mismo modo que sucedía en el caso de repartos inversamente proporcionales, la práctica habitual cosiste en reducir estas situaciones a otras de reparto directamente proporcional respecto de una sola magnitud. En concreto lo que se propone como regla es:

Repartir de forma directamente proporcional respecto a $p_{i}^{j}$ e inversamente proporcional respecto a $q_{i}^{j}$ equivale a repartir de forma directamente proporcional respecto $\frac{\Pi p_{i}^{j}}{\Pi q_{i}^{j}}$.

Una vez aplicada esta regla el problema se resuelve por alguno de los métodos descritos en IV.3.4.1.

\section{IV.3.9.2. Propuesta alternativa}

Nuestra propuesta se basa en la capacidad que tienen los alumnos de construir nuevas magnitudes a partir de otras dadas y que ya han ejercitado al afrontar situaciones de proporcionalidad compuesta (ver sección IV.3.7.2.). Así, cuando se propone una situación en la que se debe efectuar un reparto de forma que en el criterio aparecen diversas magnitudes, se pretende que el alumno construya una nueva magnitud (dotada de un significado concreto) de modo que el problema se convierta en un reparto al que se puedan aplicar las ideas y técnicas de IV.3.4.2. 


\section{Ejemplo:}

Dos albañiles han realizado una obra por la que reciben un pago de 3700 euros. El primer albañil ha trabajado 3 días, 5 horas diarias; y el segundo albañil ha trabajado 4 días, durante 4 horas al día. ¿Cuál debe ser el pago que reciba cada uno?

En este caso el reparto debe hacerse teniendo en cuenta las magnitudes "número de días trabajados” y “número de horas diarias trabajadas”. Sin embargo es fácil traducir el problema dado del siguiente modo:

“Repartir un pago de 3700 euros entre dos personas si la primera ha trabajado 15 horas y la segunda lo ha hecho 16 horas."

Es decir, a partir de las magnitudes anteriores se ha construido la magnitud "número de horas totales trabajadas” y el nuevo problema consiste en efectuar un reparto respecto de esta nueva magnitud. 


\section{CAPÍtulo V:}

\section{FASE DE ACCIÓN.}

\section{V.1. INTRODUCCIÓN}

En el capítulo anterior hemos abordado la Fase de Planificación, desarrollando completamente una propuesta didáctica para la enseñanza de la Proporcionalidad Aritmética en Secundaria. La propuesta teórica que se ha presentado incluye todos los aspectos relacionados con la proporcionalidad que aparecen actualmente en el currículum de E.S.O y que generalmente se presentan en los cursos $1^{\circ}, 2^{\circ}$ y $4^{\circ}$. La experimentación en el aula se llevó a cabo con alumnos de $1^{\circ}$ de E.S.O. por lo que los contenidos presentados tuvieron que ajustarse y adaptarse a los contenidos programados para ese curso (razón, magnitudes directa e inversamente proporcionales y porcentajes), así como al tiempo que las profesoras de dichos grupos tenían previsto dedicar al tema de la proporcionalidad.

En este capítulo, además de presentar en detalle las actividades diseñadas fruto de la adaptación antes indicada, se presentan en detalle todos los aspectos relativos a la Fase de Acción en la que el investigador se constituye en profesor de aula, siendo dicho profesor quién dirige todo el proceso de aprendizaje presentando las tareas, orientando a los alumnos, valorando y reorientando las respuestas de los mismos y, finalmente, institucionalizando los conceptos y procedimientos objeto de la instrucción.

\section{V.2. Planificación de LA FASE de ACCIÓN}

Se diseñó una propuesta en 11 sesiones: ocho de trabajo en clase por parte de los alumnos, con intervenciones iniciales y finales por parte del investigador, en las que se 
desarrollaron las actividades denominadas “Actividad de aula”. Dos sesiones (la séptima y la décima) se reservaron para recapitular lo trabajado hasta ese momento y la última sesión se dedicó a la resolución de un examen escrito, necesario para que las profesoras de los respectivos grupos pudieran llevar a la evaluación.

En su práctica habitual los alumnos debían realizar trabajo en casa. Por esta razón se diseñaron también siete “Tareas de casa” pensadas para reforzar lo trabajado en clase y, en algunos casos, para que sirvieran de excusa a la hora de introducir conceptos nuevos.

\section{V.2.1. Participantes}

La implementación de la propuesta didáctica diseñada se ha llevado a cabo en el I.E.S. Avempace de la ciudad de Zaragoza. Participan dos grupos naturales de alumnos de $1^{\circ}$ E.S.O. con un total de 56 alumnos que serán identificados con los códigos A1, A2,..., A56. En la tabla siguiente se resumen algunos datos al respecto.

\begin{tabular}{|c|c|c|c|}
\cline { 2 - 4 } \multicolumn{1}{c|}{} & Alumnos & Alumnas & Total \\
\hline Grupo 1 & 12 & 17 & 29 \\
\hline Grupo 2 & 7 & 20 & 27 \\
\hline Total & 19 & 37 & 56 \\
\hline
\end{tabular}

Uno de los alumnos sufría una forma leve del Síndrome de Asperger ${ }^{1}$. Pese a que dicho alumno presentaba ciertas dificultades en cuanto a su socialización, lo cierto es que se hallaba plenamente integrado en su clase y su ritmo de trabajo fue idéntico al de sus compañeros. En consecuencia, no excluiremos a dicho alumno del análisis posterior que se efectuará.

\section{V.2.2. Temporalización}

Se contempla implementar 11 sesiones de clase de 50 minutos cada una. Estas 11 sesiones se organizan en torno a los focos de investigación establecidos. En el siguiente

1 El Síndrome de Asperger es un trastorno de tipo autísta cuyos afectados muestran principalmente dificultades en la interacción social y en la comunicación. 
cuadro se presenta la distribución temporal de sesiones, actividades y tareas para cada uno de los núcleos.

\begin{tabular}{|c|c|c|c|}
\hline Núcleo de contenido & Sesiones & Actividades de aula & Tareas de casa \\
\hline Razón y condición de regularidad & 1,2 y 3 & 1,2 y 3 & 1,2 y 3 \\
\hline Proporcionalidad directa y porcentajes & 4,5 y 6 & 4,5 y 6 & 4 y 5 \\
\hline Proporcionalidad inversa & 8 y 9 & 7 y 8 & 6 y 7 \\
\hline
\end{tabular}

Las sesiones 7 y 10 se dedicarán a recapitular el trabajo realizado hasta ese momento. La sesión 7 se ubica justo antes de la introducción de la proporcionalidad inversa, que supone una cierta ruptura con el trabajo anterior. La undécima y última sesión se reserva para la realización de una prueba de evaluación.

Estas sesiones se siguiendo las condiciones habituales de enseñanza. La fase experimental comenzó el martes 9 de marzo de 2010 y concluyó el jueves 25 de marzo de ese mismo año.

\section{V.2.3. Secuenciación}

A continuación se detalla la secuenciación prevista, junto con el tiempo estimado para cada una de las partes en las que se dividirá cada sesión de trabajo:

1. Sesión 1: (50 minutos)

Se lleva a cabo en clase la Actividad de aula 1 (Introducción del concepto de razón), con la siguiente distribución temporal:

- $\quad$ Trabajo de los alumnos (25 min)

- Puesta en común (15 min)

- Intervención del profesor (10 min)

\section{Trabajo en casa:}

Se pide a los alumnos que realicen individualmente la Tarea de casa 1 (Intercambio en la otra dirección). 
3. Sesión 2: (50 minutos)

- Puesta en común de la Tarea de casa 1 y relación con lo obtenido en la Sesión 1. (15 min)

- Se lleva a cabo en clase la Actividad de aula 2 (La condición de regularidad) con la siguiente distribución temporal:

o Trabajo de los alumnos (20 min)

o Puesta en común e intervención del profesor (15 min)

4. Sesión 3: (50 minutos)

Se lleva a cabo en clase la Actividad de aula 3 (Comparar razones en situaciones de intercambio) con la siguiente distribución temporal:

- Trabajo de los alumnos (35 min)

- Puesta en común e intervención del profesor (15 min)

\section{Trabajo en casa:}

Se pide a los alumnos que realicen individualmente la Tarea de casa 2 (Reconocimiento de condiciones de regularidad y razones).

6. Sesión 4: (50 minutos)

- Puesta en común del trabajo realizado en casa. Definición de magnitudes directamente proporcionales y de la constante de proporcionalidad. (20 $\min$.

- Se lleva a cabo en clase la Actividad de aula 4 (Reconocer magnitudes directamente proporcionales) con la siguiente distribución temporal:

o Trabajo de los alumnos (20 min)

o Puesta en común e intervención del profesor (10 min)

\section{Trabajo en casa:}

Se pide a los alumnos que realicen individualmente en casa la Tarea de casa 3 (Comparación de razones en situaciones cualesquiera). 
8. Sesión 5: (50 minutos)

- Puesta en común del trabajo realizado en casa. (15 min)

- Se lleva a cabo en clase la Actividad de aula 5 (Búsqueda de cantidades desconocidas en situaciones de proporcionalidad directa) con la siguiente distribución temporal:

o Trabajo de los alumnos (25 min)

o Puesta en común e intervención del profesor (10 min)

\section{Trabajo en casa:}

Se pide a los alumnos que realicen individualmente en casa la Tarea de casa 4 (Búsqueda de cantidades desconocidas en situaciones de proporcionalidad directa).

10. Sesión 6: (50 minutos)

- Puesta en común del trabajo realizado en casa. Presentación del porcentaje. (20 min)

- Se lleva a cabo en clase la Actividad de aula 6 (Porcentajes) con la siguiente distribución temporal:

o Trabajo de los alumnos (20 min)

o Puesta en común e intervención del profesor (10 min)

\section{Trabajo en casa:}

Se pide a los alumnos que elaboren individualmente en casa la Tarea de casa 5 (Porcentajes).

12. Sesión 7: (50 minutos)

- Puesta en común del trabajo realizado en casa. (20 min)

- Recapitulación de razones y proporcionalidad directa. (30 min)

\section{Trabajo en casa:}

Se pide a los alumnos que elaboren individualmente en casa la Tarea de casa 6 (Reconocimiento de condiciones de regularidad y razones II). 
14. Sesión 8: (50 minutos)

- Puesta en común del trabajo realizado en casa. Definición de magnitudes inversamente proporcionales y de la constante de proporcionalidad. (25 $\min )$

- Se lleva a cabo en clase la Actividad de aula 7 (Reconocer magnitudes inversamente proporcionales) con la siguiente distribución temporal:

o Trabajo de los alumnos (15 min)

o Puesta en común e intervención del profesor (10 min)

15. Sesión 9: (50 minutos)

Se lleva a cabo en clase la Actividad de aula 8 (Búsqueda de cantidades desconocidas en situaciones de proporcionalidad inversa) con la siguiente distribución temporal:

- $\quad$ Trabajo de los alumnos (35 min)

- Puesta en común e intervención del profesor (15 min)

\section{Trabajo en casa:}

Se pide a los alumnos que realicen individualmente en casa la Tarea de casa 7 (Búsqueda de cantidades desconocidas en situaciones de proporcionalidad inversa).

17. Sesión 10: (50 minutos)

- Puesta en común del trabajo realizado en casa. (20 min)

- Recapitulación de proporcionalidad inversa. (30 min)

18. Sesión 11: (50 minutos)

Prueba final. 


\section{V.3. ACTIVIDADES Y TAREAS DISEÑADAS PARA EL TRABAJO DE LOS ALUMNOS}

En las siguientes páginas se van a detallar tanto las “Actividades de clase” como las “Tareas de casa”. El orden de presentación será el mismo en el que se planea plantearlas a los alumnos.

\section{V.3.1 Actividad de aula 1: Introducción del concepto de razón}

Esta actividad está diseñada para observar el tipo de razonamientos utilizados por los alumnos en una situación de proporcionalidad. Además, se tiene en cuenta que los alumnos se enfrentan por primera vez a este tipo de situaciones y carecen de herramientas “formales” para afrontarlas.

\section{V.3.1.1 Objetivos}

1. Introducir a los alumnos en la dinámica de las situaciones de intercambio.

2. Hacer ver al alumno las ventajas del razonamiento multiplicativo en dichas situaciones.

3. Presentar la idea de razón entre magnitudes de distinta naturaleza.

4. Definir la razón en términos de "tanto por uno".

\section{V.3.1.2 Contenidos}

1. La razón entre magnitudes en una situación de intercambio.

\section{V.3.1.3 Metodología}

Los alumnos trabajan por parejas. A cada pareja se le entregan tijeras y unas 25 pajitas. En un lugar visible de la clase se muestra un cartel como el siguiente:

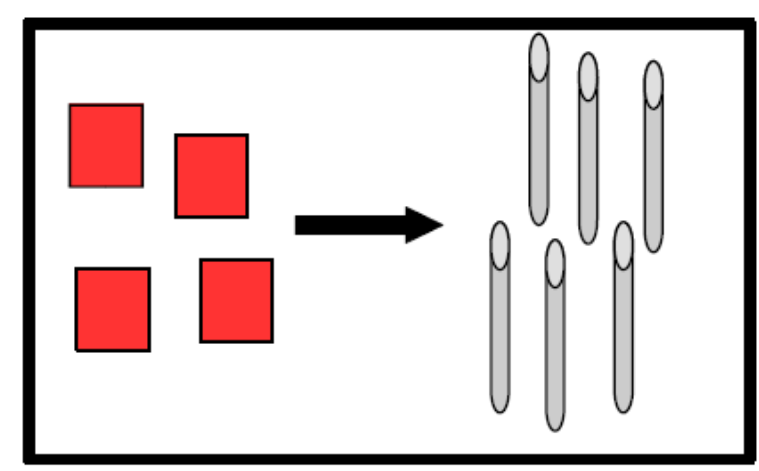


Además, cada pareja recibe un sobre de tamaño grande dentro del que hay seis sobres más pequeños. Estos sobres más pequeños contienen cierto número de tarjetas de cartulina. En concreto:

\begin{tabular}{|l|c|}
\hline Sobre 1: 2 tarjetas. & Sobre 4: 10 tarjetas. \\
\hline Sobre 2: 8 tarjetas. & Sobre 5: 1 tarjeta. \\
\hline Sobre 3: 6 tarjetas. & Sobre 6: 3 tarjetas. \\
\hline
\end{tabular}

Las cantidades de tarjetas que contiene cada sobre no son arbitrarias. Así para las dos primeras es fácil observar relaciones multiplicativas sencillas respecto a la cantidad de tarjetas que se indica en el cartel (2 es la mitad de 4 y 8 es el doble). Las dos siguientes poseen una relación multiplicativa sencilla con la cantidad del primer sobre, pero también pueden obtenerse de forma aditiva fácilmente a partir de las cantidades de los dos primeros y del cartel. El quinto sobre en cierto modo es el punto de inflexión de la actividad, allí se les “fuerza” a obtener la cantidad de pajitas que se obtiene a cambio de 1 tarjeta (suponiendo que no hayan obtenido esa información previamente). Finalmente, en el último no hay relaciones multiplicativas sencillas (salvo la obvia con la unidad) y está pensado para comprobar si los alumnos utilizan la información obtenida en el anterior apartado o si, por el contrario, buscan otro tipo de estrategia.

Dentro de cada uno de los sobres se entregará a la pareja dos fichas similares al modelo siguiente:

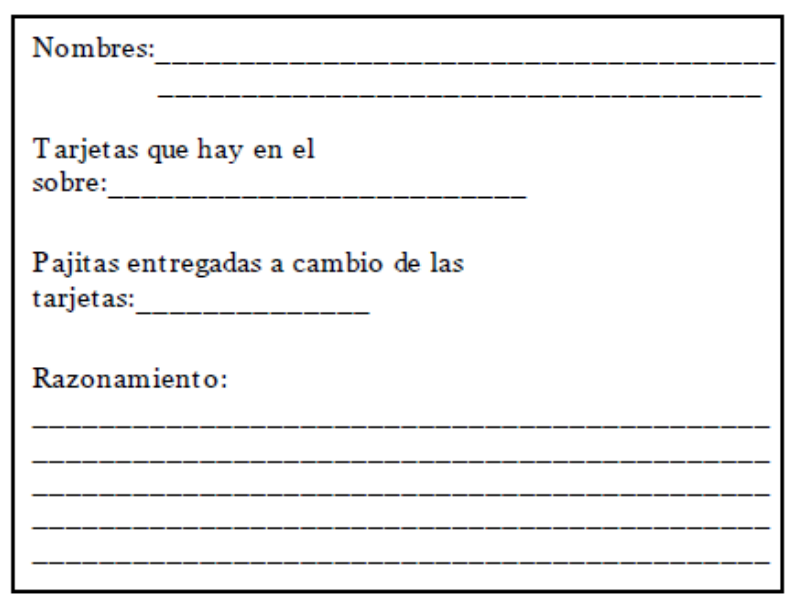


La actividad se desarrolla en tres fases:

1. Presentación y trabajo de los alumnos: Se indica a los alumnos que, para cada sobre, deben decidir cuántas pajitas deben entregarse a cambio de las tarjetas que hay en el mismo; teniendo en cuenta el mensaje gráfico que tienen a la vista. Una vez decidido han de poner por escrito en la ficha el motivo que les ha llevado a tomar tal decisión. La pareja conserva una de las fichas y entrega otra al profesor.

2. Discusión colectiva sobre los resultados de los alumnos: Se dibuja una tabla como la que se adjunta y los alumnos proponen sus respuestas y discuten las de sus compañeros.

3. Intervención final del profesor: El profesor recoge las propuestas que considera más interesantes y concluye introduciendo la idea de razón como "tanto por uno".

\section{V.3.1.4 Evaluación}

Para la evaluación de la actividad se utilizarán las fichas entregadas por los alumnos así como el diario de clase. Durante la puesta en común el profesor evaluará igualmente las respuestas de los alumnos.

\section{V.3.2 Tarea de casa 1: Intercambio en la otra dirección}

Esta tarea está diseñada como una continuación de la Actividad 1 realizada en clase. En ella se presenta la misma situación de intercambio trabajada por parejas en el aula, pero a la inversa. Es decir, cambiando los papeles de tarjetas y pajitas de tal modo que ahora las tarjetas se obtienen a cambio de las pajitas y no al revés. Sin embargo, en este caso los alumnos trabajan individualmente.

La tarea consta de dos actividades bien diferenciadas. En la primera los alumnos deben utilizar la información gráfica proporcionada en el enunciado (similar a la que se les dio en la Actividad de aula 1) para averiguar cuántas tarjetas se obtendrían a cambio de diversas cantidades de pajitas. En concreto, se proporcionan a los alumnos 6 cantidades distintas de pajitas: 3, 9, 1, 4, 5 y 7. 
Para las dos primeras es fácil observar relaciones multiplicativas sencillas (3 es la mitad de 6 y 9 es el triple de 3). La tercera constituye el punto de inflexión de la actividad, allí se les "fuerza” a obtener la cantidad de tarjetas que se obtiene a cambio de 1 pajita con el fin de ver si en los apartados siguientes utilizan esa información. En los tres apartados finales no hay relaciones multiplicativas sencillas (salvo la obvia con la unidad) y, como hemos dicho, están pensados para comprobar si los alumnos utilizan la información obtenida en el tercer apartado o si, por el contrario, buscan otro tipo de estrategia.

En la segunda se les pide el valor numérico y el significado de la razón entre tarjetas y pajitas. El concepto de razón se introdujo al final de la primera sesión de clase. En esta actividad, más allá del cálculo del valor numérico de la razón, se quería observar si los alumnos eran capaces de verbalizar su significado como "tanto por uno". También se pretendía observar si surgían problemas con respecto al orden de las magnitudes involucradas.

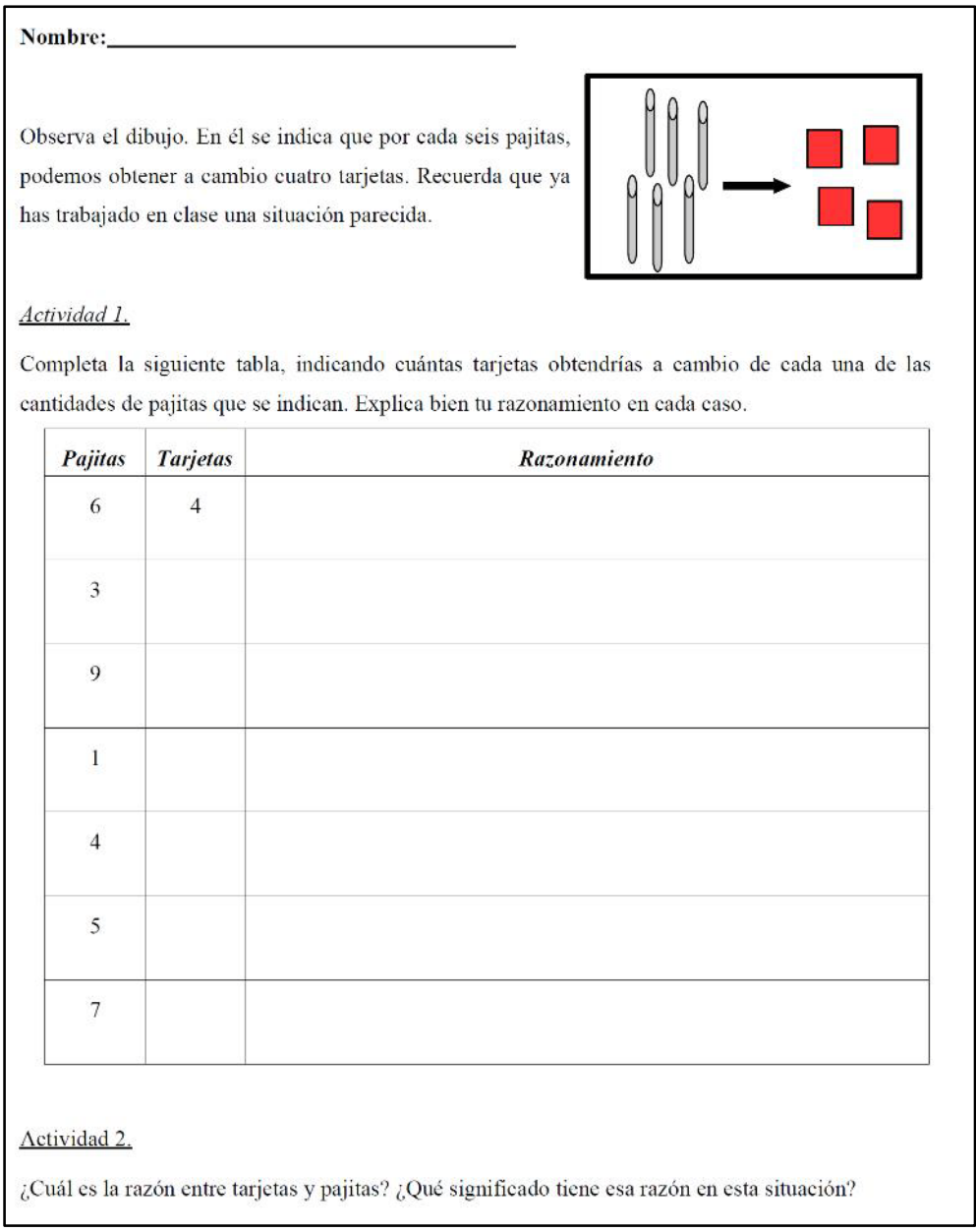

\section{V.3.2.1 Objetivos}

1. Reforzar el concepto de razón entre magnitudes en una situación de intercambio.

2. Mostrar la reversibilidad de las situaciones de intercambio.

3. Observar qué sucede con la razón cuando se “invierte” el sentido de un intercambio. 
4. Enfatizar el hecho de que la razón no es sólo un objeto numérico.

\section{V.3.2.2 Contenidos}

1. La razón entre magnitudes en una situación de intercambio.

2. La razón inversa en una situación de intercambio.

\section{V.3.2.3 Metodología}

Esta tarea está diseñada para ser llevada a cabo por cada alumno individualmente en su casa. En gran medida la tarea supone una reproducción del trabajo realizado en la Actividad de clase 1.

Nuevamente la tarea se desarrolla en tres fases:

1. Trabajo del alumno: El estudiante debe completar una ficha como la que se muestra en la figura adjunta.

2. Discusión colectiva sobre los resultados de los alumnos: El profesor recoge las fichas realizadas por los alumnos. A continuación se completa en la pizarra una tabla similar a la de la ficha. Los alumnos proponen las respuestas y discuten las de sus compañeros.

3. Intervención final del profesor: El profesor recoge las ideas que considera más interesantes, recuerda el concepto de razón introducido en la Actividad de clase 1 e indica la idea de razón inversa presente en esta tarea.

\section{V.3.2.4 Evaluación}

Para la evaluación de la actividad se utilizarán las fichas entregadas por los alumnos así como el diario de clase. Durante la puesta en común el profesor evaluará igualmente las respuestas de los alumnos.

\section{V.3.3 Actividad de aula 2: La condición de regularidad}

Tanto en la Actividad 1 como en la Tarea 1 los alumnos se han enfrentado a situaciones en las que aparecían dos magnitudes relacionadas de tal modo que tenía sentido definir la razón entre ellas. Sin embargo, en el trabajo desarrollado no se hacía 
patente que para poder definir dicha razón era necesario que todas las tarjetas y pajitas manejadas fuesen iguales.

En esta actividad se presenta a los alumnos un cartel informativo en apariencia similar al de la Actividad 1 (salvo por el hecho de que el mensaje ya no es gráfico, sino verbal). Sin embargo, el material que deben manejar consta de tarjetas y pajitas de dos tamaños diferentes. Puesto que el mensaje del cartel es incompleto (no hay referencia al tamaño del material en cuestión), se pretende observar las distintas formas de afrontar dicho problema por parte de los alumnos.

La organización interna de la actividad se realiza en base a cuatro partes. Las tres primeras coinciden con los tres primeros sobres. Los dos primeros sobres son relativamente independientes y muestran la existencia de dos magnitudes diferentes, en el tercer sobre los alumnos se enfrentan a la necesidad de “sumar” esas dos magnitudes distintas. La cuarta parte está formada por los dos últimos sobres. En esta última parte debe observarse la consistencia o no de los argumentos de los alumnos

Con todo esto se pretende hacer énfasis en la importancia de la magnitud involucrada (y no sólo en el valor numérico) así como mostrar una de las condiciones que debe darse para poder hablar de la razón entre dos magnitudes: la condición de regularidad.

\section{V.3.3.1 Objetivos}

1. Reforzar el concepto de razón entre magnitudes en una situación de intercambio.

2. Reforzar la idea de reversibilidad en las situaciones de intercambio.

3. Introducir la necesidad de una "condición de regularidad" para poder hablar de razón entre magnitudes de distinta naturaleza.

\section{V.3.3.2 Contenidos}

1. La razón entre magnitudes en una situación de intercambio.

2. La condición de regularidad. 


\section{V.3.3.3 Metodología}

Los alumnos trabajan por parejas. En un lugar visible de la clase se muestra un cartel como el siguiente:

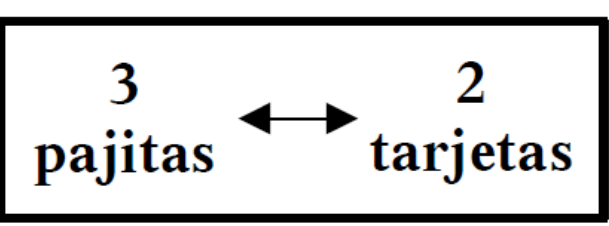

A cada pareja se le entrega un sobre grande dentro del que hay cantidad arbitraria (pero suficiente) de tarjetas de dos tamaños (grandes y pequeñas), además de 5 sobres más pequeños dentro de los cuales hay una determinada cantidad de pajitas de dos tamaños (grandes y pequeñas). En concreto:

\begin{tabular}{|c|}
\hline Sobre 1: 1 pajita grande. \\
\hline Sobre 2: 1 pajita pequeña. \\
\hline Sobre 3: 1 pajita grande y 1 pequeña \\
\hline Sobre 4: 2 pajitas pequeñas y 1 grande \\
\hline Sobre 5: 2 pajitas grandes y 1 pequeña. \\
\hline
\end{tabular}

Además, dentro de cada uno de los sobres pequeños habrá dos fichas similares al modelo siguiente:

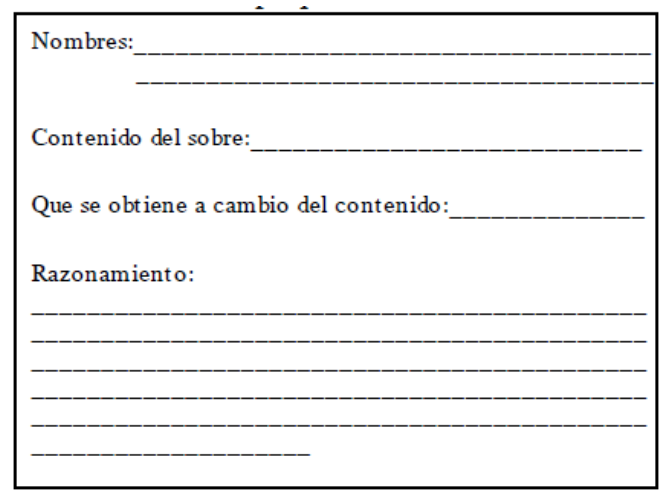

La actividad se desarrolla en tres fases:

1. Presentación y trabajo de los alumnos: Se indica a los alumnos que, para cada sobre, deben decidir cuántas tarjetas y de qué tipo deben entregarse a cambio de las pajitas que hay en el mismo; teniendo en cuenta el mensaje que tienen a la vista. Una vez decidido han de poner por escrito en la ficha el motivo que les ha llevado a tomar tal decisión. La pareja conserva una de las fichas y entrega la otra al profesor. 
2. Discusión colectiva sobre los resultados de los alumnos: Se discuten las respuestas dadas por los alumnos en cada uno de los casos y especialmente, sobre la incompletitud de la consigna dada a los alumnos al inicio de la tarea y la necesidad de fijar un criterio fijo para el intercambio.

3. Intervención final del profesor: El profesor recoge las ideas más interesantes aportadas por los alumnos y concluye formulando con precisión la idea de condición de regularidad.

\section{V.3.3.4 Evaluación}

Para la evaluación de la actividad se utilizarán las fichas entregadas por los alumnos así como el diario de clase. Durante la puesta en común el profesor evaluará igualmente las respuestas de los alumnos.

\section{V.3.4 Actividad de aula 3: Comparar razones en situaciones de intercambio}

En esta actividad se pretendía comprobar si los alumnos utilizaban espontáneamente la idea de razón (trabajada ya en dos sesiones de clase y en una tarea individual en casa), a la hora de comparar distintas situaciones de intercambio para elegir la más ventajosa.

Los carteles informativos se presentaban con mensajes gráficos, con una flecha doble indicando que las situaciones son reversibles (esto ya había sido advertido por los alumnos tras trabajar la Actividad 1 y la Tarea 1), pero con los dibujos en los dos sentidos posibles. Es decir, se presentaban dos carteles con las tarjetas en primer lugar y otros dos a la inversa. Con esto se pretendía afianzar la reversibilidad además de que los alumnos tuvieran que tener claro el orden en el que efectuar las operaciones para obtener la información requerida.

Aparte de la dificultad que pudiera conllevar el cálculo de la razón apropiada para cada una de las cuatro situaciones presentadas, el núcleo de la actividad lo constituía comprender que será más ventajosa aquella situación en la que la razón correspondiente sea mayor. Como veremos, la gran mayoría de los alumnos no observó esto y, en consecuencia, realizó la actividad de forma incorrecta. 


\section{V.3.4.1 Objetivos}

1. Reforzar el concepto de razón en situaciones de intercambio.

2. Calcular razones en situaciones de intercambio.

3. Utilizar las razones como herramienta para la comparación de situaciones de intercambio.

\section{V.3.4.2 Contenidos}

1. La razón entre magnitudes en una situación de intercambio.

2. La condición de regularidad.

\section{V.3.4.3 Metodología}

Los alumnos trabajan por parejas. En un lugar visible de la clase se
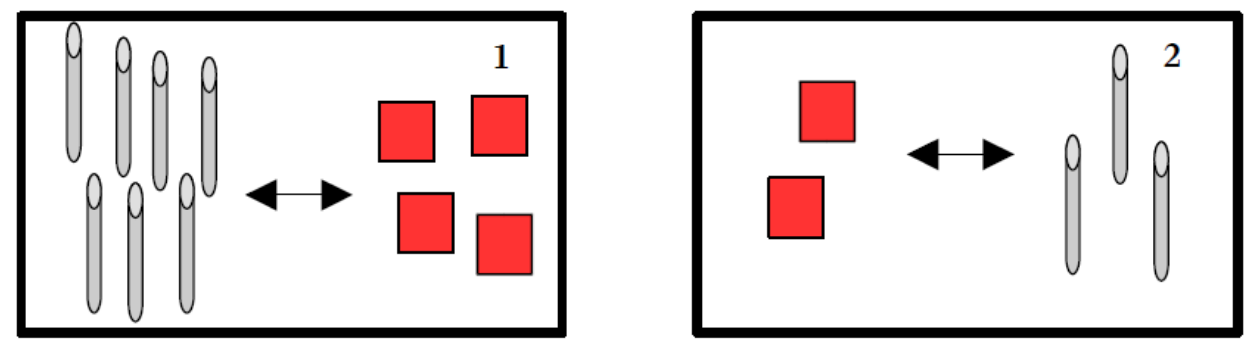
muestran carteles como los siguientes:

A cada pareja
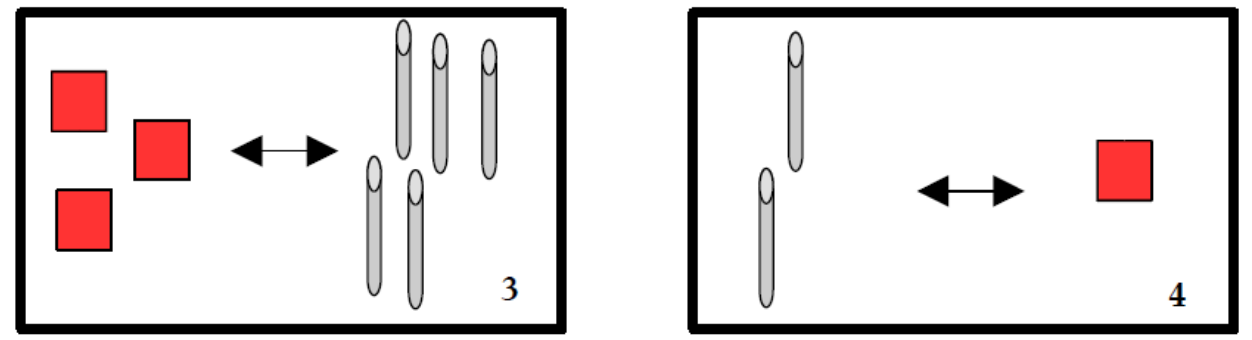
se le entregan pajitas, tarjetas y tijeras; indicándole que no es obligatorio que los use. También les se entregan dos fichas como la siguiente:

Nombres:

A) Si tuvieras que cambiar pajitas por tarjetas, ¿qué cartel te resulta más ventajoso? Razónalo.

B) Si tuvieras que cambiar tarjetas por pajitas, ¿qué cartel te resulta más ventajoso? Razónalo.

¿Has utilizado material? 
La actividad se desarrolla en tres fases:

1. Presentación y trabajo de los alumnos: Se indica a los alumnos que deben responder a las preguntas de la ficha teniendo en cuenta la información proporcionada en los carteles. La pareja conserva una de las fichas y entrega la otra al profesor.

2. Discusión colectiva sobre los resultados de los alumnos: Se discuten las respuestas dadas por los alumnos a cada una de las preguntas. Si hay discrepancias se insta a los alumnos a que presenten y discutan sus argumentos.

3. Intervención final del profesor: El profesor recoge las ideas más interesantes aportadas por los alumnos y concluye planteando la utilidad de la idea de razón a la hora de resolver este tipo de tareas.

\section{V.3.4.4 Evaluación}

Para la evaluación de la actividad se utilizarán las fichas entregadas por los alumnos así como el diario de clase. Durante la puesta en común el profesor evaluará igualmente las respuestas de los alumnos.

\section{V.3.5 Tarea de casa 2: Reconocimiento de condiciones de regularidad y razones}

En esta tarea se presentan varias situaciones en las que el alumno debe indicar si es posible definir una o más razones, señalando además las condiciones de regularidad necesarias para hacerlo.

Esta tarea supone un cambio importante respecto del trabajo llevado a cabo por los alumnos hasta este punto. Hasta ahora, el contexto en el que los alumnos han trabajado era el de situaciones de intercambio (en concreto pajitas y tarjetas) mientras que en esta tarea aparecen situaciones muy diferentes (por más que puedan reinterpretarse en términos de intercambios). Además las situaciones que se presentan están “alejadas” del alumno en el sentido de que hasta ahora siempre se había trabajado con materiales que el alumno podía (si quería) manipular; ahora las situaciones se presentan en contextos hipotéticos en los que el alumno debe situarse mentalmente para poder trabajar. 
Pese a que las situaciones del enunciado se presentaban al alumno en una secuenciación relativamente aleatoria, es posible separarlas en tres grupos. El primer grupo sería el formado por las situaciones 1, 2, 5, 7 y 8; en estas situaciones es posible, bajo las condiciones de regularidad apropiadas, definir las razones entre las magnitudes involucradas. El segundo grupo está formado por las situaciones 3, 4 y 9. En ellas no es posible definir razones entre las magnitudes involucradas porque no están relacionadas (en tareas y actividades posteriores se analizará la posibilidad de magnitudes que sí están relacionadas pero entre las que no se pueden definir razones y veremos que esta posibilidad ocasiona problemas a los alumnos). Finalmente, el tercer grupo de situaciones es el formado por la 6 y la 10; estas situaciones tienen en común el hecho de que aparecen 3 magnitudes, con las dificultades que ello conlleva.

\section{V.3.5.1 Objetivos}

1. Extender la idea de razón en situaciones no de intercambio.

2. Reforzar la necesidad de una condición de regularidad a la hora de definir la razón entre dos magnitudes en una situación dada.

3. Reconocer las razones que se puedan definir en una determinada situación y comprender su significado.

4. Calcular la razón en aquellas situaciones en las que es posible hacerlo.

5. Observar que existen situaciones en las que no se puede definir la razón entre las magnitudes involucradas.

6. Introducir el concepto de magnitudes directamente proporcionales.

\section{V.3.5.2 Contenidos}

1. La razón entre magnitudes en una situación de intercambio.

2. La razón entre magnitudes en situaciones cualesquiera.

3. La condición de regularidad.

4. Magnitudes directamente proporcionales en una situación dada. 


\section{V.3.5.3 Metodología}

Esta tarea está diseñada para ser llevada a cabo por cada alumno individualmente en su casa. Esta tare, por un lado, está pensada a modo de recapitulación de los conceptos más importantes presentados hasta el momento y, por otro lado, como introducción del concepto de magnitudes directamente proporcionales.

Se entrega a los alumnos una hoja de trabajo en la que se presentan diversas situaciones. En cada una de ellas se pide que indiquen las condiciones de regularidad necesarias para poder definir razones entre las magnitudes involucradas (si es que se pueden definir) así como el significado de dichas razones. En concreto, la hoja de trabajo es similar a la siguiente:

\section{Nombre:}

En clase hemos visto que para poder definir una razón entre dos magnitudes es necesario que se cumplan ciertas “condiciones de regularidad”. A continuación te presentamos varias situaciones. En cada una de ellas te pedimos que definas todas las razones que aparezcan, que digas lo que significan y que indiques cuáles son las "condiciones de regularidad” necesarias para poder definir dichas razones. Si en alguna de ellas no puedes definir ninguna razón entre las magnitudes que aparecen, indica el por qué.

Situación 1: En una tribu del Amazonas Situación 2: En 4 horas limpió 37 cambian 5 lanzas por 3 escudos. cristales.

Situación 3: Laura tiene 10 años y tiene una Situación 4: En la planta 5 hay 28 estatura de $120 \mathrm{~cm}$. enfermos ingresados.

Situación 5: Al comprar 3 camisetas me Situación 6: Mis 2 perros tardan 4 días regalaron 4 discos. en terminarse 1 saco de comida.

Situación 7: Por 125 dólares me han dado 155 Situación 8: Para preparar naranjada euros. se mezclan 3 litros de zumo de naranja con 5 litros de agua.

Situación 9: El 10 de junio cumplí 16 años. Situación 10: Leyendo 2 horas al día tardo 7 días en terminar un libro de 426 páginas. 
Como se observa, entre dichas situaciones aparecerán magnitudes directamente proporcionales, inversamente proporcionales y magnitudes no relacionadas de ninguna de las dos formas anteriores.

Nuevamente la tarea se desarrolla en tres fases:

1. Trabajo del alumno: El estudiante debe completar la hoja de trabajo entregada.

2. Discusión colectiva sobre los resultados de los alumnos: El profesor recoge las hojas de trabajo completadas por los alumnos. A continuación se plantea en la pizarra una selección de las situaciones que el profesor considera más interesante abordar con los alumnos. Para cada una de ellas, los estudiantes plantean sus respuestas y discuten las de los demás.

3. Intervención final del profesor: El profesor actúa como moderador en las discusiones anteriores, aclarando los puntos conflictivos y destacando las ideas más interesantes de los alumnos. La intervención del profesor concluye introduciendo el concepto de magnitudes directamente proporcionales tomando como ejemplo alguna de las situaciones anteriores y confrontándola claramente con alguna situación en la que no exista tal relación.

\section{V.3.5.4 Evaluación}

Para la evaluación de la actividad se utilizará la hoja de trabajo entregada por los alumnos así como el diario de clase. Durante la puesta en común el profesor evaluará igualmente las respuestas de los alumnos.

\section{V.3.6 Actividad de aula 4: Reconocer magnitudes directamente proporcionales}

Esta es la primera actividad en la que aparece el concepto de magnitudes directamente proporcionales. Este concepto había sido introducido por el profesor al final de la Tarea 2 como un nombre para aquellos casos en los que se puede definir la razón entre las dos magnitudes. En cualquier caso, el manejo de este concepto no era importante a la hora de realizar la actividad, puesto que era suficiente con buscar parejas de magnitudes entre las que se pudiera definir la razón (bajo las condiciones de regularidad adecuadas), y parejas entre las que esto fuera imposible. 
Además de lo anterior, en esta actividad se pretendía observar el manejo de las magnitudes por parte de los alumnos. Aunque en cada ejercicio las magnitudes correspondientes se presentan descontextualizadas, hay que tener en cuenta que el alumno puede (y debe) imaginar un contexto en el que plantear el ejercicio; es decir, un contexto en el que las seis magnitudes presentadas aparezcan con sentido.

En cada ejercicio aparecen variables que no son magnitudes, magnitudes no relacionadas, magnitudes relacionadas de forma directamente proporcional $\mathrm{y}$ magnitudes que están relacionadas pero no mediante una proporcionalidad directa. En algunos casos aparecen magnitudes inversamente proporcionales, pero en este punto de la propuesta no se introduce ese concepto.

\section{V.3.6.1 Objetivos}

1. Reforzar el significado de razón como “tanto por uno”.

2. Reforzar la idea de condición de regularidad.

3. Reconocer magnitudes directamente proporcionales.

4. Reconocer magnitudes que no son directamente proporcionales.

\section{V.3.6.2 Contenidos}

1. La razón entre magnitudes en situaciones cualesquiera.

2. La condición de regularidad.

3. Magnitudes directamente proporcionales en una situación dada.

\section{V.3.6.3 Metodología}

Los alumnos trabajan por parejas. A cada pareja se le entregan dos fichas de trabajo idénticas (una para ellos y otra que recogerá el profesor al finalizar la actividad).

En la ficha se presentan varios ejercicios. En cada uno de ellos aparecen diversas magnitudes. Los alumnos deben relacionar una pareja de magnitudes que sean directamente proporcionales, indicando en ese caso las condiciones de regularidad necesarias así como el significado de las razones que se pueden definir. También deben indicar una pareja de magnitudes que no sean directamente proporcionales, señalando el motivo. La hoja es similar a la siguiente: 


\section{Nombres:}

Recuerda que dos magnitudes son directamente proporcionales cuando podemos definir una razón entre ellas (teniendo en cuenta que se deben cumplir ciertas condiciones de regularidad).

En cada uno de los ejercicios:

1. Busca una pareja de magnitudes que sean directamente proporcionales, señalando la condición de regularidad que deben cumplir. ¿Qué significado tiene la razón entre ellas?

2. Busca una pareja de magnitudes que no sean directamente proporcionales, indicando las razones por las que no lo son.

\section{Ejercicio 1:}

Velocidad en kilómetros por hora. Distancia, en kilómetros, recorrida por el móvil.

Edad, en años, del conductor. Tiempo, en horas, empleado en el recorrido.

El número de la matrícula del coche.

El número de pasajeros.

\section{Ejercicio 2:}

Número de alumnos en el patio. Superficie, en metros cuadrados, del patio de recreo.

Edad media de los alumnos.

Estatura media de los alumnos.

Anchura del patio.

Hora de comienzo de las clases.

\section{Ejercicio 3:}

Número de libros.

Número de páginas.

Precio de cada libro.

Edad, en años, del comprador.

El tamaño de la letra del texto.

Número de fotografías de cada libro.

La actividad se desarrolla en tres fases:

1. Presentación y trabajo de los alumnos: El profesor describe la actividad y los alumnos, por parejas, deben completar el mayor número de ejercicios posible.

2. Discusión colectiva sobre los resultados de los alumnos: Se plantea al menos uno de los ejercicios y la clase al completo discute las respuestas propuestas por algunos de sus compañeros.

3. Intervención final del profesor: El profesor refina las ideas planteadas por los alumnos y haciendo uso de las mismas analiza completamente uno de los 
ejercicios. Se concluye recordando los conceptos de razón, condición de regularidad y magnitudes directamente proporcionales.

\section{V.3.6.4 Evaluación}

Para la evaluación de la actividad se utilizarán las hojas de trabajo entregadas por los alumnos así como el diario de clase. Durante la puesta en común el profesor evaluará igualmente las respuestas de los alumnos.

\section{V.3.7 Tarea de casa 3: Comparación de razones en situaciones cualesquiera}

Esta tarea estaba pensada como una ampliación de la Actividad 3 en la que se presentaba la utilidad de la razón para comparar distintas situaciones en las que aparecen involucradas las mismas magnitudes (aunque dicha actividad, en cierto sentido, fue fallida). En realidad, viendo los resultados que se obtuvieron en la Actividad 3, los resultados obtenidos en esta tarea fueron mucho mejores de lo esperado. Posiblemente se deba a que los contextos planteados en esta tarea sean más familiares para el alumno y así, aunque de forma inconsciente en algunos casos, surge de forma natural el uso de la razón como herramienta de comparación.

Los ejercicios que forman esta tarea pueden separarse en tres grupos. El primer grupo está formado por los ejercicios 1, 2, 3 y 6; en estos ejercicios aparecen dos magnitudes relacionadas de forma directamente proporcional (bajo las suposiciones adecuadas), y además la razón sirve para comparar las dos situaciones presentadas. El segundo grupo es el formado por los ejercicios 4 y 5; en estos ejercicios o bien no tiene sentido definir la razón entre las variables involucradas (es el caso del ejercicio 4, donde sólo hay una magnitud), o bien la razón no es un elemento adecuado para comparar las dos situaciones (ejercicio 5). El ejercicio 7 constituye por sí sólo el tercer grupo; en este ejercicio aparecen tres magnitudes (como vimos esto pone en dificultades a los alumnos), además el cálculo de la razón que resultaría útil para resolver el problema implica la “construcción” de la magnitud vaca×día (cuyo significado es muy poco intuitivo) y la introducción de un valor desconocido para la cantidad total de leche producida. No obstante el ejercicio se puede resolver de forma relativamente sencilla utilizando otras ideas. 
Así pues, podríamos presentar el siguiente esquema que presenta las distintas tipologías de ejercicios:

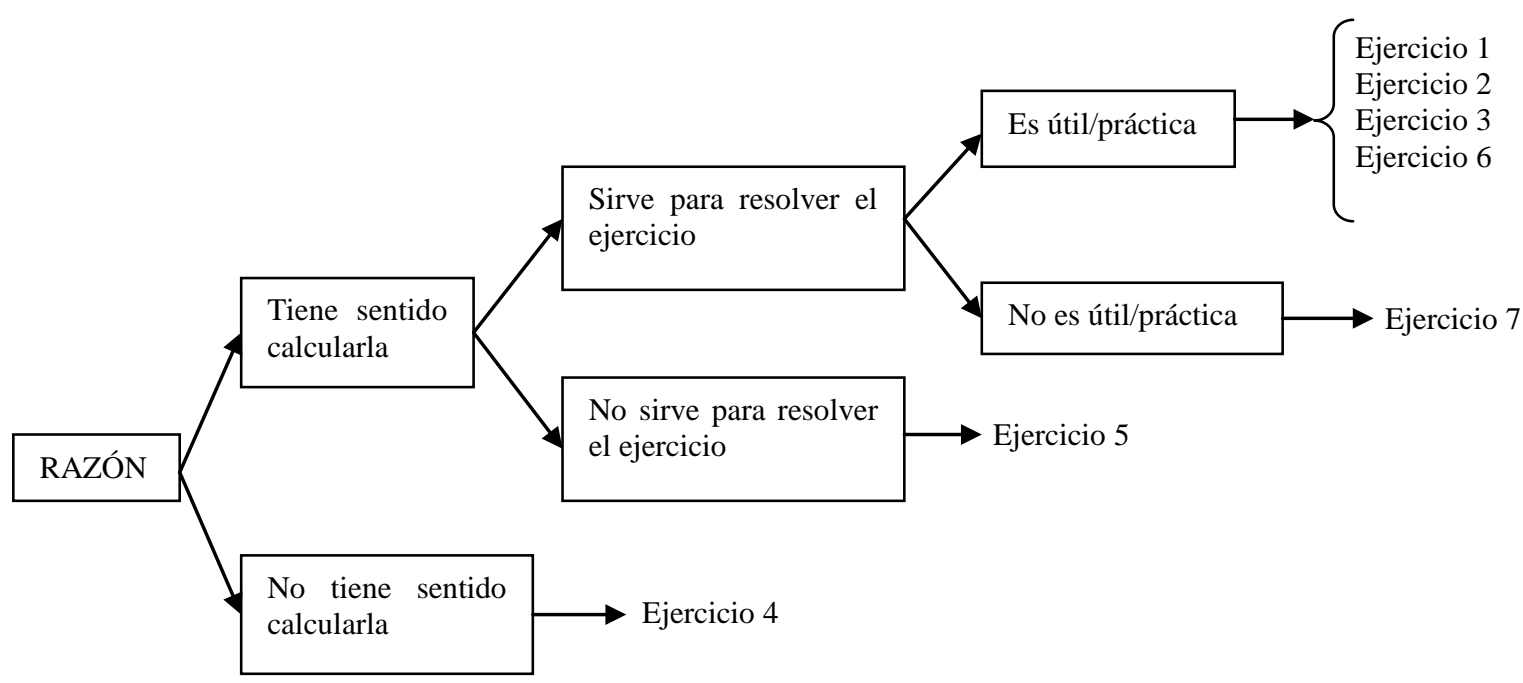

\section{V.3.7.1 Objetivos}

1. Reforzar el significado de razón como "tanto por uno”.

2. Calcular razones en diversas situaciones.

3. Utilizar el significado anterior de la razón para comparar distintas situaciones.

4. Observar que existen situaciones en las que la razón no sirve como criterio de comparación.

\section{V.3.7.2 Contenidos}

1. La razón entre magnitudes en situaciones cualesquiera.

2. La condición de regularidad.

\section{V.3.7.3 Metodología}

Esta tarea está diseñada para ser llevada a cabo por cada alumno individualmente en su casa. Se pretende que esta tarea refuerce las ideas trabajadas en la Actividad de aula 3.

Se entrega a los alumnos una hoja de trabajo en la que se presentan diversas parejas de situaciones. En cada una de ellas se pide que analicen dichas parejas haciendo uso, cuando sea posible, de la razón entre las magnitudes involucradas. 
La hoja entregada es como la siguiente:

Nombre:

En clase hemos visto que en ciertas ocasiones la razón nos sirve para descubrir qué situación es más ventajosa para nosotros cuando tenemos varias opciones entre las que elegir. Con esta idea en la cabeza, trata de resolver los siguientes ejercicios. Pero, ¡cuidado! Recuerda que no siempre podemos definir la razón entre dos magnitudes. Ejercicio 1:

En el banco A cambian 120 dólares por 170 euros, y en el banco B cambian 180 euros por 130 dólares. Si quieres cambiar euros a dólares, ¿¿a qué banco irías?

Ejercicio 2:

El futbolista $\mathrm{N}$ ha marcado 18 goles en los 22 partidos que ha jugado, mientras que el futbolista $\mathrm{P}$ ha marcado 25 goles en los 38 partidos jugados, ¿qué futbolista ofrece mayor rendimiento goleador?

\section{Ejercicio 3:}

Una receta de naranjada indica que hay que mezclar 0,5 litros de naranja con 1,5 litros de agua. Otra receta dice que hay que mezclar 1,5 litros de naranja con 5 litros de agua.

¿Cuál de las dos recetas proporciona un sabor de naranja más fuerte?

\section{Ejercicio 4:}

En segundo curso aprobé 7 asignaturas y en tercer curso aprobé también 7 asignaturas. ¿En qué curso obtuve mejor rendimiento?

\section{Ejercicio 5:}

En colegio A hay matriculados 450 alumnos y en colegio B hay matriculados 320 alumnos. En el colegio A hay 35 profesores, mientras que en colegio B hay 25 profesores. ¿En cuál de los colegios los alumnos obtienen mejores calificaciones? Ejercicio 6:

En una tienda si compras 3 discos te regalan 4 camisetas y en otra tienda te regalan 5 camisetas al comprar 4 discos, ¿en qué tienda es más rentable comprar?

\section{Ejercicio 7:}

Cuatro vacas negras dan tanta leche en cinco días como tres vacas marrones en seis días. ¿Qué clase de vaca es mejor lechera, la negra o la marrón? 
Como se observa, en algunos ejercicios es posible utilizar la razón como herramienta para comparar las situaciones presentadas, mientras que en otros se puede definir la razón entre las magnitudes implicadas, pero esa razón no es útil a la hora de comparar las situaciones y, finalmente, en otros ejercicios ni siquiera es posible definir la razón.

La tarea se desarrolla en tres fases:

1. Trabajo del alumno: El estudiante debe completar la hoja de trabajo.

2. Discusión colectiva sobre los resultados de los alumnos: El profesor recoge la hoja de trabajo completada por el alumno. A continuación se plantea en la pizarra una selección de los ejercicios que el profesor considera más interesante trabajar con los alumnos (de acuerdo con la distinción anterior). En cada uno de ellos se recaban las respuestas e ideas de los alumnos y se promueve la discusión.

3. Intervención final del profesor: El profesor actúa como moderador en las discusiones anteriores, aclarando los puntos conflictivos y enfatizando las ideas más interesantes de los alumnos. Por último, se presenta de nuevo la utilidad de la razón a la hora de comparar ciertas situaciones haciendo énfasis, no obstante, en que no siempre es así.

\section{V.3.7.4 Evaluación}

Para la evaluación de la actividad se utilizará la hoja de trabajo entregada por los alumnos así como el diario de clase. Durante la puesta en común el profesor evaluará igualmente las respuestas de los alumnos.

\section{V.3.8 Actividad de aula 5: Búsqueda de cantidades desconocidas en situaciones de proporcionalidad directa}

Esta actividad, llevada a cabo en clase por parejas, supone la primera toma de contacto de los alumnos con los clásicos ejercicios de búsqueda de cantidades desconocidas en situaciones de proporcionalidad.

En los cinco ejercicios planteados tiene sentido calcular la razón entre las magnitudes involucradas, siempre bajo las condiciones de regularidad apropiadas. 
Ahora bien, sólo en el Ejercicio 1 son razonables las condiciones de regularidad necesarias. De hecho, en el Ejercicio 4 se habla de tiempos necesarios para elevar la temperatura de un recipiente, situación en la que las variables están relacionadas de forma exponencial negativa.

De todas formas, en el resto de ejercicios aparecen razones que, pese a ser poco realistas, se utilizan a menudo (o al menos se usan otras similares) como son: periódicos por habitante o teléfonos móviles por alumno. En esas situaciones se ha prestado especial atención a si el alumno ha sido capaz de hacer explícitas las condiciones o las suposiciones necesarias para hablar de razón.

\section{V.3.8.1 Objetivos}

1. Reforzar el reconocimiento de magnitudes directamente proporcionales.

2. Reforzar el reconocimiento de magnitudes que no son directamente proporcionales.

3. Recordar el significado de razón como "tanto por uno" y la necesidad de la condición de regularidad.

4. Utilizar la razón como "tanto por uno" para resolver problemas de búsqueda de cantidades desconocidas.

\section{V.3.8.2 Contenidos}

1. La razón entre magnitudes en situaciones cualesquiera.

2. La condición de regularidad.

3. Magnitudes directamente proporcionales.

\section{V.3.8.3 Metodología}

Los alumnos trabajan por parejas. A cada pareja se le entregan dos fichas de trabajo idénticas (una para ellos y otra que recogerá el profesor al finalizar la actividad).

En la ficha se presentan varios ejercicios de búsqueda de cantidades desconocidas. Los alumnos no se habían enfrentado previamente a ejercicios de esta naturaleza. La hoja entregada es: 
Nombres:

Recordad que dos magnitudes son directamente proporcionales si se puede definir una razón entre ellas. Además la razón entre dos magnitudes es la cantidad de la primera que se corresponde con una unidad de la segunda. Con esta idea, tratad de resolver los siguientes problemas.

\section{Ejercicio 1:}

Para obtener 4200 litros de mosto hacen falta 6300 kilogramos de uva, ¿cuántos kilogramos de uva se necesitan para obtener 3560 litros de mosto?

\section{Ejercicio 2:}

En un libro de 360 páginas hay 15 capítulos, ¿¿cuántos capítulos tendrá un libro de 288 páginas?

Ejercicio 3:

En una ciudad de 600000 habitantes se editan 4 periódicos, ¿cuántos periódicos se editarán en una ciudad de 1050000 habitantes

\section{Ejercicio 4:}

Se tarda 9 minutos para aumentar 5 grados la temperatura de un recipiente de 12 litros, ¿qué tiempo se tardará en aumentar 17 grados la temperatura de dicho recipiente?

\section{Ejercicio 5:}

En una clase de 25 alumnos hay 14 teléfonos móviles, ¿¿cuántos teléfonos móviles habrá en una clase de 18 alumnos?

Se observa, como en actividades anteriores, una variedad de situaciones. En este caso se presentan magnitudes directamente proporcionales, magnitudes relacionadas pero no directamente proporcionales y magnitudes no relacionadas en absoluto.

La actividad se desarrolla en tres fases:

1. Presentación y trabajo de los alumnos: El profesor describe la actividad y los alumnos, por parejas, deben completar el mayor número de ejercicios posible.

2. Discusión colectiva sobre los resultados de los alumnos: Se plantean los ejercicios que el profesor considera más interesantes, y los alumnos presentan y discuten sus respuestas, haciendo las preguntas necesarias para que aparezcan el mayor número de ideas y argumentos posible. 
3. Intervención final del profesor: El profesor refina las ideas de los alumnos para presentar el modo de atacar los problemas de cantidades desconocidas, teniendo en cuenta la tipología descrita más arriba.

\section{V.3.8.4 Evaluación}

Para la evaluación de la actividad se utilizarán las hojas de trabajo entregadas por los alumnos así como el diario de clase. Durante la puesta en común el profesor evaluará igualmente las respuestas de los alumnos.

\section{V.3.9 Tarea de casa 4: Búsqueda de cantidades desconocidas en situaciones de proporcionalidad directa}

Esta tarea estaba pensada como una ampliación de la Actividad 5, realizada por parejas en clase. En este caso se pretendía que los alumnos trabajaran individualmente en casa para afianzar el trabajo realizado en clase.

En la tarea se presentaban esencialmente dos tipos de problemas: aquellos en los que tenía sentido (bajo las condiciones de regularidad adecuadas) hallar la razón entre las magnitudes involucradas y, por tanto, se podía encontrar la cantidad desconocida y aquellos en los que no era posible.

Los ejercicios 1, 3, 5 y 6 eran "resolubles" en el sentido que hemos indicado antes. Sin embargo, en los ejercicios 2 y 4 no tenía sentido el cálculo de la razón. Ahora bien, en estos dos últimos ejercicios el motivo era distinto. Mientras en el ejercicio 2 las dos magnitudes involucradas (edad y propina semanal) no están relacionadas, en el ejercicio 4 las magnitudes relevantes (número de perros y duración de la comida) están relacionadas pero de forma (a lo sumo) inversamente proporcional. En los ejercicios 3 y 4 aparecen en el enunciado 3 magnitudes (esto ya sucedió en tareas anteriores y dio problemas a los alumnos), si bien una de ellas puede suponerse fija y, por tanto, obviarse en la solución del problema.

Finalmente; los ejercicios 5 y 6, en los que se remite al alumno a la cantidad de una magnitud correspondiente a 100 unidades de la otra, estaban pensados para servir como pretexto a la hora de introducir la idea de porcentaje. 


\section{V.3.9.1 Objetivos}

1. Reforzar el concepto de razón como "tanto por uno".

2. Utilizar dicho concepto para resolver problemas de cantidades desconocidas en situaciones de proporcionalidad directa.

3. Observar que existen magnitudes que están relacionadas pero que no son directamente proporcionales.

4. Observar que existen magnitudes que no están relacionadas.

5. Introducir la idea de "tanto por ciento".

\section{V.3.9.2 Contenidos}

1. La razón entre magnitudes en situaciones cualesquiera.

2. La condición de regularidad.

3. Magnitudes directamente proporcionales.

\section{V.3.9.3 Metodología}

Esta tarea está diseñada para ser llevada a cabo por cada alumno individualmente en su casa. Se pretende que esta tarea refuerce las ideas trabajadas en la Actividad de aula 5 .

Se entrega a los alumnos una hoja de trabajo en la que se presentan varios ejercicios de búsqueda de cantidades desconocidas. En concreto, la hoja de trabajo entregada es:

Nombre:

En clase hemos comprobado cómo el uso de la razón nos permite resolver problemas en los que dos magnitudes son directamente proporcionales y queremos encontrar la cantidad de una de las magnitudes que se corresponde con una cantidad conocida de la otra. Estos ejercicios van en la misma dirección.

Ejercicio 1:

3 docenas de huevos cuestan 3,5 euros. ¿Cuánto costarán 25 huevos?

Ejercicio 2:

María tiene 13 años y recibe una propina semanal de 7 euros. ¿Qué propina recibirá a los 


\section{7 años?}

\section{Ejercicio 3:}

Un grupo de 3 obreros tarda 2 días en embaldosar una superficie de 200 metros cuadrados. ¿Cuántos días tardarán en embaldosar una superficie de 350 metros cuadrados?

\section{Ejercicio 4:}

Con un saco de comida para perros los 2 perros de Luis pueden comer durante todo un mes, ¿cuánto tiempo les durará esa misma comida a los 3 perros de María?

\section{Ejercicio 5:}

En las rebajas de una tienda una camisa que cuesta 20 euros tiene un descuento de 3 euros. ¿Cuánto descuento tendrá un abrigo que cuesta 100 euros?

\section{Ejercicio 6:}

Para hacer hormigón un albañil junta 2 kilos de cemento con 4 kilos de arena. Si quiere fabricar 12 kilos de hormigón ¿cuántos kilos de cada material debe utilizar? ¿Y si quiere fabricar 100 kilos?

Como se observa, se presentan magnitudes directamente proporcionales, magnitudes relacionadas pero no directamente proporcionales y magnitudes no relacionadas en absoluto. Los dos últimos ejercicios están pensados para que sirvan como introducción a la idea de "tanto por ciento".

La actividad se desarrolla en tres fases:

1. Trabajo del alumno: El estudiante debe completar la hoja de trabajo.

2. Discusión colectiva sobre los resultados de los alumnos: El profesor recoge la hoja de trabajo completada por el alumno. A continuación se resuelven en común una selección de los ejercicios que el profesor considera más interesantes según la tipología indicada más arriba.

3. Intervención final del profesor: El profesor recoge las ideas más significativas de los alumnos y recapitula los conceptos de la actividad anterior. Su intervención concluye introduciendo la idea de porcentaje como "tanto por cien” a partir del análisis de uno de los dos últimos ejercicios. 


\section{V.3.9.4 Evaluación}

Para la evaluación de la actividad se utilizarán las hojas de trabajo entregadas por los alumnos así como el diario de clase. Durante la puesta en común el profesor evaluará igualmente las respuestas de los alumnos.

\section{V.3.10 Actividad de aula 6: Porcentajes}

Esta actividad supone el primer encuentro de los alumnos con situaciones problemáticas que involucran el concepto de tanto por ciento. A partir de los dos últimos ejercicios de la Tarea 4 se había introducido en clase la idea de porcentaje como “tanto por ciento” en analogía con la razón introducida como "tanto por uno”. Es decir, se indicó que el porcentaje que una magnitud representa respecto de otra es la cantidad de la primera que se corresponde con 100 unidades de la segunda.

En la actividad se plantean cuatro ejercicios. Cada uno de ellos consta de varios apartados en los que se hacen diversas preguntas relacionadas directamente con los porcentajes, con la idea de razón o con otros aspectos. En concreto:

1. En el Ejercicio 1 se pide calcular la cantidad que se corresponde con un cierto porcentaje del total [problema directo], una razón entres dos cantidades de magnitud y el porcentaje que representa una cierta cantidad respecto del total. Aparece también una pregunta que involucra ideas de complementariedad.

2. En el Ejercicio 2 se pide calcular el total conociendo la cantidad que se corresponde con un determinado porcentaje [problema inverso] y una razón. Además hay una pregunta “trampa” para observar la comprensión que los alumnos tienen de la situación.

3. En el Ejercicio 3 se pide un descenso porcentual (calcular un porcentaje y restarlo del total), el porcentaje que cierta cantidad representa respecto de otra y el cálculo de un precio original conociendo el precio tras un descenso porcentual dado.

4. En el cuarto ejercicio se pide un aumento porcentual, el porcentaje de subida que supone una cierta variación en un precio y una discusión sobre la comparación de dos aumentos de precio. 
Aunque las ideas subyacentes en todos los ejercicios son las mismas, hay diferencias suficientes como para justificar que, en la siguiente sección, analicemos cada uno de ellos por separado.

\section{V.3.10.1 Objetivos}

1. Presentar el concepto de porcentaje como "tanto por ciento".

2. Comprender la relación entre razón y porcentaje.

3. Resolver, utilizando el significado de "tanto por ciento" diversos problemas relacionados con porcentajes.

\section{V.3.10.2 Contenidos}

1. El porcentaje.

2. La razón entre magnitudes en situaciones cualesquiera.

3. La condición de regularidad.

4. Magnitudes directamente proporcionales.

\section{V.3.10.3 Metodología}

Los alumnos trabajan por parejas. A cada pareja se le entregan dos fichas de trabajo idénticas (una para ellos y otra que recogerá el profesor al finalizar la actividad).

En la ficha se presentan varios ejercicios en los que se hace necesario el uso de la idea de razón como tanto por uno y el de porcentaje como "tanto por ciento". Los alumnos no se habían enfrentado anteriormente a este tipo de ejercicios y tan conocían la definición de porcentaje como "tanto por ciento". La hoja entregada a cada pareja es la siguiente:

\section{Nombres:}

Recordad que el porcentaje que una magnitud representa respecto de una segunda magnitud es justamente la cantidad de la primera magnitud que se corresponde con 100 unidades de la segunda. Teniendo esto en cuenta debéis tratar de resolver los siguientes problemas: 


\section{Ejercicio 1:}

En una ciudad hay un 52\% de mujeres. Si la población total es de 725.000 habitantes:

i. ¿Cuántas mujeres viven en esa ciudad?

ii. ¿Cuántos hombres viven en la ciudad?

iii. ¿Cuál es la razón entre hombres y mujeres?

iv. ¿Cuál es el porcentaje de hombres respecto de la población total de la ciudad?

\section{Ejercicio 3:}

En una tienda de electrodomésticos un televisor LCD de 32 pulgadas cuesta 425 euros. Durante las rebajas el dueño decide hacer un descuento del 20\%.

i. ¿Cuál es el precio del televisor durante las rebajas?

ii. ¿Qué porcentaje representa el precio rebajado respecto del precio sin rebajar?

iii. Un DVD ha costado durante las rebajas 125 euros, ¿cuánto costaba antes de las rebajas?

\section{Ejercicio 2:}

Se sabe que en un determinado pueblo sólo el 3\% de la gente es pelirroja. Si en ese pueblo hay exactamente 625 pelirrojos:

i. ¿Cuántas personas viven en ese pueblo?

ii. ¿Cuántas personas rubias viven allí?

iii. ¿Cuál es la razón entre el número de pelirrojos y el total de la población?

\section{Ejercicio 4:}

Debido a la subida del precio de la gasolina, los billetes de autobús también van a subir de precio. En concreto la subida va a ser del $4,5 \%$.

i. Si un billete de autobús cuesta 1,10 euros, ¿cuánto costará después de la subida?

ii. Si un litro de gasolina ha pasado de costar 0,98 euros a costar 1,1 euros, ¿cuál es el porcentaje de subida del precio de la gasolina?

iii. ¿ ¿Es justa la subida del precio en el billete de autobús?

En los ejercicios aparecen cuestiones relacionadas con el significado del porcentaje y con su relación con el concepto de razón. También aparecen problemas directos e inversos, aumentos y disminuciones porcentuales.

La actividad se desarrolla en tres fases: 
1. Presentación y trabajo de los alumnos: El profesor describe la actividad y los alumnos, por parejas, deben completar el mayor número de ejercicios posible.

2. Discusión colectiva sobre los resultados de los alumnos: Se plantean las cuestiones que el profesor considera más interesantes y los alumnos presentan y discuten sus respuestas, se hacen las preguntas necesarias para que aparezcan el mayor número de ideas y argumentos posible.

3. Intervención final del profesor: El profesor refina las ideas de los alumnos para presentar claramente la idea de “tanto por ciento”, su relación con la razón y, como consecuencia, el modo de atacar los problemas presentados.

\section{V.3.10.4 Evaluación}

Para la evaluación de la actividad se utilizarán las hojas de trabajo entregadas por los alumnos así como el diario de clase. Durante la puesta en común el profesor evaluará igualmente las respuestas de los alumnos.

\section{V.3.11 Tarea de casa 5: Porcentajes}

Esta tarea estaba pensada como continuación de la Actividad 6. Como de costumbre, en este caso los alumnos trabajaron individualmente en sus casas después de haber trabajado en clase la citada actividad.

Aunque el tema central de la tarea son los porcentajes (problemas directos e inversos, aumentos y disminuciones porcentuales), también hay preguntas relativas al significado de la razón y de cálculo de cantidades desconocidas; más en concreto:

1. En el Ejercicio 1 se plantea el problema inverso (calcular el total conocida la cantidad correspondiente a un porcentaje), y el problema directo (calcular la cantidad correspondiente a un porcentaje del total). También hay una pregunta referente al significado de la razón entre dos magnitudes y otra "con trampa” relacionada con la idea de complementariedad.

2. En el Ejercicio 2 se plantea un problema de búsqueda de cantidad desconocida en una situación de proporcionalidad directa, y también un problema de disminución porcentual y comparación de dos situaciones. 
3. El Ejercicio 3 plantea una pregunta abierta relacionada con una situación de descuentos porcentuales.

4. En el Ejercicio 5 se vuelve sobre la idea de razón, se pide el cálculo del porcentaje que una magnitud representa respecto de otra y, finalmente, se plantea un nuevo problema de proporcionalidad para aplicar las ideas anteriores.

5. En el Ejercicio 5 se plantea la necesidad de comparar dos aumentos de precio para utilizar el porcentaje de subida como herramienta frente a la subida en términos absolutos. También se vuelve sobre la idea del porcentaje como "tanto por cien”.

$\mathrm{Al}$ igual que en la actividad anterior estudiaremos las respuestas de los alumnos en cada ejercicio separadamente.

\section{V.3.11.1 Objetivos}

1. Reforzar el concepto de porcentaje.

2. Resolver usando el significado de "tanto por ciento" diversas tipologías de problemas.

3. Comprender los significados de las razones y porcentajes que aparecen en una situación determinada y utilizarlos adecuadamente.

\section{V.3.11.2 Contenidos}

1. El porcentaje.

2. La razón entre magnitudes en situaciones cualesquiera.

3. La condición de regularidad.

4. Magnitudes directamente proporcionales.

\section{V.3.11.3 Metodología}

Esta tarea está diseñada para ser llevada a cabo por cada alumno individualmente en su casa. Se pretende que esta tarea refuerce las ideas trabajadas en la Actividad de aula 6.

Se entrega a los alumnos una hoja de trabajo en la que se presentan varios ejercicios similares a los de dicha actividad y que involucran distintos aspectos 
relacionados con los porcentajes. La hoja de trabajo a completar por los alumnos es la siguiente:

\section{Nombre:}

En clase hemos presentado lo que significa el porcentaje y has resuelto problemas en los que aparecía ese concepto. Recuérdalos y trata de resolver los siguientes.

\section{Ejercicio 1:}

En el Parque del Agua hay una gran variedad de árboles. El 7\% de ellos son olmos y el $11 \%$ fresnos. Sabemos que hay 468 olmos.

i. ¿Cuántos árboles hay en total?

ii. ¿ ¿Cuántos de dichos árboles son fresnos?

iii. ¿ ¿Cuál es la razón entre fresnos y olmos?

iv. ¿ ¿Cuántos tilos hay en parque del agua?

\section{Ejercicio 2:}

En un anuncio de un coche nos dicen que el nuevo modelo consume un 15\% menos de gasolina que el modelo antiguo. El modelo antiguo gasta 7 litros de gasolina cada 100 kilómetros.

i. ¿ ¿Cuántos litros de gasolina necesita el modelo antiguo para recorrer 175 kilómetros?

ii. Hacemos una prueba con el nuevo modelo y descubrimos que necesita 9 litros para recorrer 150 kilómetros. ¿Es engañosa la publicidad?

\section{Ejercicio 3:}

En una tienda de ropa ves el siguiente cartel:

¿Qué opinas?

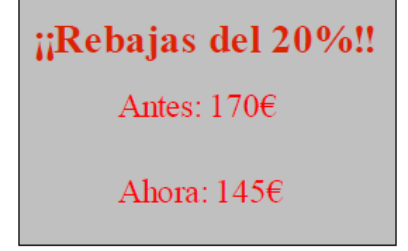

\section{Ejercicio 4:}

Para elaborar refresco de naranja se deben mezclar 400 mililitros de zumo de naranja con un litro de agua.

i. ¿ ¿Cuál es la razón entre el agua y el zumo?

ii. ¿Cuál es el porcentaje de zumo de naranja respecto del total de refresco?

iii. ¿Qué harías para elaborar 2 litros de refresco?

\section{Ejercicio 5:}

Ayer, en el Mercado Central, los tomates costaban 1,05 euros el kilo. Hoy, sin embargo, 
cuestan 1,35 euros el kilo. Ayer las naranjas costaban 0,68 euros el kilo y hoy cuestan 0,90 euros el kilo.

i. ¿Qué ha subido más de precio, el tomate o las naranjas?

ii. ¿ ¿Qué porcentaje supone el precio de los tomates hoy respecto a ayer?

De nuevo se ha tratado de abarcar el mayor número de situaciones problemáticas diferentes: problemas directos e inversos, aumentos y disminuciones porcentuales, significado del porcentaje como "tanto por ciento” y su relación con la razón como “tanto por uno”...

La actividad se desarrolla en tres fases:

1. Trabajo del alumno: El estudiante debe completar la hoja de trabajo.

2. Discusión colectiva sobre los resultados de los alumnos: El profesor recoge la hoja de trabajo completada por los alumnos. A continuación se resuelven en común una selección de las situaciones que el profesor considera más interesantes según la tipología indicada más arriba.

3. Intervención final del profesor: El profesor recoge las ideas y argumentos más significativos de los alumnos, recapitulando todo lo trabajado hasta el momento relacionado con los porcentajes.

\section{V.3.11.4 Evaluación}

Para la evaluación de la actividad se utilizarán las hojas de trabajo entregadas por los alumnos así como el diario de clase. Durante la puesta en común el profesor evaluará igualmente las respuestas de los alumnos.

\section{V.3.12 Tarea de casa 6: Reconocimiento de condiciones de regularidad y razones II}

En esta tarea se presentan a los alumnos distintas situaciones en las que aparecen una o varias magnitudes relacionadas (o no) entre sí. En cada situación se pide a los alumnos que indiquen, caso de existir, magnitudes que varían, magnitudes que permanecen constantes y, cuando sea posible, señalar la razón entre las dos magnitudes que, supuestamente, varían así como las condiciones de regularidad necesarias. 
Salvo en la situación 3 (en la que sólo aparece una magnitud) y en la 5 (en la que aparecen dos), en todas las demás hay al menos tres magnitudes en juego; si bien es cierto que alguna puede estar “oculta” (veremos lo que esto quiere decir).

En las situaciones en las que aparecen tres magnitudes interrelacionadas, para poder hablar de dos magnitudes que varían, siempre debe suponerse que la tercera de ellas es fija. La riqueza de las situaciones planteadas reside en que puede suponerse constante cualquiera de las tres magnitudes e indicar que las otras dos son las que varían. Lo que cambia en cada caso, por supuesto, es la relación existente entre las dos magnitudes que varían. Por ejemplo, en la situación 2, cuyo enunciado es: “Con los bocadillos que se han preparado, cada uno de los 60 alumnos que van de excursión puede comer 5 bocadillos a lo largo del día” se pueden hacer las siguientes consideraciones:

- El número total de bocadillos es constante y entonces el número de alumnos y los bocadillos por alumno varían (de forma inversamente proporcional, aunque los alumnos aún no pueden expresar esto).

- El número total de alumnos es constante y entonces los bocadillos por alumno y el número total de alumnos varían (nuevamente de forma inversamente proporcional).

- Los bocadillos por alumno son fijos y entonces el número de alumnos y el de bocadillos varían de forma directamente proporcional. En este caso los alumnos sí tienen el lenguaje apropiado, la razón es justamente la tercer magnitud en juego y la condición de regularidad es justamente suponer que dicha razón es constante.

En fin, más allá de un análisis relativamente exhaustivo como el que acabamos de realizar; que ningún alumno ha realizado, lo que se pretendía era observar el manejo de las magnitudes y la comprensión de las situaciones en las que estas aparecen por parte de los alumnos.

\section{V.3.12.1 Objetivos}

1. Reconocer las razones que se puedan definir en una determinada situación y comprender su significado. 
2. Observar que magnitudes varían y cuáles no en una situación concreta.

3. Calcular la razón en aquellas situaciones en las que es posible hacerlo.

4. Observar que existen situaciones en las que no se puede definir la razón entre las magnitudes involucradas.

5. Introducir el concepto de magnitudes inversamente proporcionales y de constante de proporcionalidad.

\section{V.3.12.2 Contenidos}

1. La razón entre magnitudes en situaciones cualesquiera.

2. La condición de regularidad.

3. Magnitudes directamente proporcionales en una situación dada.

\section{V.3.12.3 Metodología}

Esta tarea está diseñada para ser llevada a cabo por cada alumno individualmente en su casa. Esta tarea (que puede verse como una continuación de la Tarea de casa 2), por un lado, está pensada a modo de nueva recapitulación de los conceptos más importantes presentados hasta el momento (excepto el porcentaje), y por otro lado, como introducción del concepto de magnitudes inversamente proporcionales.

Se entrega a los alumnos una hoja de trabajo en la que se presentan diversas situaciones. En cada una de ellas se pide que indiquen las magnitudes que varían, las que se mantienen constantes (si existen), así como las condiciones de regularidad necesarias para poder definir razones entre las magnitudes involucradas (si es que se pueden definir) o el motivo por el que no se pueda definir la razón en su caso. En concreto:

\section{Nombres:}

A continuación te presentamos diversas situaciones. En cada una de ellas debes indicar las magnitudes que varían, si alguna magnitud se mantiene constante y las razones que se puedan definir en cada situación (diciendo las condiciones de regularidad que se deben cumplir). Si entre dos magnitudes no se puede definir la razón indica los motivos. 
Situación 1: Para pagar el autobús de una Situación 2: Con los bocadillos que excursión de 350 kilómetros cada uno de los 34 se han preparado, cada uno de los 60 pasajeros tiene que pagar 45 euros. alumnos que van de excursión puede comer 5 bocadillos a lo largo del día.

Situación 3: En una caja caben 120 pelotas de Situación 4: Abriendo el grifo 8 tenis, tanto si son de color amarillo como si son minutos se llena una bañera de 225 de color verde. litros.

Situación 5: Estudio 5 horas diarias para Situación 6: Los 120 kilogramos de preparar los exámenes finales de las 7 café, después de tostarlos, pesan 96 asignaturas que hay en $4^{\circ}$ curso. kilogramos.

Como se observa, entre dichas situaciones aparecerán magnitudes directamente proporcionales, inversamente proporcionales y magnitudes no relacionadas de ninguna de las dos formas anteriores.

Nuevamente la tarea se desarrolla en tres fases:

1. Trabajo del alumno: El estudiante debe completar la hoja de trabajo entregada.

2. Discusión colectiva sobre los resultados de los alumnos: El profesor recoge las hojas de trabajo de los alumnos. A continuación se plantea en la pizarra una selección de las situaciones que el profesor considera más interesante abordar con los alumnos. Para cada una de ellas los estudiantes plantean sus respuestas y discuten las de los demás.

3. Intervención final del profesor: El profesor actúa como moderador en las discusiones anteriores, aclarando los puntos conflictivos y concretando las ideas más interesantes de los alumnos. Para concluir el profesor introduce el concepto de magnitudes inversamente proporcionales tomando como ejemplo alguna de las situaciones anteriores y confrontándolo claramente con alguna situación en la que no exista tal relación.

\section{V.3.12.4 Evaluación}

Para la evaluación de la actividad se utilizará la hoja de trabajo entregada por los alumnos así como el diario de clase. Durante la puesta en común el profesor evaluará igualmente las respuestas de los alumnos. 


\section{V.3.13 Actividad de aula 7: Reconocer magnitudes inversamente proporcionales}

Esta es la primera actividad en la que aparece de manera esencial el concepto de magnitudes inversamente proporcionales. Este concepto había sido introducido por el profesor al final de la Tarea 6 como un nombre para un tipo muy concreto de las situaciones que aparecían.

Además de trabajar la idea de la proporcionalidad inversa, en esta actividad se pretendía observar nuevamente el manejo de las magnitudes por parte de los alumnos. Aunque en cada ejercicio las magnitudes correspondientes se presentan descontextualizadas, hay que tener en cuenta que el alumno puede, y debe, imaginar un contexto en el que plantear el ejercicio; es decir, un contexto en el que las seis magnitudes presentadas aparezcan con sentido.

En cada ejercicio pueden aparecer variables que no son magnitudes, magnitudes no relacionadas, magnitudes relacionadas de forma inversamente proporcional y magnitudes que están relacionadas pero no mediante una proporcionalidad inversa.

\section{V.3.13.1 Objetivos}

1. Reconocer magnitudes inversamente proporcionales.

2. Reconocer magnitudes que no son inversamente proporcionales.

3. Identificar la constante de proporcionalidad en una situación de proporcionalidad inversa.

4. Reforzar la idea de condición de regularidad.

\section{V.3.13.2 Contenidos:}

1. Magnitudes inversamente proporcionales en una situación dada.

2. La constante de proporcionalidad en situaciones de proporcionalidad inversa.

3. La razón entre magnitudes en situaciones cualesquiera.

4. La condición de regularidad. 


\section{V.3.13.3 Metodología}

Esta actividad es similar a la Actividad de aula 4. Los alumnos trabajan por parejas. A cada pareja se le entregan dos fichas de trabajo idénticas (una para ellos y otra que recogerá el profesor al finalizar la actividad).

En la ficha se presentan varios ejercicios. En cada uno de ellos aparecen diversas magnitudes. Los alumnos deben relacionar una pareja de magnitudes que sean inversamente proporcionales, indicando en ese caso las condiciones de regularidad necesarias así como la constante de proporcionalidad y los significados de las razones entre esta constante y las magnitudes que varían. También deben indicar una pareja de magnitudes que no sean inversamente proporcionales, señalando el motivo. La hoja de trabajo es la siguiente:

\section{Nombres:}

Recuerda que dos magnitudes son inversamente proporcionales, bajo ciertas condiciones de regularidad, cuando no se puede definir una razón entre ellas pero existe una tercera magnitud que permanece constante de manera que sí que se puede definir la razón entre dicha magnitud constante y cada una de las otras dos magnitudes.

En cada uno de los ejercicios,

1. Busca una pareja de magnitudes que sean inversamente proporcionales, señalando las condiciones de regularidad que se deben cumplir y la constante de proporcionalidad. ¿Qué significado tiene la razón entre la constante de proporcionalidad y cada una de las otras dos magnitudes?

2. Busca una pareja de magnitudes que no sean inversamente proporcionales, indicando las razones por las que no lo son.

\section{Ejercicio 1:}

Kilogramos de naranjas.

Precio de cada naranja.

Peso de cada naranja.

\section{Ejercicio 2:}

Número de grifos.

Temperatura del agua.

Metros de profundidad de la piscina.
Número de naranjas por kilogramo. Precio del kilogramo de naranjas. Diámetro de una naranja. Capacidad de una piscina. Tiempo de apertura de los grifos. Número de bañistas. 


\section{Ejercicio 3:}

Número de libros.

Número de páginas.

Precio de cada libro.

Edad, en años, del comprador.

El tamaño de la letra del texto. Número de fotografías de cada libro.

La actividad se desarrolla en tres fases:

1. Presentación y trabajo de los alumnos: El profesor describe la actividad y los alumnos, por parejas, deben completar el mayor número de ejercicios posible.

2. Discusión colectiva sobre los resultados de los alumnos: Se plantea al menos uno de los ejercicios y la clase al completo discute las respuestas propuestas por algunos de sus compañeros.

3. Intervención final del profesor: El profesor refina las ideas planteadas por los alumnos y, haciendo uso de las mismas, analiza completamente uno de los ejercicios. Se concluye recordando los conceptos de razón, constante de proporcionalidad, condición de regularidad y magnitudes inversamente proporcionales.

\section{V.3.13.4 Evaluación}

Para la evaluación de la actividad se utilizarán las hojas de trabajo entregadas por los alumnos así como el diario de clase. Durante la puesta en común el profesor evaluará igualmente las respuestas de los alumnos.

\section{V.3.14 Actividad de aula 8: Búsqueda de cantidades desconocidas en situaciones de proporcionalidad inversa}

Esta actividad fue pensada como un primer acercamiento a los problemas de búsqueda de cantidades desconocidas en situaciones de proporcionalidad inversa. Se trabajó en clase por parejas lo que explicará el progresivo aumento de respuestas en blanco conforme avanza la actividad.

Los cinco ejercicios propuestos pueden clasificarse en tres grupos. En primer lugar encontramos los ejercicios 1 y 4. En ellos las magnitudes presentadas son inversamente proporcionales, pero la magnitud que las relaciona (la superficie de la fachada en el primero y el alimento disponible en el segundo), no puede calcularse 
explícitamente. Por otra parte, en los ejercicios 2 y 5 la magnitud que liga las dos magnitudes inversamente proporcionales (pulsaciones necesarias para escribir el informe y metros cúbicos de tierra que deben transportarse, respectivamente), sí pueden calcularse a partir de los datos del problema. Esto supone una diferencia importante que se reflejará en el número de alumnos que resuelven correctamente los ejercicios. Por último, el ejercicio 3 muestra una situación en la que las magnitudes involucradas no están relacionadas y, en caso de estarlo, la relación debiera ser de proporcionalidad directa.

A la hora de valorar las respuestas de los alumnos distinguiremos cada una de las tres tipologías de ejercicios anteriormente descritas.

\section{V.3.14.1 Objetivos}

1. Reforzar el reconocimiento de magnitudes inversamente proporcionales.

2. Reforzar el reconocimiento de magnitudes que no son inversamente proporcionales.

3. Recordar el significado de razón como "tanto por uno" y el de la condición de regularidad.

4. Buscar la constante de proporcionalidad en situaciones de proporcionalidad inversa.

5. Utilizar la constante, la razón como “tanto por uno” y el significado de las operaciones para resolver problemas de búsqueda de cantidades desconocidas.

\section{V.3.14.2 Contenidos}

1. Magnitudes inversamente proporcionales.

2. La constante de proporcionalidad en situaciones de proporcionalidad inversa.

3. La razón entre magnitudes en situaciones cualesquiera.

4. La condición de regularidad. 


\section{V.3.14.3 Metodología}

Los alumnos trabajan por parejas. A cada pareja se le entregan dos fichas de trabajo idénticas (una para ellos y otra que recogerá el profesor al finalizar la actividad).

Esta actividad es similar a la Actividad de aula 5. En la ficha se presentan varios ejercicios de búsqueda de cantidades desconocidas; los alumnos no ya se habían enfrentado previamente a ejercicios de esta naturaleza en situaciones de proporcionalidad directa. La hoja de trabajo es:

\section{Nombres:}

Recordad que dos magnitudes son inversamente proporcionales si no se puede definir una razón entre ellas, pero existe una magnitud constante de forma que sí que se puede definir la razón entre dicha constante y las magnitudes involucradas. Con esta idea, tratad de resolver los siguientes problemas.

\section{Ejercicio 1:}

Tres pintores tardan 7 días en pintar una fachada. Si hubiesen trabajado 5 pintores, ¿Cuántos días habrían tardado en pintar esa fachada?

\section{Ejercicio 2:}

Una mecanógrafa, que hace 380 pulsaciones por minuto tarda 4 horas en escribir un informe. Si hiciese 450 pulsaciones por minuto, ¿¿cuánto tiempo tardará en escribir el informe?

\section{Ejercicio 3:}

De los 350 participantes en una maratón han terminado 260 atletas, ¿cuántos hubiesen finalizado la maratón si se presentan 200 atletas?

\section{Ejercicio 4:}

Un ganadero tiene pienso para alimentar a 300 terneros durante tres meses. Si tuviese 200 terneros, ¿durante cuántos días los podría alimentar?

\section{Ejercicio 5:}

Para trasladar la tierra producida al hacer un desmonte se necesitaron 100 camiones cada uno de los cuales transportó 12 metros cúbicos de tierra. ¿Cuántos viajes de camión se hubiese necesitado si la capacidad de los camiones fuese de 15 metros cúbicos?

Se presentan en los ejercicios magnitudes inversamente proporcionales $y$ magnitudes no relacionadas. 
La actividad se desarrolla en tres fases:

1. Presentación y trabajo de los alumnos: El profesor describe la actividad y los alumnos, por parejas, deben completar el mayor número de ejercicios posible.

2. Discusión colectiva sobre los resultados de los alumnos: Se plantean los ejercicios que el profesor considera más interesantes y los alumnos presentan y discuten sus respuestas, haciendo las preguntas necesarias para que aparezcan el mayor número de ideas y argumentos posible.

3. Intervención final del profesor: El profesor refina las ideas de los alumnos para presentar el modo de atacar los problemas de cantidades desconocidas en situaciones de proporcionalidad inversa.

\section{V.3.14.4 Evaluación}

Para la evaluación de la actividad se utilizarán las hojas de trabajo entregadas por los alumnos así como el diario de clase. Durante la puesta en común el profesor evaluará igualmente las respuestas de los alumnos.

\section{V.3.15 Tarea de casa 7: Búsqueda de cantidades desconocidas en situaciones de proporcionalidad inversa}

Esta tarea fue diseñada como una continuación a la Actividad 8 llevada a cabo en grupos en clase. En este caso los alumnos debían trabajar individualmente en sus casas tomando como base aquello que se introdujo en la discusión de la actividad. El tema central de la tarea son las situaciones de proporcionalidad inversa; en concreto situaciones de búsqueda de una cantidad desconocida.

De los seis ejercicios planteados, en cuatro de ellos (ejercicios 1, 2, 5 y 6) las magnitudes involucradas pueden suponerse inversamente proporcionales. De ellos, en el primero la cantidad de la magnitud “oculta” que sirve para relacionar las dos magnitudes inversamente proporcionales puede calcularse explícitamente (gracias a que una de las magnitudes es una razón, como ya comentamos en la actividad anterior). En los otros tres la cantidad de magnitud “oculta” no puede calcularse.

En los otros dos ejercicios las magnitudes presentadas no pueden suponerse inversamente proporcionales. De hecho, en el Ejercicio 3 ni siquiera hay relación entre 
las magnitudes (duración de un campamento y edad media de los campistas), y en el Ejercicio 4, en el mejor de los casos (bajo condiciones de regularidad adecuadas), las magnitudes que aparecen (gasto mensual en teléfono móvil y número de días que posee el mes), serían directamente proporcionales.

Se ha pretendido, pues, presentar un abanico relativamente amplio de situaciones aunque se le ha concedido especial importancia al concepto central que se pretendía trabajar: las magnitudes inversamente proporcionales.

\section{V.3.15.1 Objetivos}

1. Reforzar el reconocimiento de magnitudes inversamente proporcionales.

2. Reforzar el reconocimiento de magnitudes que no son inversamente proporcionales.

3. Recordar el significado de razón como "tanto por uno” y el de la condición de regularidad.

4. Buscar la constante de proporcionalidad en situaciones de proporcionalidad inversa.

5. Utilizar la constante de proporcionalidad, la razón como “tanto por uno” y el significado de las operaciones para resolver problemas de búsqueda de cantidades desconocidas.

\section{V.3.15.2 Contenidos}

1. Magnitudes inversamente proporcionales.

2. La constante de proporcionalidad en situaciones de proporcionalidad inversa.

3. La razón entre magnitudes en situaciones cualesquiera.

4. La condición de regularidad.

\section{V.3.15.3 Metodología}

Esta tarea está diseñada para ser llevada a cabo por cada alumno individualmente en su casa. Se pretende que esta tarea refuerce las ideas trabajadas en la Actividad de aula 8 y es similar a la Tarea de casa 4. 
Se entrega a los alumnos una hoja de trabajo en la que se presentan varios ejercicios de búsqueda de cantidades desconocidas. En concreto:

\section{Nombre:}

En clase hemos comprobado cómo el uso de la constante de proporcionalidad y de la razón nos permite resolver problemas en los que dos magnitudes son inversamente proporcionales y queremos encontrar la cantidad de una de las magnitudes que se corresponde con una cantidad conocida de la otra. Estos ejercicios van en la misma dirección.

\section{Ejercicio 1:}

Un grifo que vierte 18 litros por minuto emplea 28 horas en llenar un depósito, ¿qué tiempo emplearía si su caudal fuese de 42 litros por minuto?

\section{Ejercicio 2:}

Para atender un pedido de refrescos una fábrica tarda 8 horas utilizando 12 máquinas embotelladoras.

i.Si se estropean 4 máquinas, ¿cuánto tiempo tardará en hacerse el pedido?

ii.Si se quiere hacer el pedido en 3 horas, ¿cuántas máquinas harán falta?

\section{Ejercicio 3:}

En un campamento de 15 días de duración la edad media de los campistas es de 13 años, ¿Cuál es la edad media de los campistas de otro campamento que va a durar 21 días?

\section{Ejercicio 4:}

Pedro paga 36 euros por las llamadas de teléfono realizadas durante un mes de 31 días, ¿Cuánto pagará por las llamadas realizadas durante un mes de 28 días?

\section{Ejercicio 5:}

Veinte obreros realizan una obra; al cabo de quince días han hecho la mitad. ¿Cuantos obreros hay que agregar para terminar la obra en cuatro días?

\section{Ejercicio 6:}

Para limpiar los cristales de un edificio 15 personas tardan 6 horas. ¿Cuántas personas hay que añadir para limpiar los cristales en 5 horas?

En este caso se presentan entre los ejercicios situaciones de proporcionalidad inversa, situaciones en las que las magnitudes no están relacionadas y situaciones en las 
que puede suponerse (aceptando ciertas condiciones de regularidad) que la relación existente es de proporcionalidad directa.

La actividad se desarrolla en tres fases:

1. Trabajo del alumno: El estudiante debe completar la hoja de trabajo.

2. Discusión colectiva sobre los resultados de los alumnos: El profesor recoge las hojas completadas por los alumnos. A continuación se resuelven en común una selección de los ejercicios que el profesor considera más interesantes según la tipología indicada más arriba.

3. Intervención final del profesor: El profesor recoge las ideas más significativas de los alumnos y recapitula los conceptos principales trabajados en esta tarea y en la actividad anterior.

\section{V.3.15.4 Evaluación}

Para la evaluación de la actividad se utilizarán las hojas de trabajo entregadas por los alumnos así como el diario de clase. Durante la puesta en común el profesor evaluará igualmente las respuestas de los alumnos.

\section{V.4 DESARROLlo DE LAS SESIONES}

En el apartado V.2 hemos presentado la planificación de la fase de acción indicando y, entre otros aspectos, se indicaron la temporalización y la secuenciación previstas a la hora de desarrollar las actividades y tareas presentadas en el apartado V.3. Como es natural casi nunca se produce una coincidencia entre lo planificado y lo que finalmente sucede. En este apartado, además de consignar las divergencias que se dieron entre ambos aspectos, recogemos las incidencias más importantes de cada una de las sesiones de trabajo.

\section{V.4.1 Sesión 1}

Esta sesión tuvo lugar el martes día 9 de marzo de 2010, en horarios de 10:20 a 11:10 (el grupo 1) y de 12:20 a 13:10 (el grupo 2).

En el grupo 1 se ausentó el alumno A8; en el grupo 2 no hubo ausencias. 
El ritmo en el trabajo autónomo de los alumnos fue bastante diferente en ambos grupos, siendo mucho mayor en el segundo. De hecho, en el grupo 1 la intervención final del profesor apenas pudo esbozarse y fue necesario retomar la idea de razón brevemente en el inicio de la segunda sesión.

\section{V.4.2 Sesión 2}

Esta sesión tuvo lugar el miércoles día 10 de marzo de 2010, en horarios de 8:15 a 9:05 (el grupo 1) y de 9:10 a 10:00 (el grupo 2).

En esta sesión no hay ausencias en ninguno de los grupos.

Algunos alumnos muestran ya una cierta influencia externa a la hora de realizar la Tarea de casa 1. En concreto A5 había mirado el libro de texto para tratar de completarla y los alumnos A35 y A43 hacen referencia explícita en la puesta en común a la regla de 3. Preguntados por el investigador, A43 señala que había aprendido esa técnica en $6^{\circ}$ de Primaria y A35 que se la explicaron sus padres.

Nuevamente hay diferencias en cuanto al ritmo de trabajo al realizar la Actividad de aula 2. Algunos alumnos mostraban cierto estupor ante una situación abierta en la que no se esperaba nada demasiado concreto de ellos.

\section{V.4.3 Sesión 3}

Esta sesión tuvo lugar el jueves día 11 de marzo de 2010, en horarios de 9:10 a 10:00 (el grupo 1) y de 11:10 a 12:00 (el grupo 2).

En el grupo 1 no hubo ausencias. En el grupo 2 se ausentó el alumno A35.

Aunque no estaba previsto se comienza la clase en ambos grupos con una recapitulación del concepto de razón, de las dos razones posibles en una situación y de la idea de condición de regularidad. Los alumnos muestran una clara tendencia a quedarse sólo con el valor numérico de la razón dejando algo de lado su significado.

En cuanto a la actividad planificada para los alumnos, el desarrollo no fue demasiado satisfactorio debido a la interpretación que los alumnos hicieron de la idea “ser más ventajoso”. Este hecho quedará de manifiesto en el análisis de la actividad que se hará en el capítulo siguiente. No obstante se entabló una discusión con los alumnos 
sobre el significado de “ventajoso” que obligó a cambiar el contexto (en concreto se les indicó que pensaran que en vez de cartulinas se trataba de billetes de 500 euros).

\section{V.4.4 Sesión 4}

Esta sesión tuvo lugar el viernes día 12 de marzo de 2010, en horarios de 13:20 a 14:10 (el grupo 1) y de 10:20 a 11:10 (el grupo 2).

En esta sesión no hay ausencias en ninguno de los grupos.

En la puesta en común de la Tarea de casa 2 se comentan las situaciones 2, 4, 8 y 9. Los alumnos no parecen tener problemas a la hora de indicar que dos magnitudes no están relacionadas y en general definen bien las razones y las condiciones de regularidad; aunque hay que "forzarles” un poco. Algunos alumnos no traen la Tarea y la entregan al día siguiente.

A la hora de trabajar la Actividad de aula 4 surge una cierta confusión sobre lo que deben realizar. En el grupo 1, además, se suma el hecho de que la última hora de la semana. Aparecen grandes dificultades a la hora de manejar la pareja velocidad-tiempo. Se concluye comentando en común el ejercicio 1 de la Actividad.

Una de las profesoras me dice que algunos alumnos le han pedido ayuda para completar la Tarea de casa. También me comenta la preocupación de algunos alumnos sobre si habrá examen. Están preocupados por su nota media.

\section{V.4.5 Sesión 5}

Esta sesión tuvo lugar el martes día 16 de marzo de 2010, en horarios de 10:20 a 11:10 (el grupo 1) y de 12:20 a 13:10 (el grupo 2).

En el grupo 1 se ausenta A14 y no hubo ausencias en el grupo 2.

Se ponen en común los ejercicios 2 y 4 de la Tarea de casa 3.

A la hora de resolver la Actividad de aula 5 algunos alumnos utilizan la Regla de tres espontáneamente (uno indica que le habló de la Regla de tres "una amiga de su madre, que sabe de ciencias”). Se comentan en grupo los ejercicios 1 y 5 y un alumno menciona que "esto es como lo de las pajitas y las tarjetas".

El alumno A11 pregunta si el trabajo de clase cuenta para nota. 


\section{V.4.6 Sesión 6}

Esta sesión tuvo lugar el miércoles día 17 de marzo de 2010, en horarios de 8:15 a 9:05 (el grupo 1) y de 9:10 a 10:00 (el grupo 2).

Nuevamente se ausenta A14 en el grupo 1 y también falta a clase A50 en el grupo 2.

Se resuelven en grupo los ejercicios 2, 3 y 5 de la Tarea de casa 4. Hay, en general, poca participación; sobre todo en el grupo 1 (la clase es a primera hora). Se termina introduciendo el concepto de porcentaje.

Los alumnos trabajan en parejas la Actividad de aula 6 hasta el final de la clase. Decido no hacer puesta en común y dedicar la siguiente sesión íntegramente al trabajo con porcentajes.

\section{V.4.7 Sesión 7}

Esta sesión tuvo lugar el jueves día 18 de marzo de 2010, en horarios de 9:10 a 10:00 (el grupo 1) y de 11:10 a 12:00 (el grupo 2).

Nuevamente se ausenta el alumno A14 en el grupo 1. No hay ausencias en el grupo 2.

Dedicamos los 50 minutos de clase a la Tarea de casa 5. Hay una escasa participación, no parece haber calado bien el concepto de porcentaje; sin embargo casi todos los alumnos conocen el algoritmo para el cálculo de porcentajes y tratan de aplicarlo. Es más, al preguntarles sobre qué es el porcentaje, muchos responden indicando el modo de calcularlo.

Los alumnos me dicen que al día siguiente se van todos de excursión, por lo que no habrá clase. Como resulta imposible alargar el calendario de sesiones, pues llegan las vacaciones de Semana Santa, el equipo investigador decide omitir la Actividad de aula 7. La Tarea de casa 6 la recogeré a la siguiente semana. 


\section{V.4.8 Sesión 8}

Esta sesión debería haber lugar el viernes día 19 de marzo de 2010, en horarios de 13:20 a 14:10 (el grupo 1) y de 10:20 a 11:10 (el grupo 2). Debido a una excursión inesperada no hubo clase con ninguno de los dos grupos.

\section{V.4.9 Sesión 9}

Esta sesión tuvo lugar el martes día 23 de marzo de 2010, en horarios de 10:20 a 11:10 (el grupo 1) y de 12:20 a 13:10 (el grupo 2).

En el grupo 1 se ausentan A6 y A8. En el grupo 2 no hay ausencias.

Ponemos en común las situaciones 1 y 2 de la Tarea de casa 6. La situación 2 resulta, como era de esperar, mucho más fácil de manejar por los alumnos. Tras la puesta en común se utilizan esas situaciones para presentar el concepto de proporcionalidad inversa.

En lugar de la Actividad de aula 7 se propone a los alumnos la Actividad de aula 8 que supone buscar cantidades desconocidas en situaciones de proporcionalidad inversa. La puesta en común sale bastante bien, aunque hablan los mismos alumnos de siempre. Como la proporcionalidad inversa no se ha podido trabajar demasiado el equipo investigador decide que se dedique la última sesión a resolver completamente en grupo la Tarea de casa 7.

Al final de la clase me preguntan dudas en privado A26 y A14; este último porque ha faltado varios días. Además el alumno A17 se me acerca y me hace una interesante observación: Me indica que se ha dado cuenta de que cuando hay proporcionalidad directa las dos magnitudes aumentan a la vez y que si hay proporcionalidad inversa, cuando una aumenta la otra disminuye. Para evitar la confusión le indico que la observación es muy interesante y que es cierta, pero que tiene que ser cuidadoso porque esas condiciones no le garantizan la proporcionalidad directa o inversa de las magnitudes.

\section{V.4.10 Sesión 10}

Esta sesión tuvo lugar el miércoles día 24 de marzo de 2010, en horarios de 8:15 a 9:05 (el grupo 1) y de 9:10 a 10:00 (el grupo 2). 
En el grupo 2 no hay ausencias y en el grupo 1 vuelve a faltar A6.

Se dedica todo el tiempo a completar en común la Tarea de casa 7. No hay mucha participación, pero las respuestas son interesantes. Tratamos de hacer énfasis en la caracterización de la proporcionalidad inversa, en las posibles formas de afrontar los problemas de búsqueda de cantidades desconocidas y en las diferencias entre ambas relaciones de proporcionalidad.

\section{V.4.11 Sesión 11}

Esta sesión tuvo lugar el jueves día 25 de marzo de 2010, en horarios de 9:10 a 10:00 (el grupo 1) y de 11:10 a 12:00 (el grupo 2).

Esta sesión se dedicó a la realización de una prueba final de evaluación. La única ausencia fue la del alumno A39 del grupo 2. Para este alumno se preparó una prueba alternativa que realizó al regreso de las vacaciones de Semana Santa.

Excepto 4 alumnos: A21, A33, A42 y A44 todos los demás completan el examen en menos de los 50 minutos disponibles. 


\section{CAPíTULO VI:}

\section{OBSERVACIÓN Y REFLEXIÓN.}

\section{VI.1. INTRODUCCIÓN}

En el Capítulo IV se ha presentado una propuesta didáctica original diseñada para tratar de mejorar la enseñanza de la proporcionalidad aritmética en secundaria. En el Capítulo VI se ha descrito la implementación en el aula de $1^{\circ}$ de E.S.O. de una adaptación de parte de dicha propuesta. En este capítulo vamos a analizar los datos obtenidos en la fase experimental y reflexionar sobre las observaciones realizadas.

En el Capítulo I se describieron los focos de investigación, o núcleos de contenido, en torno a los que se organizaba la propuesta didáctica llevada al aula en la fase experimental así como los aspectos clave que se pretendían analizar en cada uno de ellos:

1. Razón y condición de regularidad.

i. El concepto de razón.

ii. La condición de regularidad.

iii. Comparación de razones.

iv. Análisis de situaciones

2. Proporcionalidad directa y porcentajes.

i. Reconocimiento y distinción de magnitudes directamente proporcionales.

ii. Búsqueda de cantidades desconocidas.

iii. Porcentajes. 
3. Proporcionalidad inversa.

i. Análisis de situaciones.

ii. Reconocimiento y distinción de magnitudes inversamente proporcionales.

iii. Búsqueda de cantidades desconocidas.

\section{VI.1.1 Unidades de análisis}

En el apartado anterior hemos descrito los tres focos de investigación en torno a los que se articula la propuesta didáctica que se ha implementado. En este apartado presentaremos las unidades de análisis que nos permitirán analizar las respuestas dadas por los alumnos en cada una de las actividades de aula y tareas de casa propuestas.

\section{VI.1.1.1 Unidades para el primer foco de investigación.}

En este foco de investigación se introduce un modelo estable basado en los intercambios para introducir el concepto de razón. A partir del trabajo sobre este modelo se introducen las condiciones necesarias para la existencia de la razón así como el uso de la razón a la hora de comparar situaciones. Finalmente se pretende que el alumno aplique estas ideas a situaciones más o menos arbitrarias. Estos cuatro aspectos que acabamos de citar son los puntos centrales que pretendemos analizar.

\section{Punto 1. El concepto de razón.}

El punto de partida de la propuesta se encuentra en el trabajo en una situación de intercambio en la que, a partir de una información gráfica los alumnos deben decidir la cantidad de una de las magnitudes en juego que se obtiene a cambio de distintas cantidades de la otra. Este trabajo se desarrolla en la Actividad de aula 1 y en la Tarea de casa 1. En ellas las unidades de análisis son las mismas:

\begin{tabular}{|c|}
\hline Valor numérico incorrecto \\
\hline Valor numérico correcto pero razonamiento incorrecto o ausente \\
\hline Valor numérico y razonamiento correctos. \\
\hline
\end{tabular}


Con ellas queremos observar si el alumno comprende la dinámica que rige las situaciones de trueque, pero también si hace o no explícitos sus razonamientos y si estos son correctos. Sobre esto último, estamos interesados en caracterizar las diferentes técnicas que los alumnos utilizan a la hora de dar sus respuestas. En concreto, se encuentran las siguientes categorías:

\begin{tabular}{|c|}
\hline Estrategia multiplicativa \\
\hline Estrategia aditiva \\
\hline Uso de la razón directa \\
\hline Uso de la razón inversa \\
\hline
\end{tabular}

En la Tarea de casa 1, además, se analizará si los alumnos han asimilado el significado de la razón como "tanto por uno" y su carácter no meramente numérico. Para ello, en la pregunta correspondiente se utilizan las siguientes categorías:

\begin{tabular}{|c|}
\hline Respuesta sin sentido o incompleta \\
\hline Da el valor pero no entiende el significado \\
\hline Indica el valor y el significado correctos, pero de la razón inversa de la que se pide \\
\hline Indica el valor y el significado correctos de la razón pedida \\
\hline
\end{tabular}

\section{Punto 2. La condición de regularidad.}

Una vez que se ha introducido el significado del concepto de razón se plantea la cuestión de cuándo es posible hablar de razón en una situación concreta y de cuáles son las condiciones que deben cumplirse para ello. Este aspecto se introduce fundamentalmente en la Actividad de aula 2 donde el contexto de trabajo sigue siendo el mismo que en la Actividad de aula 1, pero el mensaje proporcionado a los alumnos es premeditadamente incompleto. En concreto, en el mensaje no se hace mención a la existencia de diversos tamaños en los objetos que deben intercambiar. Las unidades de análisis que se utilizan en esta actividad son:

\begin{tabular}{|c|}
\hline Respuesta incorrecta \\
\hline Razonamiento correcto, sin distinguir los tamaños \\
\hline Razonamiento correcto, relacionando tarjetas grandes con pajitas \\
grandes y pequeñas con pequeñas. \\
\hline
\end{tabular}


En particular queremos ver si, aunque sea tácitamente, los alumnos asumen el hecho de que todos los objetos involucrados en el intercambio han de ser iguales entre sí.

\section{Punto 3. Comparar razones.}

El primer uso que se da al concepto de razón entre dos magnitudes es el de comparar situaciones de intercambio diferentes en las que se intercambian los mismos objetos, para así decidir cual resulta más ventajosa. Esto se hace en la Actividad de aula 3; las respuestas obtenidas se clasifican según las siguientes unidades de análisis:

\begin{tabular}{|c|}
\hline Respuesta incorrecta \\
\hline Razonamiento correcto, errores operativos \\
\hline Respuesta completamente correcta \\
\hline
\end{tabular}

Aquí se entiende por razonamiento correcto aquel que implique en cierto modo el uso de la idea de razón.

En la Tarea de casa 3 también se trabaja la idea de comparación de situaciones mediante el uso de razones, pero ya no se presentan situaciones puramente de intercambio, sino más generales. Respecto a las diversas situaciones que se plantean, podemos presentar el siguiente esquema:

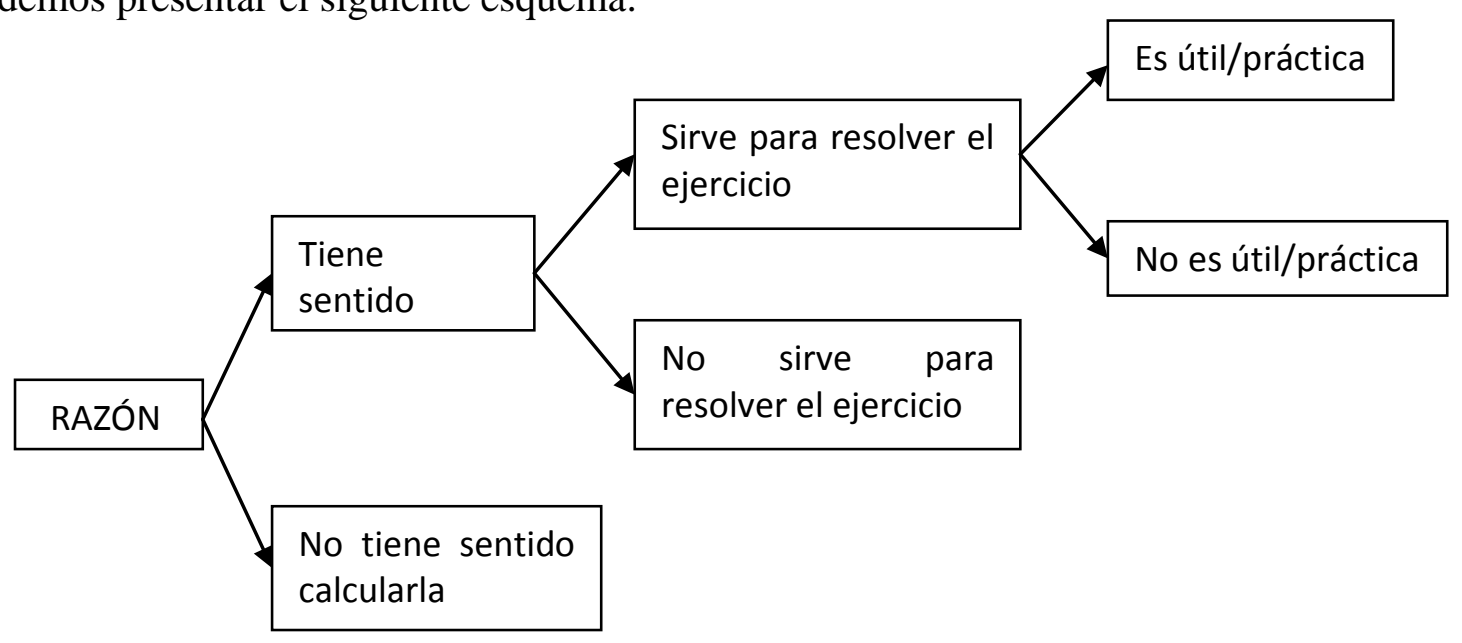

Evidentemente, en función de la situación en la que nos encontremos, las unidades de análisis para las respuestas de los alumnos serán diferentes. En particular se han elegido las siguientes: 


\begin{tabular}{|c|c|}
\hline \multirow{5}{*}{$\begin{array}{c}\text { La razón es útil para comparar las } \\
\text { situaciones }\end{array}$} & Respuesta incorrecta sin usar razones \\
\hline & Respuesta incorrecta usando razones \\
\hline & $\begin{array}{l}\text { Respuesta correcta sin razonamiento o con } \\
\text { razonamiento incorrecto }\end{array}$ \\
\hline & Respuesta parcialmente correcta \\
\hline & Respuesta totalmente correcta \\
\hline \multirow{4}{*}{$\begin{array}{l}\text { La razón no tiene sentido o no sirve para } \\
\text { comparar las situaciones }\end{array}$} & Responde incorrectamente usando razones \\
\hline & Responde incorrectamente sin usar razones \\
\hline & $\begin{array}{c}\text { Indica la imposibilidad de responder, pero } \\
\text { no lo argumenta }\end{array}$ \\
\hline & $\begin{array}{l}\text { Argumenta correctamente que no puede } \\
\text { responderse a la pregunta }\end{array}$ \\
\hline \multirow{4}{*}{$\begin{array}{l}\text { La razón sirve para comparar, pero no es } \\
\text { útil o práctica. }\end{array}$} & Respuesta arbitraria sin razonar \\
\hline & Respuesta incorrecta sin calcular razones \\
\hline & Trata de calcular una razón sin sentido \\
\hline & Respuesta correcta \\
\hline
\end{tabular}

\section{Punto 4. Análisis de diferentes situaciones}

Una vez que se han introducido el concepto de razón y la idea de condición de regularidad y que el alumno ya está familiarizado con situaciones que no son necesariamente de intercambio es interesante plantear situaciones generales para que el alumno las analice. Esto se hace en la Tarea de casa 2 y, teniendo en cuenta el punto de la propuesta en que se inserta dicha tarea, son dos los tipos de situaciones que se presentan:

- Situaciones en las que las magnitudes no están relacionadas (y por tanto no se puede definir la razón).

- Situaciones en las que puede definirse la razón, asumiendo las condiciones de regularidad necesarias.

Para cada una de estas posibilidades se plantean diferentes unidades de análisis:

\begin{tabular}{|l|c|}
\hline \multirow{2}{*}{ Tiene sentido definir la razón } & Respuesta incorrecta \\
\cline { 2 - 2 } & Señala condiciones de regularidad \\
\cline { 2 - 2 } & Señala que existen dos razones distintas \\
\hline
\end{tabular}




\begin{tabular}{|c|c|}
\hline \multirow{2}{*}{$\begin{array}{c}\text { Las magnitudes no están } \\
\text { relacionadas }\end{array}$} & Indica el significado de alguna razón \\
\cline { 2 - 2 } & Calcula numéricamente alguna razón \\
\cline { 2 - 2 } & Calcula (incorrectamente) la razón \\
\hline & da motica que no se puede definir la razón, pero no \\
\cline { 2 - 2 } & Razona que no se puede definir la razón \\
\hline
\end{tabular}

\section{VI.1.1.2 Unidades para el segundo foco de investigación.}

El foco anterior concluye con el análisis de diversas situaciones en la que se presentan parejas de magnitudes. Entre dichas situaciones se encuentra el caso en que es posible (bajo condiciones de regularidad adecuadas) definir la razón entre las magnitudes implicadas. En ese tipo de situaciones las magnitudes implicadas reciben la denominación de directamente proporcionales.

En este foco de investigación se pretende que los alumnos identifiquen magnitudes directamente proporcionales y distingan aquellas que no lo son. También se persigue que apliquen el concepto de razón y los significados de las operaciones entre magnitudes a la hora de resolver problemas de búsqueda de cantidades desconocidas y, en particular, en problemas de porcentajes. Estos son los tres puntos que analizaremos en este foco de investigación.

\section{Punto 1. Reconocimiento y distinción de magnitudes directamente proporcionales.}

Este primer punto se trabaja especialmente en la Actividad de aula 4. En dicha actividad se presentan distintas situaciones y, para cada una de ellas, diversas variables implicadas (que pueden ser o no magnitudes). Se pretende que los alumnos den un par de magnitudes directamente proporcionales y un par de variables que no lo sean (y los motivos). Las unidades de análisis para esta actividad son las siguientes:

\begin{tabular}{|c|}
\hline Identifica correctamente magnitudes directamente proporcionales \\
\hline Identifica incorrectamente magnitudes directamente proporcionales \\
\hline Da las razones entre magnitudes directamente proporcionales \\
\hline Señala condiciones de regularidad \\
\hline Indica correctamente magnitudes no relacionadas \\
\hline
\end{tabular}




\section{Punto 2. Búsqueda de cantidades desconocidas.}

Posiblemente uno de los aspectos más importantes a la hora de manejar el concepto de magnitudes directamente proporcionales sea el de aplicar las ideas presentadas hasta el momento en los típicos problemas en los que se conocen dos cantidades correspondientes de las magnitudes implicadas y se desea encontrar la cantidad desconocida de una de ellas correspondiente a una cantidad conocida de la otra. Entre las situaciones planteadas a los alumnos encontramos tres tipos esencialmente diferentes que, para su análisis, requerirán de unidades diferentes:

- Situaciones en las que las magnitudes implicadas son (o pueden suponerse) directamente proporcionales.

- Situaciones en las que las magnitudes implicadas no guardan relación alguna.

- Situaciones en las que las magnitudes implicadas están relacionadas, pero no son directamente proporcionales.

Las respectivas unidades de análisis son las siguientes:

\begin{tabular}{|c|c|}
\hline \multirow{4}{*}{$\begin{array}{l}\text { Magnitudes directamente } \\
\text { proporcionales }\end{array}$} & Respuesta incorrecta \\
\hline & Indica que no se puede hallar la razón \\
\hline & $\begin{array}{l}\text { Resuelve usando razones sin señalar } \\
\text { condición de regularidad }\end{array}$ \\
\hline & $\begin{array}{l}\text { Resuelve usando razones señalando } \\
\text { condición de regularidad }\end{array}$ \\
\hline \multirow{4}{*}{ Magnitudes no relacionadas } & $\begin{array}{c}\text { Responde incorrectamente usando } \\
\text { razones }\end{array}$ \\
\hline & $\begin{array}{c}\text { Responde incorrectamente sin usar } \\
\text { razones }\end{array}$ \\
\hline & $\begin{array}{c}\text { Indica la imposibilidad de responder, } \\
\text { pero no lo argumenta }\end{array}$ \\
\hline & $\begin{array}{l}\text { Argumenta correctamente que no puede } \\
\text { responderse a la pregunta }\end{array}$ \\
\hline \multirow{2}{*}{$\begin{array}{c}\text { Magnitudes relacionadas pero no } \\
\text { directamente proporcionales }\end{array}$} & Respuesta incorrecta sin indicaciones \\
\hline & Razona como si fueran directamente \\
\hline
\end{tabular}




\begin{tabular}{|l|c|}
\hline \multirow{4}{*}{} & proporcionales \\
\cline { 2 - 3 } & $\begin{array}{c}\text { Señala que no hay proporcionalidad } \\
\text { directa o que no se puede hacer }\end{array}$ \\
\cline { 2 - 3 } & $\begin{array}{c}\text { Respuesta correcta sin razonar o con } \\
\text { razonamiento incorrecto }\end{array}$ \\
\cline { 2 - 3 } & Respuesta y razonamiento correctos \\
\hline
\end{tabular}

\section{Punto 3. Porcentajes.}

El concepto de porcentaje se concibe en la propuesta que llevamos a la práctica como una cierta “modificación” del de razón como "tanto por uno”. De este modo los conceptos y los procedimientos que se pretende que aplique el alumno son en gran medida similares a los anteriores. No obstante, el cálculo de un porcentaje conlleva un importante aspecto algorítmico y, en ocasiones, resulta complicado para los estudiantes separar el concepto de la técnica de cálculo.

Los problemas de porcentajes presentan una gran riqueza de situaciones: problemas directos e inversos, aumentos y disminuciones porcentuales, relación entre razón y porcentajes, etc. Esta riqueza hace que las unidades de análisis sean muy variadas y que varíen bastante entre unos ejercicios y otros. Algunas de las principales unidades de análisis que utilizaremos a la hora de estudiar las respuestas de los alumnos son las siguientes:

\begin{tabular}{|c|}
\hline Resuelve correctamente el problema directo o inverso \\
\hline Calcula correctamente el porcentaje pedido \\
\hline Aplica correctamente el aumento o descuento \\
\hline Halla correctamente el precio inicial a partir del rebajado o aumentado \\
\hline Compara adecuadamente dos subidas o bajadas \\
\hline Indica el significado de la razón \\
\hline Indica correctamente la imposibilidad de dar una respuesta \\
\hline
\end{tabular}

\section{VI.1.1.3 Unidades para el tercer foco de investigación.}

Hasta el momento los alumnos tan sólo han distinguido entre magnitudes directamente proporcionales y aquellas que no lo son. En este tercer núcleo se introduce un segundo tipo de relación entre magnitudes: la proporcionalidad inversa. Las 
magnitudes inversamente proporcionales se caracterizan nuevamente haciendo uso del concepto de razón, aunque en este caso entra en juego una idea nueva: la constante de proporcionalidad.

Además del análisis de situaciones de un modo más profundo (considerando magnitudes que varían o que permanecen constantes) y del reconocimiento y la distinción de las magnitudes inversamente proporcionales, en este foco de investigación pretendemos que los alumnos hagan uso de las ideas de razón y constante de proporcionalidad y de los significados de las operaciones entre magnitudes a la hora de resolver problemas de búsqueda de cantidades desconocidas. Estos tres puntos estructurarán el análisis de las respuestas de los alumnos.

\section{Punto 1. Análisis de diferentes situaciones.}

El alumno ya ha realizado con anterioridad actividades en las que se le solicitaba analizar una situación concreta en la que aparecían dos magnitudes. Ahora, se le solicita analizar situaciones con algo más de detalle, puesto que en ciertas situaciones existen magnitudes “ocultas” que, sin embargo, juegan un importante papel. En la Tarea de casa 6 se presentan a los alumnos los siguientes tipos de situaciones:

- Situaciones en las que aparecen dos magnitudes explícitamente y existe una tercera, implícita, que relaciona a las dos anteriores, y cuya razón con cada una de ellas puede determinarse.

- Situaciones en las que las magnitudes no guardan relación o bien una de las variables no es una magnitud.

Las unidades de análisis en cada caso son las siguientes:

\begin{tabular}{|c|c|}
\hline \multirow{2}{*}{$\begin{array}{c}\text { Existe una magnitud “oculta” que } \\
\text { relaciona las dos magnitudes del } \\
\text { enunciado }\end{array}$} & Señala la magnitud “oculta” \\
\cline { 2 - 2 } $\begin{array}{c}\text { Nelaciona correctamente algún par de } \\
\text { magnitudes }\end{array}$ \\
\cline { 2 - 2 } $\begin{array}{c}\text { No hay relación o una de las variables no } \\
\text { es una magnitud. }\end{array}$ & Indica correctamente alguna razón \\
\cline { 2 - 2 } & Indica que sólo hay una magnitud \\
\cline { 2 - 2 } & Otro tipo de respuesta aceptable \\
\hline
\end{tabular}

Punto 2. Reconocimiento y distinción de magnitudes inversamente proporcionales. 
Este punto se trabaja especialmente en la Actividad de aula 7. En dicha actividad se presentan distintas situaciones y, para cada una de ellas, diversas variables implicadas (que pueden ser o no magnitudes. Se pretende que los alumnos den un par de magnitudes inversamente proporcionales y un par de variables que no lo sean (y los motivos). Las unidades de análisis para esta actividad son las siguientes:

\begin{tabular}{|c|}
\hline Identifica correctamente magnitudes inversamente proporcionales \\
\hline Identifica incorrectamente magnitudes inversamente proporcionales \\
\hline Señala la constante de proporcionalidad \\
\hline Señala condiciones de regularidad \\
\hline Indica correctamente magnitudes no relacionadas \\
\hline
\end{tabular}

\section{Punto 3. Búsqueda de cantidades desconocidas.}

Como en el caso de la proporcionalidad directa, es de gran importancia a la hora de manejar el concepto de magnitudes inversamente proporcionales aplicar las ideas presentadas hasta el momento en los típicos problemas en los que se conocen dos cantidades correspondientes de las magnitudes implicadas, y se desea encontrar la cantidad desconocido de una de ellas correspondiente a una cantidad conocida de la otra. Entre las situaciones planteadas a los alumnos encontramos cuatro tipos esencialmente diferentes que, para su análisis, requerirán de categorías diferentes:

- Situaciones en las que las magnitudes implicadas son inversamente proporcionales y el valor de la constante de proporcionalidad puede calcularse explícitamente.

- Situaciones en las que las magnitudes implicadas son inversamente proporcionales pero el valor de la constante de proporcionalidad no puede calcularse explícitamente.

- Situaciones en las que las magnitudes implicadas no guardan relación alguna.

- Situaciones en las que las magnitudes implicadas pueden suponerse (bajo condiciones apropiadas) directamente proporcionales.

Las respectivas unidades de análisis son las siguientes: 


\begin{tabular}{|c|c|}
\hline \multirow{4}{*}{$\begin{array}{l}\text { Magnitudes inversamente } \\
\text { proporcionales }\end{array}$} & Respuesta incorrecta sin razonar \\
\hline & Calcula una razón carente de sentido \\
\hline & $\begin{array}{l}\text { Respuesta correcta sin razonar o con mal } \\
\text { razonamiento }\end{array}$ \\
\hline & Respuesta correcta con razonamiento correcto \\
\hline \multirow{3}{*}{ Magnitudes no relacionadas } & Da alguna respuesta numérica \\
\hline & $\begin{array}{l}\text { Indica que no se puede sin razonar o por alguna } \\
\text { razón incorrecta }\end{array}$ \\
\hline & Indica que no se puede por algún motivo aceptable \\
\hline \multirow{4}{*}{$\begin{array}{l}\text { Magnitudes directamente } \\
\text { proporcionales }\end{array}$} & Respuesta numérica incorrecta \\
\hline & Dice que no hay relación \\
\hline & $\begin{array}{c}\text { Asume proporcionalidad directa, sin indicar } \\
\text { regularidad }\end{array}$ \\
\hline & $\begin{array}{c}\text { Indica regularidad y resuelve como si hubiera } \\
\text { proporcionalidad directa }\end{array}$ \\
\hline
\end{tabular}

En lo que sigue analizaremos las respuestas dadas por los alumnos a las actividades de aula y tareas de casa propuestas para cada uno de los focos anteriores.

\section{VI.1.2. Errores de los alumnos en la prueba final.}

Como ya se indicó en el Capítulo I, el estudio de las respuestas dadas por los alumnos en la prueba final se centrará específicamente en el análisis de los errores cometidos por los mismos.

A continuación vamos a detallar los errores que se han considerado de un mayor interés. Los errores que comenten los alumnos están relacionados en gran medida con el tipo de enseñanza que han recibido. En consecuencia, este listado no pretende constituir una clasificación exhaustiva de los posibles errores que puede cometer un alumno a la hora de resolver tareas relacionadas con la proporcionalidad en general, sino más bien un listado de los errores “interesantes” que surgen en el contexto de nuestra propuesta concreta.

A la hora de estudiar los errores cometidos por los alumnos vamos a considerar 2 variables: 


\section{- Variable C:}

Esta variable recoge todos aquellos errores de carácter conceptual. En concreto esta variable puede tomar los siguientes valores:

1. Valor C0: El alumno no llega a comprender la situación o a relacionar correctamente las magnitudes implicadas en la situación presentada.

2. Valor CR1: El alumno omite la condición de regularidad necesaria para definir el concepto de razón.

3. Valor CR2: El alumno señala el significado inverso del que corresponde a la razón que está considerando.

4. Valor CR3: El alumno sólo señala la existencia de una razón en la situación considerada, frente a las dos - al menos - que siempre existen.

5. Valor CR4: El alumno identifica la razón únicamente con la idea de "tanto por uno" incluso en una situación de proporcionalidad inversa.

6. Valor CP1: El alumno confunde magnitudes D.P. con magnitudes I.P. o viceversa.

7. Valor CP2: El alumno identifica como proporcionales (ya sea directa o inversamente) magnitudes que no lo son.

8. Valor CP3: El alumno señala que no hay relación entre magnitudes que sí guardan una relación de proporcionalidad (ya sea directa o inversa).

9. Valor CP4: El alumno identifica el concepto de proporcionalidad directa con la existencia de relación entre las magnitudes implicadas y el de proporcionalidad inversa con la no existencia de relación entre ellas.

Obsérvese que se han distinguido dos tipos de valores de la variable C. Aquellos codificados como CRx se refieren a errores relativos al concepto de razón, mientras que los codificados como CPx hacen referencia a errores relativos a la proporcionalidad de magnitudes. 
- Variable P: Bajo esta variable se agruparán todos aquellos errores de carácter conceptual. Esta variable puede tomar los siguientes valores:

1. Valor P0: El alumno utiliza un procedimiento de resolución inadecuado en la situación planteada.

2. Valor P1: El alumno aplica técnicas “externas”, es decir, métodos de resolución correctos desde el punto de vista de la enseñanza "tradicional” pero que no han sido tratados durante la propuesta

3. Valor P2: El alumno comete errores aritméticos en el transcurso de la resolución del problema.

Adicionalmente, codificaremos como $\mathbf{A}$ aquellos alumnos que dejen el ejercicio sin responder.

\section{VI.2. OBSERVACIÓN Y REFLEXIÓN DEL PRIMER FOCO DE INVESTIGACIÓN}

En este foco de investigación se introduce un modelo estable basado en los intercambios para introducir el concepto de razón. A partir del trabajo sobre este modelo se introducen las condiciones necesarias para la existencia de la razón así como el uso de la razón a la hora de comparar situaciones. Finalmente, se pretende que el alumno aplique estas ideas a situaciones más o menos arbitrarias. Estos cuatro aspectos que acabamos de citar son los puntos centrales que pretendemos analizar.

\section{VI.2.1 Punto 1: El concepto de razón}

El punto de partida de la propuesta se encuentra en el trabajo en una situación de intercambio en la que, a partir de una información gráfica, los alumnos deben decidir la cantidad de una de las magnitudes en juego que se obtiene a cambio de distintas cantidades de la otra. Este trabajo se desarrolla en la Actividad de aula 1 y en la Tarea de casa 1.

\section{VI.2.1.1 Análisis y valoración de la Actividad de aula 1}

\section{Descripción de la actividad}

En un lugar visible de la clase se muestra un cartel como el siguiente, en el que se indica visualmente que 4 tarjetas se convierten en 6 pajitas: 


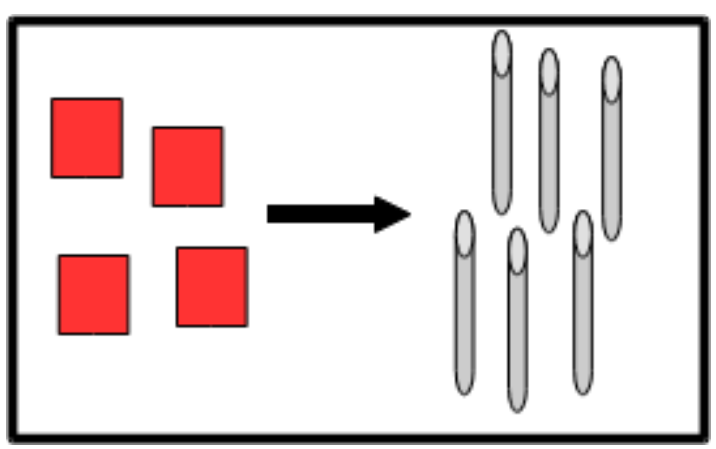

Se forman parejas de alumnos. A cada pareja se le van entregando sobres que contienen una determinada cantidad de tarjetas y una cantidad suficiente de pajitas (20) para que puedan manipular. En concreto, los sobres contienen las siguientes cantidades de tarjetas:

\begin{tabular}{|l|l|}
\hline Sobre 1: 2 tarjetas. & Sobre 4: 10 tarjetas. \\
\hline Sobre 2: 8 tarjetas. & Sobre 5: 1 tarjeta. \\
\hline Sobre 3: 6 tarjetas. & Sobre 6: 3 tarjetas. \\
\hline
\end{tabular}

El trabajo de la pareja es decidir cuántas pajitas se obtienen a cambio de las tarjetas contenidas en el sobre. La decisión tomada por la pareja debe ser reflejada en una ficha en la que debían incluir tanto el número de pajitas correspondiente como un razonamiento o explicación del método obtenido seguido para la resolución.

\begin{tabular}{l} 
Nombres: \\
Tarjetas que hay en el sobre: $\_$ \\
Pajitas entregadas a cambio de las tarjetas: \\
Razonamiento: \\
\hline \\
\hline
\end{tabular}




\section{Análisis de la actividad}

El estudio y análisis de las producciones de los alumnos se organizará según la estructura interna de la actividad, que se ha descrito en los párrafos anteriores. Distinguiremos cuatro partes bien diferenciadas: la primera formada por los dos primeros sobres, la segunda por el tercero y el cuarto; la tercera parte se dedicará al quinto sobre $\mathrm{y}$, finalmente, la cuarta parte está dedicada al último de los sobres entregado a los alumnos.

Las unidades de análisis de la actividad son las siguientes:

\begin{tabular}{|c|c|}
\hline 0 & No entrega o no asiste a clase \\
\hline 1 & Respuesta en blanco \\
\hline 2 & Valor numérico incorrecto \\
\hline 3 & Valor numérico correcto pero razonamiento incorrecto o \\
& ausente $^{1}$ \\
\hline 4 & Valor numérico y razonamiento correctos. \\
\hline
\end{tabular}

\section{Sobres 1 y 2:}

Recuérdese que en el sobre 1 se preguntaba por las pajitas obtenidas a cambio de 2 tarjetas y en el sobre 2 por las obtenidas a cambio de 8 tarjetas. La información que se proporciona al alumno es que, por cada 4 tarjetas, se obtienen 6 pajitas. Los resultados obtenidos en estos dos apartados, de acuerdo a las unidades de análisis anteriores, pueden verse en la siguiente tabla:

\begin{tabular}{|c|c|c|c|c|c|c|}
\hline \multicolumn{2}{|c|}{} & $\mathbf{0}$ & $\mathbf{1}$ & $\mathbf{2}$ & $\mathbf{3}$ & $\mathbf{4}$ \\
\hline \multirow{2}{*}{ Sobre 1 } & $\mathbf{N}^{\mathbf{0}}$ de resp. & 0 & 0 & 2 & 2 & 23 \\
\cline { 2 - 7 } & Porcentaje & $0 \%$ & $0 \%$ & $7^{\prime} 4 \%$ & $7^{\prime}{ }^{\prime} \% \%$ & $85^{\prime} 2 \%$ \\
\hline \multirow{2}{*}{ Sobre 2 } & $\mathbf{N}^{\mathbf{0}}$ de resp. & 0 & 1 & 1 & 1 & 24 \\
\cline { 2 - 7 } & Porcentaje & $0 \%$ & $3{ }^{\prime} 7 \%$ & $3{ }^{\prime} 7 \%$ & $3{ }^{\prime} 7 \%$ & $88{ }^{\prime} 9 \%$ \\
\hline
\end{tabular}

En estos primeros sobres, dadas las sencillas relaciones multiplicativas entre las cantidades involucradas, el porcentaje de aciertos es muy alto. Además, como veremos

1 Incluimos aquí aquellos casos en los que el razonamiento se limite a describir las operaciones aritméticas realizadas. 
más adelante, la práctica totalidad de los alumnos que responden de forma completamente correcta, lo hacen utilizando argumentos de tipo multiplicativo.

El único error importante detectado corresponde a la pareja formada por los alumnos A3 y A7 (ver Figura VI.1) y se debe, pensamos, a una incorrecta comprensión del trabajo a realizar. De hecho, el error que cometen se propaga a todos los sobres que lograron completar (sólo hasta el tercero).

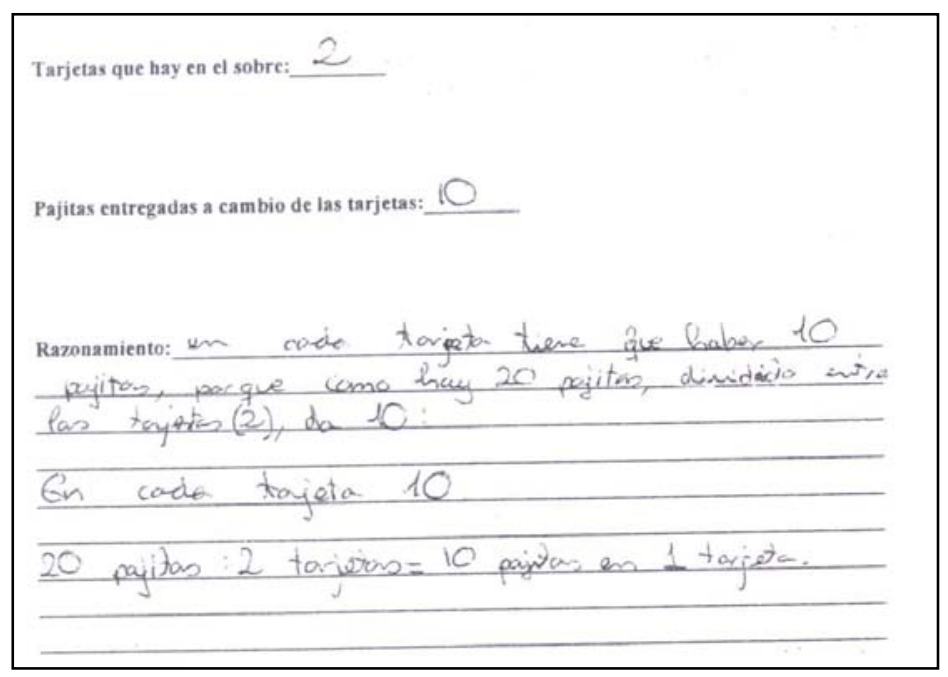

Figura VI.1.

En lugar de tratar de deducir las pajitas que se obtendrían a cambio de 2 tarjetas, estos alumnos han pensado que lo que debían hacer era repartir las 20 pajitas que se proporcionaban como material adicional entre las 2 tarjetas que contenía el sobre. No han interpretado que la información proporcionada en el cartel era invariante. Así, en el sobre 2, que contenía 8 tarjetas, la respuesta proporcionada por estos alumnos fue 2’5; resultado de dividir 20 entre 8.

El otro error detectado en el sobre 1 (cometido por la pareja A5 y A27) es, en apariencia, fruto de un despiste puesto que el resto de apartados son respondidos correctamente. Por esto no lo comentamos.

Tampoco aparecen razonamientos incorrectos; tan solo dos parejas que se limitan a indicar como razonamiento una mera redacción de la información numérica que proporcionan.

Ahora nos vamos a centrar en el análisis de las respuestas de aquellos alumnos que resuelve correctamente estos apartados. Las diferentes estrategias utilizadas se 
recogen en la tabla siguiente. Como se indicó más arriba, la variedad de estrategias utilizadas en estos dos primeros sobres es reducida.

\begin{tabular}{|c|c|c|c|}
\hline \multicolumn{2}{|c|}{} & Multiplicativa & Razón directa \\
\hline Sobre 1 & $\mathbf{N}^{\mathbf{0}}$ de resp. & 19 & 4 \\
\cline { 2 - 4 } & Porcentaje & $82^{\prime}{ }^{\prime} 6 \%$ & $17^{\prime} 4 \%$ \\
\hline Sobre 2 & $\mathbf{N}^{\mathbf{0}}$ de resp. & 20 & 4 \\
\cline { 2 - 4 } & Porcentaje & $833^{\prime} 3 \%$ & 16 '7\% \\
\hline
\end{tabular}

Aclaremos un poco lo que entendemos por cada una de estas estrategias:

- Estrategia multiplicativa: Agrupamos bajo este epígrafe a los alumnos que razonan en base a relaciones multiplicativas entre las cantidades involucradas. Por ejemplo, que 8 es el doble de 4.

- Razón directa: Estos alumnos calculan las pajitas que le corresponden a una tarjeta y usan ese dato de forma correcta multiplicando por las cantidades dadas de tarjetas.

Era esperable el hecho de que la práctica totalidad de los alumnos se apoyara en estos dos primeros sobres en razonamientos del tipo "2 es la mitad de” y “8 es el doble de”. Empleando, además, en ambos apartados el cartel informativo como referencia; es decir, nadie observó que 8 es cuatro veces 2. Un ejemplo paradigmático de razonamiento de este tipo es el dado por los alumnos A12 y A17 en el sobre 2: "Si 4 tarjetas son 6 pajitas, el doble de tarjetas 8, es el doble de pajitas 12” (Figura VI.2):

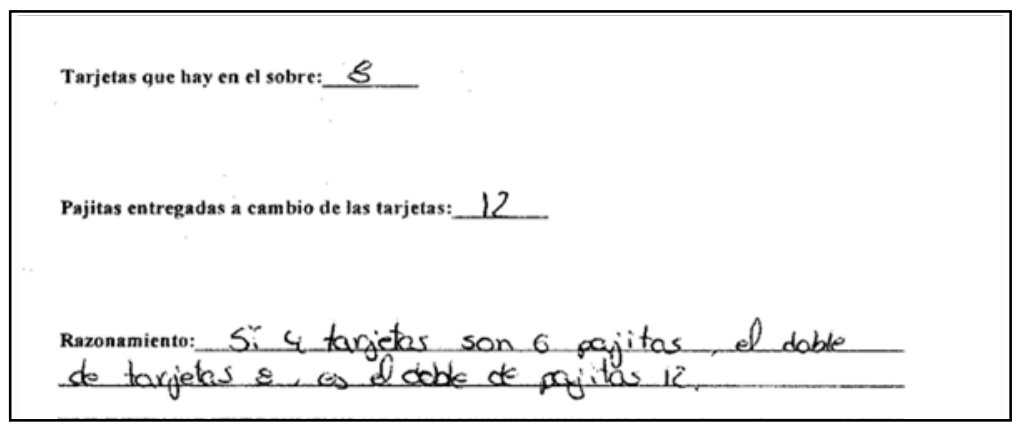

Figura VI.2.

Lo que sí que resulto hasta cierto punto sorprendente (por lo inesperado) fue la tan temprana aparición de estrategias que involucran el cálculo de la razón directa entre pajitas y tarjetas; es decir, la obtención como paso previo de la cantidad de pajitas que 
se corresponden con una tarjeta. Así lo hicieron, los alumnos A14 y A26: “6 pajitas divides entre 4 tarjetas tendrás el número de pajitas por cada tarjeta entonces las sumas [se entiende multiplicas] por dos y te saldrá” (Figura VI.3)

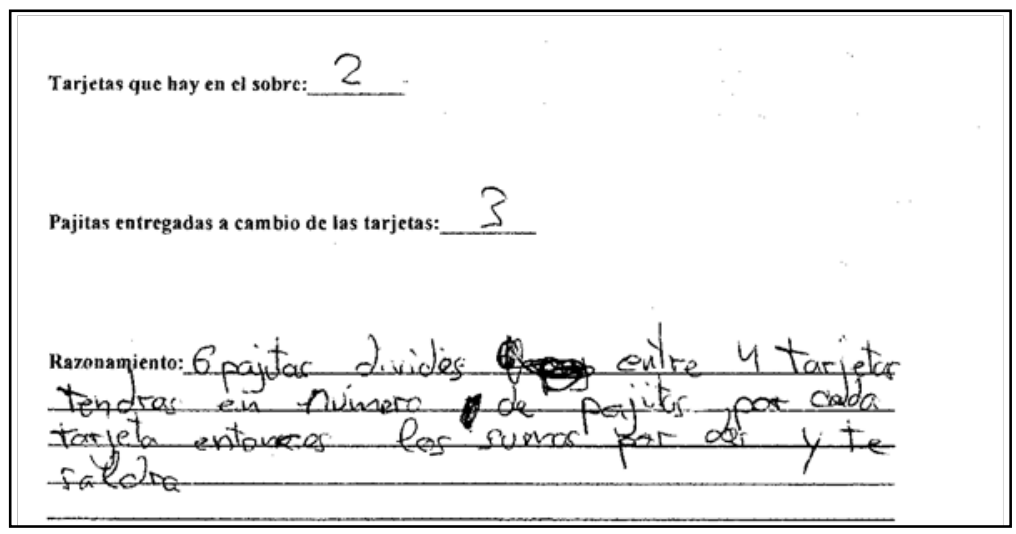

Figura VI.3.

Los alumnos que utilizan esta estrategia demuestran un buena comprensión de la situación, entendiendo que en un intercambio (si se sobreentiende que la tasa de cambio es fija) lo importante es precisamente calcular esa tasa de cambio que es la cantidad de una de las magnitudes que se obtiene a cambio de una unidad de la otra. Esto es lo que posteriormente recibirá el nombre de razón. Además, los alumnos que utilizan esta estrategia ya no la abandonan en todo el transcurso de la actividad lo que demuestra que han captado la importancia y utilidad de la estrategia elegida frente a las otras que implican la búsqueda de relaciones entre cantidades de un modo individualizado para cada uno de los sobres. Es digna de mención la falta de “escrúpulos” de los alumnos a la hora de decir que a cada tarjeta le corresponden 1'5 pajitas. Aunque se les proporcionaron pajitas y tijeras para que manipularan sólo un grupo lo hizo y nadie se sorprendió por la necesidad de “fraccionar” las pajitas que, en principio eran entes indivisibles.

\section{Sobres 3 y 4:}

En el sobre 3 se preguntaba por las pajitas obtenidas a cambio de 6 tarjetas y en el sobre 4 por las obtenidas a cambio de 10 tarjetas. En este caso sigue habiendo relaciones multiplicativas sencillas pero no con la cantidad de tarjetas del cartel, sino con la del sobre 1, esto hará que aparezcan nuevas estrategias de resolución que veremos más adelante. Los resultados obtenidos en estos dos apartados, de acuerdo a las unidades de análisis anteriores, pueden verse en la siguiente tabla: 


\begin{tabular}{|c|c|c|c|c|c|c|}
\hline \multicolumn{2}{|c|}{} & $\mathbf{0}$ & $\mathbf{1}$ & $\mathbf{2}$ & $\mathbf{3}$ & $\mathbf{4}$ \\
\hline \multirow{2}{*}{ Sobre 3 } & $\mathbf{N}^{\mathbf{0}}$ de resp. & 0 & 1 & 3 & 2 & 21 \\
\cline { 2 - 7 } & Porcentaje & $0 \%$ & $3{ }^{\prime} 7 \%$ & $11^{\prime} 1 \%$ & $7^{\prime}{ }^{\prime} \% \%$ & $77^{\prime} 8 \%$ \\
\hline \multirow{2}{*}{ Sobre 4 } & $\mathbf{N}^{\mathbf{0}}$ de resp. & 0 & 4 & 1 & 1 & 21 \\
\cline { 2 - 7 } & Porcentaje & $0 \%$ & $14^{\prime} 8 \%$ & $3^{\prime} 7 \%$ & $3^{\prime} 7 \%$ & $77^{\prime} 8 \%$ \\
\hline
\end{tabular}

Nuevamente el porcentaje de aciertos es muy elevado en estos sobres, puesto que las cantidades involucradas siguen mostrando relaciones sencillas, ya sean de tipo multiplicativo o aditivo. No hay alumnos que proporcionen una respuesta correcta con un argumento erróneo; sí que aparecen otra vez argumentos que en realidad son descripciones.

Respecto a los errores, además del ya reseñado en el apartado anterior y de una pareja (A5 y A27) que se equivocan al multiplicar 6 por 1’5 (obtienen 7’5 en vez de 9; es decir, indican un producto pero en realidad suman) aparece un nuevo error mucho más interesante. Lo comete la pareja formada por A33 y A49 (Figura VI.4).

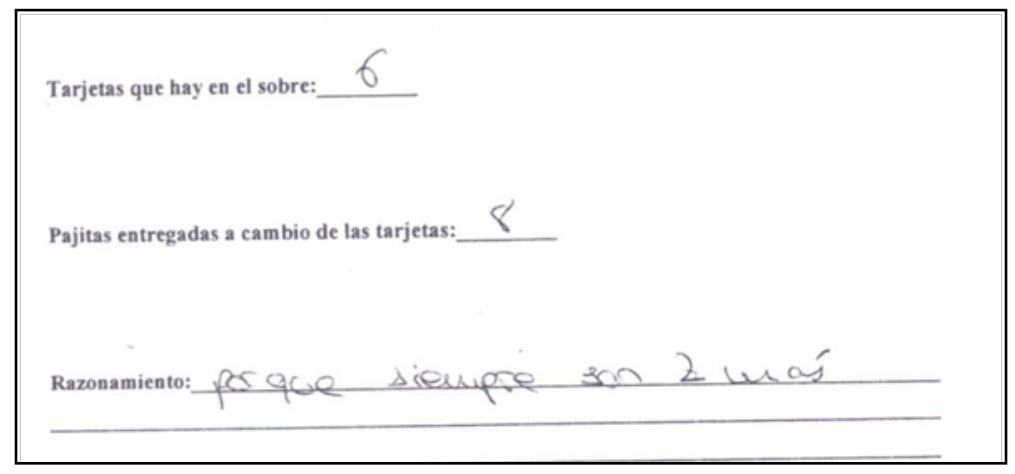

Figura VI.4.

Esta pareja resolvió correctamente los dos primeros apartados, pero a la hora de enfrentarse a los sobres 3 y 4 abandona la estrategia multiplicativa y, en su lugar, se fija en el hecho de que en el cartel hay 2 pajitas más que tarjetas y dicen "porque siempre son 2 más”. Es notorio que esta pareja no repara en que esta respuesta (y la que dan en el sobre 4, donde indican que a 10 tarjetas les corresponden 12 pajitas y no 15 como debería ser) no es consistente con lo que obtuvieron para los dos primeros sobres. Desafortunadamente, esta pareja no llegó a completar los dos últimos sobres, que nos habrían proporcionado una mayor información sobre su modo de pensar. 
Las diferentes estrategias utilizadas por aquellas parejas que responden correctamente se recogen en la tabla siguiente. Aparecen las mismas estrategias que en los dos sobres anteriores y además surgen las estrategias de tipo aditivo.

\begin{tabular}{|c|c|c|c|c|}
\hline \multicolumn{2}{|c|}{} & Multiplicativa & Aditiva & Razón directa \\
\hline Sobre 3 & $\mathbf{N}^{\mathbf{0}}$ de resp. & 4 & 6 & 11 \\
\cline { 2 - 5 } & Porcentaje & $19 \%$ & $28{ }^{\prime} 6 \%$ & $52^{\prime} 4 \%$ \\
\hline Sobre 4 & $\mathbf{N}^{\mathbf{0}}$ de resp. & 5 & 5 & 11 \\
\cline { 2 - 5 } & Porcentaje & $23^{\prime} 8 \%$ & $23{ }^{\prime} 8 \%$ & $52^{\prime} 4 \%$ \\
\hline
\end{tabular}

Además de la entrada en escena de las estrategias aditivas (bajo este epígrafe a los alumnos que razonan en base a relaciones aditivas entre las cantidades involucradas. Por ejemplo, que 6 es la suma de 4 y 2) lo que más llama la atención es el notable aumento del uso de la razón directa. Quizás este aumento se deba a la colaboración e influencia entre distintas parejas, pero no disponemos de datos para corroborarlo.

Todos los alumnos que utilizan estrategias aditivas en el sobre 3 lo hacen observando que 6 es la suma de 4 y 2, por lo que sabiendo las pajitas obtenidas a cambio de dichas cantidades de tarjetas puede hallarse la cantidad buscada. En la Figura VI.5 se muestra la respuesta de A55 y A56: “Porque te dan 6 pajitas por 4 tarjetas, te quedan 2 tarjetas, como 2 es la mitad de 4, tres es la mitad de 6, sumas 6+3=9”.

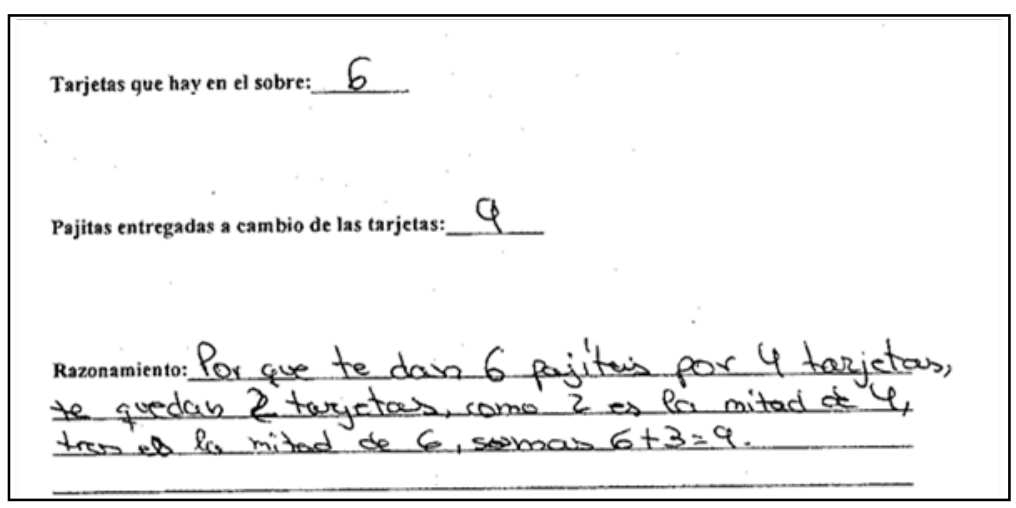

Figura VI.5.

En el caso del sobre 4 hay más variación y algunos alumnos descomponen 10 como la suma de 8 y 2 (y utilizan la información de los sobres 1 y 3) y otros lo descomponen como la suma de 4, 4 y 2 (tal es el caso de A42 y A50 en la Figura VI.6 siguiente): 


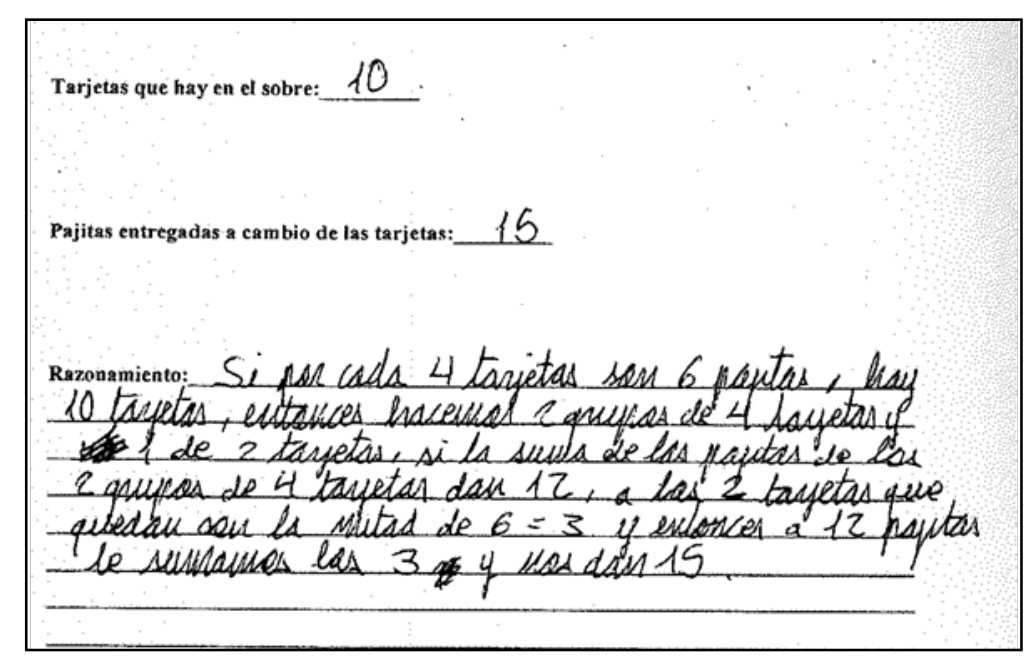

Figura VI.6.

El razonamiento es algo enrevesado: “Si por cada 4 tarjetas son 6 pajitas, hay 10 tarjetas, entonces hacemos 2 grupos de 4 tarjetas y 1 de 2 tarjetas, si la suma de las pajitas de los 2 grupos de 4 tarjetas dan 12, a las 2 tarjetas que quedan son la mitad de $6=3$ y entonces a 12 pajitas le sumamos las 3 y nos dan 15”. Sin embargo muestra claramente el proceso mental seguido por los alumnos así como el razonamiento parcial de tipo multiplicativo que hay dentro (al igual que en el de la pareja anterior). No en vano estas parejas resuelven multiplicativamente los dos primeros apartados.

En cuanto a las estrategias multiplicativas, además de la obvia de que 6 es el triple de 2 y de que 10 es 5 por 2, nos encontramos con algunos razonamientos más sofisticados, como el de A15 y A28 que se muestra a continuación en la Figura VI.7:

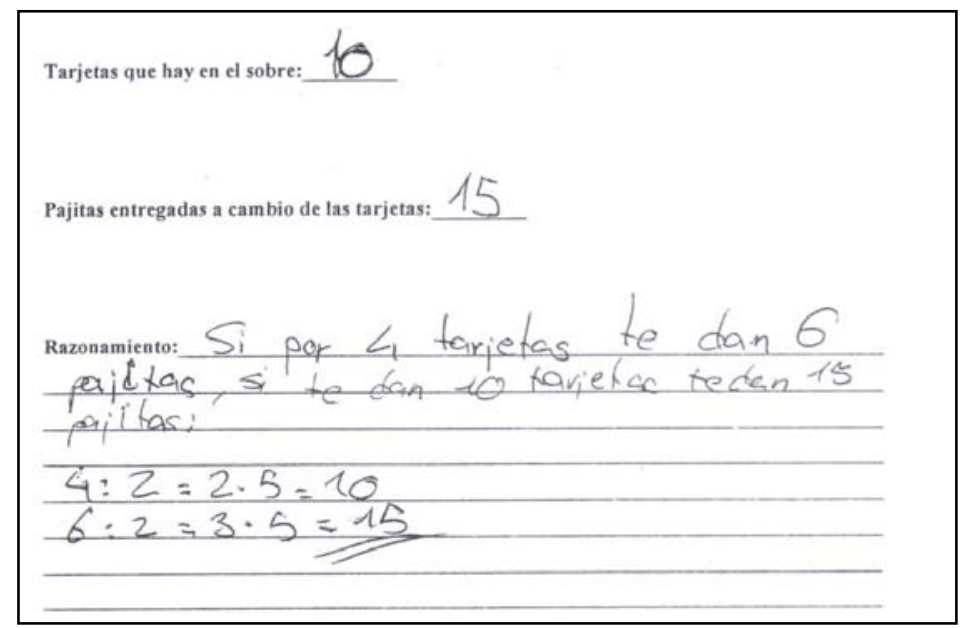

Figura VI.7.

Este tipo de razonamiento está provocado por la necesidad del alumno de utilizar la información del cartel sin observar que el trabajo realizado en los sobres anteriores 
también es de utilidad. De este modo se “construye” el 10 a partir del 4 dividiendo por 2 y multiplicando por 5 en lugar de utilizar la información del sobre 1.

Lo elaborado de las respuestas presentadas hasta ahora contrasta con la simplicidad de los argumentos dados por aquellas parejas que vienen utilizando la razón directa desde el primer sobre. Así, la pareja formada por A37 y A47 dice en el sobre 4 (ver Figura VI.8): “Si una tarjeta son 1'5 pajitas multiplicamos esto por 10, es decir corremos la coma un lugar y nos da 15”.

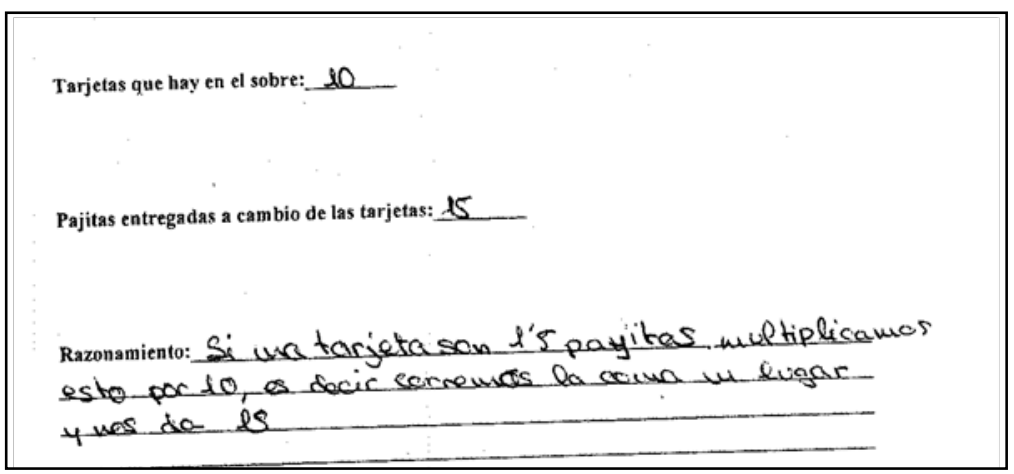

Figura VI.8.

Sobre 5

En el sobre 5 se incluía una única tarjeta. De este modo se forzaba a los alumnos a calcular la razón entre pajitas y tarjetas, si es que no lo habían hecho ya (de hecho la mitad de los alumnos que respondían correctamente a los apartados anteriores lo hacía sin recurrir a la idea de razón). Los resultados obtenidos en este apartado, de acuerdo a las unidades de análisis presentadas anteriormente, pueden verse en la siguiente tabla:

\begin{tabular}{|c|c|c|c|c|c|c|}
\hline \multicolumn{2}{|c|}{} & $\mathbf{0}$ & $\mathbf{1}$ & $\mathbf{2}$ & $\mathbf{3}$ & $\mathbf{4}$ \\
\hline \multirow{2}{*}{ Sobre 5 } & $\mathbf{N}^{\mathbf{0}}$ de resp. & 0 & 7 & 2 & 0 & 18 \\
\cline { 2 - 7 } & Porcentaje & $0 \%$ & $25{ }^{\prime} 9 \%$ & $7^{\prime} 4 \%$ & $0 \%$ & $666^{\prime} 7 \%$ \\
\hline
\end{tabular}

Lo que más llama la atención en estos resultados es el aumento del porcentaje de respuestas en blanco. Este aumento se debe a que algunos alumnos no llegaron a completar la actividad; de hecho el porcentaje de respuestas en blanco aumentará en el último sobre.

No se recogen respuestas numéricas correctas con argumentos incorrectos y, respecto a errores cometidos, además del que viene cometiendo la pareja A33 y A49 
(que ya se mencionó anteriormente) aparece otro interesante cometido por A22 y A25 (ver Figura VI.9 a continuación):

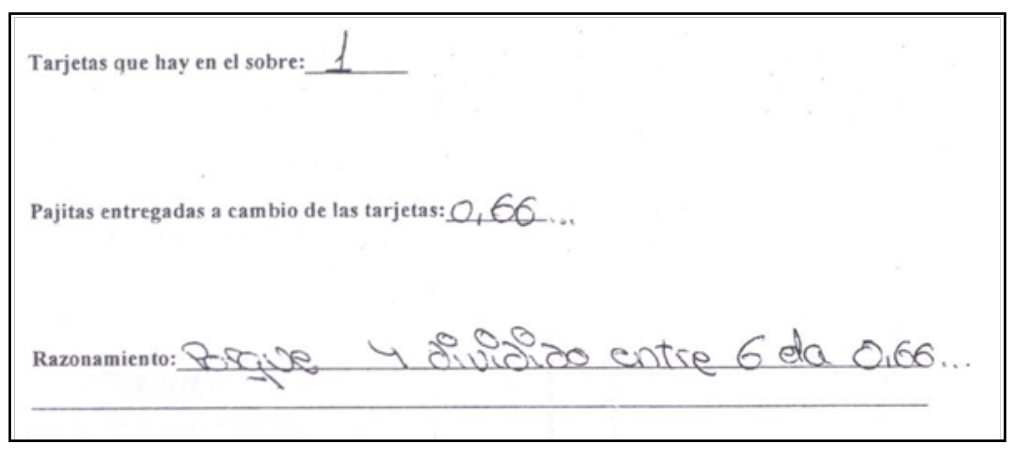

Figura VI.9.

En su respuesta, esta pareja ha efectuado el reparto al revés. En vez de repartir las 6 pajitas entre las 4 tarjetas para obtener la cantidad de pajitas obtenidas a cambio de 1 tarjeta lo hicieron a la inversa sin reparar en su error. Esta pareja respondió correctamente desde un punto de vista numérico en los sobres anteriores, pero sin presentar razonamiento; el último sobre no llegaron a completarlo.

Se han encontrado esencialmente dos estrategias entre los alumnos que responden correctamente. Éstas vienen reflejadas en la tabla siguiente:

\begin{tabular}{|c|c|c|c|}
\hline \multicolumn{2}{|c|}{} & Multiplicativa & Razón directa \\
\hline Sobre 5 & $\mathbf{N}^{\mathbf{0}}$ de resp. & 7 & 11 \\
\cline { 2 - 4 } & Porcentaje & 38 ’9\% & 61 '1\% \\
\hline
\end{tabular}

Estas dos estrategias muestran dos modos esencialmente distintos (y excluyentes) de concebir la situación por parte de los alumnos. Aquellos que razonan multiplicativamente incluso para hallar el valor unitario perciben que ambas magnitudes (tarjetas y pajitas) están relacionadas. Cuando la cantidad de una se multiplica por un número, la cantidad correspondiente de la otra también se multiplica por ese mismo número pero, sin embargo, no admiten operaciones que "mezclen” cantidades de magnitudes distintas. No contemplan la idea de “repartir” las pajitas entre las tarjetas. Estos alumnos tendrán más dificultades a la hora de asimilar la idea de razón como “tanto por uno”. Así, A35 y A43 dicen (ver Figura VI.10): “en este caso se necesita la cuarta parte de 4 y 6 para el resultado”. 


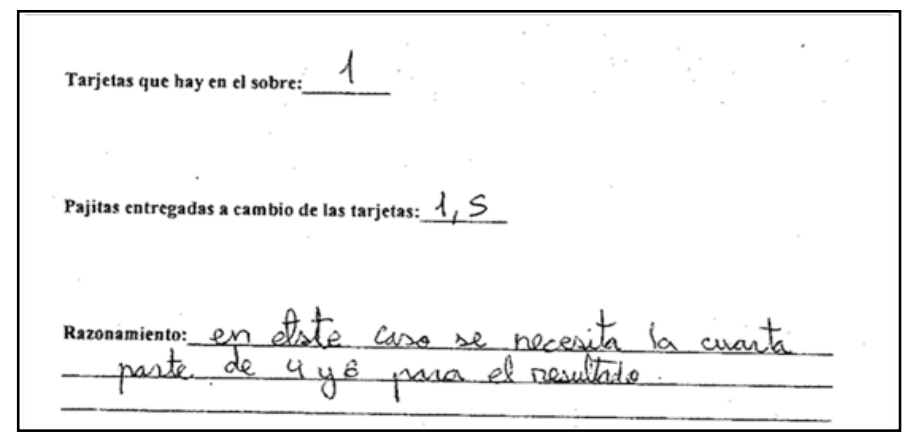

Figura VI.10.

Por otro lado, los alumnos que han utilizado la idea de reparto para obtener las pajitas correspondientes a una tarjeta sí que han admitido una operación en la que las cantidades involucradas corresponden a magnitudes distintas. Para ellos, la idea de reparto está más clara y tendrán menos problemas concibiendo la razón como “tanto por uno”. La mayoría de los alumnos que razonan de este modo lo hacen utilizando la información del cartel, repartiendo las 6 pajitas entre las 4 tarjetas; sólo una pareja (A40 y A52, Figura VI.11) lo hace utilizando la información del sobre 1 en su lugar:

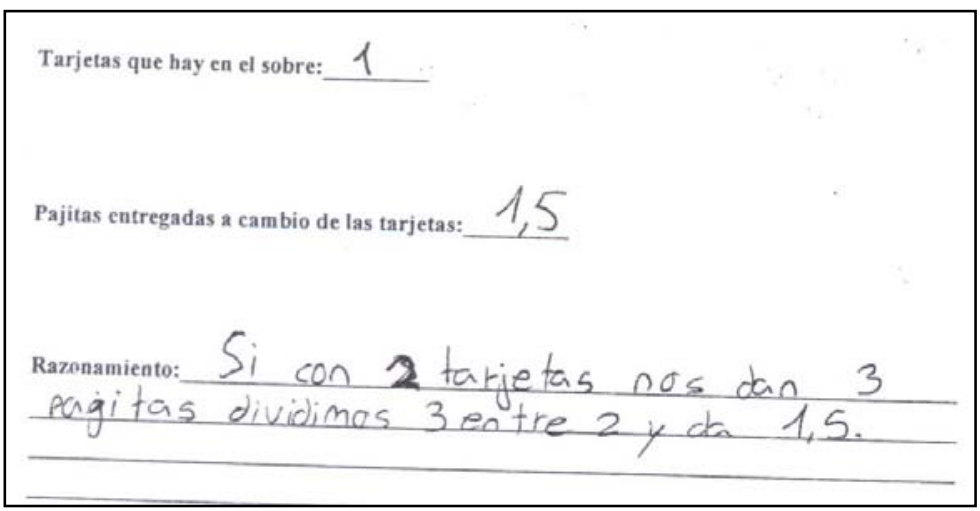

Figura VI.11.

Como se verá en la Tarea 1, que se analizará más adelante, la distinción entre estas dos tipologías de alumnos se mantendrá, aunque el porcentaje de respuestas multiplicativas se reducirá drásticamente debido a la institucionalización de la idea de razón llevada a cabo por el profesor.

\section{$\underline{\text { Sobre } 6}$}

En este último sobre aparecían 3 tarjetas y se pretendía observar si, una vez obtenido el valor correspondiente a una tarjeta, los alumnos utilizaban dicho valor para resolver este apartado o si, por el contrario, reaparecían estrategias de tipo aditivo. Los resultados obtenidos en este apartado pueden verse en la siguiente tabla: 


\begin{tabular}{|c|c|c|c|c|c|c|}
\hline \multicolumn{2}{|c|}{} & $\mathbf{0}$ & $\mathbf{1}$ & $\mathbf{2}$ & $\mathbf{3}$ & $\mathbf{4}$ \\
\hline \multirow{2}{*}{ Sobre 6 } & $\mathbf{N}^{\mathbf{0}}$ de resp. & 0 & 11 & 2 & 1 & 13 \\
\cline { 2 - 7 } & Porcentaje & $0 \%$ & 40 '7\% & $7^{\prime} 4 \%$ & 3 '7\% & $48 \% 2 \%$ \\
\hline
\end{tabular}

Sólo una pareja da un valor numérico acertado sin razonamiento. Además, el único error “nuevo” que aparece es el cometido por la pareja formada por A16 y A24, que dice que a 3 tarjetas les corresponden 2 pajitas siguiendo un razonamiento que hemos sido incapaces de desentrañar (ver Figura VI.12): “4 fichas=6 pajitas, tenemos 3 fichas 1er paso: Dividimos entre 3,1,3 fichas=2 pajitas”.

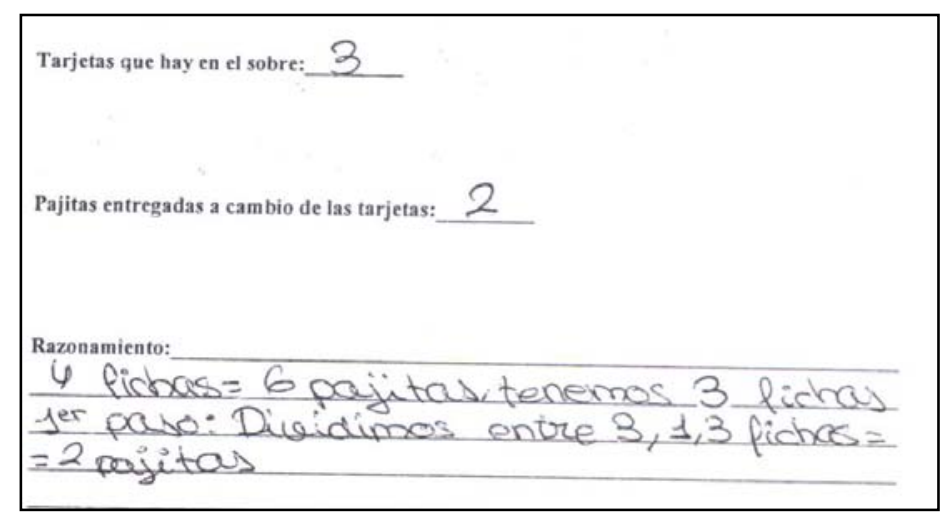

Figura VI.12.

Por último, las estrategias seguidas por los alumnos que respondieron correctamente se distribuyen del siguiente modo:

\begin{tabular}{|c|c|c|c|}
\hline \multicolumn{2}{|c|}{} & Aditiva & Multiplicativa/ Razón directa \\
\hline Sobre 5 & $\mathbf{N}^{\mathbf{o}}$ de resp. & 3 & 10 \\
\cline { 2 - 4 } & Porcentaje & $23 ’ 1 \%$ & 76 ’9\% \\
\hline
\end{tabular}

Como cabía esperar, algunos alumnos, pese a haber calculado las pajitas correspondientes a 1 tarjeta, vuelven a optar por estrategias aditivas (todo ellos observando que 3 es 2 más 1). Todos los alumnos que razonan así utilizaron estrategias multiplicativas en el apartado anterior, lo que viene a reforzar las tesis sostenidas más arriba respecto a su falta de comprensión de la razón como “tanto por uno”. Un ejemplo de este modo de razonar es la pareja A31 y A36 (ver Figura VI.13) cuando dice: “Porque si en 2 tarjetas hay 3 pajitas y en 1 tarjeta hay 1'5 si las sumamos sale 4'5”. 


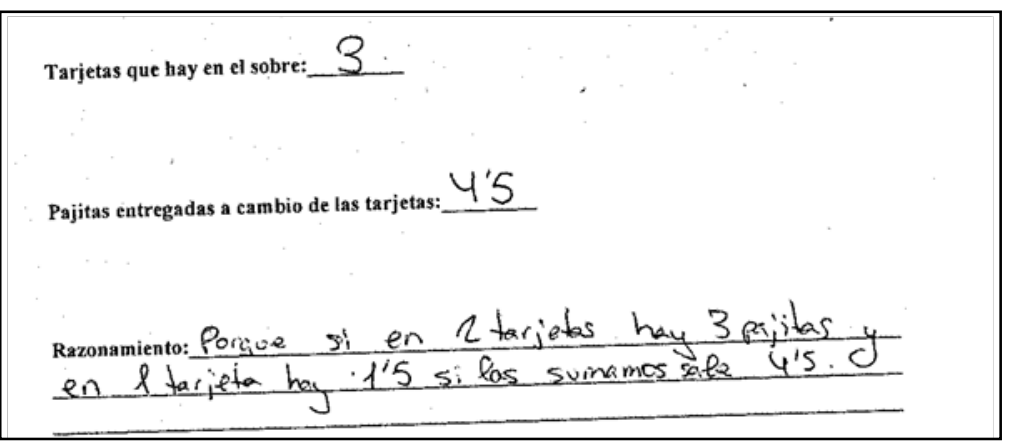

Figura VI.13.

En cuanto al resto de los alumnos, que no razonan aditivamente, a veces es complicado por sus explicaciones deducir si tienen una concepción multiplicativa de la situación o si están empleando la idea de razón. Esto es así porque la operación a efectuar es la misma, multiplicar 3 por 1'5 y en ocasiones las explicaciones de los alumnos no son todo lo claras que se desearía. En algunos casos, los alumnos utilizan expresiones como "como en casos anteriores" y podemos deducir que utilizan la idea de razón o reiteran que primero dividen 6 entre 4 para después multiplicar el resultado por 3. Sin embargo, hemos preferido agrupar todos estos tipos de respuesta bajo un mismo epígrafe.

\section{VI.2.1.2 Análisis y valoración de la Tarea de casa 1}

\section{Enunciado}

Observa el dibujo. En él se indica que, por cada seis pajitas, podemos obtener a cambio cuatro tarjetas. Recuerda que ya has trabajado en clase una situación parecida.

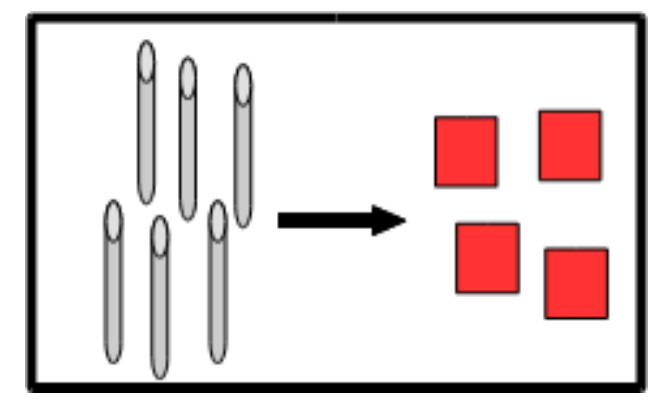

Actividad 1.

Completa la siguiente tabla, indicando cuántas tarjetas obtendrías a cambio de cada una de las cantidades de pajitas que se indican. Explica bien tu razonamiento en cada caso. 


\begin{tabular}{|c|c|l|}
\hline Pajitas & Tarjetas & \\
\hline 6 & 4 & \\
\hline 3 & & \\
\hline 9 & & \\
\hline 1 & & \\
\hline 4 & & \\
\hline 5 & & \\
\hline 7 & & \\
\hline
\end{tabular}

\section{Actividad 2.}

¿Cuál es la razón entre tarjetas y pajitas? ¿Qué significado tiene esa razón en esta situación?

\section{Análisis de la tarea}

El estudio y análisis de las producciones de los alumnos se organizará según la estructura interna de la tarea, que ya se ha descrito en los párrafos anteriores. Analizaremos cada actividad por separado y, dentro de la actividad 1, distinguiremos tres partes bien diferenciadas: la primera formada por los dos primeros apartados, la segunda por el tercer apartado y, finalmente, la tercera parte constituida por los tres últimos apartados de la actividad 1.

Las unidades de análisis de esta actividad son las siguientes:

\begin{tabular}{|c|c|}
\hline 0 & No entrega o no asiste a clase \\
\hline 1 & Respuesta en blanco $^{\text {Valor numérico incorrecto }}{ }^{2}$ \\
\hline 2 & Valor numérico correcto pero razonamiento incorrecto o $^{\text {ausente }^{3}}$ \\
\hline 3 & C $^{2}$ \\
\hline
\end{tabular}

2 No tendremos en cuenta errores de redondeo en los decimales. 


\begin{tabular}{|l|l|}
\hline 4 & Valor numérico y razonamiento correctos. \\
\hline
\end{tabular}

Como ya hemos mencionado anteriormente, vamos a dividir el análisis de esta actividad en tres partes.

\section{Actividad 1, apartados 1 y 2:}

Recuérdese que en el apartado 1 se preguntaba por las tarjetas obtenidas a cambio de 3 pajitas y en el apartado 2 por las obtenidas a cambio de 9 pajitas. La información que se proporciona - gráficamente - al alumno es que, por cada 6 pajitas se obtienen 4 tarjetas. Los resultados obtenidos en estos dos apartados, de acuerdo a las unidades de análisis anteriores, pueden verse en la siguiente tabla:

\begin{tabular}{|c|c|c|c|c|c|c|}
\hline \multicolumn{2}{|c|}{} & $\mathbf{0}$ & $\mathbf{1}$ & $\mathbf{2}$ & $\mathbf{3}$ & $\mathbf{4}$ \\
\hline Apartado 1 & $\mathbf{N}^{\mathbf{0}}$ de resp. & 2 & 0 & 1 & 11 & 42 \\
\cline { 2 - 7 } & Porcentaje & 3'6\% & $0 \%$ & $1{ }^{\prime} 8 \%$ & $199^{\prime} 6 \%$ & $75 \%$ \\
\hline \multirow{2}{*}{ Apartado 2 } & $\mathbf{N}^{\mathbf{0}}$ de resp. & 2 & 0 & 1 & 16 & 37 \\
\cline { 2 - 7 } & Porcentaje & 3'6\% & $0 \%$ & $1^{\prime} 8 \%$ & $28{ }^{\prime} 6 \%$ & $66 \%$ \\
\hline
\end{tabular}

Es notorio el alto porcentaje de respuestas totalmente correctas, mayor aún si se descartan los 2 alumnos que no entregaron la tarea. La mayor parte de los alumnos que responden correctamente estos apartados hacen uso de las relaciones multiplicativas sencillas entre las cantidades dadas (3 es la mitad de 6 y 9 es el triple de 3). Sin embargo, aparecen también otras estrategias interesantes que serán analizadas posteriormente.

Desde un punto de vista meramente numérico tan sólo hay un error para cada uno de estos apartados. Curiosamente son alumnos diferentes: A51 falla en el apartado $1 \mathrm{y}$ A52 en el 2, aunque son errores esencialmente diferentes. En la Figura VI.14 leemos la respuesta de A52: "Si por seis pajitas nos dan cuatro y por tres pajitas nos dan dos por nueve nos darán 8”.

3 Incluimos aquí aquellos casos en los que el razonamiento se limite a describir las operaciones aritméticas realizadas. 
Ge por seis pexitu nos dancuatroy por tier peyiter nos den ebs por nueve nos desén odvo.

Figura VI.14.

Aparentemente el alumno se ha dado cuenta de que puede obtener el 9 a partir del 6 y del 3 aditivamente, pero al hacer lo mismo con las cantidades correspondientes de tarjetas las ha multiplicado en vez de sumarlas. Por su parte, en la Figura VI.15 que sigue vemos la respuesta de A51: "Porque si una cartulina son 1'5 [pajitas], la multiplicamos por 3 cartulinas, que dan 4'5 palitos”.

\section{Porque siuna cartulina son l's, lo multiplicomos por 3 coatul tivor que don y's palitor}

Figura VI.15.

En este caso el error está más claro (y es más importante). El alumno calcula correctamente las pajitas correspondientes a una cartulina, pero no observa que para dar la respuesta correcta debía dividir la cantidad de pajitas dada entre ese valor y no multiplicarlo. El error surge, creemos, al tratar de repetir el esquema de la Actividad 1 realizada en clase. Allí se obtenía la razón como "tanto por uno" para después multiplicar dicha razón por las cantidades dadas. Aquí el alumno pretende hacer lo mismo, pero al calcular la razón inversa a la que se necesita no observa que debe dividir.

Respecto a los alumnos que responden correctamente desde un punto de vista numérico, pero no argumentan correctamente, podemos distinguir tres situaciones distintas: alumnos que no dan ningún argumento y dejan en blanco ese espacio en la ficha, alumnos cuyo razonamiento se limita a una descripción de las operaciones realizadas y alumnos que dan un razonamiento incorrecto. La gran mayoría de los alumnos agrupados en este apartado caen dentro de los dos primeros grupos. Pensamos que, en parte, esto es debido a dificultades a la hora de verbalizar sus razonamientos y a que algunos alumnos copian sus respuestas de compañeros. Como ejemplo del segundo caso tenemos al alumno A41, cuyas respuestas a los apartados 1 y 2 son las que aparecen en la Figura VI.16 siguiente: 


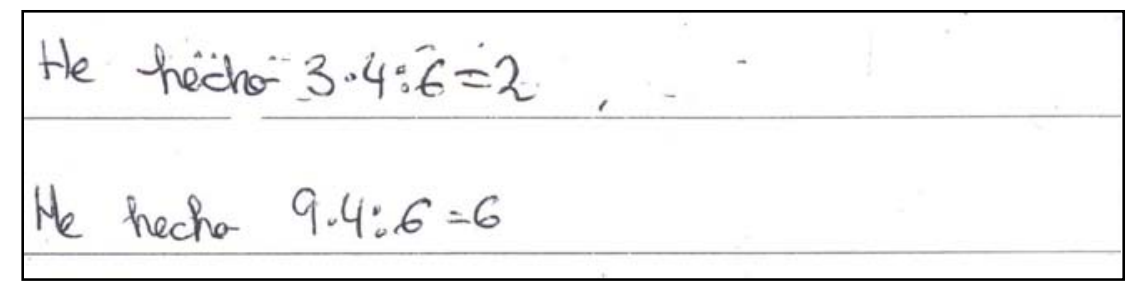

Figura VI.16.

Más interesante es centrarse en aquellos alumnos que proporcionan un argumento incorrecto. Hay que tener en cuenta que en todos estos casos los alumnos dieron una respuesta numérica correcta, el problema surge al tratar de verbalizar su forma de hallar dicha respuesta. Lo que hacen estos alumnos es, en cierto modo, comprobar que la respuesta dada es correcta. Así, por ejemplo, A22 (ver Figura VI.17) dice “dividiendo 3 entre 2 da 1,5”.

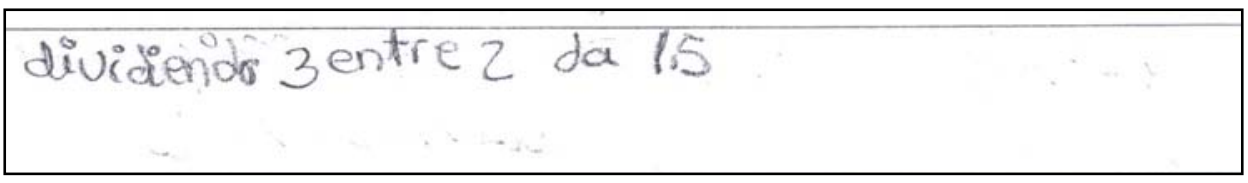

Figura VI.17.

Para este alumno el razonamiento, que debería ser una explicación del porqué de su respuesta, es una comprobación. En la información que se le da, al dividir las 6 pajitas entre las 4 tarjetas obtiene 1,5, y como si tiene 3 pajitas y 2 tarjetas le sale lo mismo, se da por satisfecho. Pero no hay ninguna indicación de cómo llegar a ese 2.

Ahora nos vamos a centrar en el análisis de las respuestas de aquellos alumnos que resuelve correctamente estos apartados. Las diferentes estrategias utilizadas se recogen en la tabla siguiente.

\begin{tabular}{|c|c|c|c|c|c|}
\hline & & Multiplicativa & Aditiva & Razón directa & Razón inversa \\
\hline \multirow[t]{2}{*}{ Apartado 1} & $\mathrm{~N}^{\mathrm{o}}$ de resp. & 32 & 0 & 3 & 7 \\
\hline & Porcentaje & $76^{\prime} 2 \%$ & $0 \%$ & 7’1\% & $16^{\prime} 7 \%$ \\
\hline \multirow[t]{2}{*}{ Apartado 2} & $\mathrm{~N}^{\mathrm{o}}$ de resp. & 17 & 10 & 3 & 7 \\
\hline & Porcentaje & $45^{\prime} 9 \%$ & $27 \%$ & 8'1\% & $19 \%$ \\
\hline
\end{tabular}

Aclaremos un poco lo que entendemos por cada una de estas estrategias:

- Estrategia multiplicativa: Agrupamos bajo este epígrafe a los alumnos que razonan en base a relaciones multiplicativas entre las cantidades involucradas. Por ejemplo, que 3 es la mitad de 6. 
- Estrategia aditiva: Agrupamos bajo este epígrafe a los alumnos que razonan en base a relaciones aditivas entre las cantidades involucradas. Por ejemplo, que 9 es la suma de 6 y 3.

- Razón directa: Estos alumnos calculan las tarjetas que le corresponden a una pajita y usan ese dato de forma correcta multiplicando por las cantidades dadas de pajitas.

- Razón inversa: Estos alumnos calculan las pajitas que se corresponden con una tarjeta y usan ese dato de forma correcta, dividiendo las cantidades dadas de tarjetas.

Como era de esperar, en estos dos apartados (sobre todo en el primero) la estrategia mayoritaria es la multiplicativa, dado la visible relación entre 6 y 3. Esta estrategia es abandonada por un número significativo de alumnos en el apartado 2, quizás por el deseo de utilizar también en este apartado la información del enunciado sin observar que lo obtenido en un apartado puede servir de base para el siguiente. Tal es el caso de A55 (ver Figura VI.18), que razona multiplicativamente en el primer apartado (“Porque si divides seis y cuatro para dos da esto") y aditivamente en el segundo (“Porque son 6 pajitas y 4 cartulinas, como son 3 pajitas más son dos cartulinas más”).

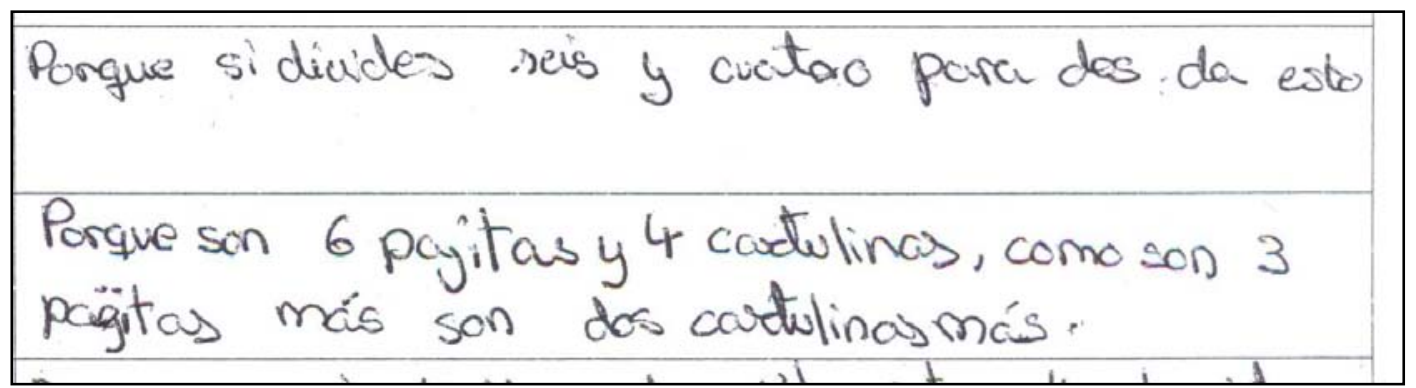

Figura VI.18.

El resto de alumnos que abandonan la estrategia multiplicativa del primer apartado pasan a razonar incorrectamente. Algunos alumnos, como por ejemplo A1 (Figura VI.19) relacionan multiplicativamente el dato del apartado 2 con el del enunciado, sin pasar por el apartado 1. De este modo aparece una especie de trabalenguas ("El triple de la mitad de las pajitas, es igual al triple de la mitad de las tarjetas”) que, sin embargo, resulta del agrado del alumno, posiblemente por su carácter esquemático y algorítmico. 


\section{Eltiple delamitad de las pajitas, es igual de triple déla mitad de lastarjetas}

\section{Figura VI.19.}

Mucha mayor "fidelidad" se observa en alumnos que utilizan razonamientos basados en la razón, ya sea la directa o la inversa (especialmente ésta última). Los alumnos que en estos dos primeros apartados usan una de estas dos estrategias ya no la abandonan en toda la actividad. La explicación de este hecho, pensamos, se encuentra en que los alumnos que utilizan estas estrategias han comprendido más profundamente la dinámica de una situación de intercambio y han observado la utilidad de conocer la cantidad de una de las magnitudes que se corresponde con una unidad de la otra. Como ejemplo de alumno que utiliza la razón directa mostramos la respuesta de A16 en la Figura VI.20:

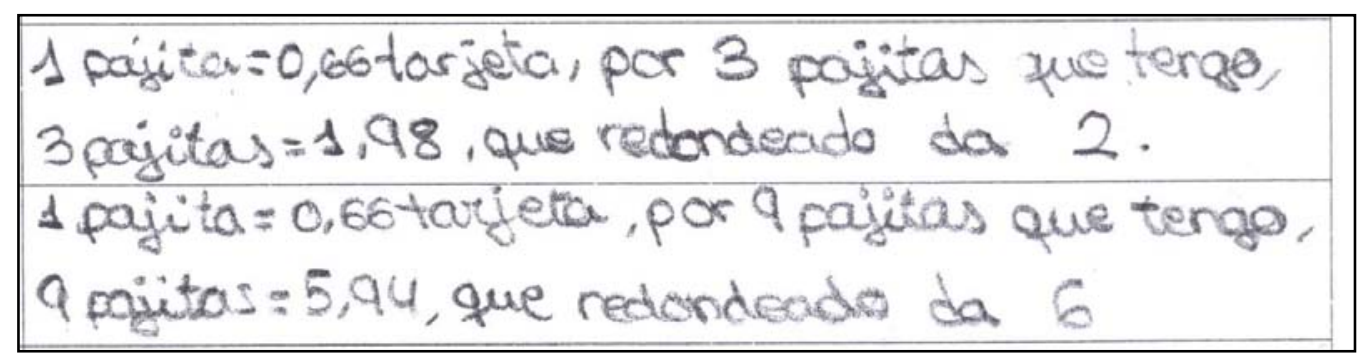

Figura VI.20.

Este ejemplo saca a colación un aspecto interesante, aunque al margen del estudio que estamos realizando: el del manejo de los decimales. A ello dedicaremos algunas líneas al final.

Los alumnos que usan la estrategia de la razón directa, en realidad, están reproduciendo la Actividad 1 realizada en clase teniendo en cuenta lo que se comentó al final de la sesión correspondiente. El esquema que habrían seguido sería algo como lo siguiente:

1. Identificar las magnitudes involucradas, cuál "nos dan” y cuál "nos piden”.

2. Utilizar el enunciado para calcular la cantidad de la que la que "nos piden" se corresponde con una unidad de la que "nos dan".

3. Multiplicar dicha cantidad por las cantidades que nos van dando. 
Sin embargo, los alumnos que han utilizado la estrategia de la razón inversa no han reproducido en el mismo sentido la Actividad 1, porque dicha estrategia no apareció en la puesta en común y, por tanto, no hubo lugar a discutir su validez o utilidad. Es posible que los alumnos que han seguido esta estrategia recordaran que era interesante calcular un valor unitario, pero no cuál en concreto. De este modo, han calculado la razón inversa de la que necesitarían para reproducir lo hecho en la Actividad 1. A partir de aquí, algunos alumnos se han dado cuenta de que con el valor obtenido debían dividir las sucesivas cantidades de pajitas que les daban: "Porque si divides tres, que son las pajitas totales entre uno coma cinco que es lo que vale una tarjeta, te salen dos tarjetas es lo que equivale a tres pajitas”. (Ver la respuesta de A32 en la Figura VI.21).

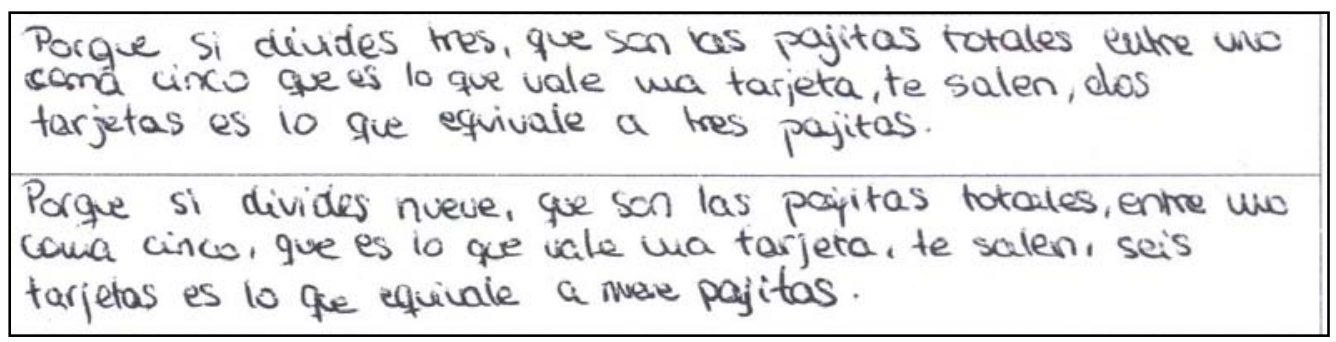

Figura VI.21.

Otros alumnos calcularon esta misma razón inversa, pero trataron de utilizarla, según el mismo esquema de la Actividad 1, multiplicando. De aquí surge uno de los errores que hemos tratado antes y que se repetirá a lo largo de esta primera parte de la tarea.

\section{Actividad 1, apartado 3:}

En el apartado 1 se solicitaba a los alumnos el cálculo de las tarjetas obtenidas a cambio de 1 pajita. En cierto sentido, este apartado es el más importante y el punto de inflexión de la primera actividad. La idea es ver si en los apartados siguientes los alumnos que no se habían inclinado por la estrategia de la razón directa la elegían al tener a su disposición dicha razón. Veremos que esto es así, aunque sólo en parte, dependiendo principalmente de la estrategia seguida a la hora de resolver este apartado. Los resultados obtenidos en este apartado, de acuerdo a las unidades de análisis anteriores, pueden verse en la siguiente tabla:

\begin{tabular}{|l|c|c|c|c|c|c|}
\hline \multicolumn{2}{|c|}{} & $\mathbf{0}$ & $\mathbf{1}$ & $\mathbf{2}$ & $\mathbf{3}$ & $\mathbf{4}$ \\
\hline Apartado 3 & $\mathbf{N}^{\mathbf{0}}$ de resp. & 2 & 1 & 11 & 16 & 26 \\
\hline
\end{tabular}




\begin{tabular}{|c|c|c|c|c|c|c|}
\hline & Porcentaje & 3'6\% & 1'8\% & $19^{\prime} 6 \%$ & $28{ }^{\prime} 6 \%$ & $466^{\prime} 4 \%$ \\
\hline
\end{tabular}

Aunque el porcentaje de aciertos se mantiene alto, sobre todo si nos fijamos únicamente en la faceta numérica (un 75\%), aparece una cantidad no despreciable de alumnos que responden con un valor numérico equivocado. El porcentaje de alumnos que dan un valor numérico correcto pero no razonan adecuadamente se mantiene con respecto al apartado 2. Estos porcentajes se mantendrán estables en lo que resta de la actividad.

Entre los alumnos que no dan una respuesta numérica correcta, casi todos cometen el mismo error, ya indicado antes: calcular las pajitas correspondientes a una tarjeta y multiplicar en vez de dividir por dicho valor. El problema es pues, en nuestra opinión, de comprensión tanto del significado de la razón calculada como de la división. Posiblemente recuerden el número 1'5 de la Actividad 1 y tengan un vago recuerdo de cómo se resolvió dicha Actividad, pero no tratan de entender lo que hacen o lo entienden mal. En este apartado aparece un error esporádico nuevo, lo comente el alumno A55 (Figura VI.22).

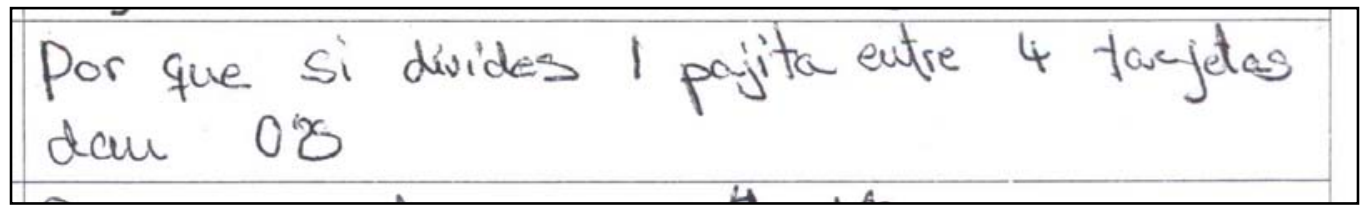

Figura VI.22.

El alumno responde: “Porque si divides 1 pajita entre 4 tarjetas dan 0'25”. Es difícil entender el motivo de este error. En los dos apartados anteriores el alumno respondió correctamente empleando estrategias multiplicativas y aditivas, respectivamente. Quizás recordara la necesidad de hacer una división e hizo esta aleatoriamente. El resto de apartados los resuelve - también incorrectamente dividiendo cada una de las cantidades dadas entre el valor 0’25 calculado en este apartado (los apartados 4 y 5) y aditivamente el apartado 6.

Entre los alumnos que no dan un razonamiento correcto a un valor numérico acertado no aparecen aspectos nuevos a reseñar. La gran mayoría de los alumnos agrupados bajo este epígrafe indican únicamente las operaciones efectuadas. Si bien es cierto que de dichas operaciones puede, hasta cierto punto, inferirse la estrategia que está utilizando; preferimos no hacer conjeturas a ese respecto. 
Aunque pareciera no haber muchas opciones a la hora de resolver este apartado, lo cierto es que se han encontrado tres estrategias esencialmente distintas. Se recogen en la siguiente tabla:

\begin{tabular}{|c|c|c|c|c|}
\hline \multicolumn{2}{|c|}{} & Multiplicativa & Razón directa & Razón inversa \\
\hline Apartado 3 & $\mathbf{N}^{\mathbf{0}}$ de resp. & 5 & 14 & 7 \\
\cline { 2 - 5 } & Porcentaje & $199^{\prime} 2 \%$ & 53 ' $\%$ & $27 \%$ \\
\hline
\end{tabular}

- Estrategia multiplicativa: Los alumnos que razonan según esta estrategia utilizan la (obvia) relación multiplicativa entre 6 y 1.

- Razón directa: Agrupamos aquí a los alumnos que utilizan el significado de la división como reparto para calcular la razón directa entre las magnitudes involucradas.

- $\quad$ Razón inversa: Como antes, los alumnos que usan este razonamiento hacen uso de la razón inversa entre las magnitudes involucradas y del significado de la división.

En este apartado, la mayor parte de los alumnos que razonan correctamente lo hacen calculando la razón mediante la división como reparto. Así el alumno A37 (ver Figura VI.23) dice: "he dividido 4 entre séis para saber cuantas tarjetas te dan a cambio de una pajita”.

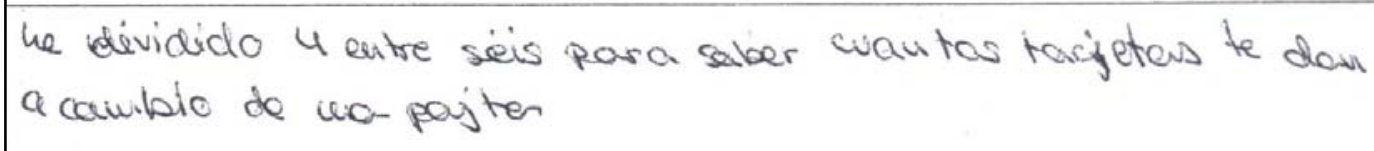

Figura VI.23.

Este razonamiento muestra a las claras la concepción del alumno de la división como un reparto. Esta concepción contrasta claramente con la estrategia seguida por otros alumnos. Por ejemplo, A1 (ver Figura VI.24) razona diciendo: “Es la sexta parte de las pajitas, es igual a la sexta parte de las tarjetas”.

Es la sexta parte de las pafitas, es igu of a la sexta parte de las targietas

Figura VI.24. 
Este alumno mantiene su estrategia multiplicativa y, para él, calcular el valor correspondiente a la unidad no tiene nada de especial. Estas dos formas, esencialmente distintas, de encontrar el valor correspondiente a la unidad marcan la distinción entre aquellos alumnos que mantienen las estrategias multiplicativas o aditivas y aquellos que las abandonan a favor del uso de la razón directa. Ninguno de los alumnos que opta por la estrategia multiplicativa en este apartado utiliza la estrategia de la razón directa en los siguientes. En su lugar, como veremos, reaparecen las estrategias aditivas.

\section{Actividad 1, apartados 4, 5 y 6 :}

Tras el apartado 3 se presentaban los tres últimos apartados en los que se quería comprobar si los alumnos abandonaban las estrategias a favor del uso de la razón directa entre las magnitudes involucradas (que habían calculado en el apartado anterior). Para incentivar dicho abandono, además, las cantidades de pajitas proporcionadas en estos apartados eran 4, 5 y 7 respectivamente; de tal modo que las relaciones multiplicativas entre ellas y con las cantidades anteriores no eran directas (salvo la obvia con la unidad). Los resultados obtenidos en estos dos apartados, de acuerdo a las unidades de análisis anteriores, pueden verse en la siguiente tabla:

\begin{tabular}{|l|c|c|c|c|c|c|}
\hline \multicolumn{2}{|c|}{} & $\mathbf{0}$ & $\mathbf{1}$ & $\mathbf{2}$ & $\mathbf{3}$ & $\mathbf{4}$ \\
\hline \multirow{2}{*}{ Apartado 4 } & $\mathbf{N}^{\mathbf{0}}$ de resp. & 2 & 3 & 10 & 12 & 29 \\
\cline { 2 - 7 } & Porcentaje & $3^{\prime} 6 \%$ & $5^{\prime} 4 \%$ & $17^{\prime} 9 \%$ & $21^{\prime} 4 \% \%$ & $51^{\prime} 7 \%$ \\
\hline Apartado 5 & $\mathbf{N}^{\mathbf{0}}$ de resp. & 2 & 5 & 10 & 11 & 28 \\
\cline { 2 - 7 } & Porcentaje & $3{ }^{\prime} 6 \%$ & $8{ }^{\prime} 9 \%$ & $17^{\prime} 9 \%$ & $19^{\prime} 6 \%$ & $50 \%$ \\
\hline Apartado 6 & $\mathbf{N}^{\mathbf{0}}$ de resp. & 2 & 5 & 8 & 11 & 30 \\
\cline { 2 - 8 } & Porcentaje & $3^{\prime} 6 \%$ & $8{ }^{\prime} 9 \%$ & $14^{\prime} 3 \%$ & $19^{\prime} 6 \%$ & $53^{\prime} 6 \%$ \\
\hline
\end{tabular}

Lo primero que salta a la vista es la similar distribución de los resultados en los tres apartados. La explicación, para nosotros, está en el hecho de que los tres apartados presentan la misma dificultad esencial a los alumnos, por lo que el tipo de respuesta que dan es esencialmente el mismo en todos ellos. Más de la mitad de los alumnos responden de un modo completamente correcto, y si nos fijamos únicamente en el aspecto numérico el porcentaje de aciertos sube hasta el 70\% más o menos. No obstante, es notorio el aumento de respuestas en blanco debidas posiblemente a tratarse de los últimos apartados. 
En estos tres apartados no surgen errores esencialmente nuevos por parte de los alumnos. Los que dan un valor numérico equivocado se debe a que calculan la razón inversa (entre pajitas y tarjetas, es decir, las pajitas correspondientes a 1 tarjeta) y después multiplican en vez de dividir.

Con respecto a los alumnos que razonan incorrectamente pero obtienen un valor numérico correcto, tampoco aparecen aspectos nuevos a reseñar. Algunos se limitan a describir las operaciones realizadas y otros a comprobar más bien que a justificar.

Finalmente, veamos las estrategias de resolución de los alumnos que responden correctamente. Como hemos mencionado ya, en estos apartados reaparecen las estrategias aditivas especialmente entre alumnos que utilizaron una estrategia multiplicativa para hallar el valor unitario en el apartado 3. En la tabla siguiente se realiza el estudio cuantitativo de estas estrategias:

\begin{tabular}{|l|l|c|c|c|c|}
\hline \multicolumn{2}{|c|}{} & Multiplicativa & Aditiva & Razón directa & Razón inversa \\
\hline Apartado 4 & $\mathbf{N}^{\mathbf{0}}$ de resp. & 4 & 2 & 17 & 6 \\
\cline { 2 - 6 } & Porcentaje & $13^{\prime} 8 \%$ & $6{ }^{\prime} 9 \%$ & $58{ }^{\prime} 6 \%$ & $20^{\prime} 7 \%$ \\
\hline Apartado 5 & $\mathbf{N}^{\mathbf{0}}$ de resp. & 4 & 3 & 15 & 6 \\
\cline { 2 - 6 } & Porcentaje & $14^{\prime} 3 \%$ & $10^{\prime} 7 \%$ & $533^{\prime} 6 \%$ & $21^{\prime} 4 \%$ \\
\hline Apartado 6 & $\mathbf{N}^{\mathbf{0}}$ de resp. & 4 & 3 & 16 & 7 \\
\cline { 2 - 6 } & Porcentaje & $13^{\prime} 3 \%$ & $1 \%$ & $533^{\prime} 3 \%$ & $23^{\prime} 4 \%$ \\
\hline
\end{tabular}

No vamos a describir aquí las distintas estrategias, pues ya han aparecido discutidas en apartados anteriores. La estrategia mayoritaria es la de la razón directa, elegida por más de la mitad de los alumnos que razonan correctamente. Es interesante e importante resaltar aquí la diferencia conceptual entre la estrategia multiplicativa y la de razón directa, sobre todo porque ambas se plasman en la misma operación aritmética. Como ejemplo de la diferencia entre ambas, mostramos primero la respuesta de A19 al apartado 6: “7 lo obtengo multiplicando 1.7 entonces $0, \hat{6}$ lo multiplico por 7 que da 4,̂ิ" (ver Figura VI.25).

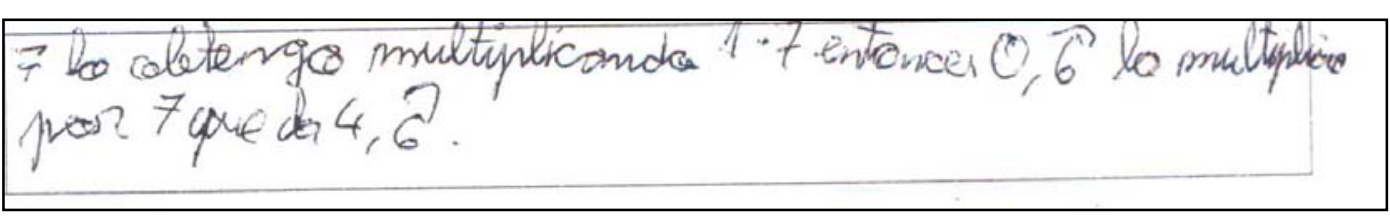

Figura VI.25. 
Este alumno está utilizando una estrategia multiplicativa puesto que el motivo de efectuar el producto entre la cantidad de pajitas dada y las tarjetas correspondientes a una pajita es la relación multiplicativa entre 7 y 1 . Sin embargo, el alumno A12 (Figura VI.26) responde en el apartado 5: “Si por cada pajita me dan 0'6 de tarjeta y tengo 5 pajitas, lo multiplico por 5”.

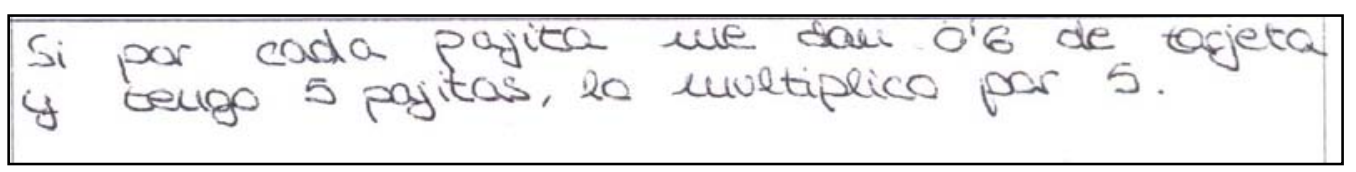

Figura VI.26.

En este caso, la operación aritmética a efectuar es la misma que en el anterior; sin embargo, la motivación es bien distinta. Aquí, el alumno razona pensando que lo que corresponde a 5 pajitas es cinco veces lo que le corresponde a 1 pajita. La diferencia es sutil, pero existe.

En cuanto a estrategias aditivas, en los apartados 4 y 5 encontramos el único ejemplo de razonamiento utilizando restas. Los razonamientos aditivos presentados hasta el momento siempre se basaban en la descomposición de la cantidad dada en suma de dos o más cantidades dadas en los apartados anteriores. Sin embargo, el alumno A24 (ver Figura VI.27) razona sustractivamente, y escribe: "6 pajitas=4 tarjetas, si quitas 1 quitas media tarjeta=3,5”.

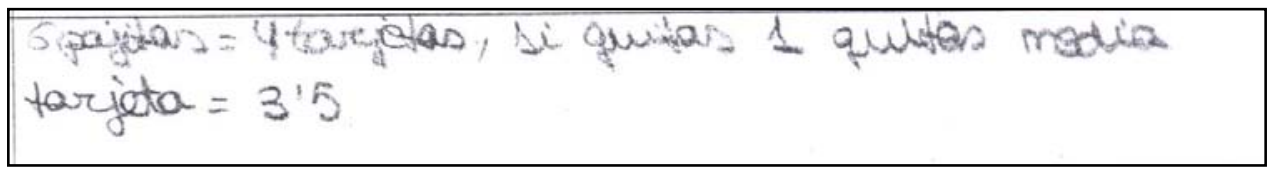

Figura VI.27.

Como hemos indicado antes, los de este alumno son los únicos ejemplos de razonamiento de este tipo que han aparecido. Así pues, han aparecido razonamientos sumando, restando, multiplicando y dividiendo.

Las dos estrategias que usan la razón en algún modo no aportan nada nuevo al análisis que estamos realizando; por lo que no comentaremos nada sobre ellas en estos apartados. 


\section{Actividad 2:}

En la actividad 2 se pedía a los alumnos que indicaran explícitamente tanto el valor como el significado de la razón que aparecía en la tarea. Esta pregunta, con mucho, ha resultado la más complicada para los alumnos. Los motivos, además de en la dificultad del concepto, hay que buscarlos en el poco tiempo transcurrido desde su presentación y también (en el caso de los alumnos de uno de los grupos) en el hecho de que, durante la sesión de trabajo en clase, apenas quedó tiempo para institucionalizar el concepto.

Las unidades de análisis de esta actividad son las siguientes:

\begin{tabular}{|c|c|}
\hline 0 & No entrega o no asiste a clase \\
\hline 1 & Respuesta en blanco \\
\hline 2 & Respuesta sin sentido o incompleta \\
\hline 3 & Da el valor pero no entiende el significado \\
\hline 4 & Indica el valor y el significado correctos, pero de la razón inversa de la que se \\
& pide \\
\hline 5 & Indica el valor y el significado correctos de la razón pedida \\
\hline
\end{tabular}

De acuerdo con estas unidades de análisis los resultados obtenidos en esta actividad son los siguientes:

\begin{tabular}{|c|c|c|c|c|c|c|c|}
\hline \multicolumn{2}{|c|}{} & $\mathbf{0}$ & $\mathbf{1}$ & $\mathbf{2}$ & $\mathbf{3}$ & $\mathbf{4}$ & $\mathbf{5}$ \\
\hline \multirow{2}{*}{ Actividad 2 } & $\mathbf{N}^{\mathbf{0}}$ de resp. & 2 & 9 & 12 & 7 & 7 & 19 \\
\cline { 2 - 8 } & Porcentaje & $33^{\prime} 6 \%$ & $166^{\prime} 1 \%$ & $21^{\prime} 4 \%$ & $12{ }^{\prime} 5 \%$ & $12{ }^{\prime} 5 \%$ & $333^{\prime} 9 \%$ \\
\hline
\end{tabular}

Entre las respuestas sin sentido tiene especial interés la del alumno A1 (ver la Figura VI.28) que denota a las claras una influencia externa: "Es una proporcionalidad directa, porque contra mas pajitas mas tarjetas y viceversa".

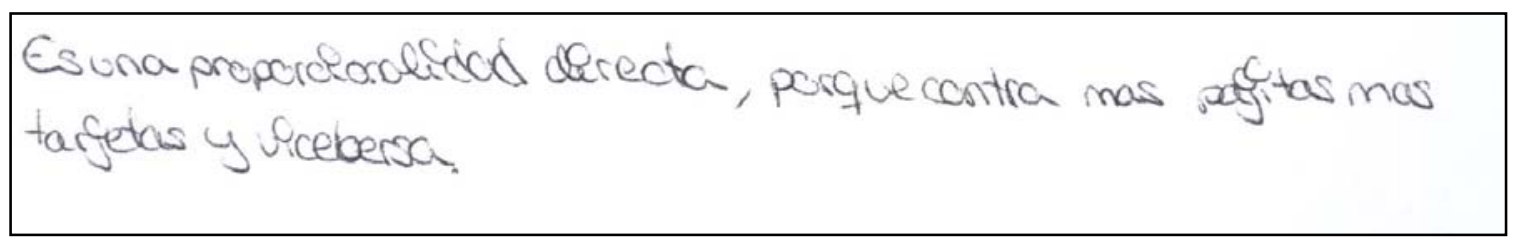

Figura VI.28.

Pensamos que este alumno ha recibido algún tipo de ayuda para realizar la tarea y puesto que el término 'razón' se sale de lo habitual, la persona que le ha ayudado ha 
indicado la “razón” por la que efectúa los cálculos para realizar la tarea. De hecho el alumno A1 resuelve todos los apartados por estrategias multiplicativas sin considerar la razón como "tanto por uno".

Una de las mayores dificultades a la hora de poner por escrito lo que se les pedía está relacionada con el orden de las palabras. La razón entre tarjetas y pajitas (la que se solicitaba) es la cantidad de tarjetas obtenidas a cambio de una pajita. Así, algunos alumnos, como A20 en la Figura VI.29, muestran su confusión: “La razón no es tarjetas y pajitas, es pajitas y tarjetas”.

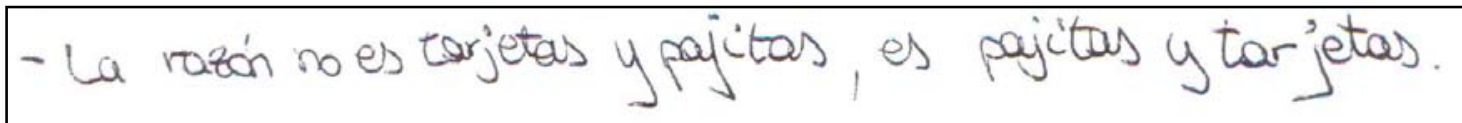

Figura VI.29.

Algunos alumnos dan el valor numérico correcto en un orden incorrecto de las magnitudes, otros dan el valor equivocado para el orden que se pide. Finalmente, otros, indican la razón inversa a la que se pedía; especialmente aquellos que se inclinaron por la estrategia de la razón inversa.

En cualquier caso, un porcentaje no despreciable, la tercera parte de los alumnos, responde de forma completamente correcta a la actividad 2. Algunos de forma muy clara, como A39, cuya declaración se muestra en la Figura VI.30: “0,6̂. 0,6̂ es la cantidad de tarjetas que te dan por cada pajita”.

$$
0,6 \cdot 0,6 \text { es la cantidad de targetas que te dan por cada pajita. }
$$

Figura VI.30.

\section{VI.2.1.3 Reflexiones relativas al punto 1}

1. Resulta interesante observar el hecho de que nadie mostró extrañeza, ni verbalmente ni por escrito, ante el hecho de que algunas respuestas implicaran cantidades no enteras de pajitas. Quizás haber utilizado otro tipo de objetos (como libros, o canicas) que den menos pie a pensar que se pueden fraccionar habría contribuido a hacer aparecer este tipo de extrañeza. Sin embargo pensamos que los alumnos, a la hora de manejar magnitudes, están muy habituados a preocuparse más por el valor numérico que por su interpretación 
(más allá de la preocupación inculcada por el profesorado de “poner siempre las unidades”).

2. En principio la actividad estaba pensada para que los alumnos manipularan el material. Por ello se proporcionó a cada pareja 20 pajitas para que pudieran efectuar repartos, hacer montones, etc... Sin embargo, casi todos los alumnos se lanzaron desde el principio a razonar utilizando lápiz y papel además de la calculadora. Este uso constante de la calculadora se prolongó durante toda la experiencia y, en ocasiones, fue una fuente de errores y problemas para los alumnos. Esto, en parte, también explica la falta de extrañeza ante las 1’5 pajitas, que muy pocos alumnos escribieran "una pajita y media” verbalmente y que nadie empleara las fracciones.

3. Tan sólo un grupo de tres alumnos (A30, A34 y A41) utilizaron de forma significativa el material. Su estrategia fue distribuir 3 pajitas por cada 2 tarjetas del siguiente modo:

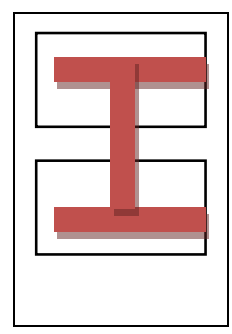

Esta manipulación explica la elección del verbo “poner” en la redacción de las respuestas de este grupo (Figura VI.31): "Porque ponemos una pajita en cada cartulina y luego le añadimos media pajita”.

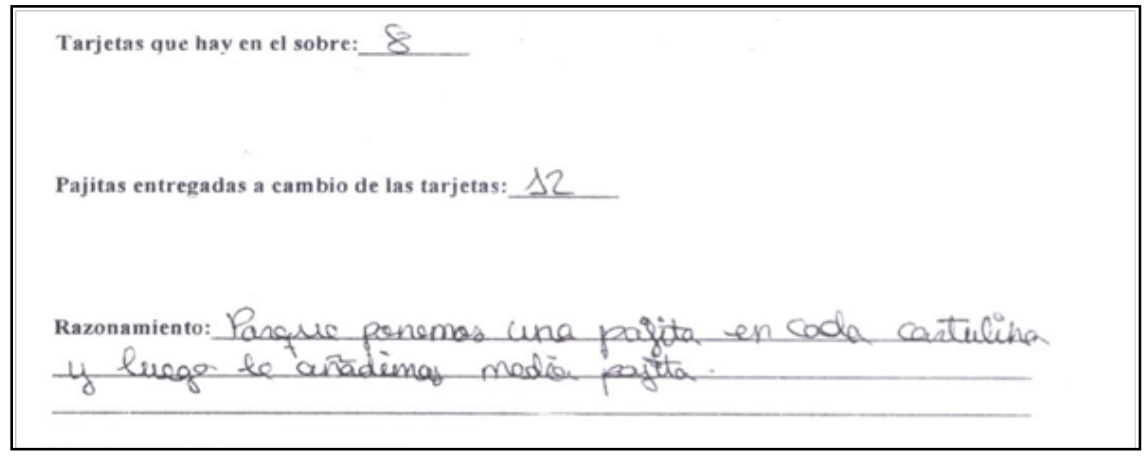

Figura VI.31.

4. Cabe destacar que la mayoría de los alumnos utiliza decimales y no fracciones tanto a la hora de hacer operaciones como a la de indicar los resultados por 
escrito. Además, ningún alumno indica extrañeza o dificultades ante el hecho de que aparezcan cantidades fraccionarias de tarjetas. Esto ya sucedía en la Actividad de aula 1. Posiblemente sea debido a lo habituados que se encuentran os alumnos a trabajar pegados a la calculadora. De hecho, al manejar los decimales, se efectúan redondeos arbitrarios, algunos utilizan el símbolo de decimal periódico pero multiplican después como si fuera exacto, etc...

5. Además, en esta primera tarea comienza a apreciarse la influencia de familiares y/o profesores particulares. Ya se ha señalado un caso en el que se apreciaban influencias externas en las respuestas de un alumno que se refería a la proporcionalidad directa. No es el único ejemplo que podemos mostrar, en la producción de A41 (ver Figura VI.32) se observan claras reminiscencias del algoritmo de la Regla de Tres:

\begin{tabular}{|c|c|c|}
\hline Pajitas & Tarjectas & \multicolumn{1}{|c|}{ Razonamiento } \\
\hline 6 & 4 & \\
\hline 3 & 2 & He hécho $3 \cdot 4: 6=2$ \\
\hline 9 & 6 & He hecho $9 \cdot 4: 6=6$ \\
\hline 1 & 0,6 & He hecho $5 \cdot 4: 6=0,6$ \\
\hline 4 & 2,6 & He hecho $4 \cdot 4: 6=2,6$ \\
\hline 5 & $3, \widehat{6}$ & He hecho $5 \cdot 4: 6=3, \widehat{6}$ \\
\hline 7 & 4,6 & He hecho $7 \cdot 4: 6=4, \widehat{6}$ \\
\hline
\end{tabular}

Figura VI.32.

6. Otro aspecto interesante es el gusto de los alumnos por la repetición de un mismo esquema. En este sentido son relativamente pocos los alumnos que muestran más de una estrategia a lo largo de toda la tarea. Esta repetición se lleva incluso al plano gramatical, repitiendo en todos los apartados una misma frase en la que sólo se cambian los números involucrados.

7. Hay casos en los que resulta realmente complicado descubrir los caminos que han llevado al alumno a dar sus respuestas. El ejemplo siguiente (Figura VI.33) se corresponde con el alumno A26, afectado de Síndrome de Asperger, que 
seguía las clases con normalidad. Comienza con las sencillas estrategias multiplicativas, cuando se le piden las tarjetas que se obtienen por una pajita (eran 2/3) lo redondea a $0 \mathrm{y}$, sin embargo resuelve correctamente (salvo redondeo) el resto de apartados. Obsérvese además la curiosa forma de indicar verbalmente los números decimales.

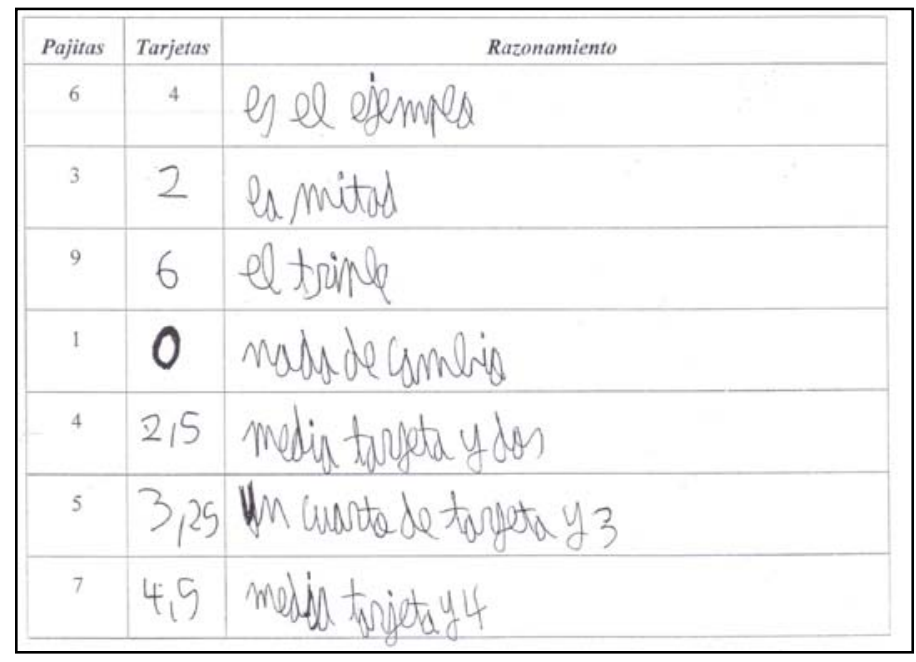

Figura VI.33.

8. El porcentaje de respuestas completamente correctas es inferior en la tarea de casa 1, pero el porcentaje de errores no es significativamente mayor. El porcentaje que más aumenta es el de respuestas correctas numéricamente pero sin razonamiento. Esto puede ser debido a que en la Actividad de aula 1, uno de los miembros de la pareja no comprendiera el razonamiento del otro y fuera incapaz de reproducirlo solo en casa.

9. En la tarea de casa 1 no aparecen fallos del tipo "si me dan dos pajitas más tendré dos tarjetas más” que están relacionados con un error en la percepción de la relación que liga ambas magnitudes. Sin embargo, el error más común está relacionado con el manejo de las magnitudes y con los significados “inversos” que tiene una razón y su razón inversa. Este error no apareció en la Actividad de aula 1 y será una de las mayores dificultades de los alumnos durante toda la propuesta. Posiblemente la aparición de este error tenga que ver con que en la tarea de casa 1 la situación era la inversa de la de la actividad de aula 1.

10. Respecto a las estrategias utilizadas por los alumnos que responden correctamente, en aquellos casos en los que las relaciones multiplicativas o 
aditivas son sencillas, estas estrategias son las preferidas por los alumnos; y esto pese a la institucionalización de la idea de razón que se llevó a cabo al final de la Actividad de aula 1. La influencia de la Actividad de aula 1 queda patente en la aparición de la estrategia “razón inversa”.

\section{VI.2.2 Punto 2: La condición de regularidad}

Una vez que se ha introducido el significado del concepto de razón, se plantea la cuestión de cuándo es posible hablar de razón en una situación concreta y de cuáles son las condiciones que deben cumplirse para ello. Este aspecto se introduce fundamentalmente en la Actividad de aula 2

\section{VI.2.2.1 Análisis y valoración de la Actividad de aula 2}

\section{Descripción de la actividad}

En un lugar visible de la clase se muestra un cartel como el siguiente, en el que se indica verbalmente que 3 pajitas equivalen a 2 tarjetas ( $\mathrm{y}$ viceversa):

\section{$\stackrel{3}{\text { ajitas }} \longleftrightarrow \begin{gathered}2 \\ \text { tarjetas }\end{gathered}$}

Se forman parejas de alumnos (las mismas que en la Actividad 1 y que se mantendrán durante toda la propuesta). A cada pareja se le entrega un sobre grande que contiene una cantidad arbitraria (pero suficiente) de tarjetas de ambos tamaños, también se le dan 5 sobres más pequeños, dentro de los cuales hay una determinada cantidad de pajitas. En concreto:

\begin{tabular}{|c|}
\hline Sobre 1: 1 pajita grande. \\
\hline Sobre 2: 1 pajita pequeña. \\
\hline Sobre 3: 1 pajita grande y 1 pequeña. \\
\hline Sobre 4: 2 pajitas pequeñas y 1 grande. \\
\hline Sobre 5: 2 pajitas grandes y 1 pequeña. \\
\hline
\end{tabular}


La tarea que tienen que hacer los alumnos consiste en decidir qué debe entregarse a cambio de lo que hay en cada uno de los sobres, teniendo en cuenta el mensaje que tienen a la vista. Una vez decidido, deben poner su respuesta por escrito junto con el motivo que les ha llevado a tomar tal decisión en una ficha como la siguiente:

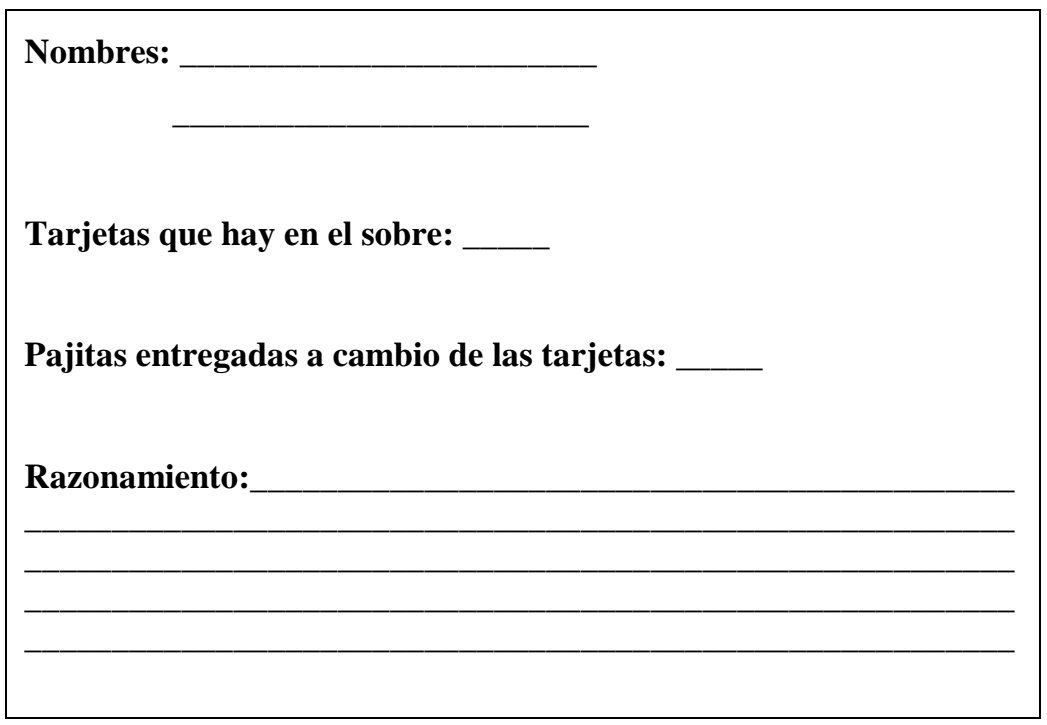

\section{Análisis de la actividad}

El estudio y análisis de las producciones de los alumnos se organizará según la estructura interna de la actividad que se ha descrito en el apartado anterior. Distinguiremos cuatro partes bien diferenciadas: la primera formada por el primer sobre, la segunda por el segundo sobre; la tercera parte se dedicará al tercer sobre y, finalmente, la cuarta parte está dedicada a los dos últimos sobres entregados a los alumnos.

Las unidades de análisis de esta actividad son las siguientes:

\begin{tabular}{|c|c|}
\hline 0 & No entrega o no asiste a clase \\
\hline 1 & Respuesta en blanco \\
\hline 2 & Respuesta incorrecta \\
\hline 3 & Razonamiento correcto, sin distinguir los tamaños \\
\hline 4 & $\begin{array}{r}\text { Razonamiento correcto, relacionando tarjetas grandes con } \\
\text { pajitas grandes y pequeñas con pequeñas. }\end{array}$ \\
\hline
\end{tabular}

En esta actividad, aunque sí puede hablarse de respuestas incorrectas (como de hecho veremos) no es tan sencillo hablar de respuestas correctas, debido precisamente a la pretendida ambigüedad del enunciado presentado a los alumnos. Sin embargo, sí que 
puede analizarse la corrección de los argumentos de los alumnos y, sobre todo, su consistencia.

\section{Sobre 1:}

En el sobre 1 los alumnos encuentran una pajita (que a posteriori descubrirán que es de tamaño grande). Aunque en este punto los alumnos desconocían el hecho de que también había pajitas pequeñas, hay que tener en cuenta que ya tenían a su disposición tarjetas de dos tamaños. Los resultados, según las unidades de análisis anteriores, están reflejados en la siguiente tabla:

\begin{tabular}{|c|c|c|c|c|c|c|}
\hline \multicolumn{2}{|c|}{} & $\mathbf{0}$ & $\mathbf{1}$ & $\mathbf{2}$ & $\mathbf{3}$ & $\mathbf{4}$ \\
\hline \multirow{2}{*}{ Sobre 1 } & $\mathbf{N}^{\mathbf{0}}$ de resp. & 0 & 0 & 2 & 23 & 1 \\
\cline { 2 - 7 } & Porcentaje & $0 \%$ & $0 \%$ & $7{ }^{\prime} 7 \%$ & $88^{\prime} 5 \%$ & 3'8\% \\
\hline
\end{tabular}

Llama la atención que tan sólo una pareja (la formada por A37 y A47) haya hecho la puntualización de que la pajita es "grande” así como que lo que la cantidad correspondiente es de tarjetas "grandes”. Nótese que esta pareja utiliza explícitamente en término 'razón': “Averiguamos la razón entre tarjetas y pajas y lo que nos da es 0’ $\widehat{6}$ ” (ver Figura VI.34).

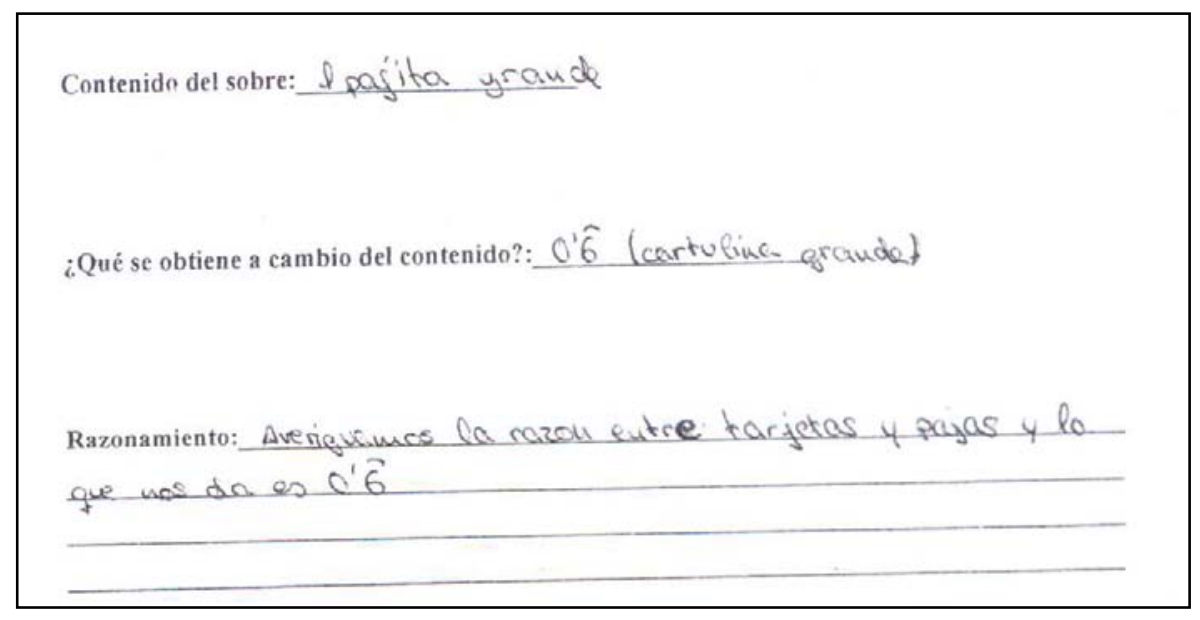

Figura VI.34.

Como hemos indicado más arriba, en el momento de resolver este apartado, los alumnos desconocían la existencia de dos tamaños de pajitas, pero sí sabían que había dos tipos de tarjetas. Además, nada les impedía volver sobre sus pasos una vez abiertos los sobres posteriores. Es posible que fuera esto lo que hizo esta pareja, pero no tenemos pruebas para afirmarlo. 
Tan sólo dos parejas han proporcionado respuestas totalmente incorrectas en este primer sobre. Una de ellas (A32 y A39) comete el error ya presentado en actividades anteriores de invertir el papel de las magnitudes involucradas. Así, dejando de lado la mención al tamaño, esta pareja dividió las 3 pajitas entre las 2 tarjetas para hallar cuántas tarjetas correspondían a 1 pajita (ver Figura VI.35): “Porque si dividimos 3:2 nos da el resultado de lo que vale una pajita".

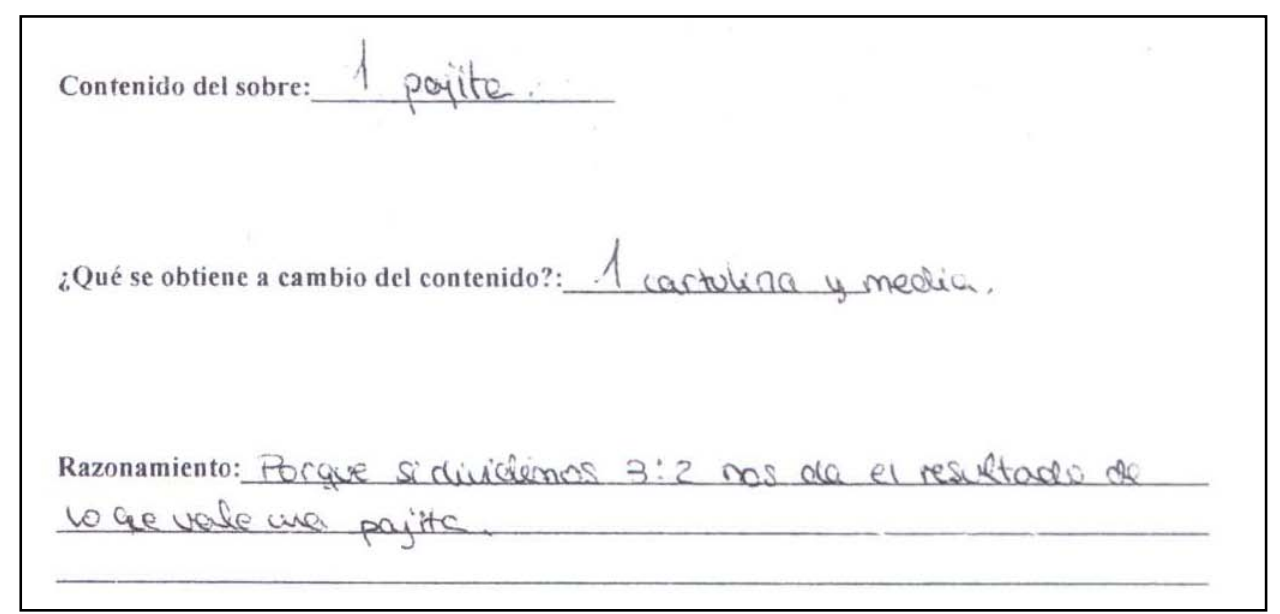

Figura VI.35.

Para ilustrar aún más las dificultades de los alumnos a la hora de manejar correctamente el orden de las operaciones para calcular la razón correspondiente, podemos presentar el caso de la pareja formada por A5 y A27 (Figura VI.36):

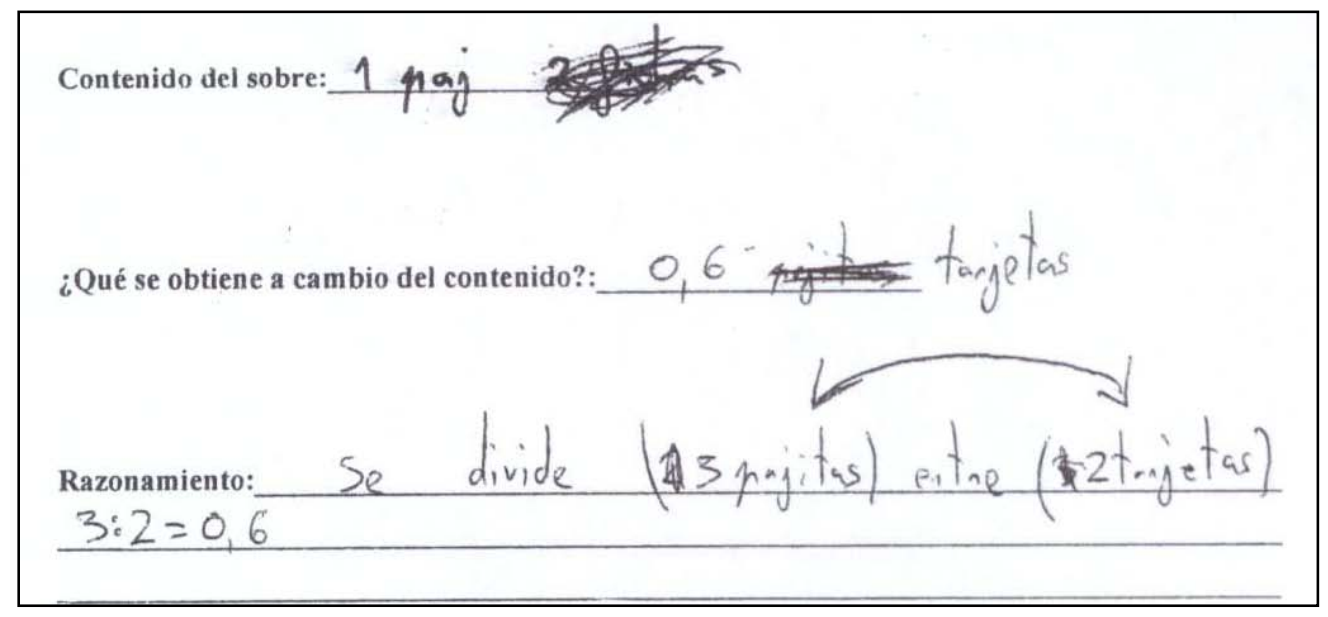

Figura VI.36.

Sin entrar en detalles sobre el escaso rigor en el manejo de los decimales, es sorprendente la operación "3:2=0,6" que demuestra que una vez obtenido el resultado, tienen problemas a la hora de reproducir sus ideas por escrito. 
Finalmente, la gran mayoría de los alumnos responde correctamente pero sin hacer mención explícita a los tamaños de los objetos implicados. Entre ellos encontramos parejas que no presentan un razonamiento claro (salvo indicar la operación que han efectuado). Es interesante reseñar que sigue apareciendo la dicotomía entre alumnos que hallan la razón mediante razonamientos multiplicativos (ver Figura VI.37 siguiente, correspondiente a la pareja A39 y A53, que ilustra claramente este caso):

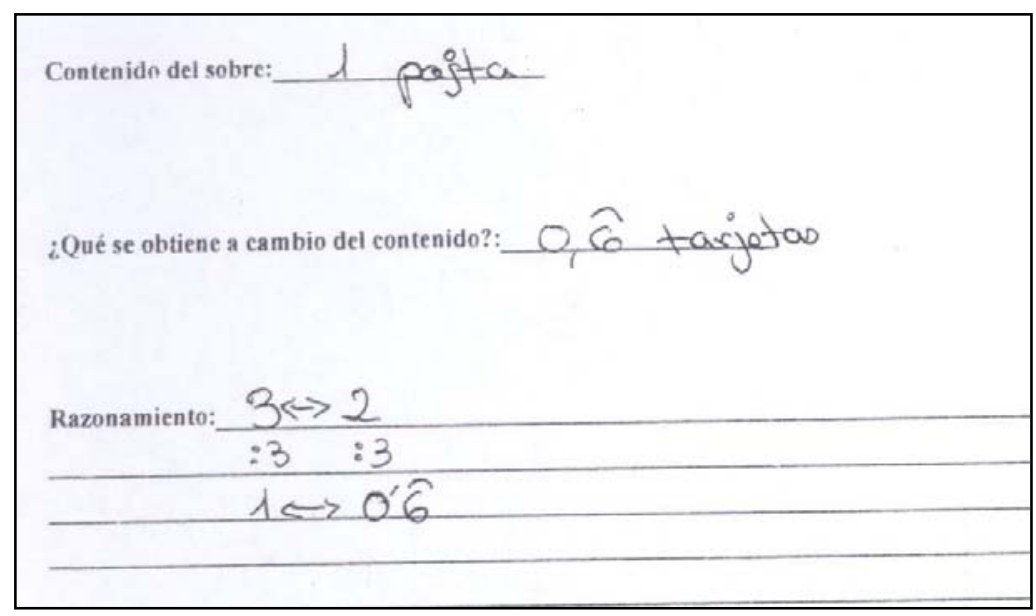

Figura VI.37.

y alumnos que hallan la razón como producto de un reparto (en la Figura VI.38, A42 y A50 afirman: “Si repartes las tarjetas entre las pajitas, te da lo que vale una pajita”):

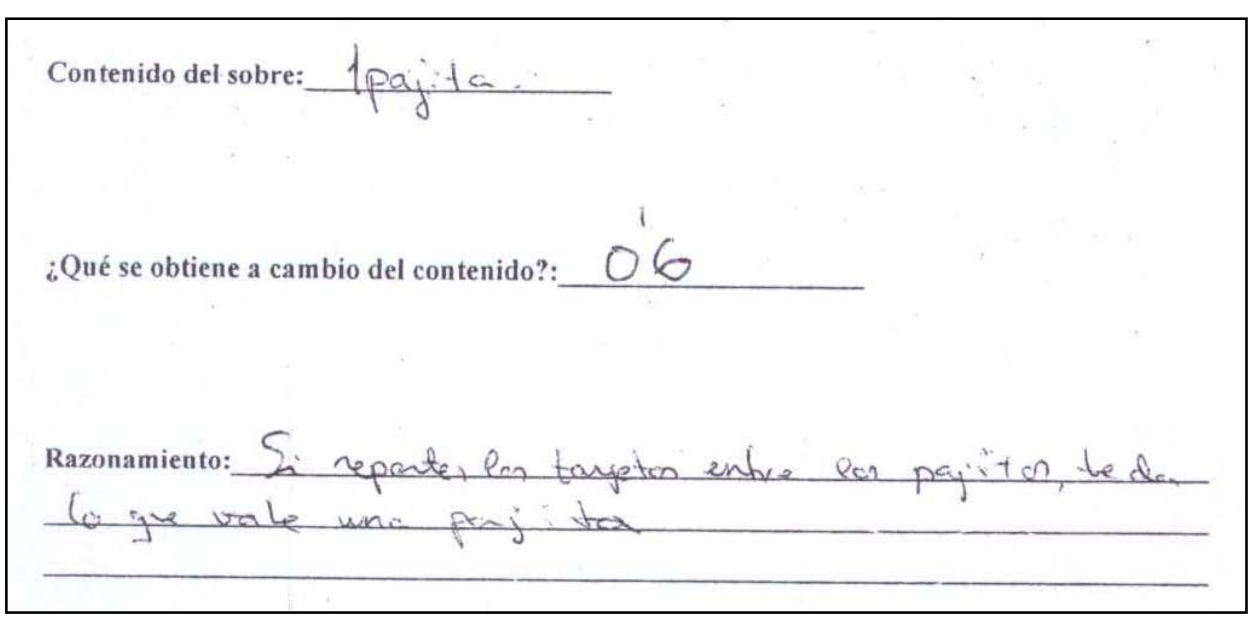

Figura VI.38.

Sobre 2:

El contenido del sobre 2 era una pajita de tamaño pequeño. En este punto entra en juego todavía más la ambigüedad del mensaje presentado a los alumnos. Como consecuencia, habrá alumnos para los que el contenido de este sobre siga siendo "una 
pajita”, para otros será "una pajita pequeña” y, finalmente, habrá parejas que identifiquen esta pajita de menor tamaño con “media pajita”. Esta última identificación no es aceptable puesto que las pajitas de tamaño pequeño no eran la mitad de largas que las de tamaño grande. La explicación a esta identificación hay que buscarla, por un lado, en el hecho de que dos tarjetas pequeñas hacían una grande y, por otro, en el deseo de los alumnos de referirlo todo a una única unidad para evitar los inconvenientes en el manejo de dos magnitudes distintas simultáneamente. Los resultados obtenidos tras el análisis de las respuestas de los alumnos se muestran en la tabla siguiente:

\begin{tabular}{|c|c|c|c|c|c|c|}
\hline \multicolumn{2}{|c|}{} & $\mathbf{0}$ & $\mathbf{1}$ & $\mathbf{2}$ & $\mathbf{3}$ & $\mathbf{4}$ \\
\hline \multirow{3}{*}{ Sobre 2 } & $\mathbf{N}^{\mathbf{0}}$ de resp. & 0 & 1 & 3 & 12 & 10 \\
\cline { 2 - 7 } & Porcentaje & $0 \%$ & $3{ }^{\prime} 8 \%$ & $11^{\prime} 5 \%$ & $46{ }^{\prime} 2 \%$ & 38 '5\% \\
\hline
\end{tabular}

Como hemos mencionado un poco más arriba, dos parejas han identificado la pajita pequeña con media pajita grande. Una de dichas parejas no ha llegado a dar una respuesta (y se contabiliza como respuesta en blanco) y la otra se ha contabilizado como respuesta incorrecta, si bien es cierto que la solución dada por dicha pareja (A6 y A11) es consistente con su elección (ver Figura VI.39) “Como 1 pajita=0’ $\widehat{6}$ como tenemos media pajita 279abrá 2 veces menos de tarjetas 0’6=0'3”:

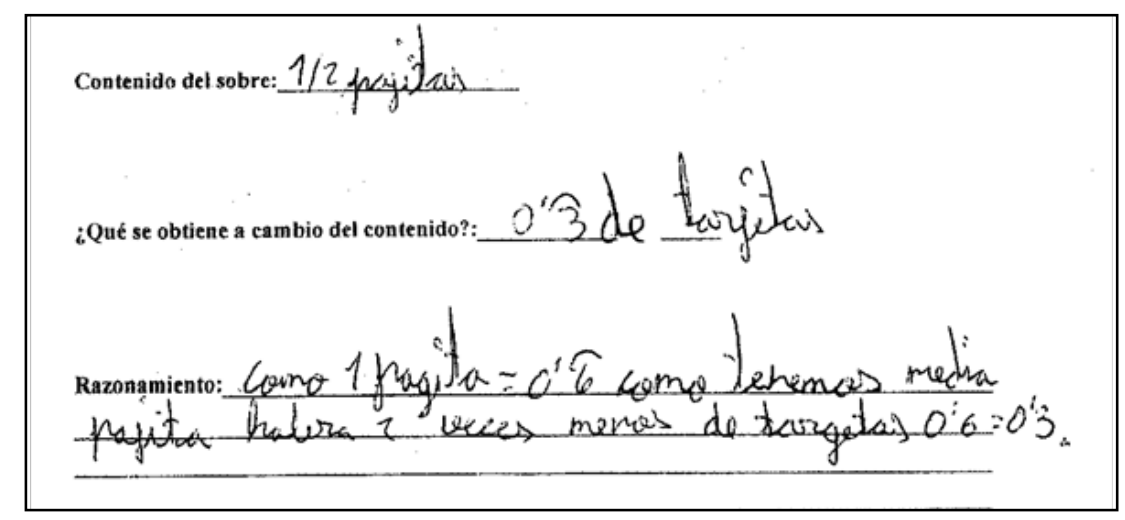

Figura VI.39.

De las otras dos respuestas incorrectas, una es la dada por la pareja A32 y A39, que comete el mismo error que se comentó en el sobre anterior, efectúa el reparto al revés. La pareja formada por A1 y A9 da una respuesta sin sentido.

El resto de las parejas se reparten casi a partes iguales entre aquellos que distinguen el tamaño (y que coinciden en que a las pajitas pequeñas les corresponden tarjetas pequeñas) y aquellos que no parecen encontrar (a tenor de sus respuestas) 
diferencia entre lo obtenido en este sobre y el anterior. Como ejemplo del primer tipo de alumnos, mostramos la respuesta de la pareja formada por A19 y A23: "Se divide el $n^{o}$ de tarjetas entre pajitas para obtener el $n^{\circ}$ de tarjetas que es 0 ' $\widehat{6}$, pero como son pajitas pequeñas se obtendrán tarjetas pequeñas” (ver Figura VI.40):

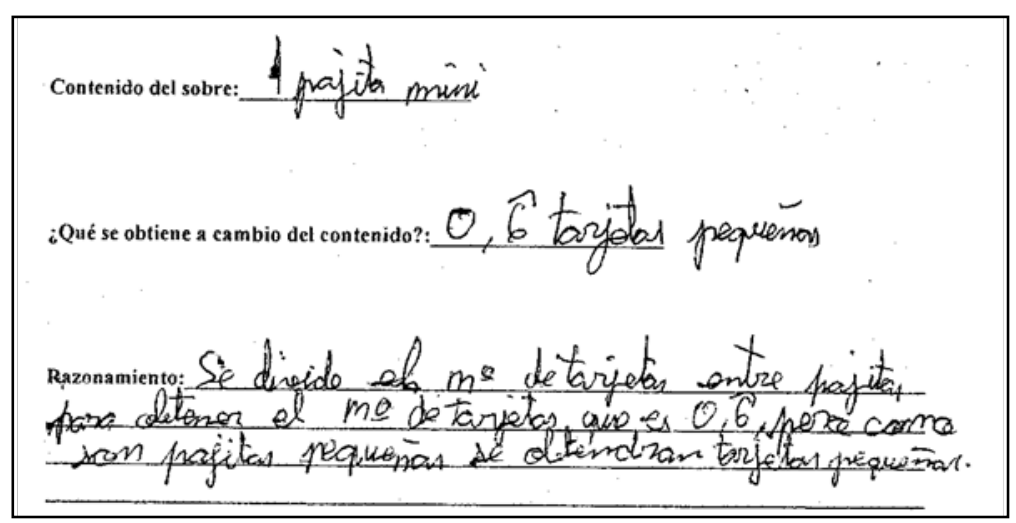

Figura VI.40.

Hay parejas que ni siquiera indican explícitamente que la pajita contenida en el sobre 2 es de distinto tamaño a la contenida en el sobre 1 y, por tanto, su respuesta en este sobre es indistinguible a la del anterior. Finalmente, hay parejas que, pese a indicar que la pajita del sobre es pequeña, no indican el tamaño de las tarjetas obtenidas a cambio; tal es el caso del grupo formado por A8, A12 y A17 (Figura VI.41):

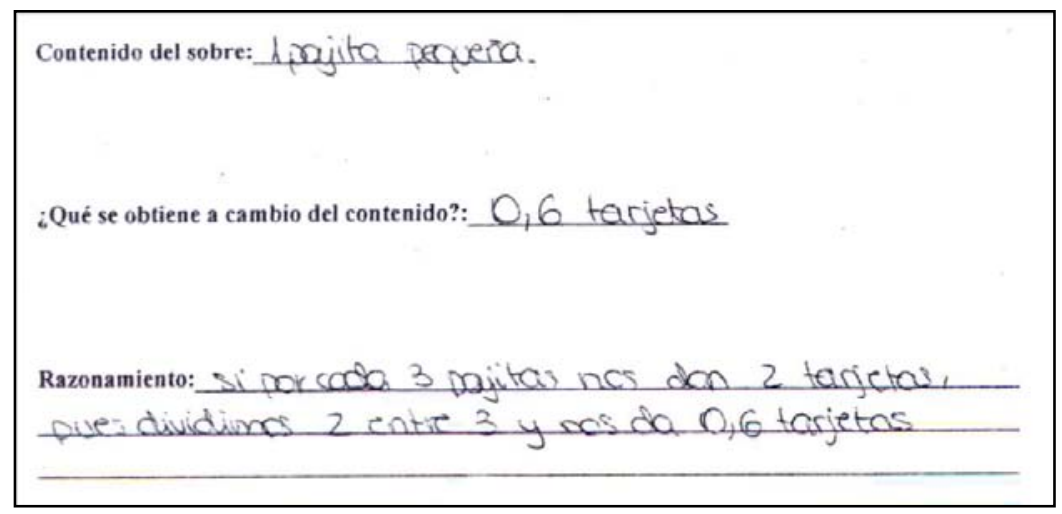

Figura VI.41.

Sobre 3:

En el sobre 3 se hace patente de forma clara el hecho de que existen dos tamaños distintos de pajitas y, además, se fuerza a los alumnos a manejar ambos tamaños (en realidad ambas magnitudes) de forma conjunta. Aquellas parejas que han identificado las pajitas pequeñas con media pajita grande cometerán en lo que sigue el mismo error: referirlo todo a la misma unidad (pajitas). Así, por ejemplo, en el sobre 3, para ellos, 
hay una pajita y media. Consideraremos estos casos como respuestas incorrectas, pese a que haya consistencia entre esa identificación y la respuesta de los alumnos. Los resultados obtenidos en este sobre son los siguientes:

\begin{tabular}{|c|c|c|c|c|c|c|}
\hline \multicolumn{2}{|c|}{} & $\mathbf{0}$ & $\mathbf{1}$ & $\mathbf{2}$ & $\mathbf{3}$ & $\mathbf{4}$ \\
\hline \multirow{2}{*}{ Sobre 3 } & $\mathbf{N}^{\mathbf{0}}$ de resp. & 0 & 6 & 8 & 4 & 8 \\
\cline { 2 - 7 } & Porcentaje & $0 \%$ & $23 \%$ & $30{ }^{\prime} 8 \%$ & $15^{\prime} 4 \%$ & $30{ }^{\prime} 8 \%$ \\
\hline
\end{tabular}

Como viene sucediendo en las actividades que ya se han analizado, a partir de este punto aumenta el número de respuestas en blanco debido a la falta de tiempo de los alumnos. Por otro lado vemos que aumenta el epígrafe de respuestas incorrectas; o lo que es lo mismo, de inconsistencias en los razonamientos de los alumnos. De hecho, el análisis de las respuestas de los alumnos en este sobre y los siguientes se hace algo más complejo que en los anteriores.

Lo más sencillo es tratar las parejas que responden “correctamente” y relacionan tarjetas grandes con pajitas grandes y pequeñas con pequeñas. No merece la pena dedicar comentarios a estos alumnos. Además, los que ya hacen correctamente este sobre con esta idea, también siguen la misma estrategia a la hora de resolver los dos últimos sobres.

Hay alumnos que no hacen el emparejamiento anterior, pero que, aun así, son consistentes. Estos alumnos, como por ejemplo la pareja formada por A2 y A20, simplemente dicen encontrar 2 pajitas en el sobre y, en consecuencia, su respuesta se limita a duplicar la dada en los dos sobres anteriores (ver Figura VI.42):

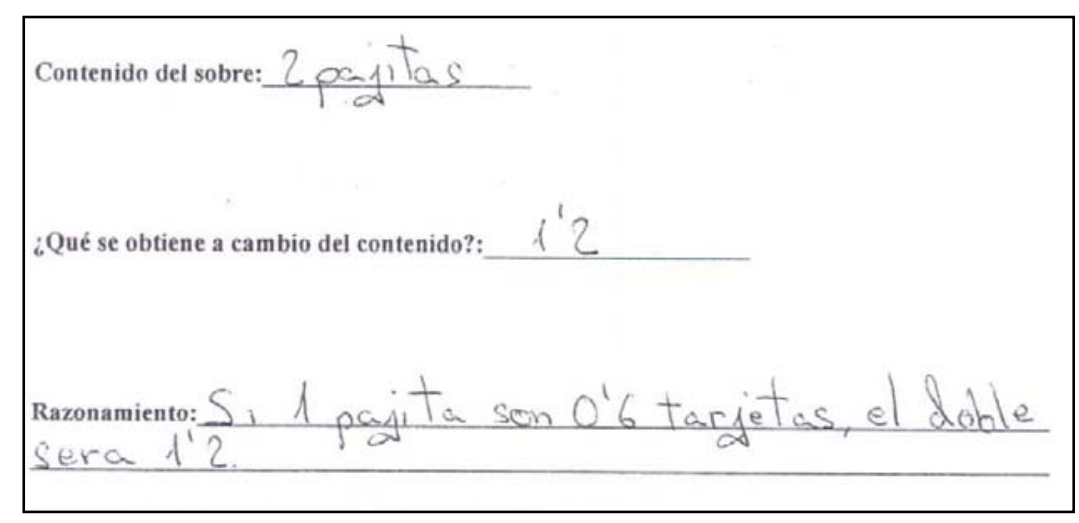

Figura VI.42.

De modo similar razonan las cuatro parejas catalogadas bajo el epígrafe 3. 
El abanico de razonamientos incorrectos es mucho más amplio. En primer lugar tenemos a las parejas que identifican las pajitas pequeñas con la mitad de una grande. De entre ellos, algunos razonan correctamente refiriéndose también a una única unidad en la magnitud "tarjetas". Tal es el caso (Figura VI.43) de A6 y A11:

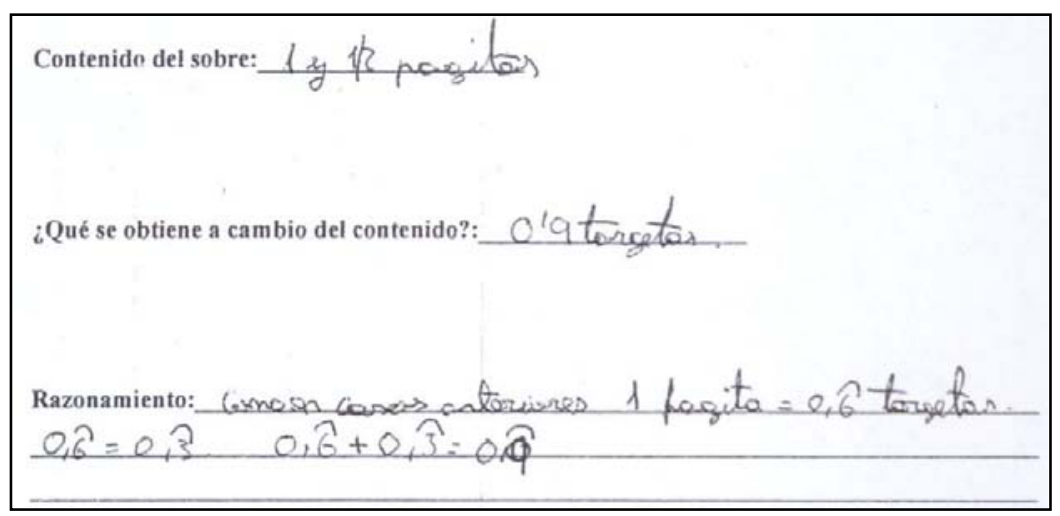

Figura VI.43.

que razonan correctamente, si bien de un modo aditivo, a partir de su trabajo anterior. Otra pareja (la formada por A32 y A38) también dicen encontrar una pajita y media en su sobre, pero como calcularon mal en los sobres anteriores (es la pareja que dividía al revés), dan una respuesta incorrecta aunque consistente con su trabajo anterior.

Pero hay errores más graves. Por ejemplo, algunos alumnos distinguen pajitas pequeñas de grandes, pero no relacionan los tamaños de las pajitas con los de las tarjetas o bien “suman” las tarjetas grandes con las pequeñas para dar una respuesta en una única unidad. La pareja formada por A55 y A56 (ver Figura VI.44) es un ejemplo.

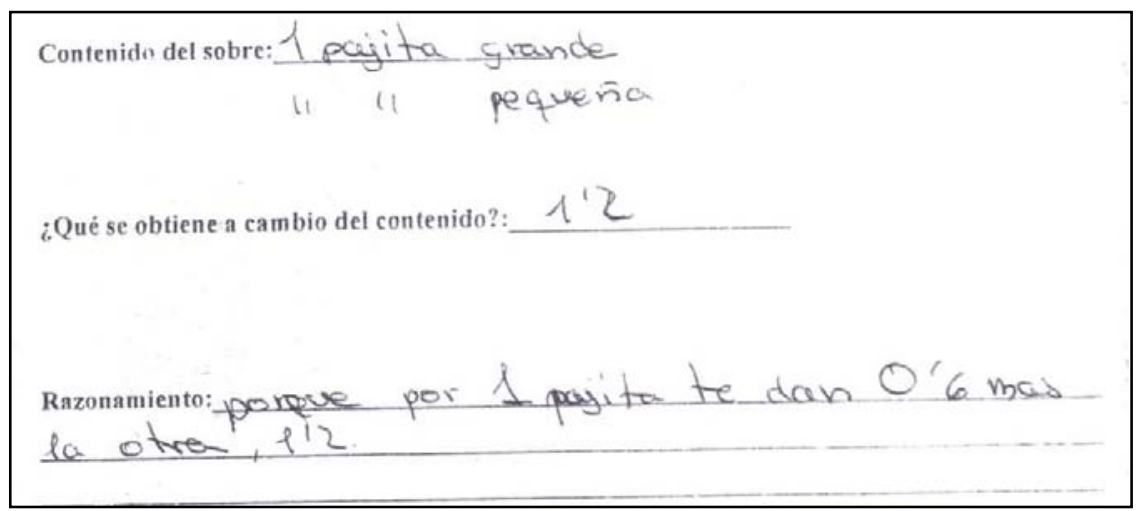

Figura VI.44.

El último error que reseñamos en este sobre es el cometido por la pareja formada por A44 y A51. Esta pareja no distingue los tamaños de las pajitas, pero a la hora de 
calcular las tarjetas correspondientes no queda muy claro su razonamiento (ver Figura VI.45):

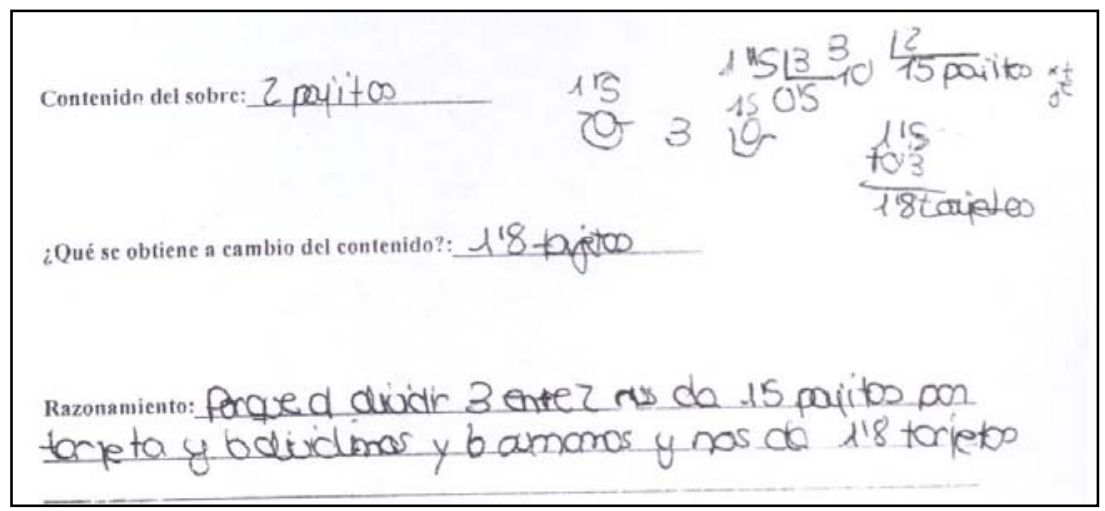

Figura VI.45.

Es extraño este razonamiento, porque en los dos sobres anteriores esta pareja efectuó la operación correcta (dividir 2 entre 3 ) mientras que aquí lo hace al revés y además después suma con el valor correspondiente a media pajita. Posiblemente hayan pedido ayuda a algún compañero y no le hayan comprendido por estar usando ideas distintas. Esta pareja no distinguía tamaños y pueden haber preguntado a una pareja que hablara de medias pajitas.

\section{Sobres 4 y 5:}

Estos dos últimos sobres iban en una dirección similar a la del sobre número 3. Se enfrentaba a los alumnos a situaciones en las que debían manejar dos magnitudes distintas (o dos unidades distintas de una misma magnitud), con las dificultades que ello conlleva. Los resultados obtenidos, de acuerdo a las unidades de análisis fijadas al inicio, son los siguientes:

\begin{tabular}{|c|c|c|c|c|c|c|}
\hline \multicolumn{2}{|c|}{} & $\mathbf{0}$ & $\mathbf{1}$ & $\mathbf{2}$ & $\mathbf{3}$ & $\mathbf{4}$ \\
\hline Sobre 4 & $\mathbf{N}^{\mathbf{0}}$ de resp. & 0 & 9 & 5 & 4 & 8 \\
\cline { 2 - 7 } & Porcentaje & $0 \%$ & $34^{\prime} 6 \%$ & $19^{\prime} 2 \%$ & $15^{\prime} 4 \%$ & $30{ }^{\prime} \% \%$ \\
\hline \multirow{3}{*}{ Sobre 5 } & $\mathbf{N}^{\mathbf{0}}$ de resp. & 0 & 11 & 5 & 3 & 7 \\
\cline { 2 - 7 } & Porcentaje & $0 \%$ & $42^{\prime} 3 \%$ & $19^{\prime} 2 \%$ & $11^{\prime} 5 \%$ & $27 \%$ \\
\hline
\end{tabular}

Si se comparan estos porcentajes se observa esencialmente un trasvase de alumnos desde el grupo de respuestas incorrectas al de respuestas en blanco. El resto se mantiene prácticamente igual. Las parejas que distinguían tamaños y relacionaban grande con grande y pequeño con pequeño siguen haciéndolo, aquellos que 
identificaban las pajitas pequeñas con media pajita grande se encuentran aquí (según ellos) con dos pajitas en el sobre 4 y dos y media en el 5, y responden en consecuencia. Lo más interesante a reseñar sea quizás lo que sucede con los alumnos que no distinguían pajitas grandes de pequeñas y las consideraban iguales. Para estas parejas en ambos sobre hay 3 pajitas y, por tanto, pueden utilizar directamente la información del cartel; como hace por ejemplo la pareja formada por A22 y A25 “2 tarjetas porque lo pone en la pizarra” (ver Figura VI.46):

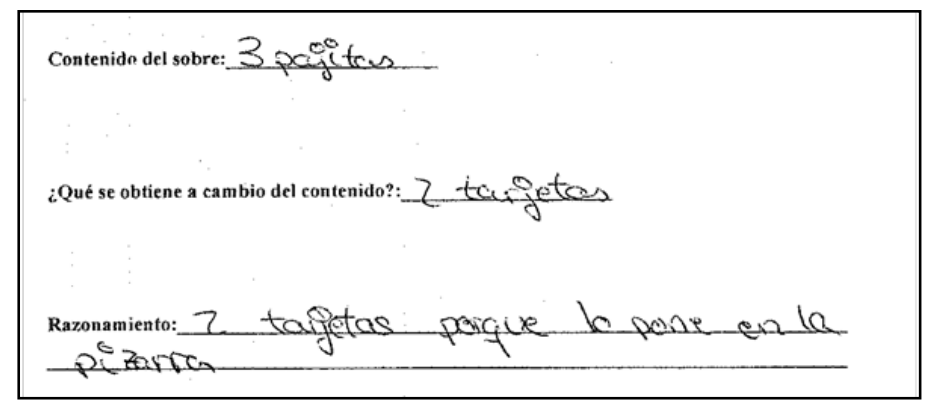

Figura VI.46.

No obstante, algunas de estas parejas que dicen encontrar tres pajitas en el sobre usan las respuestas dadas en los primeros sobre y las multiplican por 3, pero como no manejan correctamente los decimales obtienen una respuesta que no cuadra con la información del cartel (y no reparan en ello). Esto, por ejemplo, le sucede al grupo formado por A8, A12 y A17 (figura VI.47 siguiente):

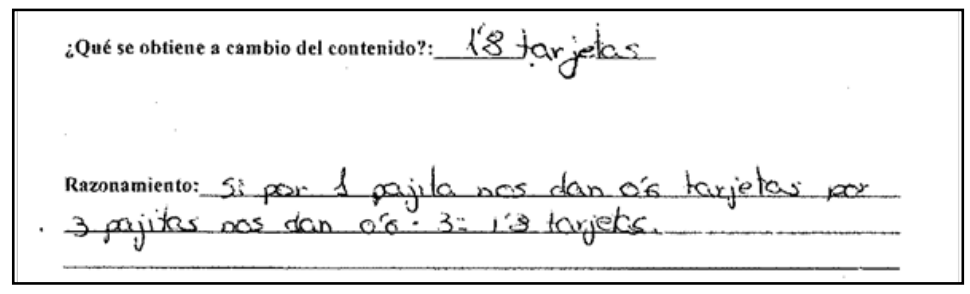

Figura VI.47.

\section{VI.2.2.2 Reflexiones relativas al punto 2}

1. Vuelve a observarse el deficiente manejo de los decimales por parte de los alumnos y su "alergia” a las fracciones. A la hora de sumar 0’ $\hat{6}+0$ ' $\widehat{6}$ nos

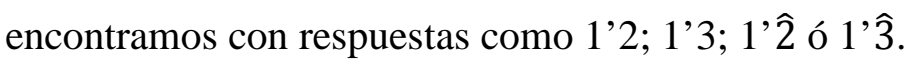

2. Los alumnos tienen grandes dificultades a la hora de manejar varias magnitudes o varias unidades de la misma magnitud simultáneamente. Se observa una tendencia natural de muchos alumnos a buscar una única unidad. 
3. Relacionado con lo anterior, aunque la diferencia de tamaño entre las pajitas grandes y pequeñas era tal que se observaba a simple vista que no era la mitad, muchos alumnos lo dieron por supuesto (quizás para facilitar las operaciones) y otros preguntaron al profesor. Esto se acentuó por el hecho de que las tarjetas pequeñas sí eran la mitad de las grandes, posiblemente este aspecto deba cambiarse en futuras puestas en práctica.

4. Muchos alumnos responden sin problemas que se obtiene lo mismo a cambio de una pajita grande que de una pequeña y parecen no percibir la ambigüedad del mensaje del cartel.

\section{VI.2.3 Punto 3: Comparar razones}

El primer uso que se da al concepto de razón entre dos magnitudes es el de comparar situaciones de intercambio diferentes en las que se intercambian los mismos objetos, para así decidir cual resulta más ventajosa. Esto se hace en la Actividad de aula 3 y en la Tarea de casa 3, si bien, en esta última ya no se presentan situaciones puramente de intercambio, sino más generales.

\section{VI.2.3.1 Análisis y valoración de la Actividad de aula 3}

\section{Descripción de la actividad}

En un lugar visible de la clase se muestran los siguientes carteles, en los que se presentan cuatro situaciones de intercambio diferentes entre pajitas y tarjetas.
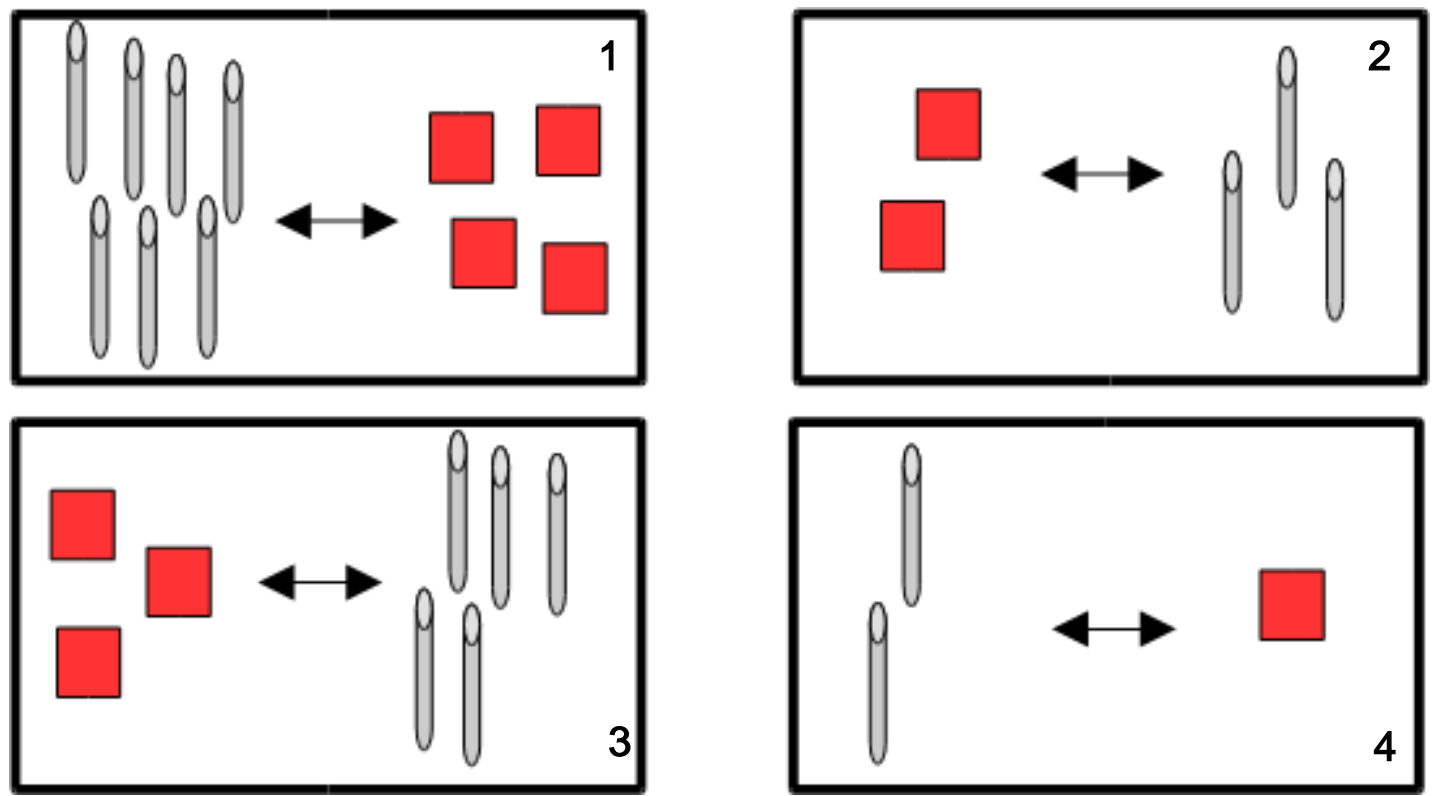
Se trabaja por parejas, como en todas las actividades. A cada pareja se le entregan pajitas y tarjetas en cantidad suficiente para trabajar. La tarea a efectuar por parte de los alumnos consiste en decidir qué situación de las anteriores resultaba más ventajosa a la hora de cambiar pajitas por tarjetas o viceversa. Como en las actividades anteriores se pedía a los alumnos que pusieran por escrito sus respuestas rellenando una ficha como la siguiente:

Nombre:

A) Si tuvieras que cambiar pajitas por tarjetas, ¿qué cartel te resulta más ventajoso? Razónalo.

B) Si tuvieras que cambiar tarjetas por pajitas, ¿qué cartel te resulta más ventajoso? Razónalo.

¿Has utilizado material?

\section{Análisis de la actividad}

Esta actividad constaba de dos partes claramente diferenciadas, aunque esencialmente la labor a realizar por parte de los alumnos era la misma en ambas partes (salvo el cambio de papeles entre tarjetas y pajitas). Por esto analizaremos conjuntamente ambos apartados de la actividad.

Las unidades de análisis de esta actividad son las siguientes:

\begin{tabular}{|c|c|}
\hline 0 & No entrega o no asiste a clase \\
\hline 1 & Respuesta en blanco \\
\hline
\end{tabular}




\begin{tabular}{|c|c|}
\hline 2 & Respuesta incorrecta \\
\hline 3 & Razonamiento correcto ${ }^{4}$, errores operativos \\
\hline 4 & Respuesta completamente correcta \\
\hline
\end{tabular}

En base a estas unidades de análisis, los resultados obtenidos en esta actividad son los siguientes:

\begin{tabular}{|c|c|c|c|c|c|c|}
\hline \multicolumn{2}{|c|}{} & $\mathbf{0}$ & $\mathbf{1}$ & $\mathbf{2}$ & $\mathbf{3}$ & $\mathbf{4}$ \\
\hline \multirow{2}{*}{ Apartado A) } & $\mathbf{N}^{\mathbf{0}}$ de resp. & 0 & 1 & 21 & 2 & 2 \\
\cline { 2 - 7 } & Porcentaje & $0 \%$ & $3^{\prime} 8 \%$ & $80^{\prime} 8 \%$ & $7^{\prime} 7 \%$ & $7^{\prime} 7 \%$ \\
\hline \multirow{2}{*}{ Apartado B) } & $\mathbf{N}^{\mathbf{0}}$ de resp. & 0 & 1 & 21 & 1 & 3 \\
\cline { 2 - 7 } & Porcentaje & $0 \%$ & $3^{\prime} 8 \%$ & $80^{\prime} 8 \%$ & $3^{\prime} 8 \%$ & $11^{\prime} 6 \%$ \\
\hline
\end{tabular}

Es evidente, a la luz de estos datos, que esta actividad resultó totalmente fallida. La gran mayoría de las parejas identificó la idea de "ser más ventajoso" con lo manejable de las operaciones; como hace por ejemplo la pareja formada por A5 y A27: “El cuatro porque como son 2 pajitas y 1 tarjeta es mas fácil hacer operaciones" (Figura VI.48):

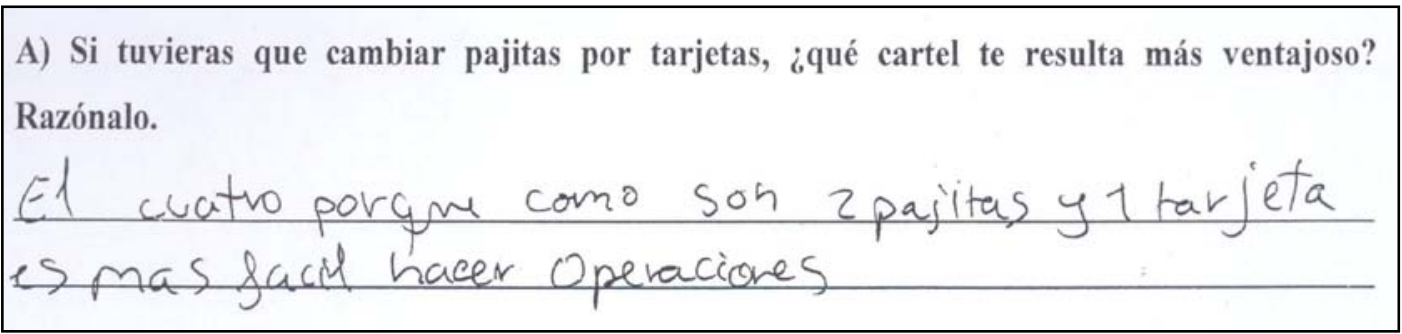

Figura VI.48.

Además de la facilidad a la hora de efectuar las operaciones, algunas parejas, como la formada por A46 y A48; se fija en la simplicidad del resultado: "El cartel de 1 tarjeta por 2 pajitas porque seria más fácil calcular a cuantas pajitas equivale una cartulina. Además el resultado es un número mas sencillo” (ver Figura VI.49):

4 Entenderemos por razonamiento correcto aquel que suponga utilizar la razón (aunque sea implícitamente) como herramienta de decisión. 
B) Si tuvieras que cambiar tarjetas por pajitas, ¿qué cartel te resulta más ventajoso? Razónalo.

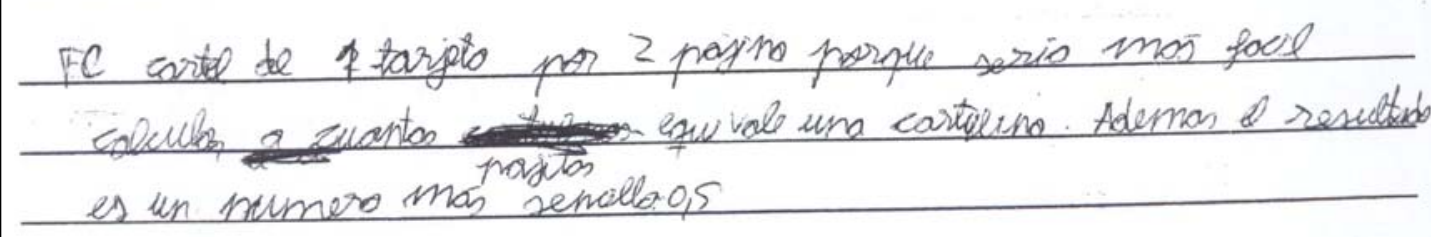

Figura VI.49.

Esta pareja, no obstante, muestra una mayor claridad de ideas. Dicen que deben calcular a cuántas pajitas equivale una tarjeta, es decir, calcular la razón entre pajitas y tarjetas; sin embargo lo calculan al revés (dividen tarjetas entre pajitas y no a la inversa) y además comparan las razones desde el punto de vista de su "sencillez" (si es que hay números más sencillos que otros, para esta pareja 1/2 es más sencillo que 2/3, 4/7 y 3/5).

Hay alumnos que llevan la idea de la sencillez de las operaciones al extremo y elijen carteles distintos en función de la paridad de la cantidad de pajitas (o tarjetas, depende del apartado) que se desea intercambiar. Así, la pareja formada por A19 y A23 (ver Figura VI.50 siguiente) dice: "El cartel de 2 tarjetas obtienes 3 pajitas y viceversa y el de 2 pajitas por 1 tarjeta y viceversa para obtener numeros pares e impares”.

B) Si tuvieras que cambiar tarjetas por pajitas, ¿qué cartel te resulta más ventajoso?

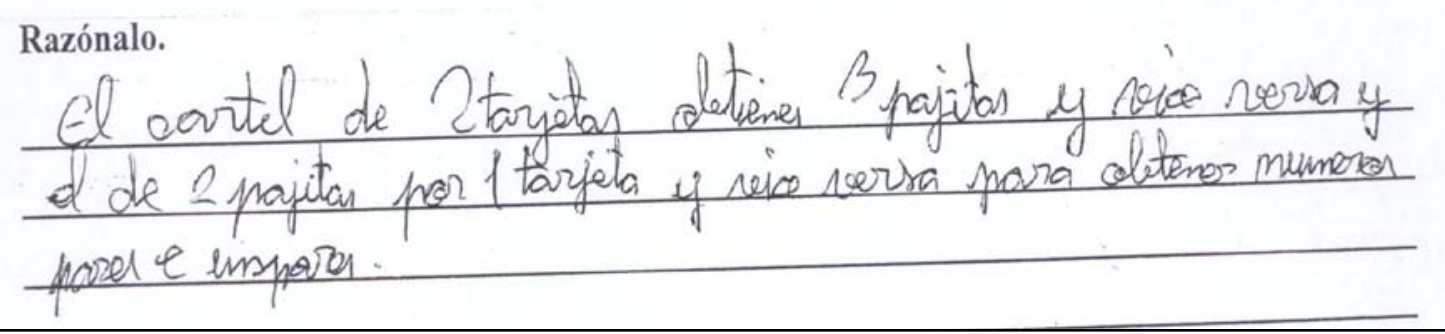

Figura VI.50.

Esta pareja ha observado correctamente la reversibilidad de las situaciones de intercambio (de ahí su expresión “y viceversa”) pero comete el mismo error que las anteriores. Eso sí, si la cantidad de tarjetas a cambiar es par, elige el cartel número 2, puesto que en él aparecen dos tarjetas y la operación se hace fácilmente (esta claro aquí el deseo de aplicar estrategias multiplicativas), mientras que si es impar, se decanta por el número 4 en el que se dice directamente la cantidad de pajitas correspondientes a una 
pajita. Sería interesante preguntar a la pareja por qué no usan también el cartel número 4 si la cantidad es par, pero la respuesta quedará en el misterio.

Otro tipo de error que se ha recogido es el cometido por la pareja formada por A1 y A9: “4- porque es la que más interesa, la que menos pajitas tienes que dar” (ver Figura VI.51):

A) Si tuvieras que cambiar pajitas por tarjetas, ¿qué cartel te resulta más ventajoso? Razónalo.

4. porque es la que más interesa, la que menos paivitas tienes que dar

Figura VI.51.

Aunque esta pareja sí se centra en las cantidades y no en la simplicidad de las operaciones, no observa que para comparar diversas situaciones en las que se intercambian las mismas mercancías deben compararse las cantidades de una obtenidas a cambio de una cantidad fija de la otra. De este modo, estos alumnos elijen a la hora de cambiar pajitas por tarjetas el cartel en el que menos pajitas deben entregar (también podrían haber elegido el cartel en el que más tarjetas aparecen, como de hecho hace alguna pareja).

Como se ha indicado ya en actividades anteriores, algunos alumnos presentan dificultades respecto al orden en que se enuncian las magnitudes en relación con el orden en el que efectuar las operaciones. Así, en esta actividad, algunas parejas no comprendían correctamente que la frase “cambiar pajitas por tarjetas” implica que ellos tienen pajitas y desean obtener tarjetas (o a la inversa). Estas dificultades justifican respuestas como la de la pareja formada por A31 y A36 (ver Figura VI.52 siguiente): “El cartel 2, porque tiene menos contenido y porque pasa de tarjetas a pajitas".

B) Si tuvieras que cambiar tarjetas por pajitas, ¿qué cartel te resulta más ventajoso? Razónalo.

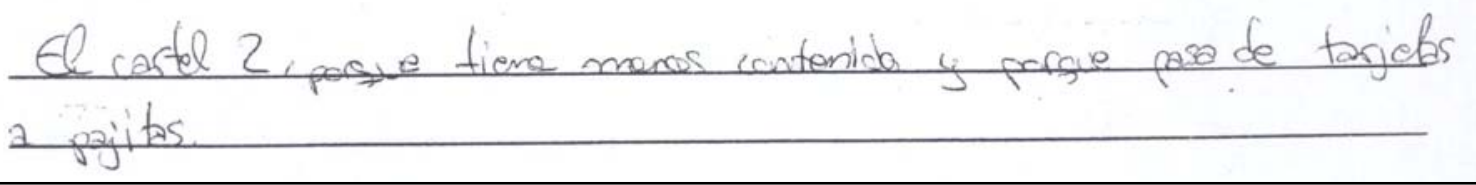

Figura VI.52. 
Dejando de lado la expresión “tiene menos contenido", que no queda clara en absoluto (pues al cartel número dos no es ni el que tiene menos tarjetas, ni el que tiene menos pajitas, ni el que menos objetos tiene de los cuatro), esta pareja elige el cartel 2 aparentemente - porque ya va en la misma “dirección” que el intercambio por el que se pregunta en el enunciado y así se ahorran problemas a la hora de pensar en qué orden hacer operaciones.

Los problemas con el orden de las operaciones se dan incluso entre aquellos alumnos que tienen clara la idea de que deben comparar las razones correspondientes a cada cartel para resolver la actividad. La pareja formada por A6 y A11 parece cometer este error en el apartado A (ver Figura VI.53):

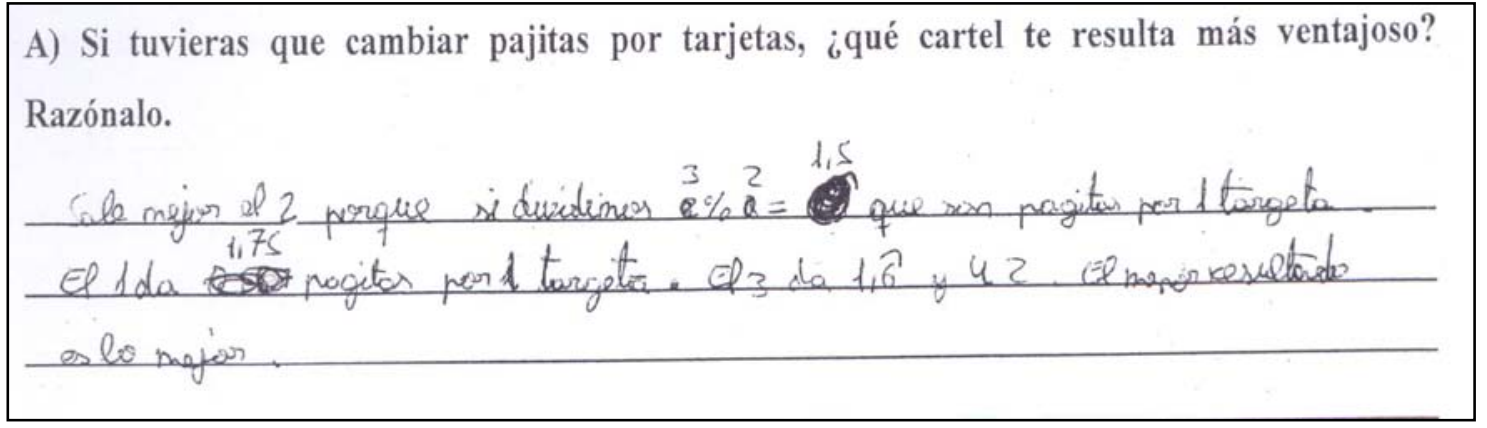

Figura VI.53.

Esta respuesta: “Sale mejor el 2 porque si dividimos 3:2=1'5 que son pajitas por 1 tarjeta. El 1 da 1'75 pajitas por 1 tarjeta. El 3 da 1' $\widehat{6}$ y 4 2. El menor resultado es lo mejor” es muy interesante. En primer lugar, lo valores encontrados por esta pareja efectivamente se corresponden a pajitas por 1 tarjeta, pero para resolver este apartado lo más directo habría sido hallar los inversos; es decir, las tarjetas por 1 pajita. No obstante, y de modo bastante sorprendente, la pareja indica acertadamente que lo mejor es el menor resultado (y no el mayor, que es lo que debería haber sido si hubieran calculado los inversos). En resumen, esta pareja no elige el cartel en el que más tarjetas se obtienen por una pajita, sino aquel en el que menos pajitas se necesitan para obtener una tarjeta. Desde luego es una forma, digamos, “poco natural” de razonar. Además, la respuesta de esta pareja al apartado B es correcta aunque incompleta por lo que no tenemos elementos de juicio suficientes para valorar sus razonamientos.

En cualquier caso la respuesta que acabamos de presentar es la más completa de las recogidas. Incluso entre aquellas parejas que utilizan la razón correctamente para 
comparar las situaciones, las respuestas deben calificarse de incompletas. Por ejemplo, el grupo formado por A8, A12 y A17 responde: “Me resultaría mas ventajoso el cartel $n^{\circ} 2$ porque por una pajita, me dan 0'6̂ tarjetas y es el cartel que más tarjetas me dan por cada pajita" (ver Figura VI.54 a continuación)

A) Si tuvieras que cambiar pajitas por tarjetas, ¿qué cartel te resulta más ventajoso? Razónalo.

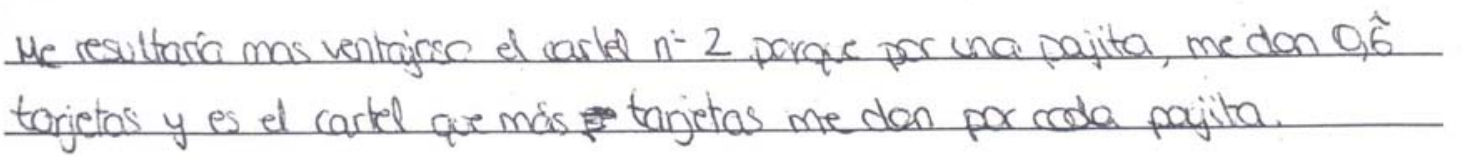

Figura VI.54.

La idea queda bien clara. Han calculado correctamente la razón entre tarjetas y pajitas en el cartel número 2 y han observado que dicho valor es el mayor de los cuatro. En realidad hemos de suponer que han calculado correctamente las otras tres razones y que las han comparado para tomar una decisión; por eso la afirmación de que la respuesta es algo incompleta.

\section{VI.2.3.2 Análisis y valoración de la Tarea de casa 3}

\section{Enunciado}

En clase hemos visto que en ciertas ocasiones la razón nos sirve para descubrir qué situación es más ventajosa para nosotros, cuando tenemos varias opciones entre las que elegir. Con esta idea en la cabeza, trata de resolver los siguientes ejercicios. Pero, ¡cuidado! Recuerda que no siempre podemos definir la razón entre dos magnitudes.

\section{Ejercicio 1:}

En el banco A cambian 120 dólares por 170 euros, y en el banco B cambian 180 euros por 130 dólares. Si quieres cambiar euros a dólares, ¿̇a qué banco irías?

\section{Ejercicio 2:}

El futbolista $\mathrm{N}$ ha marcado 18 goles en los 22 partidos que ha jugado; mientras que el futbolista P ha marcado 25 goles en los 38 partidos jugados, ¿qué futbolista ofrece mayor rendimiento goleador?

Ejercicio 3:

Una receta de naranjada indica que hay que mezclar 0,5 litros de naranja con 1,5 litros 
de agua; otra receta dice que hay que mezclar 1,5 litros de naranja con 5 litros de agua, ¿cuál de las dos recetas proporciona un sabor de naranja más fuerte?

Ejercicio 4:

En segundo curso aprobé 7 asignaturas y en tercer curso aprobé también 7 asignaturas. ¿En qué curso obtuve mejor rendimiento?

\section{Ejercicio 5:}

En el colegio A hay matriculados 450 alumnos, y en el colegio B hay matriculados 320 alumnos. En el colegio A hay 35 profesores, mientras que en el colegio B hay 25 profesores. ¿En cuál de los colegios los alumnos obtienen mejores calificaciones?

Ejercicio 6:

En una tienda, si compras 3 discos, te regalan 4 camisetas, y en otra tienda te regalan 5 camisetas al comprar 4 discos, ¿en qué tienda es más rentable comprar?

\section{Ejercicio 7:}

Cuatro vacas negras dan tanta leche en cinco días como tres vacas marrones en seis días. ¿Qué clase de vaca es más lechera, la negra o la marrón?

\section{Análisis de la tarea}

Como venimos haciendo, analizaremos por separado cada uno de los tres tipos de ejercicios que se han presentado en el apartado anterior. Además, puesto que son esencialmente distintos, también la tipología de respuestas varía de unos tipos a otros. Por ello, las unidades de análisis para las respuestas de los alumnos serán distintas en cada tipo de ejercicio.

\section{Ejercicios 1, 2, 3 y 6:}

En estos ejercicios las magnitudes involucradas pueden suponerse directamente proporcionales y, además, la razón es la herramienta más útil a la hora de comparar las dos situaciones presentadas. Las unidades de análisis para estos ejercicios son las siguientes:

\begin{tabular}{|c|c|}
\hline 0 & No entrega o no asiste a clase \\
\hline 1 & Respuesta en blanco \\
\hline 2 & Respuesta incorrecta sin usar razones \\
\hline 3 & Respuesta incorrecta usando razones \\
\hline
\end{tabular}




\begin{tabular}{|c|c|}
\hline 4 & $\begin{array}{c}\text { Respuesta correcta sin razonamiento o con razonamiento } \\
\text { incorrecto }\end{array}$ \\
\hline 5 & Respuesta parcialmente correcta ${ }^{5}$ \\
\hline 6 & Respuesta totalmente correcta \\
\hline
\end{tabular}

De acuerdo con estas unidades de análisis los resultados obtenidos por los alumnos en estos ejercicios se presentan en la siguiente tabla:

\begin{tabular}{|c|c|c|c|c|c|c|c|c|}
\hline & & 0 & 1 & 2 & 3 & 4 & 5 & 6 \\
\hline \multirow[t]{2}{*}{ Ejercicio 1} & $\mathrm{~N}^{\mathrm{o}}$ de resp. & 5 & 3 & 12 & 2 & 15 & 7 & 12 \\
\hline & Porcentaje & 8’9\% & $5 ’ 4 \%$ & $21^{\prime} 4 \%$ & 3’6\% & $26{ }^{\prime} 8 \%$ & $12 ’ 5 \%$ & $21 ’ 4 \%$ \\
\hline \multirow[t]{2}{*}{ Ejercicio 2} & $\mathrm{~N}^{\mathrm{o}}$ de resp. & 5 & 4 & 3 & 4 & 13 & 10 & 17 \\
\hline & Porcentaje & 8’9\% & 7’1\% & $5 ’ 4 \%$ & 7’1\% & $23 ’ 2 \%$ & $17 ’ 9 \%$ & $30 ’ 4 \%$ \\
\hline \multirow[t]{2}{*}{ Ejercicio 3} & $\mathrm{~N}^{\mathrm{o}}$ de resp. & 5 & 7 & 13 & 1 & 11 & 8 & 11 \\
\hline & Porcentaje & 8’9\% & $12 ’ 5 \%$ & $23 ’ 2 \%$ & 1'8\% & $19^{\prime} 6 \%$ & $14 ’ 4 \%$ & $19 ’ 6 \%$ \\
\hline \multirow[t]{2}{*}{ Ejercicio 6} & $\mathrm{~N}^{0}$ de resp. & 5 & 3 & 19 & 8 & 6 & 6 & 9 \\
\hline & Porcentaje & 8’9\% & $5 ’ 4 \%$ & $33{ }^{\prime} 9 \%$ & $14{ }^{\prime} 4 \%$ & $10^{\prime} 7 \%$ & $10^{\prime} 7 \%$ & 16’1\% \\
\hline
\end{tabular}

Como se puede observar el porcentaje de alumnos que responde correctamente (suma de los epígrafes 4, 5 y 6) es bastante alto; aunque las respuestas correctas sin razonamiento o con un razonamiento incorrecto suponen en torno a un tercio de éste porcentaje. El ejercicio con un menor porcentaje de aciertos es el número 6. Esto es, hasta cierto punto, sorprendente pues la situación que se presenta no es muy compleja. El ejercicio con un mayor porcentaje de aciertos es el segundo, seguramente por presentarse en un contexto muy familiar para los alumnos. En el ejercicio 1 aparecen diversos errores muy interesantes. Algunos reflejan los problemas de los alumnos a la hora de manejar el orden en el que aparecen las magnitudes además de indicar (como ya señalamos en la Actividad 3) el hecho de que los alumnos no acaban de comprender bien la expresión “cambiar euros a dólares”. En la Actividad 3 se utilizaba la expresión “cambiar pajitas por tarjetas” y aquí se cambió la preposición para tratar de enfatizar la dirección en la que se realiza el intercambio. El alumno A49 (ver Figura VI.55), ante la dificultad de tener que "invertir" una de las dos situaciones que plantea el enunciado,

\footnotetext{
${ }^{5}$ Por respuesta parcialmente correcta entenderemos aquellas en las que el razonamiento del alumno, aún siendo adecuado, sea incompleto.
} 
opta por elegir aquella situación en la que el enunciado proporciona la información requerida de un modo directa: “Al banco A porque te cambian $€$ por \$”

Ejercicio 1:

En el banco A cambian 120 dólares por 170 euros, y en el banco B cambian 180 euros por 130 dólares. Si quieres cambiar euros a dólares, ¿a qué banco irías?

Al banco $A$ prque te cambian $\ldots$ por

\section{Figura VI.55.}

Relacionado con los problemas a la hora de manejar las magnitudes en el orden adecuado, otro tipo de error relativamente común es el cometido por el alumno A29 (en la Figura VI.56 siguiente):

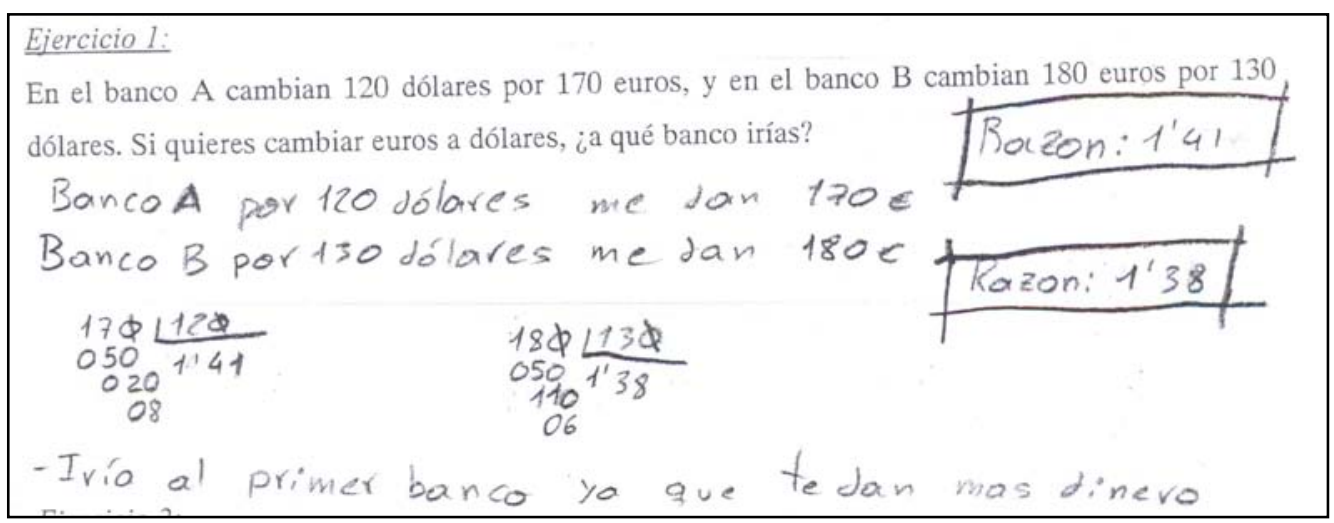

Figura VI.56.

En lugar de calcular la razón entre euros y dólares; es decir, los dólares que se obtienen por cada euro y elegir el banco con una mayor razón, este alumno elige el banco en el que le dan más euros a cambio de un dólar. El error que comete el alumno se debe a que se centra más en el método (calcular razones, elegir el que de un mayor valor) que en pararse a pensar qué significado tienen los resultados de las operaciones efectuadas y qué relación tiene ese significado con la pregunta del ejercicio.

También hay errores interesantes cometidos por alumnos que todavía no han asimilado las estrategias multiplicativas relacionadas con el concepto de razón. Así, en este caso, hay algunos alumnos que tratan de aplicar estrategias aditivas basadas en la diferencia entre euros y dólares. Se han detectado dos errores de este tipo. El primero es el cometido por A36 (en la Figura VI.57 siguiente): 


\section{Ejercicio 1:}

En el banco A cambian 120 dólares por 170 euros, y en el banco B cambian 180 euros por 130 dólares. Si quieres cambiar euros a dólares, ¿a qué banco irías?

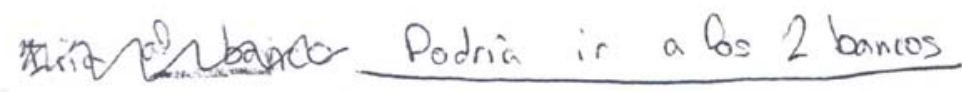

$$
\begin{array}{r}
170 \\
-120 \\
\hline 50
\end{array}=\frac{\begin{array}{l}
180 \\
130
\end{array}}{50}
$$

Figura VI.57.

Este alumno concluye que da lo mismo ir a un banco que a otro porque la diferencia entre euros y dólares es la misma en ambos bancos. Este tipo de respuestas implica que el alumno no ha asimilado la idea de que los aumentos sólo sirven para comparar situaciones si se trata de aumentos relativos y no absolutos. Este tipo de consideración será especialmente relevante a la hora de tratar los porcentajes. También relacionado con este tipo de razonamientos está el error cometido por A24 (en la Figura VI.58 siguiente):

\section{Ejercicio 1:}

En el banco A cambian 120 dólares por 170 euros, y en el banco B cambian 180 euros por 130 dólares. Si quieres cambiar euros a dólares, ¿a qué banco irías?

$$
\begin{aligned}
& 120 \not 1706 \\
& 180 \in \rightarrow 130 \not 2 \\
& \text { cualguiera de las dos Banco A - me dan } \\
& \text { meros dobares, (10 menos) pero doy menos } \\
& \text { dures ( } 10 \text { menos) } \\
& \text { Bano B:Me dan más dobees (10 mas) } \\
& \text { pero day mós eures (10 mas) }
\end{aligned}
$$

Figura VI.58.

En este caso, el error del alumno es quizás más grave, puesto que implicaría que los euros tienen el mismo valor que los dólares. Posiblemente este error sea debido a que la situación del cambio de moneda no es significativa para el alumno.

Para concluir con el ejercicio 1, mostramos una respuesta de un alumno que ha comprendido perfectamente la situación. El alumno A45 (en la Figura VI.59 siguiente) ha calculado los dólares obtenidos a cambio de un euro en ambos bancos y ha elegido el banco en el que obtiene más dólares por euro. Además, señala que ha calculado las razones y les asigna su significado. 


\section{Ejercicio 1:}

En el banco A cambian 120 dólares por 170 euros, y en el banco B cambian 180 euros por 130 dólares. Si quieres cambiar euros a dólares, ¿a qué banco irías?

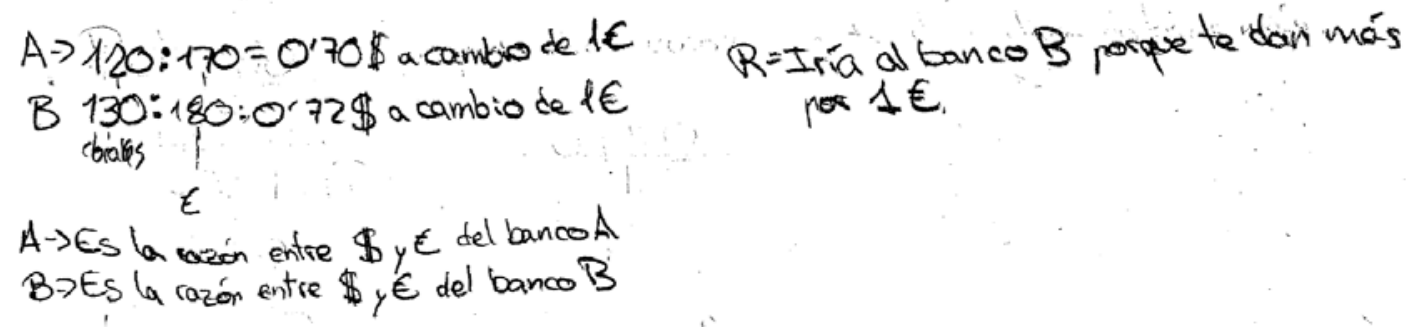

Figura VI.59.

Todos los alumnos que resuelven el ejercicio de forma correcta razonan de este modo, excepto uno. El alumno A31 usa la misma idea pero calculando las razones inversas; es decir, calculando los euros necesarios para obtener un dólar (Figura VI.60 siguiente) y eligiendo "el banco B porque para conseguir un dólar necesitas menos euros"

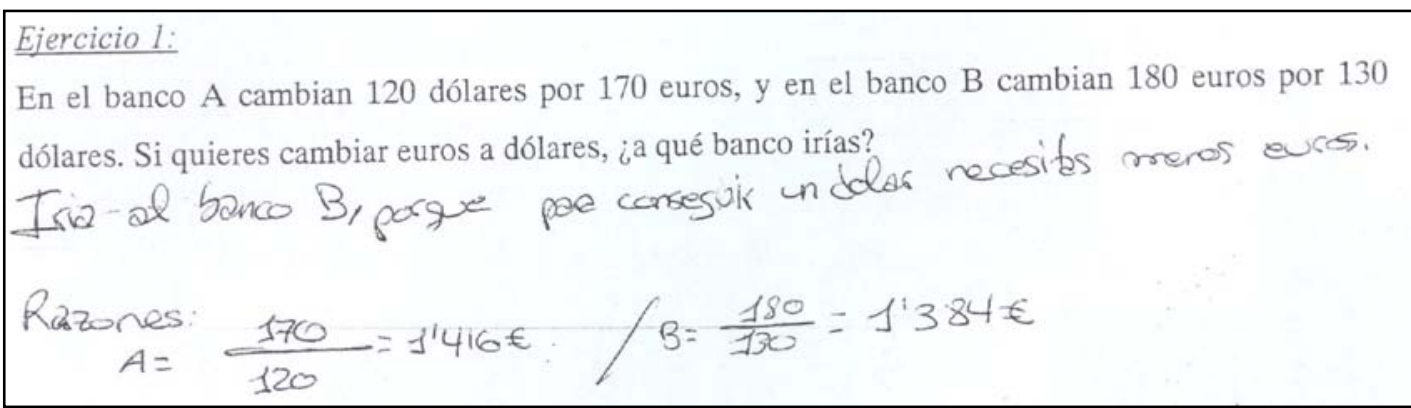

Figura VI.60.

El uso por parte de este último alumno de la razón inversa a la más natural en este caso (si es que tiene sentido hablar de naturalidad) tiene interés por cuanto el significado que le ha asignado es correcto y lo ha utilizado apropiadamente para resolver el ejercicio. Sin embargo este mismo alumno, en el Ejercicio 2 ha calculado también la razón inversa (no calcula goles por partido, sino partidos necesarios para marcar un gol) pero no le asigna el significado correcto y, por lo tanto, no resuelve correctamente el ejercicio (ver Figura VI.61 siguiente): 


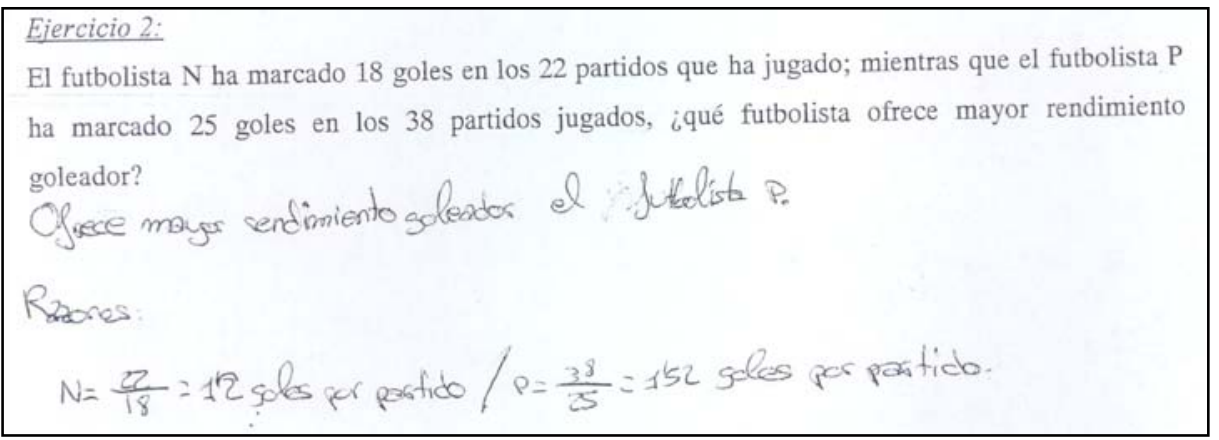

Figura VI.61.

Este error ha sido el más común junto con el siguiente, cometido por el alumno A4 (Figura VI.62). Nuevamente aparecen los razonamientos de tipo aditivo:

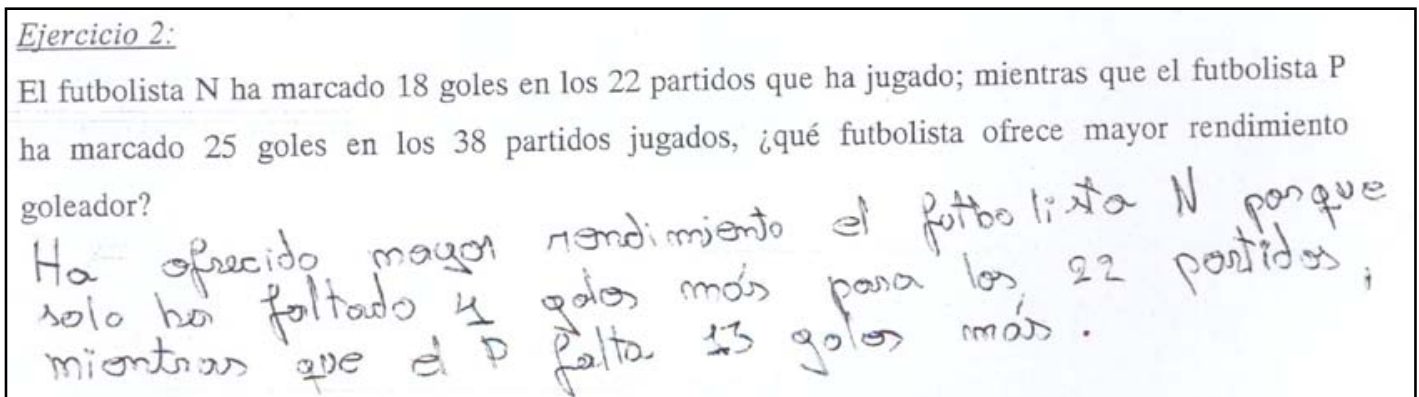

Figura VI.62.

En este caso parece que el alumno tiene en mente la idea de que el futbolista debe marcar tantos goles como partidos. Sería interesante plantear la misma situación pero con promedios goleadores superiores a un gol por partido.

De todos modos, este ejercicio ha sido el que mejores resultados ha tenido, debido seguramente a que los alumnos están habituados al manejo de promedios goleadores y otros indicadores similares provenientes del mundo del deporte. Así, la mayoría de los alumnos da una respuesta similar (con las obvias variaciones de precisión y detalle) a la de A40 (en la Figura VI.63 siguiente): "El futbolista $N$ porque ha marcado más goles respecto a partidos jugados”.

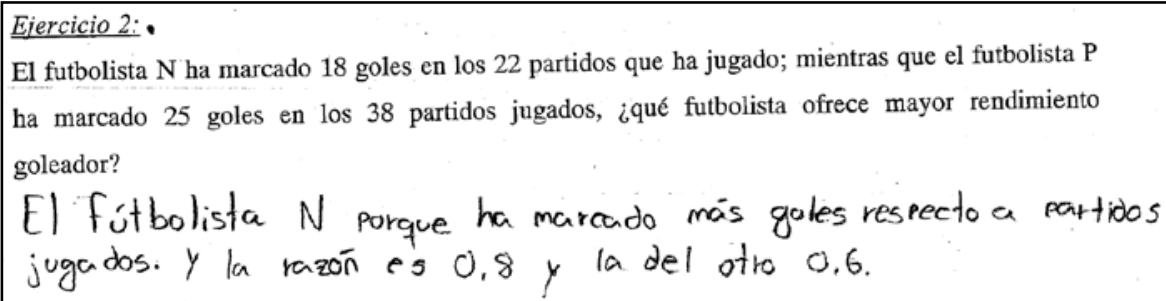

Figura VI.63 
La situación del Ejercicio 3 es bastante distinta a la de los dos ejercicios anteriores y a la del Ejercicio 6. La idea de "tener un sabor de naranja más fuerte” es bastante más difícil de aprehender que la de un promedio goleador o que la de una tasa de cambio. Así, muchos alumnos cometen el error de considerar que tendrá mayor sabor aquella mezcla que posea más cantidad de naranja sin tener en cuenta el agua utilizada en la mezcla. Es, nuevamente, el error de considerar cantidades absolutas y no relativas. El alumno A52 (en la Figura VI.64) comete precisamente este error:

\section{Ejercicio 3:}

Una receta de naranjada indica que hay que mezclar $1 / 2$ litro de naranja con $3 / 2$ litros de agua; otra receta dice que hay que mezclar $3 / 2$ litros de naranja con 5 litros de agua, ¿cuál de las dos recetas proporciona un sabor de naranja más fuerte?

La segueden porque en la primera sobo se hecher $\frac{1}{2}$ y en len segunde se becher $\frac{3}{2}$.

Figura VI.64

Una variación sobre esta misma idea es responder que tendrá mayor sabor a naranja aquella que tenga menos litros de agua como hace por ejemplo A23 (figura VI.65): “La primera porque tiene menos agua”.

\section{Ejercicio 3:}

Una receta de naranjada indica que hay que mezclar $1 / 2$ litro de naranja con $3 / 2$ litros de agua; otra receta dice que hay que mezciar $3 / 2$ litros de naranja con 5 litros de agua, ¿cuál de las dos recetas proporciona un sabor de naranja más fuerte?

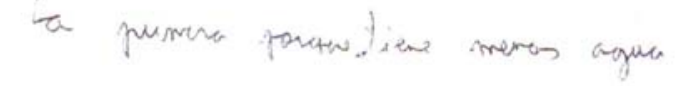

Figura VI.65.

No obstante, un porcentaje aceptable de alumnos posee la idea correcta y responde de una forma similar a como lo hace el alumno A39 en la Figura VI.66:

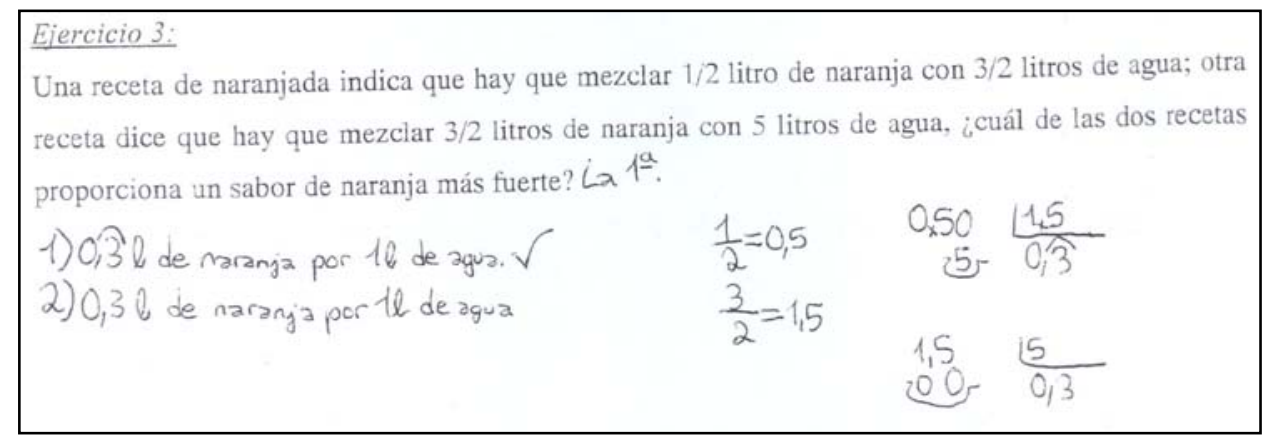

Figura VI.66. 
Sorprendentemente, el Ejercicio 6 es el que peores resultados arroja por parte de los alumnos. Parece extraño, puesto que la situación no debería resultar ajena a los alumnos y, además, no difiere sustancialmente de, por ejemplo, el Ejercicio 1. En este ejercicio se dispara el número de alumnos que responden mal, usando incorrectamente la idea de razón. En concreto, calculan la razón inversa de la que se necesita calcular. El alumno A15 (Figura VI.67 siguiente) indica explícitamente que debe "saber la razón entre discos y camisetas”. Este error ha sido el más cometido.

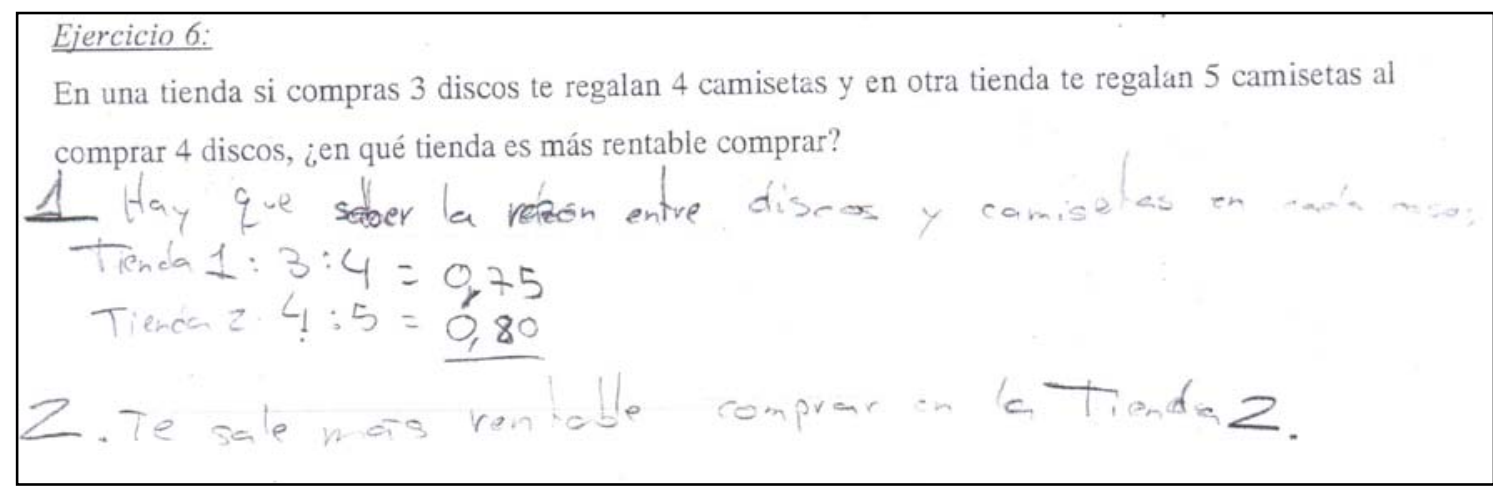

Figura VI.67.

También aparecen errores causados por el razonamiento aditivo en este ejercicio. Así el alumno A54, por ejemplo, indica que (ver Figura VI.68): “Es igual porque te dan lo mismo aunque un disco sea de más también hay una camiseta mas”.

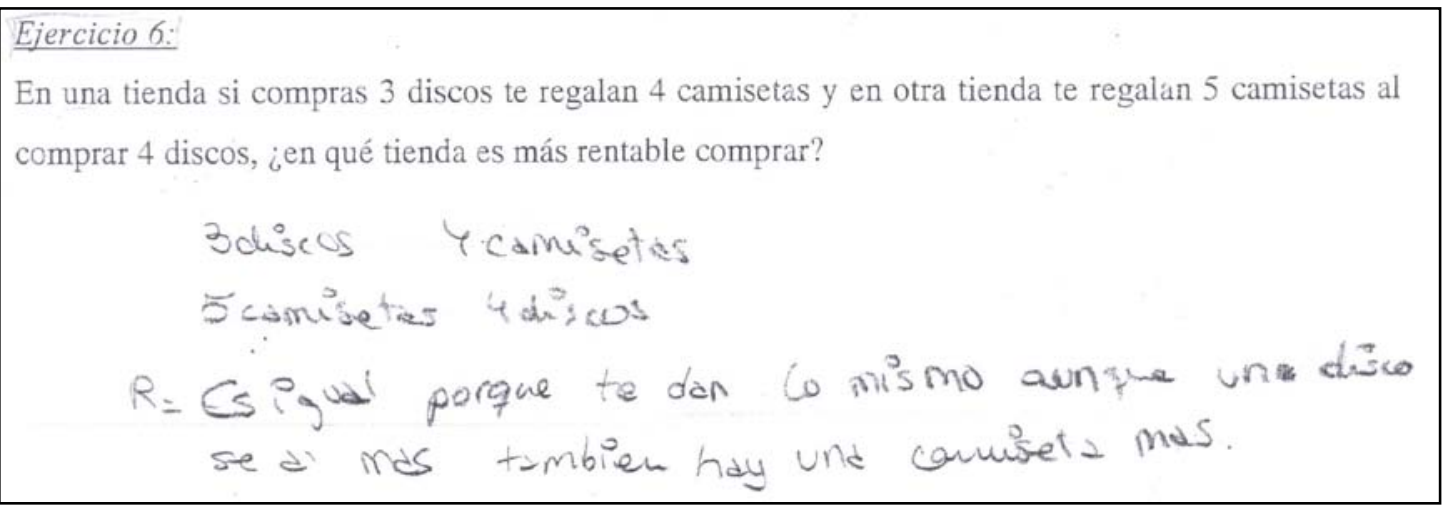

Figura VI.68.

No han sido muchos los alumnos que, como A28, han respondido adecuadamente (ver Figura VI.69): 


\section{Ejercicio 6:}

En una tienda si compras 3 discos te regalan 4 camisetas y en otra tienda te regalan 5 camisetas al comprar 4 discos, ¿en qué tienda es más rentable comprar?

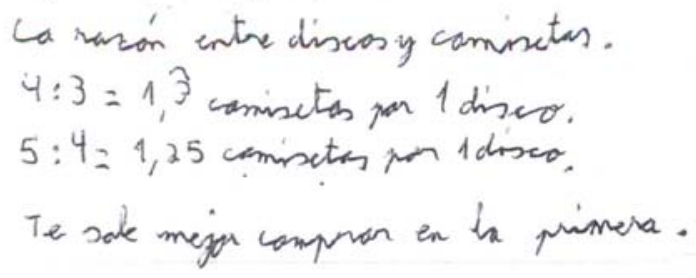

Figura VI.69.

\section{Ejercicios 4 y 5:}

En el Ejercicio 4 una de las variables involucradas no es una magnitud (el curso) y, por tanto, no tiene sentido calcular ninguna razón. Por otra parte, en el Ejercicio 5, aunque puede tener sentido calcular la razón entre profesores y alumnos, esta razón no es una herramienta útil a la hora de comparar las dos situaciones presentadas en el sentido en el que se hace la pregunta. Las unidades de análisis para estos ejercicios son las siguientes:

\begin{tabular}{|c|c|}
\hline 0 & No entrega o no asiste a clase \\
\hline 1 & Respuesta en blanco \\
\hline 2 & Responde incorrectamente usando razones \\
\hline 3 & Responde incorrectamente sin usar razones \\
\hline 4 & Indica la imposibilidad de responder, pero no lo argumenta \\
\hline 5 & Argumenta correctamente que no puede responderse a la pregunta \\
\hline
\end{tabular}

De acuerdo con estas unidades de análisis los resultados obtenidos por los alumnos en estos ejercicios se presentan en la siguiente tabla:

\begin{tabular}{|c|c|c|c|c|c|c|c|}
\hline \multicolumn{2}{|c|}{} & $\mathbf{0}$ & $\mathbf{1}$ & $\mathbf{2}$ & $\mathbf{3}$ & $\mathbf{4}$ & $\mathbf{5}$ \\
\hline \multirow{2}{*}{ Ejercicio 4 } & $\mathbf{N}^{\mathbf{0}}$ de resp. & 5 & 3 & 0 & 20 & 9 & 19 \\
\cline { 2 - 8 } & Porcentaje & $8^{\prime} 9 \%$ & $5^{\prime} 4 \%$ & $0 \%$ & $35^{\prime} 7 \%$ & $16^{\prime} 1 \%$ & $33^{\prime} 9 \%$ \\
\hline \multirow{2}{*}{ Ejercicio 5 } & $\mathbf{N}^{\mathbf{0}}$ de resp. & 5 & 5 & 5 & 10 & 14 & 17 \\
\cline { 2 - 9 } & Porcentaje & $8{ }^{\prime} 9 \%$ & $8^{\prime} 9 \%$ & $8{ }^{\prime} 9 \%$ & $17^{\prime} 9 \%$ & $25 \%$ & $300^{\prime} 4 \%$ \\
\hline
\end{tabular}

En el Ejercicio 4 se planteaba una situación en la que una de las variables no era una magnitud. En consecuencia era imposible definir ninguna razón. Muchos alumnos, 
como A35 (en la Figura VI.70 siguiente) observan esta imposibilidad; sin embargo, nadie señala que el curso no es una magnitud.

\section{Ejercicio 4:}

En segundo curso aprobé 7 asignaturas y en tercer curso aprobé también 7 asignaturas. ¿en qué curso obtuve mejor rendimiento?

No se puede rallar a noyon.

Figura VI.70.

En este ejercicio el porcentaje de respuestas incorrectas es bastante alto. Esto se debe a que muchos alumnos tratan de responder a la pregunta (puesto que, a diferencia de lo que sucede en el Ejercicio 5, la pregunta parece tener sentido a partir de los datos que se proporcionan). En esta línea, las respuestas que proporcionan algún argumento pueden clasificarse en dos grupos. Por un lado hay alumnos que tienen en cuenta consideraciones acerca de la dificultad de los cursos. Tal es el caso de A36 (Figura VI.71 siguiente) que considera que “Obtendrá mayor rendimiento en el tercer curso porque es más difícil”:

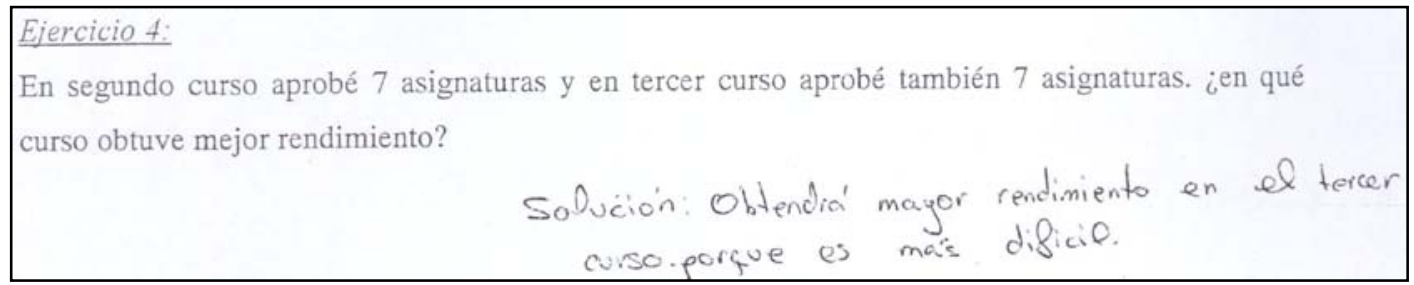

Figura VI.71.

Otros alumnos, por el contrario, no consideran factores que relativicen el número de aprobados y se fijan tan sólo en la cantidad absoluta. Estos alumnos, como A23, concluyen que el rendimiento es "el mismo porque en las dos aprobaste las mismas". Ver Figura VI.72:

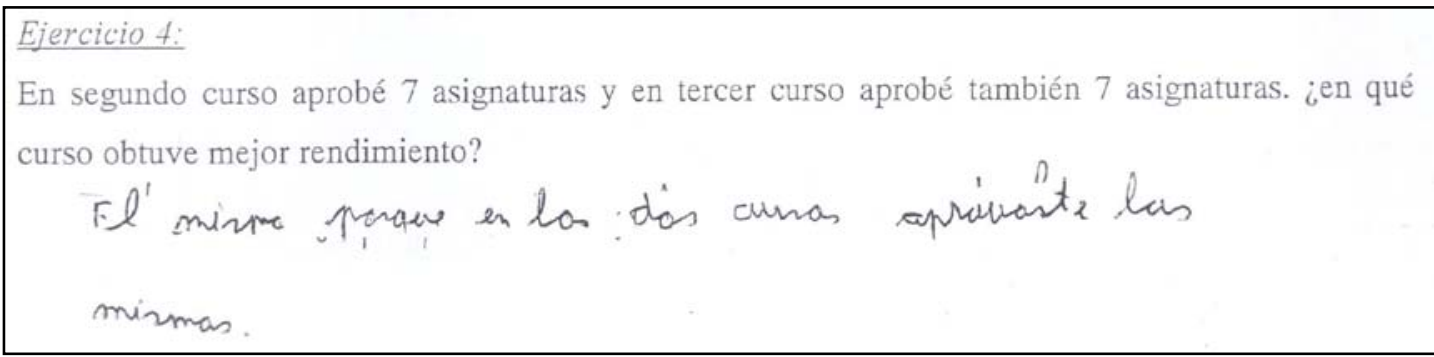

Figura VI.72. 
En cualquier caso, algo más de un tercio de los alumnos responde correctamente señalando que, en el mejor de los casos, "no sabemos cuántas asignaturas hay en cada curso ni la nota con la que ha aprobado". Ver, por ejemplo, la respuesta de A11 en la Figura VI.73:

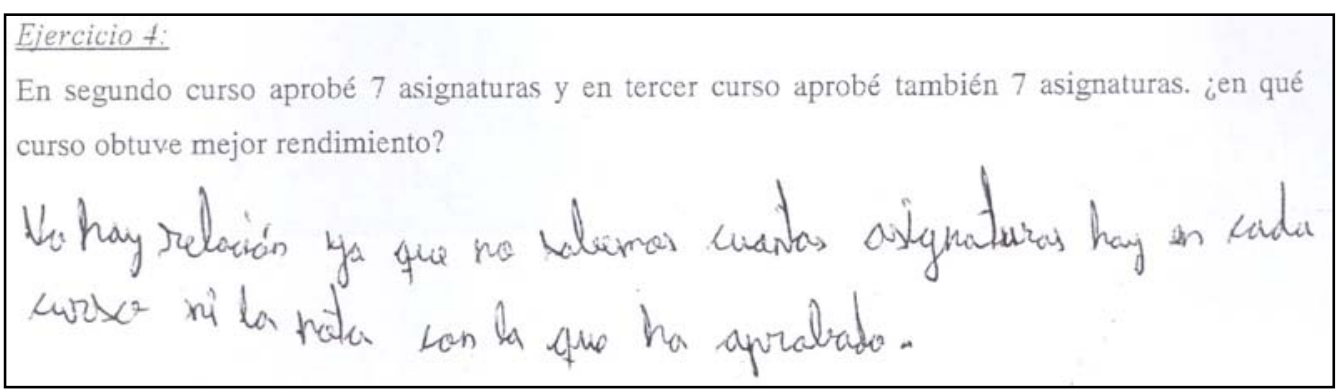

Figura VI.73.

El Ejercicio 5 era similar al anterior en el sentido de que no podía responderse a la pregunta que se planteaba, pero presentaba una diferencia importante: en este ejercicio tiene pleno sentido calcular la razón entre las magnitudes involucradas. Esto hace que algunos alumnos, como por ejemplo A13, hayan calculado esta razón (incluso asignándole un significado correcto) pero no han dado el paso de tratar de usarla para responder a la pregunta. Ver Figura VI.74:

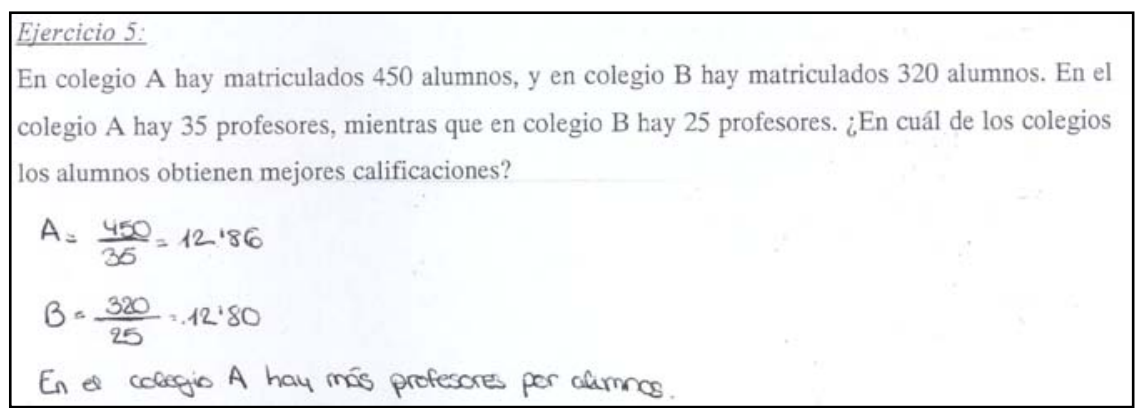

Figura VI.74.

Sí que hay alumnos, empero, que han observado este hecho. Tal es el caso de A19, que explica perfectamente la situación. Ver Figura VI.75:

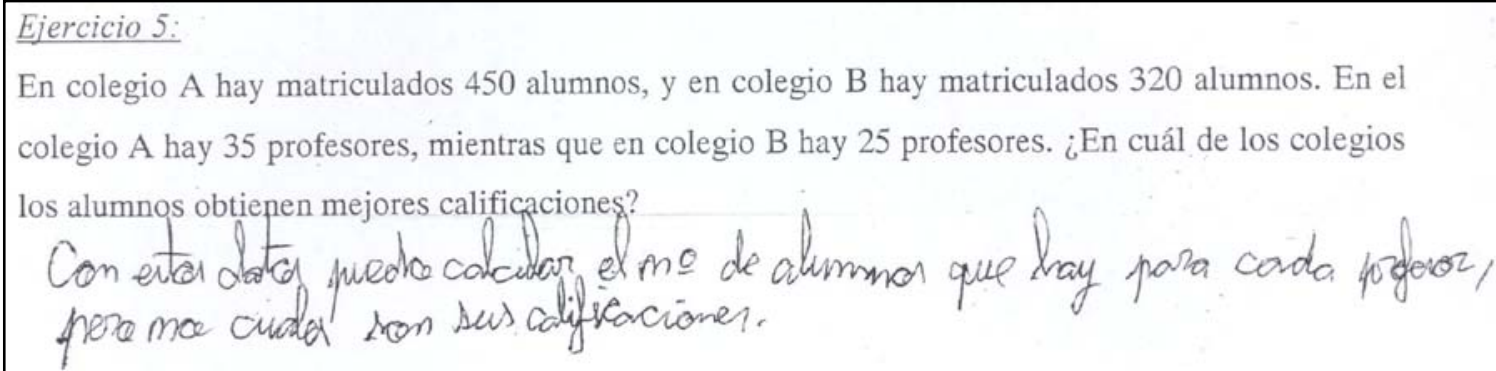

Figura VI.75. 
Otros alumnos, aunque observan que la respuesta no puede darse con los datos del problema, no afinan tanto en su respuesta. De hecho, la mayoría de las respuestas van en la dirección de la de A16 (Figura VI.76): “No tiene nada que ver las calificaciones con los profesores y alumnos que hay en un colegio".

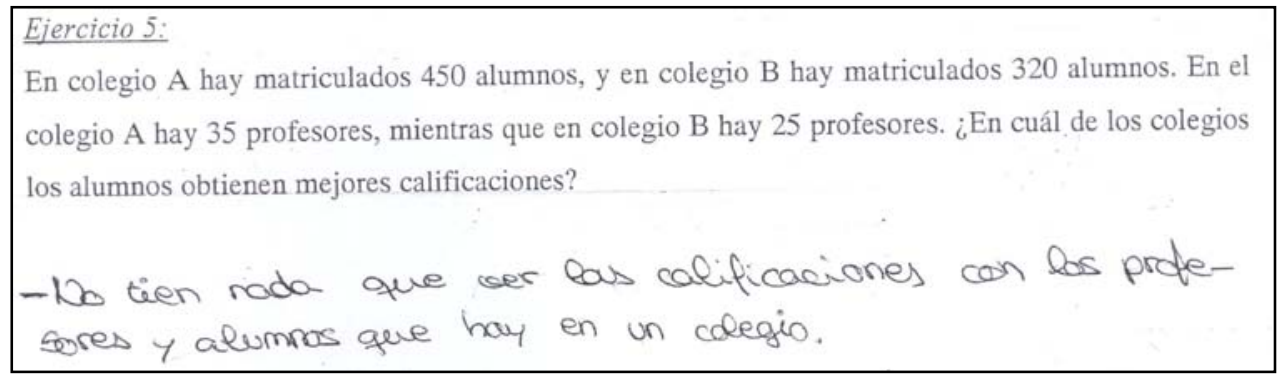

Figura VI.76.

Por último, el error más común en este ejercicio ha consistido en confundir la imposibilidad de responder a la pregunta con la imposibilidad de definir la razón entre las magnitudes involucradas. Error esperado, por otra parte. Un ejemplo típico es el alumno A21 (en la Figura VI.77):

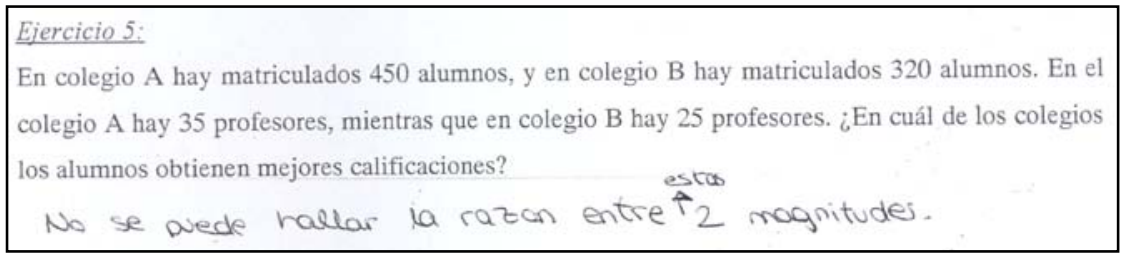

Figura VI.77.

\section{Ejercicio 7:}

En el Ejercicio 7 aparecen explícitamente dos magnitudes: número de vacas y número de días. Entre estas dos magnitudes no tiene sentido calcular la razón, sin embargo, si se hace entrar en juego una tercera magnitud “oculta” (la cantidad de leche producida), sí que tiene sentido hablar de razón. Ahora bien, la razón que resulta útil para resolver este ejercicio es leche/(vaca×día). Además de tener que hacer entrar en juego una nueva magnitud que "no se ve" en el enunciado se debe "fabricar" la magnitud vaca.día que carece de un sentido claro. Por todo esto, este ejercicio era el más complicado aunque, como se verá, existen métodos de resolución que evitan todas las dificultades anteriores. Eso sí, aplicar dichos métodos implica una buena comprensión de la situación planteada. Las unidades de análisis para estos ejercicios son las siguientes: 


\begin{tabular}{|c|c|}
\hline 0 & No entrega o no asiste a clase \\
\hline 1 & Respuesta en blanco \\
\hline 2 & Respuesta arbitraria sin razonar \\
\hline 3 & Respuesta incorrecta sin calcular razones \\
\hline 4 & Trata de calcular la razón vacas/día o viceversa \\
\hline 5 & Respuesta correcta \\
\hline
\end{tabular}

De acuerdo con estas unidades de análisis los resultados obtenidos por los alumnos en estos ejercicios se presentan en la siguiente tabla:

\begin{tabular}{|c|c|c|c|c|c|c|c|}
\hline \multicolumn{2}{|c|}{} & $\mathbf{0}$ & $\mathbf{1}$ & $\mathbf{2}$ & $\mathbf{3}$ & $\mathbf{4}$ & $\mathbf{5}$ \\
\hline \multirow{2}{*}{ Ejercicio 7 } & $\mathbf{N}^{\mathbf{0}}$ de resp. & 5 & 7 & 13 & 8 & 17 & 6 \\
\cline { 2 - 8 } & Porcentaje & $8{ }^{\prime} 9 \%$ & $12^{\prime} 5 \%$ & $23{ }^{\prime} 2 \%$ & $14{ }^{\prime} 3 \%$ & $30{ }^{\prime} 4 \%$ & 10 '7\% \\
\hline
\end{tabular}

Como se observa, la respuesta mayoritaria ha pasado por tratar de calcular la razón vacas/día o viceversa. Esta razón no tiene ningún sentido ya que en el contexto del problema todas las vacas están presentes todos los días. No procede repartir las vacas entre los días y, mucho menos a la inversa. Algunos alumnos han calculado dichas razones y les han asignado significados incorrectos que después han utilizado para resolver el problema. Por ejemplo, el alumno A28 (en la Figura VI.78 siguiente) ha calculado la razón entre días y vacas asignándole e significado “días que tarda una vaca en dar x cantidad de leche":

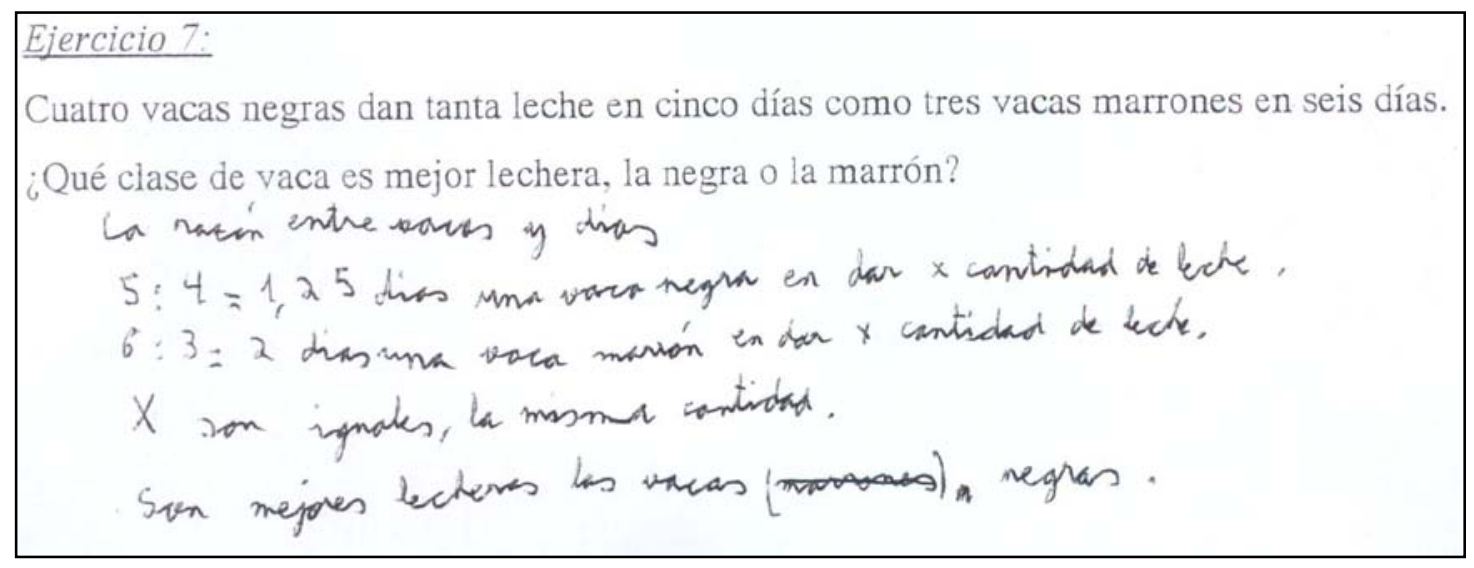

Figura VI.78.

Por su parte, A45 (en la Figura VI.79) calcula la misma razón pero en este caso le asigna el significado de "leche que da cada vaca cada día”: 


\section{Ejercicio 7: •}

Cuatro vacas negras dan tanta leche en cinco días como tres vacas marrones en seis días.

¿Qué clase de vaca es mejor lechera, la negra o la marrón?

Vacas negras $\rightarrow 5: 4=1,2 \mathrm{~S}$ (de leche) da cada vace negra cada dia. Es la razón entce días y vacas neguras kacos marrones $\rightarrow 6: 3=2$ (de lechel da cade laca mareón sada día, Es la seón entre días y vacas marrones

\section{$R=$ Es mejor lechera la vace marión.}

Figura VI.79.

Por supuesto, aunque ambos alumnos calculan la misma razón, al asignarles significados distintos ambos llegan a conclusiones opuestas.

Hay alumnos que han tratado de dar una respuesta sin emplear razones. Desafortunadamente algunos de ellos han utilizado ideas incorrectas. Estos errores han sido, básicamente, de tres tipos. En primer lugar tenemos, por ejemplo, al alumno A7 (ver Figura VI.80) que se ha fijado únicamente en el tiempo concluyendo que "la negra [es mejor] porque tarda menos tiempo":

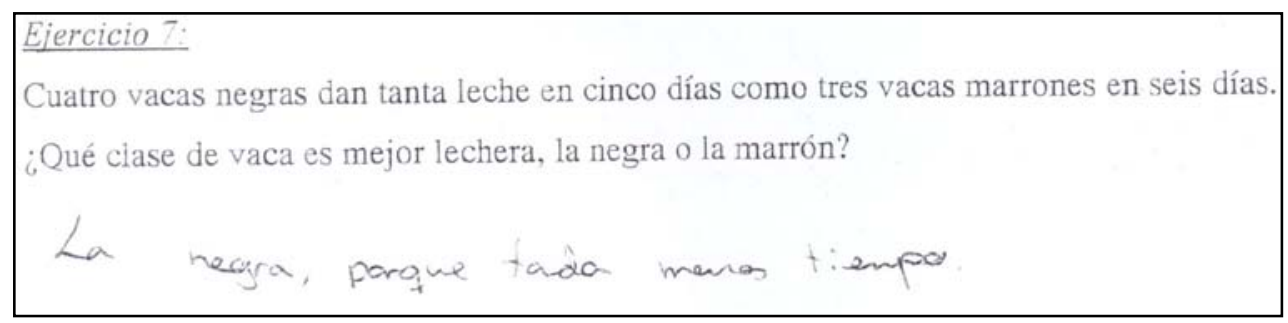

Figura VI.80.

Otros alumnos, como $\mathrm{A} 1$, se han fijado únicamente en el número de vacas afirmando que "marrón [es mejor] porque son menos vacas y te dan más leche”. Véase la Figura VI.81:

Ejercicio 7:

Cuatro vacas negras dan tanta leche en cinco días como tres vacas marrones en seis días.

¿Qué clase de vaca es mejor lechera, la negra o la marrón?

mación, porque son menos vacas y te dan mos leche

Figura VI.81.

Otros alumnos tratan de manejar a la vez ambas magnitudes pero no logran hacerlo de un modo significativo. Tal es el caso de, por ejemplo, A21 cuando dice que “una vaca menos sólo tarda un días más”, lo que no va más allá de una mera reelaboración del enunciado. Ver Figura VI.82: 


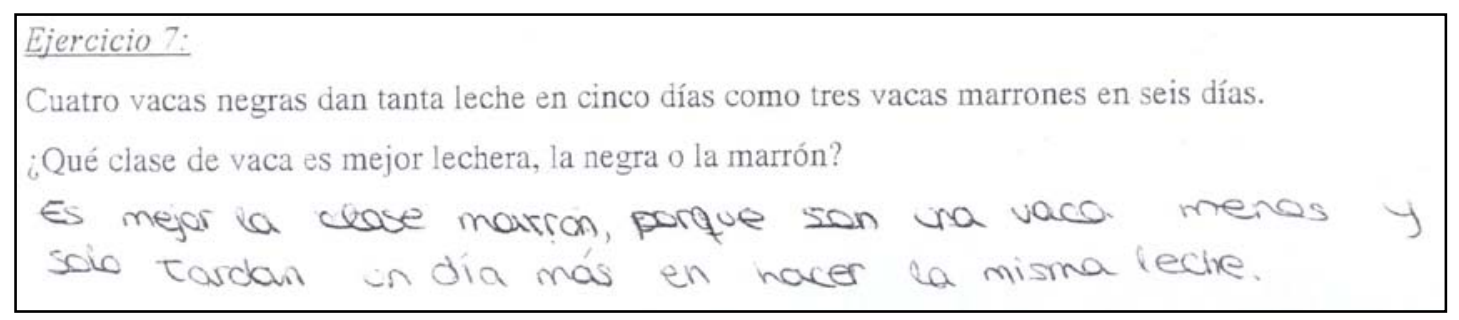

Figura VI.82.

En último lugar, vamos a tratar las respuestas correctas que los alumnos han dado a este ejercicio. Aunque han sido seis los alumnos que han respondido correctamente, sólo han aparecido cuatro tipos de respuesta. Esto se debe a que algunos alumnos han llevado a cabo la tarea conjuntamente, pese a tratarse de un trabajo individual. El primer tipo de respuesta ha sido dado por A11 y A6. Aunque es correcta no queda muy claro el razonamiento seguido por estos alumnos (ver Figura VI.83):

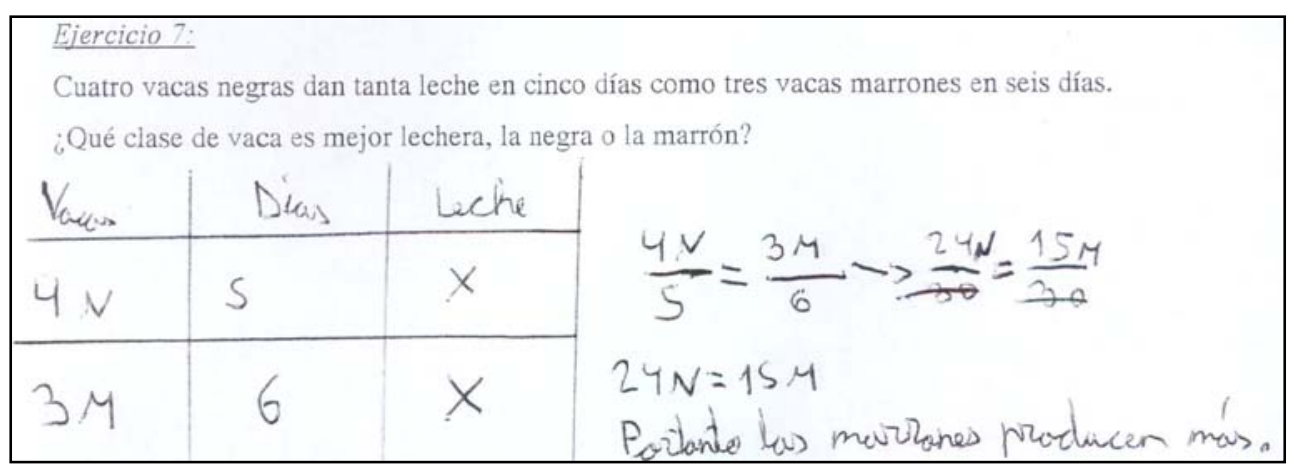

Figura VI.83.

Parece que se percibe una cierta reminiscencia del algoritmo para la regla de tres compuesta y se introduce una incógnita (innecesaria) para denotar la cantidad de leche producida por los dos grupos de vacas. Este tipo de respuesta tiene sentido pleno si se llama $N$ a la cantidad de leche que una vaca negra produce los 5 días y $M$ a lo que produce una marrón en los 6 días, pues, en tal caso, se están igualando producciones diarias de cada tipo de vaca. Pero no parece que los alumnos tengan esto en mente.

Parecido a este tipo de razonamiento (por los números a los que se llega) pero de muy distinta motivación es el empleado en la solución dada por A26. Ver Figura VI.84:

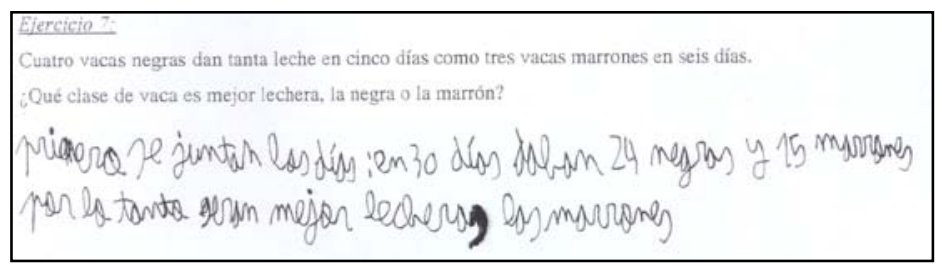

Figura Vl.84. 
Aquí también se percibe cierta reminiscencia de la regla de tres compuesta ("primero se juntan los días”) pero la idea del alumno es mucho más clara que en el caso anterior.

Un razonamiento de base radicalmente distinta es el dado por los alumnos A39 y A53. Este argumento parte de asumir que cada vaca negra da 1 litro diario y a partir de ese dato calcular lo que produciría una marrón para que se cumplan las condiciones del problema. Ver Figura VI.85:

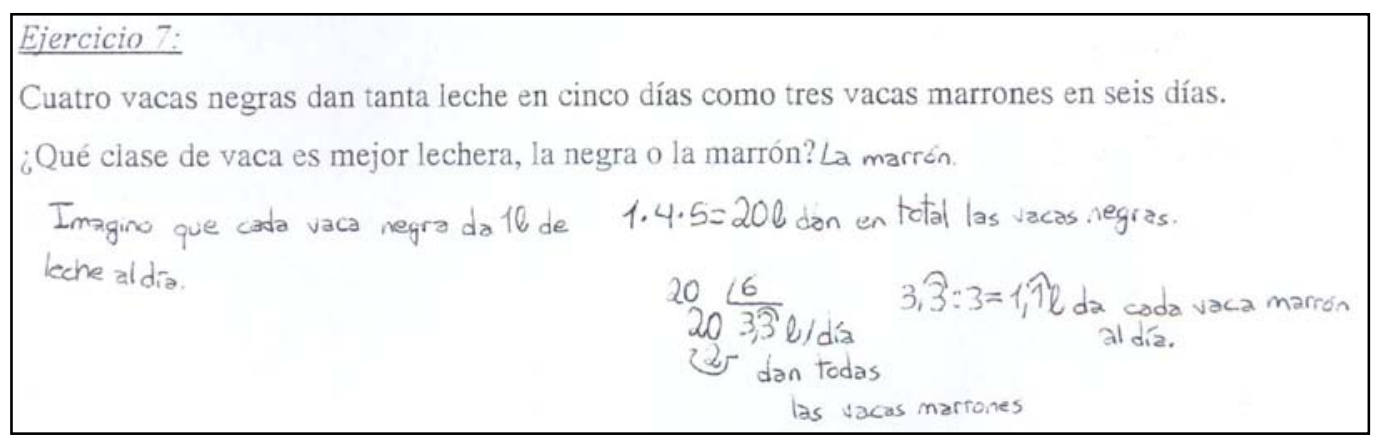

Figura VI.85.

Esta respuesta parte de la suposición (implícita) de que todas las vacas de cada tipo producen la misma cantidad de leche. En cualquier caso es una solución muy interesante.

La última respuesta correcta es la dada por el alumno A19 (en la Figura VI.86 siguiente). Su razonamiento, que transcribimos, es el siguiente: “1 vaca negra al día produce lo que han producido todas dividiendo entre 5 y entre 4, eso es lo mismo que dividir entre 20. 1 vaca marrón al día produce lo que han producido todas dividido entre 6 y entre 3 es lo mismo que dividir entre 18. La cantidad mayor es la que se obtiene con el divisor más pequeño, el 18. La vaca mejor es la marrón”:

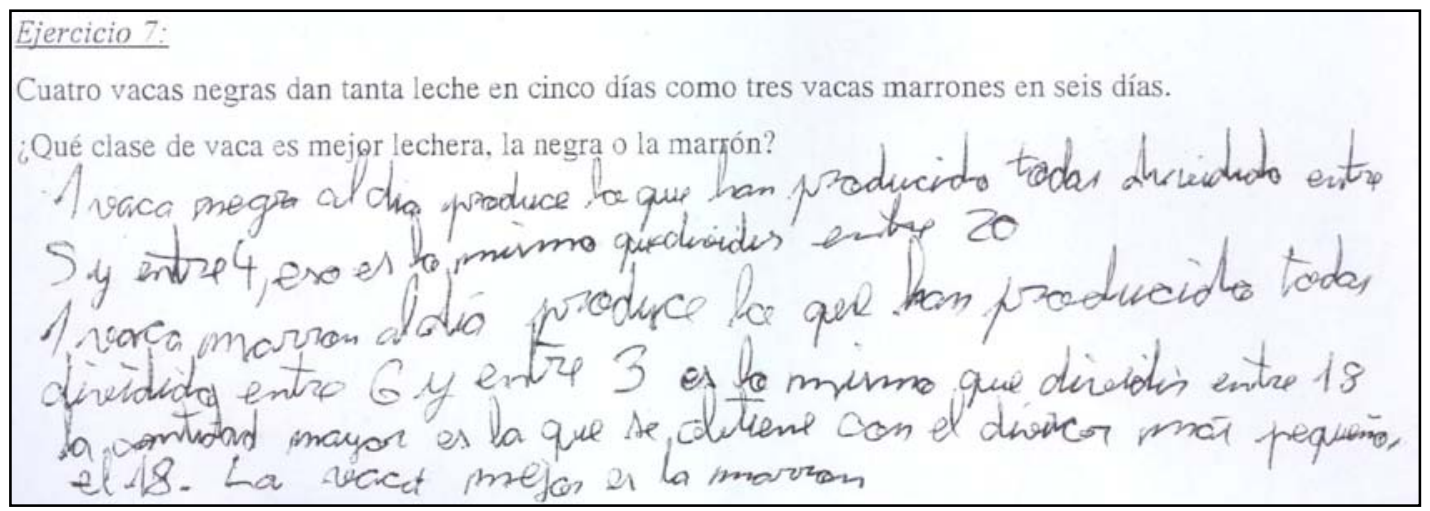

Figura VI.86. 
Esta respuesta es la que mejor ha captado la esencia del problema. De hecho, aunque no lo explicite (y quizás no fuera consciente de ello), el alumno ha calculado la razón litros de leche por vaca y día. Además demuestra un buen manejo de las operaciones y sus propiedades (como que con igual numerador el valor mayor es el de denominador menor).

\section{VI.2.3.3 Reflexiones relativas al punto 3}

1. Ha quedado claro que los alumnos no han identificado la idea de "ser más ventajoso” con la de “obtener más cantidad de una mercancía a cambio de una cierta cantidad de otra”. Curiosamente, en una tarea posterior sobre comparación de razones los resultados serán mucho mejores, así que, quizás, los malos resultados en esta actividad se deban a un mal diseño de la misma o a estar presentada demasiado pronto dentro de la propuesta.

2. Es curiosa la identificación entre “ventajoso" y “sencillez de operaciones”. Quizás sea esto un reflejo del utilitarismo fruto de los tiempos.

3. Algunos alumnos no comprenden el significado de frases como “Quiero cambiar A por B”. En concreto, parece que no entienden que esa construcción verbal implica que se tiene A y se pretende obtener B, y no a la inversa.

4. Algunos alumnos interiorizan la comparación de razones como un método a seguir a la hora de comparar situaciones, sin entrar en consideraciones sobre el significado de dichas razones o sobre si éstas tienen sentido a la hora de resolver el ejercicio. Así:

- Algunos alumnos identifican magnitudes relacionadas con magnitudes que poseen una razón.

- Algunos alumnos calculan las razones (incluso aunque no tengan sentido) y eligen la mayor, sin más.

5. La idea de razón como tanto por uno parece estar afianzada. Sin embargo, esto lleva a que, en algunos casos en los que la razón no tiene sentido, los alumnos inventen un significado que parezca plausible y sea útil para resolver el problema. 
6. Si una de las variables no es una magnitud, los alumnos parecen tener claro que no tiene sentido hablar de razones.

7. Muchos alumnos siguen pensando que la respuesta "no puede responderse a la pregunta" no es una respuesta aceptable a un problema o ejercicio de matemáticas.

8. El contexto influye mucho a la hora de facilitar la comprensión de los alumnos. Así hablar de goles por partido les resulta más fácil que de euros por cada dólar.

\section{VI.2.4 Punto 4: Análisis de situaciones}

Una vez que se han introducido el concepto de razón y la idea de condición de regularidad y que el alumno ya está familiarizado con situaciones que no son necesariamente de intercambio es interesante plantear situaciones generales para que el alumno las analice. Esto se hace en la Tarea de casa 2.

\section{VI.2.4.1 Análisis y valoración de la Tarea de casa 2}

\section{Enunciado}

En clase hemos visto que para poder definir una razón entre dos magnitudes es necesario que se cumplan ciertas “condiciones de regularidad”. A continuación te presentamos varias situaciones. En cada una de ellas te pedimos que definas todas las razones que aparezcan, que digas lo que significan y que indiques cuáles son las “condiciones de regularidad” necesarias para poder definir dichas razones. Si en alguna de ellas no puedes definir ninguna razón entre las magnitudes que aparecen, indica el por qué.

Situación 1: En una tribu del Amazonas cambian 5 lanzas por 3 escudos.

Situación 2: En 4 horas limpió 37 cristales.

Situación 3: Laura tiene 10 años y tiene una estatura de $120 \mathrm{~cm}$.

Situación 4: En la planta 5 hay ingresados 28 enfermos.

Situación 5: Al comprar 3 camisetas me regalaron 4 discos.

Situación 6: Mis 2 perros tardan 4 días en terminarse 1 saco de comida. 
Situación 7: Por 125 dólares me han dado 155 euros

Situación 8: Para preparar naranjada se mezclan 3 litros de zumo de naranja con 5 litros de agua.

Situación 9: El 10 de junio cumplí 16 años.

Situación 10: Leyendo 2 horas al día tardo 7 días en terminar un libro de 426 páginas.

\section{Análisis de la tarea}

A la hora de valorar las respuestas de los alumnos, lo haremos según los tres grupos de situaciones que venimos de describir. Por consiguiente, esta valoración estará dividida en 3 partes. Puesto que los tres grupos están formados por situaciones esencialmente diferentes, utilizaremos distintas unidades de análisis para cada uno de ellos.

Situaciones 1, 2, 5, 7 y 8:

Las unidades de análisis para este grupo de situaciones son las siguientes:

\begin{tabular}{|c|c|}
\hline 0 & No entrega o no asiste a clase \\
\hline 1 & Respuesta en blanco \\
\hline 2 & Respuesta incorrecta \\
\hline 3 & Señala condiciones de regularidad que existen dos razones distintas \\
\hline 4 & Indica el significado de alguna razón \\
\hline 5 & Calcula numéricamente alguna razón \\
\hline 6 &
\end{tabular}

Por supuesto las unidades 3, 4, 5 y 6 no son excluyentes puesto que, como veremos se dan casi todas las combinaciones posibles.

\begin{tabular}{|l|l|c|c|c|c|c|c|c|}
\hline \multicolumn{2}{|c|}{} & $\mathbf{0}$ & $\mathbf{1}$ & $\mathbf{2}$ & $\mathbf{3}$ & $\mathbf{4}$ & $\mathbf{5}$ & $\mathbf{6}$ \\
\hline Situación 1 & $\mathbf{N}^{\mathbf{0}}$ de resp. & 10 & 1 & 8 & 18 & 14 & 29 & 30 \\
\cline { 2 - 9 } & Porcentaje & $17^{\prime} 9 \%$ & $1{ }^{\prime} 8 \%$ & $14^{\prime} 3 \%$ & $32^{\prime} 1 \%$ & $25 \%$ & $51^{\prime} 8 \%$ & $533^{\prime} 6 \%$ \\
\hline Situación 2 & $\mathbf{N}^{\mathbf{0}}$ de resp. & 10 & 0 & 10 & 17 & 12 & 28 & 29 \\
\cline { 2 - 9 } & Porcentaje & $17^{\prime} 9 \%$ & $0 \%$ & $17^{\prime} 9 \%$ & $30{ }^{\prime} 4 \%$ & $21^{\prime} 4 \%$ & $50 \%$ & $51^{\prime} 8 \%$ \\
\hline Situación 5 & $\mathbf{N}^{\mathbf{0}}$ de resp. & 10 & 0 & 12 & 16 & 13 & 26 & 29 \\
\hline
\end{tabular}




\begin{tabular}{|c|c|c|c|c|c|c|c|c|}
\hline & Porcentaje & $17^{\prime} 9 \%$ & $0 \%$ & $21^{\prime} 4 \%$ & $28{ }^{\prime} 6 \%$ & $23{ }^{\prime} 2 \%$ & $466^{\prime} 4 \%$ & $51^{\prime} 8 \%$ \\
\hline Situación 7 & $\mathbf{N}^{\mathbf{0}}$ de resp. & 10 & 7 & 8 & 13 & 12 & 21 & 24 \\
\cline { 2 - 9 } & Porcentaje & $17^{\prime} 9 \%$ & $12^{\prime} 5 \%$ & $14^{\prime} 3 \%$ & $23^{\prime} 2 \%$ & $21^{\prime} 4 \%$ & $37^{\prime} 5 \%$ & $42^{\prime} 8 \%$ \\
\hline Situación 8 & $\mathbf{N}^{\mathbf{0}}$ de resp. & 10 & 10 & 8 & 10 & 10 & 23 & 23 \\
\cline { 2 - 9 } & Porcentaje & $17^{\prime} 9 \%$ & $17^{\prime} 9 \%$ & $14^{\prime} 3 \%$ & $17^{\prime} 9 \%$ & $17^{\prime} 9 \%$ & $41^{\prime} 1 \%$ & $41^{\prime} 1 \%$ \\
\hline
\end{tabular}

Si analizamos los datos presentados globalmente, se observa en primer lugar que el porcentaje de respuestas totalmente incorrectas es relativamente bajo en todas las situaciones; aunque conforme se avanza en la tarea aumenta el porcentaje de respuestas en blanco (algunos alumnos no se dieron cuenta de que la hoja de la tarea estaba impresa por las dos caras). Es significativo también el bajo porcentaje de alumnos que señala la condición de regularidad o que indica la existencia de dos razones en cada una de las situaciones. Sin embargo, los porcentajes más altos son los correspondientes a alumnos que señalan (aunque sea implícitamente) el significado de la razón y, sobre todo, los que dan una respuesta numérica.

Hasta cierto punto estos resultados eran esperables, ya que los alumnos están acostumbrados a que el resultado de un ejercicio en la clase de matemáticas es un número, unido quizás a una unidad (que en este caso indica el significado de la razón). Pese a que ya se trabajó en actividades y tareas anteriores con la existencia de dos razones en toda situación de intercambio (y se comentó por parte del profesor) parece que muchos alumnos se dan por satisfechos indicando una de ellas. Respecto a señalar las condiciones de regularidad, los alumnos no suelen estar acostumbrados a reflexionar sobre las condiciones que deben darse para que una cierta herramienta matemática sea aplicable en una situación real. Es más, algunos de los alumnos que indican condiciones de regularidad, tienen dificultades para expresarlas correctamente.

Vamos a comenzar analizando los distintos tipos de errores identificados en este tipo de situaciones. Por ejemplo, el primero es el cometido por el alumno A51 (ver Figura VI.87):

\section{Situación 1: En una tribu del Amazonas cambian 5 lanzas por 3 escudos. Quiere dear que cada 5 tanzes me don 3 escudor.}

Figura VI.87. 
Aquí el alumno no comprende la tarea propuesta y se limita a reescribir lo que se le indica en el enunciado. Esta respuesta no da pistas sobre el grado de comprensión del alumno de la situación de intercambio descrita. Alguna pista más da la respuesta del alumno A36 (Figura VI.88):

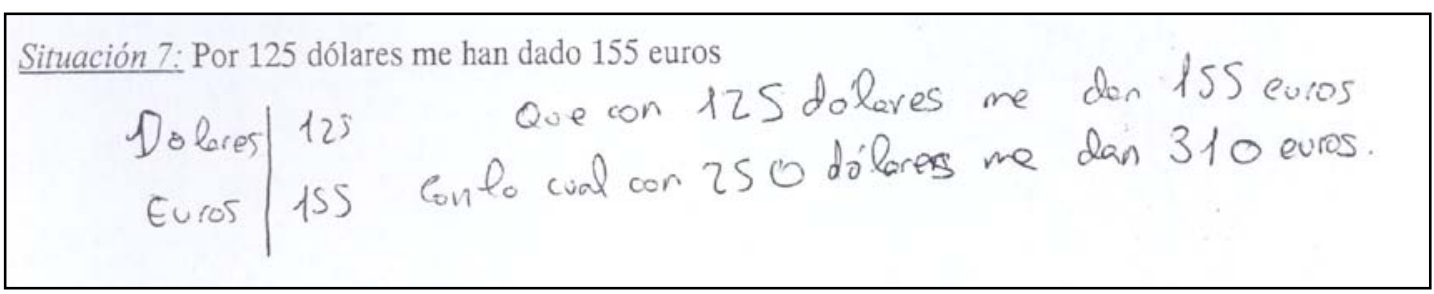

Figura VI.88.

Este alumno parece haber vislumbrado la relación que liga las dos magnitudes presentadas, si bien no explicita ni las condiciones para que dicha relación exista ni responde a ninguna de las cuestiones que se le proponen en la tarea.

Posiblemente, las dificultades de comprensión que muestran los ejemplos que acabamos de presentar estén relacionadas con la idea de que un ejercicio en clase de matemáticas debe tener que ver con encontrar un valor desconocido. Por ejemplo A33 responde: "Hay que saber con 1 hora cuántos cristales puedes limpiar, entonces el resultado lo multiplicas para cuatro y lo que te da son los cristales que has limpiado en cuatro horas" (ver Figura VI.89):

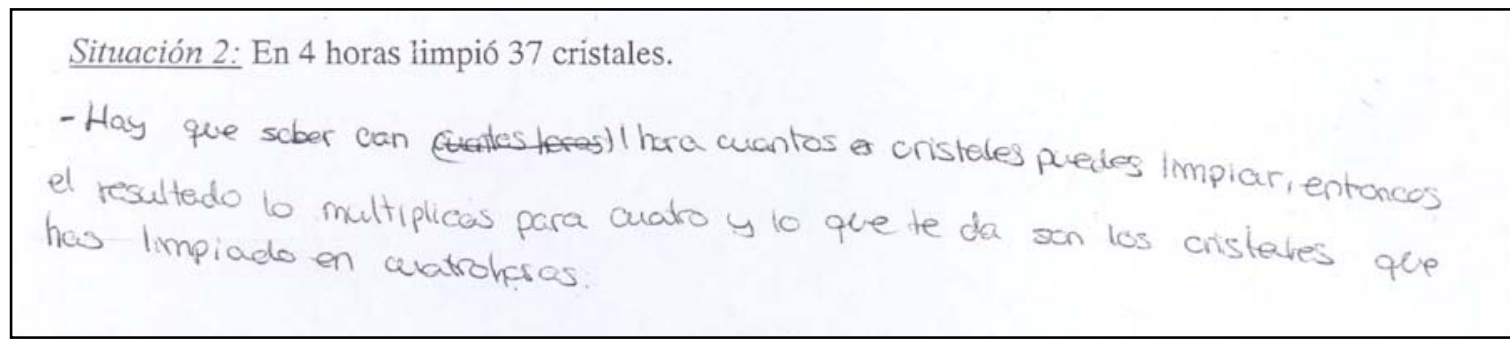

Figura VI.89.

El alumno presenta el significado de la razón entre cristales y horas (con 1 hora cuántos cristales puedes limpiar) pero lo mezcla con el innecesario deseo de calcular los cristales que limpias en 4 horas, que es precisamente la información del enunciado.

Otro error que encontramos con relativa frecuencia en esta y otras tareas es nuevamente el de invertir los papeles de las magnitudes. Así le sucede al alumno A29 (ver Figura VI.90 siguiente): 


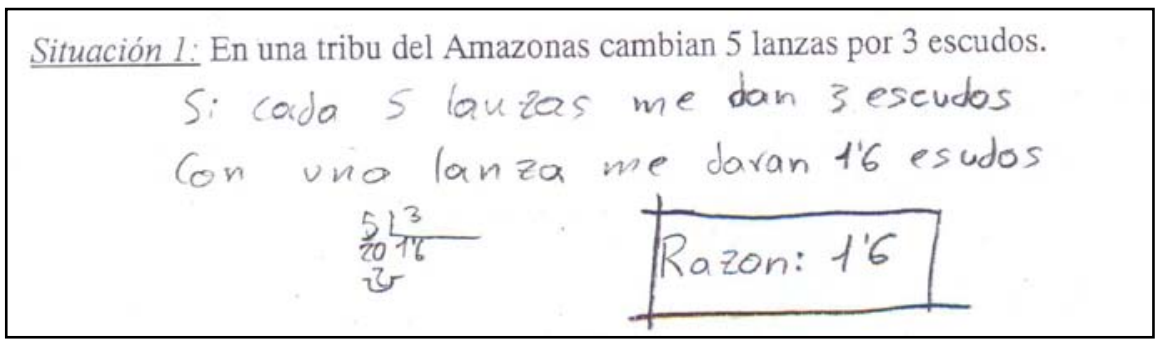

Figura VI.90.

Este alumno parece tener claro el significado de la razón como tanto por uno y también el modo de hallarla; sin embargo lo calcula al revés. Donde dice "Con una lanza me darán 1’6 escudos” intercambió los papeles de lanzas y escudos. No obstante, esto puede haber sido un error puntual, pues en el resto de las situaciones de este tipo responde correctamente (aunque de modo incompleto, como en ésta).

Un aspecto importante, que se comentará más adelante, es la influencia externa recibida por los alumnos a la hora de efectuar las tareas individuales en casa. Por ejemplo, es llamativa la respuesta de A24 (Figura VI.91 siguiente) “Proporción directa, mayor número de litros de zumo mayor número de litros de agua":

Situación 8: Para preparar naranjada se mezclan 3 litros de zumo de naranja con 5 litros de agua.

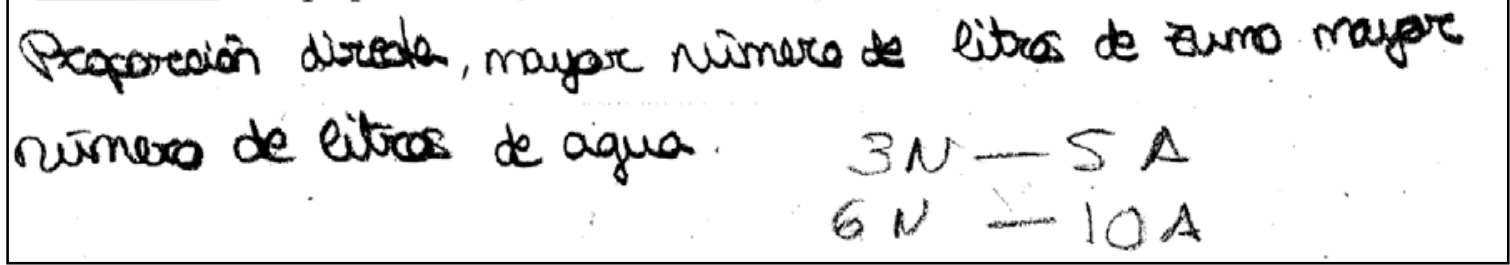

Figura VI.91.

En esta respuesta aparecen toda una serie de conceptos y términos (proporción directa, a mayor...mayor, el diagrama) que no sólo no se han trabajado ni mencionado en clase, sino que no tienen absolutamente nada que ver con la tarea a realizar. Es posible que el alumno solicitara ayuda a padres, hermanos o a otras personas y, puesto que los conceptos que involucra esta tarea (condición de regularidad, razón y su significado) se apartan de lo habitual, la ayuda que recibió fue en una dirección equivocada.

Nos centramos ahora en el análisis de las respuestas parcialmente correctas. Como hemos indicado algo más arriba, se dan casi todas las combinaciones posibles: desde alumnos que sólo indican el valor numérico o el significado de una de las razones que se pueden definir en cada situación, hasta alumnos que responden de forma muy 
satisfactoria. En las siguientes líneas trataremos de trazar una panorámica de estas respuestas.

En uno de los escalones más bajos se encontraría la respuesta dada por A20 (ver Figura VI.92) que responde únicamente indicando el significado de una de las razones existentes en la situación dada.

\section{Situación 1: En una tribu del Amazonas cambian 5 lanzas por 3 escudos. $R=N^{\circ}$ de escudos que te don por cada bariza.}

Figura VI.92.

Un poco, aunque no mucho, más elaborada es la respuesta dada por A2 (Figura VI.93 siguiente). Aunque implícitamente, el alumno indica el significado de una de las razones y además calcula su valor. Eso sí, en consonancia con lo que venimos señalando en actividades anteriores, el valor es siempre un número decimal.

$$
\begin{aligned}
& \text { Sitzación 5: Al comprar } 3 \text { camisetas me regalaron } 4 \text { discos. } \\
& \text { Por cada camiseta te regalan } 1^{\prime} \hat{3} \text { discos }
\end{aligned}
$$

Figura VI.93.

El siguiente escalón viene ilustrado por la respuesta del alumno A28 (en la Figura VI.94 siguiente). En este caso aparece indicada la condición de regularidad (bastante bien explicitada al hablar de “mismo ritmo”), el significado de la razón y su valor numérico en forma decimal y de fracción.

$$
\begin{aligned}
& \text { Situación 2: En } 4 \text { horas limpió } 37 \text { cristales. } \\
& \text { La ratón de hovas y crisitales es que limpia 9,25 cristakes en } 1 \text { hora. }
\end{aligned}
$$

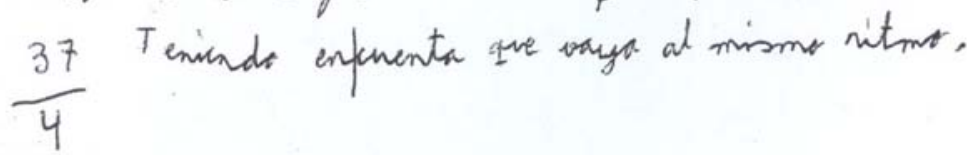

Figura VI.94.

Este último alumno muestra una comprensión de la situación bastante buena salvo por no observar - o recordar - la existencia de las dos razones inversas en cada situación. No obstante, no pensamos que este hecho sea sustantivo a la hora de decidir si un alumno comprende mejor o peor el concepto de razón. Así, respuestas como la de A38 (Figura VI.95) que dice cosas como: "La razón entre litros de agua y litros de 
zumo son los litros de agua que tocan por litros de zumo $\left(\frac{5}{3}\right)$ )" demuestran que ha asimilado el concepto de razón pero no hace mención de la condición de regularidad, que es un concepto esencial a la hora de poder hablar de razón.

Situación 8: Para preparar naranjada se mezclan 3 litros de zumo de naranja con 5 litros de agua.

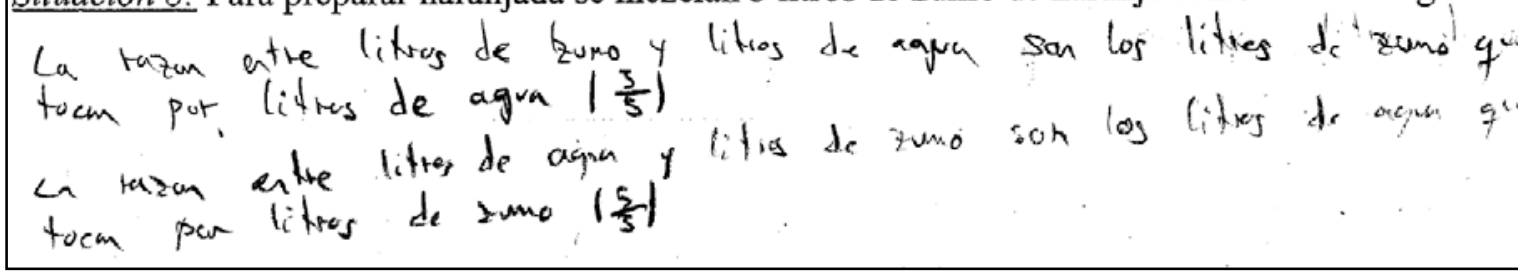
Figura VI.95.

Un ejemplo aún más claro que ilustra el hecho de que indicar que existen dos razones distintas no denota necesariamente una mejor comprensión de la situación puede ser la respuesta de A32 (en la Figura VI.96 siguiente). Este alumno sólo muestra tener claro que hay que considerar las dos posibles formas de “ordenar” las magnitudes y que después debe dividir las cantidades correspondientes.

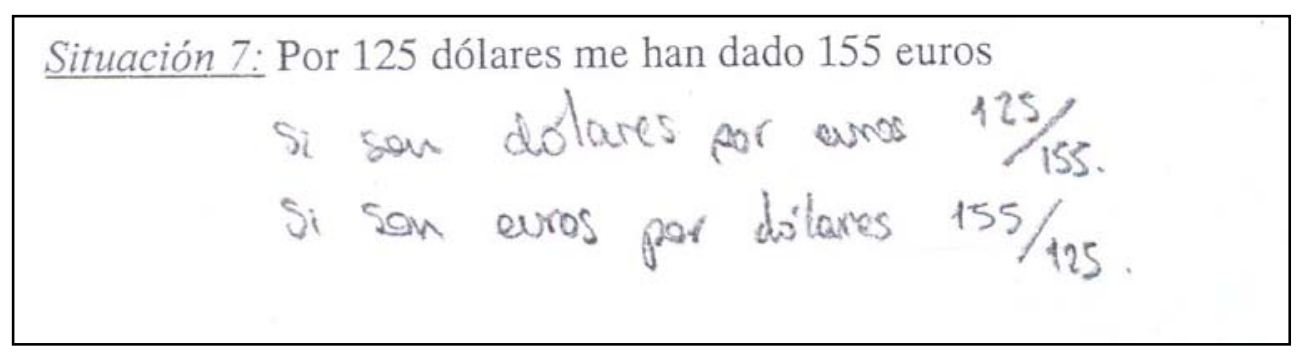

Figura VI.96.

Por último, entre los alumnos que responden satisfactoriamente vamos a presentar dos ejemplos. El primero corresponde al alumno A37 (ver Figura VI.97). En esta situación, este alumno indica perfectamente significados y valores de las dos razones existentes, aunque tiene algún problema con la condición de regularidad: “no es muy correcto hallarlo, ya que el dólar y el euro varían su valor”. Desde luego que es una objeción de lo más lícita, pero en el resto de las situaciones no se muestra tan fino.

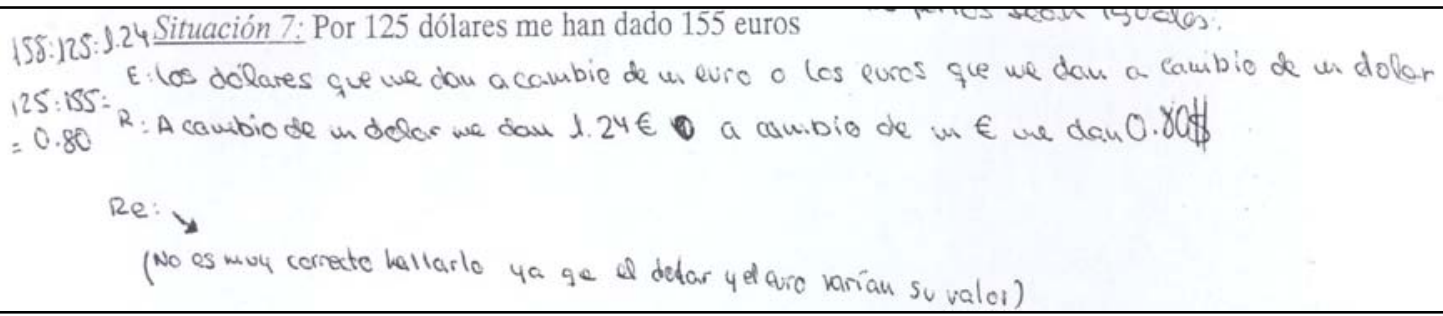

Figura VI.97. 
Por su parte, la respuesta de A39 (en la Figura VI.98 que sigue) admite pocas puntualizaciones. Quizás lo más delicado sea nuevamente a condición de regularidad que el alumno expresa como “que se heche la misma mezcla” y que, pensamos, plasma aceptablemente bien la idea de que la naranjada resultante mantenga el sabor.

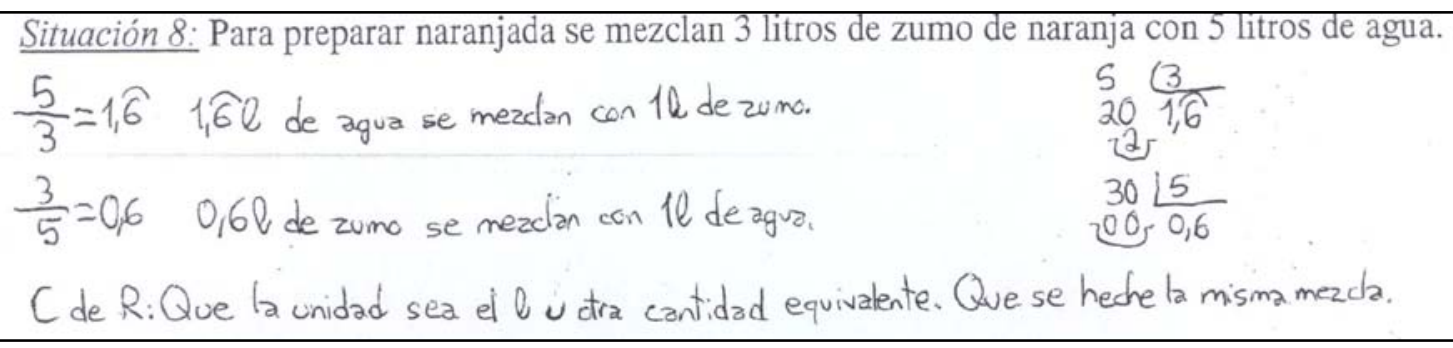

Figura VI.98.

En cualquier caso, la situación número 8 ha resultado la más problemática de este grupo; por un lado, debido a la dificultad de expresar la condición de regularidad y, por otro, a la confusión de algunos alumnos respecto a las magnitudes que aparecen y, en concreto, a observar que la naranjada es la "suma” de zumo y agua. Pero sobre estas dificultades volveremos un poco más adelante.

Situaciones 3, 4 y 9:

Estas tres situaciones tienen en común el que las dos magnitudes que aparecen en ellas no están relacionadas (de hecho en la situación 9 "el 10 de junio cumplí 16 años” tan sólo aparece una magnitud). En consecuencia las unidades de análisis para estas situaciones serán distintas de las del grupo anterior. En concreto serán las siguientes:

\begin{tabular}{|c|c|}
\hline 0 & No entrega o no asiste a clase \\
\hline 1 & Respuesta en blanco \\
\hline 2 & Calcula (incorrectamente) la razón \\
\hline 3 & Indica que no se puede definir la razón, pero no da motivos \\
\hline 4 & Razona que no se puede definir la razón \\
\hline
\end{tabular}

Estas tres situaciones se estudian juntas ya que no se puede definir una razón entre ellas. Cuando aparecen dos magnitudes no son directamente proporcionales (aunque esta terminología aún es desconocida para los alumnos). Sin embargo, las tres situaciones son ligeramente diferentes. En la situación 3 (aparecen las magnitudes edad y altura) dichas magnitudes sí guardan una cierta relación pero no de proporcionalidad y 
no siempre (sería una relación de carácter más bien estadístico). En la situación 4 (planta del hospital y enfermos) sólo aparece una magnitud (el número de enfermos) pues el 5 que indica la planta del hospital no es un cardinal (aunque, como veremos, algunos alumnos lo interpretan así). Finalmente en la situación 9 (día del cumpleaños y edad que se cumple) nuevamente sólo aparece una magnitud.

Los resultados obtenidos por los alumnos, según las unidades de análisis anteriores, se recogen en la siguiente tabla:

\begin{tabular}{|c|c|c|c|c|c|c|}
\hline \multicolumn{2}{|c|}{} & $\mathbf{0}$ & $\mathbf{1}$ & $\mathbf{2}$ & $\mathbf{3}$ & $\mathbf{4}$ \\
\hline Situación 3 & $\mathbf{N}^{\mathbf{0}}$ de resp. & 10 & 4 & 14 & 4 & 24 \\
\cline { 2 - 7 } & Porcentaje & $17^{\prime} 9 \%$ & $7^{\prime} 1 \%$ & $25 \%$ & $7^{\prime} 1 \%$ & $42^{\prime} 9 \%$ \\
\hline Situación 4 & $\mathbf{N}^{\mathbf{0}}$ de resp. & 10 & 7 & 11 & 10 & 18 \\
\cline { 2 - 7 } & Porcentaje & $17^{\prime} 9 \%$ & $12^{\prime} 5 \%$ & $19{ }^{\prime} 6 \%$ & $17^{\prime} 9 \%$ & $322^{\prime} 1 \%$ \\
\hline Situación 9 & $\mathbf{N}^{\mathbf{0}}$ de resp. & 10 & 10 & 8 & 10 & 18 \\
\cline { 2 - 7 } & Porcentaje & $17^{\prime} 9 \%$ & $17^{\prime} 9 \%$ & $14^{\prime} 1 \%$ & $17^{\prime} 9 \%$ & $322^{\prime} 1 \%$ \\
\hline
\end{tabular}

Llama la atención la estabilidad de los resultados en estas situaciones. De hecho, si unimos a los que indican que no se puede definir la razón (sin valorar lo correcto o no de sus argumentos, si los hay) tenemos la mitad de todos los alumnos (el porcentaje aumenta si se considera respecto del número de alumnos que entregan la tarea). También es reseñable que la situación con un mayor porcentaje de errores es la número 3. Esto se puede deber a que es la única en la que aparecen dos magnitudes que sí guardan una cierta relación. De este modo, algunos alumnos caen en la tentación de razonar como en las situaciones del apartado anterior. Las situaciones 4 y 9 dejan más lugar a la crítica del alumno. Como último comentario, indicamos que, como es habitual, el porcentaje de respuestas en blanco aumenta conforme se avanza en la tarea.

Como hemos indicado un poco más arriba, el porcentaje más alto de errores se ha dado en la situación 3, que involucra la edad y la estatura. Que estas dos magnitudes tengan una cierta relación, junto con que los hipotéticos significados de las razones (caso de existir) tienen un sentido muy claro, hace que se hayan obtenido respuestas como la del alumno A45 (en la Figura VI.99 siguiente) que sigue un esquema idéntico al de las situaciones del apartado anterior. 


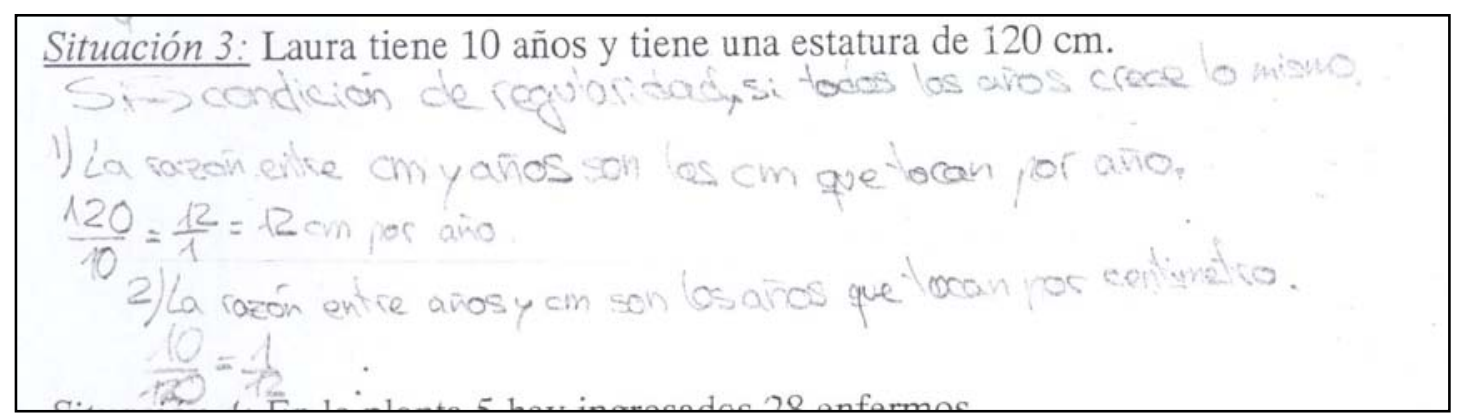

Figura VI.99.

Es obvio que la relación que pueda existir entre estas dos magnitudes no es de proporcionalidad directa. Lo más próximo a la linealidad que podría considerarse es una relación afín (teniendo en cuenta la estatura al nacer) y, de hecho, algunos alumnos responden en esta dirección. Por ejemplo, A53 dice: “[...] cada año no crecemos lo mismo. Y cuando naces ya mides $50 \mathrm{~cm}$ o algo parecido”. Ver Figura VI.100:

\section{Situación 3: Laura tiene 10 años y tiene una estatura de $120 \mathrm{~cm}$.}

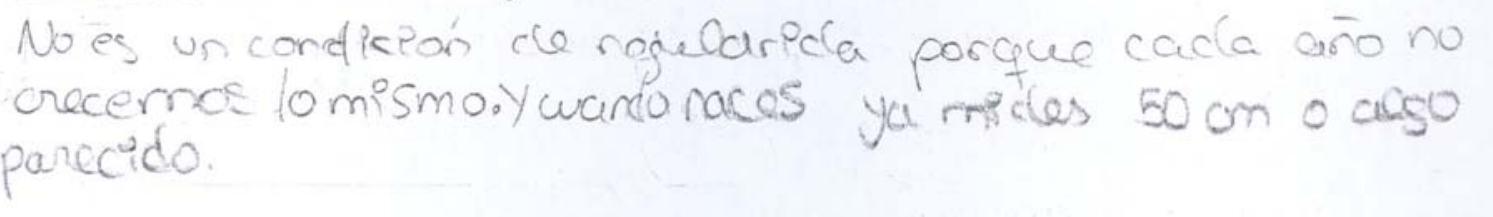

Figura VI.100.

En fin, algunos alumnos responden de forma menos elaborada aunque quizás más clara. Tal es el caso de A39 (Figura VI.101): “No hay razón porque a veces se crece más y otras menos”

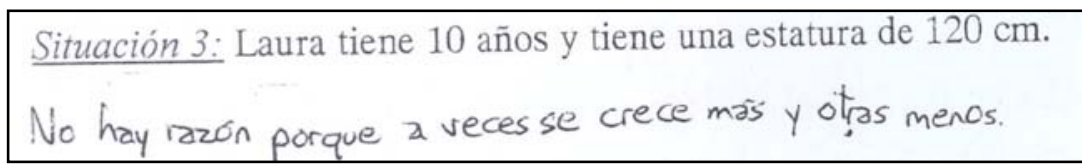

Figura VI.101.

La situación número 4 ha dado lugar a menos errores ya que uno de los números del enunciado no es un cardinal, sino un ordinal que indica la planta del hospital en la que se encuentran los enfermos. Así lo indica el alumno A28 en la Figura VI.102 siguiente:

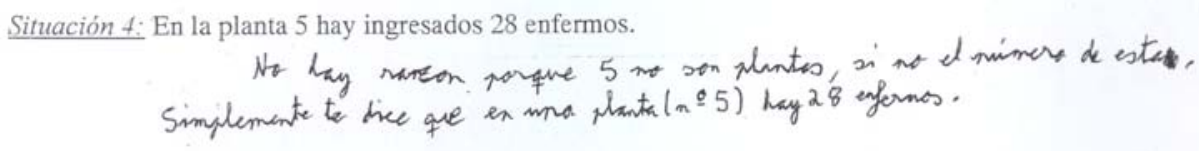

Figura VI.102. 
Sin embargo, algunos alumnos no lo interpretan de este modo y entienden que el enunciado significa que en las 5 plantas del hospital hay 28 enfermos. Con esta interpretación podrían tener sentido respuestas como la de A13 (ver Figura VI.103): “La razón es los enfermos que hay en 1 planta [...] y las condiciones de regularidad son que haya el mismo número de enfermos en las plantas”

Situación 4: En la planta 5 hay ingresados 28 enfermos.

La razón es es entermes que hay en 1 peunta por 6 tanto hay que dividir 28 enfermos entre 5 plantes y las condiciones de regularided son are haja el mismo numero de enfermos en las peantes.

Figura VI.103.

Esta última dificultad no aparece en el último apartado, donde no hay ninguna interpretación ni lectura que justifiquen la división entre la edad y la fecha. Sin embargo, algunos alumnos, como A27 (ver Figura VI.104) siguen teniendo en mente la idea de razón como tanto por uno e intentan forzar la aparición de una unidad:

Situación 9: El 10 de junio cumplí 16 años.

$$
R a_{0} z \theta_{n}=\text { cada } 10 \text { de junio complo } 1 \text { año }
$$

Figura VI.104.

También hay algunas respuestas difíciles de entender, como la de A33: "Para saber los años que cumplió el 10 de junio hay que saber el año que nació” (ver Figura VI.105):

Situación 9: El 10 de junio cumplí 16 años.

- Para saber los años que camplio el io de junio hay que saber el ard que nacio.

Figura VI.105.

No obstante, y pese a que algunos alumnos responden sin más que no existe la razón, la respuesta más común es similar a la dada por A26 (Figura VI.106): “no hay relación por el día de cumpleaños y los años que cumples” 
Situación 9: El 10 de junio cumplí 16 años.

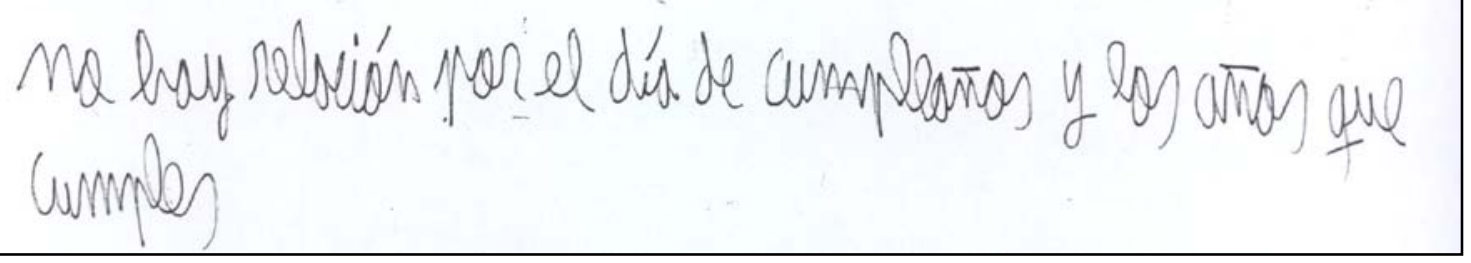

Figura VI.106.

Situaciones 6 y 10 :

En estas dos últimas situaciones se da la particularidad de que aparecen 3 magnitudes en vez de dos como en las anteriores. Esto hace que el análisis de la situación sea más complicado, puesto que pueden estudiarse distintos emparejamientos entre las magnitudes de modo que en algunos casos tiene sentido definir la razón y en otros no. Además, algunas de las magnitudes que aparecen pueden considerarse constantes o incluso puede operarse con las magnitudes que aparecen para "construir" nuevas magnitudes. No obstante, ningún alumno ha realizado un estudio pormenorizado en estas situaciones (como era de esperar en este punto de la propuesta). En cualquier caso, esta gran cantidad de posibilidades hace que el análisis de las respuestas de los alumnos sea más complicado en estas situaciones.

Las unidades de análisis para este grupo de situaciones serán las siguientes:

\begin{tabular}{|c|c|}
\hline 0 & No entrega o no asiste a clase \\
\hline 1 & Respuesta en blanco \\
\hline 2 & Respuesta incorrecta \\
\hline 3 & Respuesta parcialmente correcta $^{6}$ \\
\hline
\end{tabular}

Aunque la unidad 3 (respuesta parcialmente correcta) puede parecer ambigua, lo cierto es que la complejidad de estas situaciones hace que la variedad de respuestas de los alumnos sea tan grande que un análisis fino llevaría a clasificarlas casi individualmente.

Los resultados obtenidos por los alumnos en estas situaciones aparecen reflejados en la siguiente tabla:

${ }^{6}$ Bajo este epígrafe se agruparán aquellas respuestas que contengan algún elemento correcto o que involucren tan sólo dos de las tres magnitudes involucradas. 


\begin{tabular}{|c|c|c|c|c|c|}
\hline \multicolumn{2}{|c|}{} & $\mathbf{0}$ & $\mathbf{1}$ & $\mathbf{2}$ & $\mathbf{3}$ \\
\hline Situación 6 & $\mathbf{N}^{\mathbf{0}}$ de resp. & 10 & 7 & 23 & 16 \\
\cline { 2 - 6 } & Porcentaje & $17^{\prime} 9 \%$ & $12^{\prime}{ }^{\prime} \%$ & $41^{\prime} 1 \%$ & $288^{\prime} 5 \%$ \\
\hline Situación 10 & $\mathbf{N}^{\mathbf{0}}$ de resp. & 10 & 9 & 16 & 21 \\
\cline { 2 - 6 } & Porcentaje & $17^{\prime} 9 \%$ & $16^{\prime} 1 \%$ & $28{ }^{\prime} 5 \%$ & $377^{\prime} 5 \%$ \\
\hline
\end{tabular}

Claramente los porcentajes de respuestas incorrectas son mucho más altos que en otras situaciones, en especial en la situación 6. En la situación 10 aumenta el número de respuestas parcialmente correctas ya que las magnitudes involucradas - como veremos - admiten un manejo más intuitivo por parte de los alumnos.

La dificultad principal que los alumnos encuentran en estas situaciones es la aparición de 3 magnitudes. De hecho, algunos alumnos, como por ejemplo A13 (en la Figura VI.107), hacen explícita la extrañeza ente la aparición de 3 magnitudes: "No se cual es la razón porque hay tres magnitudes”.

Situación 10: Leyendo 2 horas al día tardo 7 días en terminar un libro de 426 páginas.

No se cuas es ra raecin porque hay tres magnitudes.

Las condiciones de regilandad es que cada día puede leer más rápido o más dento.

Figura VI.107.

En la situación 6 las magnitudes que aparecen (número de perros, número de días y número de sacos de comida) no admiten una manipulación clara. Así, algunos alumnos, como A39 (ver Figura VI.108 siguiente), se centran sólo en dos de las magnitudes que aparecen (en este caso el número de sacos y el de días) sin explicitar que la tercera magnitud se mantiene invariable:

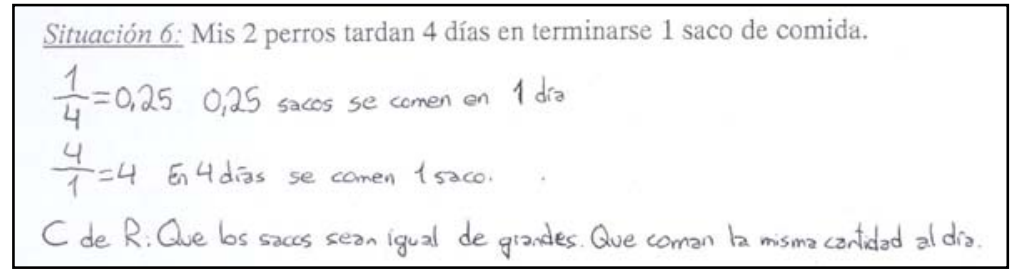

Figura VI.108.

Por otro lado, algunos alumnos sienten la necesidad de que las tres magnitudes del enunciado aparezcan reflejadas en su respuesta. Este deseo, junto con la idea de 
tanto por uno que va calando en los alumnos explica respuestas como la de A27: "Un perro tarda 1 dia en gastar 0’125 sacos de comida” (ver Figura VI.109).

Situación 6: Mis 2 perros tardan 4 días en terminarse 1 saco de comida.

$$
\text { Razón. Unpeno tonda dia en guston 0,125 sacos de come }
$$

Figura VI.109.

Una versión aún más refinada de este tipo de respuesta es la dada por A15 (en la Figura VI.110 siguiente): “La razón es de 1/8 de saco de comida por cada perro y día”.

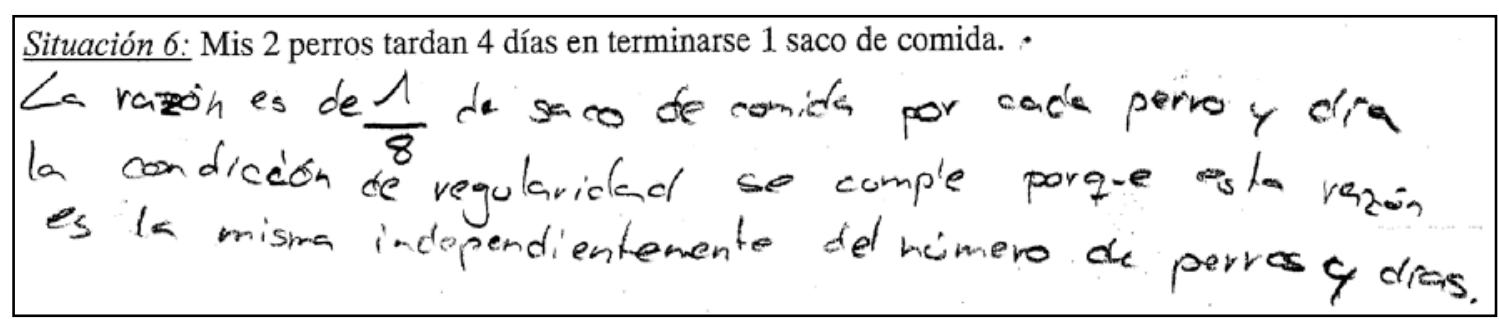

Figura VI.110.

Estas dos respuestas demuestran una buena comprensión de la situación (especialmente la segunda, que maneja con gran precisión también el lenguaje). Esta buena comprensión contrasta con respuestas como la del alumno A7 (Figura VI.111): "Si en vez de 2 perros hubiera 1, tardaría 2 días en terminarse 1/2 saco de comida”.

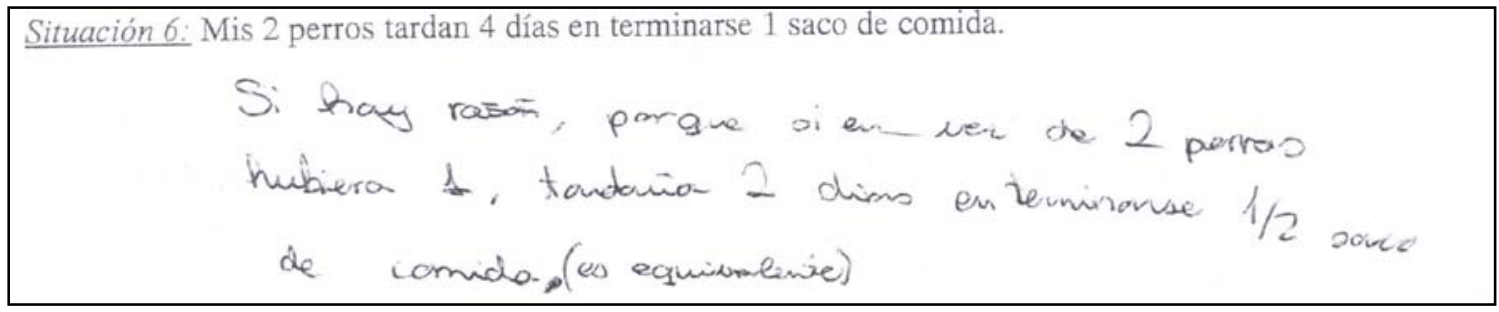

Figura VI.111.

Este alumno no ha observado la relación inversa que liga el número de perros con el número de días (si permanece fijo el de sacos de comida) y en su lugar ha considerado las tres magnitudes simultáneamente, considerando que varían de forma directa a la vez. Este tipo de error será muy importante a la hora de manejar magnitudes inversamente proporcionales, incluso cuando sólo aparezcan dos de ellas (pues la clave a la hora de manejar las magnitudes inversamente proporcionales será la existencia de una tercera magnitud constante). 
En cuanto a la situación número 10, dos de las magnitudes que aparecen; a saber, las horas de lectura diarias y los días que tarda en terminarse el libro, permiten una manipulación sencilla para obtener la magnitud "horas totales que tarda en terminar el libro”. De esta forma, la situación se transforma en una nueva (aunque equivalente) que sólo involucra dos magnitudes y que es más fácilmente resoluble por parte de los alumnos.

Muchos alumnos han respondido siguiendo la idea del párrafo anterior. Por ejemplo (ver Figura VI.112) tenemos la detallada respuesta de A53, que calcula las horas totales, señala una condición de regularidad (si las 426 páginas son iguales) y las dos razones posibles:

- Situación 10: Leyendo 2 horas al día tardo 7 días en terminar un libro de 426 páginas.

\section{$2 \times 7=14 h$ total \\ Ala semana lee:}

Condrcion de regueuridadi silos 426 paginas son igualos. 1 La ranan entre horas y paqui nas eso son las horas que tocan por pag.

2. La ranon entre pags y horan son eas poginas que becun por hora
$\frac{14}{126}$

Figura VI.112.

Hay versiones menos completas de la misma idea; por ejemplo la de A33 (Figura VI.113 siguiente) que, sin embargo, muestra claramente la búsqueda de la relación entre las dos magnitudes consideradas:

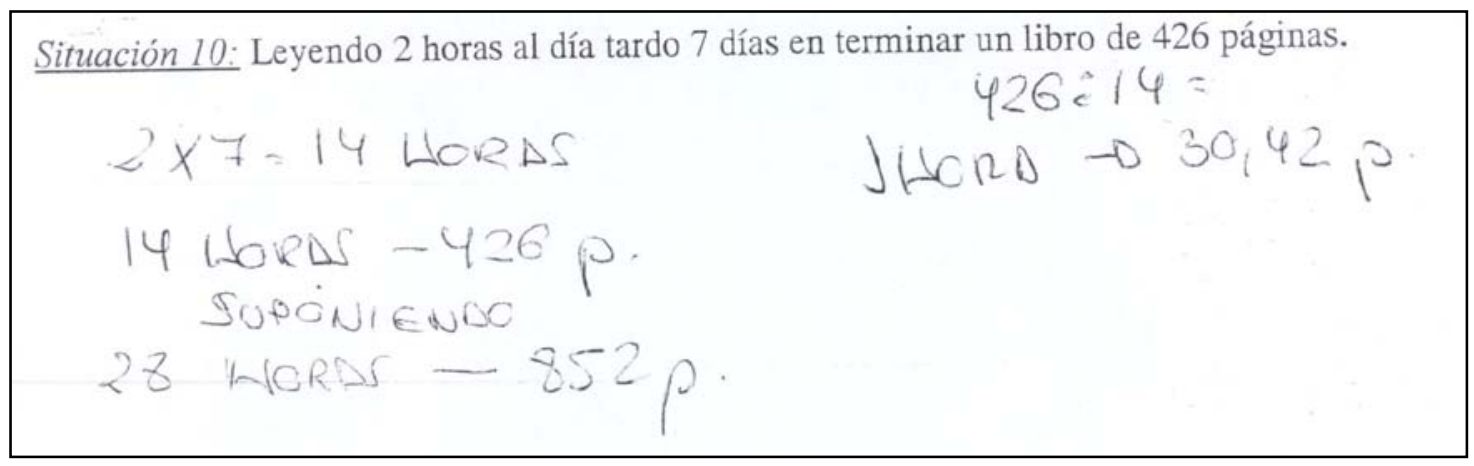

Figura VI.113. 
Por último, algunos alumnos dan respuestas similares a la de A49 (en la Figura VI.114 siguiente), que se limita a calcular la razón entre páginas y días, y entre páginas y horas pero sin mayores detalles:

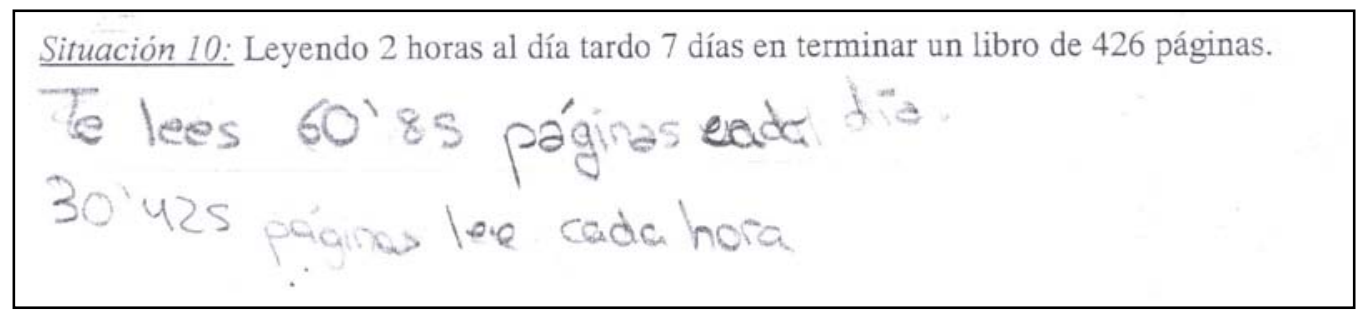

Figura VI.114.

Un error muy interesante es el cometido por el alumno A32 (ver Figura VI.115):

Situación 10: Leyendo 2 horas al día tardo 7 días en terminar un libro de 426 páginas.

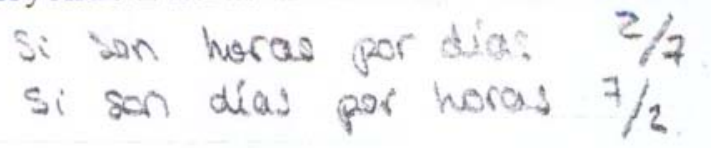

Figura VI.115.

Este error surge de no observar que la magnitud que aparece en el enunciado no es "horas” sino que es "horas al día” de tal modo que no tiene sentido considerar la razón entre esta magnitud y la magnitud “días”. La dificultad en el manejo de magnitudes que ya son razón de otras dos (en este caso "horas al día” es la razón entre horas totales y días) será constante a lo largo de toda la propuesta. Volveremos sobre esto especialmente a la hora de considerar situaciones de proporcionalidad inversa.

\section{VI.2.4.2 Reflexiones relativas al punto 4}

1. Los alumnos tienen una idea muy clara de que los ejercicios de matemáticas consisten en calcular un cierto valor desconocido. Muchos alumnos enfocan esta actividad de ese modo y buscan calcular la razón como el valor correspondiente a una unidad de una de las magnitudes. Por eso muchos alumnos dan respuestas simples como la de A2 (Figura VI.116):

Situación 1: En una tribu del Amazonas cambian 5 lanzas por 3 escudos. Por cada lanza tedan O'6 escudo

Figura VI.116. 
2. Esta tarea choca con la práctica educativa habitual. Por ello, cuando los alumnos solicitan ayuda en casa (y muchos lo hacen, aunque según se vio en la encuesta final no todos lo reconocen) no reciben las orientaciones adecuadas sino que las personas que proporcionan la ayuda lo hacen en base a la formación que ellos han recibido. En nuestro caso, esto es muy perjudicial pues hace aparecer ya en este punto respuestas como las de A24 (Figura VI.117, a continuación):
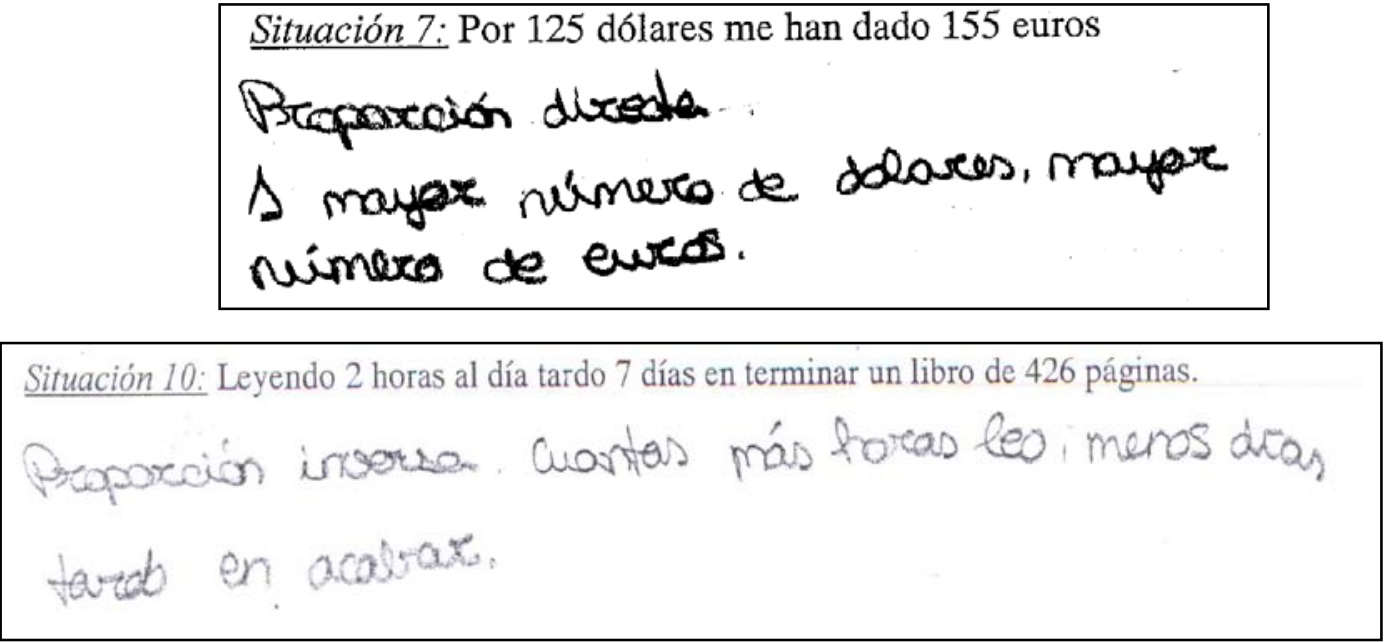

Figura VI.117.

que, además de incluir conceptos (proporcionalidad directa e inversa) que no son pertinentes en esta tarea que anticipan lo que vendrá después, presenta modos de razonar incorrectos (a más, más o a más, menos) que son incorrectos y que pretendemos evitar.

3. Los alumnos reconocen bastante bien aquellas magnitudes entre las que no se puede definir una razón por no existir relación entre ellas. Si el motivo por el que no se puede definir la razón es otro (por ejemplo lo que sucedía en la situación 10) las dificultades son (y, como veremos, serán) mayores.

\section{VI.3. OBSERVACIÓN Y REFLEXIÓN DEL SEGUNDO FOCO DE INVESTIGACIÓN}

En este foco de investigación se pretende que los alumnos identifiquen magnitudes directamente proporcionales y distingan aquellas que no lo son. También se persigue que apliquen el concepto de razón y los significados de las operaciones entre magnitudes a la hora de resolver problemas de búsqueda de cantidades desconocidas y, 
en particular, en problemas de porcentajes. Estos son los tres puntos que analizaremos en este foco de investigación.

\section{VI.3.1 Punto 1: Reconocimiento y distinción de magnitudes directamente proporcionales}

En este punto se pretende que los alumnos identifiquen magnitudes directamente proporcionales y que las distingan de aquellas que no lo son. Este primer punto se trabaja especialmente en la Actividad de aula 4.

\section{VI.3.1.1 Análisis y valoración de la Actividad de aula 4}

\section{Enunciado}

Recuerda que dos magnitudes son directamente proporcionales cuando podemos definir una razón entre ellas (teniendo en cuenta que se deben cumplir ciertas condiciones de regularidad). En cada uno de los ejercicios,

1. Busca una pareja de magnitudes que sean directamente proporcionales, señalando la condición de regularidad que deben cumplir. ¿Qué significado tiene la razón entre ellas?

2. Busca una pareja de magnitudes que no sean directamente proporcionales, indicando las razones por las que no lo son.

\section{Ejercicio 1:}

Velocidad en kilómetros por hora

Edad, en años, del conductor

El número de la matrícula del coche

\section{Ejercicio 2:}

Número de alumnos en el patio

Edad media de los alumnos

Anchura del patio
Distancia, en kilómetros, recorrida por el móvil

Tiempo, en horas, empleado en el recorrido

El número de pasajeros
Superficie, en metros cuadrados, del patio de recreo

Estatura media de los alumnos

Hora de comienzo de las clases 


\section{Ejercicio 3:}

Número de libros

Número de páginas

Precio de cada libro

Edad, en años, del comprador

El tamaño de la letra del texto

Número de fotografías de cada libro

\section{Análisis de la actividad}

Para analizar las respuestas de los alumnos, estudiaremos por separado cada uno de los tres ejercicios de los que constaba la actividad. Aunque los tres son muy similares veremos que algunas pequeñas diferencias, sobre todo respecto al contexto y el tipo de magnitudes que aparecen, justifican este análisis separado.

Las unidades de análisis para esta actividad serán las siguientes:

\begin{tabular}{|c|c|}
\hline 0 & No entrega o no asiste a clase \\
\hline 1 & Respuesta en blanco \\
\hline 2 & Identifica correctamente magnitudes directamente proporcionales \\
\hline 3 & Identifica incorrectamente magnitudes directamente proporcionales \\
\hline 4 & Da las razones entre magnitudes directamente proporcionales \\
\hline 5 & Señala condiciones de regularidad \\
\hline 6 & Indica correctamente magnitudes no relacionadas \\
\hline
\end{tabular}

Las categorías anteriores no son excluyentes, puesto que, por ejemplo, puede haber parejas que identifiquen incorrectamente magnitudes directamente proporcionales, pero que sí acierten a la hora de señalar magnitudes no relacionadas.

\section{Ejercicio 1:}

En este primer ejercicio el contexto que unifica todas las magnitudes indicadas es el de un trayecto en coche; es decir, el movimiento de un cuerpo. Las magnitudes relevantes claramente son la velocidad, la distancia y el tiempo (magnitudes provenientes de la física, principalmente). El resto de variables que aparecen o bien carecen de relación entre ellas o con las anteriores (edad del conductor, número de pasajeros), o bien no son magnitudes (número de la matrícula).

Los resultados obtenidos por los alumnos en este ejercicio aparecen reflejados según las unidades de análisis presentadas anteriormente en la siguiente tabla: 


\begin{tabular}{|c|c|c|c|c|c|c|c|c|}
\hline \multicolumn{2}{|c|}{} & $\mathbf{0}$ & $\mathbf{1}$ & $\mathbf{2}$ & $\mathbf{3}$ & $\mathbf{4}$ & $\mathbf{5}$ & $\mathbf{6}$ \\
\hline \multirow{2}{*}{ Ejercicio 1 } & $\mathbf{N}^{\mathbf{0}}$ de resp. & 0 & 4 & 2 & 21 & 1 & 1 & 17 \\
\cline { 2 - 9 } & Porcentaje & $0 \%$ & $14^{\prime} 8 \%$ & $7^{\prime} 4 \%$ & $77^{\prime} 8 \%$ & $3^{\prime} 7 \%$ & $3^{\prime} 7 \%$ & $622^{\prime} 9 \%$ \\
\hline
\end{tabular}

Los dos porcentajes más altos se corresponden con aquellas parejas de alumnos que señalan como directamente proporcionales magnitudes que no lo son (epígrafe 3) y parejas que señalan correctamente variables que no son directamente proporcionales. Únicamente dos parejas señalan correctamente magnitudes que sí son directamente proporcionales y de éstas sólo una señala el significado de las razones que pueden definirse y la condición de regularidad necesaria para hacerlo.

La pareja que responde de manera completa y correcta es la formada por los alumnos A45 y A54 (ver Figura VI.118 siguiente):

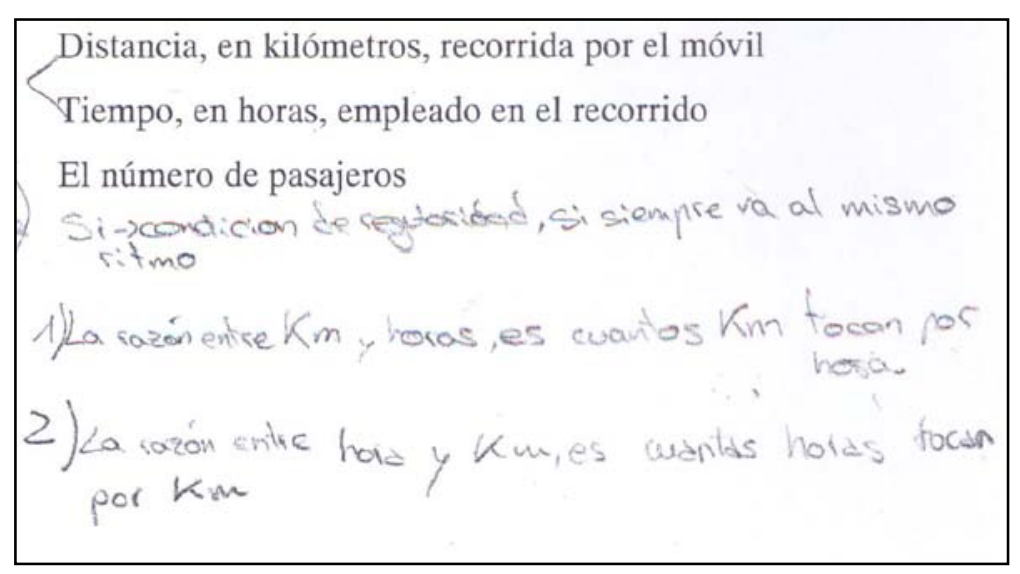

Figura VI.118.

La pareja formada por A55 y A56 también señala (acertadamente) que la distancia y el tiempo son magnitudes que pueden considerarse directamente proporcionales. Sin embargo no indican ni condiciones de regularidad, ni el significado de las razones. De hecho, la justificación dada indica que la concepción que tienen es incorrecta (ver Figura VI.119):

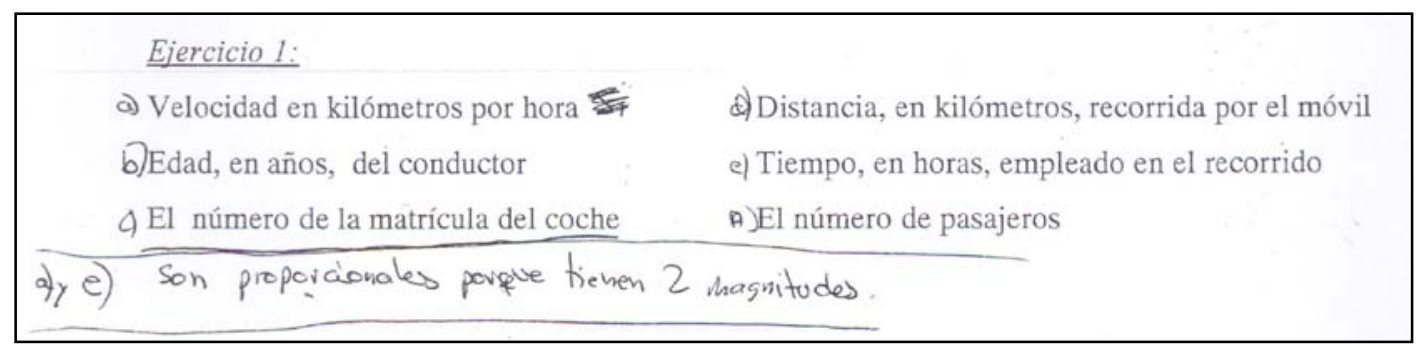

Figura VI.119. 
Dan como motivo la existencia de dos magnitudes, lo cual no es cierto. Es más, indican que la matrícula del coche y el número de pasajeros no son directamente proporcionales porque (y es cierto) “sólo tienen una magnitud”.

Otra concepción errónea respecto a la proporcionalidad directa es la que muestra la pareja formada por A42 y A50 (ver la Figura VI.120 siguiente):

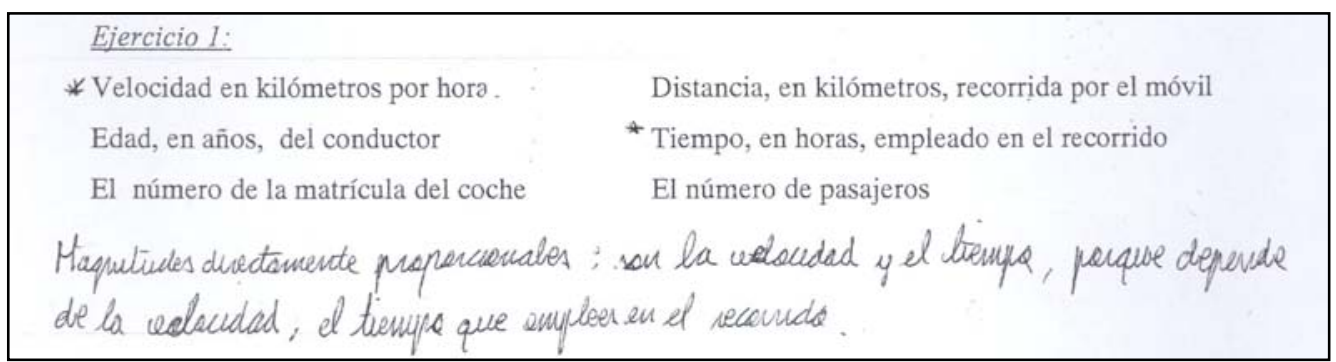

Figura VI.120.

Esta pareja señala (incorrectamente) como magnitudes directamente proporcionales a la velocidad y el tiempo, justificándolo en que “depende de la velocidad, el tiempo que empleen en el recorrido". Han identificado el ser directamente proporcionales con el estar relacionadas. Este error puede estar motivado en el hecho de que la mayoría de ejemplos trabajados hasta el momento en los que las magnitudes no eran directamente proporcionales estaban formados por parejas de magnitudes no relacionadas o bien por variables que no eran magnitudes.

Respecto a la amplísima mayoría de parejas que indican incorrectamente un par de magnitudes directamente proporcionales, casi todos señalan como tales la velocidad y el tiempo empleado. Tal es el caso de A39 y A53 (en la Figura VI.121):

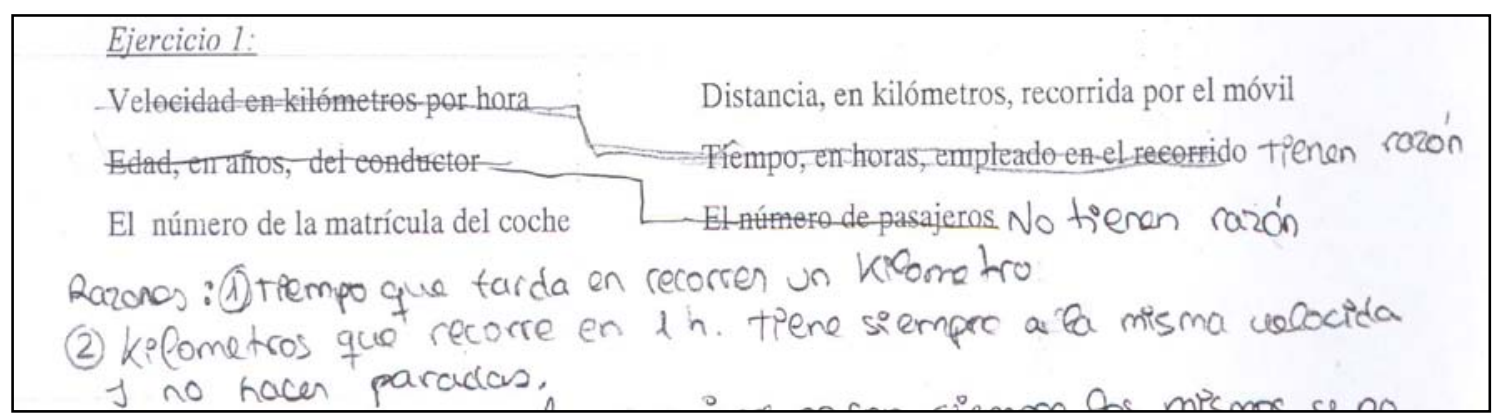

Figura VI.121.

Esta pareja pone de manifiesto las dificultades (ya mencionadas con anterioridad) que presentan los alumnos a la hora de manejar magnitudes que sean la razón de otras dos. En este caso, la velocidad es la razón entre el espacio recorrido y el tiempo 
empleado. Los alumnos, aparentemente, no captan la diferencia entre hablar de kilómetros y de kilómetros por hora y, por ello, indican que la razón entre la velocidad y el tiempo son los kilómetros que recorre en una hora ${ }^{7}$.

Por último, indicamos que un gran porcentaje de parejas acierta al indicar magnitudes (o variables) que no son directamente proporcionales. Eso sí, en todos los casos la razón es que no hay relación entre ellas. Tal es el caso, por ejemplo, de A32 y A38 (Figura VI.122 siguiente) que dicen “El número de la matrícula del coche no tiene nada que ver con el número de pasajeros”.

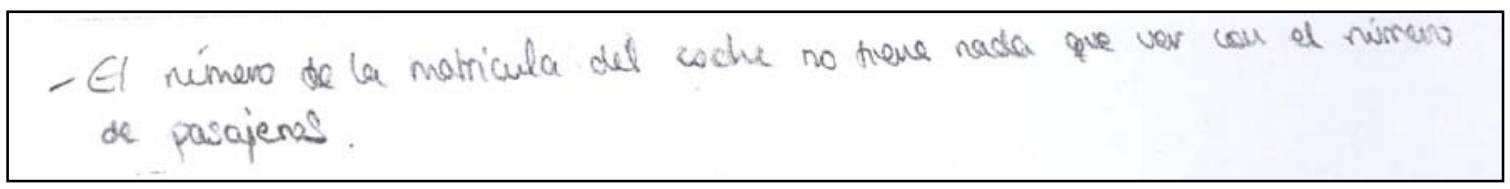

Figura VI.122.

Aunque de hecho, en este caso, el número de la matrícula no es una cantidad de ninguna magnitud.

\section{Ejercicio 2:}

En este ejercicio el contexto que unifica todas las magnitudes indicadas puede ser, por ejemplo, el patio de recreo del colegio. Las magnitudes relevantes aquí son: el número de alumnos, la superficie del patio y la anchura del mismo. El resto de variables que aparecen o bien carecen de relación entre ellas o con las anteriores (edad de los alumnos, estatura media), o bien no son magnitudes (hora de comienzo de las clases).

Respecto al ejercicio anterior hay dos diferencias importantes. La primera es que las magnitudes que aparecen en este ejercicio son mucho más comprensibles para los alumnos que las del anterior. Las relaciones entre espacio, tiempo y velocidad de un móvil (por más que éste lo haga uniformemente) parecen ser demasiado complejas o estar demasiado alejadas de los alumnos. La segunda es que en este ejercicio no aparecen magnitudes que sean la razón de otras dos.

Los resultados obtenidos por los alumnos en este ejercicio aparecen reflejados, según las unidades de análisis presentadas anteriormente, en la siguiente tabla:

7 Aunque sí que se puede definir la razón (bajo las condiciones adecuadas) entre velocidad en kilómetros por hora y tiempo en horas, serían los kilómetros por hora que aumenta (o disminuye) la velocidad al cabo de una hora. Sería, por supuesto, una aceleración. Sin embargo, el significado físico de esta magnitud es, creemos, bastante complejo. 


\begin{tabular}{|c|c|c|c|c|c|c|c|c|}
\hline \multicolumn{2}{|c|}{} & $\mathbf{0}$ & $\mathbf{1}$ & $\mathbf{2}$ & $\mathbf{3}$ & $\mathbf{4}$ & $\mathbf{5}$ & $\mathbf{6}$ \\
\hline Ejercicio 2 & $\mathbf{N}^{\mathbf{0}}$ de resp. & 0 & 13 & 13 & 1 & 2 & 1 & 9 \\
\cline { 2 - 9 } & Porcentaje & $0 \%$ & $48^{\prime} 1 \%$ & $48^{\prime} 1 \%$ & $3^{\prime} 7 \%$ & $7^{\prime} 4 \%$ & $3^{\prime} 7 \%$ & $333^{\prime} 3 \%$ \\
\hline
\end{tabular}

Casi la mitad de los alumnos deja en blanco este apartado. Esto se debe a que muchas parejas emplearon casi todo el tiempo en responder al primer ejercicio (sobre todo en uno de los grupos). En el ejercicio siguiente se repetirá esta situación que, por otro lado, es habitual en todas las actividades realizadas en el aula.

Debido en parte a lo que se ha comentado un poco más arriba el porcentaje de parejas que señala correctamente magnitudes directamente proporcionales aumenta considerablemente. Sin embargo, se mantiene el bajísimo número de parejas que demuestran comprender la situación, señalando los significados de las razones y/o las condiciones de regularidad. Por ejemplo, la pareja formada por A39 y A53 (ver Figura VI.123 siguiente) indica acertadamente que el número de alumnos en el patio y su superficie pueden considerarse magnitudes directamente proporcionales; asignan bien el significado a las razones existentes, pero no dan la condición de regularidad ${ }^{8}$.

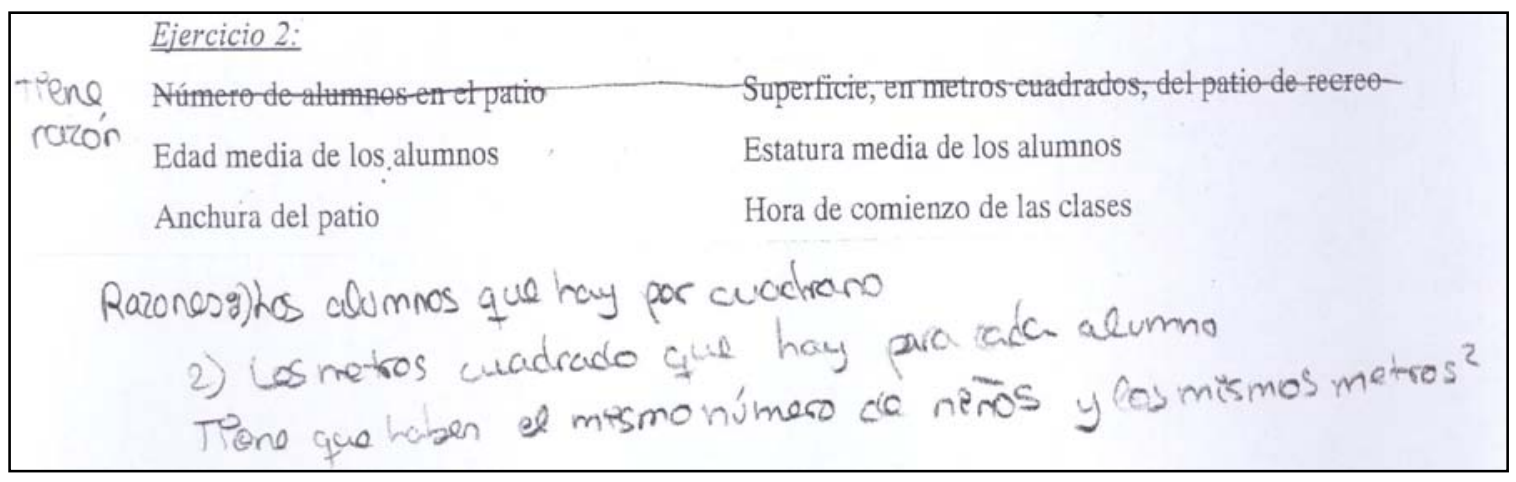

Figura VI.123.

El resto de parejas que señalan correctamente magnitudes que pueden suponerse directamente proporcionales aducen motivos incorrectos. En primer lugar, hay parejas que identifican (como ya pasó en el ejercicio anterior) ser directamente proporcionales simplemente con estar relacionadas. Tal es el caso de la pareja formada por A42 y A50 (ver Figura VI.124) que responde: "Porque según como sea la superficie de tamaño, dependerá el $n^{\circ}$ de alumnos que quepan en el patio”

\footnotetext{
${ }^{8}$ Además hemos de suponer que por número de alumnos en el patio sobreentienden número de alumnos que caben en el patio.
} 


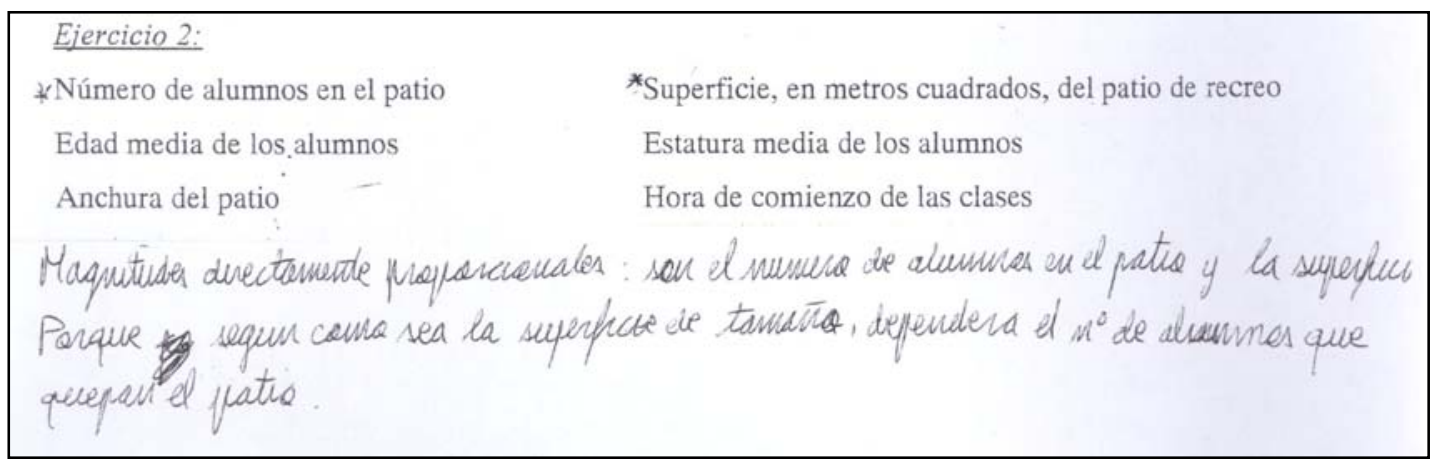

Figura VI.124.

Algunas parejas inclinan por la anchura y la superficie del patio (lo que requiere una condición de regularidad relativamente difícil de dar y que, por tanto, no dan). Tampoco en este caso los motivos que indican los alumnos son correctos. Por ejemplo, la pareja formada por A19 y A23 (en la Figura VI.125, que sigue) responde: "Porque $1 \mathrm{~m}^{2}$ es igual que $1 \mathrm{~m}$ de ancho y de largo":

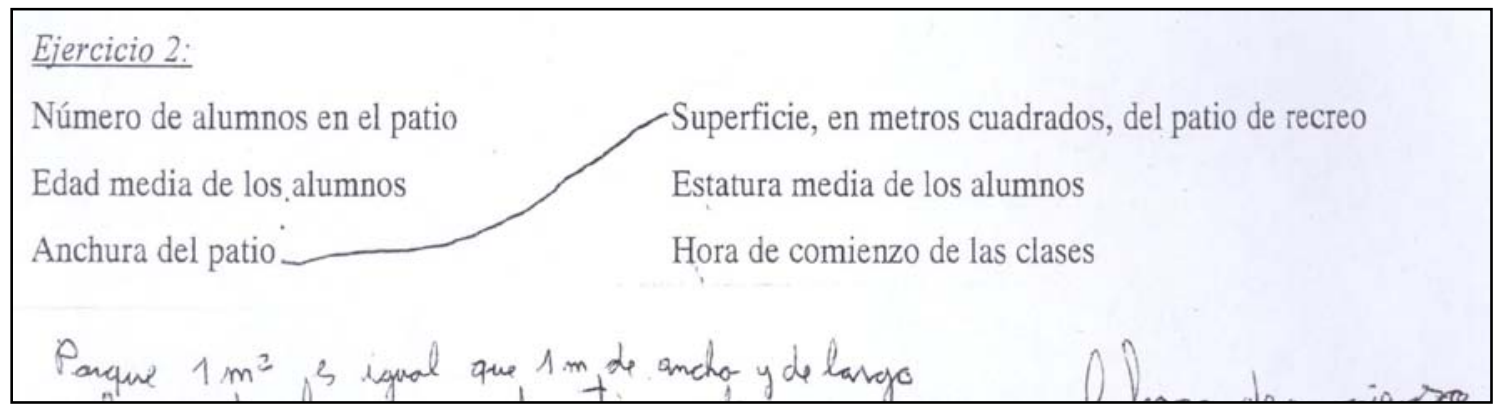

Figura VI.125.

Esta pareja involucra aquí los valores unitarios seguramente inspirados por el recuerdo de la razón como tanto por uno. Esta idea se repite en varias parejas más, seguramente por influencia de unas sobre otras.

Tan sólo una pareja señala como directamente proporcionales dos magnitudes que no lo son. Esta pareja ya cometió el mismo error en el ejercicio anterior. Consiste en identificar el mero hecho de que ambas variables sean magnitudes con ser directamente proporcionales. La causa, como dijimos, es que en la mayoría de los ejemplo de no proporcionalidad una de las variables no es una magnitud. La pareja en cuestión es la formada por A55 y A56 (ver Figura VI.126): 


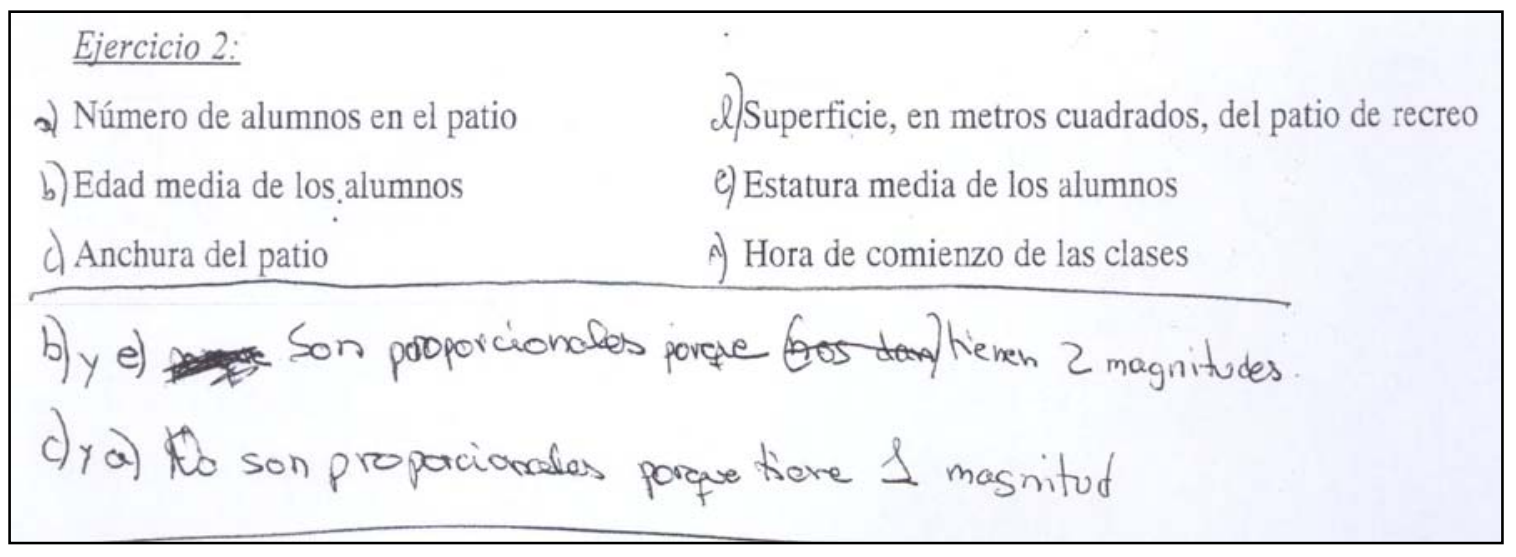

Figura VI.126.

Se observa que esta pareja señala como no proporcionales un par de variables de las que dice que sólo una es una magnitud (aunque en este caso también se equivoca).

Por último es relativamente sorprendente el descenso en el número de parejas que señala adecuadamente un par de variables que no son directamente proporcionales. La explicación es que los alumnos que ahora no lo hacen es porque dejan el apartado en blanco; dato éste que puede comprobarse numéricamente en la tabla anterior. Por otro lado, la explicación dada por los alumnos a la hora de justificar su elección vuelve a involucrar el hecho de que las variables (sean magnitudes o no) no están relacionadas entre sí. Tal es el caso, por ejemplo, de la pareja formada por A6 y A11 (Figura VI.127 siguiente) que indica que "la edad de los alumnos no tiene nada que ver con la hora de comienzo de las clases":

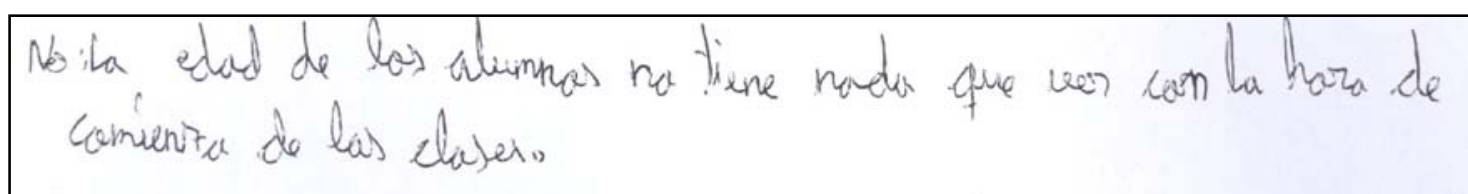

Figura VI.127.

Este par de variables, junto con la estatura y la hora de inicio de clases, son los elegidos por todos los alumnos que responden a esta parte del ejercicio. Nadie se inclina por el par edad media-estatura media (quizás por no estar muy seguros de si hay relación entre ellas) ni por ninguna de las demás posibilidades.

\section{Ejercicio 3:}

En este ejercicio podemos pensar que el contexto que unifica todas las magnitudes indicadas es, por ejemplo, una librería en la que se pretende comprar libros. Las 
magnitudes relevantes aquí son: el número de libros, el precio de cada libro. También se podría hacer jugar algún papel (algo forzado) al número de páginas y al de fotografías. El resto de variables que aparecen (edad del comprador y tamaño de la letra) carecen de relación entre ellas o con las anteriores.

Los resultados obtenidos por los alumnos en este ejercicio aparecen reflejados, según las unidades de análisis presentadas anteriormente, en la siguiente tabla:

\begin{tabular}{|c|c|c|c|c|c|c|c|c|}
\hline \multicolumn{2}{|c|}{} & $\mathbf{0}$ & $\mathbf{1}$ & $\mathbf{2}$ & $\mathbf{3}$ & $\mathbf{4}$ & $\mathbf{5}$ & $\mathbf{6}$ \\
\hline Ejercicio 3 & $\mathbf{N}^{\mathbf{0}}$ de resp. & 0 & 16 & 2 & 9 & 0 & 0 & 6 \\
\cline { 2 - 9 } & Porcentaje & $0 \%$ & $599^{\prime} 3 \%$ & $7^{\prime} 4 \%$ & $333^{\prime} 3 \%$ & $0 \%$ & $0 \%$ & $22^{\prime} 2 \%$ \\
\hline
\end{tabular}

En este ejercicio se unen varios factores que contribuyen a los pobres resultados reflejados en la tabla anterior. En primer lugar, el hecho de ser el último ejercicio hace que el número de respuestas en blanco sea altísimo. El segundo, ya de carácter conceptual, es que en este ejercicio no hay pares de magnitudes que puedan considerarse directamente proporcionales de una forma tan clara como en los dos ejercicios anteriores.

Como acabamos de decir, en este ejercicio no son muy claros los posibles pares de magnitudes directamente proporcionales. Sobre todo, porque las condiciones de regularidad necesarias, digamos que son poco realistas. Por ejemplo, la pareja formada por A6 y A11 (en la Figura VI.128) señalan como directamente proporcionales las magnitudes número de libros y número de fotografías. No señalan sin embargo la condición de regularidad, que en este caso sería que todos los libros contengan el mismo número de fotografías. A cambio, el argumento aportado es que "Si suponemos que un libro tiene 4 imágenes, 2 libros tendrán 8 imágenes” que, en realidad, no hace sino reforzar la necesidad de una condición de regularidad:

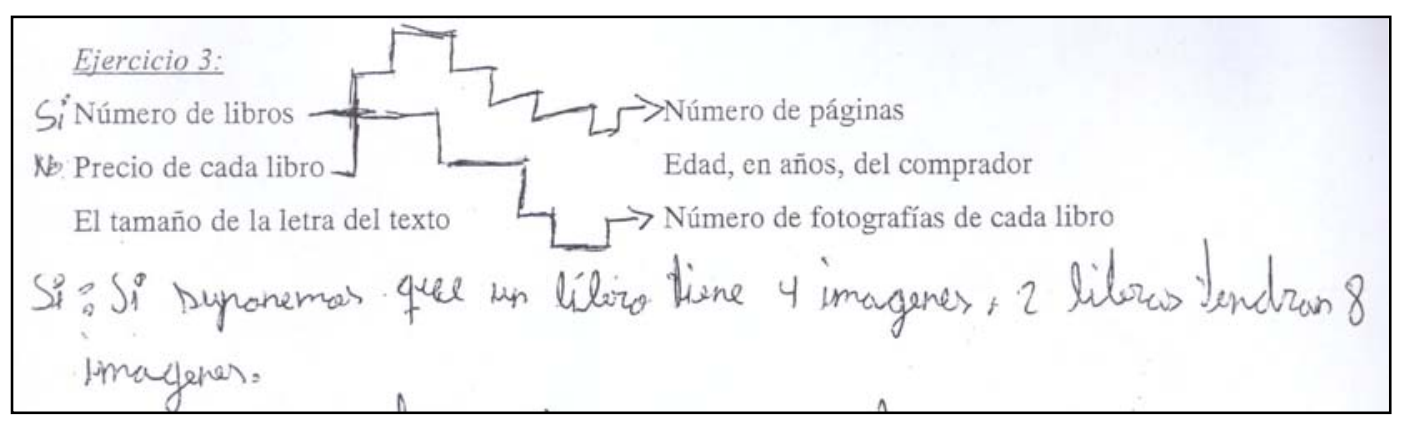

Figura VI.128. 
Otro ejemplo más interesante nos lo da la pareja formada por los alumnos A45 y A54 (Figura VI.129). Esta pareja señala como directamente proporcionales el número de páginas y el de fotografías:

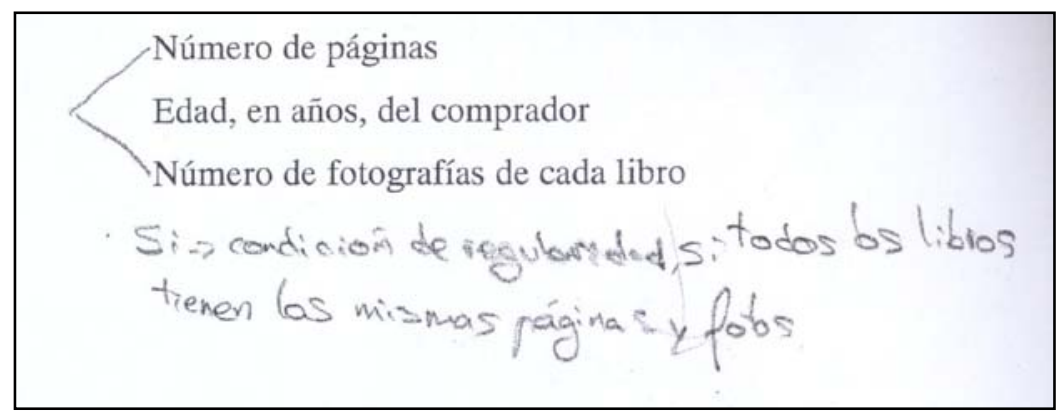

Figura VI.129.

Además, aunque la condición de regularidad es algo más compleja en este caso, la señalan correctamente: “todos los libros tienen las mismas páginas y fotos”.

Sigue persistiendo la idea de que dos magnitudes son directamente proporcionales si están relacionadas. Así, nos encontramos con alumnos que, a veces, buscan variopintas relaciones entre las magnitudes del enunciado. Así, la pareja formada por A4 y A18 (en la Figura VI.130) piensa que "según el tamaño de letra se puede saber para qué edad está hecho el libro”.

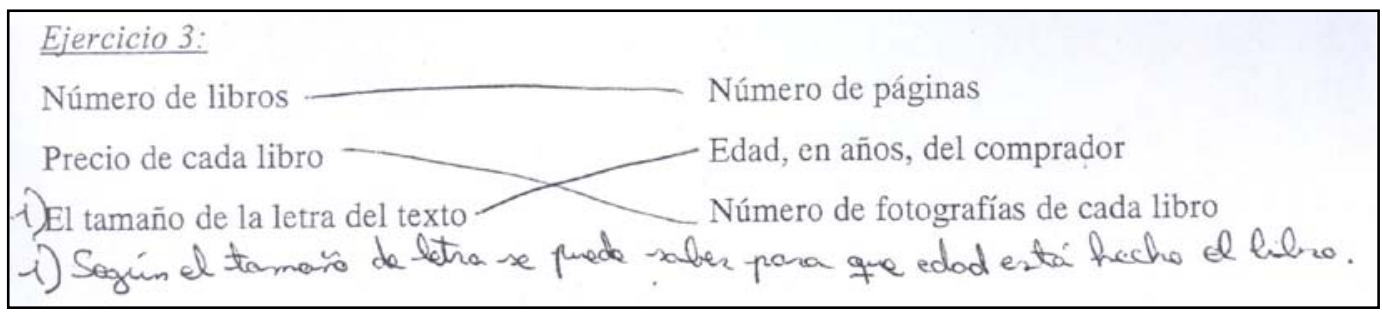

Figura VI.130.

Y la pareja formada por A19 y A23 piensa (más razonablemente) que "si la letra fuera de un cm tendría más paginas que si la letra de 1 mm” (ver Figura VI.131):

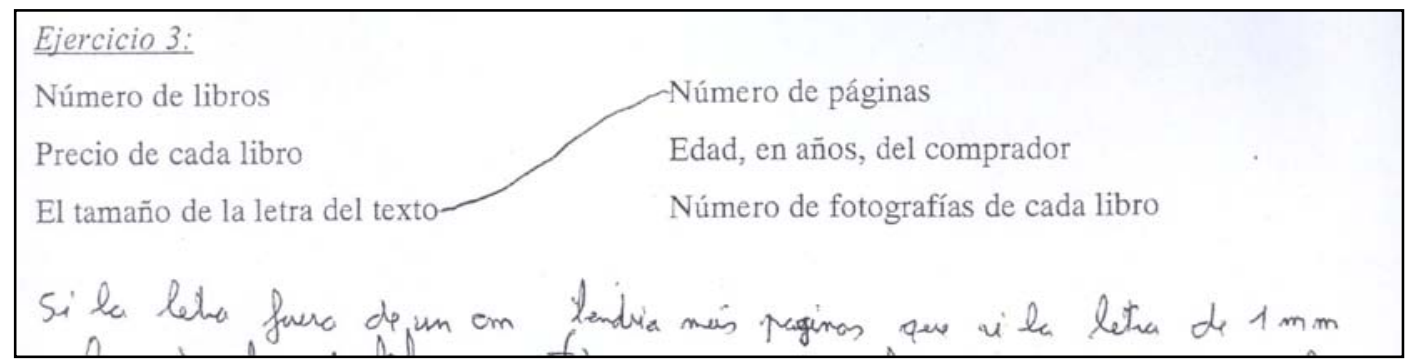

Figura VI.131. 
Algunas parejas vuelven a tener problemas con las magnitudes que son razón de otras dos. En este caso aparece el precio de cada libro, que es la razón entre el precio total y el número de libros. Algunos alumnos vuelven a pasar por alto la importante distinción entre precio total y unitario. Así, la pareja formada por los alumnos A32 y A38 (en la Figura VI.132 siguiente) señala como directamente proporcionales las magnitudes número de libros y precio de cada libro; indicando como condición de regularidad aquella que debería cumplirse si la magnitud considerada fuera el precio total.

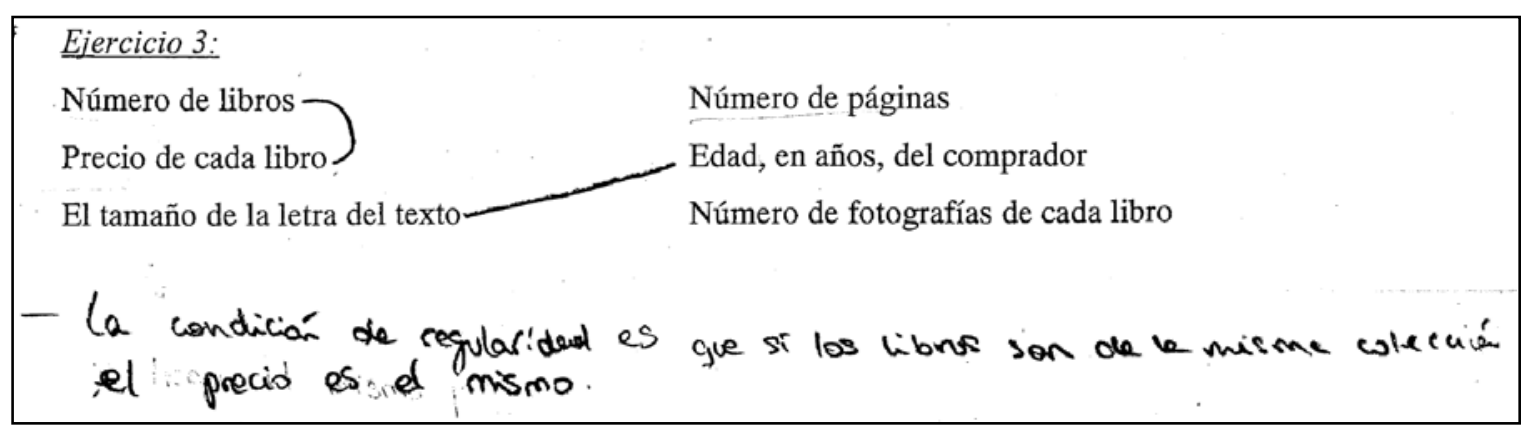

Figura VI.132.

Por último, como siempre, todos los ejemplos de magnitudes no directamente proporcionales están formados por parejas que carecen de relación entre sí. La pareja A37 y A47 (ver Figura VI.133) opta, por ejemplo, por el precio de cada libro y la edad; aunque hay algunos otros ejemplos.

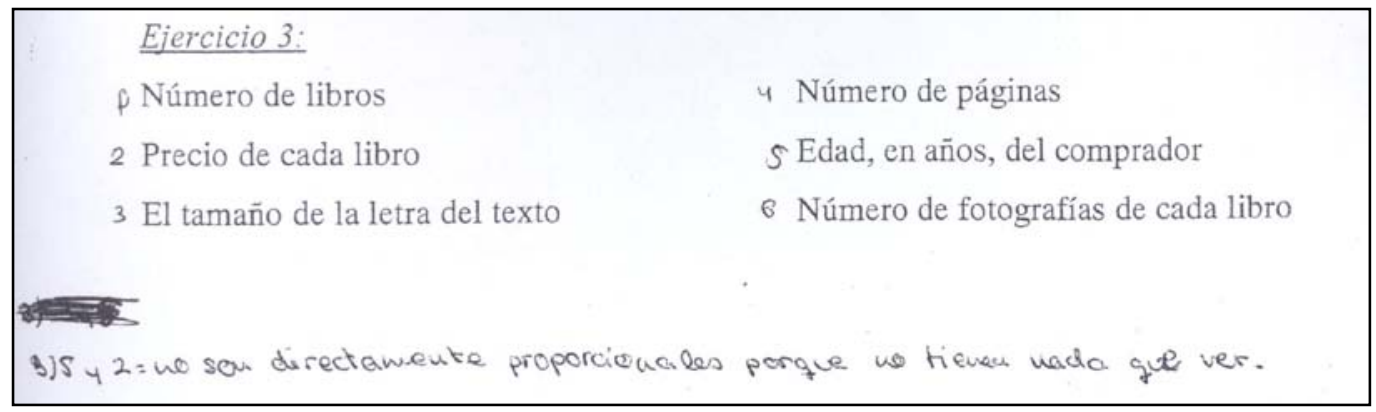

Figura VI.133.

\section{VI.3.1.2 Reflexiones relativas al punto 1}

1. Algunos alumnos tienen dificultades serias a la hora de manejar magnitudes que son la razón de otras dos. Por ejemplo, algunos alumnos manejan la velocidad como si fuera una distancia o el precio unitario como si fuera un precio total. 
2. Aparentemente, deben dejarse de lado las magnitudes que provienen de la física o cuyo significado último es puramente físico. En concreto, las relaciones entre velocidad, espacio y tiempo han dado muchos problemas a la mayor parte de los alumnos.

3. Casi todos los ejemplos de variables que no son directamente proporcionales involucran o bien magnitudes no relacionadas o bien una variable que no es una magnitud. Este hecho lleva a pensar a algunos alumnos:

i. Si hay dos magnitudes, ya se puede hablar de proporcionalidad directa. O bien,

ii. Si las dos magnitudes están relacionadas, ya hay proporcionalidad directa.

4. Incluso entre los que señalan correctamente pares de magnitudes directamente proporcionales se observa poca tendencia (por falte de comprensión o por no sentir la necesidad) a indicar tanto la condición de regularidad como el significado de las razones.

\section{VI.3.2 Punto 2: Búsqueda de cantidades desconocidas}

Posiblemente uno de los aspectos más importantes a la hora de manejar el concepto de magnitudes directamente proporcionales será el de aplicar las ideas presentadas hasta el momento en los típicos problemas en los que se conocen dos cantidades correspondientes de las magnitudes implicadas y se desea encontrar la cantidad desconocido de una de ellas correspondiente a una cantidad conocida de la otra. Este tipo de situaciones se trabajan en la Actividad de aula 5 y en la Tarea de casa 4.

\section{VI.3.2.1 Análisis y valoración de la Actividad de aula 5}

\section{Enunciado}

Recordad que dos magnitudes son directamente proporcionales si se puede definir una razón entre ellas. Además la razón entre dos magnitudes es la cantidad de la primera que se corresponde con una unidad de la segunda. Con esta idea, tratad de resolver los 


\section{siguientes problemas.}

\section{Ejercicio 1:}

Para obtener 4200 litros de mosto hacen falta 6300 kilogramos de uva, ¿cuántos

kilogramos de uva se necesitan para obtener 3560 litros de mosto?

\section{Ejercicio 2:}

En un libro de 360 páginas hay 15 capítulos, ¿cuántos capítulos tendrá un libro de 288 páginas?

\section{Ejercicio 3:}

En una ciudad de 600000 habitantes se editan 4 periódicos, ¿cuántos periódicos se editarán en una ciudad de 1050000 habitantes

\section{Ejercicio 4:}

Se tardan 9 minutos para aumentar 5 grados la temperatura de un recipiente de 12 litros, ¿qué tiempo se tardará en aumentar 17 grados la temperatura de dicho recipiente?

\section{Ejercicio 5:}

En una clase de 25 alumnos hay 14 teléfonos móviles, ¿cuántos teléfonos móviles habrá en una clase de 18 alumnos?

\section{Análisis de la actividad}

Las unidades de análisis para esta actividad son las siguientes:

\begin{tabular}{|c|c|}
\hline 0 & No entrega o no asiste a clase \\
\hline 1 & Respuesta en blanco \\
\hline 2 & Respuesta incorrecta \\
\hline 3 & Indica que no se puede hallar la razón \\
\hline 4 & Resuelve usando razones señalando condición de regularidad \\
\hline 5 &
\end{tabular}

De acuerdo con estas unidades de análisis, los resultados obtenidos por los alumnos son los siguientes: 


\begin{tabular}{|c|c|c|c|c|c|c|c|}
\hline & & 0 & 1 & 2 & 3 & 4 & 5 \\
\hline \multirow[t]{2}{*}{ Ejercicio 1} & $\mathrm{~N}^{0}$ de resp. & 0 & 10 & 5 & 0 & 11 & 0 \\
\hline & Porcentaje & $0 \%$ & $38 ' 5 \%$ & $19 ’ 2 \%$ & $0 \%$ & $42 ’ 3 \%$ & $0 \%$ \\
\hline \multirow[t]{2}{*}{ Ejercicio 2} & $\mathrm{~N}^{0}$ de resp. & 0 & 4 & 3 & 7 & 10 & 2 \\
\hline & Porcentaje & $0 \%$ & $15 ’ 4 \%$ & $11 ’ 5 \%$ & $26 ’ 9 \%$ & $38 ’ 5 \%$ & 7’7\% \\
\hline \multirow[t]{2}{*}{ Ejercicio 3} & $\mathrm{~N}^{0}$ de resp. & 0 & 7 & 3 & 8 & 8 & 0 \\
\hline & Porcentaje & $0 \%$ & $26{ }^{\prime} 9 \%$ & 11'5\% & $30 ’ 8 \%$ & $30 ’ 8 \%$ & $0 \%$ \\
\hline \multirow[t]{2}{*}{ Ejercicio 4} & $\mathrm{~N}^{\circ}$ de resp. & 0 & 16 & 3 & 2 & 2 & 3 \\
\hline & Porcentaje & $0 \%$ & 61'6\% & 11'5\% & 7’7\% & 7’7\% & 11 '5\% \\
\hline \multirow[t]{2}{*}{ Ejercicio 5} & $\mathrm{~N}^{0}$ de resp. & 0 & 16 & 5 & 4 & 1 & 0 \\
\hline & Porcentaje & $0 \%$ & 61'6\% & $19 ’ 2 \%$ & $15^{\prime} 4 \%$ & 3’8\% & $0 \%$ \\
\hline
\end{tabular}

A la vista de los resultados anteriores, que obligan además a no tener demasiado en cuenta los dos últimos ejercicios, se observa un reducido número de respuestas incorrectas. Debemos señalar que en aquellos ejercicios en los que la razón tiene sentido no hemos considerado incorrectas las respuestas que hacen uso de ella aún sin indicar las condiciones de regularidad.

El porcentaje de alumnos que hacen explícitas las condiciones de regularidad es bajísimo (nulo en algunos ejercicios) y es interesante observar que en el Ejercicio 1 nadie ha indicado que no se pueda definir la razón, cosa que sí ha sucedido en todos los demás ejercicios.

\section{Ejercicio 1:}

La respuesta mayoritaria a este ejercicio ha consistido en calcular los kilos de uva necesarios para elaborar un litro de mosto, y después multiplicar por dicho valor los litros totales de mosto que se quieren obtener. Así, por ejemplo, responde el grupo formado por A8, A12 y A17 (ver Figura VI.134): 


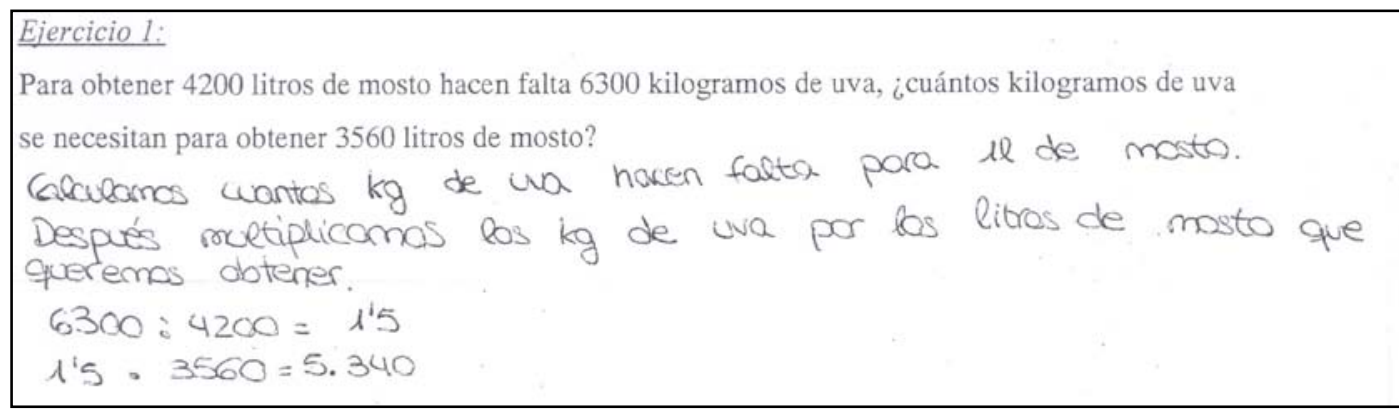

Figura VI.134.

Aunque este grupo no señala las condiciones de regularidad necesarias para que el razonamiento sea correcto, su respuesta es bastante detallada. De hecho, la mayor parte de las parejas ha dado una respuesta similar a la de la pareja formada por A10 y A29 (en la Figura VI.135 siguiente) que no va más allá de efectuar las operaciones y, eso sí, dar el significado del número obtenido:

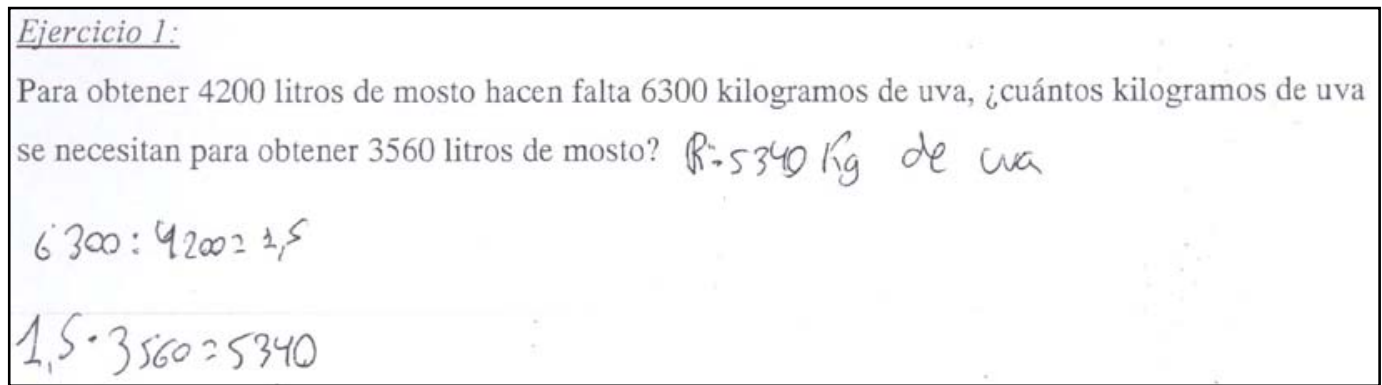

Figura VI.135.

Los escasos errores cometidos en este ejercicio puede resumirse en uno: el cometido por la pareja formada por A32 y A36 (en la Figura VI.136, que sigue). Este error surge aparentemente de no comprender el significado del resultado de dividir los litros de mosto entre los kilos de uva (litros obtenidos a partir de un kilo) e identificarlo con su inverso:

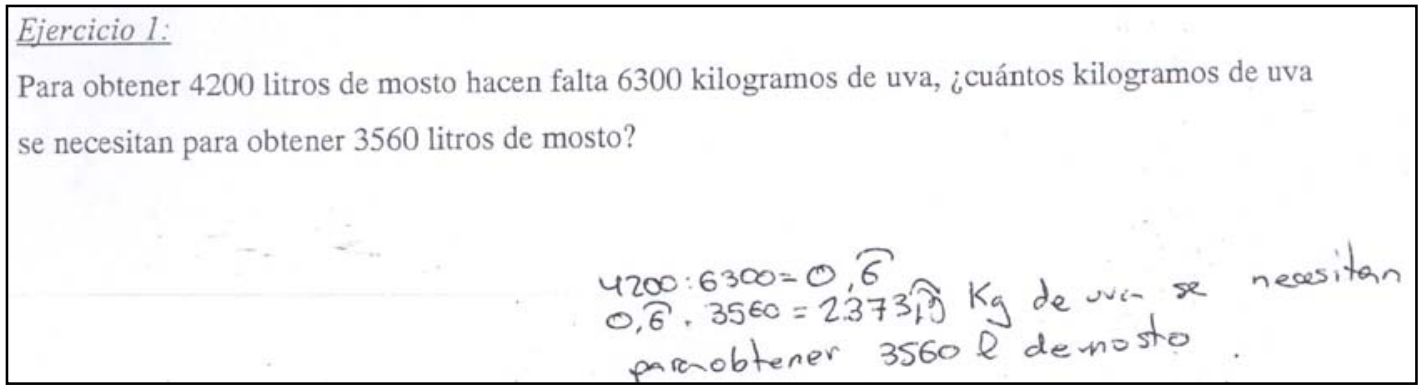

Figura VI.136. 
Aunque el ejercicio también se podía resolver hallando los litros que se obtienen a partir de un kilo de mosto y dividiendo después los litros deseados entre este valor, todos los alumnos que comienzan en esta dirección cometen el error que acabamos de señalar.

\section{Ejercicio 2:}

Nuevamente en este ejercicio la respuesta mayoritaria pasa por suponer que las magnitudes involucradas son directamente proporcionales, pero sin señalar las condiciones de regularidad necesarias. Por ejemplo, la pareja formada por A19 y A23 (en la Figura VI.137 siguiente) calcula las páginas de cada capítulo y después dividen las páginas totales entre dicho valor.

\section{Ejercicio 2:}

En un libro de 360 páginas hay 15 capítulos, ¿cuántos capítulos tendrá un libro de 288 páginas?

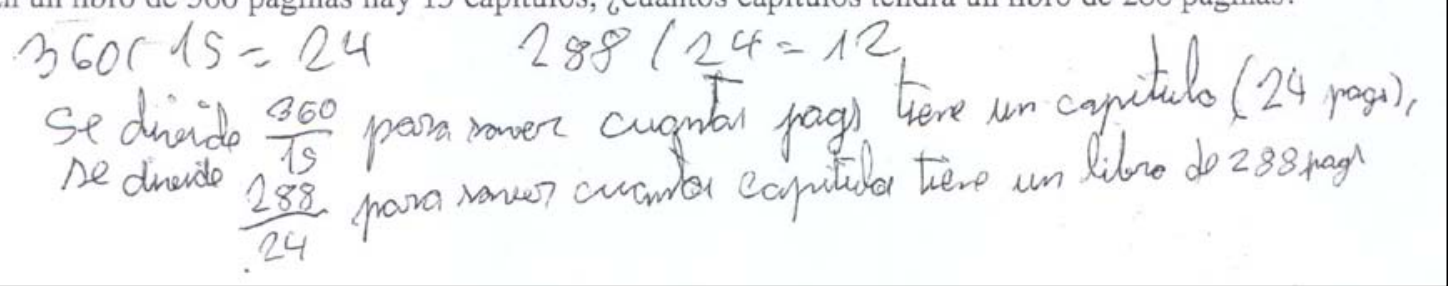

Figura VI.137.

La pareja formada por A45 y A54 sigue el mismo razonamiento, pero sí que señala la condición de regularidad necesaria (ver Figura VI.138):

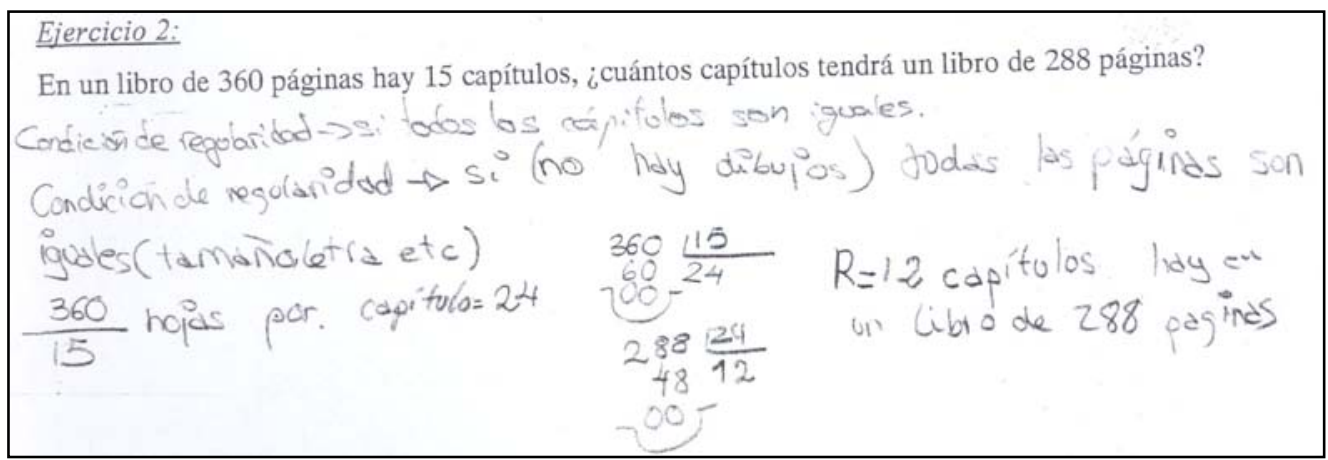

Figura VI.138.

En este ejercicio se rompe la unanimidad del ejercicio anterior y ya aparecen alumnos que muestran sus dudas ante la situación. Así, la pareja formada por A13 y A21 (ver Figura VI.139) señala que “1 capítulo puede tener más hojas o menos”: 


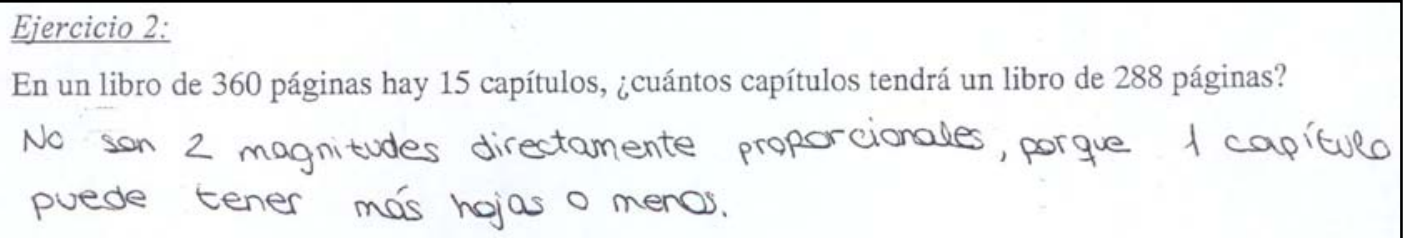

Figura VI.139.

Las respuestas incorrectas en este ejercicio han sido escasas, algunas simples errores al efectuar operaciones. El error más interesante es el cometido por la pareja A31 y A36 (en la Figura VI.140 siguiente):

Ejercicio 2:

En un libro de 360 páginas hay 15 capítulos, ¿cuántos capítulos tendrá un libro de 288 páginas?

$$
\begin{aligned}
& 360 \cdot 15=5400 \\
& 400: 288=18 \text { apritulos tendrá un 0ibro de } 288 \text { pásinas }
\end{aligned}
$$

Figura VI.140.

Es difícil interpretar las operaciones efectuadas por esta pareja en el contexto de este problema. El producto de las páginas por los capítulos no tiene un significado razonable y menos la división posterior. La única interpretación con sentido sería pensar en 15 capítulos de 360 páginas cada uno y después calcular el número de capítulos que habría si cada uno tuviese 288 páginas.

La otra posible forma de resolver este ejercicio usando razones, a saber, calculando la razón entre capítulos y páginas y después multiplicando dicho valor por al nuevo número de páginas no ha sido elegida por nadie. La dificultad de asignar un significado sencillo a la razón capítulos/página es la explicación más clara.

\section{Ejercicio 3:}

En este ejercicio continúa existiendo la división (mucho más marcada, pues coinciden en número) entre alumnos que consideran que entre las magnitudes involucradas no puede definirse la razón (como la pareja formada por A39 y A53, en la Figura VI.141, que sigue):

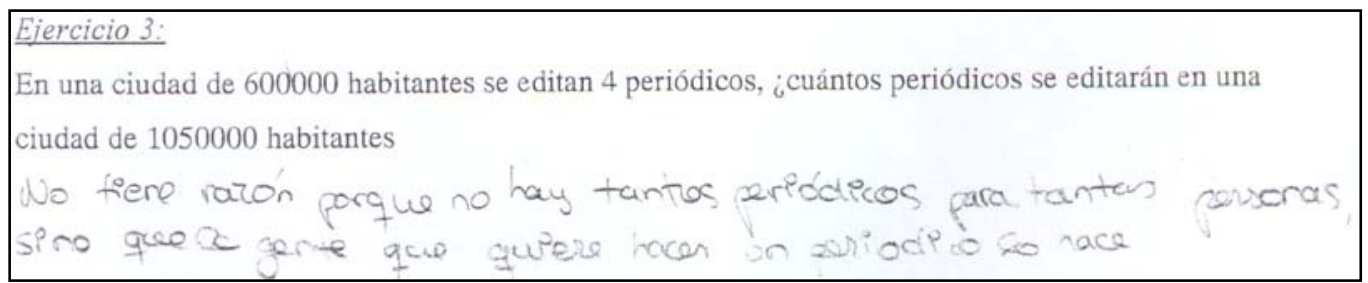

Figura VI.141. 
y aquellos otros que razonan asumiendo que la razón "habitantes por periódico” tiene sentido y puede utilizarse (como la pareja formada por A2 y A20, en la Figura VI.142:

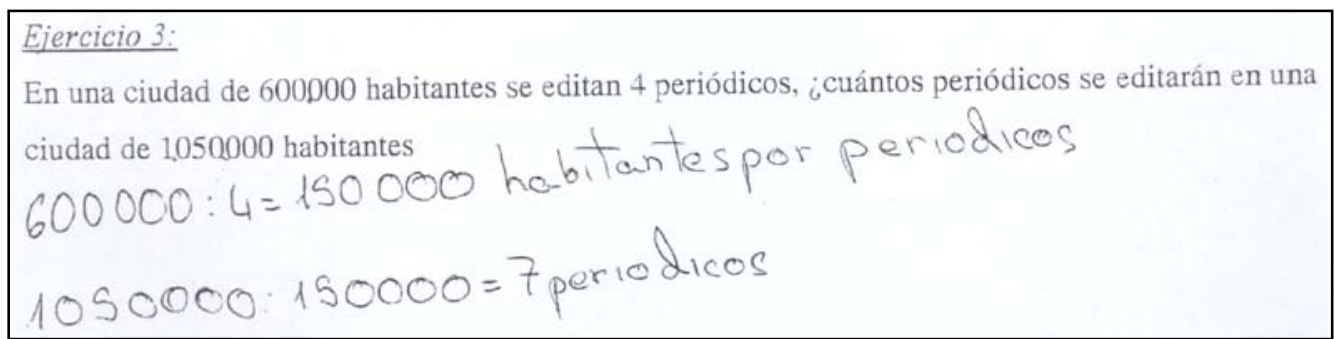

Figura VI.142.

Eso sí, en este caso tampoco hay ninguna pareja que explicite la sencilla condición de regularidad necesaria. Además, entre aquellos que utilizan la razón para resolver el problema, nadie utiliza la razón "periódicos por habitante” que es la que podría resultarles familiar. Quizás se deba a que la operación a efectuar en este caso (4 entre 600000) sea mucho más engorrosa que la inversa.

Respecto a los errores, el más interesante es el cometido por la pareja formada por A44 y A51 (ver Figura VI.143) que divide el número de habitantes de la segunda ciudad entre el número de periódicos de la primera ciudad para obtener (no se sabe muy bien cómo) el número de periódicos editados en la segunda ciudad:

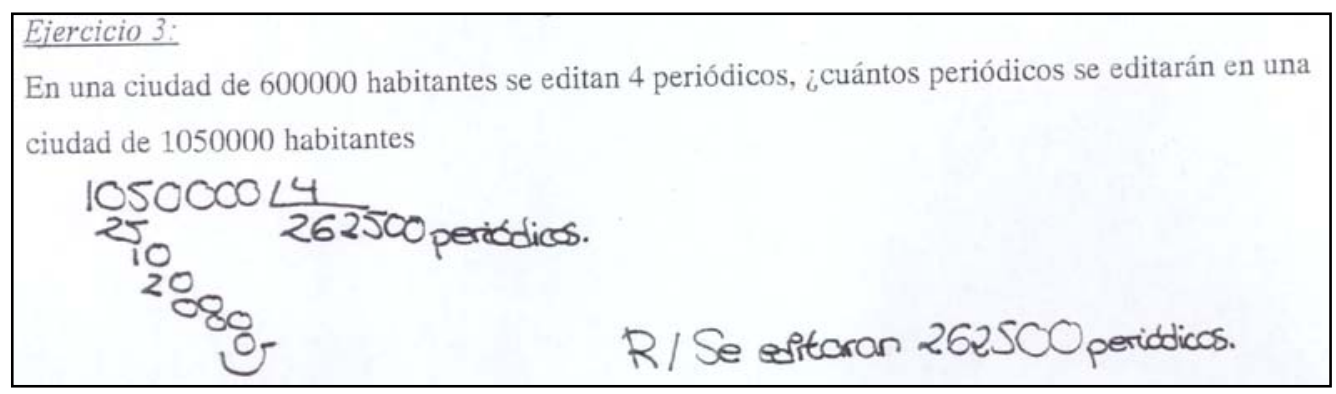

Figura VI.143.

\section{Ejercicio 4:}

Este ejercicio planteaba la situación más compleja desde el punto de vista de la comprensión. Además se incluía un dato (la capacidad del recipiente) que no debía jugar papel alguno en la resolución.

La física nos dice que el tiempo de calentamiento no es en absoluto proporcional a los grados de temperatura que deben aumentarse. Sin embargo, no se puede esperar que alumnos de $1^{\circ}$ de E.S.O. posean dichos conocimientos y es razonable un tipo de respuesta como el de la pareja formada por A37 y A47 (Figura VI.144 siguiente) 
asumiendo que sí se da dicha proporcionalidad y tratando de señalar alguna condición de regularidad:

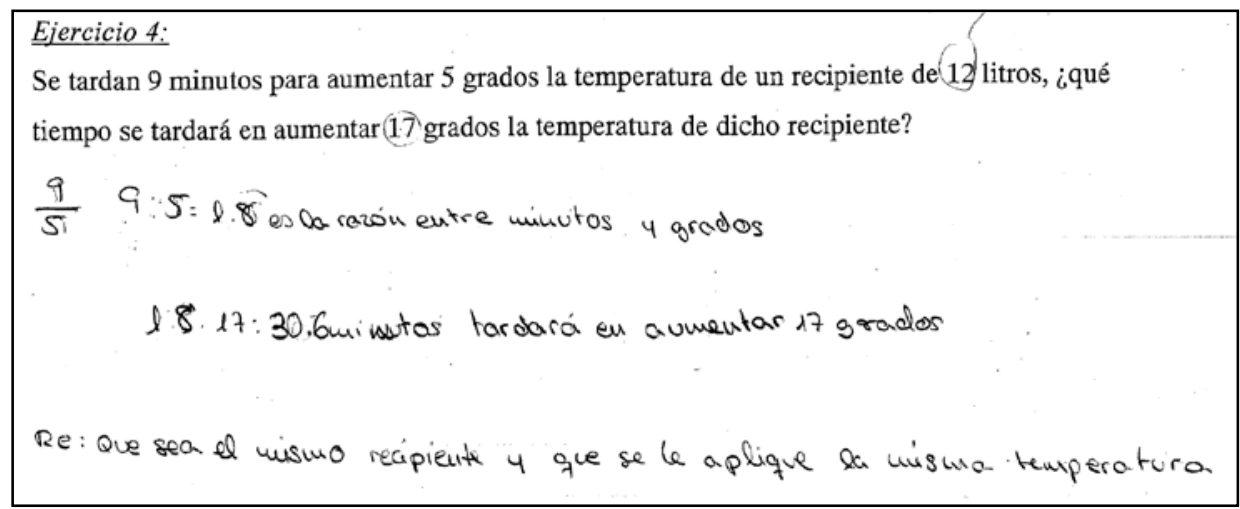

Figura VI.144.

Algunos se contentan con indicar que la relación no es de proporcionalidad y que, por tanto, no hay razón entre dichas variables. Sin embargo, la explicación es necesariamente deficiente. Así, la pareja formada por A45 y A54 dice que "no siempre se calienta igual” (ver Figura VI.145):

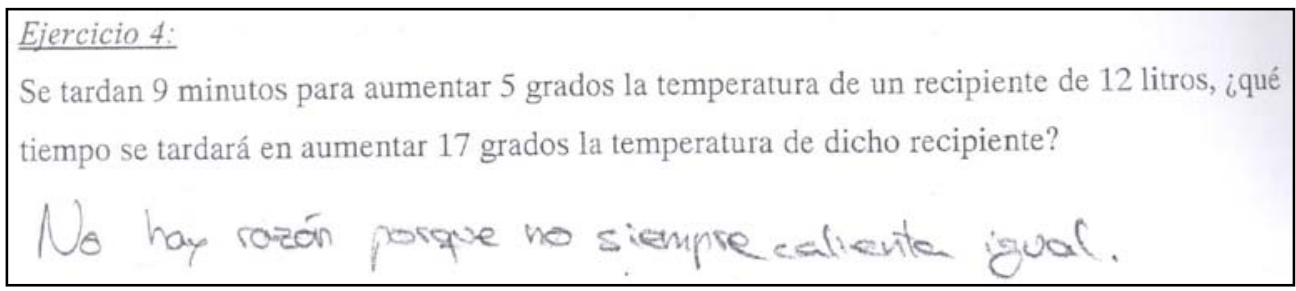

Figura VI.145.

La pareja formada por los alumnos A35 y A43 asume la proporcionalidad pero da un curioso razonamiento que nos retrotrae a los argumentos utilizados por los alumnos en las primeras tareas: “Aproximadamente 30,30 minutos ya que cada 9 minutos sube 5 y en 27 estaría a 15 y como 2 es menos de la mitad de 5 se coge menos de la mitad de 9 en total 3,5 aprox.” (véase la Figura VI.146)

\section{Ejercicio 4:}

Se tardan 9 minutos para aumentar 5 grados la temperatura de un recipiente de 12 litros, ¿qué tiempo se tardará en aumentar 17 grados la temperatura de dicho recipiente?

$$
\begin{aligned}
& \text { Aproximadamente } 30,30 \text { minutes ya que cada } 9 \text { wubes y en } 27 \text { estavía a } 15 \\
& \text { ycomo } 2 \text { es menos de la mitad de } 5 \text { se coge menos de h nitad de } 9 \text { en } \\
& \text { total } 3,5 \text { agnox. }
\end{aligned}
$$

Figura VI.146. 
Es curioso el método de obtención de 17 a partir de 5, sobre todo porque a estas alturas los alumnos ya habían dejado de lado, casi por completo, este tipo de argumentos.

Ya en el terreno de los errores no encontramos esencialmente dos de ellos. El primero consiste nuevamente en confundir los significados de una razón con su inversa. Así, la pareja formada por A13 y A21 calcula inicialmente los grados de ascenso por minuto, pero después maneja dicho valor como si fuesen los minutos necesarios para elevar un grado (ver Figura VI.147):

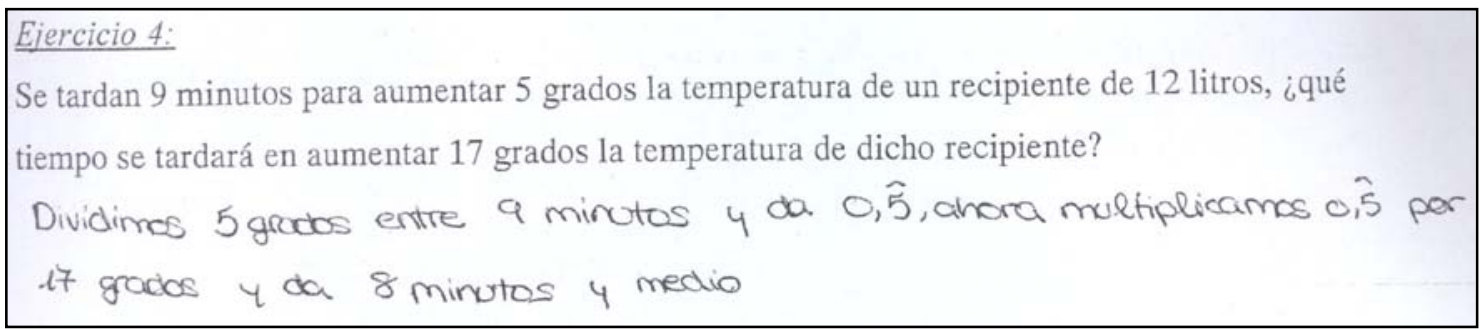

Figura VI.147.

Por otro lado, la pareja formada por A2 y A20 trata de hacer entrar en juego la capacidad del recipiente pero el ejercicio queda incompleto y, además, asignan un significado incorrecto a la operación efectuada (ver Figura VI.148 siguiente):

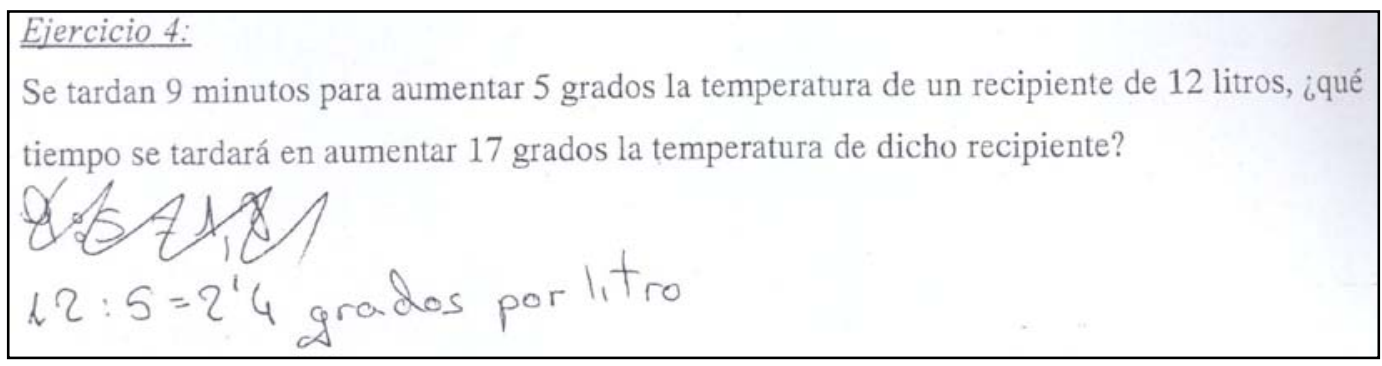

Figura VI.148.

\section{Ejercicio 5:}

Este último ejercicio, pese al elevadísimo porcentaje de respuestas en blanco, es el que mayor número de respuestas equivocadas ha recibido. Curiosamente es el único ejercicio en el que han aparecido razonamientos que involucran diferencias. Además han aparecido las dos opciones posibles, como ahora veremos.

En primer lugar, la pareja formada por los alumnos A3 y A7 ha razonado de manera que la diferencia entre los alumnos de una y otra clase debía ser igual a la diferencia entre los correspondientes cantidades de móviles (ver Figura VI.149): 


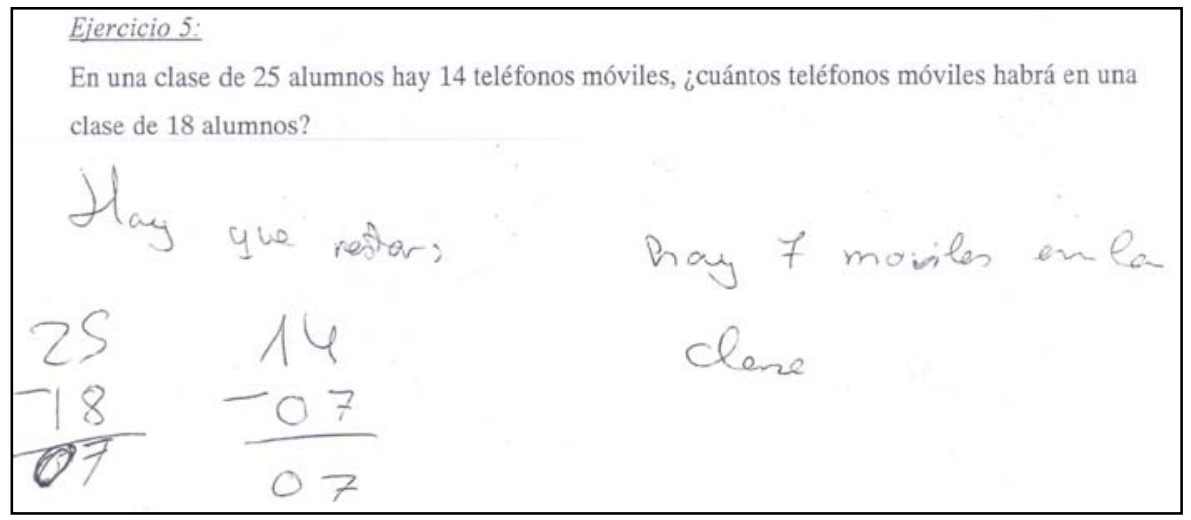

Figura VI.149.

Por su parte, la pareja formada por los alumnos A35 y A43, ha razonado de modo que debía mantenerse constante la diferencia entre alumnos y móviles en cada una de las clases (ver Figura VI.150):

\section{Ejercicio 5:}

En una clase de 25 alumnos hay 14 teléfonos móviles, ¿cuántos teléfonos móviles habrá en una clase de 18 alumnos?

$$
\begin{aligned}
& 25-14=11 \text { once móles menos que alumnas } \\
& 18-11=9
\end{aligned}
$$

Figura VI.150.

En este ejercicio también aparecen alumnos que indican que no existe la razón entre las magnitudes involucradas, como es el caso de la pareja A39 y A53 (en la Figura VI.151).

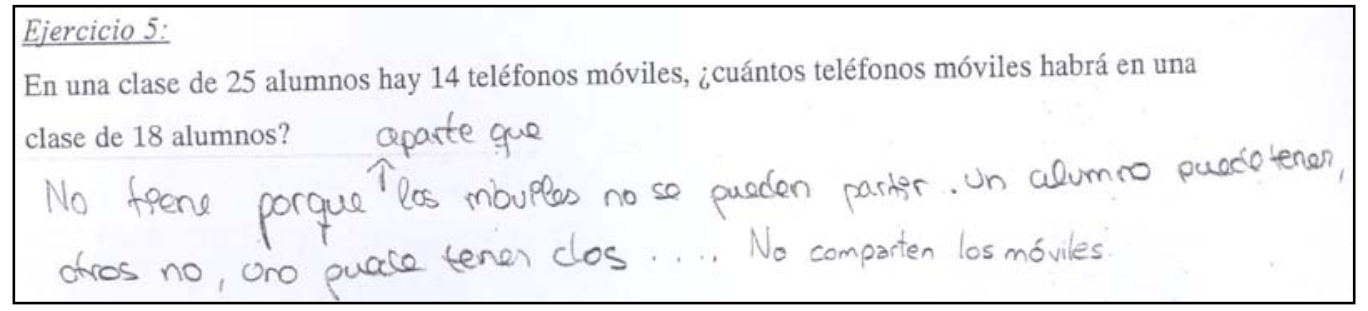

Figura VI.151.

Y también existe una pareja que razona asumiendo proporcionalidad entre las magnitudes, aunque en este ejercicio es mucho más difícil de defender dicha elección. De hecho, esta pareja (alumnos A46 y A48) no indica condiciones de regularidad y, 
además, no muestra extrañeza alguna ante una cantidad decimal de teléfonos móviles (Figura VI.152):

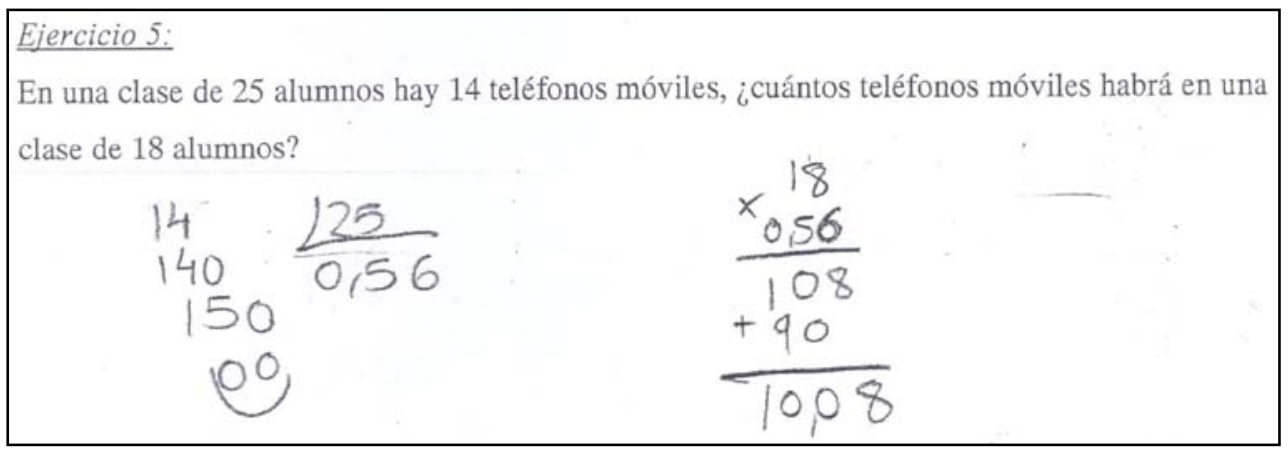

Figura VI.152.

\section{VI.3.2.2 Análisis y valoración de la Tarea de casa 4}

\section{Enunciado}

En clase hemos comprobado cómo el uso de la razón nos permite resolver problemas en los que dos magnitudes son directamente proporcionales y queremos encontrar la cantidad de una de las magnitudes que se corresponde con una cantidad conocida de la otra. Estos ejercicios van en la misma dirección.

\section{Ejercicio 1:}

3 docenas de huevos cuestan 3,5 euros. ¿Cuánto costarán 25 huevos?

\section{Ejercicio 2:}

María tiene 13 años y recibe una propina semanal de 7 euros. ¿Qué propina recibirá a los 17 años?

\section{Ejercicio 3:}

Un grupo de 3 obreros tarda 2 días en embaldosar una superficie de 200 metros cuadrados. ¿Cuántos días tardarán en embaldosar una superficie de 350 metros cuadrados?

\section{Ejercicio 4:}

Con un saco de comida para perros los 2 perros de Luis pueden comer durante todo un mes, ¿cuánto tiempo les durará esa misma comida a los 3 perros de María? 


\section{Ejercicio 5:}

En las rebajas de una tienda una camisa que cuesta 20 euros tiene un descuento de 3 euros. ¿Cuánto descuento tendrá un abrigo que cuesta 100 euros?

\section{Ejercicio 6:}

Para hacer hormigón un albañil junta 2 kilos de cemento con 4 kilos de arena. Si quiere fabricar 12 kilos de hormigón ¿cuántos kilos de cada material debe utilizar? ¿Y si quiere fabricar 100 kilos?

\section{Análisis de la tarea}

Vista la descripción anterior, estudiaremos por separado los tres tipos de ejercicios. Debido a su naturaleza esencialmente diferente, las unidades de análisis deberán variar entre unos y otros.

Ejercicios 1, 3,5 y 6:

En estos ejercicios las magnitudes involucradas pueden suponerse (suponiendo las condiciones de regularidad adecuadas) directamente proporcionales y, por tanto, tiene sentido resolver el ejercicio. Las unidades de análisis para este grupo de situaciones son las siguientes:

\begin{tabular}{|c|c|}
\hline 0 & No entrega o no asiste a clase \\
\hline 1 & Respuesta en blanco \\
\hline 2 & Respuesta incorrecta \\
\hline 3 & Indica que no se puede hallar la razón \\
\hline 4 & Respuesta correcta sin usar razones \\
\hline 5 & Resuelve usando razones señalando condición de regularidad \\
\hline 6 &
\end{tabular}

De acuerdo con estas unidades de análisis, los resultados obtenidos por los alumnos en estos ejercicios se presentan en la siguiente tabla:

\begin{tabular}{|c|c|c|c|c|c|c|c|c|}
\hline \multicolumn{2}{|c|}{} & $\mathbf{0}$ & $\mathbf{1}$ & $\mathbf{2}$ & $\mathbf{3}$ & $\mathbf{4}$ & $\mathbf{5}$ & $\mathbf{6}$ \\
\hline \multirow{2}{*}{ Ejercicio 1 } & $\mathbf{N}^{\mathbf{0}}$ de resp. & 7 & 4 & 9 & 0 & 4 & 28 & 4 \\
\cline { 2 - 9 } & Porcentaje & $12^{\prime} 5 \%$ & $7^{\prime} 1 \%$ & $16{ }^{\prime} 1 \%$ & $0 \%$ & $7^{\prime} 1 \%$ & $50 \%$ & 7'1\% \\
\hline
\end{tabular}




\begin{tabular}{|c|c|c|c|c|c|c|c|c|}
\hline \multirow[t]{2}{*}{ Ejercicio 3} & $\mathrm{~N}^{0}$ de resp. & 7 & 8 & 7 & 0 & 12 & 15 & 7 \\
\hline & Porcentaje & $12 ’ 5 \%$ & 14 '3\% & $12 ' 5 \%$ & $0 \%$ & $21 ’ 4 \%$ & $26^{\prime} 8 \%$ & $12 ’ 5 \%$ \\
\hline \multirow[t]{2}{*}{ Ejercicio 5} & $\mathrm{~N}^{0}$ de resp. & 7 & 3 & 6 & 12 & 19 & 4 & 5 \\
\hline & Porcentaje & $12 ’ 5 \%$ & $5 ’ 4 \%$ & $10^{\prime} 7 \%$ & $21 ’ 4 \%$ & 33’9\% & 7’1\% & 8’9\% \\
\hline \multirow[t]{2}{*}{ Ejercicio 6} & $\mathrm{~N}^{0}$ de resp. & 7 & 7 & 15 & 0 & 17 & 8 & 2 \\
\hline & Porcentaje & $12 ’ 5 \%$ & $12 ’ 5 \%$ & $26^{\prime} 8 \%$ & $0 \%$ & $30 ’ 3 \%$ & $14^{\prime} 3 \%$ & 3’6\% \\
\hline
\end{tabular}

Observando globalmente los datos hay varios aspectos que llaman la atención: primero, el escaso número de alumnos que indican las condiciones de regularidad necesarias para que el problema sea resoluble; segundo, que sólo en el Ejercicio 5 (que involucraba descuentos en una tienda de ropa) hay alumnos que se plantean la posibilidad de que las magnitudes involucradas no tengan relación; tercero, casi un tercio de los alumnos utilizan técnicas no relacionadas con la razón en los dos últimos ejercicios y casi un cuarto en el segundo. Por último casi la cuarta parte de los alumnos da una respuesta incorrecta en el último ejercicio, que ha sido el que menos respuestas satisfactorias (entendidas éstas como aquellas que hacen uso de la razón como tanto por uno) se han obtenido.

En el Ejercicio 1 la mitad de los alumnos razona adecuadamente utilizando la razón. Un ejemplo puede ser la respuesta dada por A35 (ver Figura VI.153):

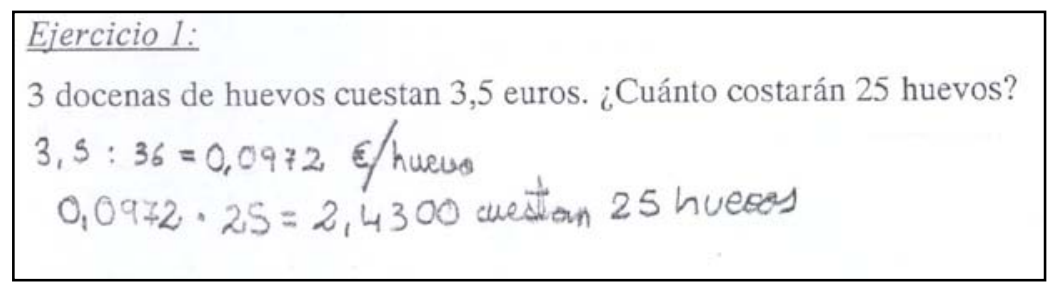

Figura VI.153.

Muy pocos alumnos indican la condición de regularidad necesaria para poder utilizar este tipo de argumentos; parece que hay situaciones en las que ese hecho está totalmente interiorizado y asumido. Tan sólo aquellos alumnos, como A39 (en la Figura VI.154 siguiente), que responden de acuerdo a un esquema en el que deben señalar todo lo que se les pide indican que es necesario que “cada huevo valga lo mismo...” 


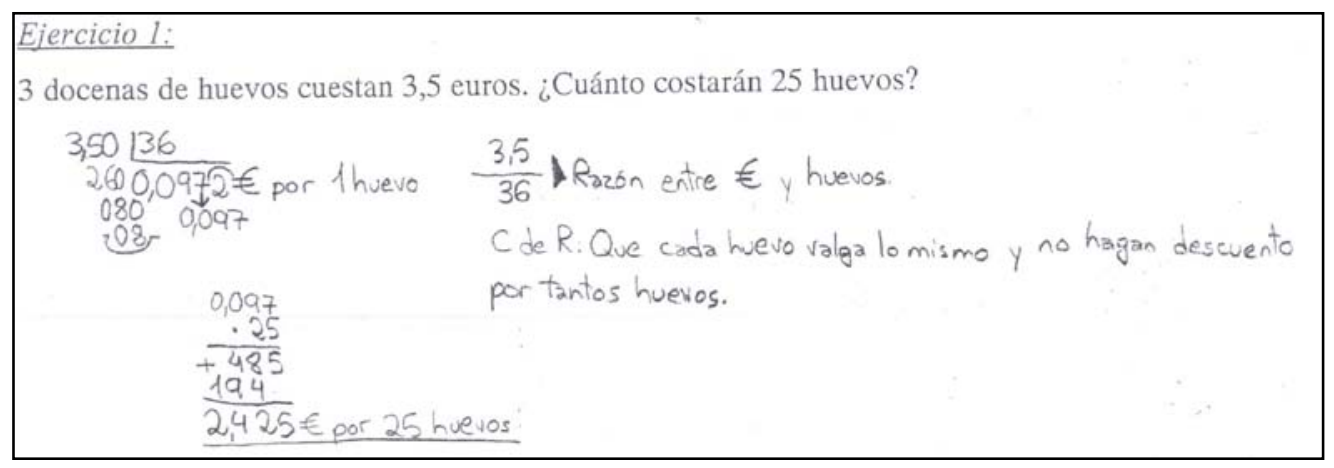

Figura VI.154.

Tan solo 9 alumnos han proporcionado una respuesta incorrecta a este ejercicio. Todos ellos han cometido un error relativo al significado de las operaciones que, de hecho, es y será recurrente. En la Figura VI.155 vemos la respuesta de A44:

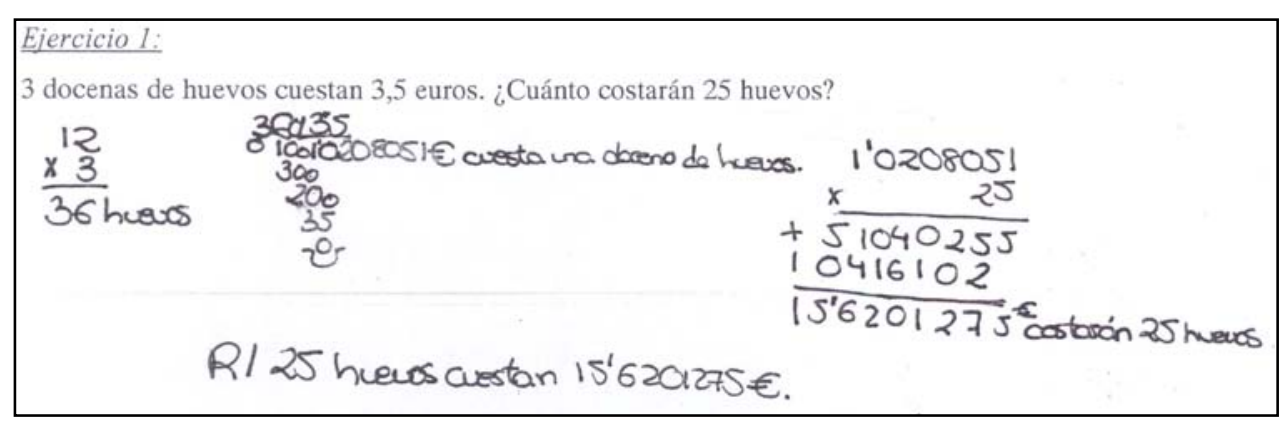

Figura VI.155.

Creemos que el error cometido por este alumno está causado por una mala comprensión del significado de las operaciones. Así, para encontrar el valor de un huevo no divide el precio de las 3 docenas entre 36, sino al revés (que serían los huevos que se obtienen por 1 euro). Sin embargo, después multiplica el valor obtenido por 25 como si conociera el precio de un huevo. Obviamos que la división es incorrecta, pues no gestiona bien los decimales.

Un argumento que, aunque correcto, deseamos evitar es el dado por A4 (ver Figura VI.156 siguiente):

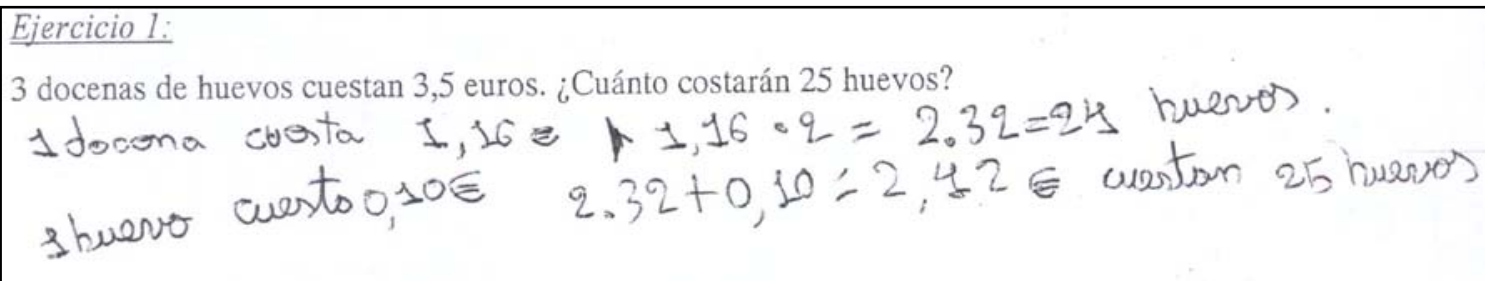

Figura VI.156. 
Aquí, el problema surge al trabajar simultáneamente con dos unidades: los huevos y las docenas de huevos. Mientras todos los demás alumnos trabajan únicamente con huevos, A4 lo hace con ambas a la vez. Así, halla el valor de una docena, pero se encuentra que para trasladar esa información a los 25 huevos ha de mezclar docenas con huevos. Por ello surge este razonamiento tan enrevesado.

Por último, mencionar la "misteriosa” aparición de reglas de tres. Misteriosa por lo innecesario y por el hecho de que nada se había mencionado ni insinuado sobre ella. El origen es bien claro: la influencia de padres, hermanos o profesores particulares. Véase por ejemplo la respuesta (figura VI.157 siguiente) de A41:

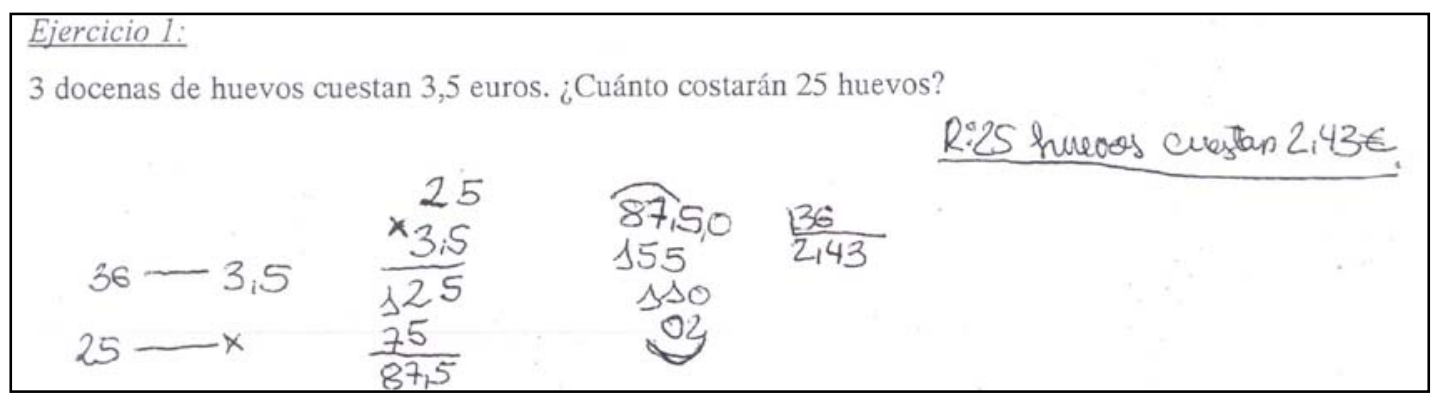

Figura VI.157.

En el Ejercicio 3 aumenta el número de alumnos que da respuestas correctas sin hacer uso de la razón. Ello se debe a la sencilla relación multiplicativa existente entre las cantidades de magnitudes involucradas. Esto hace que aparezcan respuestas como la de A36 que indica que la solución se obtiene “por lógica” (ver Figura VI.158):

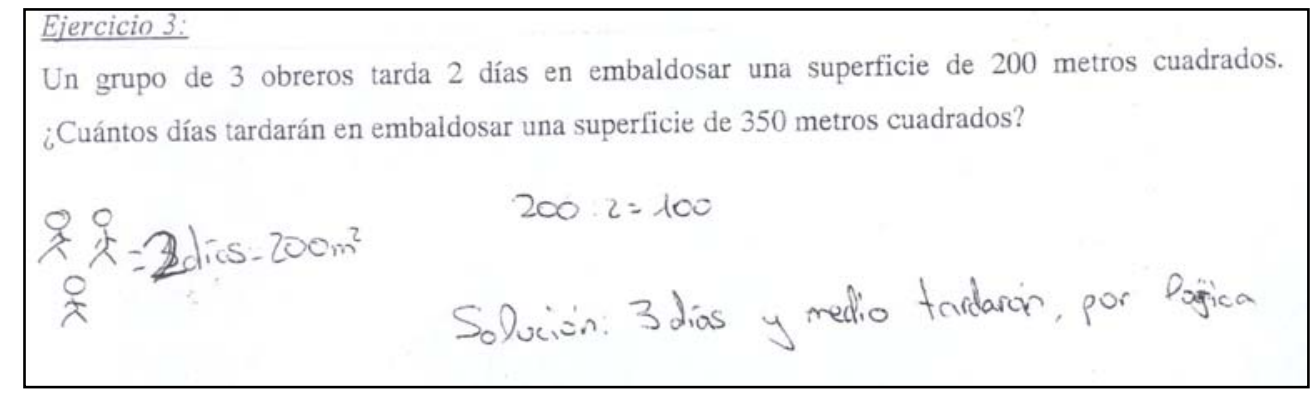

Figura VI.158.

Nuevamente son pocos (aunque más que en el ejercicio anterior) los alumnos que, como A45, señalan la condición de que “[trabajen] siempre al mismo ritmo" (ver Figura VI.159 siguiente): 


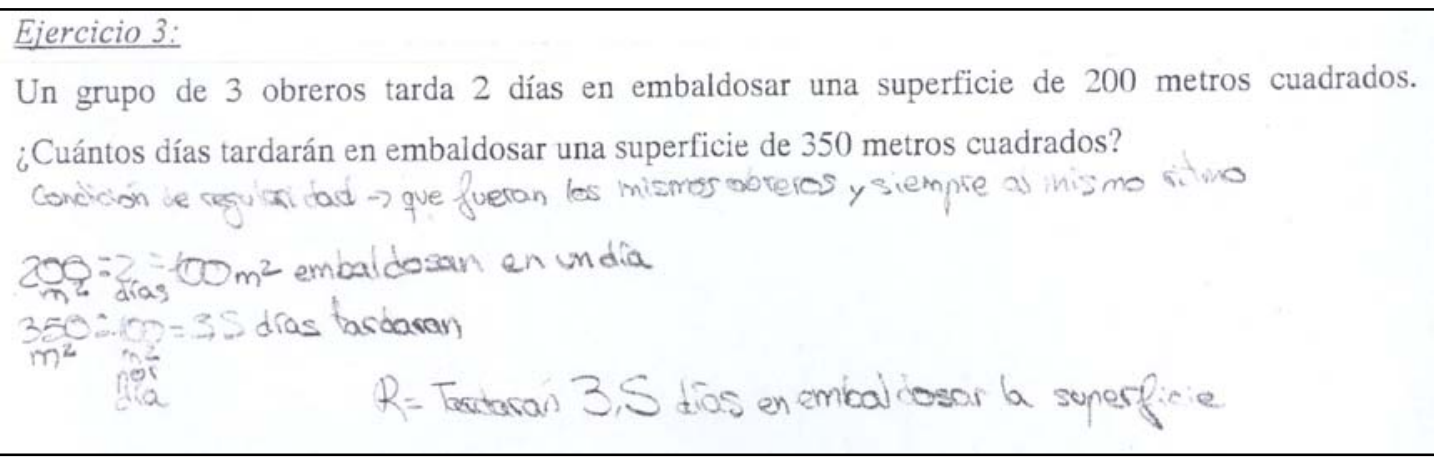

Figura VI.159.

A la hora de resolver el problema este alumno ha utilizado la razón entre superficie y días (es decir, la superficie embaldosada en un día). Sin embargo, algunos alumnos, como A19 (en la Figura VI.160, que sigue), han utilizado la razón inversa; calculando "cuántos días tardan en $1 \mathrm{~m}^{2}$ ”:

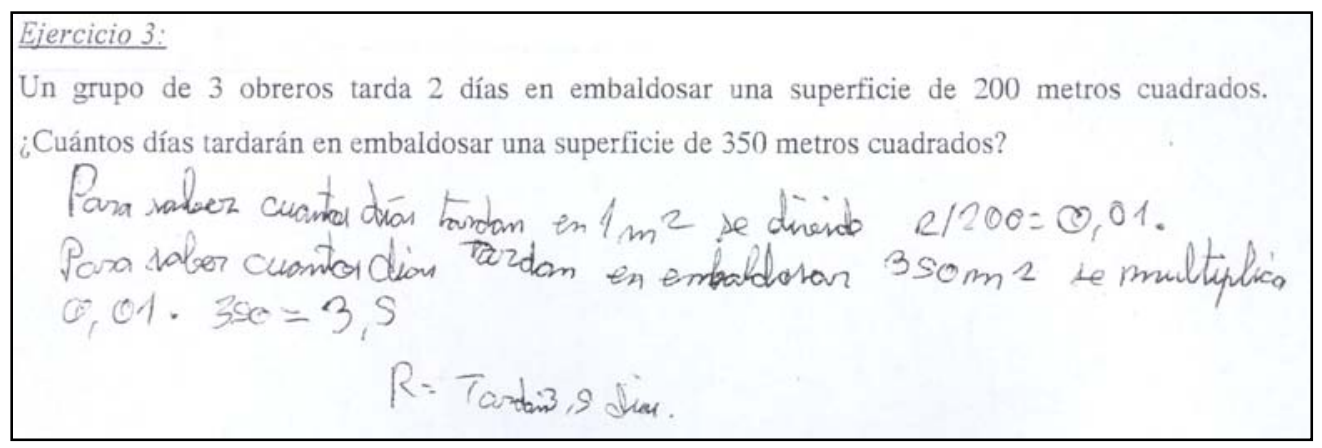

Figura VI.160.

El uso de esta razón parece menos intuitivo que el de la anterior y, en consecuencia, la respuesta del alumno demuestra una buena comprensión del significado de las operaciones efectuadas y de los resultados obtenidos.

La buena comprensión del alumno anterior contrasta con la respuesta de A20 (en la Figura VI.161 siguiente). Este alumno efectúa operaciones carentes de sentido, posiblemente llevado por el deseo de utilizar todas las cantidades que tiene a su disposición. Incluso involucra a los 3 obreros, cantidad que no juega papel alguno en la resolución del ejercicio. 
Ejercicio 3:

Un grupo de 3 obreros tarda 2 días en embaldosar una superficie de 200 metros cuadrados.

¿Cuántos días tardarán en embaldosar una superficie de 350 metros cuadrados?

$350 \cdot 3=1050: 2=525$

$523: 200=2,623$ días

$R=$ Tardarán 2,62s dées.

Figura VI.161.

Por último, el hecho de que aparezcan 3 magnitudes en el ejercicio nos podría llevar a pensar en una situación de proporcionalidad compuesta. Estas situaciones están más allá del currículum de $1^{\circ}$ de E.S.O. y, de hecho, no era el caso, puesto que la magnitud "número de obreros", como hemos dicho, no juega aquí papel alguno. Sin embargo, técnicas de resolución como la de A11 (ver la Figura VI.162 siguiente) remiten inmediatamente a algunos de los métodos habituales de resolución de ese tipo de problemas. Llama la atención el hecho de que el alumno no haya observado que la primera columna es innecesaria.

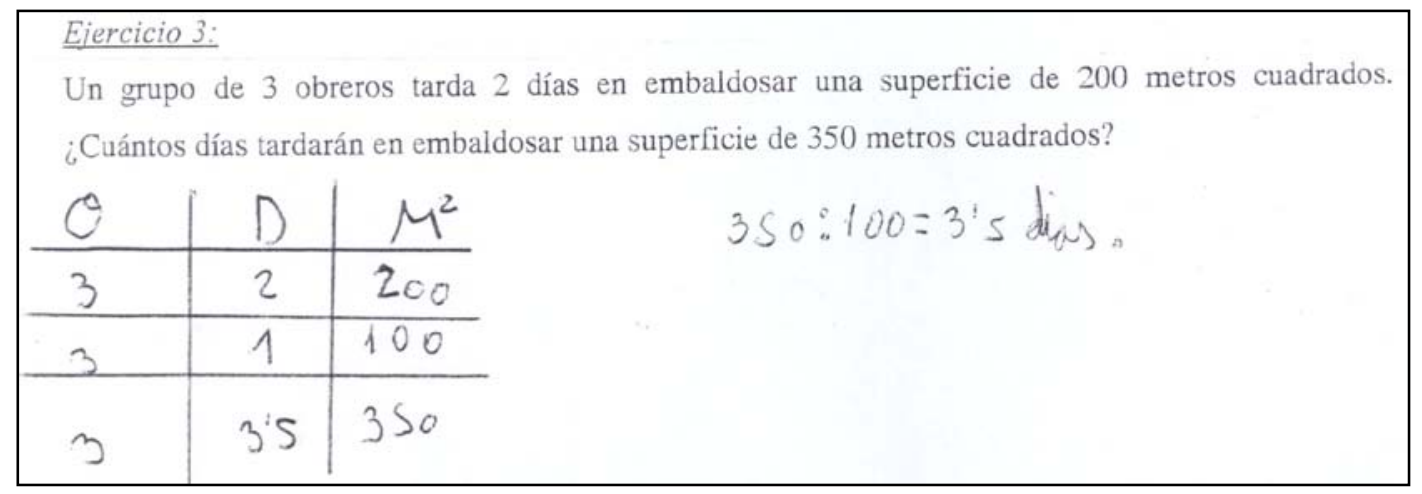

Figura VI.162.

El Ejercicio 5 es interesante fundamentalmente por dos motivos: porque es el que tiene mayor número de respuestas correctas empleando estrategias que no involucran razones y porque es el único en el que aparecen alumnos que afirman que no es posible resolver el ejercicio. Respecto a este último aspecto, podemos ver la respuesta de A33: "No se sabe porque no sabemos cuanto descuento tiene un abrigo" (ver Figura VI.163).

\section{Ejercicio 5:}

En las rebajas de una tienda una camisa que cuesta 20 euros tiene un descuento de 3 euros. ¿Cuánto descuento tendrá un abrigo que cuesta 100 euros?

- No se abe perque no sabemos ceranto descento tiene un abrigo

Figura VI.163. 
La afirmación de este alumno es totalmente cierta, pero resulta chocante que sólo en este ejercicio surja este escrúpulo mientras que en el resto se razona proporcionalmente sin que casi ningún alumno exponga las condiciones de regularidad necesarias. Existen alumnos no obstante, como A28 (en la Figura VI.164), que razonan adecuadamente calculando y entendiendo el significado de la razón entre descuento y precio (aunque el alumno dice "entre descuento y rebajas”) y entendiendo que el descuento debe ser "regular":

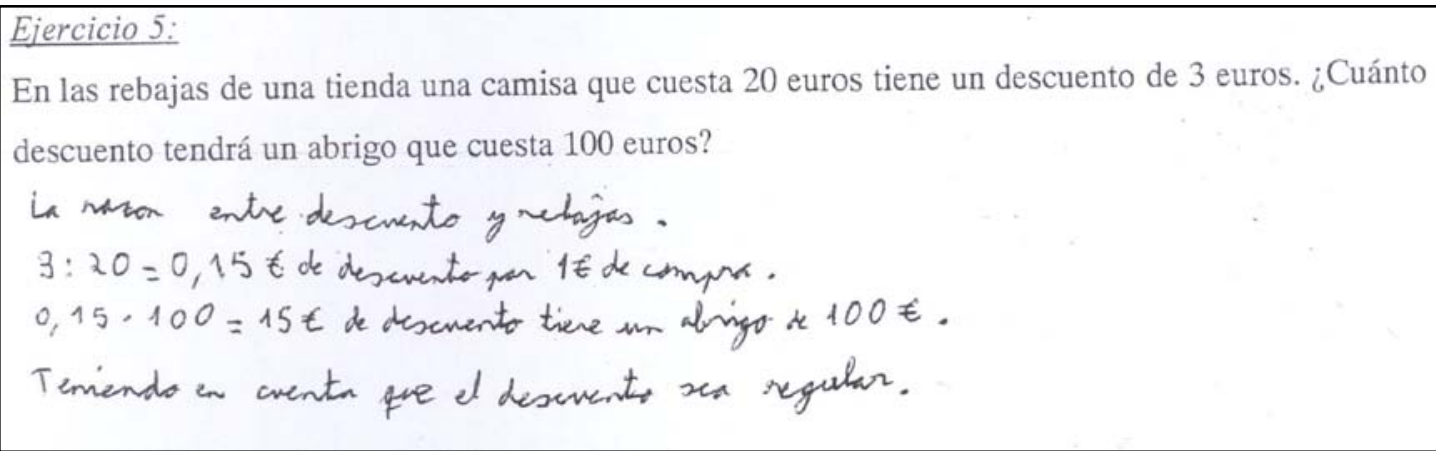

Figura VI.164.

Entre aquellas estrategias que no involucran el uso de la razón, hay dos que tienen especial interés. La primera de ellas era la más esperable, aparece ejemplificada en la Figura VI.165 donde reproducimos la respuesta del alumno A35:

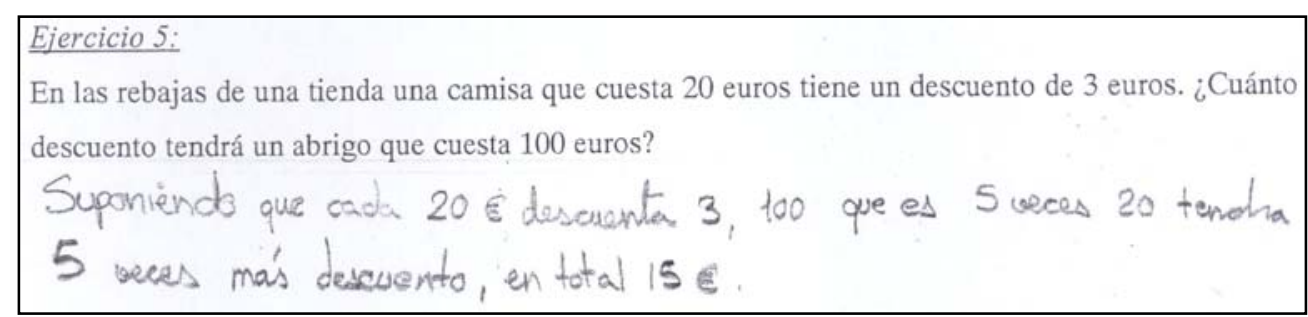

Figura VI.165.

Este alumno basa su respuesta en la relación multiplicativa existente entre los dos precios conocidos. Usa lo que en algunos lugares se denomina "razón interna”. Este alumno no ha utilizado la razón externa entre precio y descuento (o viceversa) que es la que nosotros pretendemos trabajar y que es para la que la idea de "tanto por uno" tiene pleno sentido. Aparece además otra estrategia, similar a ésta en el fondo, pero muy diferente en la forma. Se trata de la utilizada por el alumno A7 (ver Figura VI.166): 


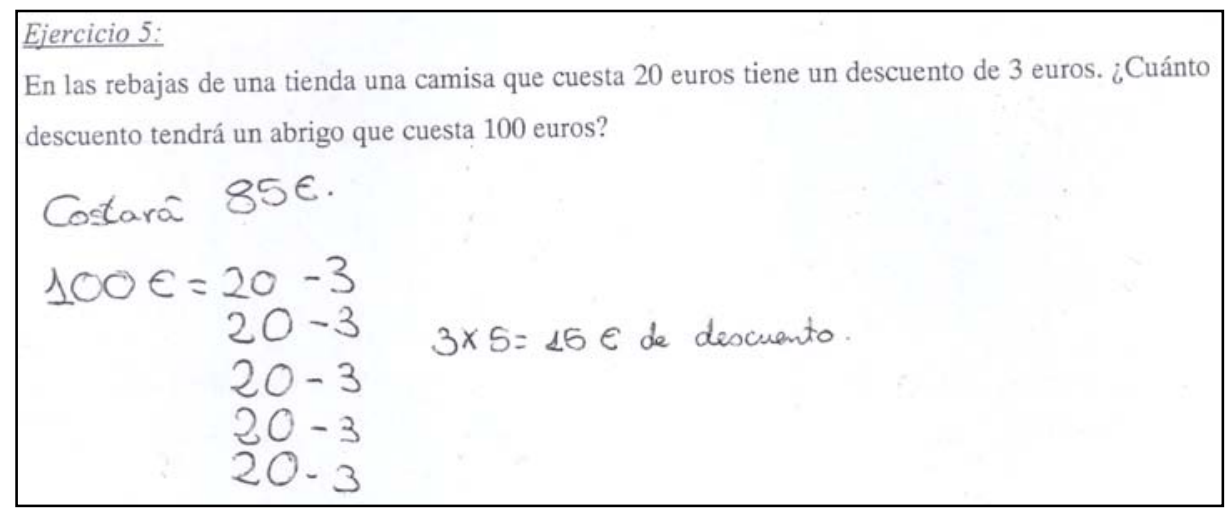

Figura VI.166.

Este alumno ha descompuesto el precio del abrigo tomando como base el de la camisa. Ha visto que cada abrigo es equivalente a cinco camisas y de ahí ha obtenido el descuento. Obviamente esta estrategia no le habría servido para cantidades tales que una no fuera múltiplo entero de la otra.

Finalmente, respecto a los errores, el más interesante ha sido el cometido por varios alumnos, entre ellos A16 (ver Figura VI.167) que ha consistido en asumir que todas las prendas tenían el mismo descuento independientemente de su valor:

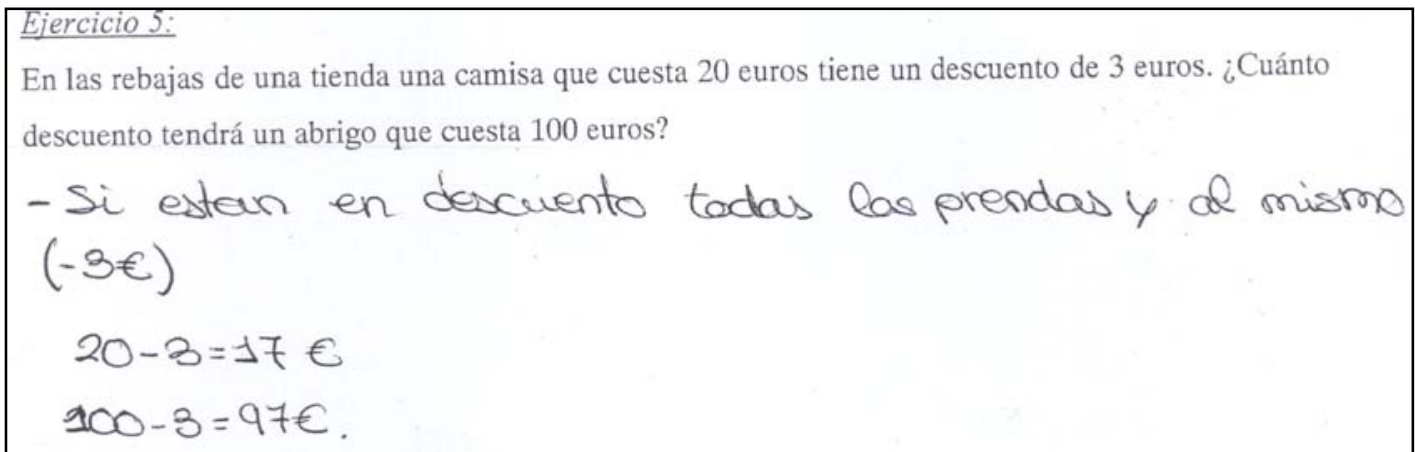

Figura VI.167.

Sensu stricto, esta respuesta no es incorrecta pues el enunciado no concreta la información sobre los descuentos que hay en la tienda. Sin embargo, pensamos que la experiencia diaria de los alumnos debe hacerles pensar que el descuento de un artículo suele ser proporcional a su precio. De hecho, sobre esto se volverá más adelante al hablar de porcentajes.

Dentro de este bloque de ejercicios, el que más respuestas incorrectas ha producido ha sido el Ejercicio 6. La mayoría son debidas a que los alumnos no han asumido que el peso del hormigón fabricado a partir de 2 kilos de cemento y 4 de arena es de 6 kilos. De nuevo esto no es estrictamente cierto, pues se añade agua; pero en el 
contexto del problema podía suponerse sin problemas. Así, el alumno A48 ha respondido que "no nos dicen la cantidad de hormigón que se hace al principio" (ver Figura VI.168):

\section{Ejercicio 6:}

Para hacer hormigón un albañil junta 2 kilos de cemento con 4 kilos de arena. Si quiere fabricar 12

kilos de hormigón ¿cuántos kilos de cada material debe utilizar? ¿Y si quiere fabricar 100 kilos?

No se prede hacer ya que no nos dicen la cantidad de hosmigaŕ que

hade al principio

Figura VI.168.

Un error similar, aunque más grave, es el cometido, entre otros, por el alumno A20 (en la Figura VI.169 siguiente) que supone que la mezcla inicial produce 1 kilo de hormigón; lo que es a todas luces absurdo. Por lo demás, el alumno razona después proporcionalmente.

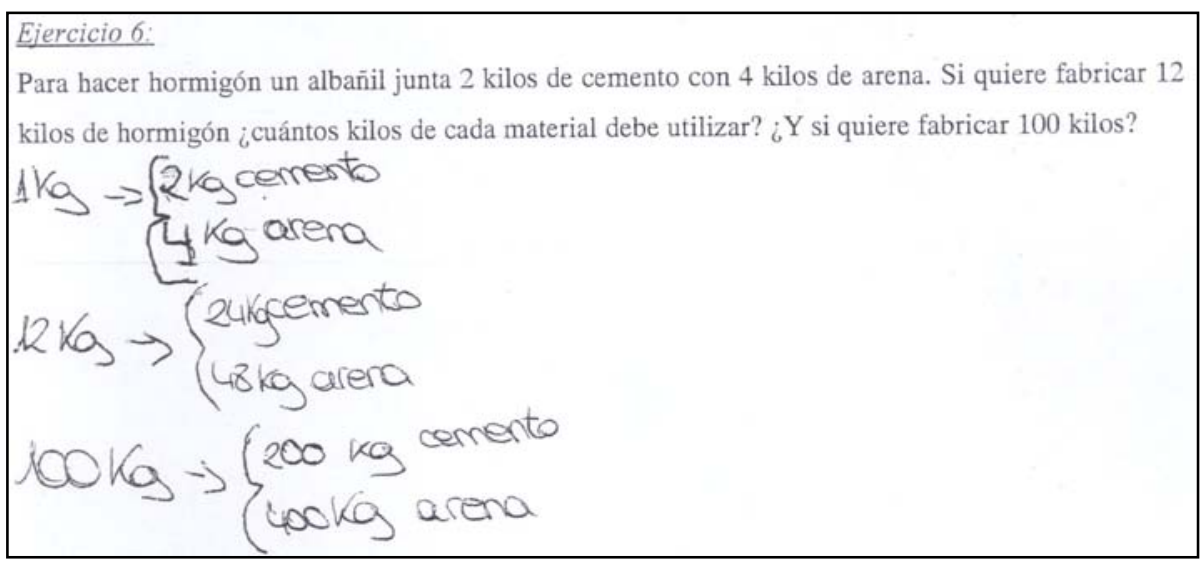

Figura VI.169.

Aunque unos pocos alumnos razonan usando razones e indicando una condición de regularidad, la respuesta correcta más habitual ha sido la dada, por ejemplo, por A19 (Figura VI.170):

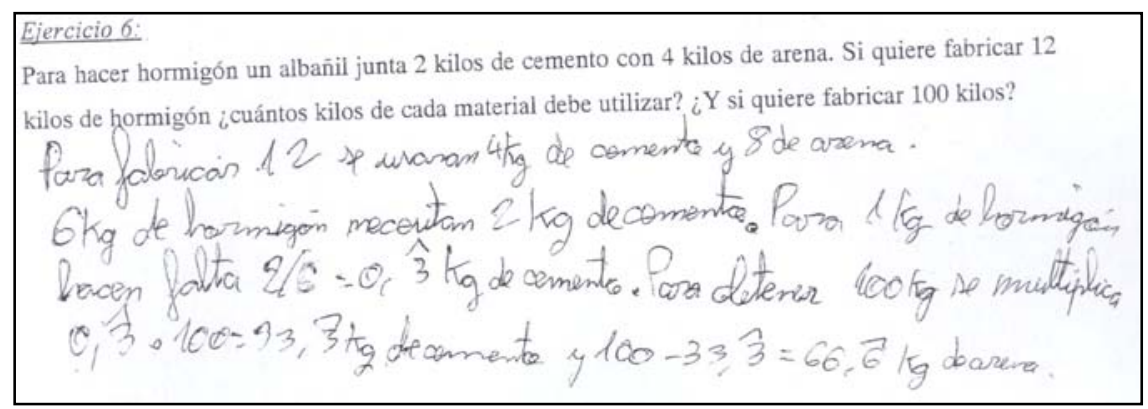

Figura VI.170. 
Para responder a la primera pregunta, simplemente duplica sin más las cantidades iniciales. Sin embargo, para responder a la segunda, como 100 no es un múltiplo entero de 6 el alumno recurre a la razón entre cemento y hormigón (calculando los kilos de cemento necesarios para obtener 1 kilo de hormigón) y razonando a partir de allí.

El hecho de que 100 no sea un múltiplo entero de 6 y que, en consecuencia, las cantidades de cemento y arena necesarias para fabricar 100 kilos de hormigón no sean enteros ha causado problemas a algunos alumnos. Así A30 (ver Figura VI.171) observa que la cantidad de arena es el doble que la de cemento. Esto implica, aunque él no lo sabe, que si quiere que las soluciones sean enteras la cantidad de hormigón fabricada ha de ser múltiplo de 3.

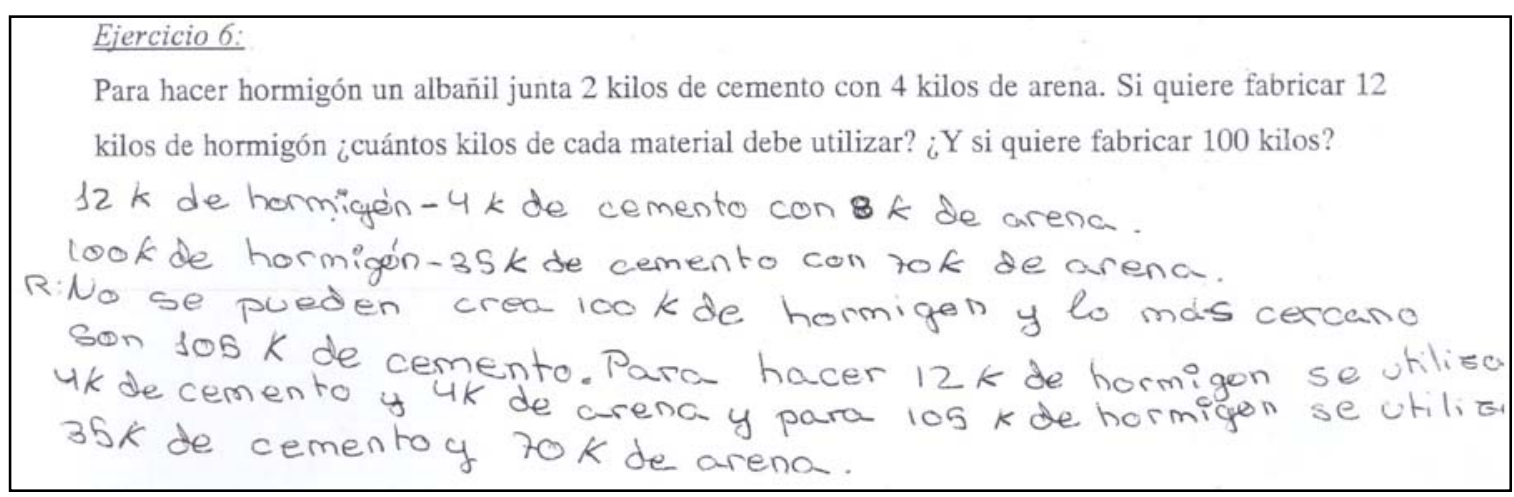

Figura VI.171.

Aunque la solución entera más cercana a 100 es la dada por 33 kilos de cemento y 66 de arena el alumno se ha inclinado (por razones oscuras) por la cantidad de 105 kilos de hormigón.

\section{Ejercicio 2:}

En este ejercicio, las magnitudes involucradas (edad y propina semanal) no están relacionadas. Incluso en el mejor de los casos la relación no sería lineal y, por supuesto, la razón como "tanto por uno" (propina recibida teniendo 1 año de edad) carece de sentido. Las unidades de análisis para este grupo de situaciones son las siguientes:

\begin{tabular}{|c|c|}
\hline 0 & No entrega o no asiste a clase \\
\hline 1 & Respuesta en blanco \\
\hline 2 & Responde incorrectamente usando razones \\
\hline 3 & Responde incorrectamente sin usar razones \\
\hline
\end{tabular}




\begin{tabular}{|c|c|}
\hline 4 & Indica la imposibilidad de responder, pero no lo argumenta \\
\hline 5 & Argumenta correctamente que no puede responderse a la \\
& pregunta \\
\hline
\end{tabular}

De acuerdo con estas unidades de análisis los resultados obtenidos por los alumnos en este ejercicio se presentan en la siguiente tabla:

\begin{tabular}{|c|c|c|c|c|c|c|c|}
\hline \multicolumn{2}{|c|}{} & $\mathbf{0}$ & $\mathbf{1}$ & $\mathbf{2}$ & $\mathbf{3}$ & $\mathbf{4}$ & $\mathbf{5}$ \\
\hline Ejercicio 2 & $\mathbf{N}^{\mathbf{0}}$ de resp. & 7 & 3 & 7 & 6 & 11 & 22 \\
\cline { 2 - 8 } & Porcentaje & $12{ }^{\prime} 5 \%$ & $5^{\prime} 4 \%$ & $12^{\prime} 5 \%$ & $100^{\prime} 7 \%$ & $199^{\prime} 6 \%$ & $399^{\prime} 3 \%$ \\
\hline
\end{tabular}

En este ejercicio más de la mitad de los alumnos indican correctamente que no puede responderse la pregunta formulada. Los motivos aducidos son variados, y van desde los que se limitan a decir que "no existe relación” hasta los que dan explicaciones más prolijas como que "no se sabe si cada año le sube o la cantidad". Como quiera que los alumnos no son muy dados a explicar sus respuestas, a veces difícil es valorar a partir de una simple frase el grado de comprensión que tienen de la situación.

Aunque el número de respuestas incorrectas en este ejercicio es reducido, son bastante variadas y pensamos que merece la pena estudiarlas con detenimiento. En primer lugar nos encontramos con el error más repetido (y esperado). Por ejemplo, lo comete el alumno A38 (ver Figura VI.172 siguiente), y consiste en razonar como si la edad y la propina fueran directamente proporcionales, calculando un hipotético aumento anual y obrando en consecuencia:

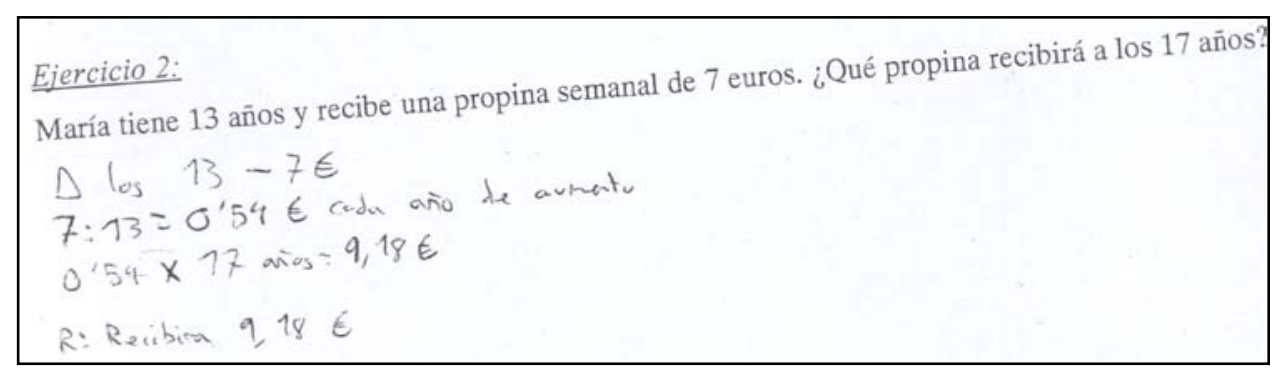

Figura VI.172.

Otro error surge de una comprensión equivocada del problema. Así el alumno A4 ha calculado el total recibido por María al cabo de los 4 años que van desde los 13 a los 17 (Figura VI.173): 


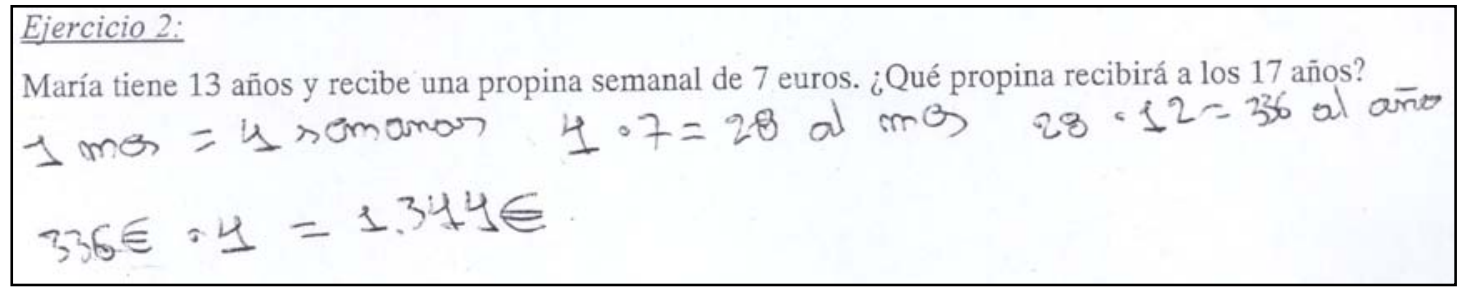

Figura VI.173.

Un error más interesante es el que comente el alumno A30, que responde en base a un argumento aditivo (ver Figura VI.174). La respuesta dada por el alumno: “le darán 11 euros” responde a que se mantenga constante la diferencia entre la edad y la propina (aunque la respuesta no lo indique explícitamente):

Ejercicio 2:

María tiene 13 años y recibe una propina semanal de 7 euros. ¿Qué propina recibirá a los 17 años? RiLe daman 11 euros.

Figura VI.174.

Finalmente, algunos alumnos, como es el caso de A20 (en la Figura VI.175), responden de forma aparentemente aleatoria; en tanto en cuanto las operaciones efectuadas carecen de sentido alguno:

$$
\begin{aligned}
& \text { Ejercicio 2: } \\
& \text { María tiene } 13 \text { años y recibe una propina semanal de } 7 \text { euros. ¿Qué propina recibirá a los } 17 \text { años? } \\
& 13 \text { años - 7€ } \\
& 17 \text { años - 31,5€ } \\
& 13 \cdot 17=221 \\
& 221: 7=31,5 € \\
& D=\text { Decebirá } 31,5 \in \text { de propina. }
\end{aligned}
$$

Figura VI.175.

\section{Ejercicio 4:}

En este ejercicio, como en el Ejercicio 3, aparecen involucradas tres magnitudes (número de sacos, número de perros y duración de la comida). Sólo dos de ellas, sin embargo, son relevantes a la hora de responder a la pregunta formulada (el número de perros y la duración de la comida). La diferencia con respecto al Ejercicio 3 radica en que, en este caso, fijado el número de sacos, las otras dos magnitudes no están relacionadas de forma directamente proporcional. Aunque el ejercicio puede resolverse, ya que bajo las condiciones de regularidad adecuadas (que todos los perros coman lo 
mismo, que los sacos sean iguales) el número de perros y la duración del saco pueden suponerse inversamente proporcionales. Ahora bien, los alumnos no se habían enfrentado aún a situaciones de este tipo y, aunque no tiene sentido calcular la razón entre perros y duración de la comida (o viceversa), sí que lo tiene la razón entre el número de sacos y cualquiera de las otras dos magnitudes (o viceversa). Las unidades de análisis para este grupo de situaciones son las siguientes:

\begin{tabular}{|c|c|}
\hline 0 & No entrega o no asiste a clase \\
\hline 1 & Respuesta en blanco \\
\hline 2 & Respuesta incorrecta sin indicaciones \\
\hline 3 & Señala que no hay proporcionalidad directa o que no se puede \\
& hacer \\
\hline 4 & Respuesta correcta sin razonar o con razonamiento incorrecto \\
\hline 6 & Respuesta y razonamiento correctos \\
\hline
\end{tabular}

De acuerdo con estas unidades de análisis los resultados obtenidos por los alumnos en este ejercicio se presentan en la siguiente tabla:

\begin{tabular}{|c|c|c|c|c|c|c|c|c|}
\hline \multicolumn{2}{|c|}{} & $\mathbf{0}$ & $\mathbf{1}$ & $\mathbf{2}$ & $\mathbf{3}$ & $\mathbf{4}$ & $\mathbf{5}$ & $\mathbf{6}$ \\
\hline Ejercicio 4 & $\mathbf{N}^{\mathbf{0}}$ de resp. & 7 & 2 & 6 & 6 & 19 & 9 & 7 \\
\cline { 2 - 10 } & Porcentaje & $122^{\prime} 5 \%$ & $3{ }^{\prime} 6 \%$ & $10{ }^{\prime} 7 \%$ & $10{ }^{\prime} \% \%$ & $333^{\prime} 9 \%$ & $16{ }^{\prime} 1 \%$ & $12{ }^{\prime} 5 \%$ \\
\hline
\end{tabular}

Sorprendentemente, la respuesta más repetida tiene que ver con la imposibilidad de resolver el ejercicio. Algunos alumnos se limitan a decir que "no se puede hallar" (A35) o que "no son directamente proporcionales" (A31), sin dar ningún tipo de explicación o justificación. Otros, por su parte, sí que dan argumentos que apoyen su respuesta, como por ejemplo A46 (en la Figura VI.176 siguiente). No obstante aunque algunas de estas objeciones son razonables ("no dice [...] cuanta comida comen cada día”) otras ya no lo son tanto ("no dice cuanta cantidad de comida hay en el saco"): 


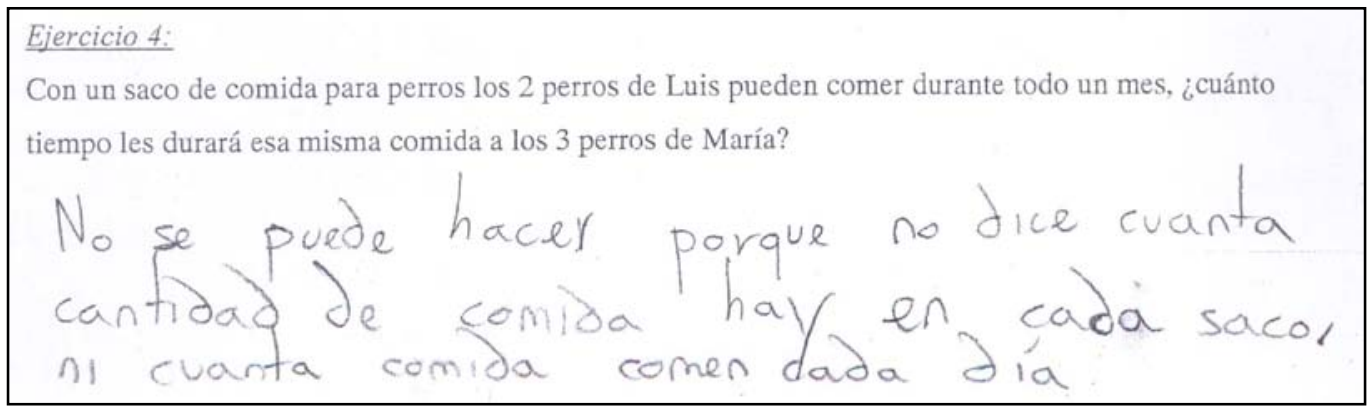

Figura VI.176.

Aunque está claro que si no sabemos que todos los perros comen lo mismo el ejercicio no puede resolverse, la cantidad exacta de comida que hay en el saco es irrelevante. Estos dos son los únicos argumentos presentados por los alumnos que dan este tipo de respuesta.

Las siguientes respuestas con mayor número de alumnos son ya las correctas; repartidas casi a partes iguales entre los que, como A45, razonan adecuadamente (ver Figura VI.177), aunque no todos explicitan la condición de regularidad:

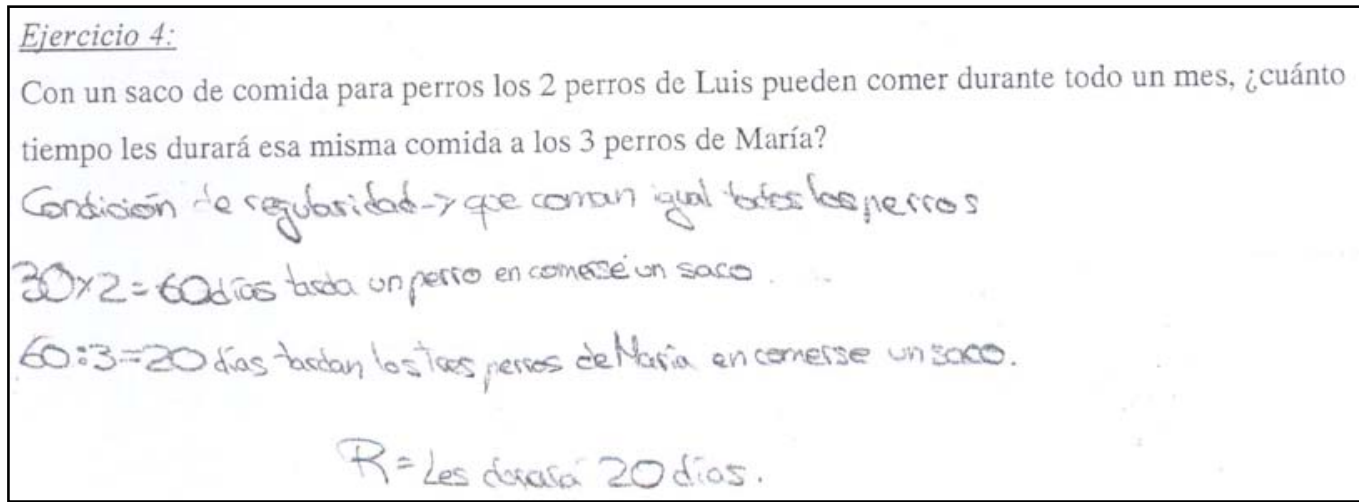

Figura VI.177.

y los que simplemente hacen las operaciones correspondientes o emplean técnicas no presentadas en clase y que, como ya hemos dicho antes, reflejan una influencia externa que es a veces indeseable. Tal es el caso de A24, en la Figura VI.178, que emplea la Regla de Tres inversa y, por si fuera poco, el lenguaje algebraico: 


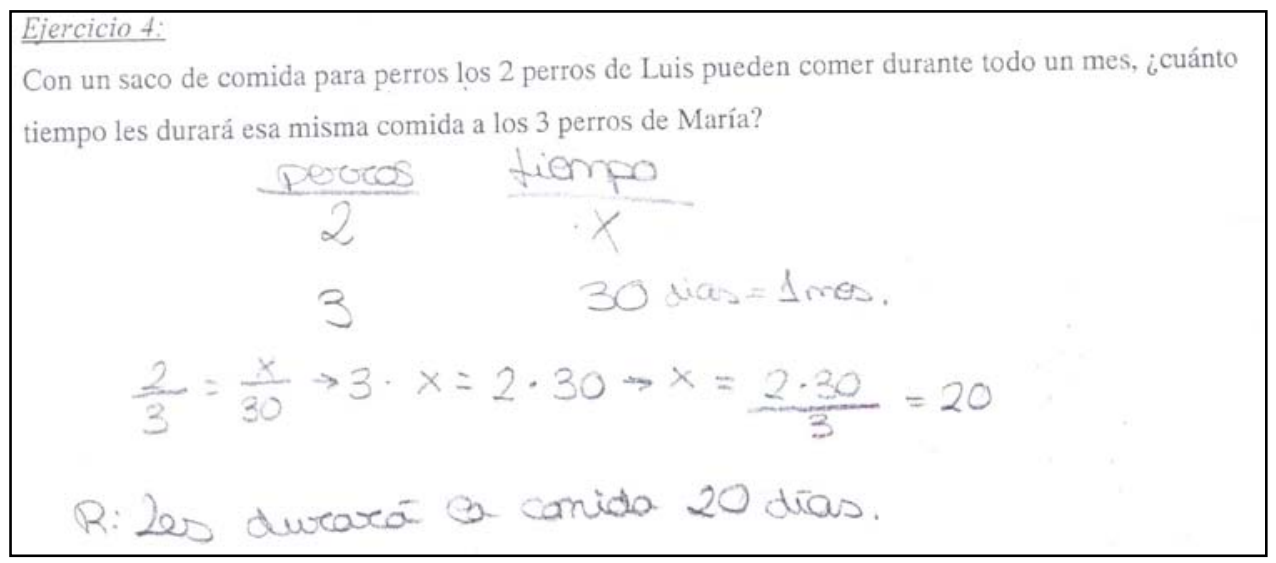

Figura VI.178.

Respecto a respuestas incorrectas desde un punto de vista numérico, éstas se reparten a partes iguales entre los que dan una cantidad sin indicación alguna de cómo han llegado a ella (ver la respuesta de A36 en la Figura VI.179 siguiente):

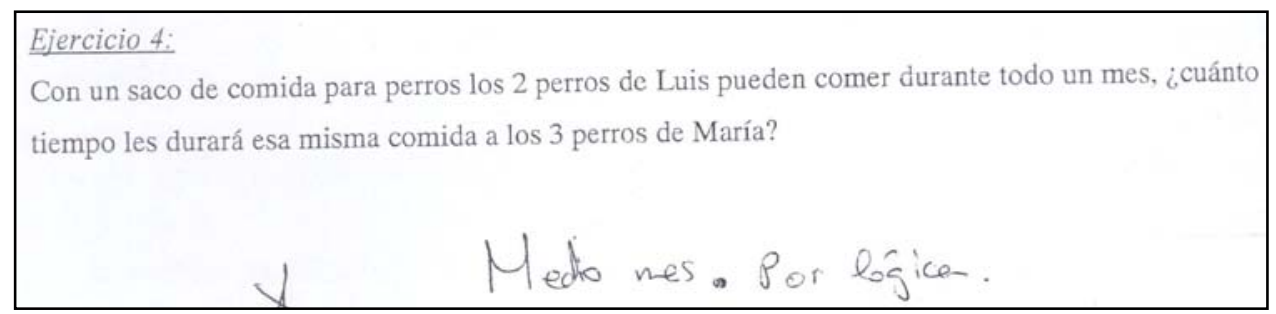

Figura VI.179.

Son más interesantes las respuestas de aquellos que razonan como si las magnitudes ‘número de perros’ y ‘duración de la comida’ fueran directamente proporcionales. En este caso, las formas de expresar la idea varían entre unos y otros alumnos, pero esencialmente el razonamiento queda recogido en la respuesta de A7 (Figura VI.180):

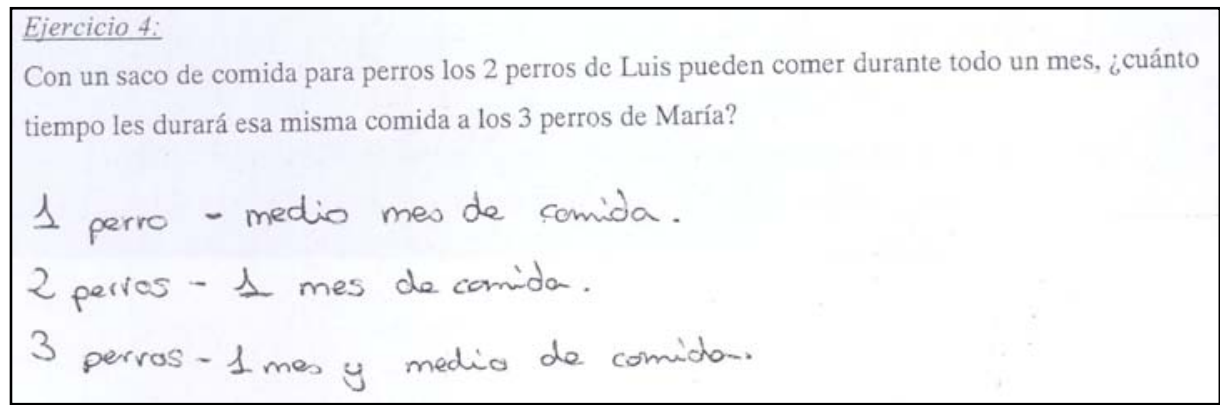

Figura VI.180.

\section{VI.3.2.3 Reflexiones relativas al punto 2}

1. En todos los ejercicios, salvo en el primero, hay alumnos que asumen que las magnitudes son directamente proporcionales y alumnos que dicen que no tiene 
sentido calcular la razón. Así pues, parece que hay contextos que favorecen el “espíritu crítico” de los alumnos.

2. Cuando se resuelve un ejercicio haciendo uso de la razón, siempre hay dos razones que pueden utilizarse y, en consecuencia, dos modos distintos de atacar el problema. En estos ejercicios todos los alumnos que utilizan la razón como herramienta usan la misma razón. Así pues, parece ser que en cada problema una de las dos razones posibles es más “natural”.

3. Ningún alumno, salvo A26 (ver Figura VI.181), utiliza nada parecido al algoritmo de la Regla de Tres. Esto cambiará en la siguiente tarea, en la que la influencia externa se apreciará claramente.

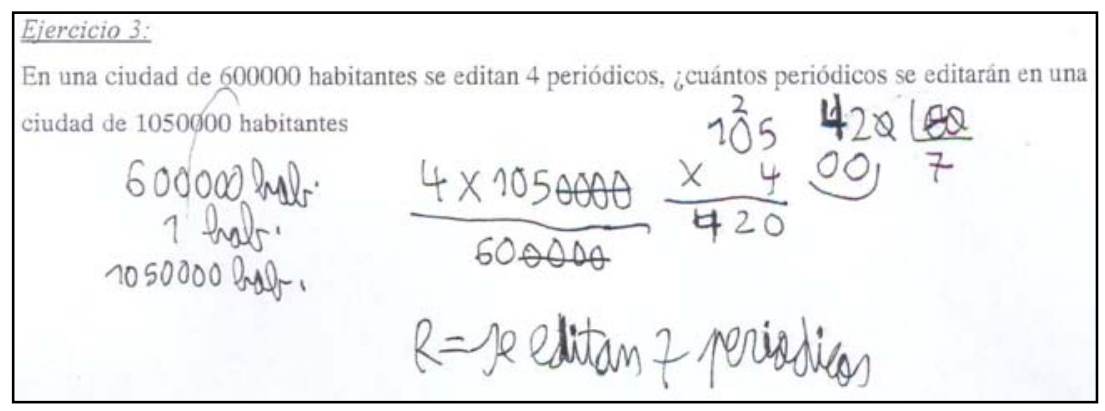

Figura VI.181.

4. Hay una cierta confusión por parte de los alumnos entre lo que significa que dos magnitudes no sean directamente proporcionales, que no tengan relación o que el problema no pueda resolverse.

5. Comienza a aparecer (en el Ejercicio 4 concretamente) la confusión de que la razón es simplemente la cantidad de una magnitud que se corresponde con una unidad de la otra, sin valorar el contexto de la situación.

6. La influencia externa se hace patente en algunos casos por el empleo de cierto vocabulario que no se ha introducido aún en clase (magnitudes inversamente proporcionales), por el uso de la Regla de Tres y por la introducción del lenguaje algebraico.

7. En general, los alumnos no sienten mucha necesidad de explicitar las condiciones de regularidad ni el significado de las operaciones que realizan. 


\section{VI.3.3 Punto 3: Porcentajes}

El concepto de porcentaje se concibe en la propuesta que llevamos a la práctica como una cierta “modificación” del de razón como “tanto por uno”. De este modo, los conceptos y los procedimientos que se pretende que aplique el alumno son en gran medida similares a los anteriores. No obstante, el cálculo de un porcentaje conlleva un importante aspecto algorítmico y, en ocasiones, resulta complicado para los estudiantes separar el concepto de la técnica de cálculo. Los porcentajes se trabajan en la Actividad de aula 6 y en la Tarea de casa 5.

\section{VI.3.3.1 Análisis y valoración de la Actividad de aula 6}

\section{Enunciado}

Recordad que el porcentaje que una magnitud representa respecto de una segunda magnitud es justamente la cantidad de la primera magnitud que se corresponde con 100 unidades de la segunda. Teniendo esto en cuenta debéis tratar de resolver los siguientes problemas:

\section{Ejercicio 1:}

En una ciudad hay un 52\% de mujeres. Si la población total es de 725.000 habitantes:

i. ¿ ¿Cuántas mujeres viven en esa ciudad?

ii. ¿ ¿Cuántos hombres viven en la ciudad?

iii. ¿ ¿Cuál es la razón entre hombres y mujeres?

iv. ¿ ¿Cuál es el porcentaje de hombres respecto de la población total de la ciudad?

\section{Ejercicio 2:}

Se sabe que en un determinado pueblo sólo el 3\% de la gente es pelirroja. Si en ese pueblo hay exactamente 625 pelirrojos:

i. ¿Cuántas personas viven en ese pueblo?

ii. ¿ ¿Cuántas personas rubias viven allí?

iii. ¿ ¿Cuál es la razón entre el número de pelirrojos y el total de la población? 


\section{Ejercicio 3:}

En una tienda de electrodomésticos un televisor LCD de 32 pulgadas cuesta 425 euros. Durante las rebajas el dueño decide hacer un descuento del $20 \%$.

i. ¿ ¿Cuál es el precio del televisor durante las rebajas?

ii. ¿ ¿Qué porcentaje representa el precio rebajado respecto del precio sin rebajar?

iii. Un DVD ha costado durante las rebajas 125 euros, ¿cuánto costaba antes de las rebajas?

\section{Ejercicio 4:}

Debido a la subida del precio de la gasolina, los billetes de autobús también van a subir de precio. En concreto la subida va a ser del 4,5\%.

i. Si un billete de autobús cuesta 1,10 euros, ¿cuánto costará después de la subida?

ii. Si un litro de gasolina ha pasado de costar 0,98 euros a costa 1,1 euros, ¿cuál es el porcentaje de subida del precio de la gasolina?

iii. ¿ ¿Es justa la subida del precio en el billete de autobús?

\section{Análisis de la tarea}

\section{Ejercicio 1:}

Este ejercicio constaba de 4 apartados: en el primero se pedía calcular la cantidad correspondiente a un porcentaje del total, en el segundo se pedía la cantidad complementaria de la anterior, en el tercero se pedía calcular una razón entre dos magnitudes y en el último se pedía el porcentaje complementario del inicial (para observar si restaban de 100\% o si utilizaban la cantidad del segundo apartado).

Las unidades de análisis para este ejercicio aparecen recogidas en la tabla siguiente. En este caso las posibilidades presentadas no son excluyentes, por lo que los porcentajes de cada fila no han de sumar 100 necesariamente:

\begin{tabular}{|c|c|}
\hline 0 & No entrega o no asiste a clase \\
\hline 1 & Respuesta en blanco \\
\hline 2 & Resuelve correctamente el problema directo \\
\hline
\end{tabular}




\begin{tabular}{|c|c|}
\hline 3 & Calcula correctamente la cantidad complementaria \\
\hline 4 & Indica al menos el significado de la razón \\
\hline 5 & Calcula correctamente el porcentaje complementario \\
\hline
\end{tabular}

De acuerdo con estas unidades de análisis, los resultados obtenidos por los alumnos son los siguientes:

\begin{tabular}{|c|c|c|c|c|c|c|c|}
\hline \multicolumn{2}{|c|}{} & $\mathbf{0}$ & $\mathbf{1}$ & $\mathbf{2}$ & $\mathbf{3}$ & $\mathbf{4}$ & $\mathbf{5}$ \\
\hline Ejercicio 1 & $\mathbf{N}^{\mathbf{0}}$ de resp. & 0 & 1 & 20 & 20 & 8 & 24 \\
\cline { 2 - 8 } & Porcentaje & $0 \%$ & $4 \%$ & $80 \%$ & $80 \%$ & $32 \%$ & $96 \%$ \\
\hline
\end{tabular}

A continuación comentaremos independientemente cada uno de los cuatro apartados del ejercicio.

\section{$\underline{\text { Apartado i) }}$}

En el primer apartado se pedía resolver lo que llamamos "problema directo", es decir, dados el total y un porcentaje calcular la cantidad correspondiente a ese porcentaje. El 80\% de los grupos de trabajo resuelven correctamente este apartado. Ahora bien, la práctica totalidad de las respuestas demuestran que la idea de "tanto por cien” no había calado aún entre los estudiantes. Por ejemplo, el grupo formado por A3 y A7 da la respuesta que se observa en la Figura VI.182:

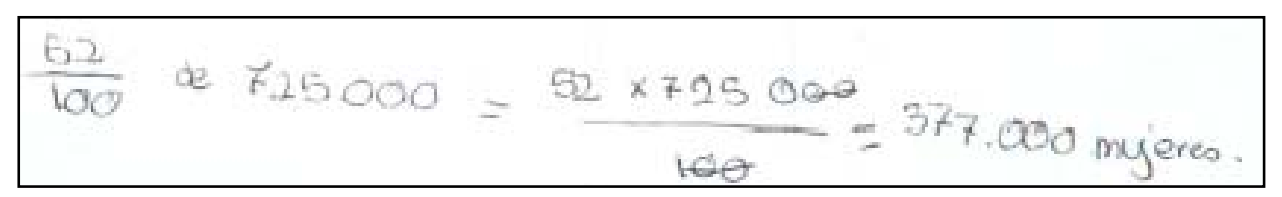

Figura VI.182.

En esta respuesta, además de una notación en forma de fracción (no introducida por el profesor), se observa que la idea de "tanto por cien” no parece subyacer a los cálculos efectuados por el alumno, puesto que, de ser así, se debería realizar primero la división por 100. Por ejemplo, así lo hace el grupo formado por A19 y A23 (ver Figura VI.183) aunque no queda realmente claro, pues no dan ningún apunte sobre el significado que pueda tener el resultado de la división entre 100:

lación total es de 725.000 habitantes:
$729000 / 10027290 ; 7250-52=377.000$ muyeres

Figura VI.183. 
Sólo un grupo, el formado por A39 y A53, da un apunte sobre un posible significado de esa división; si bien es cierto que dicho significado no es el que pretendíamos introducir (ver Figura VI.184):

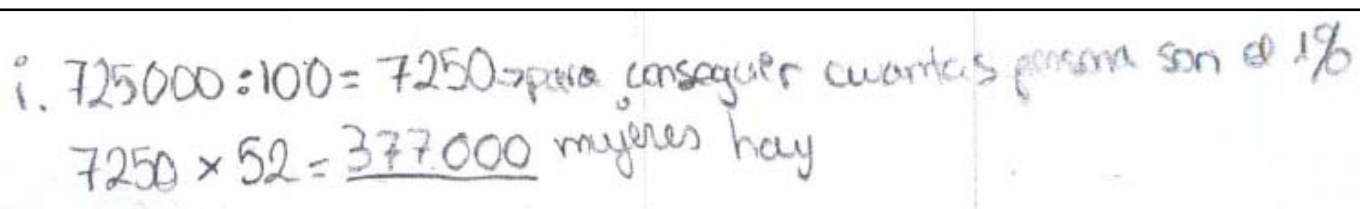

Figura VI.184.

Con respecto a los errores cometidos en este apartado, dejando de lado las equivocaciones al efectuar operaciones aritméticas, el más interesante es el cometido por el grupo formado por A16 y A24 (en la Figura VI.185 siguiente):

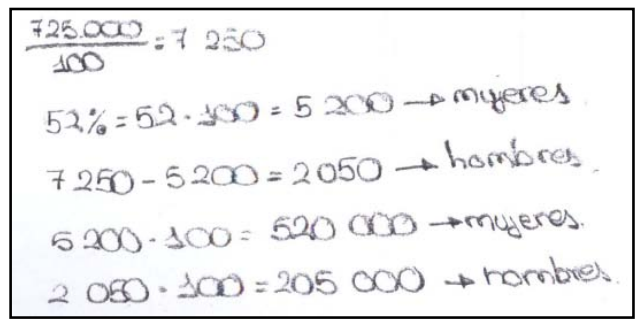

Figura VI.185.

La respuesta dada por estos alumnos fue que había 520000 mujeres. En primer lugar dividieron el total por 100 y después convirtieron 52\% en 5200 para después volverlo a multiplicar por 100. Sólo utilizaron el total para calcular el número de hombres (se preguntaba en el apartado siguiente). Es muy difícil comprender la motivación detrás de este razonamiento. Curiosamente esta identificación de 52\% con 5200 (aunque después no volvieron a multiplicar por 100) también la efectuó en grupo formado por A55 y A56, aunque no puede hablarse de influencia mutua al pertenecer a clases diferentes. Sólo estos dos grupos cometieron errores de concepto al resolver este apartado.

\section{$\underline{\text { Apartado ii) }}$}

En el apartado segundo se pedía hallar la cantidad complementaria de la encontrada en el apartado anterior. Como se observa en la tabla anterior, y como es lógico, el porcentaje de aciertos en este apartado es el mismo que en el anterior. El procedimiento de resolución único por parte de todos los alumnos ha sido restar del total la cantidad hallada en el apartado anterior. Incluso los que resuelven mal el 
apartado anterior emplean este procedimiento. Creemos que no es necesario mostrar ningún ejemplo en este apartado.

\section{$\underline{\text { Apartado iii) }}$}

El tercer apartado, en el que se pedía la razón entre hombre y mujeres, es el que menor porcentaje de éxito ha tenido. Tan sólo 8 grupos han indicado al menos el significado de dicha razón. Por ejemplo, el grupo formado por A32, A38 y A42 indica únicamente, aunque de modo correcto, que la razón entre hombres y mujeres es: “el $n^{o}$ de hombres que le toca a cada mujer” (ver Figura VI.186).

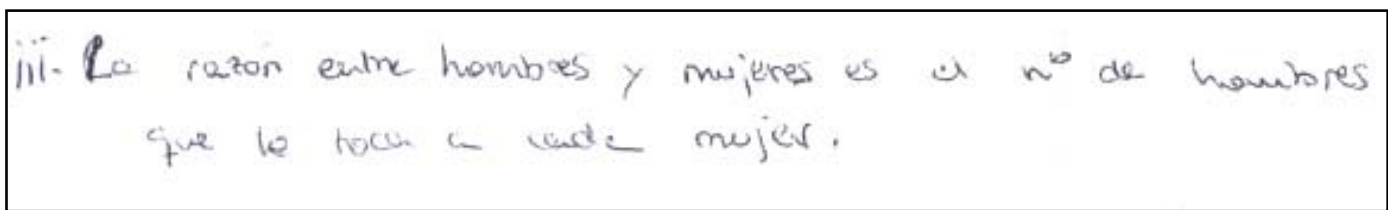

Figura VI.186.

Otros grupos sí que indican el valor numérico de la razón. De éstos hay algunos, como el formado por A45 y A54 (en la Figura VI.187 siguiente), que emplean los valores totales de hombres y mujeres para calcular dicha razón:

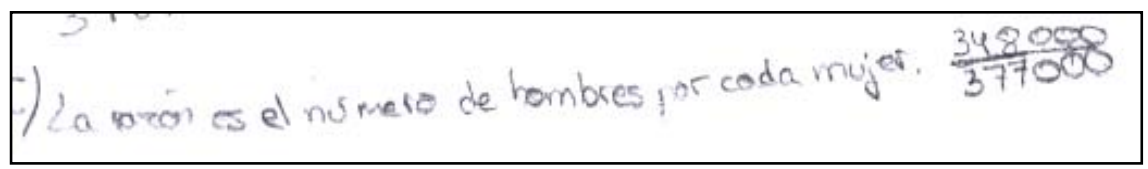

Figura VI.187.

Sin embargo, grupos como el formado por A37 y A47 (en la Figura VI.188) utilizan los porcentajes (aunque el porcentaje de hombres no se pedía hasta el apartado siguiente) y el hecho de que la razón sea la misma requiere pasar de la relación partetodo a la parte-parte:

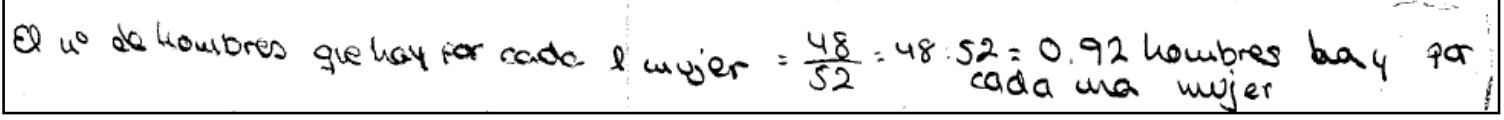

Figura VI.188.

Con respecto a los errores cometidos en este apartado, el único interesante es el cometido por dos grupos de alumnos. Uno de ellos, por ejemplo, el formado por A4, A15 y A28. Este error ya había aparecido con anterioridad y consiste en confundir la 
razón entre hombres y mujeres con su inversa. En concreto estos grupos calculan las mujeres que le corresponden a cada hombre (ver Figura VI.189):

$$
\begin{aligned}
& 377.000: 348,000=1,0834.000=348.000 \text { hambes: } \\
&
\end{aligned}
$$

Figura VI.189.

Es notorio el hecho de que ninguno de estos grupos señala condición de regularidad alguna. El resto de grupos o bien dejó este apartado en blanco o bien dio respuestas carentes de sentido. Unas y otras indicaban la falta de comprensión del significado del término 'razón'.

\section{$\underline{\text { Apartado iv) }}$}

En este último apartado se pedía calcular el porcentaje complementario del del enunciado. Se quería observar si los alumnos utilizaban la cantidad obtenida en el apartado ii) para hallar este porcentaje o si daban por supuesto (cosa que no se había comentado en clase) el hecho de que todos los porcentajes han de sumar 100.

El resultado fue abrumador. Salvo un grupo que entregó en blanco todos los demás asumieron que los porcentajes debían sumar 100 y obtuvieron el porcentaje de hombres restando el 52\% de mujeres al 100\% total. Algunos explicitaron la operación y otros simplemente dieron el resultado (casi a partes iguales).

\section{Ejercicio 2:}

Este ejercicio constaba de 3 apartados: en el primero se pedía calcular la cantidad total conociendo la cantidad correspondiente a un determinado porcentaje; en el segundo se formulaba una pregunta que no podía responderse con los datos del problema. En el tercero se volvía a pedir una razón, aunque en este caso entre una parte y el total. Las unidades de análisis para este ejercicio aparecen recogidas en la tabla siguiente. Nuevamente las posibilidades presentadas no son excluyentes:

\begin{tabular}{|l|c|}
\hline 0 & No entrega o no asiste a clase \\
\hline 1 & Respuesta en blanco \\
\hline 2 & Resuelve correctamente el problema inverso \\
\hline 3 & Indica correctamente que no puede saberse el número de rubios \\
\hline
\end{tabular}




\begin{tabular}{|l|l|}
\hline 4 & Indica al menos el significado de la razón \\
\hline
\end{tabular}

De acuerdo con estas unidades de análisis, los resultados obtenidos por los alumnos son los siguientes:

\begin{tabular}{|c|c|c|c|c|c|c|}
\hline \multicolumn{2}{|c|}{} & $\mathbf{0}$ & $\mathbf{1}$ & $\mathbf{2}$ & $\mathbf{3}$ & $\mathbf{4}$ \\
\hline \multirow{2}{*}{ Ejercicio 2 } & $\mathbf{N}^{\mathbf{0}}$ de resp. & 0 & 7 & 12 & 13 & 3 \\
\cline { 2 - 7 } & Porcentaje & $0 \%$ & $28 \%$ & $48 \%$ & $52 \%$ & $12 \%$ \\
\hline
\end{tabular}

En este ejercicio, y en los siguientes de forma aún más acusada, se dispara el número de respuestas en blanco, puesto que los alumnos perdieron mucho tiempo resolviendo el primer ejercicio. Pese a que los resultados pueden dejar de ser significativos, a continuación comentaremos independientemente cada uno de los tres apartados del ejercicio.

\section{Apartado i)}

En este apartado se proporcionaba la cantidad correspondiente al 3\% y se pedía el cálculo del total. Casi la mitad de los grupos ha respondido correctamente a este apartado. El hecho de que el resultado final no fuera un número entero (pese a que se trataba de habitantes de un pueblo) ha hecho que algunos grupos hayan redondeado su respuesta. Otros no han tenido ningún problema en considerar habitantes “decimales”. Por ejemplo, el grupo formado por A19 y A23 (ver Figura VI.190) dan la siguiente respuesta:

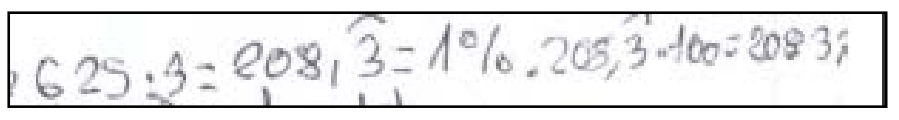

Figura VI.190.

Estos alumnos calculan primero la cantidad correspondiente al 1\% para después hallar el total. Aunque este tipo de resolución no hace uso realmente del significado del porcentaje, sí que demuestra un cierto manejo de la situación. Se observa también el redondeo que mencionábamos antes.

La respuesta anterior contrasta con la dada por los alumnos A45 y A54 (en la Figura VI.191 siguiente) tanto por el orden en el que se efectúan las operaciones (no es lo mismo multiplicar primero por 100 y después dividir entre 3 que a la inversa) como por el hecho de que estos alumnos no redondean el valor numérico final: 


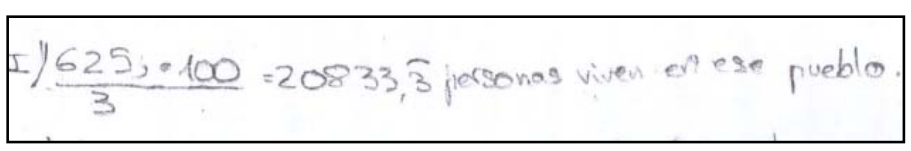

Figura VI.191.

El error más repetido en este apartado queda ilustrado por la respuesta del grupo formado por los alumnos A2 y A20 (ver Figura VI.192):

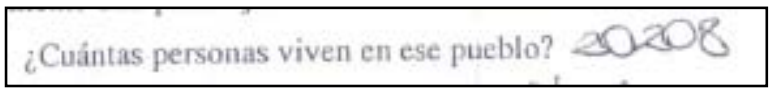

Figura VI.192.

El resultado obtenido (20208 personas) ha sido dado como respuesta por 4 grupos y surge de calcular no ya el $100 \%$ a partir de los datos conocidos, sino el $97 \%$ (que es exactamente 20208’3...). La explicación del error es pues clara.

Relacionado en parte con este error presentamos ahora el cometido por los alumnos A6 y A11 (ver Figura VI.193):

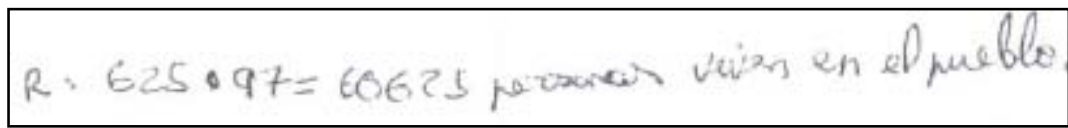

Figura VI.193.

En este caso quizás resulta más complicado dar una justificación del error. Posiblemente estos alumnos conocieran por otros medios un algoritmo para el manejo con los porcentajes y cometieran un doble error didáctico debido a una mala instrucción: olvidar dividir por 3 y calcular el 97\% en vez del 100\%.

\section{$\underline{\text { Apartado ii) }}$}

En este apartado, conociendo la cantidad de pelirrojos de la ciudad (y el total, calculado en el apartado anterior) se preguntaba por el número de rubios de la ciudad. Evidentemente esta pregunta no puede responderse con los datos del problema, porque los rubios no son el “complementario” de los pelirrojos (frente al ejercicio anterior en el que las cantidades de hombres y mujeres sí lo eran). Algo más de la mitad responde acertadamente (el porcentaje aumenta bastante si no consideramos las respuestas en blanco).

Algunos alumnos simplemente responden que "no se puede hacer" (como por ejemplo el grupo formado por A1 y A9). Otros tratan de dar alguna razón, como A39 y 
A53, que dicen que no se puede "porque no nos dan ningún porcentaje”. Con todo, la respuesta del grupo formado por A22 y A25 es más afinada al decir que no se puede “porque también hay gente castaña”.

Como resulta evidente, los pocos alumnos que tratan de resolver el ejercicio lo hacen restando del total el número de pelirrojos. Tal es el caso de A26 en la Figura VI.194 siguiente:

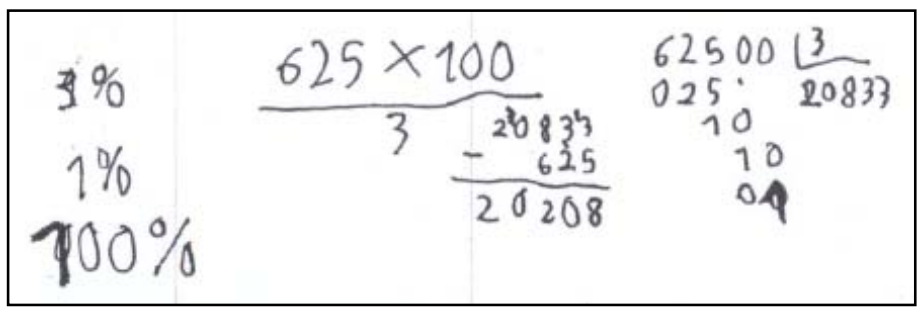

Figura VI.194.

\section{$\underline{\text { Apartado iii) }}$}

En este apartado se volvía a hacer énfasis en el significado de la razón como “tanto por uno”. Sin embargo, son muy pocos los grupos que señalan correctamente al menos el significado de la razón entre pelirrojos y el total de la población. Muchos grupos, además, dejan en blanco este apartado en concreto.

De las tres respuestas aceptables obtenidas la más satisfactoria es la dada por el grupo formado por los alumnos A39 y A53 (ver Figura VI.195):

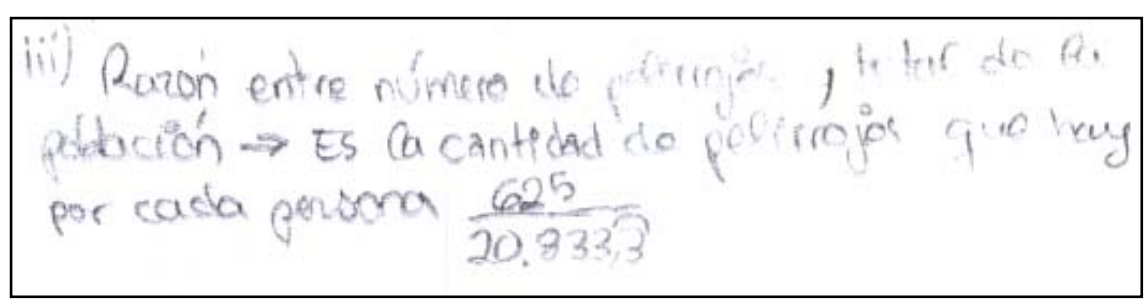

Figura VI.195.

Aunque la notación fraccionaria mezclada con los decimales debería resultar extraña, estos alumnos tienen completamente claro el significado de la razón. Es notorio el hecho de que utilizan los valores totales para calcular el valor numérico de la razón buscada. Esto contrasta con la respuesta del grupo formado por A37 y A47 que, tras algunos razonamientos erráticos y pese a hablar de pelirrojos por cada 100 habitantes dan una expresión correcta para la razón entre pelirrojos y habitantes empleando los 
porcentajes. No queda claro, no obstante, si realmente este grupo comprende lo que ha hecho (ver Figura VI.196):

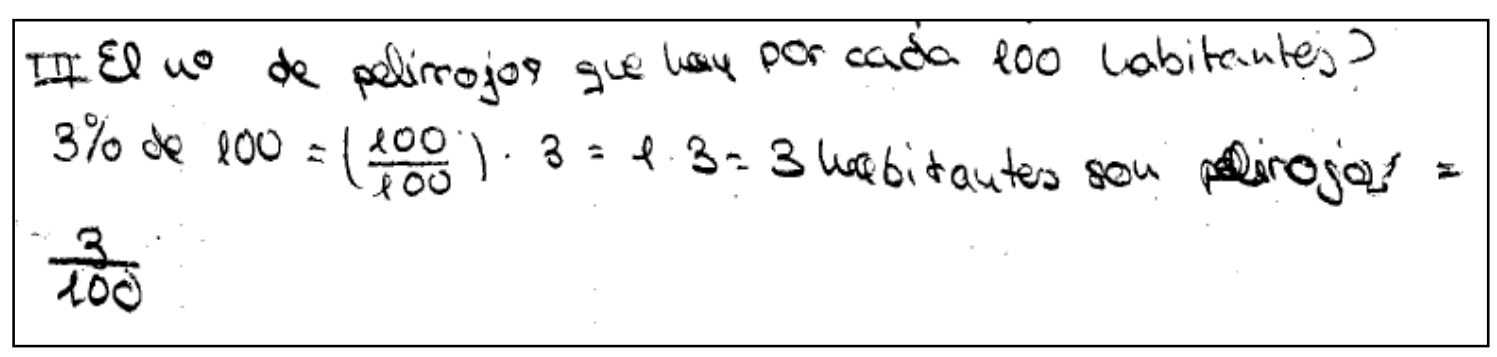

Figura VI.196.

A medio camino entre los dos ejemplos anteriores, la pareja formada por los alumnos A5 y A27 comete el error (Figura VI.197) de mezclar porcentajes con valores totales y da como valor de la razón el cociente entre el porcentaje de pelirrojos y el total de la población (al menos lo que ellos consideraban total, que también resulta incorrecto):

iii. ¿Cuál es la razón entre el número de pelirrojos y el total de la población?

Figura VI.197.

El resto de los errores cometidos por los alumnos consisten básicamente en dar respuestas carentes de sentido debidas a una falta de comprensión del significado del término 'razón’. Así, A6 y A11 dicen “pues que el 3\% del pueblo son pelirrojos y el resto no”. Más cerca de la idea de razón está, sin embargo la respuesta de A19 y A23: “que por 20837,3... hay 625 pelirrojos”. Hemos de dejar de lado, claro está, el deficiente manejo de los decimales.

\section{Ejercicio 3:}

En este ejercicio se va un paso más allá en cuanto a dificultad se refiere introduciendo la idea de disminución porcentual. En el primer y tercer apartados se trabaja esta idea en las dos direcciones posibles; a saber: aplicar una disminución porcentual a un precio, y calcular el precio original a partir del precio final y del porcentaje de descuento. En el segundo apartado se pretendía hacer énfasis en el significado de porcentaje como "tanto por cien" teniendo cuidado con las magnitudes implicadas: precio rebajado y precio sin rebajar. Las unidades de análisis para este 
ejercicio aparecen recogidas en la tabla siguiente. Nuevamente las posibilidades presentadas no son excluyentes:

\begin{tabular}{|c|c|}
\hline 0 & No entrega o no asiste a clase \\
\hline 1 & Respuesta en blanco \\
\hline 2 & Calcula correctamente el porcentaje pedido \\
\hline 3 & Halla correctamente el precio inicial a partir del rebajado \\
\hline 4 &
\end{tabular}

De acuerdo con estas unidades de análisis, los resultados obtenidos por los alumnos son los siguientes:

\begin{tabular}{|c|c|c|c|c|c|c|}
\hline \multicolumn{2}{|c|}{} & $\mathbf{0}$ & $\mathbf{1}$ & $\mathbf{2}$ & $\mathbf{3}$ & $\mathbf{4}$ \\
\hline Ejercicio 3 & $\mathbf{N}^{\mathbf{o}}$ de resp. & 0 & 10 & 14 & 6 & 0 \\
\cline { 2 - 7 } & Porcentaje & $0 \%$ & $40 \%$ & $56 \%$ & $24 \%$ & $0 \%$ \\
\hline
\end{tabular}

Además del nuevo aumento en el número de respuestas en blanco, llama la atención el hecho de que ningún grupo fue capaz de encontrar el precio original a partir del precio rebajado. Volveremos sobre ello al analizar el tercer apartado. También es bastante bajo el número de grupos que halla el porcentaje que representa el precio sin rebajar respecto del inicial. Sin embargo, casi todos los alumnos que responden (más de la mitad del total) son capaces de aplicar correctamente un descuento. Analicemos ahora cada apartado separadamente.

\section{$\underline{\text { Apartado i) }}$}

En este apartado se pedía aplicar un descuento porcentual al precio de un determinado objeto. Casi la totalidad de los alumnos que han respondido lo ha hecho correctamente, aunque con diversos grados de profundidad en sus razonamientos, claro está. Por ejemplo, el grupo formado por A45 y A54 respondió como se muestra en la Figura VI.198:

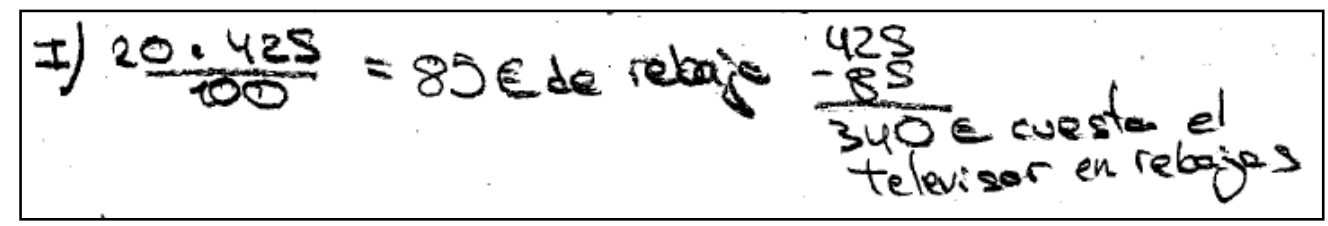

Figura VI.198. 
Todas las respuestas siguen este mismo esquema. Tan sólo se ha detectado un error en este apartado. Ha sido el cometido por el grupo formado por A32, A38 y A42 (ver Figura VI.199) que ha consistido en calcular sólo el descuento y no el precio final:

$$
\begin{aligned}
& 20 \% \text { de } 425=\left(\frac{425}{100}\right): 20=425: 20=85 \text { e de decuento } \\
& 425-85=340 \text { e costan' le tele durante las rebairas. }
\end{aligned}
$$

Figura VI.199.

\section{$\underline{\text { Apartado ii) }}$}

Son muy pocos los grupos que, como el formado por A31 y A36 (en la Figura VI.200), responden correctamente a este apartado, en el que se pedía el porcentaje que el precio final supone respecto del inicial:

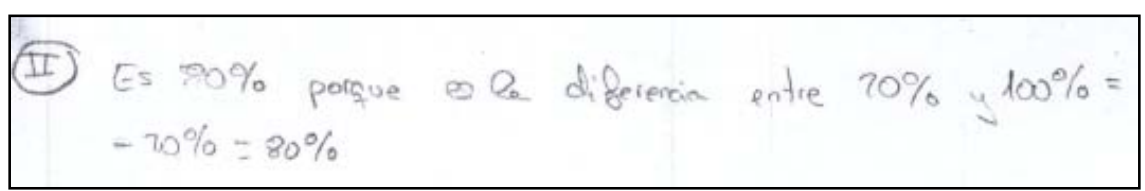

Figura VI.200.

En principio, eran dos las formas de afrontar este apartado. La primera es la recién ilustrada, considerando que el precio final es el "complementario" del descuento (cosa que no es obvia, creemos). La segunda no ha sido seguida por ninguno de los 6 grupos que responden correctamente y consistía en utilizar el precio inicial y el precio final para obtener el porcentaje como "tanto por ciento".

En cuanto a errores, hemos hallado dos tipos. El primero queda ilustrado por la respuesta del grupo formado por A44 y A51 (ver Figura VI.201) y consiste en dar como respuesta la cantidad descontada:

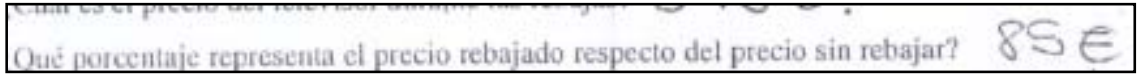

Figura VI.201.

El segundo es el cometido, por ejemplo, por el grupo A39 y A53 y consiste en dar el porcentaje de descuento y no su “complementario” (ver Figura VI.202): 


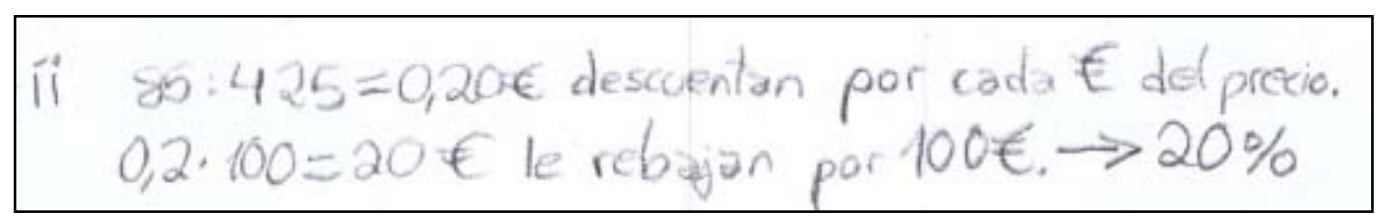

Figura VI.202.

En el fondo, ambos errores surgen o bien de una mala comprensión del significado del término 'porcentaje' (sobre todo en el primer caso) o de la no observación de cuáles eran las dos magnitudes involucradas (precio rebajado y precio sin rebajar, y no descuento y precio sin rebajar).

\section{$\underline{\text { Apartado iii) }}$}

En el contexto del ejercicio este apartado era el más complicado. Se pedía el precio inicial conociendo el precio final. Este hecho, unido a la falta de tiempo, hace que ningún grupo respondiera correctamente. No obstante, las respuestas incorrectas han sido sólo de tres tipos.

La respuesta mayoritaria ha consistido en indicar que no se conocía en porcentaje de descuento en este caso; es decir, no se asumía que el 20\% del enunciado era válido para todas las situaciones. Tal ha sido la respuesta, entre otros, del grupo formado por A40 y A52 (ver Figura VI.203):

$$
\text { iii- No nus dan datos de cuante seha rebajodo }
$$

Figura VI.203.

Otros grupos sí que han considerado que el apartado podía resolverse. El formado por los alumnos A55 y A56 (en la Figura VI.204 siguiente) ha asumido erróneamente que el descuento en términos absolutos (y no relativos, como es el caso) se mantiene constante. De ese modo si el descuento ha sido de $85 €$ les resulta sencillo calcular el supuesto precio inicial:

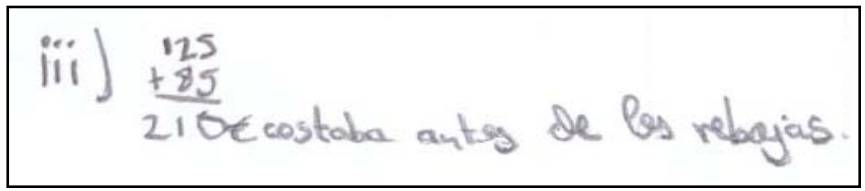

Figura VI.204.

Por su parte, el grupo formado por A44 y A51 comete también un error interesante y muy habitual (Figura VI.205). Dan por supuesto que la operación inversa 
de rebajar un $20 \%$ es subir un 20\%. Esto, claro está, es falso y así los alumnos calculan el supuesto precio inicial sumando un $20 \%$ al precio final.

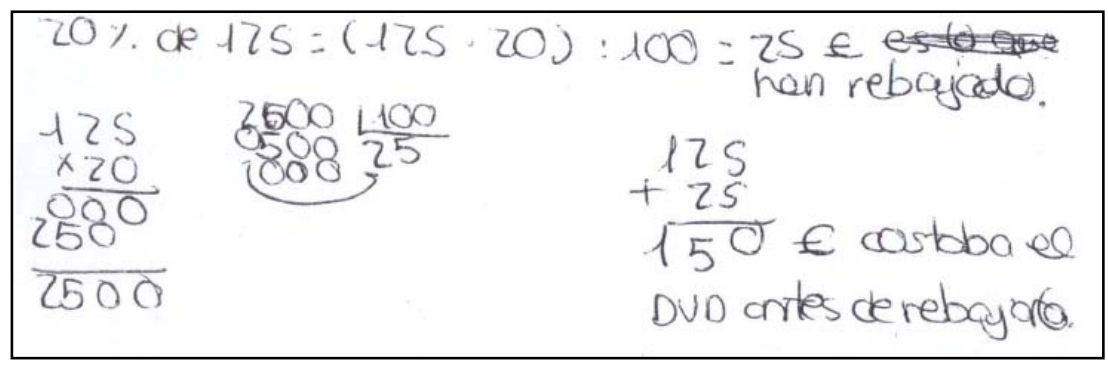

Figura VI.205.

\section{Ejercicio 4:}

Este ejercicio volvía nuevamente sobre las variaciones porcentuales, en este caso aumentos. Se proponía tanto el cálculo de un precio final conocidos el inicial y el porcentaje de subida como la búsqueda del porcentaje de subida conociendo los dos precios (éste último apartado más complicado). El último apartado requería un análisis crítico de las respuestas anteriores. Las unidades de análisis para este ejercicio aparecen recogidas en la tabla siguiente. Nuevamente las posibilidades presentadas no son excluyentes:

\begin{tabular}{|c|c|}
\hline 0 & No entrega o no asiste a clase \\
\hline 1 & Respuesta en blanco \\
\hline 2 & Aplica correctamente el aumento \\
\hline 3 & Calcula correctamente el porcentaje de subida \\
\hline 4 & Compara adecuadamente las dos subidas \\
\hline
\end{tabular}

De acuerdo con estas unidades de análisis, los resultados obtenidos por los alumnos son los siguientes:

\begin{tabular}{|c|c|c|c|c|c|c|}
\hline \multicolumn{2}{|c|}{} & $\mathbf{0}$ & $\mathbf{1}$ & $\mathbf{2}$ & $\mathbf{3}$ & $\mathbf{4}$ \\
\hline Ejercicio 4 & $\mathbf{N}^{\mathbf{0}}$ de resp. & 0 & 15 & 7 & 0 & 1 \\
\cline { 2 - 7 } & Porcentaje & $0 \%$ & $60 \%$ & $28 \%$ & $0 \%$ & $4 \%$ \\
\hline
\end{tabular}

El número de grupos que no realizó ninguno de los apartados de este ejercicio se dispara hasta los 15, un $60 \%$ de los 25 grupos totales. Además, la mayor parte de los que respondieron algún apartado, lo hizo sólo al primero. Este hecho hace que los 
resultados relativos a este ejercicio no sean significativos. No obstante, vamos a analizar las (escasas) respuestas obtenidas.

\section{$\underline{\text { Apartado i) }}$}

En este apartado, similar al Apartado i) del ejercicio anterior, se solicitaba el cálculo del nuevo precio de un billete de autobús a partir del precio anterior y del porcentaje de subida del precio. Este apartado es el único del ejercicio en el que se han obtenido respuestas satisfactorias. Siete de los diez grupos que responden lo hacen adecuadamente. Algunos grupos no nos dan pistas y se limitan a indicar el resultado final. Sin embargo, entre los que señalan las operaciones realizadas encontramos dos esquemas, como en toda la actividad, a la hora de calcular el aumento del precio. Ambos esquemas son equivalentes, claro está, pero uno es más apropiado que otro a la hora de entender la idea de porcentaje como “tanto por cien”.

El grupo formado por los alumnos A35 y A43, por ejemplo, a la hora de calcular el 4’5\% de 1'10€ multiplica primero por 4’5 y divide después por 100 (ver Figura VI.206):

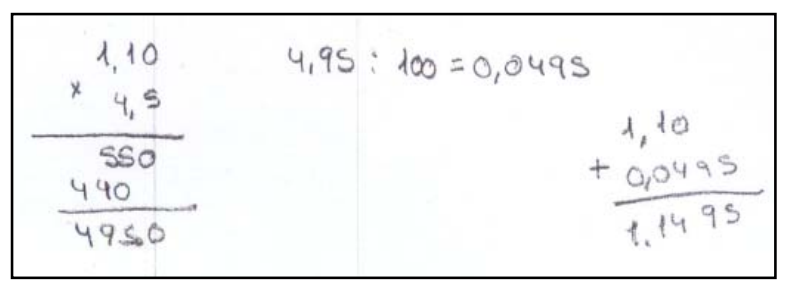

Figura VI.206.

Por su parte, el grupo formado por A40 y A52 razona al revés: dividiendo primero por 100 y multiplicando después por 4’5 (ver Figura VI.207):

$$
\begin{aligned}
& 1-10: 100=0,011 \cdot 4,5=0,0495 \rightarrow 0,0495+1,10=1,14 \text { a.proxi } \\
& \text { mado es } 1,15
\end{aligned}
$$

Figura VI.207.

La segunda estrategia es la que está más directamente relacionada con la idea de “tanto por cien” en paralelismo con el “tanto por uno” de la razón. Los alumnos que emplean la primera estrategia posiblemente apliquen un algoritmo mecanizado, aprendido memorísticamente, para calcular porcentajes. 
En este apartado el único error constatable ha sido el cometido por el grupo formado por A30, A34 y A41 que sólo ha calculado el importe de la subida, sin sumarlo al precio original para obtener el nuevo precio.

\section{$\underline{\text { Apartados ii) y iii) }}$}

En el apartado ii), conociendo los precios antes y después de una subida, se pedía calcular el porcentaje de dicho aumento. Ningún grupo ha respondido correctamente a este apartado porque, de hecho, sólo un grupo (el formado por los alumnos A44 y A51) ha dado una respuesta. Esta respuesta es incorrecta puesto que confunden la subida en términos absolutos con el porcentaje; además de efectuar unos cálculos un tanto confusos (ver figura más abajo).

En el apartado iii) se pedía comparar las subidas de los dos apartados anteriores. La pregunta tenía la dificultad añadida de que el aumento de mayor porcentaje era menor en términos absolutos. Como es evidente, sólo el grupo anterior ha respondido también al apartado iii). Lo ha hecho correctamente porque, pese a errar en el apartado anterior, su respuesta en este apartado ha sido consistente con sus respuestas anteriores.

En la Figura VI.208 siguiente se muestra la respuesta de este grupo. Curiosamente, no respondieron al primer apartado:

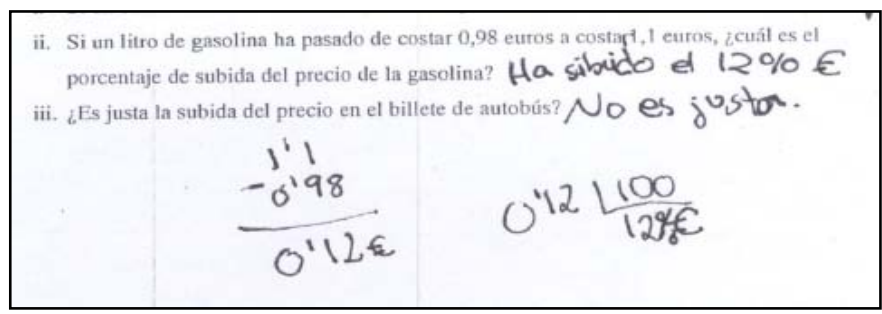

Figura VI.208.

\section{VI.3.3.2 Análisis y valoración de la Tarea de casa 5}

\section{Enunciado}

En clase hemos presentado lo que significa el porcentaje y has resuelto problemas en los que aparecía ese concepto. Recuérdalos y trata de resolver los siguientes.

\section{Ejercicio 1:}

En el Parque del Agua hay una gran variedad de árboles. El 7\% de ellos son olmos y el 


\section{$11 \%$ fresnos. Sabemos que hay 468 olmos. \\ i. ¿ ¿Cuántos árboles hay en total? \\ ii. ¿ ¿Cuántos de dichos árboles son fresnos? \\ iii. ¿ ¿Cuál es la razón entre fresnos y olmos? \\ iv. ¿ ¿Cuántos tilos hay en parque del agua?}

\section{Ejercicio 2:}

En un anuncio de un coche nos dicen que el nuevo modelo consume un $15 \%$ menos de gasolina que el modelo antiguo. El modelo antiguo gasta 7 litros de gasolina cada 100 kilómetros.

i. ¿Cuántos litros de gasolina necesita el modelo antiguo para recorrer 175 kilómetros?

ii. Hacemos una prueba con el nuevo modelo y descubrimos que necesita 9 litros para recorrer 150 kilómetros. ¿Es engañosa la publicidad?

\section{Ejercicio 3:}

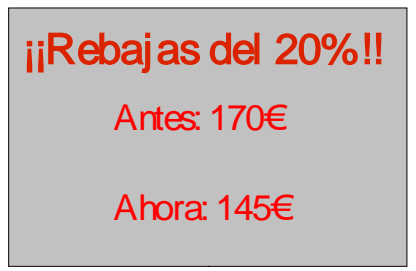

¿Qué opinas?

\section{Ejercicio 4:}

Para elaborar refresco de naranja se deben mezclar 400 mililitros de zumo de naranja con un litro de agua.

i. ¿ ¿Cuál es la razón entre el agua y el zumo?

ii. ¿Cuál es el porcentaje de zumo de naranja respecto del total de refresco?

iii. ¿ ¿Qué harías para elaborar 2 litros de refresco?

\section{Ejercicio 5:}

Ayer, en el Mercado Central, los tomates costaban 1,05 euros el kilo. Hoy, sin embargo, cuestan 1,35 euros el kilo. Ayer las naranjas costaban 0,68 euros el kilo y hoy cuestan 0,90 euros el kilo.

i. ¿ ¿Qué ha subido más de precio, el tomate o las naranjas? 
ii. ¿ ¿Qué porcentaje supone el precio de los tomates hoy respecto a ayer?

\section{Análisis de la tarea}

\section{Ejercicio 1:}

Este ejercicio constaba de 4 apartados: en el primero se pedía calcular la cantidad total de árboles conociendo la cantidad correspondiente a un cierto porcentaje del total, en el segundo se trataba de calcular la cantidad correspondiente a un cierto porcentaje del total (problemas inverso y directo respectivamente), el tercero pretendía recordar la idea de razón entre dos magnitudes y, finalmente, el cuarto apartado era una pregunta “trampa” que no podía responderse con los datos del problema.

Las unidades de análisis para este ejercicio aparecen recogidas en la tabla siguiente. En este caso las posibilidades presentadas no son excluyentes y, por tanto, los porcentajes de cada fila no han de sumar 100 necesariamente:

\begin{tabular}{|c|c|}
\hline 0 & No entrega o no asiste a clase \\
\hline 1 & Respuesta en blanco \\
\hline 2 & Resuelve correctamente el problema inverso \\
\hline 3 & Resuelve correctamente el problema directo \\
\hline 4 & Indica al menos el significado de la razón \\
\hline 5 & Justifica que no puede calcularse el número de tilos \\
\hline
\end{tabular}

De acuerdo con estas unidades de análisis, los resultados obtenidos por los alumnos son los siguientes:

\begin{tabular}{|c|l|c|c|c|c|c|c|}
\hline \multicolumn{2}{|c|}{} & $\mathbf{0}$ & $\mathbf{1}$ & $\mathbf{2}$ & $\mathbf{3}$ & $\mathbf{4}$ & $\mathbf{5}$ \\
\hline \multirow{2}{*}{ Ejercicio 1 } & $\mathbf{N}^{\mathbf{0}}$ de resp. & 12 & 3 & 27 & 26 & 12 & 18 \\
\cline { 2 - 8 } & Porcentaje & $21^{\prime} 4 \%$ & $5^{\prime} 4 \%$ & 48 ' $\%$ & $466^{\prime} 4 \%$ & $21^{\prime} 4 \%$ & $32^{\prime} 1 \%$ \\
\hline
\end{tabular}

Se observa un alto porcentaje de respuestas correctas a la hora de resolver los problemas directo e inverso, porcentaje que es aún mayor si se calcula respecto al número de tareas entregadas (44) y no respecto del número de alumnos (56). Como era de esperar, dada su mayor dificultad conceptual, estos porcentajes bajan acusadamente en los dos últimos apartados. Esto concuerda con los resultados obtenidos en la Actividad 6, de contenido similar, realizada en clase. A continuación comentaremos independientemente cada uno de los cuatro apartados del ejercicio. 


\section{Apartado i)}

En este apartado, conocida la cantidad correspondiente al 7\% del total, se pedía calcular dicha cantidad total. Junto con el siguiente ha sido el que mayor número de respuestas correctas ha recibido. Es interesante indicar que con los datos del problema se obtenía un número decimal como respuesta. Algunos alumnos no se han encontrado con este problema al truncar sus cálculos al segundo decimal (y así al multiplicar por 100 desaparecían los decimales), otros han redondeado al final de sus cálculos (muy pocos han indicado explícitamente este redondeo). Finalmente hay alumnos que han dado como respuesta el decimal obtenido sin reparar en la imposibilidad de una cantidad no entera de árboles.

Entrando ya en un análisis de las respuestas, algunos alumnos han dado sin más indicación la respuesta numérica (probablemente habiendo hecho los cálculos en la calculadora o en una hoja aparte). De los que indican las operaciones efectuadas, las respuestas mayoritarias son dos, que como dijimos en la Actividad 6, demuestran dos ideas distintas sobre el porcentaje. Así, alumnos como A19 (ver Figura VI.209 siguiente) primero dividen la cantidad correspondiente al $7 \%$ entre 7 para hallar la cantidad correspondiente a un 1\% y después multiplican por 100 para hallar el total.

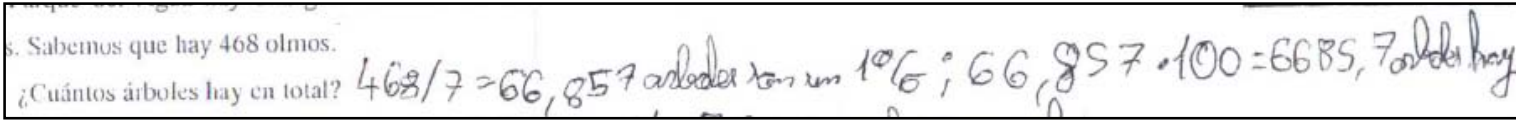

Figura VI.209.

Distinto es el modo de pensar de alumnos como A15 (en la Figura VI.210 siguiente) que, aunque implícitamente, primero multiplica por 100 y después divide por 7 o; al menos, tiene una idea más algorítmica sobre el cálculo de porcentajes que le lleva a aplicar una fórmula cerrada en la que el orden en que se efectúan las operaciones carece ya de sentido y significado.

$$
\text { I: } \frac{468 \cdot 100}{7}=6.685 \text { aiboles }
$$

Figura VI.210. 
La respuesta que más parece aclarar la idea de porcentaje como "tanto por cien” que queremos transmitir es la del alumno A11 (en la Figura VI.211, que sigue) que indica abiertamente la idea de que de cada 100 árboles, 7 son olmos:

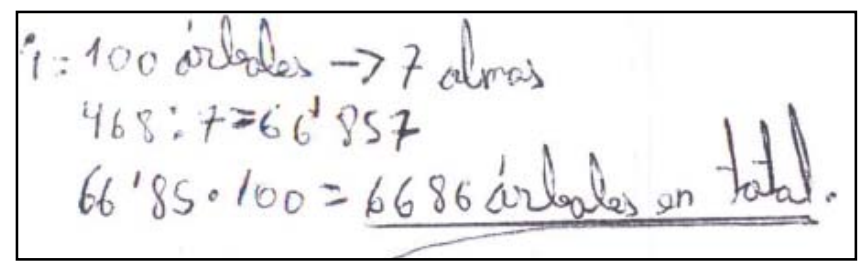

Figura VI.211.

Respecto a errores, vamos a presentar dos por lo paradigmático de los mismos (de hecho ya aparecieron en la Actividad 6). El primero es el cometido por el alumno A23 (ver Figura VI.212) que para hallar el total simplemente multiplica por 100 la cantidad correspondiente al 7\%:

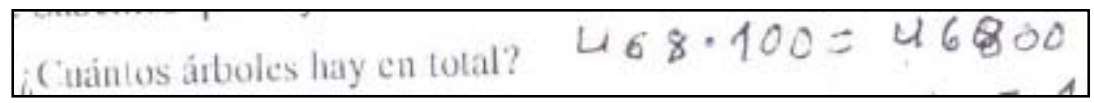

Figura VI.212.

Este error parece demostrar una total incomprensión del significado del porcentaje. El hecho de multiplicar por 100 parece estar motivado por la locución "por cien”. Por su parte el alumno A5 comete un error bastante habitual (ver Figura VI.213):

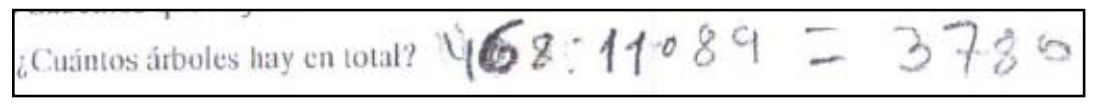

Figura VI.213.

Dejando de lado el hecho de que usa el 11\% y no el 7\% como debería, comete el error de pensar que para calcular el 100\% a partir del 11\% debe multiplicar por 89 (el complementario de 11 hasta 100). Este error es relativamente común y supone el reflejo de la idea de que al hablar de porcentajes todo debe sumar 100.

Para terminar el análisis de este apartado presentamos la respuesta del alumno A6 (ver Figura VI.214) que, si bien no puede catalogarse estrictamente como un error, sí que demuestra una débil comprensión de la situación por parte del alumno:

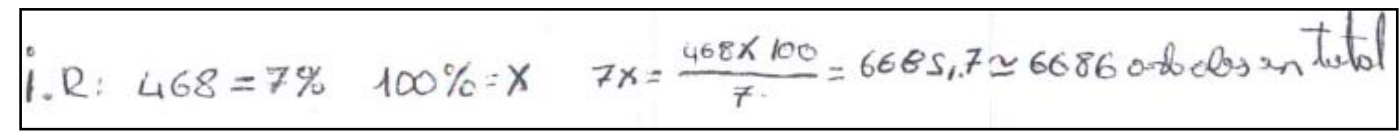

Figura VI.214. 
Se introduce (extraña e innecesariamente) una incógnita que (evidentemente) el alumno no sabe manejar más allá de una fórmula aprendida de memoria.

\section{$\underline{\text { Apartado ii) }}$}

Como era de esperar dada su similitud, los resultados en este apartado han sido casi idénticos que los del apartado anterior. Los tipos de respuestas y los errores cometidos han sido igualmente los mismos y por esta razón no vamos a presentar ejemplos concretos que redunden en lo presentado a la hora de analizar el apartado i). Para calcular la cantidad correspondiente al $11 \%$ del total se han encontrado 3 estrategias diferentes. Una de ellas hasta cierto punto inesperada que, de hecho, sólo la ha utilizado un alumno.

Las dos estrategias esperadas eran: por una parte, calcular el 11\% tomando como base la cantidad correspondiente al $1 \%$ encontrada en el apartado anterior sin hacer referencia al total (como hace el alumno A13 en la Figura VI.215 siguiente):

$$
\text { 11) } 66 \cdot 86 \cdot 11=735 \cdot 46
$$

Figura VI.215.

y, por otra, hacer referencia explícita a la cantidad total hallada en el apartado anterior y calcular su 11\% (como hace el alumno A24 en la Figura VI.216):

$$
6685,+1 \cdot 11 \%=735,42 \text { feernos }
$$

Figura VI.216.

La tercera estrategia no hace referencia ni al $1 \%$ ni al total, sino que pasa por el uso (de origen desconocido) de una regla de tres. Así lo hace el alumno A30 que, además, utiliza claramente el algoritmo usual de la regla de tres (ver Figura VI.217):

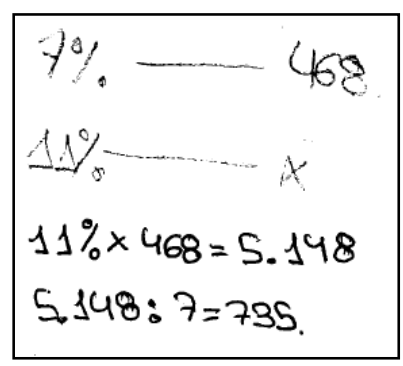

Figura VI.217. 


\section{$\underline{\text { Apartado iii) }}$}

Este apartado volvía de nuevo sobre el significado de la razón entre dos magnitudes y, dada la dificultad de este concepto, se comprende el descenso de respuestas aceptables. Aun así, en mayor o menor medida, son correctas en torno a la cuarta parte de las respuestas entregadas.

Bastantes alumnos dejan este apartado sin respuesta, otros, como A17 afirman que “no tienen razón”. Entre los que sí dan una respuesta correcta encontramos casi todas las posibilidades. Desde los que, como A54 (ver Figura VI.218), sólo indican el significado:

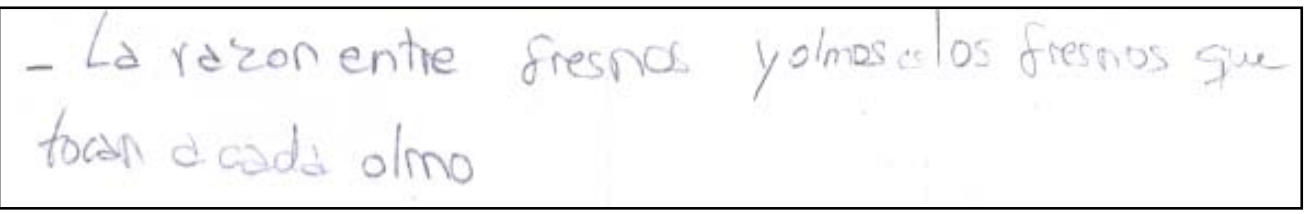

Figura VI.218.

o que, como A47 (ver Figura VI.219), sólo dan el valor numérico:

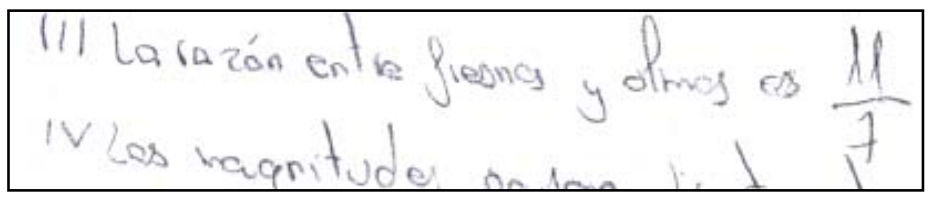

Figura VI.219

hasta los que, como A39 (en la Figura VI.220), indican tanto el significado como el valor numérico (aunque con una notación extraña):

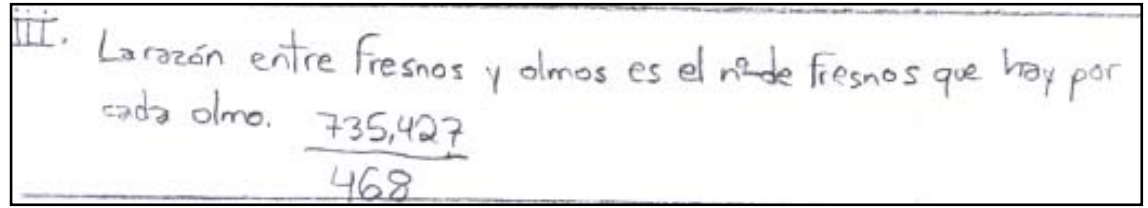

Figura VI.220.

También los hay que, como A37, no utilizan notación fraccionaria sino números decimales (ver Figura VI.221):

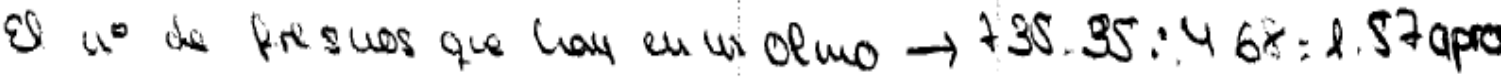

Figura VI.221. 
Con una idea parecida a la del alumno anterior, el alumno A19 (Figura VI.222) introduce los porcentajes a la hora de dar el significado de la razón en una respuesta sin mucho sentido:

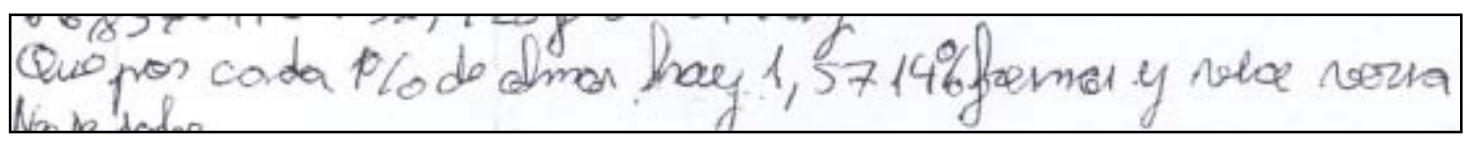

Figura VI.222.

Algunos alumnos no tienen aún una idea clara de lo que significa la razón entre dos magnitudes y se limitan a reproducir, con pocas modificaciones, la información que se da en el enunciado. Así el alumno A42 responde (ver Figura VI.223) que: "la razón es que por cada 7 olmos hay 11 fresnos” sin llegar aún a la idea de “tanto por uno”.

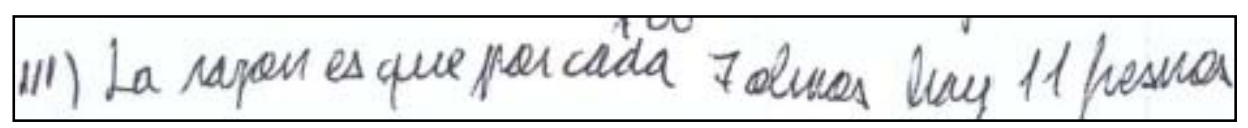

Figura VI.223.

El error más grave detectado en este apartado, por cuanto demuestra una falta total de comprensión hacia lo que se está pidiendo, es el cometido por A32 (en la Figura VI.224):

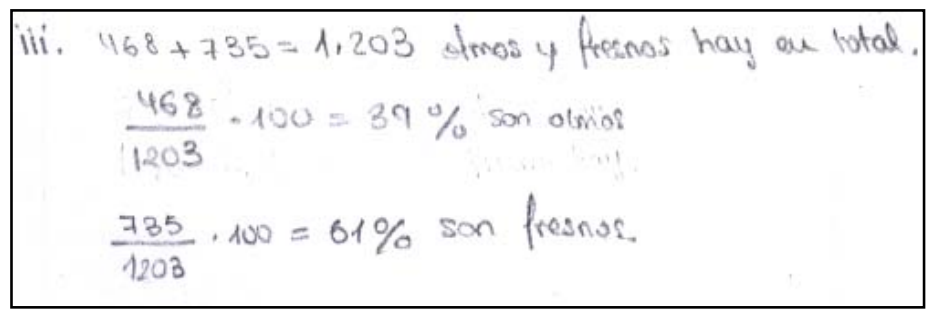

Figura VI.224.

Este alumno no parece entender qué se le está pidiendo y, sin embargo, la necesidad de dar una respuesta le lleva a hacer unos cálculos (formalmente correctos) pero que nada tienen que ver. Este ejemplo sirve como indicador, además, de lo poco que se suele enfatizar en los significados de las respuestas dadas. "Un 39\% son olmos" dice; pero un $39 \%$ ¿de qué?

\section{$\underline{\text { Apartado iv) }}$}

Este apartado era una pregunta "trampa" en el sentido de que, para poder responderla, era necesario suponer que no había en el parque más especies de árboles que las mencionadas. En otro caso era imposible responder por falta de datos. 
Casi la mitad de los alumnos que responden lo hace correctamente. Algunos alumnos, como A11 dicen que "no me dan el porcentaje de tilos” mientras otros, como A6, responden que "no podemos saber [...] porque no sabemos [...] si hay más árboles además de los tilos”. También hay alumnos que se conforma con un lacónico "no se puede hallar”, como hace A35 por ejemplo.

Los que sí dan una respuesta lo hacen, evidentemente, asumiendo que el parque no hay más tipos de árboles, pese a que el enunciado nada dice al respecto. Así lo hace A17 (ver Figura VI.225), suponiendo que los tilos corresponden al 82\% restante cuando no consideramos ni olmos ni fresnos. Para calcular la cantidad correspondiente no resta del total las cantidades de los otros dos tipos de árboles ni calcula el 82\% del total directamente, sino que utiliza como base la cantidad obtenida en el apartado i) para el 1\% de los árboles:

$$
\begin{aligned}
\text { IV } \mid 100-18 & =82 \% \text { son tilos } \\
66.82 & =5.412 \text { son tilos }
\end{aligned}
$$

Figura Vl.225.

Con todo, la respuesta más detallada es, sin duda la del alumno A45 en la Figura VI.226:

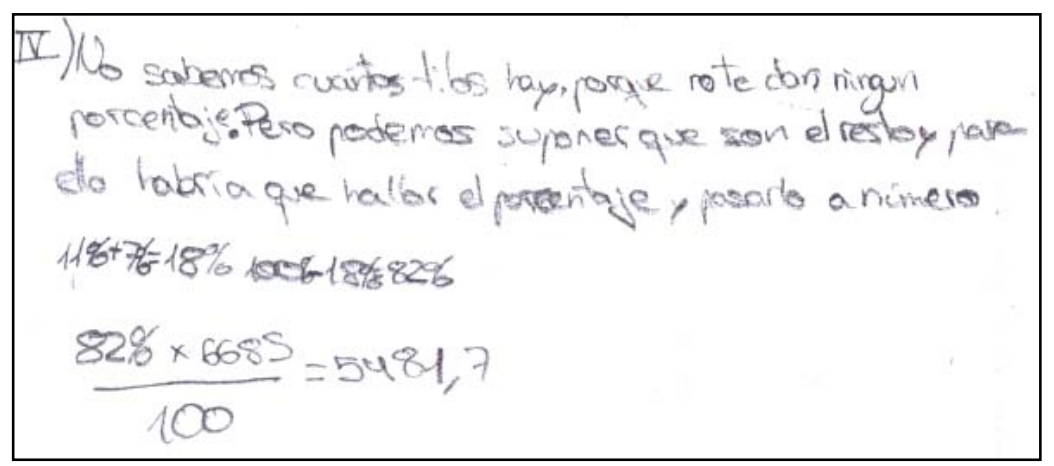

Figura VI.226.

puesto que indica tanto que "no sabemos cuántos tilos hay, porque no te dan ningún porcentaje" como que "podemos suponer que son el resto"; es decir, es consciente tanto de la imposibilidad de resolver con los datos dados como de la suposición necesaria para poder hacerlo.

\section{Ejercicio 2:}


Este ejercicio es algo más complicado que el anterior. En él aparecen involucradas ideas de disminuciones porcentuales, de comparaciones y de búsqueda de cantidades desconocidas en situaciones de proporcionalidad directa. En concreto, el apartado primero del ejercicio es un ejemplo típico de esto último. Por su parte, el segundo apartado vuelve a implicar un cálculo similar junto con una disminución porcentual y una pregunta abierta respecto a lo engañoso o no de la publicidad. Es decir, la respuesta al ejercicio no es simplemente numérica. Somos conscientes de que este tipo de preguntas abiertas suele causar a los alumnos dificultades mayores.

Para este ejercicio, las unidades de análisis aparecen recogidas en la tabla siguiente.

\begin{tabular}{|c|c|}
\hline 0 & No entrega o no asiste a clase \\
\hline 1 & Respuesta en blanco \\
\hline 2 & Halla correctamente la cantidad desconocida en el Apartado i) \\
\hline 3 & Aplica correctamente el descenso porcentual \\
\hline 4 & Responde razonadamente a la pregunta del Apartado ii) \\
\hline
\end{tabular}

De acuerdo con estas unidades de análisis, los resultados obtenidos por los alumnos son los siguientes:

\begin{tabular}{|c|c|c|c|c|c|c|}
\hline \multicolumn{2}{|c|}{} & $\mathbf{0}$ & $\mathbf{1}$ & $\mathbf{2}$ & $\mathbf{3}$ & $\mathbf{4}$ \\
\hline \multirow{2}{*}{ Ejercicio 2 } & $\mathbf{N}^{\mathbf{0}}$ de resp. & 12 & 4 & 29 & 18 & 16 \\
\cline { 2 - 7 } & Porcentaje & $21^{\prime} 4 \%$ & $7^{\prime} 1 \%$ & $51^{\prime} 8 \%$ & 32 '1\% & 28 '6\% \\
\hline
\end{tabular}

El número de alumnos que resuelve correctamente el primer apartado es muy alto, más incluso de lo que se esperaba. Si descontamos los alumnos que no entregan y aquellos que responden en blanco el porcentaje sube casi hasta el 73\%. En el segundo apartado el número de aciertos es sensiblemente inferior, aunque no es desdeñable. Llama la atención que algunos alumnos operan correctamente con los datos, pero no llegan a interpretarlos para dar la respuesta verbal que pedía el problema.

\section{Apartado i)}

En este apartado se proponía un ejercicio de búsqueda de una cantidad desconocida en una situación de proporcionalidad directa. Este tipo de ejercicios ya se 
había trabajado anteriormente y se pretendía observar si los alumnos habían asimilado las ideas subyacentes.

La mayor parte de las respuestas razonan en un modo similar a como lo hace el alumno A8 (ver Figura VI.227) calculando el consumo por kilómetro y multiplicando después por los kilómetros considerados:

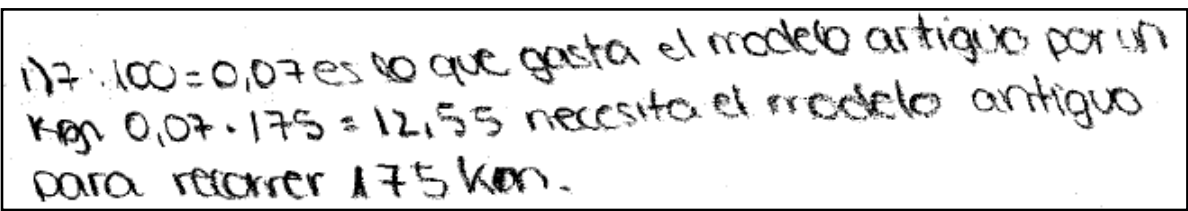

Figura VI.227.

Aunque no se hace mención a la razón entre las magnitudes, parece que queda claro su uso al hablar de "lo que gasta [...] por un km”. Algunos alumnos, como por ejemplo A53, sí que hacen mención expresa a la razón entre las magnitudes involucradas, si bien es cierto que, en este caso, las operaciones efectuadas por el alumno no parecen reflejar el uso de esta razón (ver Figura VI.228):

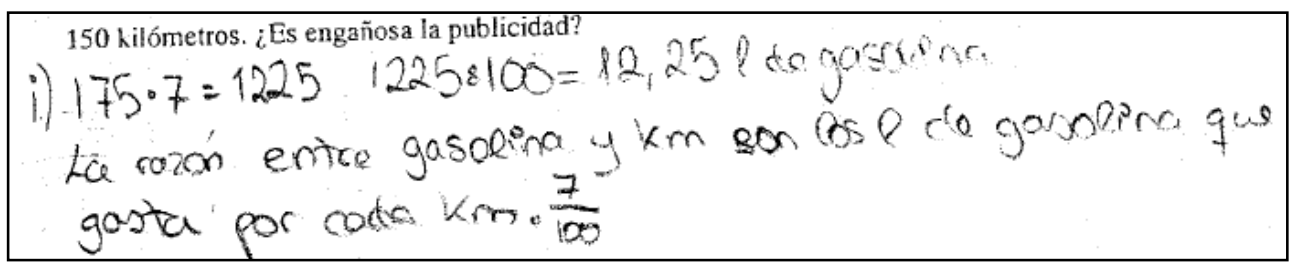

Figura VI.228.

Tan sólo el alumno A39 explicita (Figura VI.229) la condición de regularidad necesaria para poder resolver el problema con todo rigor:

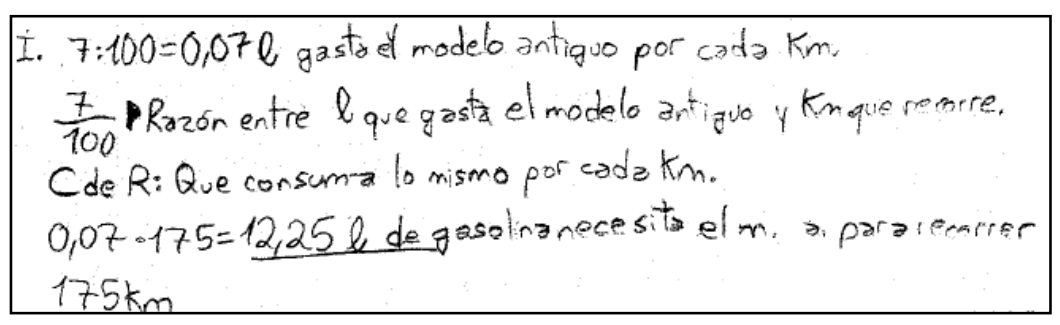

Figura Vl.229.

Como se observa, todas las respuestas anteriores se han basado en el cálculo del consumo por kilómetro. Tan solo unos pocos alumnos han utilizado la otra posibilidad; a saber, calcular los kilómetros que se pueden recorrer con un litro de gasolina. Así lo hace el alumno A28 (ver Figura VI.230), aunque parece tener alguna dificultad con el orden en que aparecen las magnitudes al hablar de la razón entre ellas: 


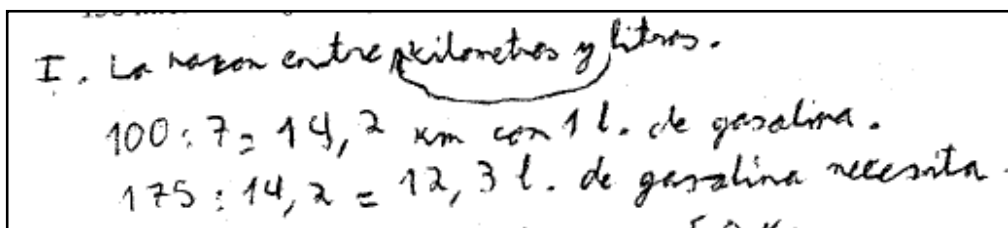

Figura VI.230.

Estas dos estrategias recogen prácticamente la totalidad de las respuestas correctas. No obstante, aparecen algunas estrategias más sofisticadas que no pasan por el uso directo de la razón entre las magnitudes. Por ejemplo, A37 (Figura VI.231) calcula los litros necesarios para recorrer 75 kilómetros observando que 75 son los 3/4 de 100 con lo que calcula los 3/4 de los 7 litros necesarios para recorrer $100 \mathrm{Km}$, sumando dicha cantidad a los 7 litros. Una estrategia similar es la que pretende utilizar el alumno A40 que, sin embargo, acaba en un ir y venir sin mucho sentido (este es el único error reseñable cometido por algún alumno en este apartado):

$$
\begin{aligned}
& I: \frac{1}{4} \text { de } 100 \mathrm{~km}=25 \rightarrow 25: 7=3,57 \\
& 3.57 \cdot 7=25 \cdot 7=175 \\
& 100: 7=14,28 \quad 75: 7=10,7 \\
& 14.28+10,71=25 \rightarrow \text { dasta } 25 \mathrm{~L} \text { en } 175 \mathrm{~km} .
\end{aligned}
$$

Figura VI.231.

Por último, un único alumno, el A24, resuelve este apartado haciendo uso de la regla de tres. Eso sí, con toda su parafernalia: disposición de los datos tabularmente, flechas e incluso uso de una incógnita.

\section{$\underline{\text { Apartado ii) }}$}

El carácter abierto de la pregunta formulada en este apartado hacía que la posible respuesta admitiera diversos enfoques (aunque no ha habido mucha variedad de casos). Este carácter abierto ha supuesto dificultades añadidas para a algunos alumnos, como por ejemplo a A21 (ver Figura VI.232), que calcula correctamente el hipotético consumo por kilómetro del nuevo coche, pero no va más allá, y no es capaz de interpretar ese resultado para contestar a la pregunta. 


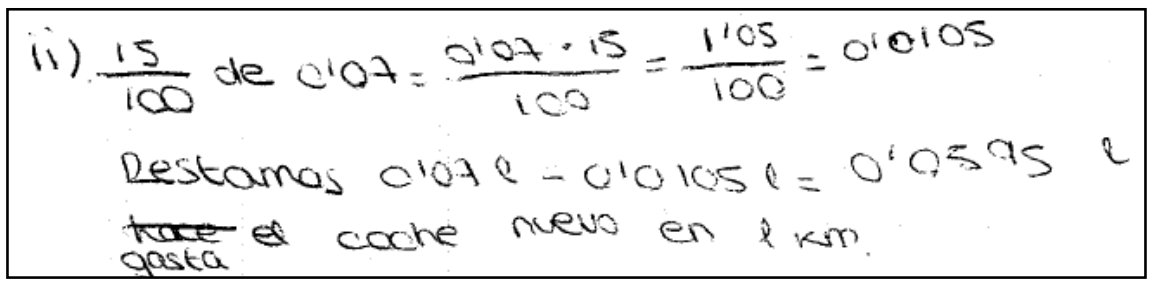

Figura VI.232.

El hecho de que se pregunte sobre lo engañoso o no de una publicidad hace que algunos alumnos discrepen respecto a lo que significa "ser engañoso”. Así, para algunos alumnos como A12 consideran que "no es muy engañosa” porque la diferencia entre lo real y lo publicitado es escasa (ver Figura VI.233):

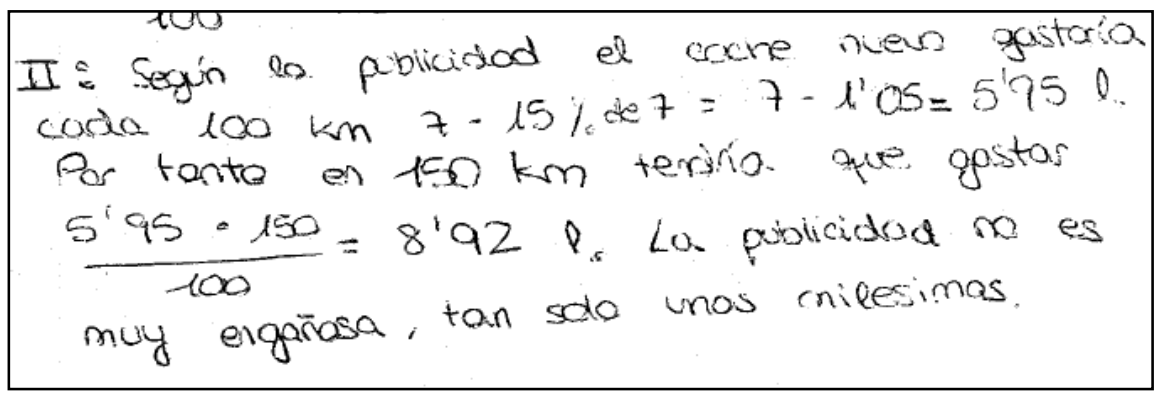

Figura VI.233.

Obsérvese que en este ejemplo se ha utilizado para la comparación el consumo por cada 150 kilómetros. También hay alumnos que han comparado los consumos por kilómetro. Tal es el caso de A8 que, en la Figura VI.224, (dejando de lado el error aritmético) llega a la misma conclusión que su compañero anterior:

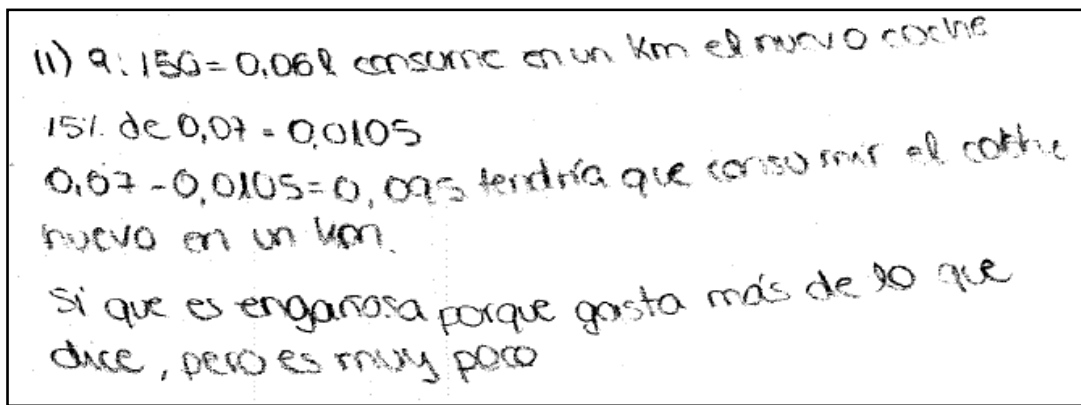

Figura VI.224.

La escasa diferencia existente entre las cantidades publicitadas y las reales hace que los alumnos poco cuidadosos con el manejo de los decimales y del redondeo concluyan que la información dada es veraz. Así, el alumno A28 redondea 1’575 a 1’5 y concluye que “la publicidad no es engañosa” (ver Figura VI.225): 


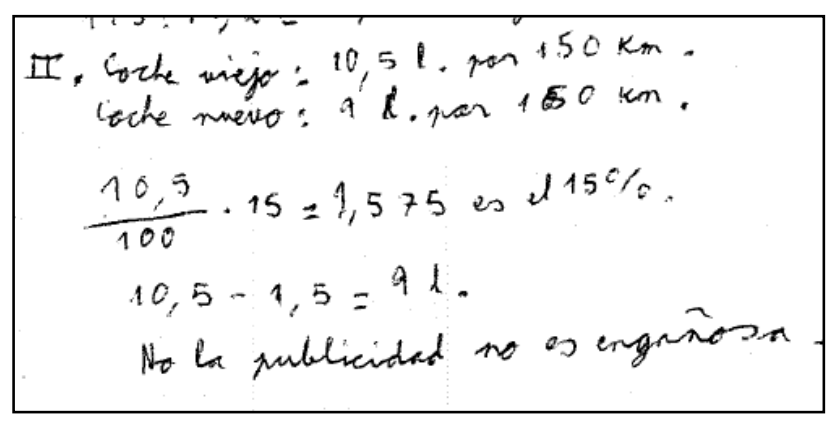

Figura VI.225.

También hay alumnos que, aunque efectúan las operaciones correctamente y aprecian la diferencia, concluyen que la publicidad no es engañosa sin justificación alguna. Por ejemplo, así lo hace A24. Otros alumnos responden aleatoriamente sin efectuar cálculo alguno. No se han detectado errores de concepto en este apartado.

\section{Ejercicio 3:}

Este ejercicio plantea una situación abierta, muy similar al apartado ii) del ejercicio anterior, pero en un contexto más sencillo. Se presenta un cartel con dos informaciones contradictorias: por un lado, el porcentaje de descuento y, por otro, el precio original y el rebajado. Como es natural, el precio rebajado es mayor de lo que debería ser en caso de haber aplicado correctamente el descuento. La pregunta hecha a los alumnos es simplemente su opinión sobre el cartel mostrado, nuevamente la respuesta abierta es una dificultad añadida al ejercicio.

Para este ejercicio, las unidades de análisis aparecen recogidas en la tabla siguiente.

\begin{tabular}{|c|c|}
\hline 0 & No entrega o no asiste a clase \\
\hline 1 & Respuesta en blanco \\
\hline 2 & Aplica el descuento porcentual correctamente \\
\hline 3 & Interpreta correctamente los resultados \\
\hline
\end{tabular}

De acuerdo con estas unidades de análisis, los resultados obtenidos por los alumnos son los siguientes:

\begin{tabular}{|c|c|c|c|c|c|}
\hline \multicolumn{2}{|c|}{} & $\mathbf{0}$ & $\mathbf{1}$ & $\mathbf{2}$ & $\mathbf{3}$ \\
\hline Ejercicio 3 & $\mathbf{N}^{\mathbf{0}}$ de resp. & 12 & 4 & 28 & 28 \\
\cline { 2 - 6 } & Porcentaje & $21{ }^{\prime} 4 \%$ & $7^{\prime} 1 \%$ & $50 \%$ & $50 \%$ \\
\hline
\end{tabular}


El número de respuestas correctas es bastante alto en este ejercicio; al contrario de lo que sucedía en el último apartado del ejercicio anterior no hay alumnos que no sean capaces de interpretar los resultados obtenidos. No hemos tenido en cuenta algunos errores aritméticos a la hora de restar el descuento al precio inicial, siempre y cuando el procedimiento fuera el correcto y la respuesta fuese consistente con los cálculos realizados.

Una posible forma de afrontar el problema era calcular el precio que debería tener el objeto rebajado suponiendo que la información del cartel fuese la correcta. De este modo razonan todos los alumnos que responden correctamente, menos uno. Por ejemplo, A32 (en la Figura VI.226 siguiente) concluye que el precio debería ser de $136 €$; inferior al que se anuncia y que, por tanto "no te están haciendo la rebaja del 20\%":

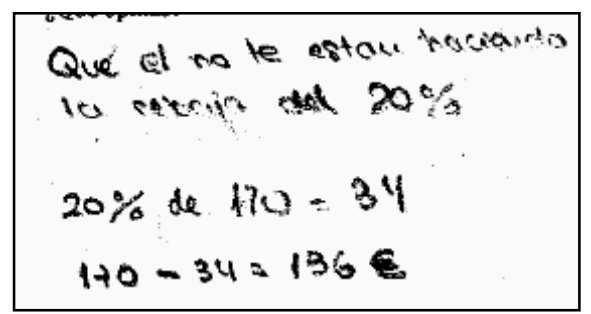

Figura VI.226.

El otro posible enfoque consiste no ya en comparar precio real e hipotético, sino descuento real e hipotético. Así razona el alumno A39 (ver Figura VI.227):

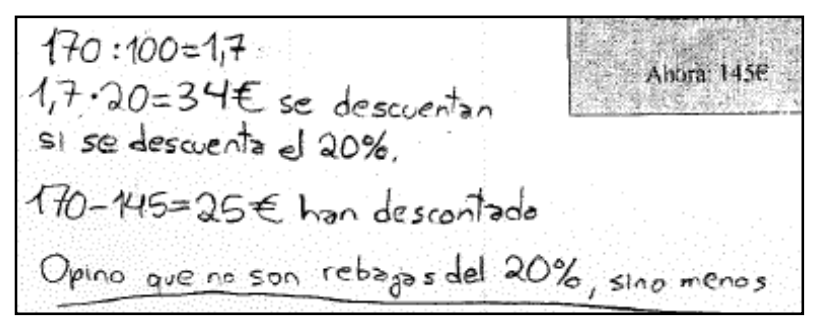

Figura VI.227.

Aunque algunos han dado respuestas sin sentido, como A20, que respondió: “que con la rebaja la ropa de la tienda está mucho más barata y las personas comprarán más ropa", hay errores más interesantes a tener en cuenta. Por ejemplo, A44 (en la figura VI.228, que sigue) confunde el porcentaje de descuento con el descuento en términos absolutos, afirmado así que "las rebajas son del 25\%” cuando en realidad el descuento es de $25 €$ (como de hecho calcula): 


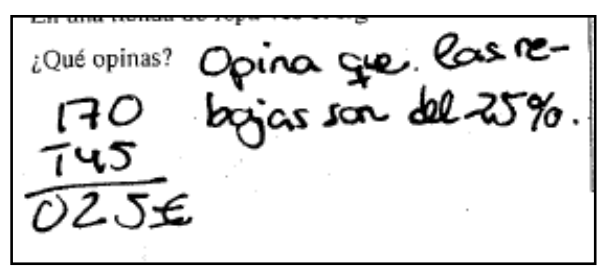

Figura VI.228.

Por su parte, el alumno A40 comete el error de calcular el descuento a partir del precio ya rebajado y no del precio original (ver Figura VI.229) aunque la conclusión final es, casualmente, la misma:

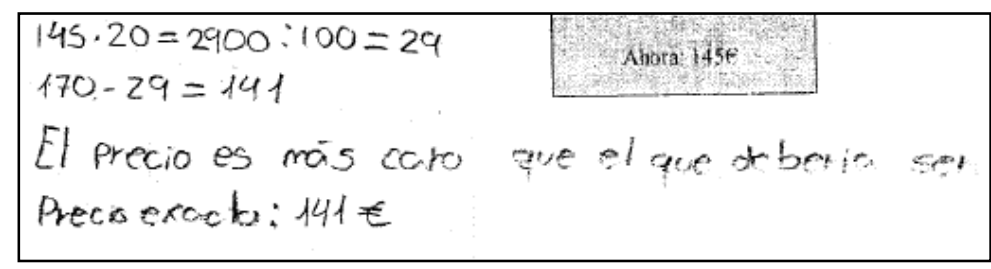

Figura VI.229.

\section{Ejercicio 4:}

Este ejercicio vuelve de nuevo sobre cuestiones más bien conceptuales, como el significado de la razón o el de porcentaje como "tanto por cien”. Estos dos aspectos se trabajan en los dos primeros apartados, mientras que el tercero requiere del uso del porcentaje y/o de la razón anteriores en un problema de búsqueda de cantidades desconocidas.

Para este ejercicio, las unidades de análisis aparecen recogidas en la tabla siguiente.

\begin{tabular}{|c|c|}
\hline 0 & No entrega o no asiste a clase \\
\hline 1 & Respuesta en blanco \\
\hline 2 & Señala al menos el significado de la razón \\
\hline 3 & Calcula correctamente el porcentaje pedido \\
\hline 4 & Encuentra las cantidades necesarias de ambos ingredientes \\
\hline
\end{tabular}

De acuerdo con estas unidades de análisis, los resultados obtenidos por los alumnos son los siguientes: 


\begin{tabular}{|c|c|c|c|c|c|c|}
\hline \multicolumn{2}{|c|}{} & $\mathbf{0}$ & $\mathbf{1}$ & $\mathbf{2}$ & $\mathbf{3}$ & $\mathbf{4}$ \\
\hline \multirow{2}{*}{ Ejercicio 4 } & $\mathbf{N}^{\mathbf{0}}$ de resp. & 12 & 7 & 16 & 14 & 15 \\
\cline { 2 - 7 } & Porcentaje & $21^{\prime}{ }^{\prime} \%$ & $12^{\prime}{ }^{\prime} \%$ & $28{ }^{\prime} 6 \%$ & $25 \%$ & $26{ }^{\prime} 8 \%$ \\
\hline
\end{tabular}

En este ejercicio y en el siguiente (como veremos) aumenta ligeramente el número de respuestas en blanco. La cantidad de respuestas acertadas es prácticamente el mismo en los tres apartados, lo que parece demostrar que aquellos alumnos que tienen asimilados los significados de razón y porcentaje resuelven con facilidad el último apartado que implica una aplicación de dichos conceptos.

Apartado i)

Como hemos indicado un poco más arriba, en este apartado volvemos sobre el significado de la razón entre dos magnitudes. La particularidad es que, en este caso, ambas magnitudes son partes de un todo, lo que podría provocar algunas dificultades a la hora de asimilar su significado pues al hablar de "litros de agua por cada litro de zumo" (como es el caso) no estamos diciendo que en cada litro de zumo hay cierta cantidad de agua, sino que se junta esa cantidad de agua con un litro de zumo para formar la mezcla considerada. Veremos que la redacción de las respuestas de algunos alumnos refleja esta dificultad.

Como viene siendo habitual cuando se pregunta por la razón entre dos magnitudes, nos encontramos con alumnos que se han quedado únicamente con su significado (son calcular su valor numérico concreto), como es el caso de A17, en la Figura VI.230 siguiente:

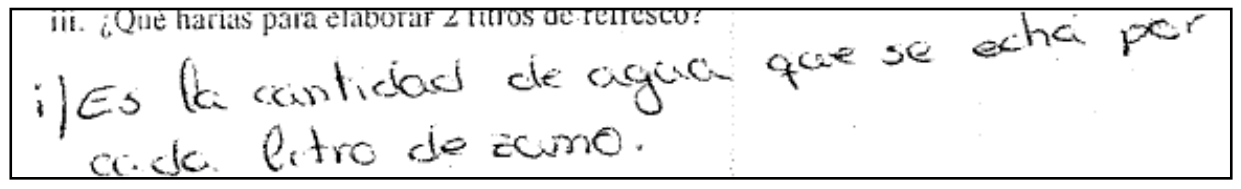

Figura VI.230.

En el otro extremo encontramos a los alumnos que únicamente se centran en el aspecto numérico, sin dar indicaciones sobre el significado, como A47 (Figura VI.231) por ejemplo:

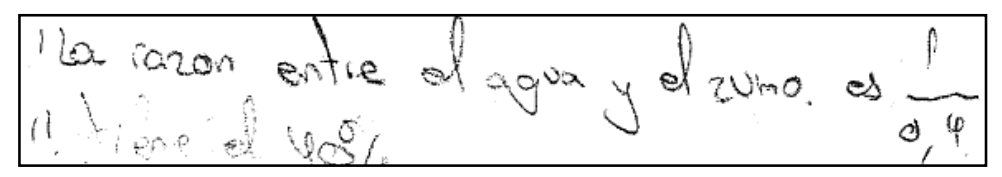

Figura VI.231. 
Aunque también hay alumnos que indican correctamente ambos aspectos, dejando de lado, no obstante, la condición de regularidad. Así lo muestra A39, cuya redacción “cantidad de agua por 11 de zumo” (Figura VI.232) parece dar a entender que es agua en el zumo más que con él; como dijimos antes:

$$
\begin{aligned}
& \text { I. Racón entre agua y zumo es la cantidad de agua que hay por } \\
& \text { Il de eumo } \frac{1}{0,4}=2,5 \quad 1: 0,4=2,50 \text { de agua hay por } 1 \text { lde aume }
\end{aligned}
$$

Figura Vl.232.

El orden de las magnitudes involucradas en la razón es uno de los aspectos que ponen en mayores dificultades a los alumnos. A28 (Figura VI.233) ejemplifica esta dificultad cambiando los papeles del agua y del zumo (aunque la idea de "tanto por uno" esta clara):

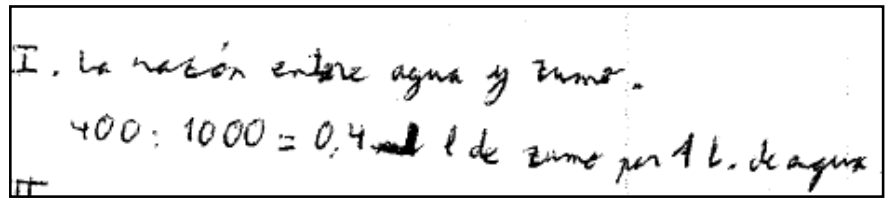

Figura VI.233.

Finalmente, aunque pocos, algunos alumnos todavía no han asimilado ni siquiera el significado de la razón entre dos magnitudes; el alumno A51 (Figura VI.234) es un claro ejemplo:

\section{i) La ruzố ente e cgo y el zumo es los litor quénecesitan para hacen es refingo}

Figura VI.234.

\section{$\underline{\text { Apartado ii) }}$}

En este apartado se pedía a los alumnos calcular el porcentaje que representa el zumo respecto del total de refresco. La dificultad principal radicaba (y muchos alumnos han tenido problemas con ello) en que para poder contestar era necesario comprender que la cantidad total de refresco se obtiene sumando los volúmenes de agua y zumo que se mezclan. Así, por ejemplo, el alumno A37 responde que "no se puede hacer porque no te pone el total de refresco”, y el alumno A13 utiliza (de forma incorrecta, ver Figura VI.235) como volumen total el volumen de agua, como si al añadir el zumo el volumen 
no aumentara o como si los $400 \mathrm{ml}$ de zumo ya formaran parte de ese litro (lo que no es el caso):

$$
\text { i) } \frac{400}{1000}=0.4 \cdot 100=40 \%
$$

Figura VI.235.

Algunos alumnos, como por ejemplo A17, calculan el porcentaje buscado correctamente y, además, las operaciones realizadas parecen indicar una buena comprensión del significado del porcentaje puesto que primero se divide el volumen de zumo entre el total (obteniendo así la cantidad de zumo por litro de refresco) para después multiplicar por 100 (ver Figura VI.236):

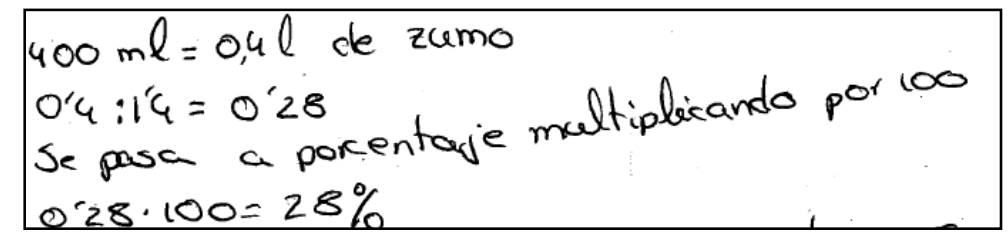

Figura VI.236.

Esto cálculos contrastan radicalmente, pese a que ambos llevan obviamente a la misma respuesta, con los efectuados por A11 (Figura VI.237):

$$
\begin{aligned}
& \therefore=1^{\prime} 4 \text { I nefresa tieni } 0^{\prime} 4 \text { l maranta } \\
& 100: 194=71142 \\
& 7142.04=28^{\circ} 57^{\circ}
\end{aligned}
$$

Figura VI.237.

Aunque es posible dar un significado a las operaciones efectuadas (por ejemplo, ver cuántas veces está contenido un volumen de 1,4 litros en uno de 100 litros para después multiplicar por los 0,4 litros de zumo que hay en cada uno de ellos), parece un significado más forzado y puede denotar que este alumno aplica sin más un algoritmo de cálculo. No obstante, en cuanto a oscuridad se refiere, el uso injustificado de la regla de tres se lleva la palma (ver la respuesta del alumno A3 en la Figura VI.238 siguiente): 


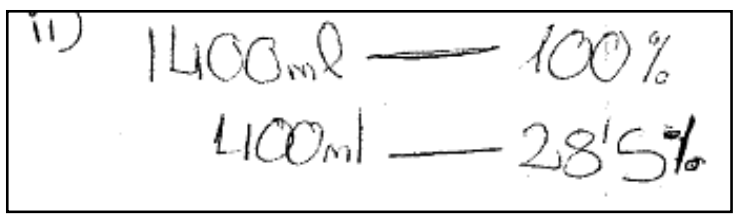

Figura VI.238.

\section{Apartado iii)}

En este último apartado del ejercicio los alumnos debían aplicar los resultados de los apartados anteriores para averiguar la cantidad necesaria de cada ingrediente para hacer dos litros de refresco. Las distintas respuestas dadas por los alumnos en este apartado van en paralelo con las dadas en el apartado anterior. Así, aquellos alumnos (como A37) que decían necesitar la cantidad total de refresco para calcular el porcentaje dicen aquí que "no se puede hallar porque al principio no te dicen la cantidad de refresco que fabricas".

Por su parte, los alumnos que no sumaban los volúmenes de agua y zumo, considerando que con 400 mililitros de zumo y con 1 litro de agua se fabricaba 1 litro de refresco, simplemente multiplican por dos estas cantidades (ver la respuesta de A38 en la Figura VI.239):

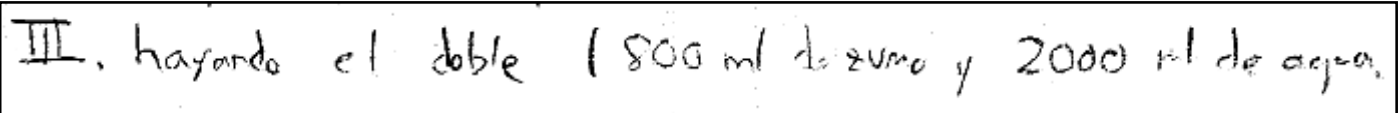

Figura VI.239

Para resolver correctamente el apartado se podía hacer uso del porcentaje hallado en el apartado anterior, como hace por ejemplo A53 (ver Figura VI.240):

$$
\begin{aligned}
& \text { iil } 28,5+\% \text { de } 2 e-i \quad 28,57 \cdot 100=0,225 t \\
& 0,2857 \cdot 2=0,5714 l+0 \text { zumo } \\
& \text { 2. } 594 \\
& 1,10860 \text { de agja }
\end{aligned}
$$

Figura VI.240.

En este caso, hay que calcular la cantidad correspondiente al 28'57\% de 2 litros para encontrar la cantidad de zumo y restar dicha cantidad a los 2 litros para obtener la de agua. Sin embargo, también puede resolverse este apartado recurriendo simplemente a la idea de razón como “tanto por uno”, como hace A8 en la Figura VI.241 siguiente: 


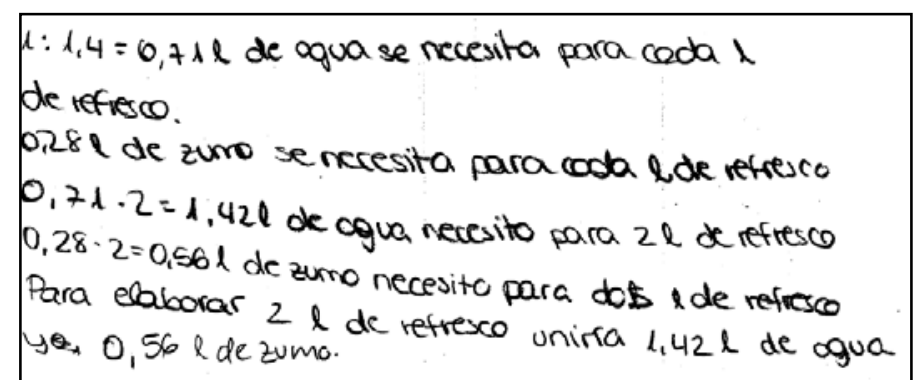

Figura VI.241.

Aquí, el alumno calcula el zumo y el agua necesarios para elaborar 1 litro de refresco y así le basta multiplicar por dos dichas cantidades para obtener la respuesta. Este método demuestra un buen manejo de los conceptos y de las magnitudes involucradas.

\section{Ejercicio 5:}

En este ejercicio se planteaba un caso típico de comparación de dos subidas de precio, para ilustrar la idea de que para que la comparación tenga sentido debe hacerse en términos relativos. En el ejemplo presentado el producto que sufre una mayor subida absoluta es el que menor subida relativa sufre. Además, en el segundo apartado se volvía sobre la idea de porcentaje con la dificultad de que el porcentaje pedido es superior al $100 \%$ lo que, como veremos, ha ocasionado grandes dificultades.

Para este ejercicio, las unidades de análisis aparecen recogidas en la tabla siguiente.

\begin{tabular}{|c|c|}
\hline 0 & No entrega o no asiste a clase \\
\hline 1 & Respuesta en blanco \\
\hline 2 & Compara precios en términos absolutos \\
\hline 3 & Compara precios en términos relativos \\
\hline 4 & Calcula correctamente el porcentaje pedido \\
\hline
\end{tabular}

De acuerdo con estas unidades de análisis, los resultados obtenidos por los alumnos son los siguientes:

\begin{tabular}{|c|c|c|c|c|c|c|}
\hline \multicolumn{2}{|c|}{} & $\mathbf{0}$ & $\mathbf{1}$ & $\mathbf{2}$ & $\mathbf{3}$ & $\mathbf{4}$ \\
\hline Ejercicio 5 & $\mathbf{N}^{\mathbf{0}}$ de resp. & 12 & 5 & 30 & 7 & 6 \\
\cline { 2 - 7 } & Porcentaje & $21^{\prime} 4 \%$ & $8^{\prime} 9 \%$ & $533^{\prime} 6 \%$ & $12{ }^{\prime} 5 \%$ & 10 '7\% \\
\hline
\end{tabular}


Es notable el número de alumnos que compara (incorrectamente) la subida de precios en términos absolutos. Es posible que la redacción de la pregunta “¿Qué ha subido más de precio?” lleve a engaño puesto que ya se trabajaron actividades en las que se debía comparar en términos relativos y, en esos casos, el porcentaje de respuestas acertadas fue mayor. Por otro lado, ya hemos comentado que la aparición de un porcentaje mayor que el $100 \%$ supuso una seria dificultad a los alumnos, como de hecho queda reflejado en la tabla anterior.

\section{$\underline{\text { Apartado i) }}$}

Es hasta cierto punto sorprendente el bajo porcentaje de aciertos en este apartado. Hasta 30 alumnos dan una respuesta análoga a la de A8 (que mostramos a continuación en la Figura VI.242):

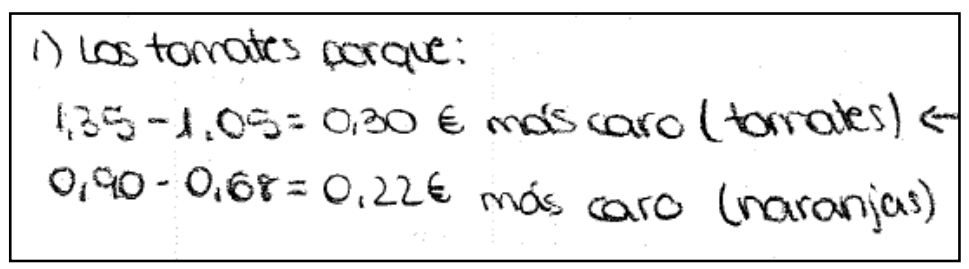

Figura VI.242.

Claramente la atención del alumno se centra únicamente en el valor absoluto de la subida. Cabe preguntarse si, cambiando el contexto de la situación, una subida de 30 céntimos en el precio de un coche de $18000 €$ seguiría pareciéndole mayor. No obstante unos pocos alumnos si razonan convenientemente y piensan que lo relevante en esta situación es la subida relativa. Por ejemplo, A31 responde del modo que vemos en la Figura VI.243:

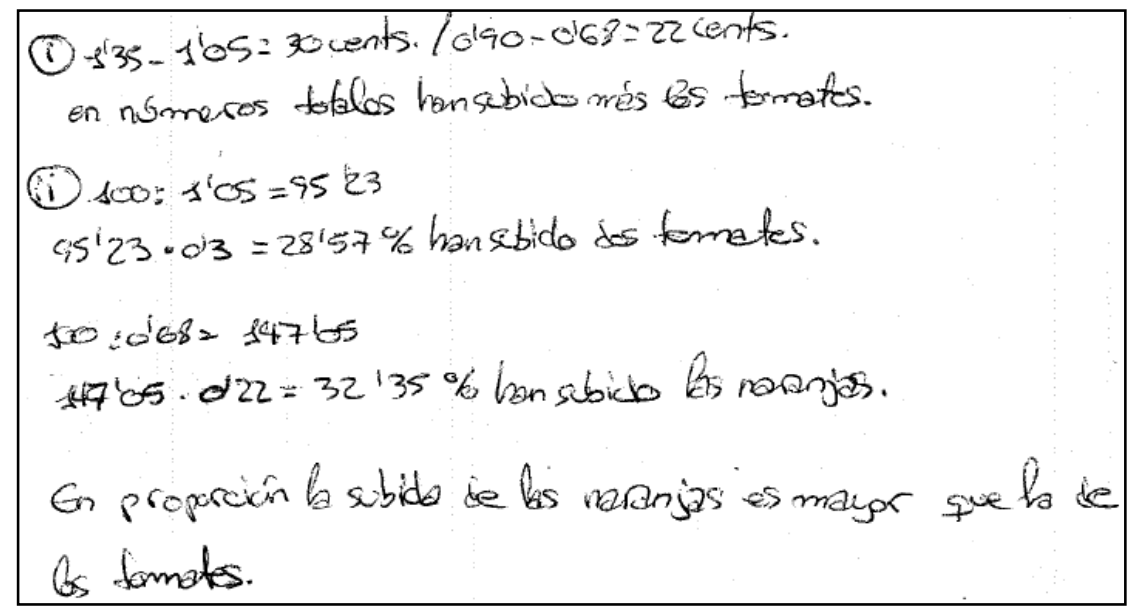

Figura VI.243. 
Pero, aún así, se resiste a considerar sólo la subida relativa e incluye como parte de la respuesta que “en números totales han subido más los tomates”.

\section{$\underline{\text { Apartado ii) }}$}

En este apartado, el porcentaje de aciertos también ha sido bajísimo, seguramente a causa de la extrañeza que supondrá a los alumnos el encontrarse con un porcentaje superior al 100\% (aunque, de hecho, teniendo en cuenta la definición como "tanto por cien”, que prescinde de la idea de partir en 100 partes y coger unas cuantas; esto no debería ser así). Tan sólo 6 alumnos responden correctamente. Por ejemplo A40 calcula correctamente el porcentaje, aunque utilizando un algoritmo que no deja muy claro el significado de las operaciones (ver Figura VI.244):

$$
\text { ii. } \begin{aligned}
1,35 \cdot 100 & =135 \\
135: 1,05 & =128,57 \%
\end{aligned}
$$

Figura VI.244.

También A39 responde acertadamente, pero su estrategia es completamente distinta (ver la Figura VI.245 siguiente):

$$
\begin{aligned}
& \text { III } 100+28,57 \ldots=128,57 \% \text { estas pagando respecto al } \\
& \text { precio de zyer. }
\end{aligned}
$$

Figura VI.245.

Debe indicarse que, con lo trabajado en clase, no estaba justificado el razonamiento de este alumno; es decir, que tenga sentido sumar porcentajes de este modo no se había trabajado en clase. Queda pues la duda de si realmente este alumno comprendía lo que hizo o si se trató de un salto al vacío.

Aunque la respuesta mayoritaria a este apartado fue no responder, un número no desdeñable de alumnos calcularon el porcentaje que suponía la subida de precio de los tomates (incluso alumnos que compararon las subidas en términos absolutos y que, por tanto, no lo calcularon en el apartado anterior). Tal es el caso, por ejemplo, del alumno A17 (ver Figura VI.246): 


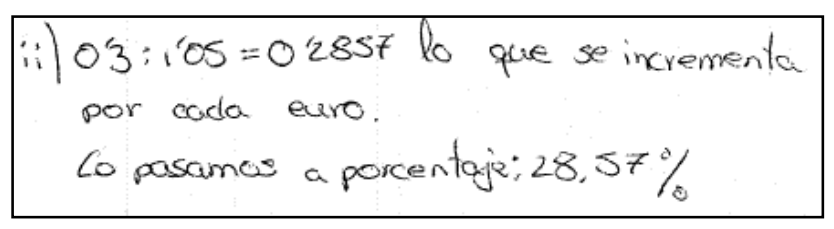

Figura VI.246.

Posiblemente los alumnos que así han respondido no hayan comprendido correctamente lo que se pedía en este apartado.

\section{VI.3.3.3 Reflexiones relativas al punto 3}

1. Los alumnos son bastante capaces de calcular la cantidad correspondiente a un cierto porcentaje del total [problema directo], aunque muy pocos parecen utilizar la idea de “tanto por cien”.

2. También hay un buen porcentaje de aciertos a la hora de resolver el problema inverso; es decir, a la hora de calcular el total a partir de la cantidad correspondiente a un porcentaje del mismo. No obstante, en este caso hay algunas dificultades.

3. Muchos alumnos parecen estar familiarizados con algoritmos para el cálculo de porcentajes.

4. El significado de la razón entre dos magnitudes no parece estar muy afianzado todavía entre los alumnos y muy pocos lo enuncian con claridad.

5. Como consecuencia del primer comentario los alumnos calculan bastante bien los aumentos y disminuciones porcentuales cuando se plantean de forma directa.

6. El manejo de los números decimales es muy deficiente; sobre todo cuando aparecen decimales periódicos.

7. Pese a no haberse comentado en clase la idea de que los porcentajes correspondientes a cantidades “complementarias” deben sumar 100 está presente en bastantes alumnos.

8. Los alumnos resuelven con bastante solvencia los problemas directo e inverso, aunque a veces las operaciones que efectúan están sustentadas más en un proceso algorítmico que en el significado de las mismas. Esto es así, pese a que 
no se presentó en el aula algoritmo alguno. Posiblemente ya lo hubieran trabajado en cursos anteriores o recibieran algún tipo de influencia externa.

9. Hay aún dificultades a la hora de manejar el concepto de razón. Pocos alumnos señalan su significado, menos aún manejan tanto el significado como el valor numérico simultáneamente y ninguno ha hecho mención a la condición de regularidad.

10. En relación con el primer punto, los aumentos y disminuciones porcentuales se manejan correctamente, con la misma salvedad que ya hemos hecho antes. Las comparaciones entre porcentajes y cantidades iniciales y finales se manejan aceptablemente bien.

11. Aunque sólo aparecía en un apartado de un ejercicio, los porcentajes superiores al 100\% parecen causar dificultades. Posiblemente debería hacerse hincapié en esa idea.

12. Sorprendentemente, muy pocos alumnos han considerado que para evaluar una subida de precio no hay que fijarse en su valor absoluto, sino en su valor relativo con respecto del precio inicial. Posiblemente sería bueno trabajar esto con situaciones cotidianas empleando catálogos de supermercados, por ejemplo.

\section{VI.4. OBSERVACIÓN Y REFLEXIÓN DEL TERCER FOCO DE INVESTIGACIÓN}

Además del análisis de situaciones de un modo más profundo (considerando magnitudes que varían o que permanecen constantes) y del reconocimiento y la distinción de las magnitudes inversamente proporcionales, en este foco se pretende que los alumnos hagan uso de las ideas de razón y constante de proporcionalidad y de los significados de las operaciones entre magnitudes a la hora de resolver problemas de búsqueda de cantidades desconocidas. Estos son los tres puntos que analizaremos en este foco de investigación.

\section{VI.4.1 Punto 1: Análisis de situaciones}

El alumno ya ha realizado con anterioridad actividades en las que se le solicitaba analizar una situación concreta en la que aparecían dos magnitudes. Ahora, en la Tarea 
de casa 6, se le solicita analizar situaciones con algo más de detalle puesto que en ciertas situaciones existen magnitudes “ocultas” que, sin embargo juegan un importante papel.

\section{VI.4.1.1 Análisis y valoración de la Tarea de casa 6}

\section{Enunciado}

A continuación te presentamos diversas situaciones. En cada una de ellas debes indicar las magnitudes que varían, si alguna magnitud se mantiene constante y las razones que se puedan definir en cada situación (diciendo las condiciones de regularidad que se deben cumplir). Si entre dos magnitudes no se puede definir la razón indica los motivos.

Situación 1: Para pagar el autobús de una excursión de 350 kilómetros cada uno de los 34 pasajeros tiene que pagar 45 euros.

Situación 2: Con los bocadillos que se han preparado, cada uno de los 60 alumnos que van de excursión puede comer 5 bocadillos a lo largo del día.

Situación 3: En una caja caben 120 pelotas de tenis, tanto si son de color amarillo como si son de color verde.

Situación 4: Abriendo el grifo 8 minutos se llena una bañera de 225 litros.

Situación 5: Estudio 5 horas diarias para preparar los exámenes finales de las 7 asignaturas que hay en $4^{\circ}$ curso.

Situación 6: Los 120 kilogramos de café pesan, después de tostarlos, 96 kilogramos.

\section{Análisis de la tarea}

Como ya hemos indicado algo más arriba, no todas las situaciones presentadas son del mismo tipo. Así, en la situación 3 sólo aparece una magnitud, en la situación 5 sólo aparecen 2, en la situación 1 aparecen explícitamente 3 magnitudes y, por último, en el resto de las situaciones aparecen 3 magnitudes, pero sólo dos de ellas lo hacen explícitamente. Este hecho motiva el que dividamos nuestro análisis en tres partes. Antes de iniciar dicho análisis, señalamos que la variabilidad en la tipología de las respuestas ha hecho muy difícil un análisis cuantitativo de estas situaciones. Es por ello que las categorías en las que se agrupan las respuestas serán, quizás, algo ambiguas. 
Será pues más interesante el espacio dedicado al análisis cualitativo de las respuestas de los alumnos.

Situaciones 1, 2, 4 y 6:

En estas situaciones aparecen explícitamente 2 ó 3 magnitudes:

1. Distancia recorrida, número de pasajeros y precio por persona.

2. Número de alumnos y bocadillos por alumno.

4. Tiempo de llenado y capacidad de la bañera.

6. Kilos de café sin tostar, kilos de café tostado.

Mientras que en algunas de ellas pueden encontrarse magnitudes que no aparecen explícitamente y que se hallan, en cierto modo, ocultas:

1. Precio total.

2. Bocadillos totales.

4. Flujo del grifo.

6. Pérdida de peso por kilo al tostar café.

El grado de “ocultación” de estas magnitudes varía según la situación (como veremos más adelante) y, de ello, dependerá que los alumnos las tengan o no en consideración.

Las unidades de análisis para estas situaciones aparecen recogidas en la tabla siguiente:

\begin{tabular}{|c|c|}
\hline 0 & No entrega o no asiste a clase \\
\hline 1 & Respuesta en blanco \\
\hline 2 & Señala la magnitud “oculta” \\
\hline 3 & Relaciona correctamente algún par de magnitudes \\
\hline 4 & Indica correctamente alguna razón \\
\hline
\end{tabular}

De acuerdo con estas unidades de análisis, los resultados obtenidos por los alumnos son los siguientes:

\begin{tabular}{|l|l|l|l|l|l|}
\hline & 0 & 1 & 2 & 3 & 4 \\
\hline
\end{tabular}




\begin{tabular}{|c|c|c|c|c|c|c|}
\hline \multirow[t]{2}{*}{ Situación 1} & $\mathrm{~N}^{\circ}$ de resp. & 15 & 7 & 12 & 10 & 9 \\
\hline & Porcentaje & $26 ’ 8 \%$ & $12 ’ 5 \%$ & $21^{\prime} 4 \%$ & 17’9\% & $16 ' 1 \%$ \\
\hline \multirow[t]{2}{*}{ Situación 2} & $\mathrm{~N}^{0}$ de resp. & 15 & 6 & 12 & 8 & 5 \\
\hline & Porcentaje & $26 ’ 8 \%$ & $10 ’ 7 \%$ & $21 ' 4 \%$ & $14 ’ 3 \%$ & 8’9\% \\
\hline \multirow[t]{2}{*}{ Situación 4} & $\mathrm{~N}^{\circ}$ de resp. & 15 & 4 & 0 & 6 & 24 \\
\hline & Porcentaje & $26 ’ 8 \%$ & 7’1\% & $0 \%$ & $10^{\prime} 7 \%$ & $42 ’ 8 \%$ \\
\hline \multirow[t]{2}{*}{ Situación 6} & $\mathrm{~N}^{0}$ de resp. & 15 & 9 & 0 & 5 & 12 \\
\hline & Porcentaje & $26 ’ 8 \%$ & $16 ’ 1 \%$ & $0 \%$ & 8’9\% & $21 ’ 4 \%$ \\
\hline
\end{tabular}

Saltan a la vista los bajos porcentajes obtenidos. Tan sólo en la situación 4 hay un buen número de alumnos que indican la razón entre dos de las magnitudes involucradas. De hecho, esta tarea junto con la Actividad 3, son las que peores resultados han dado. A continuación analizaremos separadamente cada una de las situaciones.

Situación 1:

A la hora de analizar esta situación, en primer lugar, nos encontramos con alumnos como A52 que no parece entender lo que se le pide y contesta que "no se puede definir porque no se sabe cuánto cuesta un litro de gasolina”. Para este alumno el único objetivo parece ser dar con una respuesta numérica concreta y así, parte de la tarea solicitada (señalar magnitudes) puede que no sea considerada como una labor realmente matemática. Esto queda también puesto de manifiesto muy claramente en respuestas como la del alumno A22 (ver Figura VI.247) que hacen cálculos aparentemente aleatorios utilizando todas las cantidades disponibles:

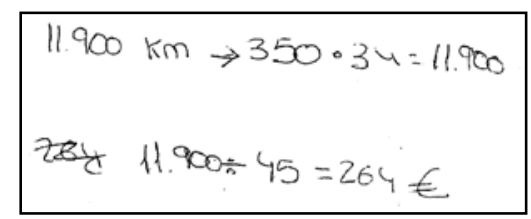

Figura VI.247.

Otros alumnos, como A32, sí prestan atención a las magnitudes, pero su respuesta, "las magnitudes no varían porque los kilómetros, los pasajeros y los euros son exactos”, demuestra que no se maneja la magnitud como un ente abstracto y sólo se utilizan cantidades de la magnitud. Esta visión dificulta la posibilidad de pesar en magnitudes que varían a la vez.

La misma observación vale para el alumno A53 (ver Figura VI.248): 


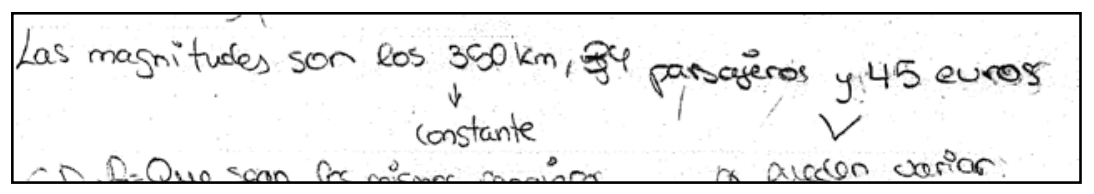

Figura VI.248.

Este alumno sigue pensando en las magnitudes "pegadas" a las cantidades concretas del enunciado, pero, sin embargo, piensa que dos de ellas (pasajeros y euros) pueden variar mientras que la distancia es constante. Es interesante indicar que confunde la magnitud euros por persona con euros. Este error es muy común y hace que alumnos como A54 den respuestas como la de la Figura VI.249 siguiente:

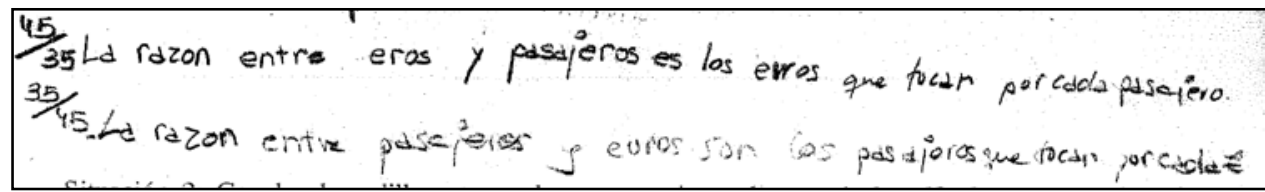

Figura VI.249.

$\mathrm{Al}$ no observar que la magnitud son euros por pasajero se comete un error grave al intentar señalar la razón entre euros y pasajeros, pues se calcula una hipotética razón entre euros por pasajero y pasajeros que, por supuesto, carece de sentido.

Hay alumnos que sí calculan correctamente la razón entre dos magnitudes para las que sí tiene sentido dicha razón. Por ejemplo A39 calcula la razón entre kilómetros y euros por pasajero y su inversa, dando además un significado correcto al resultado y tratando de dar una condición de regularidad (Figura VI.250):

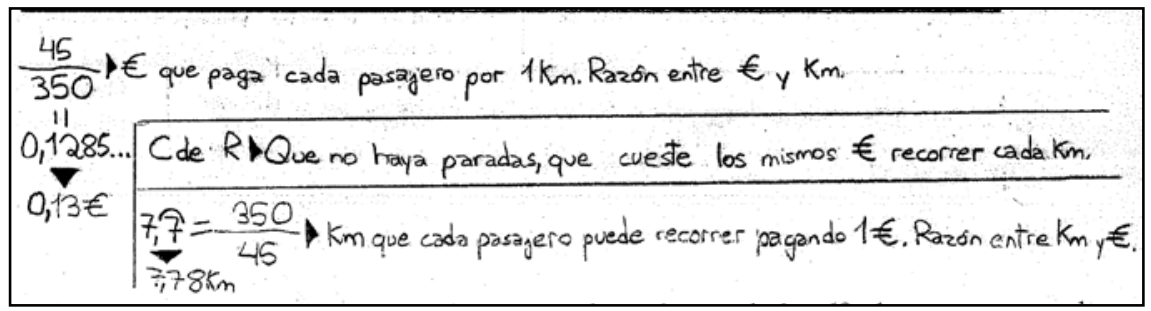

Figura VI.250.

Por su parte, el alumno A53 (del que ya hemos hablado) encuentra la magnitud “oculta” (euros totales) y calcula la razón entre dicha magnitud y los pasajeros, indicando su significado (ver Figura VI.251, aunque el valor numérico de la razón no se aprecia bien): 


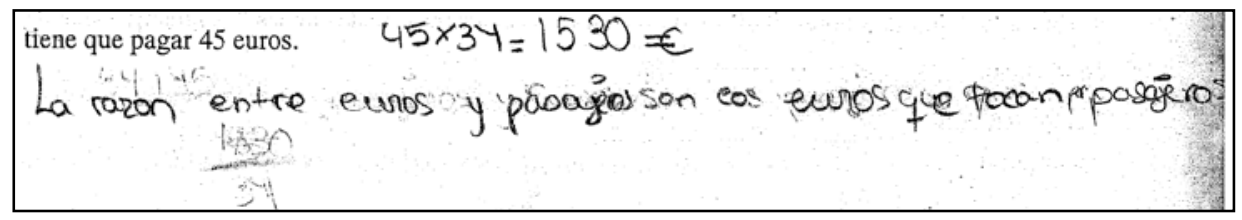

Figura VI.251.

Finalmente, hay alumnos que prescinden completamente (o casi) de las consideraciones numéricas. Por ejemplo A26 da la siguiente respuesta: "1530€ vale la excursión y es la magnitud constante, sin embargo, el $n^{o}$ de pasajeros y el precio que debe pagar cada uno sí que puede variar, si van más pasajeros, pagaran menos. Y si van menos pagarán más” (ver Figura VI.252). Esta respuesta no hace mención de conceptos como la razón, pero sí que demuestra una buena comprensión de la situación y un cierto manejo de las magnitudes implicadas:

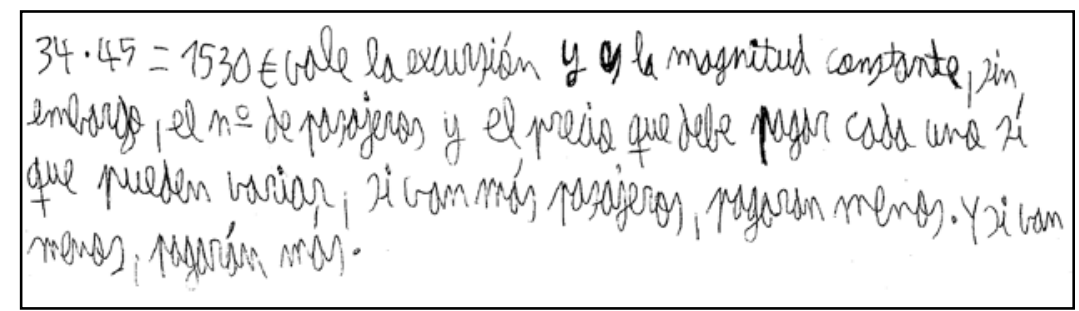

Figura VI.252.

En la misma dirección va la respuesta de A47, que prescinde más incluso de lo numérico y escribe: “Si hubiera menos kilómetros los pasajeros pagarían menos, si hubiera más Km los pasajeros pagarían más” (lo que es cierto) pero sigue: "Si hubiera más pasajeros, pagarían más, si hubiera menos pasajeros pagarían menos”. Afirmación que, cuando menos, es sorprendente.

\section{Situación 2:}

Esta situación es muy similar a la anterior, salvo por el hecho de que aparece una magnitud menos. Esta similitud hace que la tipología de las respuestas sea prácticamente idéntica a la de la situación anterior. Sin embargo, en este caso, una de las tres magnitudes ya es la razón entre las otras dos. Esto explica la reducción en el número de alumnos que señala correctamente dicha razón.

Posiblemente, la respuesta más satisfactoria sea la del alumno A31 (ver Figura VI.253 siguiente): 


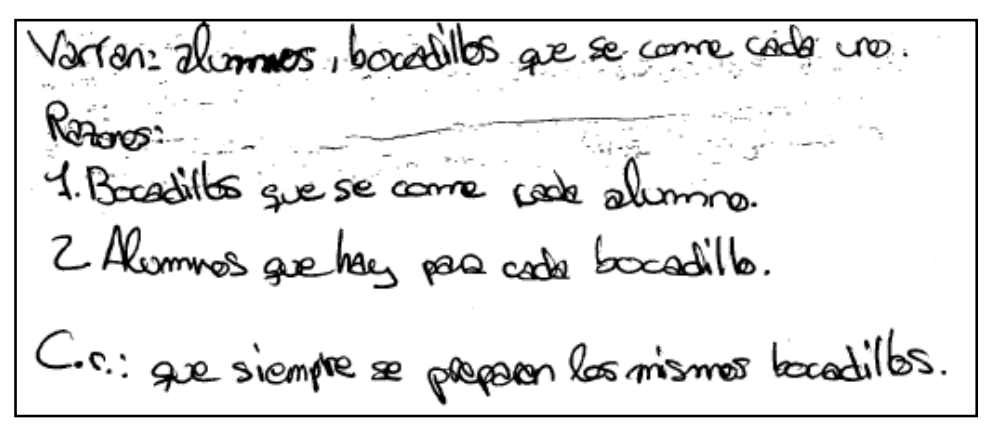

Figura VI.253.

Salvo la ausencia de mención explícita a la tercera magnitud constante (el número total de bocadillos, que está apuntada, no obstante, en la condición de regularidad) y quizás su cálculo explícito, es una respuesta bastante completa.

Sigue habiendo alumnos, como por ejemplo A35 cuya respuesta mostramos en la Figura VI.254, que prescinden de consideraciones numéricas:

$$
\text { CUANTOS + ALUMNOS, MENES BOCOPILLOS/DÍA }
$$

Figura VI.254.

Mientras que otros, como A54 (Figura VI.255), no tienen muy claro lo que se les pide y no acaban de asimilar que la respuesta a un ejercicio en clase de matemáticas no tiene por qué ser necesariamente un número:

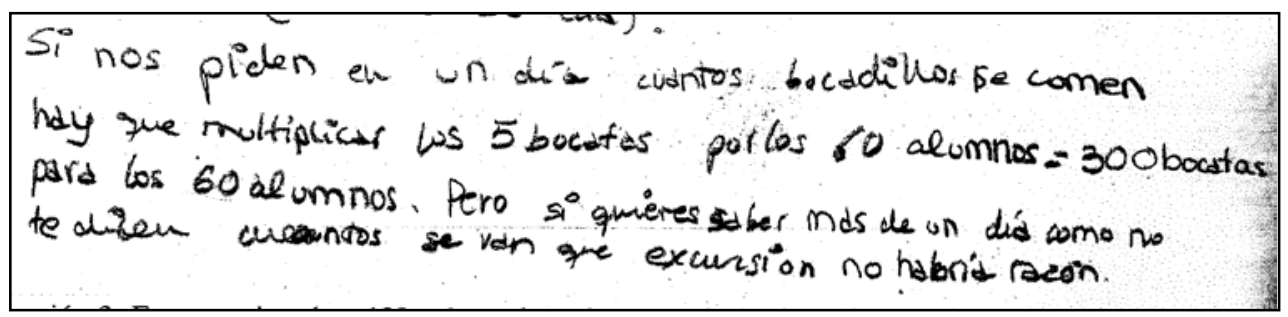

Figura VI.255.

Situación 4:

En esta situación se da la particularidad de que la magnitud “oculta” es justamente el flujo del grifo; es decir, justamente la razón entre las dos magnitudes presentadas explícitamente. Este hecho justifica el elevado número de alumnos que calculan la razón en esta situación. En cambio, ningún alumno identifica esta razón con una magnitud digna de ser mencionada. 
La variabilidad en las respuestas vuelve a ser muy grande. Junto a alumnos como A51 que dicen: “no se puede definir la magnitud, porque cada vez que abres el grifo no se pierde la misma agua, si lo abres más fuerte sale más rápido y con más presión, y si lo abres despacio saldrá menos y con menos presión”, nos encontramos respuestas como la de A19 (ver Figura VI.256), a la que sólo le falta la mención expresa de qué magnitudes varían y cuáles son constantes.

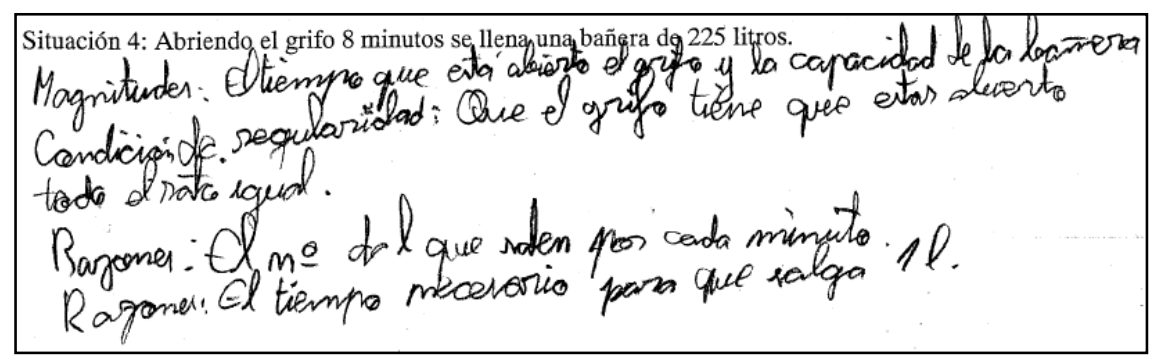

Figura VI.256.

A este respecto, de la variabilidad o no de las magnitudes, encontramos también gran diversidad. Así el alumno anterior no entra en el asunto, A38 afirma que "no hay magnitud variable” (por razones que ya se apuntaron en el análisis de la Situación 1) y, para A55, la magnitud variable son los minutos y los litros son constantes (quizás por pensar en la bañera como en algo fijo). En todo caso, estas respuestas parecen demostrar nuevamente una incomprensión de las situaciones presentadas puesto que si no hay variables, la situación es estática y las preguntas carecen de sentido, y si sólo una es variable, ¿en función de qué varía?

En consecuencia, son muchos los alumnos que pasan de puntillas por esta cuestión y que, en mayor o menor medida, se limitan a hablar de aquello en lo que están más cómodos: los números. Como ejemplo de esto, la respuesta de A16 que vemos en la Figura VI.257:

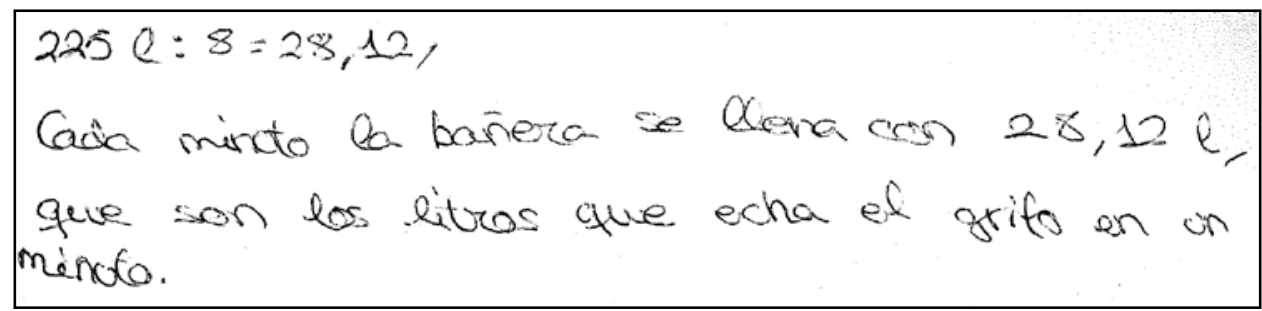

Figura VI.257. 


\section{Situación 6:}

En esta situación ningún alumno señaló explícitamente la magnitud “oculta” que, como en la situación anterior, coincidía con la razón entre las dos magnitudes que se presentaban. Eso sí, por experiencias anteriores, el número de alumnos que; como A11 (ver Figura VI.258), señalan correctamente una razón y enuncian con claridad la condición de regularidad necesaria fue mayor de lo esperado.

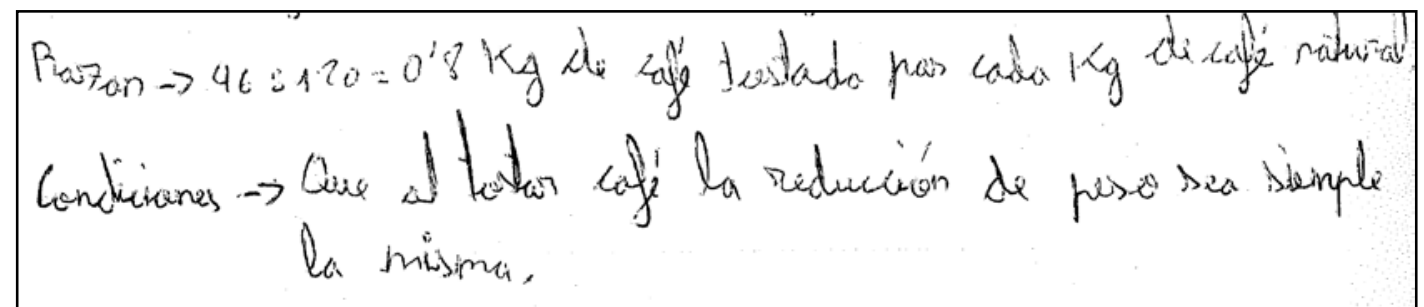

Figura VI.258.

Muy pocos alumnos, sin embargo, presentan en este ejercicio las dos razones posibles. Quizás el alumno A37 nos dé una pista cuando dice que “al revés no puede ser porque no se puede pasar de tostado a natural de nuevo". También hay otros que, como A45, por ejemplo, consideran que "no hay razón porque no tienen que ver las magnitudes entre ellas”. De nuevo, como en las situaciones anteriores los alumnos no logran demostrar un cierto manejo de las magnitudes; ni siquiera parecen tener clara la distinción entre magnitud y cantidad de magnitud. Así, A53, que además utiliza de forma sorprendente porcentajes, indica que "las magnitudes son los $120 \mathrm{Kg}$ y los 96 Kg.” (ver Figura VI.259):

$$
\begin{aligned}
& \text { Las magnitude son los } 120 \mathrm{~kg} \text { y cos } 96 \mathrm{~kg} . \\
& \frac{96}{120}: 100=9600: 120=80 \% \text { de poso queda } \\
& 120-96=24 \quad \frac{24}{120} \cdot 100=2400: 120=20 \% \text { lo que ha pond ido }
\end{aligned}
$$

Figura VI.259.

Y por último, hay alumnos como A29, que (Figura VI.260) consideran constantes ambos pesos y que se encuentran con que sólo se les ocurre calcular el peso perdido en el tueste: 


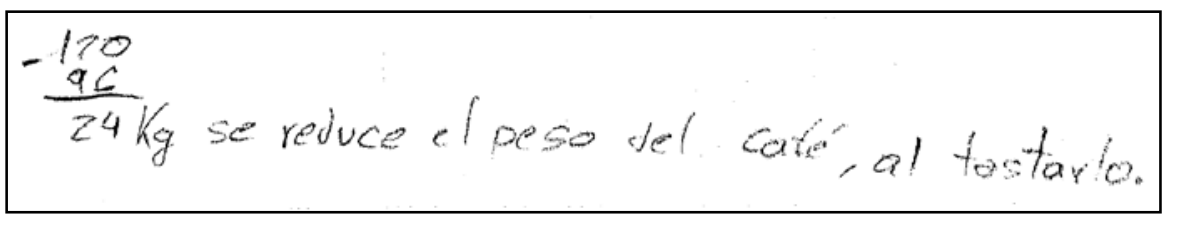

Figura VI.260.

\section{Situación 3:}

En esta situación únicamente aparece una magnitud (el número de pelotas de tenis que caben en una caja, aunque algunos alumnos han introducido la magnitud número de cajas), mientras que los colores son lo que llamaríamos “cualidades sensoriales”. Este hecho ha causado cierta confusión a los alumnos que no han sabido muy bien cómo gestionar una situación en la que sólo aparecía una cantidad. Esta dificultad se debe, seguramente, al hecho ya comentado de la necesidad de efectuar operaciones y de producir un resultado numérico concreto a la hora de enfrentarse a un problema matemático.

Las unidades de análisis para estas situaciones aparecen recogidas en la tabla siguiente:

\begin{tabular}{|c|c|}
\hline 0 & No entrega o no asiste a clase \\
\hline 1 & Respuesta en blanco \\
\hline 2 & Indica que sólo hay una magnitud \\
\hline 3 & Intenta hacer entrar en juego los colores \\
\hline 4 & Otro tipo de respuesta aceptable \\
\hline
\end{tabular}

De acuerdo con estas unidades de análisis, los resultados obtenidos por los alumnos son los siguientes:

\begin{tabular}{|c|c|c|c|c|c|c|}
\hline \multicolumn{2}{|c|}{} & $\mathbf{0}$ & $\mathbf{1}$ & $\mathbf{2}$ & $\mathbf{3}$ & $\mathbf{4}$ \\
\hline Situación 3 & $\mathbf{N}^{\mathbf{0}}$ de resp. & 15 & 4 & 6 & 11 & 7 \\
\cline { 2 - 7 } & Porcentaje & $266^{\prime} 8 \%$ & $7^{\prime} 1 \%$ & $10{ }^{\prime} 7 \%$ & $199^{\prime} 6 \%$ & $12^{\prime} 5 \%$ \\
\hline
\end{tabular}

Muy pocos alumnos señalan explícitamente el hecho de que sólo hay una magnitud. Lo hace por ejemplo A45 (ver Figura VI.261) que, por influencia de los casos en los que sí señala una razón, insiste en dar una condición de regularidad: 


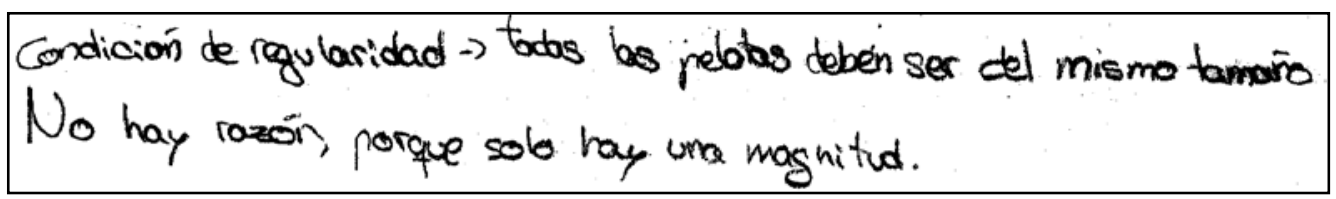

Figura VI.261.

Mucho más común es el caso de alumnos que indican algo similar a lo que dice A24: "No hay relación entre el número de pelotas de tenis y su color". Sin embargo, esta afirmación parece aceptar implícitamente que el color es una magnitud. Esta consideración se hace explícita en la respuesta de A13, "La magnitud que varía es el color de las pelotas”, que demuestra bien a las claras la falta de una idea precisa del concepto de magnitud.

Un paso más allá va el alumno A48, que, aún sin saberlo, considera las magnitudes número de pelotas verdes y número de pelotas amarillas al dar la respuesta de la Figura VI.262:

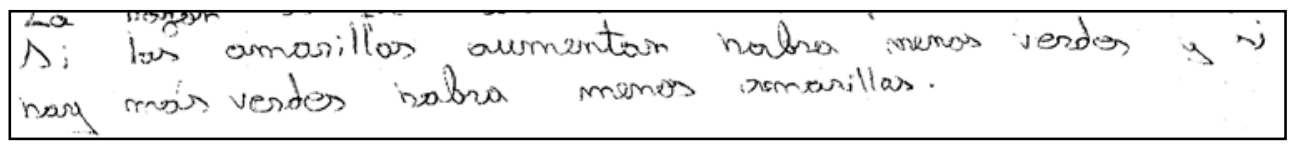

Figura VI.262.

Aunque, claro está, la relación en este caso es aditiva y lo que se mantendría constante es la suma de ambas magnitudes por lo que no se trata de una situación como las que se venían trabajando con anterioridad. El salto a una situación multiplicativa lo da A5 al hacer una suposición gratuita en su respuesta y decir que "1/2 de pelotas de la caja son amarillas y otro 1/2 son verdes" (Figura VI.263):

$$
\begin{aligned}
& \frac{1}{2} \text { de plotas de la caja son amarillas y otro } \frac{1}{2} \\
& \text { verdes }
\end{aligned}
$$

Figura VI.263.

La única posibilidad de introducir correctamente la idea de razón en esta situación es considerar que existe otra magnitud “oculta” en el enunciado, que es el número de cajas. Así, se puede dar una respuesta como la de A38 en la Figura VI.264 siguiente: 


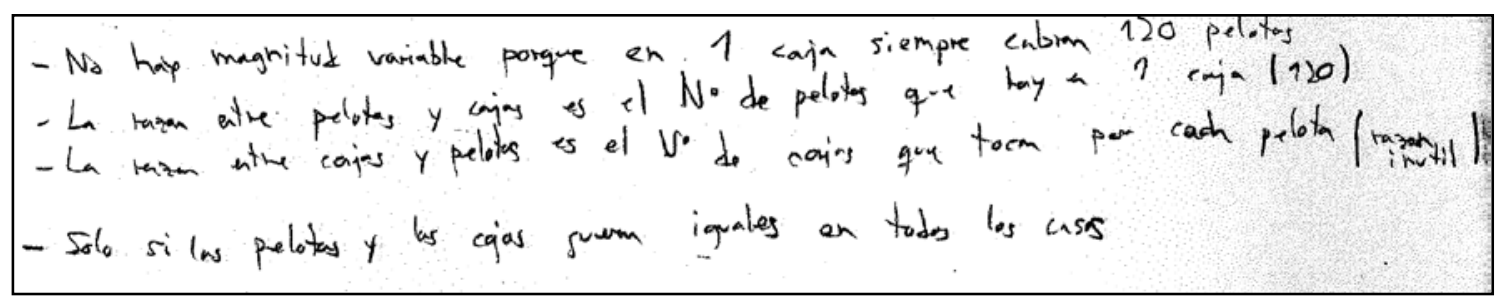

Figura VI.264.

que, pese a cierta imprecisión, sólo muestra algún problema con la idea de magnitud variable y constante. La misma idea, aunque menos desarrollada, se intuye tras la respuesta de A35: “es constante el $n^{o}$ pelotas/caja”. Finalmente, la confusión indicada al inicio del análisis de esta situación queda bien clara a la vista de la respuesta dada por A48: "No se puede hacer porque nos falta un dato".

\section{Situación 5:}

En esta última situación también aparece un número que no es una cantidad de magnitud; a saber, el curso del que se habla. Pero sí que aparecen dos magnitudes que pueden relacionarse. Es decir, la situación es similar a la Situación 4 por ejemplo aunque un dato puede actuar de distracción.

Las unidades de análisis para estas situaciones aparecen recogidas en la tabla siguiente:

\begin{tabular}{|c|c|}
\hline 0 & No entrega o no asiste a clase \\
\hline 1 & Respuesta en blanco \\
\hline 2 & Señala el curso como magnitud \\
\hline 3 & Indica correctamente la razón entre las dos magnitudes \\
\hline
\end{tabular}

De acuerdo con estas unidades de análisis, los resultados obtenidos por los alumnos son los siguientes:

\begin{tabular}{|c|c|c|c|c|c|}
\hline \multicolumn{2}{|c|}{} & $\mathbf{0}$ & $\mathbf{1}$ & $\mathbf{2}$ & $\mathbf{3}$ \\
\hline Situación 5 & $\mathbf{N}^{\mathbf{0}}$ de resp. & 15 & 4 & 7 & 15 \\
\cline { 2 - 6 } & Porcentaje & $266^{\prime} 8 \%$ & 7'1\% & $12{ }^{\prime} 5 \%$ & 26 '8\% \\
\hline
\end{tabular}

Como se observa, no son muchos los alumnos que consideran el curso como una magnitud. Los que lo hacen actúan de dos formas distintas. Algunos, como A39, lo señalan como magnitud, pero después completan el ejercicio sin que el curso juegue papel alguno (ver Figura VI.265): 


\begin{tabular}{|c|c|c|}
\hline $\begin{array}{l}\text { Magnitudes que varían: horas de estudio } \\
\text { Magnitudes constantes: } 7 \text { asignaturas } 44^{\circ} \text { curso. }\end{array}$ & \multicolumn{2}{|c|}{$\begin{array}{l}\text { Cde R: Que tenga un examen por asignajura, } \\
\text { que no varien las asignaturas, que necesite } \\
\text { estudiar lo mismo de cada asignatura, que tenga } \\
\text { tos mismos dias para estudiar cada examen }\end{array}$} \\
\hline $\begin{array}{l}\frac{5}{7} \text { Horas que estudia lasignatura Razón e } \\
\text { (aldía) } \\
0,7142 \ldots \rightarrow 0,71\end{array}$ & horas y asignaturas. & \multirow[t]{2}{*}{$\begin{array}{l}\text { (todos los exámenes } \\
\text { el mismo dra). }\end{array}$} \\
\hline$\frac{7}{5}$ Asignatur zs que estud & turas $y$ & \\
\hline
\end{tabular}

Figura VI.265.

Este alumno comete el mismo error que en las demás situaciones a la hora de indicar si las magnitudes varían o son constantes. Sólo habla de una variable, lo que carece de sentido. Hay alumnos, como A29, que indican el curso como magnitud y que después no son capaces de dejar de lado esa supuesta magnitud y concluyen que "no se puede definir ninguna razón” (Figura VI.266):

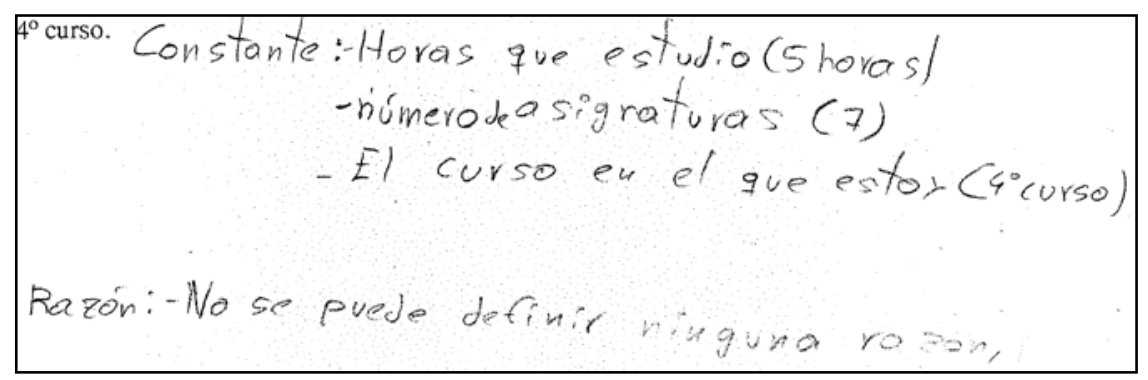

Figura VI.266.

Esta imposibilidad puede estar también relacionada con el hecho de que para este alumno todas las magnitudes son constantes.

En cualquier caso, la mayoría de los alumnos vuelve a dejar de lado la mención de las magnitudes. Incluso aquellos que parecen hacer un análisis más fino de la situación, como A24 en la Figura VI.267:

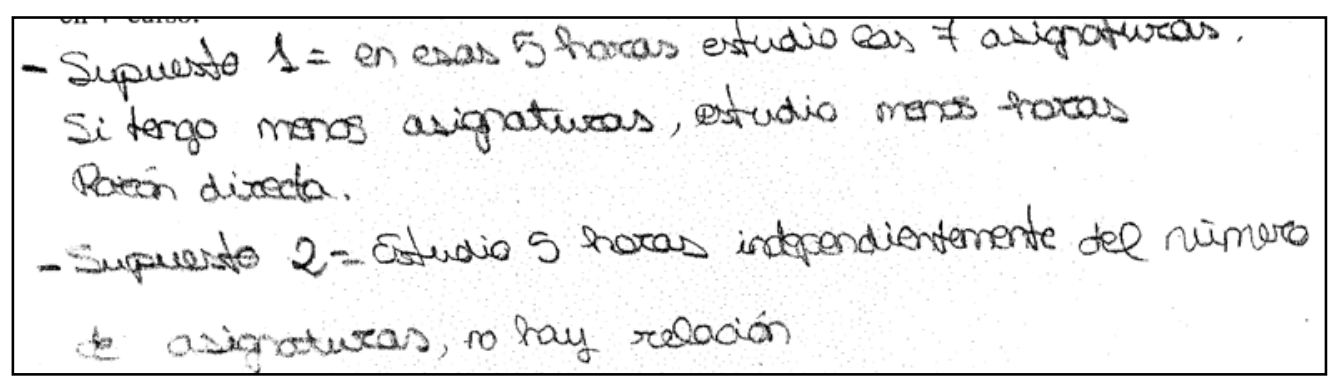

Figura VI.267. 
Este alumno, además, incluye el término "razón directa” que parece denotar cierta influencia externa. Por lo demás, la distinción de casos es interesante e incluso pertinente.

La influencia externa mostrada en el ejemplo anterior, que aparece en otros muchos alumnos que hablan incluso de "proporcionalidad directa" e “inversa" queda también patente en el error cometido por A35 (ver Figura VI.268) que nos lleva al tan conocido “a más, más”:

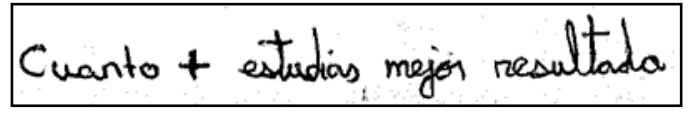

Figura VI.268.

Por último, en este apartado ha aparecido un curioso error cometido por el alumno A3 (en la Figura VI.269 siguiente):

$$
\text { Caca doso dias } 10 \text { hras y } 7 \text { asignativan repetidas por dos }=14
$$

Figura VI.269.

Al introducir la magnitud días, como una de las magnitudes son horas diarias, se ha cometido el error de considerar que la otra son asignaturas diarias; lo que no tiene sentido alguno.

\section{VI.4.1.2 Reflexiones relativas al punto 1}

1. Los alumnos, en general, no parecen tener demasiados problemas a la hora de diferenciar magnitudes de aquello que no lo son; aunque cuando aquello que no es una magnitud va acompañado de un valor numérico (curso frente a color, por ejemplo) la confusión aumenta.

2. Se puede afirmar que los alumnos tienen serios problemas a la hora de comprender lo que significa que una magnitud sea variable o constante. Sobre todo, se muestran incapaces de analizar una situación en la que suponiendo constante una magnitud las otras varían una en relación a la otra.

3. Ante una situación en la que aparecen 3 magnitudes de modo que siendo una constante las otras varían a la vez, los alumnos no son capaces de ver la 
situación bajo distintos puntos de vista; es decir, no analizan la misma situación suponiendo que es constante otra de las magnitudes y no la inicial.

4. Como ya se ha indicado en tareas anteriores, aparecen dificultades al manejar magnitudes que son la razón de otras dos. Así, cuando se les proporciona explícitamente una magnitud que es razón de otras dos, el número de alumnos que señala esa razón cuando se le pide baja muchísimo en relación a cuando la razón es desconocida.

5. La gran mayoría de los alumnos no parece concebir un problema de matemáticas en el que la "respuesta” no es numérica sino que es la descripción de una situación.

\section{VI.4.2 Punto 3: Búsqueda de cantidades desconocidas}

Como en el caso de la proporcionalidad directa es de gran importancia a la hora de manejar el concepto de magnitudes inversamente proporcionales el aplicar las ideas presentadas hasta el momento en los típicos problemas en los que se conocen dos cantidades correspondientes de las magnitudes implicadas y se desea encontrar la cantidad desconocido de una de ellas correspondiente a una cantidad conocida de la otra. Estos aspectos se trabajan en la Actividad de aula 8 y en la Tarea de casa 7.

\section{VI.4.2.1 Análisis y valoración de la Actividad de aula 8}

\section{Enunciado}

Recordad que dos magnitudes son inversamente proporcionales si no se puede definir una razón entre ellas, pero existe una magnitud constante de forma que sí que se puede definir la razón entre dicha constante y las magnitudes involucradas. Con esta idea, tratad de resolver los siguientes problemas.

\section{Ejercicio 1:}

Tres pintores tardan 7 días en pintar una fachada. Si hubiesen trabajado 5 pintores, ¿cuántos días habrían tardado en pintar esa fachada?

\section{Ejercicio 2:}

Una mecanógrafa, que hace 380 pulsaciones por minuto tarda 4 horas en escribir un 
informe. Si hiciese 450 pulsaciones por minuto, ¿cuánto tiempo tardará en escribir el informe?

Ejercicio 3:

De los 350 participantes en una maratón han terminado 260 atletas, ¿cuántos hubiesen finalizado la maratón si se presentan 200 atletas?

\section{Ejercicio 4:}

Un ganadero tiene pienso para alimentar a 300 terneros durante tres meses. Si tuviese 200 terneros, ¿durante cuántos días los podría alimentar?

\section{Ejercicio 5:}

Para trasladar la tierra producida al hacer un desmonte se necesitaron 100 camiones cada uno de los cuales transportó 12 metros cúbicos de tierra. ¿Cuántos viajes de camión se hubiese necesitado si la capacidad de los camiones fuese de 15 metros cúbicos?

\section{Análisis de la actividad}

Como acabamos de señalar, la valoración de las producciones de los alumnos se organizará en tres grupos de ejercicios según la naturaleza de las situaciones planteadas en cada uno de ellos.

\section{Ejercicios 1 y 4:}

En estos ejercicios las magnitudes involucradas pueden suponerse inversamente proporcionales, aunque la tercera magnitud existente que las relaciona no puede calcularse de modo explícito. En general este hecho (lo veremos sobre todo en la siguiente tarea) dificulta la labor de los alumnos.

Las unidades de análisis para este grupo de situaciones son las siguientes:

\begin{tabular}{|c|c|}
\hline 0 & No entrega o no asiste a clase \\
\hline 1 & Respuesta en blanco \\
\hline 2 & Respuesta incorrecta sin razonar \\
\hline 3 & Calcula una razón carente de sentido \\
\hline 4 & Respuesta correcta sin razonar o con mal razonamiento \\
\hline
\end{tabular}




\begin{tabular}{|l|l|}
\hline 5 & Respuesta correcta con razonamiento correcto \\
\hline
\end{tabular}

De acuerdo con estas unidades de análisis los resultados obtenidos por los alumnos en estos ejercicios se presentan en la siguiente tabla:

\begin{tabular}{|c|c|c|c|c|c|c|c|}
\hline \multicolumn{2}{|c|}{} & $\mathbf{0}$ & $\mathbf{1}$ & $\mathbf{2}$ & $\mathbf{3}$ & $\mathbf{4}$ & $\mathbf{5}$ \\
\hline \multirow{2}{*}{ Ejercicio 1 } & $\mathbf{N}^{\mathbf{0}}$ de resp. & 0 & 3 & 6 & 5 & 8 & 5 \\
\cline { 2 - 8 } & Porcentaje & $0 \%$ & $11^{\prime} 1 \%$ & $22^{\prime} 2 \%$ & $18^{\prime} 5 \%$ & $29{ }^{\prime} 7 \%$ & $18^{\prime} 5 \%$ \\
\hline \multirow{2}{*}{ Ejercicio 4 } & $\mathbf{N}^{\mathbf{0}}$ de resp. & 0 & 14 & 10 & 2 & 1 & 0 \\
\cline { 2 - 8 } & Porcentaje & $0 \%$ & $51^{\prime}, 8 \%$ & $37^{\prime} 1 \%$ & $7^{\prime}{ }^{\prime} 4 \%$ & $3{ }^{\prime} 7 \%$ & $0 \%$ \\
\hline
\end{tabular}

El reparto de las respuestas varía mucho entre ambos ejercicios debido fundamentalmente a la falta de tiempo, como ya dijimos antes. Tan sólo la mitad de las parejas escribe algo en el Ejercicio 4 y sólo una lo resuelve correctamente, aunque sin razonar. En el Ejercicio 1 el porcentaje de respuestas correctas (dejando de lado el razonamiento de los alumnos) es de casi el 50\% e incluso algunas parejas razonan apropiadamente, como veremos, sus respuestas.

\section{Ejercicio 1:}

Al ser este el primer ejercicio es el que menos respuestas en blanco posee. Sin embargo, el resto de respuestas están muy repartidas entre los 4 apartados restantes. Aunque con muy poca diferencia, el tipo de respuesta predominante es la de aquellos alumnos que responden correctamente sin aportar argumento alguno, como hacen por ejemplo A5 y A27 (ver Figura VI.270) que se limitan a indicar las operaciones necesarias:

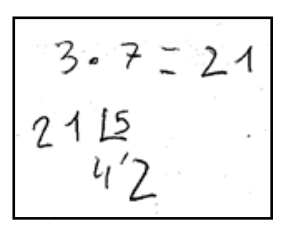

Figura VI.270.

Esta respuesta contrasta con la dada por los alumnos A12 y A17 que, de hecho, ni siquiera efectúan las operaciones necesarias (aunque el razonamiento es bueno, ver Figura VI.271): 


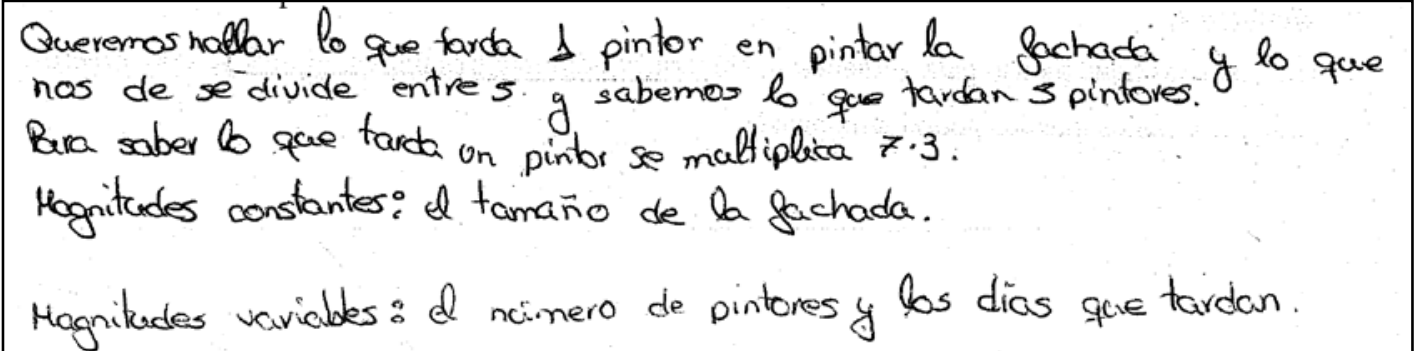

Figura VI.271.

Estos alumnos, además, señalan adecuadamente la magnitud constante que sirve para relacionar las dos magnitudes inversamente proporcionales.

Un número relativamente importante de alumnos comete el error de calcular la razón entre obreros y días. Pensando, equivocadamente, que no todos los obreros trabajan todos los días. Este tipo de error ya se constató en actividades anteriores y será uno de los principales obstáculos a la hora de resolver este tipo de situaciones. Como ejemplo mostramos la respuesta de la pareja formada por A32 y A38 quienes, además, resuelven el problema como si se tratara de una situación de proporcionalidad directa (ver Figura VI.272):

Si dividives 3 pint. entre 7 dias 10,4 en un dia un pintor
$0,4 \cdot 5$ te salen 2 días qe rabejau 5 pintores.

Figura VI.272.

Relacionado con la idea de razón, hay algunos alumnos que han asimilado únicamente la idea de “tanto por uno” y responden que la razón entre días y pintores es “21 días que tarda un pintor en pintar la fachada”; tal es el caso por ejemplo de A15 y A28.

Entre aquellos alumnos que responden incorrectamente podemos distinguir entre los que, como la pareja formada por A33 y A49 operan aleatoriamente en busca de la respuesta (ver Figura VI.273):

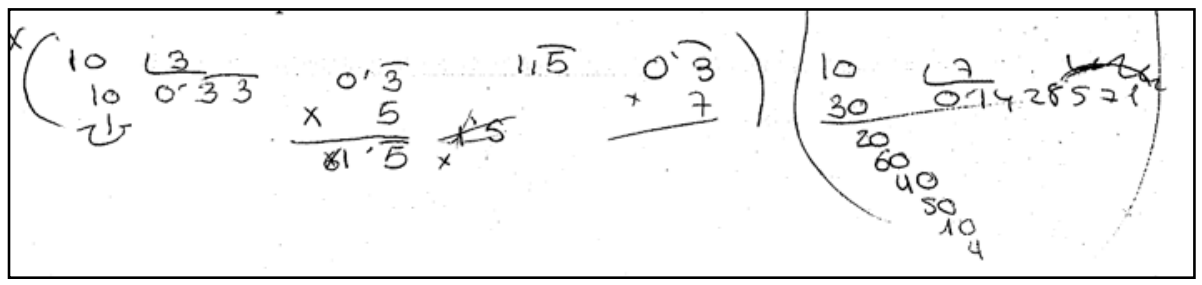

Figura VI.273. 
y aquellos que, como hacen A42 y A50, se conforman con decir que "no se puede hacer porque depende del tiempo que trabajan".

Aunque hemos dicho que la magnitud constante que liga el número de pintores y los días de trabajo es la superficie de la fachada, que no puede calcularse explícitamente, no es menos cierto que podría pensarse que dicha magnitud constante es más bien la cantidad de fachas de que se pintan; en cuyo caso si puede calcularse (es trivialmente 1) y este dato puede emplearse para resolver el ejercicio como han hecho la pareja formada por A39 y A53 (ver Figura VI.274 siguiente) y la pareja formada por A45 y A54 (ésta última con problemas al manejar los decimales periódicos):

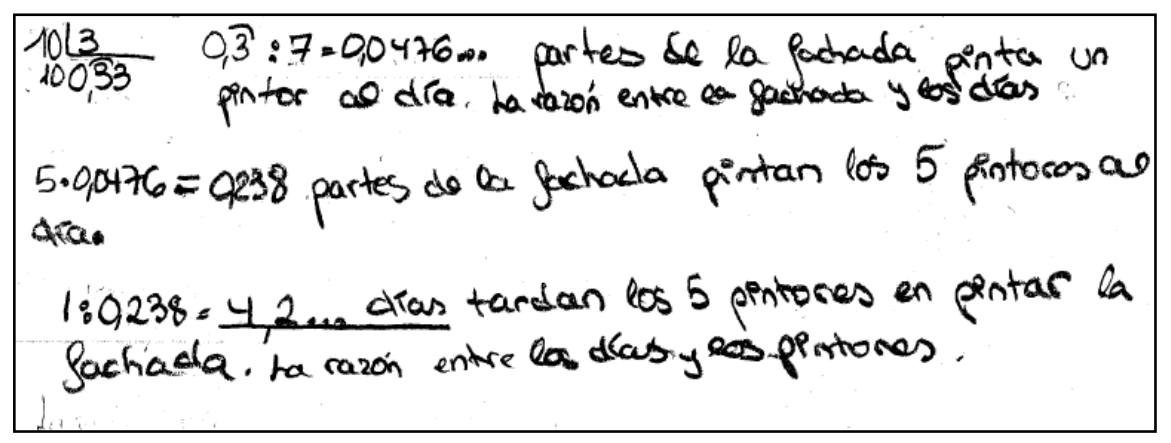

Figura VI.274.

\section{Ejercicio 4:}

En este ejercicio el número de respuestas en blanco hace que no puedan sacarse conclusiones realistas. No obstante presentaremos algunas respuestas interesantes dadas por los alumnos.

En este caso, como en el anterior, la magnitud que relacionaba las dos magnitudes inversamente proporcionales (la cantidad de comida) no podía calcularse. Aunque no era necesario hacerlo para resolver el problema, este hecho ha provocado desconcierto en algunos alumnos, como en la pareja formada por A46 y A48 que ha señalado que "nos falta el dato de cuánta cantidad de alimento tiene”. También hay alumnos “escépticos”, como la pareja formada por A31 y A36, quienes afirman que: "no tiene nada que ver porque los terneros no comen siempre lo mismo".

En todo caso, siempre es mejor una respuesta como las anteriores frente a la dada por la pareja formada por A22 y A25 (ver Figura VI.275): 


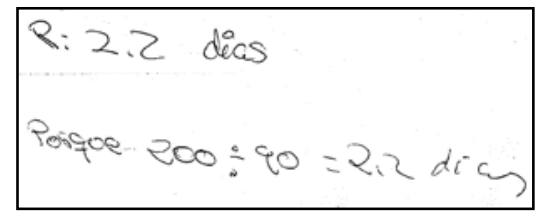

Figura VI.275.

Estos alumnos han dividido los 200 terneros entre los 90 días que tienen 3 meses. El significado de dicha operación y por qué el resultado son días quedan en el misterio. Hay más ejemplos de operaciones extrañas. Así la pareja formada por A16 y A24 concluyen que si se dividen 300 terneros entre 3 meses se obtiene la sorprendente conclusión de que los terneros comen $100 \mathrm{Kg}$ al mes (ver Figura VI.276):

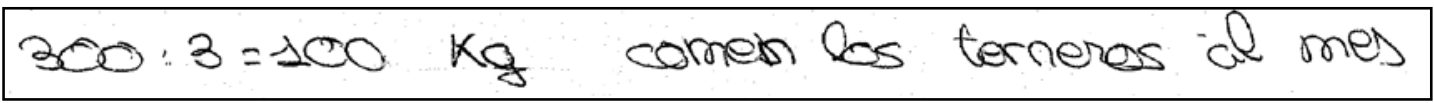

Figura VI.276.

Por su parte, la pareja formada por A5 y A27comete el error ya típico (véase Figura VI.277) de pensar que alimentar 300 terneros durante 3 meses es equivalente a alimentar 100 terneros al mes:

$$
300: 3=100 \text { terneros } x 1 \text { mes }
$$

Figura VI.277.

Tan solo el alumno A11 dio una respuesta correcta desde un punto de vista numérico y, aunque su resolución muestra bien a las claras su razonamiento (ver Figura VI.278), no queda claro si lo entiende o si se trata más bien de un procedimiento aprendido (sobre todo porque este alumno repite una vez tras otra este esquema de

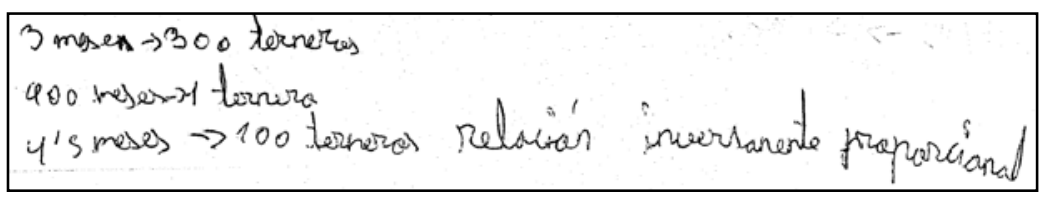

Figura VI.278.

resolución):

\section{Ejercicios 2 y 5 :}

En estos ejercicios las magnitudes involucradas pueden suponerse inversamente proporcionales. Además la tercera magnitud que sirve para relacionar dichas magnitudes puede calcularse explícitamente, cosa que algunos alumnos harán.

Las unidades de análisis para este grupo de situaciones son las siguientes: 


\begin{tabular}{|c|c|}
\hline 0 & No entrega o no asiste a clase \\
\hline 1 & Respuesta en blanco \\
\hline 2 & Calcula una razón carente de sentido \\
\hline 3 & Respuesta correcta sin razonar o con mal razonamiento \\
\hline 4 & Respuesta correcta con razonamiento correcto \\
\hline 5 & \\
\hline
\end{tabular}

De acuerdo con estas unidades de análisis los resultados obtenidos por los alumnos en estos ejercicios se presentan en la siguiente tabla:

\begin{tabular}{|c|c|c|c|c|c|c|c|}
\hline \multicolumn{2}{|c|}{} & $\mathbf{0}$ & $\mathbf{1}$ & $\mathbf{2}$ & $\mathbf{3}$ & $\mathbf{4}$ & $\mathbf{5}$ \\
\hline \multirow{2}{*}{ Ejercicio 2 } & $\mathbf{N}^{\mathbf{0}}$ de resp. & 0 & 10 & 3 & 5 & 1 & 7 \\
\cline { 2 - 8 } & Porcentaje & $0 \%$ & $37^{\prime} 1 \%$ & $11^{\prime} 1 \%$ & $18{ }^{\prime} 5 \%$ & $3{ }^{\prime} 7 \%$ & $25^{\prime} 6 \%$ \\
\hline \multirow{2}{*}{ Ejercicio 5 } & $\mathbf{N}^{\mathbf{0}}$ de resp. & 0 & 21 & 4 & 0 & 0 & 2 \\
\cline { 2 - 8 } & Porcentaje & $0 \%$ & $77^{\prime} 8 \%$ & $14^{\prime} 8 \%$ & $0 \%$ & $0 \%$ & $7^{\prime} 4 \%$ \\
\hline
\end{tabular}

En el Ejercicio 5, el último de la actividad, prácticamente no se han producido respuestas, y sólo 2 han sido satisfactorias. En el Ejercicio 2 las respuestas obtenidas se reparten a partes iguales entre aciertos (dejando de lado el razonamiento) y errores.

\section{Ejercicio 2:}

La totalidad de grupos que han resuelto este ejercicio correctamente lo ha hecho siguiendo un razonamiento similar al de la pareja formada por A14 y A26, que mostramos en la Figura VI.279:

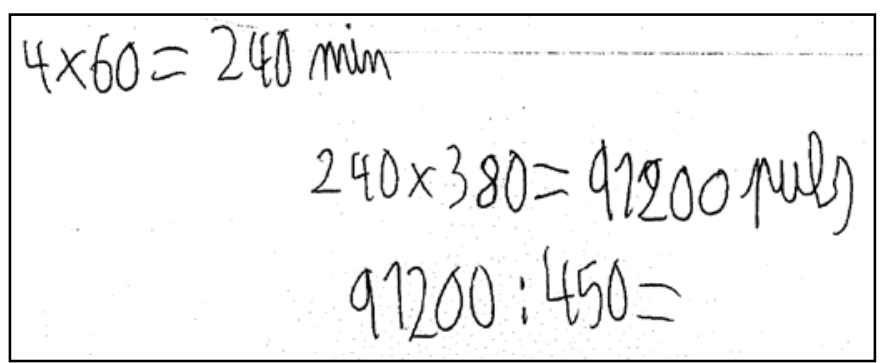

Figura VI.279.

Aunque les ha faltado hacer la última operación, está claro que han calculado el número total de pulsaciones necesario para mecanografiar el informe y después han dividido dicho número por las 450 pulsaciones por minuto. Este razonamiento es posible gracias a que, a diferencia de los ejercicios anteriores, es posible calcular 
explícitamente una cantidad de magnitud que relaciona las magnitudes variables involucradas en el problema. Porque, pese a que según la pareja A32 y A38 "no tiene nada que ver las pulsaciones con la velocidad que harás el informe”, la relación es clara.

Entre las respuestas incorrectas, de nuevo las operaciones sin sentido (ver en la Figura VI.280 la respuesta de A22 y A25):

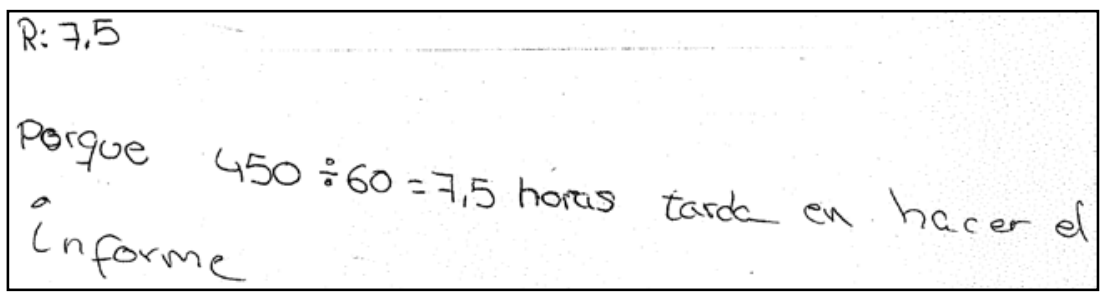

Figura VI.280.

Junto con alumnos que calculan la razón entre dos magnitudes que no admiten tal razón, como la pareja formada por A4 y A18 que calculan la razón entre horas y pulsaciones (ver Figura VI.281) sin observar que, en realidad, la magnitud que tienen entre manos es pulsaciones por minuto; que ya es una razón:

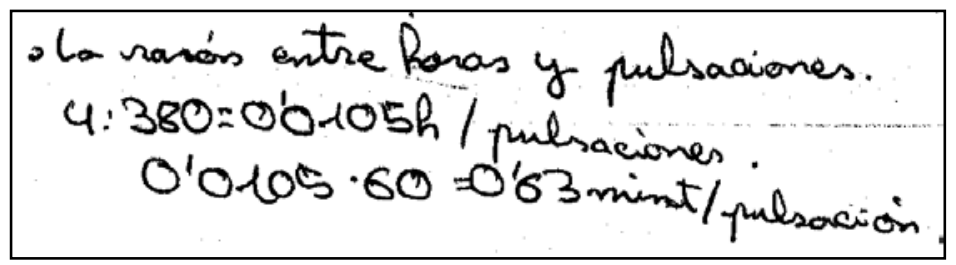

Figura VI.281.

\section{Ejercicio 5:}

En este ejercicio tan sólo se han obtenido 6 respuestas. De ellas, el grupo formado por A46 y A48 ha considerado que “falta el número de viajes que hacen”; Afirmación extraña por cuanto justamente esa es la incógnita del problema. Otros 4 grupos dan respuestas arbitrarias sin razonamiento alguno y tan sólo 2 responden correctamente.

De estos dos grupos, de nuevo el alumno A11 utiliza su técnica infalible (aprendida no se sabe dónde, aunque se sospecha) para resolver el problema (ver la Figura VI.282 siguiente): 


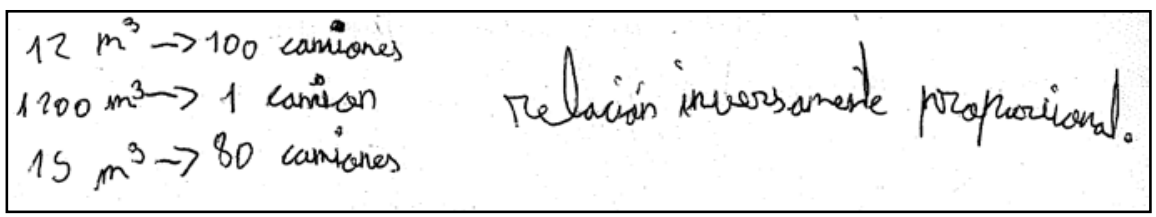

Figura VI.282

El otro grupo, formado por los alumnos A33 y A49 hace un razonamiento mucho más razonable desde el punto de vista de lo trabajado con anterioridad (ver Figura VI.283). Dejando de lado una extraña operación (multiplicar por 3, que parece tener que ver con el hecho de manejar metros cúbicos) estos alumnos han calculado el volumen total de tierra a desplazar (la magnitud “oculta” que relaciona las otras dos) y han utilizado ese dato para resolver el problema:

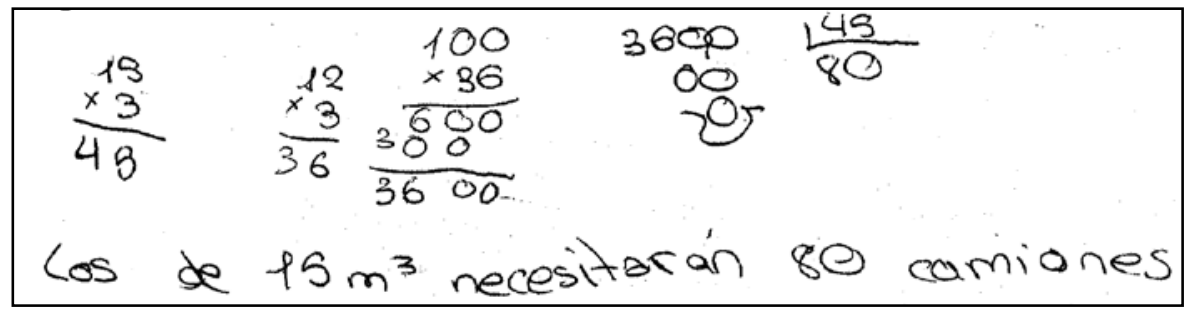

Figura VI.283.

\section{Ejercicio 3:}

En este ejercicio, las magnitudes involucradas no son inversamente proporcionales. De hecho, la relación entre el número de corredores que terminan una maratón y el de los que la comienzan no tiene por qué existir. En el mejor de los casos, y asumiendo la condición de regularidad de que se mantiene constante la razón entre corredores que terminan y los que empiezan, la relación sería de proporcionalidad directa.

Las unidades de análisis para este grupo de situaciones son las siguientes:

\begin{tabular}{|c|c|}
\hline 0 & No entrega o no asiste a clase \\
\hline 1 & Respuesta en blanco \\
\hline 2 & Respuesta arbitraria \\
\hline 3 & Razona aditivamente \\
\hline 4 & Razonamiento directamente proporcional \\
\hline 5 & Responde que no se puede saber \\
\hline
\end{tabular}


De acuerdo con estas unidades de análisis los resultados obtenidos por los alumnos en estos ejercicios se presentan en la siguiente tabla:

\begin{tabular}{|c|c|c|c|c|c|c|c|}
\hline \multicolumn{2}{|c|}{} & $\mathbf{0}$ & $\mathbf{1}$ & $\mathbf{2}$ & $\mathbf{3}$ & $\mathbf{4}$ & $\mathbf{5}$ \\
\hline Ejercicio 3 & $\mathbf{N}^{\mathbf{0}}$ de resp. & 0 & 11 & 1 & 4 & 0 & 11 \\
\cline { 2 - 8 } & Porcentaje & $0 \%$ & $40^{\prime} 7 \%$ & $3{ }^{\prime} 7 \%$ & $14^{\prime} 8 \%$ & $0 \%$ & $400^{\prime} 7 \%$ \\
\hline
\end{tabular}

Dejando a un lado las respuestas en blanco, la respuesta mayoritaria pasa por indicar que el ejercicio no puede resolverse. Las respuestas concretas van desde el simple “no se puede hacer", de la pareja A5 y A27, hasta el algo más largo "no tiene nada que ver el número de atletas con las bajas si hubiera menos participantes”, de A32 y A38. La pareja formada por A22 y A25 continua dando respuestas aleatorias y en este caso responde que 200 atletas, si más.

Nos ha resultado sorprendente que ninguna pareja razonara multiplicativamente como si las magnitudes fueran directamente proporcionales, puesto que parece que el ejercicio se presta a ello. Más sorprendente aún es la aparición de 4 respuestas que utilizan razonamientos aditivos, de las que la dada por la pareja formada por A19 y A23 (ver Figura VI.284) es la más detallada:

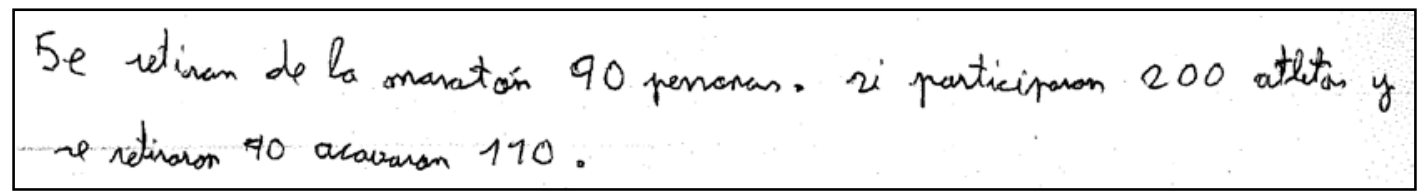

Figura VI.284.

\section{VI.4.2.2 Análisis y valoración de la Tarea de casa 7}

\section{Enunciado}

En clase hemos comprobado cómo el uso de la constante de proporcionalidad y de la razón nos permite resolver problemas en los que dos magnitudes son inversamente proporcionales y queremos encontrar la cantidad de una de las magnitudes que se corresponde con una cantidad conocida de la otra. Estos ejercicios van en la misma dirección.

\section{Ejercicio 1:}

Un grifo que vierte 18 litros por minuto emplea 28 horas en llenar un depósito, ¿qué 
tiempo emplearía si su caudal fuese de 42 litros por minuto?

\section{Ejercicio 2:}

Para atender un pedido de refrescos una fábrica tarda 8 horas utilizando 12 máquinas embotelladoras.

i. Si se estropean 4 máquinas, ¿¿cuánto tiempo tardará en hacerse el pedido?

ii. Si se quiere hacer el pedido en 3 horas, ¿cuántas máquinas harán falta?

\section{Ejercicio 3:}

En un campamento de 15 días de duración la edad media de los campistas es de 13 años, ¿cuál es la edad media de los campistas de otro campamento que va a durar 21 días?

\section{Ejercicio 4:}

Pedro paga 36 euros por las llamadas de teléfono realizadas durante un mes de 31 días, ¿Cuánto pagará por las llamadas realizadas durante un mes de 28 días?

\section{Ejercicio 5:}

Veinte obreros realizan una obra; al cabo de quince días han hecho la mitad. ¿Cuantos obreros hay que agregar para terminar la obra en cuatro días?

\section{Ejercicio 6:}

Para limpiar los cristales de un edificio 15 personas tardan 6 horas. ¿Cuántas personas hay que añadir para limpiar los cristales en 5 horas?

\section{Análisis de la tarea}

A la hora de analizar las respuestas de los alumnos estudiaremos separadamente los tres tipos de actividades presentados en el apartado anterior. De este modo, podremos adaptar las unidades de análisis a la especificidad de cada situación.

\section{Ejercicios 1, 2, 5 y 6:}

En estos ejercicios las magnitudes involucradas pueden suponerse inversamente proporcionales, aunque la tercera magnitud existente que las relaciona no siempre puede calcularse de modo explícito (esto sólo es así en el Ejercicio 1). 
Las unidades de análisis para este grupo de situaciones son las siguientes:

\begin{tabular}{|c|c|}
\hline 0 & No entrega o no asiste a clase \\
\hline 1 & Respuesta en blanco o incompleta \\
\hline 2 & Calcula una razón carente de sentido \\
\hline 3 & Respuesta incorrecta por motivo distinto a 2 \\
\hline 4 & Respuesta correcta sin razonar o con mal razonamiento \\
\hline 5 & Respuesta correcta con razonamiento correcto \\
\hline
\end{tabular}

Los resultados obtenidos por los alumnos en estos ejercicios, de acuerdo con estas unidades de análisis, se presentan en la siguiente tabla:

\begin{tabular}{|c|c|c|c|c|c|c|c|}
\hline & & 0 & 1 & 2 & 3 & 4 & 5 \\
\hline \multirow[t]{2}{*}{ Ejercicio 1} & $\mathrm{~N}^{\circ}$ de resp. & 11 & 6 & 10 & 5 & 8 & 16 \\
\hline & Porcentaje & $19 ’ 6 \%$ & $10 ’ 7 \%$ & 17’9\% & 8’9\% & $14 ’ 3 \%$ & $28{ }^{\prime} 6 \%$ \\
\hline \multirow[t]{2}{*}{ Ejercicio 2} & $\mathrm{~N}^{\mathrm{o}}$ de resp. & 11 & 6 & 8 & 9 & 11 & 11 \\
\hline & Porcentaje & $19 ’ 6 \%$ & $10 ’ 7 \%$ & $14 ’ 3 \%$ & $16 ’ 1 \%$ & $19 ’ 6 \%$ & $19^{\prime} 6 \%$ \\
\hline \multirow[t]{2}{*}{ Ejercicio 5} & $\mathrm{~N}^{\circ}$ de resp. & 11 & 7 & 8 & 10 & 10 & 10 \\
\hline & Porcentaje & $19 ’ 6 \%$ & $12 ’ 5 \%$ & $14 ’ 3 \%$ & $17 ’ 9 \%$ & 17’9\% & $17^{\prime} 9 \%$ \\
\hline \multirow[t]{2}{*}{ Ejercicio 6} & $\mathrm{~N}^{\mathrm{o}}$ de resp. & 11 & 3 & 9 & 9 & 13 & 11 \\
\hline & Porcentaje & $19 ’ 6 \%$ & $5 ’ 4 \%$ & 16 '1\% & 16’1\% & $23{ }^{\prime} 2 \%$ & 19’6\% \\
\hline
\end{tabular}

Lo primero que sorprende a la vista de estos datos es que todos los ejercicios tienen un reparto similar de las respuestas y que, entre las respuestas que no están en blanco el reparto es también bastante homogéneo. También parece que quedan claras las dificultades a la hora de comprender que hay situaciones en las que la razón carece de sentido. Sin embargo, es posible que el énfasis que se ha hecho a lo largo de la propuesta en presentar la idea de razón como "tanto por uno" haya dado lugar a estos errores. A continuación, vamos a repasar las respuestas de los alumnos en cada uno de los ejercicios.

\section{Ejercicio 1:}

Como decíamos, bastantes alumnos tratan aquí de calcular la razón entre litros y horas sin observar que la magnitud involucrada en la situación es "litros por minuto", es 
decir, ya es una razón. Carece de sentido dar una respuesta como la de A47 (ver Figura VI.285) puesto que durante las 28 horas el agua fluye al mismo ritmo:

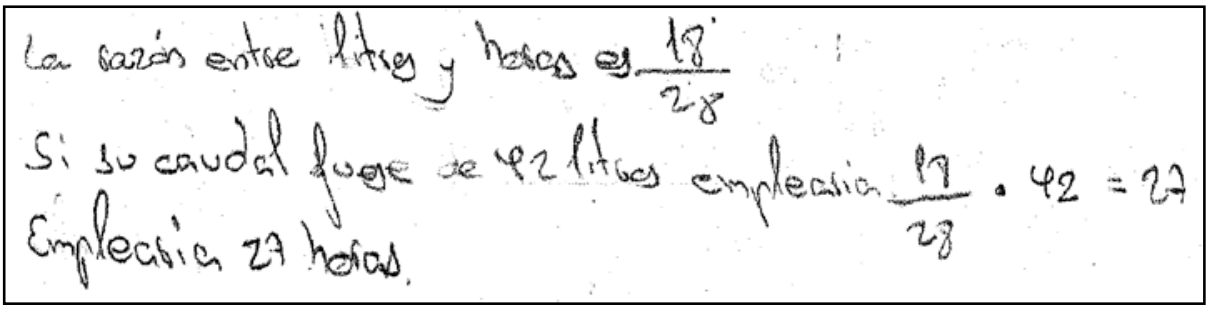

Figura VI.285.

Seguramente este error es debido a una falta de comprensión del significado de la magnitud "litros por minuto". Además, se observa como el alumno reproduce el esquema de resolución de un problema de proporcionalidad directa, por lo que se diría que este alumno ha tratado de aplicar un método más que comprender una situación.

En cualquier caso, el alumno anterior, al menos, trata de aplicar un método presentado en clase. No se puede decir lo mismo de los siguientes alumnos, que aplican sorprendentemente (o al menos lo intentan) el algoritmo de la regla de tres simple inversa (ni siquiera insinuado en clase). El alumno A31 lo hace exitosamente (ver Figura VI.286):

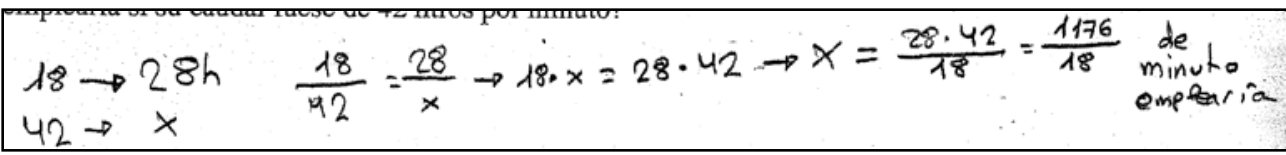

Figura VI.286.

Mientras que, por su parte, el alumno A36 no tiene tanta suerte y falla en la disposición de los datos (ver Figura VI.287):

$$
{ }_{42 \rho-28 \text { hoos }}^{18 \rho}=\frac{18}{42}=\frac{x}{28}=18 \cdot 28: 42=12 \text { hores empleare. }
$$

Figura VI.287.

Estos dos ejemplos muestran bien a las claras algunos de los aspectos que queremos evitar: el manejo puramente formal de las cantidades, la importancia de la disposición de los datos frente a su significado, el uso descontextualizado y absurdo del lenguaje algebraico... Incluso el alumno que aplica correctamente el algoritmo no demuestra que comprende la situación. 
La diferencia entre la respuesta de A31 y la del alumno A52 (en la Figura VI.288 siguiente) es notable (A52 muestra una muy profunda comprensión de la situación, mientras que A31 se limita a reproducir una técnica de cálculo):

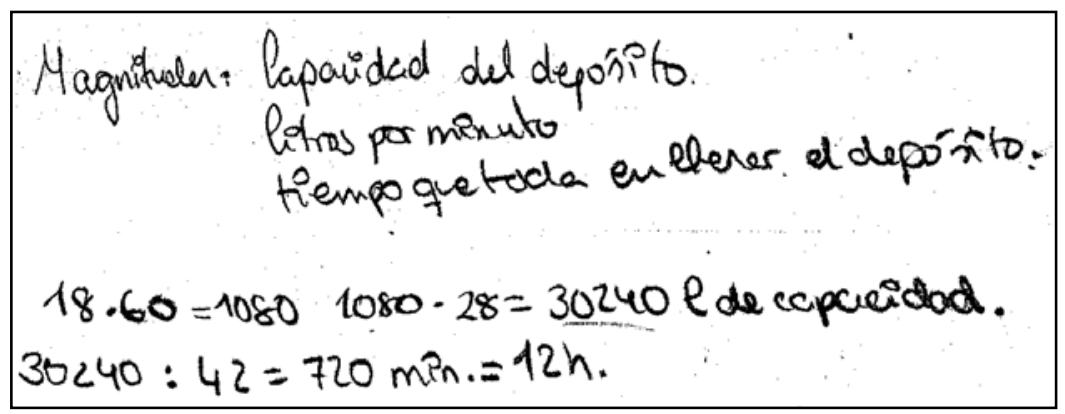

Figura VI.288.

Aparte del hecho de que este alumno señala las magnitudes involucradas, el cálculo correcto de la capacidad del depósito así como las operaciones realizadas, muestran una comprensión más clara y profunda de la situación. Pero calcular la capacidad del depósito no es la única estrategia posible; por ejemplo, el alumno A19 da la respuesta que mostramos en la Figura VI.289:

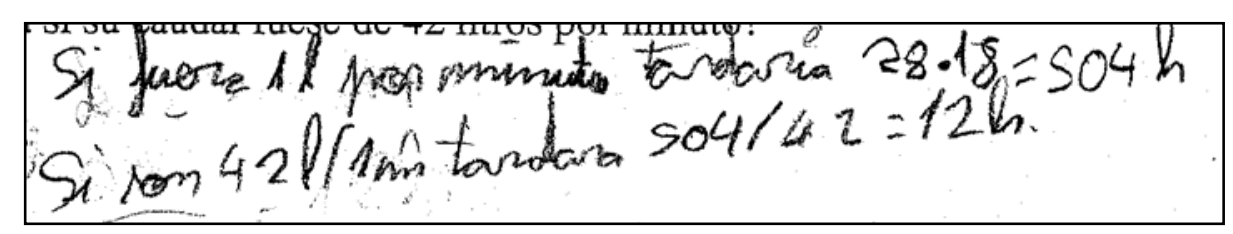

Figura VI.289.

Donde, si dejamos de lado la mezcla de minutos y horas (pese a que no es un error sin importancia), la idea está clara y es esencialmente distinta de lo anterior.

Como error curioso (y persistente, puesto que este alumno responderá así en los 6 ejercicios) mostramos la respuesta de A34; que aplica argumentos aditivos cuando ya se daban casi por erradicados (ver Figura VI.290):

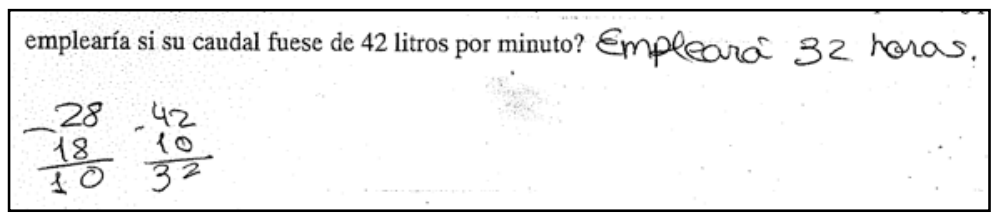

Figura VI.290.

Nótese que el orden no es consistente pues 28-18=42-32 pero el orden de las magnitudes cambia. 


\section{Ejercicio 2:}

Como quedó puesto de manifiesto en la tabla anterior, la tipología de las respuestas no va a variar mucho entre el anterior ejercicio y éste. Entre los alumnos que responden correctamente encontramos esencialmente tres tipos de respuestas. El primero consiste en calcular el número total de horas de trabajo necesarias (horas de máquina se debería decir, para ser exactos) para completar el pedido y, a partir de este dato, resolver el ejercicio. Este tipo de razonamiento lo utiliza por ejemplo el alumno A53 (ver Figura VI.291):

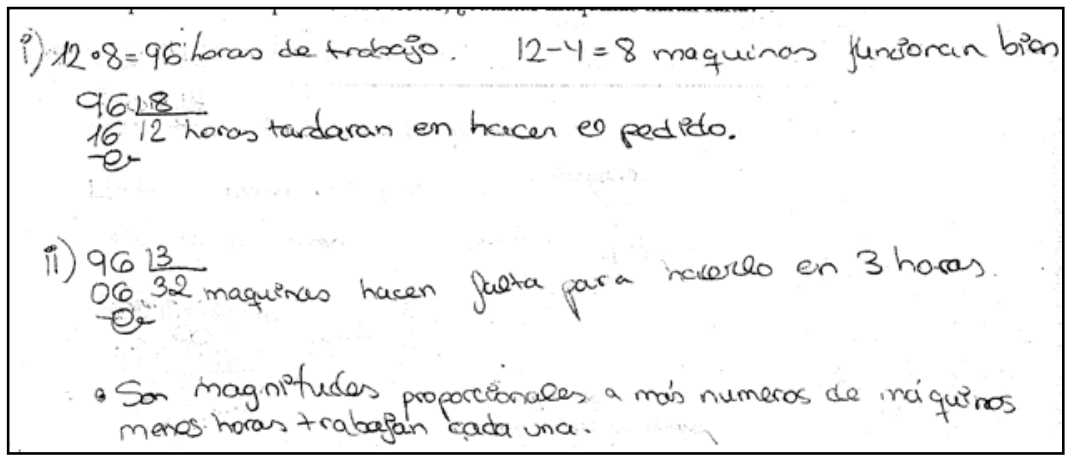

Figura VI.291.

Otra posible estrategia es la seguida, por ejemplo, por el alumno A17 (ver Figura VI.292). Consiste en interpretar el resultado de multiplicar horas por máquinas no como las horas de máquina totales de trabajo, sino como el tiempo que necesita una máquina:

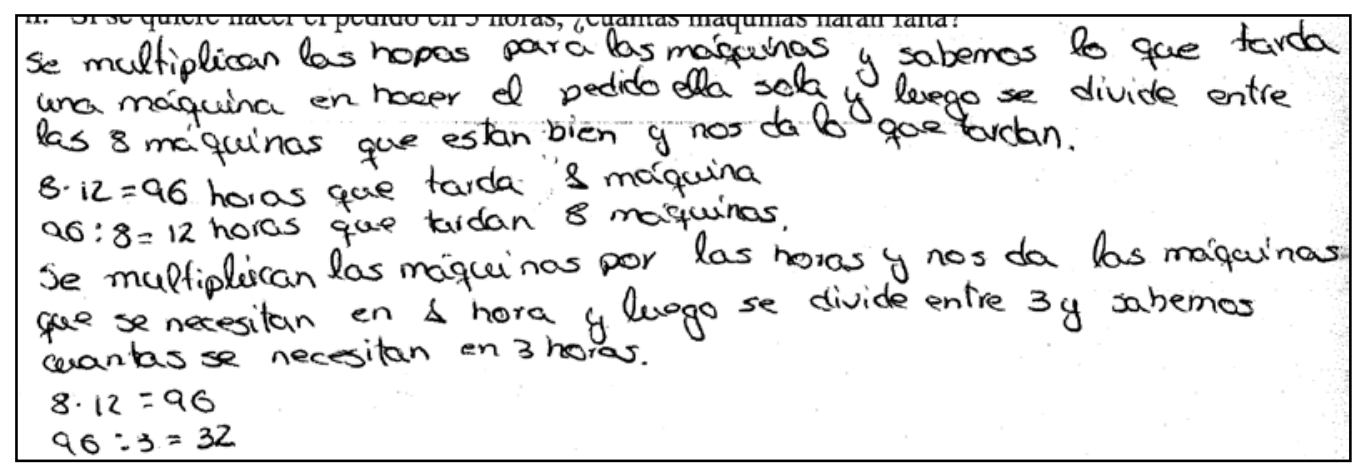

Figura VI.292.

Aunque, efectivamente, el número total de horas de trabajo es exactamente lo que tardaría una máquina, es interesante observar que hay alumnos que lo perciben de una u otra forma prioritariamente. La tercera estrategia ya apareció en el análisis de la Actividad 8. Surge al entender que la magnitud "oculta” que liga las horas necesarias con el número de máquinas es el pedido mencionado en el enunciado; cuya cantidad no 
puede conocerse. Una posible solución es la dada por A39 en la Figura VI.293, que considera como magnitud el número de pedidos, con lo que su cantidad ya es conocida (es 1):

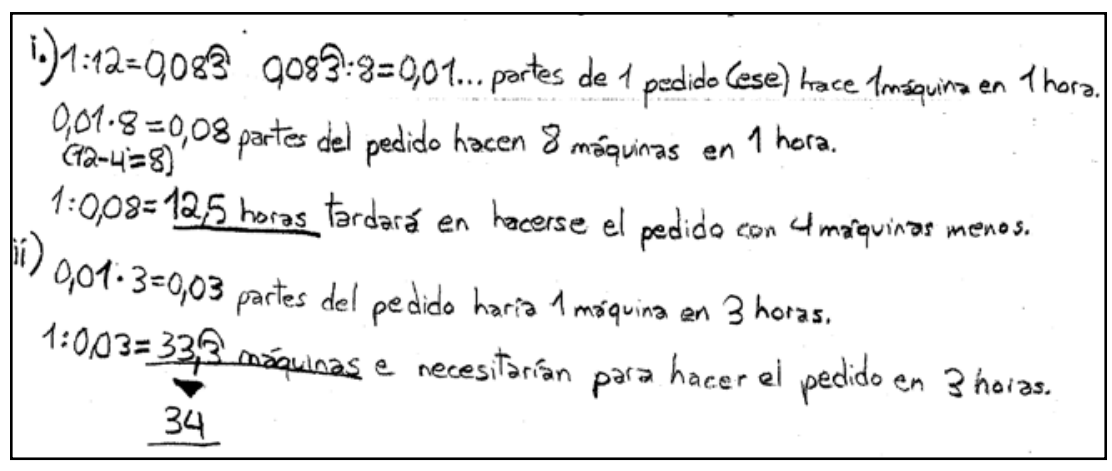

Figura VI.293.

Las discrepancias numéricas se deben a un incorrecto manejo de los decimales que podría haberse evitado empleando fracciones.

En todo caso las tres respuestas anteriores muestran una buena comprensión de las magnitudes implicadas en la situación, así como del significado de las operaciones efectuadas con ellas. Un ejemplo que ilustra la despreocupación que muchos alumnos tienen a este respecto puede ser la respuesta dada por A42 (en la Figura VI.294 siguiente) que simplemente indica las operaciones necesarias para resolver el ejercicio sin indicación alguna sobre su sentido o significado:

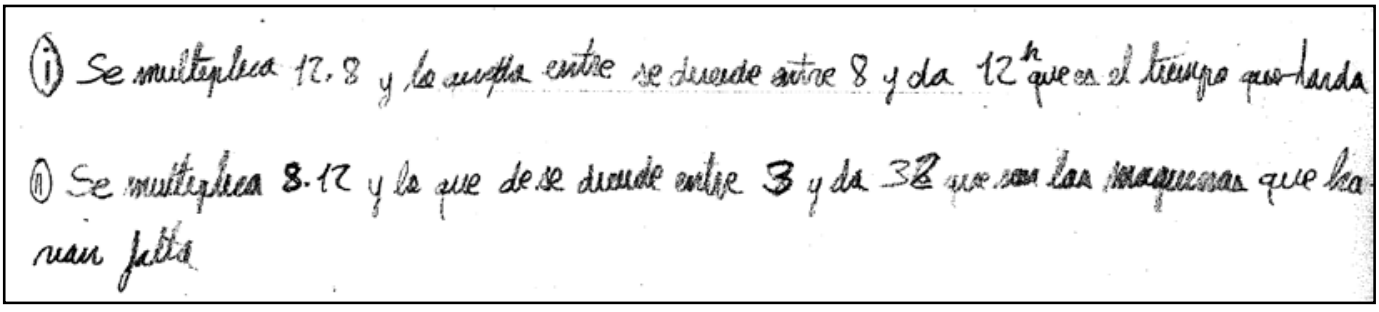

Figura VI.294.

En cuanto a errores, aparecen básicamente los mismos que en el anterior ejercicio. El alumno A34 sigue razonando aditivamente manteniendo constantes las diferencias entre los pares de magnitudes (no entre valores de la misma magnitud). El alumno A16 trata de calcular el tiempo correspondiente a una máquina como si la situación fuera de proporcionalidad directa, calculando una hipotética razón entre máquinas y horas (ver Figura VI.295): 


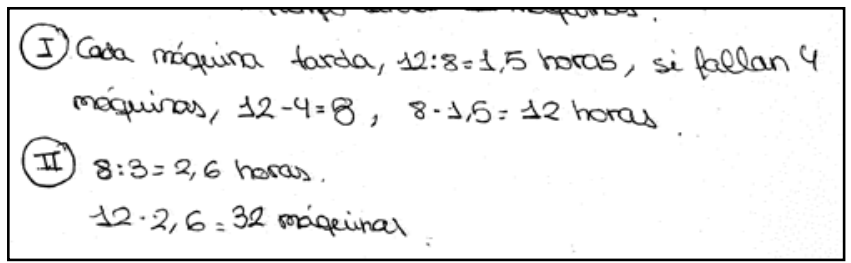

Figura VI.295.

Además de no darse cuenta de que no tiene sentido “repartir” las máquinas entre las horas, puesto que las máquinas trabajan todas las horas, no observa que en cualquier caso para saber lo que tarda 1 máquina debería dividir tiempo entre número de máquinas y no al revés. Las operaciones efectuadas en el segundo apartado carecen de sentido aunque lleven a una respuesta correcta.

Por último una nueva muestra de los problemas que ocasiona el uso de la regla de tres (que apuntamos de nuevo, ni siquiera se mencionó en clase) por cuanto induce a procedimientos memorísticos y ajenos al contexto del problema. El alumno A24 dispone los datos incorrectamente y el error es así inevitable (Figura VI.296):

$$
\begin{array}{ll}
\text { I) } & \frac{8}{x}=\frac{12}{8} ; x=\frac{8.8}{12}=3,38 \\
\text { II) } \quad \frac{8}{3}=\frac{12}{x} ; x=\frac{12.3}{8}=4,5
\end{array}
$$

Figura VI.296.

\section{Ejercicio 5:}

Este ejercicio tiene la peculiaridad de que no se solicitaba el número de obreros necesarios para concluir la obra en 4 días, sino cuántos habría que añadir a los ya existentes. Algunos alumnos, como por ejemplo A23, resuelven esencialmente bien el ejercicio (dejando a un lado la falta de explicaciones o la estrategia seguida), pero no tienen en cuenta que para responder correctamente hay que restar a la cantidad obtenida los obreros iniciales (ver Figura VI.297):

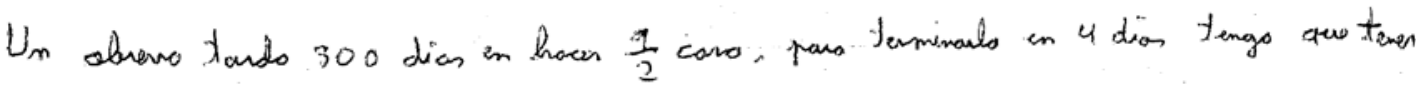

$$
\begin{aligned}
& 75 \text { olvenos }
\end{aligned}
$$

Figura VI.297. 
Otro aspecto concreto del enunciado que ha causado dificultades es el hecho de que se preguntaba por los obreros necesarios para terminar la obra; es decir, para hacer la mitad restante. Algunos alumnos, como A37, han calculado los obreros necesarios para hacer la obra completa en 4 días (ver Figura VI.298):

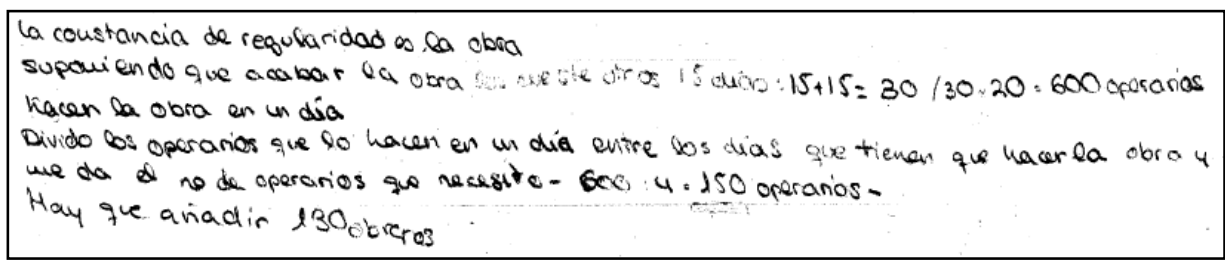

Figura VI.298.

En cualquier caso, estos errores son poco importantes frente a respuestas como la de A35 (en la Figura VI.299 siguiente):

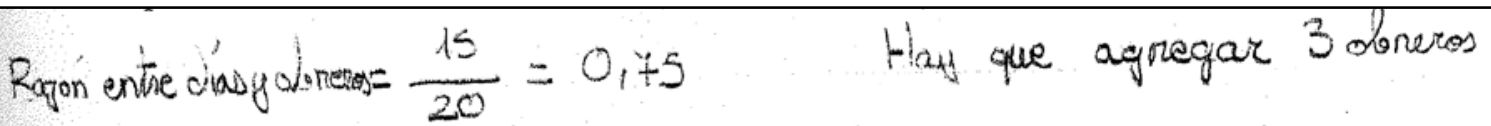

$$
\begin{aligned}
& 0,75 \cdot 4=3
\end{aligned}
$$

Figura VI.299.

Este alumno incurre en el ya habitual error de pensar que los 15 obreros trabajan repartidamente a lo largo de los 20 días de trabajo y así en cuatro días habrían pasado por la obra tan sólo 3 obreros. El alumno A3, por su parte, razona como si las magnitudes fueran directamente proporcionales de modo que las relaciones multiplicativas entre sus cantidades deben conservarse y después considera 11 días (la diferencia entre 15 y 4) a la hora de calcular los obreros necesarios. Y para terminar, en vez de restar su respuesta anterior a 20 (para calcular los obreros a añadir) se los suma (ver Figura VI.300):

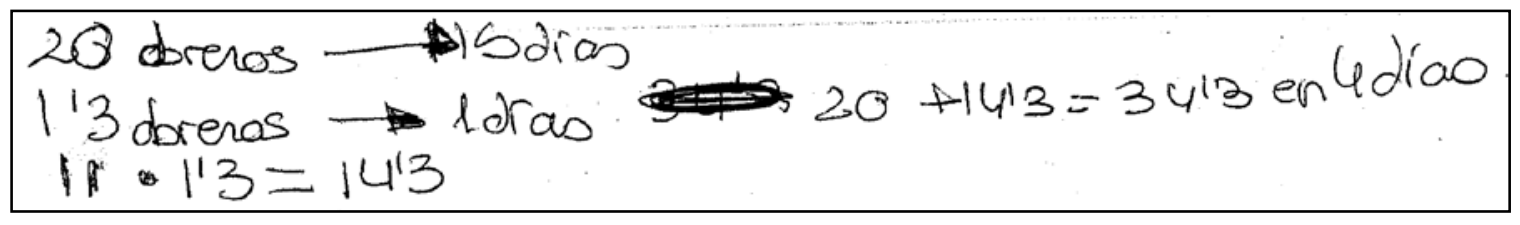

Figura VI.300.

El alumno A34 continúa con sus restas (ver la Figura VI.301 siguiente): 


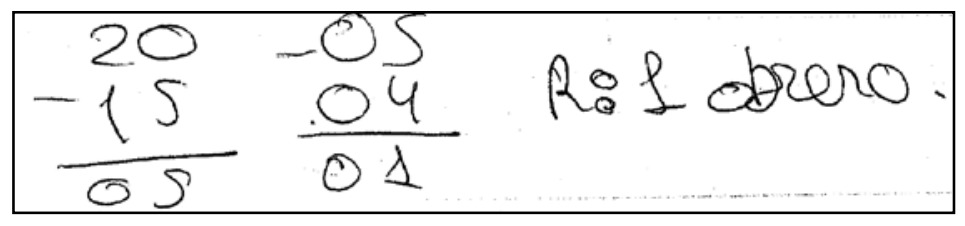

Figura VI.301

Aunque en este caso resulta interesante observar que para ser consistente con la técnica que utiliza en el resto de ejercicios (salvo en el 6) debería haber hecho 4-5 (véase, por ejemplo, su respuesta al Ejercicio 1 más arriba). Como en ese caso el resultado es negativo opta por restar al revés, pero en tal caso no se conservan las diferencias entre las magnitudes puesto que 20-15 no es lo mismo que 4-1.

Respecto a respuestas acertadas, nuevamente el alumno A39 razona considerando que 1 obra es la cantidad de la magnitud que relaciona el número de obreros con los días necesarios para terminar y calcula la parte de obra que hace un obrero en un día para, a partir de allí, resolver el ejercicio (no presentamos la respuesta porque es esencialmente igual que la del ejercicio anterior). Aquellos alumnos que consideran que no puede calcularse una cantidad para la magnitud "obra”, como es el caso de A28, cuya respuesta aparece en la Figura VI.302, multiplican los obreros por los días e interpretan el resultado bien como los obreros necesarios para hacer la obra en un día, como los días necesarios para que concluya la obra un solo obrero:

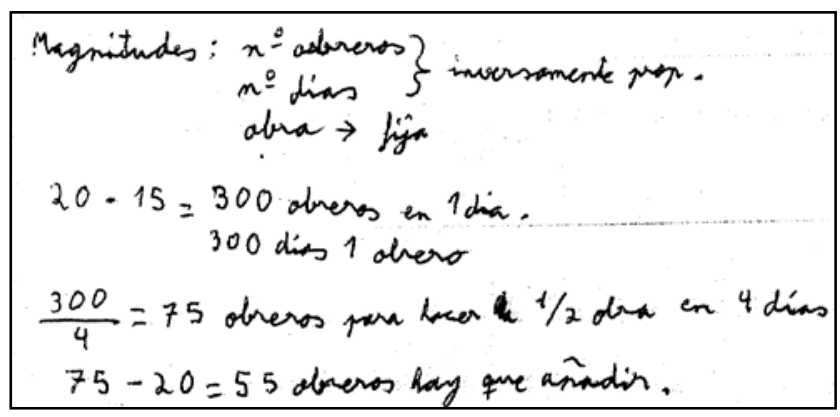

Figura VI.302

Por último, en este ejercicio aparecen alumnos que afirman que las magnitudes presentadas no tienen relación entre ellas. Tal es el caso de A24, que afirma que "no todos los días han podido realizar el mismo trabajo” (Figura VI.303):

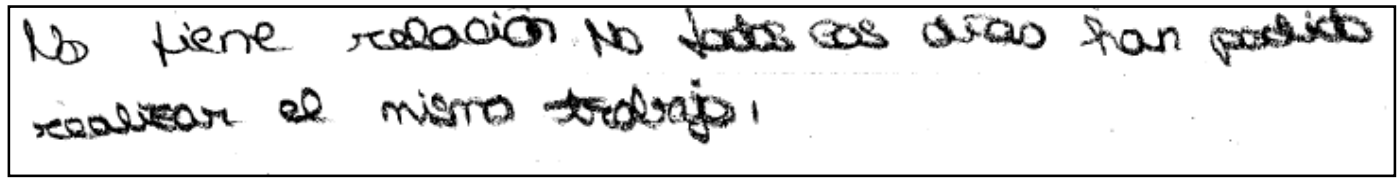

Figura VI.303. 


\section{Ejercicio 6:}

En este ejercicio nuevamente aparecía la pregunta de cuántas personas hay que añadir y no la de cuántas personas son necesarias. Como antes, esto ha sido causa de confusión para algunos alumnos. En este ejercicio ya no aparecen respuestas esencialmente diferentes de las dadas en los ejercicios anteriores, así que no vamos a presentar ninguna producción de los alumnos. La tipología de respuestas es idéntica como, por otra parte, ya reflejaba la tabla anterior. Pero además es que los errores cometidos y las estrategias correctas también coinciden.

\section{Ejercicio 3:}

En este ejercicio aparecían las magnitudes “duración de un campamento” y “edad media de los campistas” que, evidentemente, carecen de relación. En este ejercicio, en contra de lo que sucederá en el siguiente, no hay hipótesis razonables que permitan hablar de proporcionalidad.

Las unidades de análisis para este grupo de situaciones son las siguientes:

\begin{tabular}{|c|c|}
\hline 0 & No entrega o no asiste a clase \\
\hline 1 & Respuesta en blanco o incompleta \\
\hline 2 & Da alguna respuesta numérica \\
\hline 3 & Indica que no se puede sin razonar o por alguna razón incorrecta \\
\hline 4 & Indica que no se puede por algún motivo aceptable \\
\hline
\end{tabular}

Los resultados obtenidos por los alumnos en estos ejercicios de acuerdo con estas unidades de análisis se presentan en la siguiente tabla:

\begin{tabular}{|c|c|c|c|c|c|c|}
\hline \multicolumn{2}{|c|}{} & $\mathbf{0}$ & $\mathbf{1}$ & $\mathbf{2}$ & $\mathbf{3}$ & $\mathbf{4}$ \\
\hline Ejercicio 3 & $\mathbf{N}^{\mathbf{o}}$ de resp. & 11 & 2 & 4 & 16 & 23 \\
\cline { 2 - 7 } & Porcentaje & $199^{\prime} 6 \%$ & 3'6\% & 7'1\% & $28{ }^{\prime} 6 \%$ & $41^{\prime} 1 \%$ \\
\hline
\end{tabular}

Es destacable el bajísimo número de alumnos que tratan de dar una respuesta numérica al ejercicio. Además, de esos cuatro alumnos, ninguno da una respuesta que suponga que las magnitudes son proporcionales (inversa o directamente). Por ejemplo, A34 vuelve a razonar utilizando sus curiosas restas (ver Figura VI.304): 


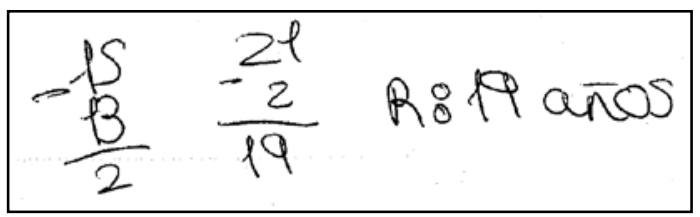

Figura VI.304.

El alumno A7, por su parte, parece que también pretendía razonar de manera similar, aunque considerando las diferencias entre cantidades de la misma magnitud. No obstante, la respuesta es incompleta y no permite saber lo que este alumno quería hacer (ver Figura VI.305):

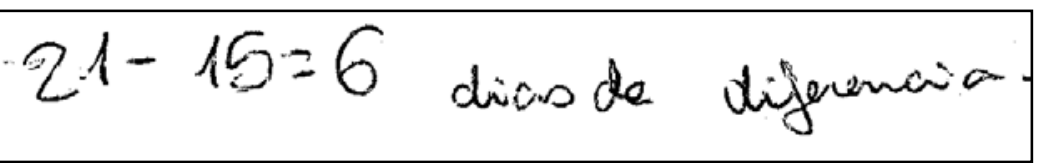

Figura VI.305.

Finalmente, las otras dos respuestas numéricas son difíciles de interpretar. Una, la del alumno A30, porque se limita a responder “17 años” y no hemos sido capaces de buscar un posible razonamiento que lleve a esa respuesta. La otra, del alumnoA22 (ver Figura VI.306) porque la operación que efectúa carece de sentido:

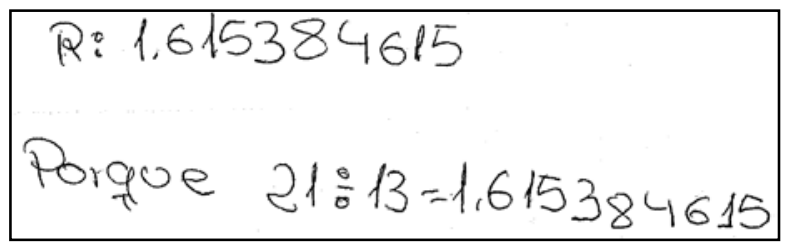

Figura VI.306.

El resto de alumnos señala que el ejercicio no puede resolverse. La respuesta mayoritaria incluye además la indicación de que no hay relación entre las magnitudes. El alumno A3, por ejemplo, responde: "no tiene que ver los días del campamento con los años de los niñ@s” y otros 22 alumnos dan una respuesta análoga. Hay, no obstante, un buen número de alumnos que, aunque dicen que el ejercicio no tiene solución, no aportan razón alguna o la que aportan es confusa. Se han encontrado esencialmente 4 tipos de respuestas que se ejemplifican con las de los alumnos siguientes:

- A24: “No guarda ningún tipo de relación porque la edad no es una magnitud”.

- A23: “No se puede hacer porque no hay condición de regularidad”.

- A48: “No son directamente proporcionales". 
- A31: "No se puede hacer".

\section{Ejercicio 4:}

En este ejercicio aparecían las magnitudes "gasto teléfono” y “días de facturación”. Estas dos magnitudes no son inversamente proporcionales. Sin embargo, pueden resultar aceptables dos respuestas: o bien decir que no hay relación entre ambas magnitudes (porque no se paga por días, porque hay un fijo mensual, etc...) o bien decir que ambas magnitudes son directamente proporcionales (suponiendo, claro está, que el gasto diario es fijo).

Las unidades de análisis para este grupo de situaciones son las siguientes:

\begin{tabular}{|c|c|}
\hline 0 & No entrega o no asiste a clase \\
\hline 1 & Respuesta en blanco o incompleta \\
\hline 2 & Respuesta numérica incorrecta \\
\hline 3 & Dice que no hay relación \\
\hline 4 & Asume proporcionalidad directa, sin indicar regularidad \\
\hline 5 & directa \\
\hline
\end{tabular}

Los resultados obtenidos por los alumnos en estos ejercicios de acuerdo con estas unidades de análisis se presentan en la siguiente tabla:

\begin{tabular}{|c|c|c|c|c|c|c|c|}
\hline \multicolumn{2}{|c|}{} & $\mathbf{0}$ & $\mathbf{1}$ & $\mathbf{2}$ & $\mathbf{3}$ & $\mathbf{4}$ & $\mathbf{5}$ \\
\hline \multirow{2}{*}{ Ejercicio 4 } & $\mathbf{N}^{\mathbf{0}}$ de resp. & 11 & 5 & 2 & 8 & 21 & 9 \\
\cline { 2 - 8 } & Porcentaje & $199^{\prime} 6 \%$ & $8{ }^{\prime} 9 \%$ & $3{ }^{\prime} 6 \%$ & $14{ }^{\prime} 3 \%$ & $37^{\prime} 5 \%$ & $166^{\prime} 1 \%$ \\
\hline
\end{tabular}

En este caso la mayor riqueza de la situación frente al ejercicio anterior hace que aparezca una mayor variedad de respuestas. La mayoritaria es la de aquellos alumnos que dan por supuesta la proporcionalidad directa entre las magnitudes implicadas sin percatarse o al menos sin indicar las condiciones necesarias. Así, el alumno A33, pese a que tiene claro el significado de las operaciones que efectúa, no parece sentir la necesidad de una justificación (ver Figura VI.307):

$$
D D I D \quad 1,56 \in \times 28=32,48 E \text { ey } 28 \text { dias }
$$

Figura VI.307. 
Otros alumnos que obvian las condiciones de regularidad parecen no tener tampoco demasiado claro el sentido de las operaciones que realizan. Por ejemplo, A42 (en la Figura VI.308 siguiente) realiza operaciones que conducen a una respuesta correcta, pero es difícil asignar un significado a dichas operaciones (y de hecho, no lo hace):

$$
\begin{aligned}
& \text { Se mulleplica } 36 \cdot 28=1008 \\
& y \text { u duede } 1000: 31=32.51 € \text { pagare por } 28 \text { dias }
\end{aligned}
$$

Figura VI.308.

Las operaciones efectuadas recuerdan sin duda al algoritmo clásico de la regla de tres. Otros alumnos utilizan este algoritmo de una forma mucho más evidente; tal es el caso de A51, en la Figura VI.309:

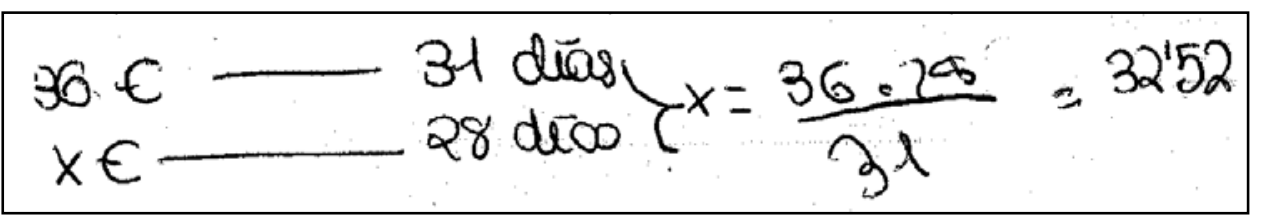

Figura VI.309.

El número de alumnos que, como A11 en la Figura VI.310, señalan (con mayor o menor acierto) condiciones de regularidad necesarias para suponer que las magnitudes son directamente proporcionales no es muy elevado:

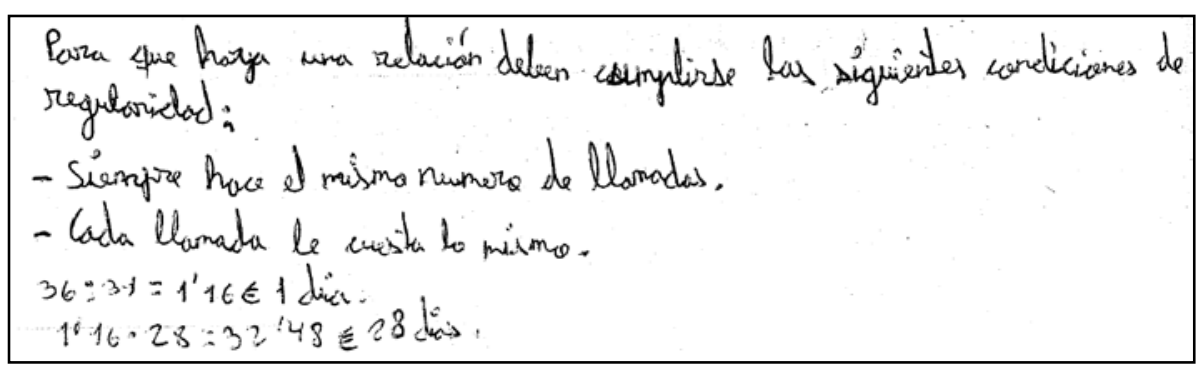

Figura VI.310.

De todos modos, la importancia de la condición de regularidad también se pone de manifiesto en aquellos alumnos cuya respuesta indica la falta de relación entre las magnitudes implicadas. En este caso, el énfasis se pone en lo que no se cumple más que en lo que se debe cumplir. Por ejemplo:

- A45: “No hay razón porque no todos los días llamas lo mismo, ni las llamadas duran lo mismo [...]". 
- A53: “No tiene razón porque en 28 días puede llamar más que en 31 días”.

- A49: "Depende de las llamadas que haga".

Por último señalar que hay dos alumnos (A34, ya comentado con anterioridad, y A20) que razonan mediante restas y, lo más sorprendente, con la misma inconsistencia que se indicó en el comentario a la respuesta de A34 al Ejercicio 1. También hay otros dos alumnos cuya respuesta se limita a un número: A30, cuya respuesta es "33€ pagará" (quizás un redondeo de 32’51€ que se obtienen asumiendo proporcionalidad directa u otro razonamiento aditivo esta vez sí, consistente) y A22, que responde “1008€” que es el resultado de multiplicar 36 y 28 (quizás una regla de tres incompleta).

\section{VI.4.2.3 Reflexiones relativas al punto 3}

- Los alumnos tienen problemas a la hora de manejar magnitudes que son razón de otras dos. Por ejemplo, confunden la magnitud pulsaciones por minuto con la magnitud pulsaciones. Esto les lleva a calcular razones y/o efectuar operaciones carentes de sentido.

- En las situaciones de proporcionalidad inversa que involucran personas trabajando durante varios días, animales alimentados durante varios días o similares suponen un serio problema para los alumnos. En concreto, muchos alumnos parecen pensar que 3 personas trabajando 3 días es lo mismo que una persona trabajando cada uno de esos días.

- En las situaciones en las que se puede calcular explícitamente la cantidad de la magnitud que sirve de nexo entre las dos que son inversamente proporcionales los alumnos parecen tener tendencia a calcular dicha magnitud y a resolver con mayor éxito el problema.

- Justamente la diferencia entre las dos situaciones anteriores radica en que en la segunda (punto anterior) una de las magnitudes variables es la razón entre la constante "oculta" y la otra variable.

- Sorprendentemente aún aparecen ejemplos de razonamiento aditivo en situaciones que podrían ser de proporcionalidad directa. 
- Los alumnos siguen teniendo ciertos problemas en aquellas situaciones que involucran personas o máquinas trabajando durante cierto tiempo. En concreto, tienen a calcular la razón entre trabajadores y tiempo sin observar, como ya dijimos anteriormente, que todos los trabajadores lo hacen durante todo el tiempo (o al menos así se asume para poder razonar).

- Hay muy poca tendencia a indicar las condiciones de regularidad necesarias para que las preguntas efectuadas tengan sentido.

- Los alumnos parecen reconocer bien aquellas situaciones en las que las magnitudes no están relacionadas.

- En algunas situaciones de proporcionalidad directa sigue habiendo una separación de los alumnos entre los que lo asumen sin más, los que indican la condición de regularidad como algo necesario y los que la señalan como un impedimento a la resolución del problema.

- La influencia externa es muy alta en las tareas realizadas en casa. En la actividad anterior no aparecían reglas de tres y aquí lo hacen en un número no despreciable de veces.

\section{VI.5. OBSERVACIÓN Y REFLEXIÓN DE LA PRUEBA FINAL}

\section{Enunciado}

1.- Indica para estas situaciones (si se puede) las razones que aparecen y su significado. Señala también las condiciones de regularidad necesarias para poder hacerlo. Cuando no sea posible hablar de razón explica por qué:

a) En 2 horas han pasado 5 autobuses. (Alternativa: En 2 horas ha recogido 60 kilos de uva.)

b) A las 3 de la tarde he quedado con 5 amigos.

c) 2 personas han tardado 5 días en pintar la casa. (Alternativa: 2 amigos han tardado 25 minutos en terminar sus deberes.)

d) 3 cajas de leche cuestan 2 euros. (Alternativa: 3 paquetes de café cuestan 5 euros.)

2.- Una fuente arroja 50 litros de agua en 6 horas. ¿Cuánto tardará en arrojar 35 litros de agua? 
(Alternativa: Un coche consume 7 litros de gasolina cada 100 kilómetros. ¿Cuántos kilómetros podrá recorrer con 20 litros de gasolina?)

3.- Pagando 75 euros al mes tardaré 11 meses en pagar la televisión que me acabo de comprar. ¿Cuánto tardaré en pagarla si pago 165 euros al mes?

(Alternativa: Un agricultor podando 3 árboles por hora tarda 15 horas en podar los árboles de un campo. ¿Cuánto tardará otro agricultor podando 2 árboles por hora?)

4.- La biblioteca pública de Zaragoza tiene 425250 libros. De ellos, el 6\% son libros de matemáticas.

a) ¿Cuántos libros de matemáticas hay en la biblioteca?

b) En la biblioteca también hay CD de música. Sabemos que hay 2145 CD de música clásica y que éstos suponen el 11\% del total de CD. ¿Cuántos CD de música hay en total en la biblioteca?

(Alternativa: En Zaragoza viven unos 683000 habitantes. De ellos, un 22\% son mayores de 60 años.

a) ¿Cuántas personas mayores de 60 años hay en Zaragoza?

b) En marzo el paro en Aragón aumentó en unas 2000 personas. Si ese aumento supuso el 2\% con respecto al mes anterior. ¿Cuántos parados hubo el mes anterior en Aragón?)

5.- Fernando tiene 13 años y pesa 47 kilos. ¿Cuánto pesará a los 40 años?

(Alternativa: Fernando tiene 13 años y mide 150 centímetros. ¿Cuánto medirá a los 40 años?)

6.- Indica si las siguientes magnitudes están relacionadas. Si lo están señala si son directamente proporcionales o inversamente proporcionales. Justifícalo.

a) La cantidad de azúcar necesaria para hacer una tarta y el número de raciones de la tarta. (Alternativa: La cantidad de sal necesaria para hacer una receta y el número de comensales.)

b) La edad de una persona y la velocidad a la que puede correr. (Alternativa: La edad de una persona y el peso que puede levantar.)

c) El número de personas que hay trabajando en una obra y el tiempo que tardan en terminarla. (Alternativa: El número de personas que va a una excursión y el precio que debe pagar cada una.)

\section{Análisis de la prueba}

Esta prueba fue diseñada con un doble fin: por un lado, se trata de un test que nos permita evaluar la propuesta didáctica desarrollada y, por otro, debía servir como herramienta de evaluación y calificación de los alumnos (algo necesario puesto que la 
propuesta se insertó en el desarrollo normal del curso). Como es natural, aquí nos vamos a centrar en realizar un análisis de aquellos aspectos que nos interesan: el grado de adquisición de los conceptos trabajados por parte de los alumnos y el modo en que estos conceptos se reflejan en la adquisición de ciertas destrezas que se plasman en la resolución de problemas. Dejaremos de lado cualquier tipo de calificación. Sin embargo, como veremos, el hecho de que para los alumnos éste fuera "un examen más” tendría una importancia que podrá rastrearse en las respuestas de los alumnos. La prueba se desarrolló durante una sesión de clase de unos 50 minutos y fue realizada por 54 alumnos (otros 2 alumnos completaron, como se comentará, una prueba análoga en idénticas condiciones).

Como se observa en el enunciado presentado anteriormente, existen dos enunciados para cada cuestión (excepto para una de ellas, la 1.- b). Esto se debe a que los alumnos A36 y A39 no asistieron a clase el día que se llevó a cabo la prueba. La necesidad de evaluar a dichos alumnos por parte de la profesora del grupo llevó a plantearles una prueba alternativa tan pronto como se reintegraron a las clases. No obstante, dado que salta a la vista que las cuestiones planteadas en ambas pruebas son de idéntica dificultad y de enunciado similar, se tendrán en cuenta las respuestas de estos dos alumnos junto a las del resto de sus compañeros.

En la prueba aparecen todos los aspectos fundamentales presentados y trabajados a lo largo de la propuesta didáctica. En concreto:

- El concepto de razón y la condición de regularidad juegan su papel en el ejercicio 1 (de forma explícita) y en los ejercicios 2, 3, 4, 5 y 6 (más bien a modo de "herramienta”).

- El concepto de magnitudes directamente proporcionales aparece de modo explícito en el ejercicio 6 (apdo. a) y de forma implícita en los ejercicios 2 y 4.

- El concepto de magnitudes inversamente proporcionales aparece de modo explícito en el ejercicio 6 (apdo. c) y de forma implícita en el ejercicio 3.

- La idea de que pueden existir magnitudes no relacionadas o relacionadas de un modo que no se corresponde con ninguno de los dos anteriores se presenta en los ejercicios 6 (apdo. b) y 5. 
- El concepto y el cálculo de porcentajes son los aspectos principales del ejercicio 4 (situación directa en el apartado a e inversa en el b).

Como se ve, algunas ideas aparecen involucradas en diferentes ejercicios; si bien el papel que juegan en cada uno de ellos es diferente. Veremos más adelante cómo este diferente papel influye en el modo en que los alumnos manejan dichas ideas

\section{Valoración de la prueba}

En capítulos anteriores ya se ha indicado que el análisis de las respuestas dadas por los alumnos en esta prueba se va a centrar especialmente en el estudio de los errores cometidos por los alumnos en relación con los conceptos y procedimientos fundamentales presentados y trabajados a lo largo de la propuesta didáctica. Aunque es evidente que cada uno de dichos conceptos o procedimientos no aparece aisladamente en cada uno de los ejercicios, analizaremos separadamente cada uno de ellos.

Los errores que tendremos en consideración al analizar las respuestas de los alumnos, y que ya se presentaron en la sección VI.1.2., son los siguientes:

\begin{tabular}{|c|c|c|}
\hline C & \multicolumn{2}{|r|}{ ERRORES CONCEPTUALES } \\
\hline & CO & $\begin{array}{l}\text { El alumno no llega a comprender la situación o a relacionar completa y } \\
\text { correctamente las magnitudes implicadas en la situación presentada. }\end{array}$ \\
\hline & CR1 & $\begin{array}{l}\text { El alumno omite la condición de regularidad necesaria para definir el concepto de } \\
\text { razón. }\end{array}$ \\
\hline & CR2 & $\begin{array}{l}\text { El alumno señala el significado inverso del que corresponde a la razón que está } \\
\text { considerando. }\end{array}$ \\
\hline & CR3 & $\begin{array}{l}\text { El alumno sólo señala la existencia de una razón en la situación considerada, frente a } \\
\text { las dos - al menos - que siempre existen. }\end{array}$ \\
\hline & CR4 & $\begin{array}{l}\text { El alumno identifica la razón únicamente con la idea de “tanto por uno” incluso en } \\
\text { una situación de proporcionalidad inversa. }\end{array}$ \\
\hline & CP1 & El alumno confunde magnitudes D.P. con magnitudes I.P. o viceversa. \\
\hline & CP2 & $\begin{array}{l}\text { El alumno identifica como proporcionales (ya sea directa o inversamente) } \\
\text { magnitudes que no lo son. }\end{array}$ \\
\hline & CP3 & $\begin{array}{l}\text { El alumno señala que no hay relación entre magnitudes que sí guardan una relación } \\
\text { de proporcionalidad (ya sea directa o inversa). }\end{array}$ \\
\hline & CP4 & $\begin{array}{l}\text { El alumno identifica el concepto de proporcionalidad directa con la existencia de } \\
\text { relación entre las magnitudes implicadas y el de proporcionalidad inversa con la no } \\
\text { existencia de relación entre ellas. }\end{array}$ \\
\hline
\end{tabular}




\begin{tabular}{|c|c|c|}
\hline \multirow[t]{4}{*}{$\mathbf{P}$} & \multicolumn{2}{|r|}{ ERRORES PROCEDIMENTALES } \\
\hline & P0 & $\begin{array}{c}\text { El alumno utiliza un procedimiento de resolución inadecuado en la situación } \\
\text { planteada. }\end{array}$ \\
\hline & P1 & $\begin{array}{l}\text { El alumno aplica técnicas “externas”, es decir, métodos de resolución correctos desde } \\
\text { el punto de vista de la enseñanza “tradicional” pero que no han sido tratados durante } \\
\text { la propuesta. }\end{array}$ \\
\hline & $\mathbf{P 2}$ & El alumno comete errores aritméticos en el transcurso de la resolución del problema. \\
\hline A & & RESPUESTA EN BLANCO \\
\hline
\end{tabular}

\section{Ejercicio 1:}

En este ejercicio se planteaban 4 situaciones. En dos de ellas (a y d) aparecen dos situaciones entre las que, bajo las condiciones de regularidad adecuadas, pueden definirse las razones entre las magnitudes implicadas. En las otras dos situaciones esto no es posible, aunque por motivos diferentes. Mientras en la situación b) una de las cantidades no es una magnitud (las 3 de la tarde) y, además, no hay relación entre las variables presentadas; en la situación c) aparecen dos magnitudes que sí que están relacionadas pero entre ellas no tiene sentido definir la razón, pues no tiene sentido la idea de "tanto por uno".

Esta diferencia entre los apartados hace que descompongamos el análisis de este ejercicio en 3 partes. Es importante observar que, por la naturaleza propia de este ejercicio, tan sólo tiene sentido plantearse la aparición de errores conceptuales relativos a la idea de razón.

\section{Apartados a) y d):}

Los errores cometidos por los alumnos en estos apartados, de acuerdo con la clasificación dada anteriormente se presentan en la tabla siguiente. En estos dos apartados no ha habido respuestas en blanco y, como es natural al tratarse de situaciones en las que sí es posible definir la razón entre las magnitudes, no hay posibilidad de que aparezca el error CR4. Los resultados obtenidos en ambos apartados, como cabría esperar, son bastante similares:

\begin{tabular}{|c|c|c|c|c|c|}
\hline \multicolumn{2}{|c|}{} & C0 & CR1 & CR2 & CR3 \\
\hline $\begin{array}{c}\text { Ejercicio 1 } \\
\text { Apartado a) }\end{array}$ & $\mathbf{N}^{\mathbf{0}}$ de resp. & 17 & 14 & 6 & 22 \\
\cline { 2 - 6 } & Porcentaje & $30{ }^{\prime} 4 \%$ & $25 \%$ & $10{ }^{\prime} 7 \%$ & $399^{\prime} 3 \%$ \\
\hline
\end{tabular}




\begin{tabular}{|c|c|c|c|c|c|}
\hline $\begin{array}{c}\text { Ejercicio 1 } \\
\text { Apartado d) }\end{array}$ & $\mathbf{N}^{\mathbf{o}}$ de resp. & 12 & 18 & 7 & 24 \\
\cline { 2 - 6 } & Porcentaje & $21^{\prime} 4 \%$ & $32^{\prime} 1 \%$ & $12^{\prime} 5 \%$ & $42^{\prime} 9 \%$ \\
\hline
\end{tabular}

En estos apartados una respuesta se ha considerado completamente correcta cuando el alumno ha señalado correctamente la condición de regularidad y las dos razones existentes junto con sus significados. Es decir, la complejidad de una respuesta totalmente correcta es bastante grande. El número de respuestas totalmente correctas en estos apartados ha sido:

\begin{tabular}{|c|c|c|}
\cline { 2 - 3 } \multicolumn{1}{c|}{} & $\begin{array}{c}\text { Ejercicio 1 } \\
\text { Apartado a) }\end{array}$ & $\begin{array}{c}\text { Ejercicio 1 } \\
\text { Apartado d) }\end{array}$ \\
\hline $\begin{array}{c}\mathbf{N}^{\mathbf{0}} \text { de respuestas } \\
\text { totalmente correctas }\end{array}$ & 15 & 17 \\
\hline Porcentaje & $26{ }^{\prime} 8 \%$ & $30{ }^{\prime} 4 \%$ \\
\hline
\end{tabular}

Vamos a dedicar algunas líneas a comentar cada uno de los tipos de errores detectados en estos dos apartados. El más repetido ha sido CR3 (indicar sólo una de las razones posibles). Así lo hace, por ejemplo, el alumno A53 (ver la Figura VI.311 siguiente):

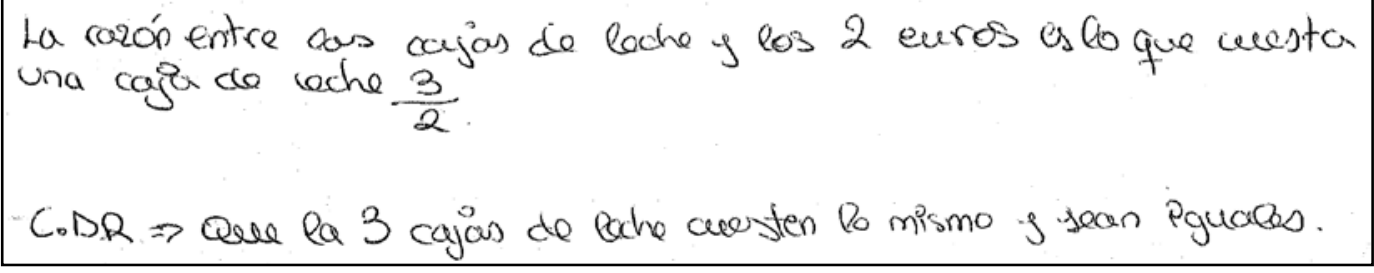

Figura VI.311.

Este alumno da la razón entre cajas de leche y euros, su valor numérico, su significado y una condición de regularidad; pero no observa la otra posible razón existente.

Mucho más interesante para nuestro objetivo es el error CR2 (indicar un significado inverso al adecuado) y que ha sido cometido, entre otros, por el alumno A32 (ver Figura VI.312): 


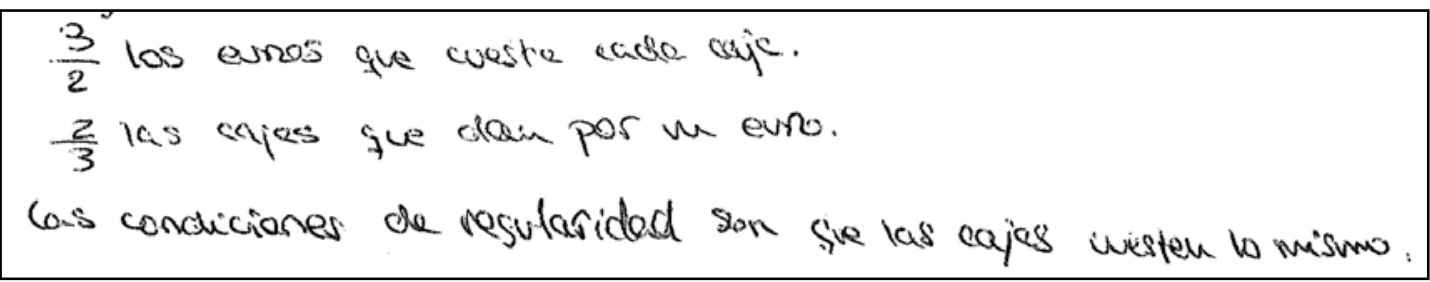

Figura VI.312.

Como se observa, este alumno señala adecuadamente la condición de regularidad, pero, sin embargo, invierte los significados de las razones. Así 3/2 indica en realidad las cajas de leche que se compran con un euro y recíprocamente, la razón entre euros y cajas de leche; 2/3, indica los euros que cuesta una caja. Sin embargo este error no parece demasiado importante puesto que se trata más bien de una cuestión de lenguaje.

Con respecto a los errores CR1 (omisión de la condición de regularidad) y CR3 (se señala sólo una razón) los resultados son algo peores en el apartado d) posiblemente debido a que la mayor familiaridad de la situación de compra-venta lleva a los alumnos a asumir tácitamente la regularidad o a considerar como más natural indicar sólo la razón entre euros y cajas que indica el precio unitario (A34 en la Figura VI.313 siguiente):

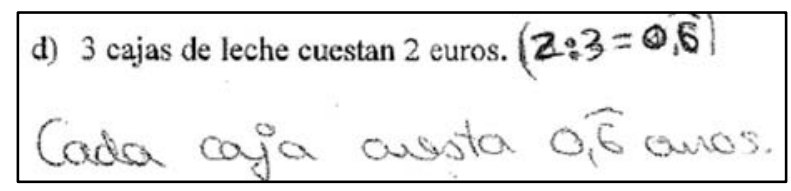

Figura VI.313.

Es muy interesante señalar además que se ha observado una gran tendencia a que ambos errores aparezcan juntos (14 alumnos en el apartado a) y 15 en el d)). Así sucede, por ejemplo, en el alumno A16 (Figura VI.314):

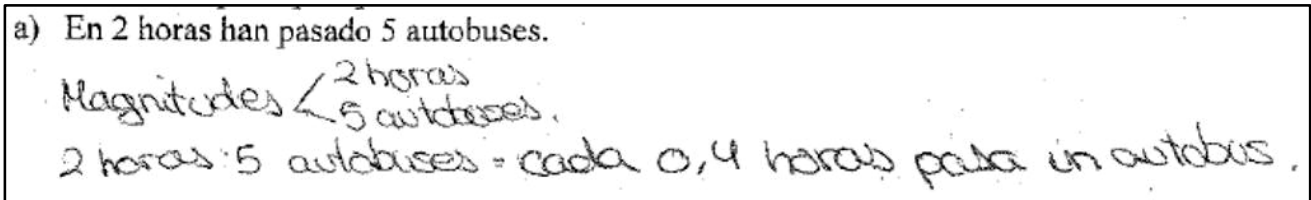

Figura VI.314.

Para terminar con el estudio de estos apartados vamos a comentar algunos ejemplos de alumnos que no han llegado a comprender la situación o a relacionar completa y correctamente las magnitudes implicadas (error C). Algunos alumnos (como A8 en la 
Figura VI.315, que sigue) han tenido problemas en el apartado a) a la hora de observar que las magnitudes involucradas estaban (o podían estar) relacionadas entre sí:

Yo creo que no se prede hables de razsón porque un hay rebación entre
estas magnitudes

Figura VI.315.

Este tipo de respuesta no ha aparecido en el apartado d). Por último, ha habido un número no desdeñable de alumnos que no han comprendido lo que se les pedía. Algunos, por ejemplo A12 (ver Figura VI.316) se han limitado a reproducir el mensaje del enunciado:

$$
3 \text { cajas de leche siempre costorán } 2 € \text { (leche y dinero) }
$$

Figura VI.316.

Otros, como puede ser el caso de A27 (en la Figura VI.317 que sigue) reelaboran algo dicha información, pero sin sacar nada en claro de ello:

$$
\begin{aligned}
& \text { En } 2 \text { homas }=5 \text { a } 5 \text { toluses } \\
& \text { En } 4 \text { honas }=10 \text { autobuses } \\
& \text { En } 8 \text { homas }=20 \text { artobuses }
\end{aligned}
$$

Figura VI.317.

Algunos alumnos, como A41, comienzan ya a dar muestras de los, a veces, perniciosos efectos de la influencia externa, hablando de "relaciones directas" y del tan manido “cuantas más, más” (ideas que estuvieron completamente desterradas durante el desarrollo de la propuesta) en un lugar donde resulta innecesario (véase la Figura VI.318).

$$
\text { Condición directa. Borqu cuentas más cajas más cueta. }
$$

Figura VI.318.

Por último, hay alumnos que dan una respuesta incompleta que no aclara si han comprendido completamente la situación. Así, por citar algunos ejemplos, A36 responde tan sólo con “sí es posible hablar de razón”, A4 sólo indica el significado de una de las razones: “cuántos autobuses han pasado en una hora” o A55 responde sólo con la condición de regularidad: "que haya la misma cantidad de leche en cada caja”. 
Al comparar las respuestas de los alumnos en estos dos apartado con los resultados obtenidos en las tareas y actividades anteriores, resulta chocante el alto porcentaje de alumnos que dan una condición de regularidad (casi la mitad) aunque esto se debe principalmente al hecho de que se les pide explícitamente. Veremos que en ejercicios posteriores, en los que la condición de regularidad es algo a asumir para poder realizar dichos ejercicios, ésta asunción se hace implícitamente por el hecho de que no se pregunta a los alumnos por ello.

\section{Apartado b):}

En este apartado la situación es esencialmente diferente a las de los dos anteriores. De hecho, en este caso de las dos variables involucradas (hora y número de amigos) sólo la segunda es una magnitud. Además, no hay relación entre ambas magnitudes. Esto hace que tan sólo 4 alumnos hayan respondido de forma esencialmente incorrecta.

Los 4 errores cometidos se pueden clasificar como errores de tipo C0. Así, el alumno A43 (ver Figura VI.319) simplemente reescribe el enunciado, demostrando que no ha sido capaz de comprender lo que se le pide:

$$
\text { aut ho los } 3 \text { queda can } 5 \text { amigo. }
$$

Figura VI.319.

El caso más preocupante, a nuestro juicio, en este apartado lo es el del alumno A34 (en la Figura VI.320 siguiente) que divide la hora del encuentro entre los amigos; algo totalmente carente de sentido. Además, identifica 0,6 horas con 6 minutos, pero este error (muy grave por otro lado) no viene al caso en este momento.

b) A las 3 de la tarde he quedado con 5 amigos. $(3: 5=0,6)$

Cada 6 minutos recojemos o quedamos con la un amigo.

Figura VI.320.

Este error es importante porque demuestra que el alumno hace operaciones acríticamente sin valorar la posibilidad o no de efectuarlas ni el significado que puedan tener. También hay otros dos alumnos (A22 y A25, ver Figura VI.321) cuya respuesta demuestra que no comprenden la situación. Ambos alumnos responden de forma 
idéntica, palabra por palabra, lo que unido a su amistad lleva a una conclusión clara, pero nuevamente esto se aparta de nuestro análisis:

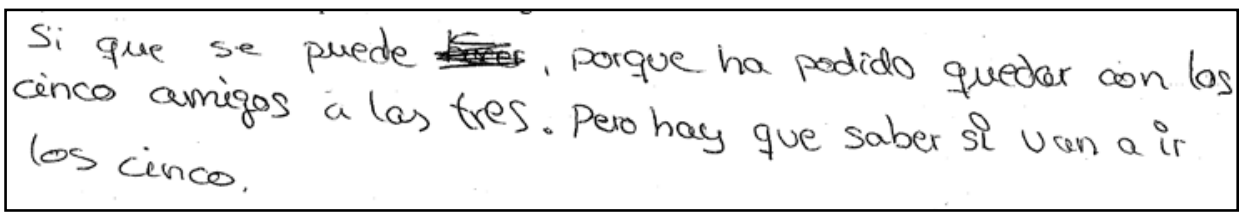

Figura VI.321.

Lo cierto es que la respuesta no da muchas pistas respecto a lo que puedan estar pensando estos alumnos a la hora de emitirla.

El resto de los alumnos, más de un 90\%, señalan que no puede hallarse la razón en la situación planteada. De ellos la gran mayoría, unas dos terceras partes, señalan que las magnitudes involucradas (aún cuando la hora del día no es una magnitud estrictamente hablando) no están relacionadas. Para este tipo de alumnos las respuestas varían desde aquellas que simplemente dicen "no tiene nada que ver la hora con los amigos” (A14) hasta los que buscan alguna explicación más elaborada como "las magnitudes no están relacionadas porque aunque sea cualquier hora no sabes los amigos (pueden ser las 4 y que haya 5 amigos)" (A54) o como "no se puede hablar de razón porque si a las 3 has quedado con 5 amigos a las 6 por ejemplo no has quedado con el doble de amigos” (A3, que afina quizás intuyendo que no tiene sentido la hipotética condición de regularidad necesaria). Un alumno (A29) indica, aun cuando aquí es irrelevante, que “estas magnitudes no están proporcionalmente relacionadas”.

El porcentaje de alumnos que han encontrado la explicación a la imposibilidad de definir la razón en el hecho de que la hora del día puede pensarse que no es una magnitud es escaso. Como ejemplo mostramos la respuesta de A28 (ver Figura VI.322):

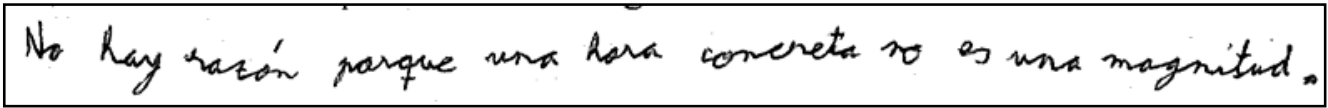

Figura VI.322.

Resulta interesante ver cómo para casi la cuarta parte de los alumnos una respuesta del tipo "no se puede" (A2) resulta completamente satisfactoria.

\section{Apartado c):}

En este apartado tampoco es posible definir la razón entre las dos magnitudes implicadas (personas que trabajan o número de amigos y tiempo que invierten en pintar 
la casa o terminar sus deberes, respectivamente). Sin embargo, la causa es radicalmente diferente a la del apartado anterior, puesto que en este caso ambas magnitudes pueden (bajo condiciones apropiadas) suponerse inversamente proporcionales. Esto quiere decir que, aunque no exista la razón entre ellas, sí que existe la razón entre una tercera magnitud (en este caso la extensión de los deberes o la superficie a pintar) y cada una de ellas.

En este apartado, por lo tanto, sí que cabe esperar la aparición de errores más interesantes. En la siguiente tabla se recogen los errores cometidos por los alumnos de acuerdo a la clasificación que dimos con anterioridad:

\begin{tabular}{|c|c|c|c|c|c|c|}
\hline \multicolumn{2}{|c|}{} & A & C0 & CR1 & CR3 & CR4 \\
\hline $\begin{array}{c}\text { Ejercicio 1 } \\
\text { Apartado c) }\end{array}$ & No de resp. & 2 & 25 & 2 & 2 & 27 \\
\cline { 2 - 7 } & Porcentaje & 3'6\% & 44'6\% & 3’6\% & 3’6\% & 48 '2\% \\
\hline
\end{tabular}

Observamos que en este caso se ha invertido la situación respecto al anterior y tan sólo 8 alumnos (un 14’3\% del total) ha dado una respuesta totalmente correcta. Unos pocos alumnos responden acertadamente que la razón entre las magnitudes indicadas no puede calcularse, no dando motivos explícitos pero analizando la situación (como es el caso de A37 en la Figura VI.323 siguiente):

\footnotetext{
Entre ellas wo sepuede definir la rozón, pero sean inversamente poopor cionales, os decir,

puedo defuir la razoi entre la constante y mo de gag otron 2 maguitudies, wal EJEMPLO: $n^{2}$ de pergevan que tarda en pintor la casa ddia.
}

Figura VI.323.

o bien indicando (es el caso de A28) que "las 2 personas no se reparten los 5 días, si no que las 2 trabajan los 5 días”. Este escaso número de aciertos muestra bien a las claras la diferencia esencial existente entre las situaciones b) y c) pese a que en ambas es imposible definir la razón entre las magnitudes del enunciado.

Observando la tabla anterior y dejando de lado los errores de tipo C0, podemos decir que el error mayoritario (causado quizás por la propia propuesta y por el hecho de tratar dos fenómenos de naturaleza radicalmente distinta - la proporcionalidad directa y la inversa - con herramientas similares) consiste en identificar la razón con el valor de una de las magnitudes asociado a un valor unitario de la otra; la idea de “tanto por uno”. 
Este error (codificado como CR4) queda perfectamente plasmado en la respuesta del alumno A19 (ver Figura VI.323):

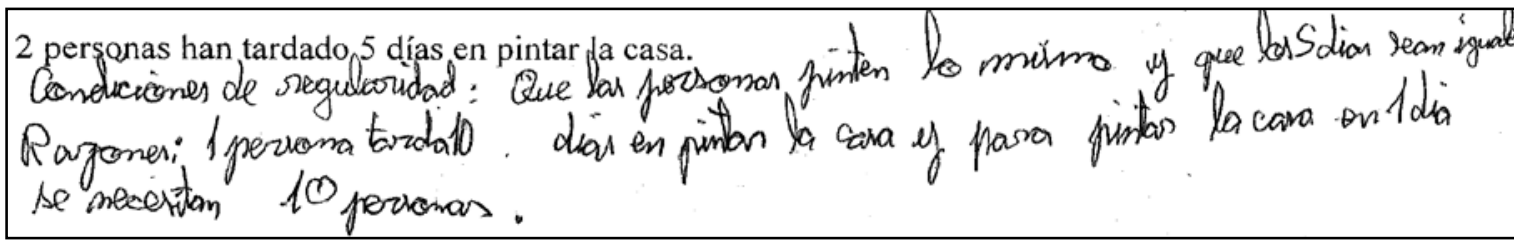

Figura VI.323.

En cuanto a errores de tipo C0, encontramos casos que se limitan a presentar la misma información que el enunciado: “es decir que han tardado dos personas 5 días en pintar una casa" (A43); que dan un mensaje que nada tiene que ver con lo pedido: "por una parte si van a la misma velocidad, tardarán lo mismo y por otra, si alguno falta igual la otra persona no tarda lo mismo” (A51) o que demuestran una clara influencia externa (ver en la Figura VI.324 la respuesta de A24):

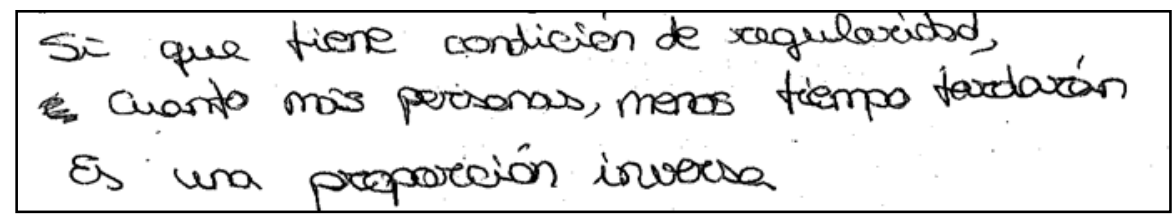

Figura VI.324.

Los casos más preocupantes (escasos, eso sí) implican que el alumno no ha comprendido que, en una situación como la presentada, el tiempo de trabajo no se reparte entre las personas que trabajan (error, que de hecho ya apareció profusamente en las tareas y actividades realizadas). Un ejemplo es la respuesta de A32 (Figura VI.325) que parece haber interiorizado tan sólo el tipo de operaciones a realizar cuando se calcula una razón:

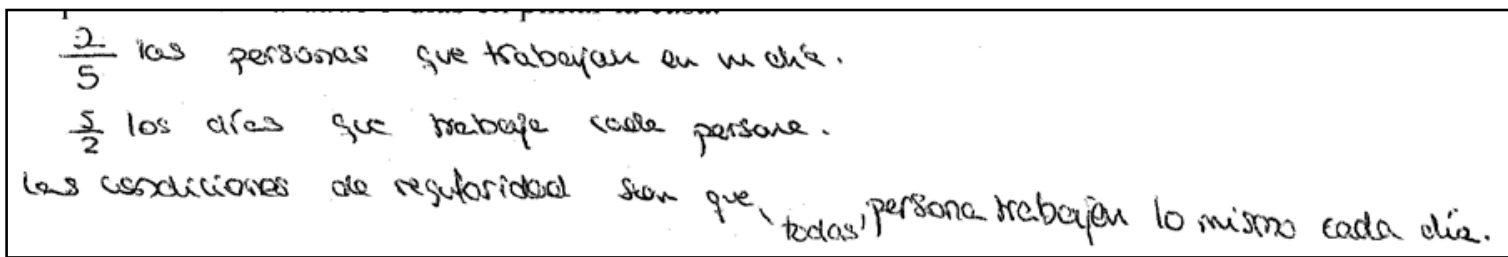

\section{Ejercicio 2:}

Figura VI.325.

Este ejercicio plantea el típico problema de búsqueda de una cantidad desconocida en un contexto en el que las magnitudes involucradas son directamente proporcionales. Así pues, las ideas de razón y de condición de regularidad aparecen, o deberían aparecer 
aquí como herramienta (en el caso de la razón) y como condición necesaria (en el caso de la condición de regularidad) para poder resolver el problema.

Es interesante observar que existen dos posibilidades a la hora de resolver este problema haciendo uso de la idea de razón como "tanto por uno”. Estas dos formas se corresponden con las dos razones posibles que cabe considerar en la situación dada. Como veremos, se darán ejemplos de ambos tipos de razonamiento. También aparecerá con cierta profusión el uso de la regla de tres, pese a que su uso no apareció ni se mencionó durante el desarrollo de la propuesta.

En este ejercicio los errores que más nos interesa estudiar son los de carácter procedimental aunque, como es obvio, al tratarse de una situación de proporcionalidad también hay que estar atentos a si los alumnos comenten errores de índole conceptual. En la tabla adjunta

\begin{tabular}{|c|c|c|c|c|c|c|c|}
\hline \multicolumn{2}{|c|}{} & A & C0 & CP1 & P0 & P1 & P2 \\
\hline Ejercicio 2 & No de resp. $^{*}$ & 3 & 5 & 1 & 5 & 14 & 2 \\
\cline { 2 - 8 } & Porcentaje & 5’4\% & 8'9\% & 1'8\% & 8'9\% & $25 \%$ & 3’6\% \\
\hline
\end{tabular}

Como se observa, el número de alumnos que recurren a técnicas externas (la regla de tres en este caso) para resolver este ejercicio no es en absoluto desdeñable. Algunos alumnos, como A3 (en la Figura VI.326), incluso mencionan el nombre de la técnica:

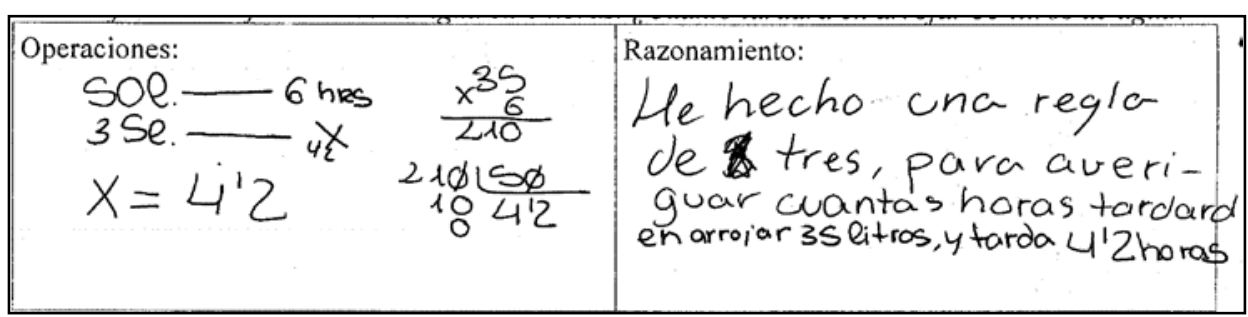

Figura VI.326.

Hay alumnos que, aunque no mencionen explícitamente la regla de tres o aunque no utilicen la típica disposición de los datos, ni una $x$ para señalar la cantidad buscada, muestran claramente en su método de resolución que han memorizado este proceso (ver respuesta de A8 en la figura VI.327): 


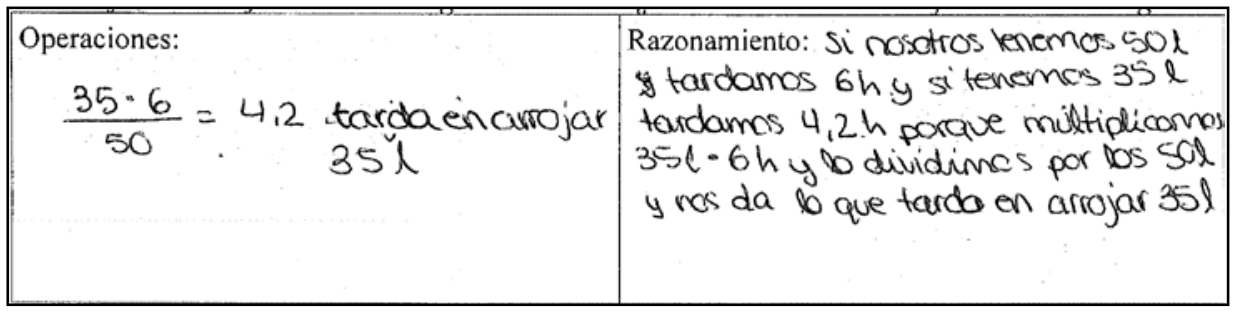

Figura VI.327.

De los 14 alumnos que han utilizado técnicas de este tipo, 12 han obtenido una respuesta correcta. Sin embargo, dos alumnos han cometido el error típico en este tipo de situaciones. En la Figura VI.328 se muestra el caso de A20:

\begin{tabular}{|c|c|}
\hline $\begin{array}{l}\text { Operaciones: } \\
\text { soe. } 6 h \\
35 e .-2 ? \\
(50 \cdot 6): 35=8 h \text { y media }\end{array}$ & $\begin{array}{l}\text { Razonamiento: } \\
\text { Si sorro so en Ghoras eso } \\
\text { quiere decir que si multiplica. } \\
\text { mos y dividimos estas mog. } \\
\text { hitudes, podremos saber } \\
\text { cuánto tarclara' en arrojar ssl }\end{array}$ \\
\hline
\end{tabular}

Figura VI.328.

Respecto a errores que suponen el uso de un procedimiento inadecuado (tipo P0), la mayor parte tienen que ver con un mal uso de las magnitudes. En la Figura VI329 siguiente, por ejemplo, el alumno A12 se ve quizás confundido por la expresión "litros por hora” y efectúa una operación que carece de significado:

\begin{tabular}{|c|c|}
\hline Operaciones: & Razonamiento: \\
\hline $\begin{array}{l}50 \mathrm{l} \cdot 6 \mathrm{~h}=300 \mathrm{l} / \mathrm{h} \\
300: 35=8^{\prime} 5 \mathrm{~h} \text { tordorac. }\end{array}$ & $\begin{array}{l}\text { Multiplicamas e por haras para } \\
\text { saber l/h y después lo dividimos } \\
\text { entre las zsl pora que nas } \\
\text { de el tiempo gee tarda. }\end{array}$ \\
\hline
\end{tabular}

Figura VI.329.

En la misma dirección encontramos casos como el alumno A51 que obtiene un resultado numérico correcto, pero a través de unas operaciones que no tienen sentido (Figura VI.330). A la hora de razonar, como es relativamente habitual, sólo describe las operaciones realizadas: 


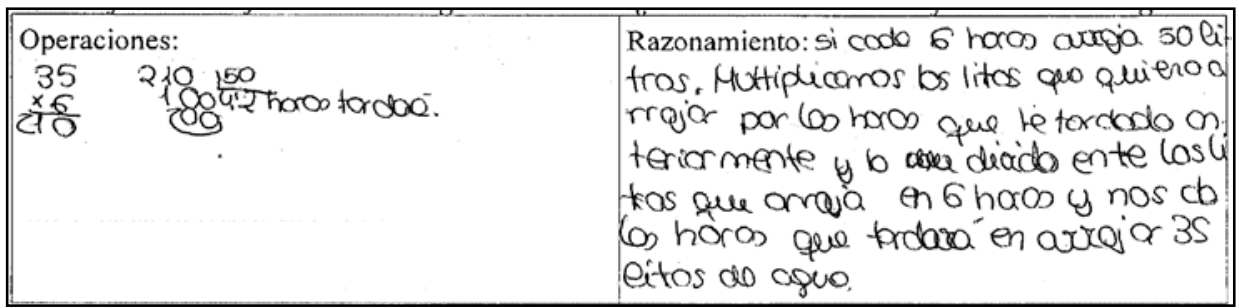

Figura VI.330.

Muy interesante, por ser el único ejemplo, es el error cometido por el alumno A18 (ver Figura VI.331):

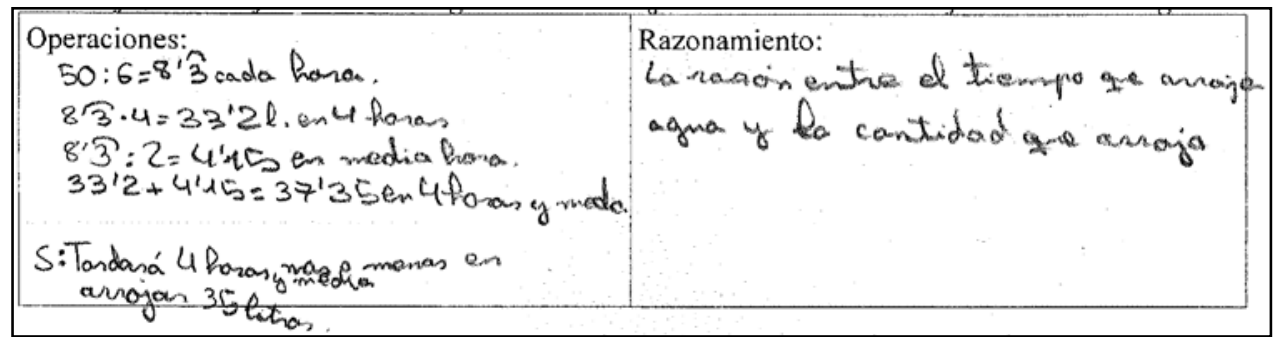

Figura VI.331.

El alumno ha calculado correctamente los litros que se vierten cada hora $(8,3 \ldots)$, pero para relacionar dicha cantidad con los 35 litros del enunciado, en vez de efectuar la división necesaria, ha tratado de construir dicha cantidad a partir de 8’3. Así, ha calculado el múltiplo más próximo y después ha considerado la mitad, obteniendo una aproximación que le ha parecido suficiente. Este tipo de razonamiento cuasi-aditivo se dio durante las primeras actividades, pero apenas había vuelto a aparecer.

Tan sólo hemos sido capaces de detectar un caso en el que se observa claramente una dificultad de tipo conceptual. Se trata del alumno A1, cuya respuesta mostramos en la Figura VI.332, a quien una mala comprensión de la situación, unida con el uso de una “mala” caracterización de la proporcionalidad, le hacen concluir que las magnitudes implicadas son inversamente proporcionales:

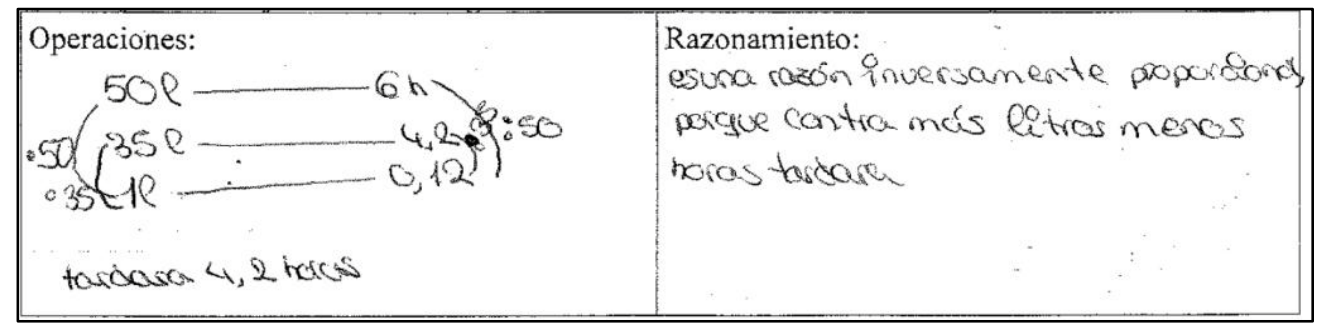

Figura VI.332. 
También encontramos casos, como el de A9 (ver Figura VI.333), en los que el alumno no llega a completar el ejercicio como consecuencia de una incorrecta o incompleta comprensión de la situación (lo que venimos llamando error de tipo C0):

\begin{tabular}{|l|l|}
\hline$\frac{50 \cdot 6}{35}=\frac{300}{35}$ & $\begin{array}{l}\text { Razonamiento: } \\
50 \text { litros } \rightarrow 6 \text { horas } \\
35 \text { fikm horas }\end{array}$ \\
\end{tabular}

Figura VI.333.

Anteriormente hemos presentado algunos casos en los que los alumnos conseguían dar una respuesta correcta pero utilizando técnicas “externas”. Sin embargo, bajo nuestro punto de vista, no podemos aceptar dichas respuestas como totalmente correctas pues, en cierto modo, suponen un fracaso de nuestra propuesta. Sin embargo hemos de decir que exactamente la mitad de los alumnos (28 en total) ha resuelto correctamente este ejercicio recurriendo a la idea de razón como "tanto por uno" y empleando las técnicas presentadas a lo largo de la propuesta. Entre estos 28 alumnos resulta extremadamente curioso, y así lo hacemos notar, que se da un reparto casi al 50\% entre alumnos que responden como A23 (ver Figura VI.334):

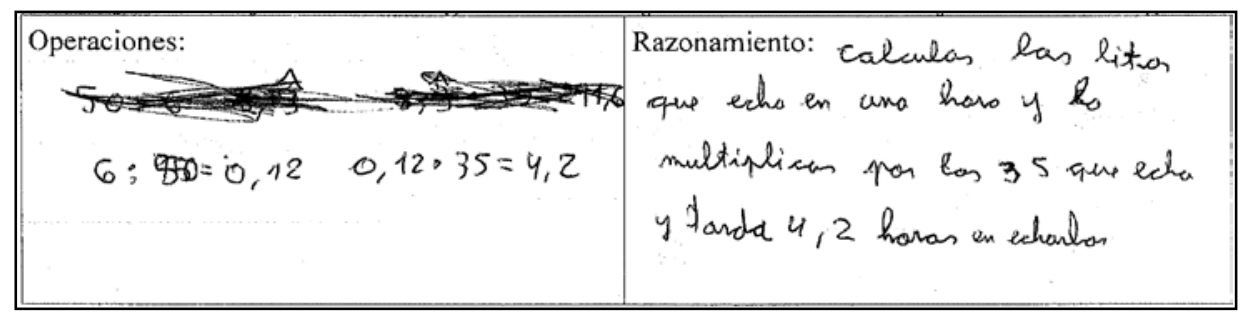

Figura VI.334.

Es decir; alumnos que de las dos posibles razones calculan aquella que les permite resolver el problema mediante una multiplicación y alumnos que como A45 (ver Figura VI.335 siguiente):

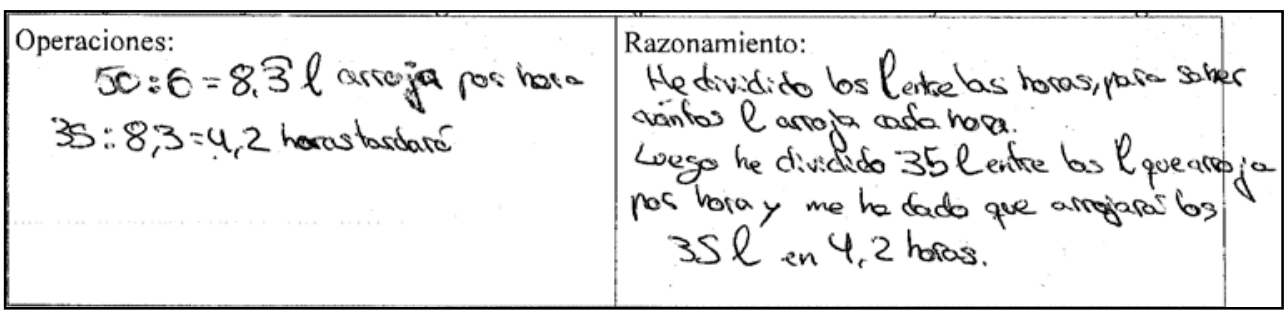

Figura VI.335. 
eligen aquella razón que implica la necesidad de una división para completar el ejercicio. No obstante, ambos casos demuestran una buena comprensión de la situación y de los significados de las operaciones efectuadas. Sin embargo resulta igualmente remarcable que sólo dos alumnos de entre estos 28 hagan mención explícita a alguna condición de regularidad necesaria para resolver el problema. Uno de ellos es A28 (en la Figura VI.336) que también menciona explícitamente el término “razón”:

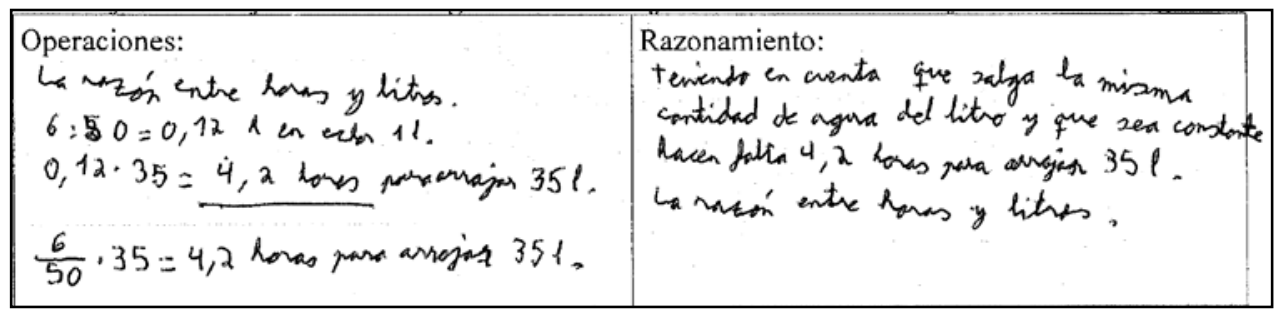

Figura VI.336.

En cualquier caso pensamos que resulta muy evidente la diferencia cualitativa entre estas últimas respuestas y las que dan los alumnos que recurren a la Regla de Tres. Esta diferencia queda patente de forma especial cuando se leen los razonamientos dados por los alumnos. En el caso de la Regla de Tres este razonamiento queda reducido a una mera descripción del procedimiento, mientras que en los últimos ejemplos presentados se observa como los alumnos indican claramente qué hacen y, sobre todo, qué obtienen como resultado de sus operaciones.

\section{Ejercicio 3:}

De nuevo se presenta a los alumnos una situación de búsqueda de una cantidad desconocida, aunque en este caso se trata de una situación en la que las magnitudes involucradas son inversamente proporcionales. En este contexto es menos esperable la aparición de la idea de razón, puesto que resultaría hasta cierto punto artificial. Mucho más natural es calcular la cantidad correspondiente a la magnitud oculta que nos sirve para poder hablar de proporcionalidad inversa (precio de la televisión en un caso, total de árboles a talar en el otro) y utilizar ese valor para resolver el problema; aunque algunos alumnos persistirán en el uso de la regla de tres.

Los errores en los que nos centraremos son los mismos que en el ejercicio anterior, aunque en este caso no se ha detectado ningún error conceptual concreto; tan 
sólo errores de tipo C0. Tampoco se han detectado errores aritméticos. En la siguiente tabla aparecen recogidas las frecuencias de cada tipo de error:

\begin{tabular}{|c|c|c|c|c|c|}
\hline \multicolumn{2}{|c|}{} & A & C0 & P0 & P1 \\
\hline Ejercicio 3 & $\mathbf{N}^{\mathbf{0}}$ de resp. & 4 & 5 & 9 & 10 \\
\cline { 2 - 6 } & Porcentaje & 7'1\% & 8'9\% & $16^{\prime} 1$ & $17^{\prime} 9 \%$ \\
\hline
\end{tabular}

$\mathrm{Al}$ igual que sucedía en el ejercicio anterior, encontramos alumnos que recurren a la regla de tres para resolver el problema, aunque el número se reduce ligeramente con respecto al ejercicio anterior. Sin embargo, la dificultad añadida que posee (en lo memorístico) el algoritmo de la Regla de Tres en el caso de magnitudes inversamente proporcionales hace que, mientras en el ejercicio anterior sólo 2 alumno de los 14 aplicaban mal el algoritmo; en este caso son 5 de los 10 alumnos los que, como A8 (en la Figura VI.337) lo aplican incorrectamente:

\begin{tabular}{|c|c|}
\hline $\begin{array}{l}\text { Operaciones: } \\
\qquad \frac{165 \cdot 11}{75}=24,2\end{array}$ & $\begin{array}{l}\text { Razonamiento: para hallare steprddema } \\
\text { tenemos que vaser una simple regla de } \\
\text { tres. Multiplicamcs } 11 \text { mes. por los } 165 \text { E } \\
\text { y después lo dividimes entre } 75 \text { nos } \\
\text { dará lo que fiene que pagar on } 165 \\
\epsilon \text { al mes. }\end{array}$ \\
\hline
\end{tabular}

Figura VI.337.

Es de destacar, por lo paradójico, la expresión “tenemos que hacer una simple regla de tres”. Además, incluso entre aquellos alumnos que aplican adecuadamente el algoritmo, la explicación dada a modo de razonamiento contrasta por su pobreza con la dada por cualquiera de los alumnos que resuelven calculan el valor de la televisión o el número de árboles (ver la respuesta de A10 en la Figura VI.338):

\begin{tabular}{|c|c|c|}
\hline $\begin{array}{l}\text { Operaciones: } \\
756 \longrightarrow 11 \text { ceses } \\
1656 \rightarrow \frac{1}{5} \text { meses }\end{array}$ & $\frac{75 \cdot 11}{265}: 5$ & 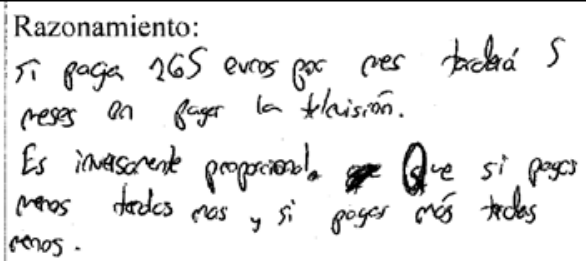 \\
\hline
\end{tabular}

Figura VI.338.

Respecto a errores conceptuales (en concreto de tipo $\mathrm{C} 0$ ), los casos más interesantes son el de A1 que responde diciendo: "no se puede hacer porque no se sabe lo que ha costado la TV” o los de A25, A36, A51 y A22 (ver éste último en la Figura 
VI.339) que simplemente realizan una serie de operaciones sin sentido (por más que el alumno se empeñe en asignar al número obtenido el significado apropiado en función de lo que se pide en el enunciado):

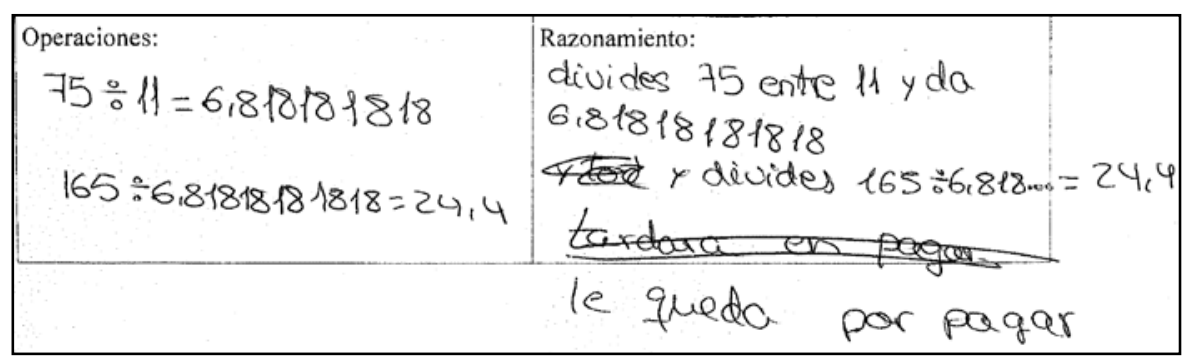

Figura VI.339.

Los errores de tipo P0 se reparten entre los alumnos que utilizan un procedimiento inadecuado fruto de que han cometido un error de tipo C0 (los cuatro casos reseñados en el párrafo anterior) y aquellos que han utilizado una versión incorrecta del algoritmo de la Regla de Tres.

En este ejercicio el porcentaje de alumnos que dan una respuesta correcta utilizando justificaciones basadas en el significado de las operaciones es mayor que en el ejercicio anterior (37 alumnos en total, un 66’1\%). La respuesta más común en este caso es similar a la del alumno A52 (ver Figura VI.340):

\begin{tabular}{|c|c|}
\hline $\begin{array}{l}\text { Operaciones: } \\
75 \cdot 11=8256 \text { cuenta len televisión. } \\
825: 165=5 \text { meres. }\end{array}$ & 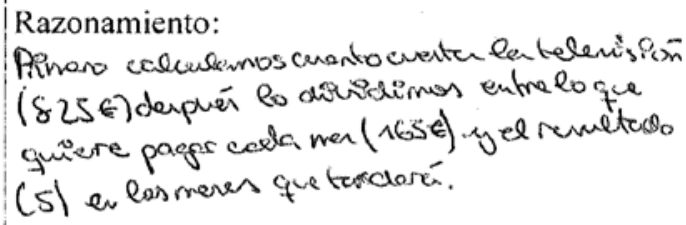 \\
\hline
\end{tabular}

Figura VI.340.

Estos alumnos calculan el precio total del televisor para después dividir por la mensualidad deseada y obtener así el número de meses necesarios para pagarla. Sin embargo, el alumno A39 razona de forma distinta (ver Figura VI.341): 


\begin{tabular}{|c|c|}
\hline $\begin{array}{l}\text { Operaciones: } \\
\frac{1}{2}=0,5 \\
3 \cdot 15=45 \text { arboles poda } e^{10} \\
45 \cdot 015=22,5\end{array}$ & $\begin{array}{l}\text { Razonamiento: } \\
\frac{1}{2} 0,5 \mathrm{~h} \text {. Tarda "dro" ea podar } 1 \text { árbol } \\
45 \text { arbales poda el } 10 \text { en total } \\
22,5 \text { horas que tarda en plantar todo }\end{array}$ \\
\hline
\end{tabular}

Figura VI.341.

Aunque no es el mismo problema, se observa claramente la estructura similar de ambos. Este alumno razona en una primera fase como sus compañeros y calcula el número total de árboles a podar. A partir de dicho dato, si hubiera razonado como el resto de alumnos le habría bastado dividir el total de árboles entre los árboles por hora que poda el segundo agricultor. Sin embargo A39 opta por calcular el tiempo que emplea dicho agricultor en podar un árbol y multiplica dicha cantidad por los árboles a podar. Es posible que en el ejercicio propuesto a A39 sea más factible razonar en el modo en que lo hace, puesto que en el otro enunciado implicaría calcular los meses necesarios para pagar $1 €$, magnitud que pese a tener sentido es, digamos, poco natural.

\section{Ejercicio 4:}

Este ejercicio estaba relacionado con el concepto y el cálculo de porcentajes. En concreto, se presentan dos apartados, en el primero se plantea el (habitualmente) llamado problema directo; que consiste simplemente en calcular un cierto porcentaje de una cantidad dada. En el segundo apartado se presenta el problema inverso que no consiste sino en calcular una cantidad total a partir de la cantidad que se corresponde con un porcentaje conocido.

A lo largo de las tareas y actividades realizadas durante la propuesta ya se observó que, quizás debido a que se trata de un contenido ya trabajado en la escuela primaria, los alumnos tenían muy afianzado el uso de los algoritmos relacionados con el cálculo de porcentajes y que, además, los aplicaban, con mayor o menor fortuna, pero sin apenas reflexión. Por esto, aunque los aspectos conceptuales del porcentaje son de gran importancia y deberían ser objeto de reflexión, nos centraremos únicamente en analizar los errores de tipo procedimental cometidos por los alumnos

Puesto que se trata de problemas inversos, estudiaremos por separado los dos apartados del ejercicio a la hora de analizar las respuestas de los alumnos. 


\section{Apartado a):}

En este apartado se proporcionaba el número total de libros de una biblioteca (o el de habitantes de una ciudad) y se hacía una pregunta de modo que para responderla era necesario calcular un porcentaje de esa cantidad.

Los errores detectados en las respuestas de los alumnos aparecen detallados en la tabla siguiente:

\begin{tabular}{|c|c|c|c|c|c|}
\hline \multicolumn{2}{|c|}{} & A & P0 & P1 & P2 \\
\hline $\begin{array}{c}\text { Ejercicio 4 } \\
\text { Apartado a) }\end{array}$ & $\mathbf{N}^{\mathbf{0}}$ de resp. & 3 & 5 & 44 & 2 \\
\cline { 2 - 6 } & Porcentaje & 5’4\% & 8'9\% & 78'6 & 3’6\% \\
\hline
\end{tabular}

Lo cierto es que los resultados reflejados en la tabla anterior hablan por sí mismos. Más de las tres cuartas partes de los alumnos aplican de forma directa un algoritmo para calcular el porcentaje buscado, sin hacer apunte ninguno sobre el significado. De estos 44 alumnos tan sólo 2 lo hacen de forma incorrecta (A6, que comete un error aritmético y A8, ver página siguiente). Las formas que adquiere el algoritmo son diversas. Encontramos alumnos que primero multiplican por 6 y después dividen por 100 (A13, en la Figura VI.342 siguiente):

\begin{tabular}{|c|c|}
\hline $\begin{array}{l}\text { Operaciones: } \\
\qquad \begin{array}{l}425250 \cdot 6=2551500 \\
6 \%\end{array} 425250=2531500 \cdot 00=25545\end{array}$ & $\begin{array}{l}\text { Razonamiento: } \\
\text { Hoyamos a } 6 \% \text { de } 425250 \text { pora saber } \\
\text { los cibro que hau de matemáticas, en toirce } \\
\text { do } 20515 \text { libros de matemáticas. }\end{array}$ \\
\hline
\end{tabular}

Figura VI.342.

Hay alumnos que operan a la inversa, primero dividiendo por 100 y después multiplicando por 6 (como A23 en la Figura VI.343):

\begin{tabular}{|c|c|}
\hline $\begin{array}{l}\text { Operaciones: } \\
\qquad \begin{array}{l}425250: 100=4252,5 \\
4252,506=25515\end{array}\end{array}$ & 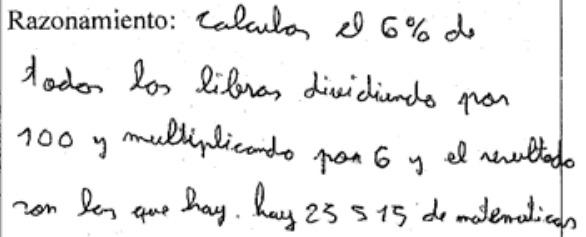 \\
\hline
\end{tabular}

Figura VI.343.

Otros alumnos utilizan la idea de porcentaje como fracción centesimal y utilizan la fracción como operador (por ejemplo, A7 en la Figura VI.344, que sigue): 


\begin{tabular}{|c|c|}
\hline Operaciones: & Razonamiento: \\
\hline 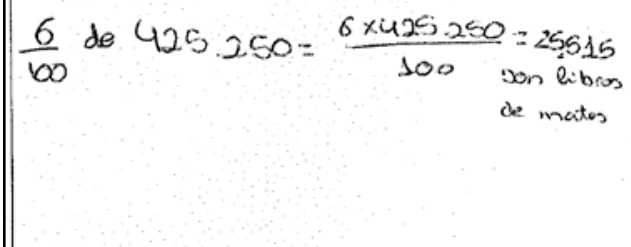 & 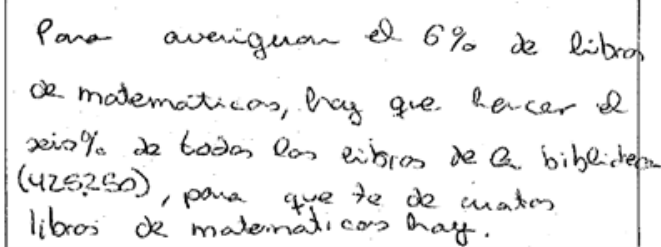 \\
\hline
\end{tabular}

Figura VI.344.

Y también los hay que disponen los datos ya en forma de fracción, con lo que es difícil saber en qué orden efectúan las operaciones (A10, en la Figura VI.345):

\begin{tabular}{|c|c|}
\hline $\begin{array}{l}\text { Operaciones: } \\
\qquad \frac{925250.6}{200}=25525\end{array}$ & 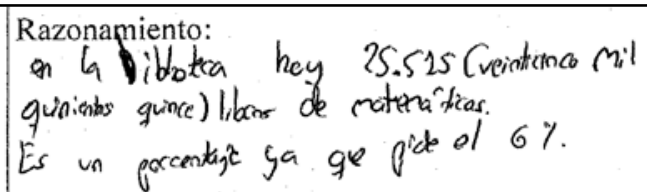 \\
\hline
\end{tabular}

Figura VI.345.

Lo que sí es común a todos los alumnos es el hecho de que el razonamiento es una mera descripción y es que, como dice el alumno A49 en su razonamiento "25515 son de matemáticas porque así se hace el porcentaje”.

Ahora bien, el colmo de la algoritmia lo representa A24; único alumno que resuelve este apartado utilizando la regla de tres y además con lenguaje algebraico (ver Figura VI.346):

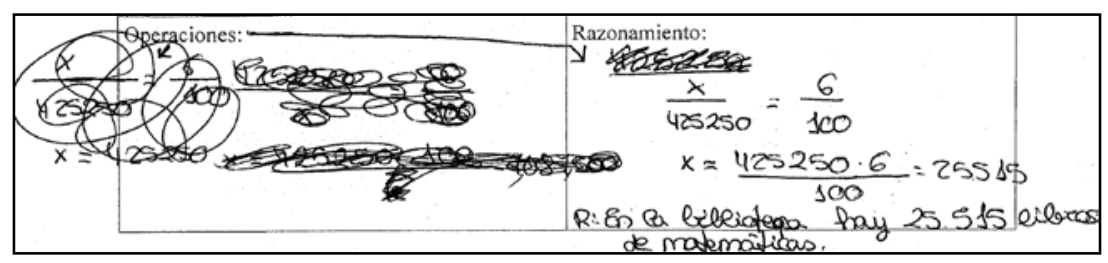

Figura VI.346.

Los inconvenientes del método se intuyen bajo los tachones.

Son escasísimos los ejemplos de alumnos que resuelven correctamente el ejercicio sin recurrir al mero uso de un algoritmo. De hecho son sólo 3 alumnos (un 5’4\%) cuyas respuestas son similares a la de A33 (ver Figura VI.347) que indica claramente el significado que posee la operación dividir por cien en este caso: 
Operaciones:

$425250: 100=4252,5$ grupos de 100

libros hay en 425250 libros.

$4252,5 \cdot 6=25515$ libros de mates hy.
Razonamiento:

Para averiguar los libros de mates que hay, hay que saber cuantos grupos de loo hay, parasaber cuantos 6 de cadal 100 libros hay en la biblisteca.

Figura VI.347.

Los errores consistentes en el uso de procedimientos inadecuados (tipo P0) varían en interés. Por ejemplo, el alumno A8 que ya hemos mencionado antes (ver Figura VI.348) calcula correctamente el porcentaje pero considera - por alguna desconocida razón - que debe hallar el complementario:

\begin{tabular}{|c|c|}
\hline $\begin{array}{l}\text { Operaciones: } \\
425250 \text { de } 6 \%=\frac{425250 \cdot 6}{100}= \\
=25515 . \\
425250-25515=399735 \text { libros } \\
\text { de matemóticas hay en } 1 a \text { bibloteca }\end{array}$ & $\begin{array}{l}\text { Razonamiento: tenemes que hallar a } 6 \% \\
425250 \text {. } \\
\text { o restarmos del total y que nos de } \\
\text { libros de maternáticas }\end{array}$ \\
\hline
\end{tabular}

Figura VI.348.

Otro error interesante consiste en simplemente dividir el total entre el porcentaje dado. Así lo hace, por ejemplo, A20 (ver Figura VI.349):

\begin{tabular}{|l|l|}
\hline Operaciones: & Razonamiento: \\
& Para saber cuántos libros hay de \\
& matemáticas hay que dividir
\end{tabular}

Figura VI.349.

Finalmente, hay algunos errores “extraños”. Así, el alumno A44 hace una cosa y dice otra (aunque ambas igualmente incorrectas, ver Figura VI.350):

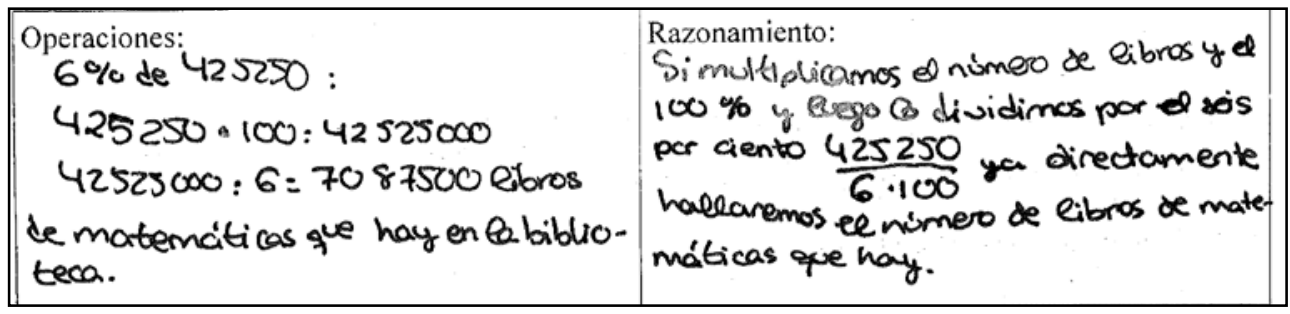

Figura VI.350.

Y el alumno A34, cuya respuesta, presentada en la Figura VI.351, resulta absolutamente indescriptible: 


$$
\begin{aligned}
& \text { Operaciones: } \quad \text { Razonamiento: En la biflioteca } \\
& 6 \%=16,66 \text {. haw } 16 \text { eibros de metes: } \\
& \text { l6\% libros de mates. }
\end{aligned}
$$

Figura VI.351.

Apartado b):

En este apartado se planteaba el problema inverso al anterior, a partir de una parte del total y del porcentaje que dicha parte representa, se pedía el cálculo de dicho total.

Los resultados obtenidos por los alumnos en estos apartados, de acuerdo con estas unidades de análisis, aparecen a continuación:

\begin{tabular}{|c|c|c|c|c|c|c|}
\hline \multicolumn{2}{|c|}{} & A & C0 & P0 & P1 & P2 \\
\hline $\begin{array}{c}\text { Ejercicio 4 } \\
\text { Apartado b) }\end{array}$ & $\mathbf{N}^{\mathbf{0}}$ de resp. & 10 & 1 & 25 & 14 & 1 \\
\cline { 2 - 7 } & Porcentaje & $17^{\prime} 9 \%$ & 1 '8\% & $44^{\prime} 6 \%$ & $25 \%$ & 1 '8\% \\
\hline
\end{tabular}

La mayor dificultad conceptual de este tipo de problema queda reflejada claramente en los resultados obtenidos, sobre todo en comparación con el apartado anterior. Casi la mitad de los alumnos utiliza un procedimiento inadecuado y aumenta mucho el número de respuestas en blanco, de tal modo que menos de la mitad de los alumnos resuelve correctamente el ejercicio y menos aún lo hacen empleando ideas relacionadas con la proporcionalidad y no meros algoritmos.

En este apartado, se ha reducido considerablemente el número de alumnos que recurren al uso de un algoritmo para resolver el problema (15 frente a los 44 del apartado anterior). Esto se debe a la mayor complejidad del mismo. Un ejemplo lo encontramos en la respuesta de A32 (ver Figura VI.352):

\begin{tabular}{|l|l|}
\hline Operaciones: & Razonamiento: \\
$2.145: 11=195 \cdot 100=19.500 \mathrm{CDs}$. & En la biblioteca has 19.500 \\
& COs de música en hotal.
\end{tabular}

Figura VI.352.

Además, siguen apareciendo las diversas versiones posibles del algoritmo, según el orden en que cada alumno piensa que debe realizar las operaciones. Si A32 primero divide y después multiplica, A47 (en la Figura VI.353) lo hace justo al revés: 


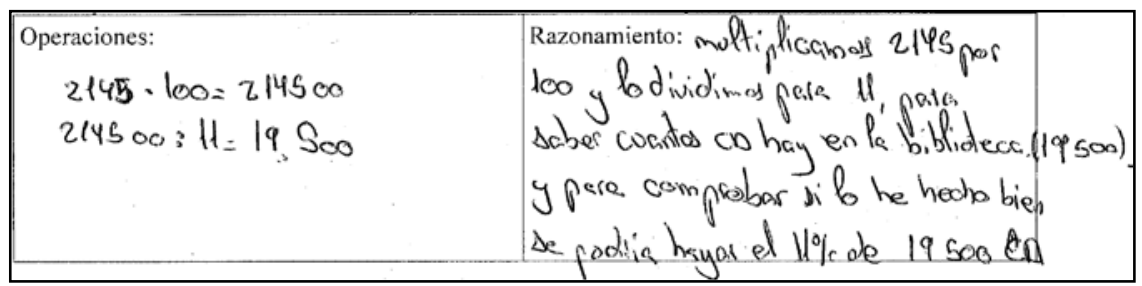

Figura VI.353.

De los 15 alumnos que recurren a métodos algorítmicos tan sólo dos no resuelven el ejercicio correctamente (A49, que comete un error aritmético, y A41, que comentaremos más adelante). Sin embargo hay 6 alumnos que, para evitar aplicar indiscriminadamente un algoritmo que probablemente no recuerdan, dan un significado a las operaciones que realizan. Es el caso de A6, por ejemplo, que recurre al cálculo de la cantidad correspondiente al 1\% del total (ver Figura VI.354):

\begin{tabular}{|c|c|}
\hline $\begin{array}{l}\text { Operaciones: } 2145: 11=195 \mathrm{CD} \text { son } 1 \% . \\
195 \cdot 100=19500 \mathrm{CD} \text { hay en tatul en la } \\
\text { bellicteca. }\end{array}$ & 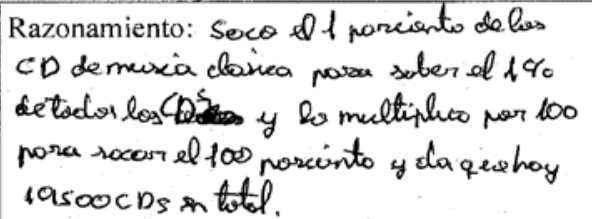 \\
\hline
\end{tabular}

Figura VI.354.

En cuanto a alumnos que utilizan procedimientos inadecuados, nos encontramos con una gran variedad de respuestas. Comentaremos algunas de las más interesantes. Por ejemplo, el alumno A41 (ver Figura VI.355) aplica el algoritmo de la Regla de tres adecuadamente, pero le falla la comprensión del enunciado y calcula el 89\% en vez del total:

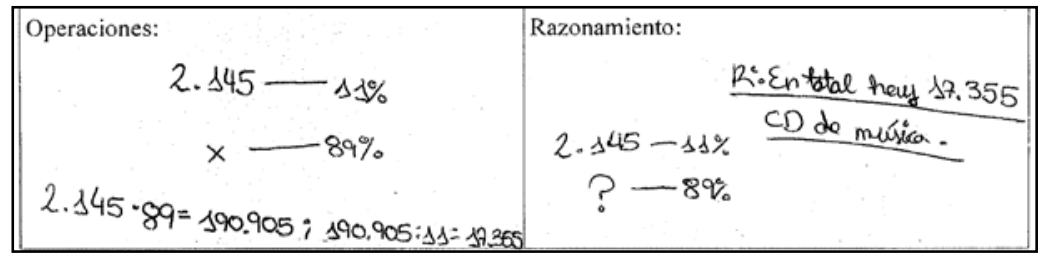

Figura VI.355.

Este problema a la hora de gestionar el $89 \%$ ha surgido en la mayor parte de los errores cometidos por los alumnos. El alumno anterior calculó (quizás sin saberlo) el 89\% del total. Otros, como A2 (en la Figura VI.356, que sigue) calculan el 89\% de la cantidad dada (que corresponde al 11\% del total) y después (en este caso, porque otros alumnos se conforman con esto) se lo suma a la cantidad dada: 


\begin{tabular}{|l|l|}
\hline Operaciones: & Razonamiento: Hay H. OS 4CD en \\
$100-11=89 \%$ & lo biblioteca. \\
$89 \%$ de $2145=1909$ & \\
$2145+1409=4054$ & \\
\hline
\end{tabular}

Figura VI.356.

Huelga decir que lo anterior carece de todo sentido. Del mismo estilo es el error cometido por A12 (en la Figura VI.357 siguiente) que, además calcula incorrectamente el 89\% de la cantidad dada (puesto que olvida dividir por 100):

\begin{tabular}{|c|c|}
\hline $\begin{array}{l}\text { Operaciones: } \\
2145-89=190905 \\
190905+2145=193050 \mathrm{CDs} \\
\text { en la biblioteca. }\end{array}$ & $\begin{array}{l}\text { Razonamiento: si el } 11 \% \text { es } 2145, \\
\text { el } 89 \% \text { restante se multiplica } \\
\text { por } 2145 \text {, para saber cuanto } \\
\text { es. Despoés, sumamos el } 11 \% \\
\text { y al } 89 \% \text { y nos do el total } \\
\text { de cos }\end{array}$ \\
\hline
\end{tabular}

Figura VI.357.

El error más común ha sido, no obstante, calcular el 11\% de la cantidad dada que ya era dicho 11\% del total. Así lo hace, por ejemplo, A53 (ver Figura VI.358):

$$
\begin{aligned}
& \text { Operaciones: } \\
& 11 \% \text { de } 2145 \text { el total }=235,95 \text { libres }
\end{aligned}
$$

Figura VI.358.

Por último, el alumno A25 ha sido el único caso en el que podemos asegurar que no se ha comprendido la situación. Este alumno respondió que "no se puede saber porque no se sabe los libros que hay en la biblioteca”. ¡Claro! Justo eso es lo que se pedía calcular.

\section{Ejercicio 5:}

Este ejercicio viene a completar, junto con los ya presentados ejercicios 2 y 3, la terna de situaciones que se pueden presentar en cuanto a problemas de búsqueda de cantidades desconocidas se refiere. Los dos anteriores se correspondían a situaciones de proporcionalidad directa e inversa. En este ejercicio, sin embargo, las magnitudes involucradas (edad y peso o edad y estatura) no están relacionadas (aunque exista una cierta correlación estadística entre ellas) y muchísimo menos lo están de un modo directa o inversamente proporcional. A esto, además, hay que añadir el hecho de que si se supone proporcionalidad directa las respuestas obtenidas son absurdas. 
Las frecuencias de los errores detectados en este ejercicio aparecen detalladas a continuación:

\begin{tabular}{|c|c|c|c|c|c|c|}
\hline \multicolumn{2}{|c|}{} & A & C0 & CP2 & P0 & P1 \\
\hline Ejercicio 5 & $\mathbf{N}^{\mathbf{0}}$ de resp. & 2 & 3 & 2 & 8 & 1 \\
\cline { 2 - 7 } & Porcentaje & 3’6\% & 7’1\% & 3'6\% & $14{ }^{\prime} 3 \%$ & 1'8\% \\
\hline
\end{tabular}

Como era de esperar, dados los antecedentes, el porcentaje de alumnos que resuelve acertadamente el ejercicio señalando que las magnitudes involucradas no están relacionadas es muy alto (46 alumnos, un 82’1\%). Sin embargo aparecen algunos errores que no por lo anecdótico dejaremos de analizar.

Tan sólo dos alumnos (A16 y A52) han razonado suponiendo que las magnitudes son directamente proporcionales y que todos los años se gana el mismo peso. En la Figura VI.359 se muestra la respuesta de A16:

\begin{tabular}{|c|c|}
\hline $\begin{array}{l}\text { Operaciones: } \\
47: 13=3,61 \mathrm{Kg} \text { engenda cada } \\
\text { año. } \\
3,61.40=144,4 \mathrm{Kg} \text { pesara' } \\
\text { avando tenga } 40 \text { años. } \\
\text { Peror para cado año tendrá } \\
\text { que engordar } 3,61 \mathrm{Kg} \text {. }\end{array}$ & $\begin{array}{l}\text { Razonamiento: } \\
\text { Primere, he calculedo } \\
\text { cuanto, peso gana cada año. } \\
\text { Y después, lo the multiplicado } \\
\text { por los } 40 \text { años queme pide. }\end{array}$ \\
\hline
\end{tabular}

Figura VI.359.

No parece extrañarle la posibilidad de que una persona de 40 años pese más de 140 kilos.

El alumno A41 es el único alumno que ha querido resolver el problema utilizando la regla de tres (ver Figura VI.360) pero no lo ha completado. Quizás observó que no tenía sentido, pero la falta de costumbre (este alumno intentó aplicar la regla de tres en todos los ejercicios numéricos del examen) le impidió dar una explicación:

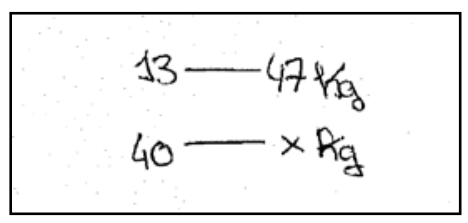

Figura VI.360.

Hay alumnos que no llegan a comprender la situación. Por ejemplo, el alumno A22 hace una serie de operaciones que carecen de sentido alguno y, además, a la hora de proporcionar un razonamiento repite exactamente las operaciones efectuadas (ver Figura VI.361): 


\begin{tabular}{|l|l|}
\hline Operaciones: & Razonamiento: \\
& Porque $47 \div 13=3,6$ \\
$40 \div 3,6=13$ & 411111111 \\
$40 \div 3,6=11,11111111$ & \\
$47+11,11111111=58,11 \ldots$ & $47+11,11111111=58,1 \ldots$ \\
\hline
\end{tabular}

Figura VI.361.

Mucho más interesante, quizás por lo inesperado, resulten los dos alumnos (A30 y A34) que razonan aditivamente manteniendo constante la diferencia entre peso y edad. Uno de ellos además (el alumno A30, en la Figura VI.362) comprende e indica que ese argumento se basa en la suposición de que todos los años se engorde un kilo:

\begin{tabular}{|c|c|}
\hline $\begin{array}{l}\text { Operaciones: } \\
-40+47 \\
\frac{13}{27}+\frac{27}{74}\end{array}$ & $\begin{array}{l}\text { Razonamiento: } \\
\text { Suponiendo que cada } \\
\text { año engordara un } \\
\text { Kilo y le fultan } 27 \text { años } \\
\text { para tener } 40 \text { les } \\
\text { Sumo los } 2 z \text { años que le }\end{array}$ \\
\hline
\end{tabular}

Figura VI.362.

En cualquier caso, como ya hemos dicho, la gran mayoría de los alumnos indica acertadamente que "este problema no se puede resolver porque las magnitudes no están relacionadas entre sí" (A15) o que "no se puede hacer porque cada año no engorda la misma cantidad de kilos” (A18). Incluso, algún alumno (A49) parece apuntar hacia la idea de función afín al decir que "no puede ser porque nació con un peso y no tiene por qué pesar siempre lo mismo más”. Finalmente, algunos alumnos (como A40 en la Figura VI.363) observan que la suposición de las condiciones de regularidad necesarias conduce a una respuesta absurda:

\begin{tabular}{|c|c|}
\hline $\begin{array}{l}\text { Operaciones: } 47: 13=3,6 \\
3,6 \cdot 40=\underline{144} \\
\text { A bs } 40 \text {, se supone que tendra } \\
144 \text { kilos. }\end{array}$ & $\begin{array}{l}\text { Razonamiento: Lo he intentado } \\
\text { calou kat pero el peso no tiene } \\
\text { que ver con la edad. Tendri que } \\
\text { tener una serie de condiciones } \\
\text { de regu kridad y suponiendo que las } \\
\text { tiene, yo te he hecho. }\end{array}$ \\
\hline
\end{tabular}

Figura VI.363.

Aunque, como es natural, viendo esta respuesta es difícil saber si el alumno simplemente resolvió el problema y al observar la respuesta pensó que era imposible y trató de justificarse o si, en efecto, comprendió la situación con todos sus matices. 


\section{Ejercicio 6:}

En el último de los ejercicios de la prueba se plantean tres situaciones. En cada una de ellas aparece una pareja de magnitudes. En concreto (y siguiendo con la habitual tricotomía que venimos presentando), en el apartado a) las magnitudes son directamente proporcionales, en el b) no están relacionadas y en el c) son inversamente proporcionales. Se pedía a los alumnos que indicaran precisamente cuál era el caso para cada pareja de magnitudes. Además de tener que analizar la situación y aplicar, en su caso, las ideas que se habían trabajado en clase sobre la proporcionalidad directa y la inversa; los alumnos debían superar la dificultad que les suele suponer enfrentarse a una cuestión matemática en la que no aparecen números.

Como veremos, en este ejercicio se manifestó de forma muy intensa (más que en cualquier otro) la influencia externa sobre los alumnos. En concreto la cantidad de respuestas que aluden a la incorrecta (pero habitual y tradicional) idea de que "si a más, más” es sinónimo de proporcionalidad directa y que “si a más, menos” lo es de inversa. Esta aparición sorprende ya que en ningún momento se hizo mención alguna de ese tipo de razonamiento, ni por parte de los alumnos, ni por parte del profesor. Posiblemente, la explicación a este hecho radique en que la alta dificultad de este ejercicio (dado su carácter conceptual) haga que los alumnos echen mano de las explicaciones recibidas fuera de clase que, aunque incorrectas, les resultan más sencillas y operativas.

Puesto que cada uno de los tres apartados se corresponde con una situación esencialmente distinta, los analizaremos por separado como viene siendo habitual.

\section{Apartado a):}

En este apartado las dos magnitudes presentadas podían suponerse (bajo las condiciones adecuadas) como directamente proporcionales. Los errores cometidos por los alumnos en este apartado, de acuerdo con la clasificación que venimos utilizando, se reparten del siguiente modo:

\begin{tabular}{|c|c|c|c|c|c|c|c|}
\hline \multicolumn{2}{|c|}{} & A & C0 & CP1 & CP3 & CP4 & P1 \\
\hline $\begin{array}{c}\text { Ejercicio 6 } \\
\text { Apartado a) }\end{array}$ & $\mathbf{N}^{\mathbf{0}}$ de resp. & 1 & 10 & 3 & 13 & 5 & 15 \\
\cline { 2 - 8 } & Porcentaje & $11^{\prime} 8 \%$ & $17^{\prime} 9 \%$ & $5{ }^{\prime} 4 \%$ & $23{ }^{\prime} \%$ & $8{ }^{\prime} 9 \%$ & $266^{\prime} 8 \%$ \\
\hline
\end{tabular}


Ya se ha hablado de la influencia externa (error de tipo P1) y los datos hablan claramente. Casi un 27\% de los alumnos, incluso algunos que no utilizan reglas de tres en los problemas, responden con frases del estilo de:

- "Directamente proporcionales porque cuando una aumenta la otra también aumenta” (A16).

- "Sí, están relacionadas directamente proporcionales. Contra mas azúcar tengamos, mas tartas obtendremos” (A11).

- “Directamente proporcional, cuanto más raciones de tarta, más azúcar” (A24).

Cinco alumnos (A4, A38, A45, A53 y A56) identifican la proporcionalidad inversa con la falta de relación entre las magnitudes (error de tipo CP4). Por ejemplo, el alumno A56 dice: “Inversamente proporcionales. No tienen nada que ver” pero, de hecho, este alumno señalará como directamente proporcionales las magnitudes del apartado c) cuya relación es inversa, argumentando que "sí se puede saber".

Un buen número de alumnos (casi la cuarta parte) considera que las magnitudes presentadas no están relacionadas (error de tipo CP3). Algunos de ellos se limitan a responder que "no están relacionadas" (como es el caso de A9). En otros casos lo que sucede es que el alumno parece no haber comprendido bien la situación; así A12 responde: "No están relacionadas porque una tarta se puede repartir en las raciones que uno quiera y puede que la tarta sea sin azúcar”. Finalmente, hay casos en los que el alumno presenta como objeción precisamente la condición de regularidad que sería necesario asumir para responder que las magnitudes son directamente proporcionales; por ejemplo A51 dice: “No están relacionadas porque en cada ración no tiene por qué haber la misma cantidad de azúcar”.

Tan solo tres alumnos (A26, A30 y A52) confunden la relación entre las magnitudes (error de tipo CP1) y responden como hace, por ejemplo, el alumno A26: “están relacionadas son inversamente proporcionales". Sin embargo, en todos los casos, la ausencia de explicación impide comprender las causas del error

Por último, veinticuatro alumnos indican que las magnitudes son directamente proporcionales. De ellos, sólo nueve aluden en mayor o menor medida a la idea de razón. Por ejemplo: 
- "Sí está relacionadas y son directamente proporcionales porque puedes dividir la cantidad de azúcar necesaria entre las raciones para saber cuánto azúcar lleva cada ración” (A45).

- "Son directamente proporcionales porque sabiendo la cantidad de azúcar y las raciones, haciendo la razón obtienes la cantidad de azúcar que tiene cada ración y tiene sentido saberlo" (A28).

- "Sí, porque cada ración de tarta tiene que llevar la misma cantidad de azúcar". (A7)

Eso sí, como salta a la vista, los alumnos que aluden explícitamente a la idea de razón no hablan de condición de regularidad y los, siquiera de pasada, la mencionan no hablan explícitamente de razón.

\section{Apartado b):}

Las magnitudes presentadas en este caso no están relacionadas de ningún modo. En general, este tipo de situaciones causaba pocos problemas entre los alumnos y los resultados, como se verá, así lo corroboran. Como venimos haciendo, en la tabla siguiente quedan recogidas las frecuencias de aparición de los errores cometidos por los alumnos:

\begin{tabular}{|c|c|c|c|c|c|c|}
\hline \multicolumn{2}{|c|}{} & A & CP1 & CP2 & CP4 & P1 \\
\hline $\begin{array}{c}\text { Ejercicio 6 } \\
\text { Apartado b) }\end{array}$ & $\mathbf{N}^{\mathbf{0}}$ de resp. & 1 & 2 & 3 & 6 & 1 \\
\cline { 2 - 7 } & Porcentaje & $1^{\prime} 8 \%$ & $3^{\prime} 6 \%$ & $5{ }^{\prime} 4 \%$ & $10^{\prime} 7 \%$ & 1 '8\% \\
\hline
\end{tabular}

Como ya se esperaba son muy pocos los alumnos que cometen algún error en este apartado.

Los alumnos A18, A33 y A40 consideran que las magnitudes implicadas son directamente proporcionales (error de tipo CP2). Por ejemplo, A40 responde que "son directamente proporcionales porque mientras vas creciendo aumentas tu capacidad de correr”. Aunque aquí parece rastrearse la influencia de la idea de que a más edad más velocidad, lo cierto es que el resto de respuestas de este alumno no indican razonamientos de este tipo. 
Sí que aparecen argumentos así (error de tipo P1) entre algunos de los alumnos que consideran que las magnitudes presentadas son inversamente proporcionales (error de tipo CP1). Por ejemplo, A31 considera que "Son inversamente proporcionales porque según te vas haciendo más mayor, si no te entrenas, vas perdiendo velocidad”. El alumno A6 hace referencia a la forma de caracterizar magnitudes inversamente proporcionales que se presentó en clase: "son inversamente proporcionales porque faltaría una tercer magnitud que nos daría la posibilidad de hacer razones entre ellas”, pero ni dice cuál es dicha tercera magnitud ni queda claro en qué pueda estar pensando. Finalmente hay seis alumnos que confunden el ser inversamente proporcionales con el no estar relacionadas (error de tipo CP4) y responden como A46: “inversamente proporcionales ya que la velocidad a la que corres no tiene nada que ver con la edad”.

Entre los alumnos que no cometen ningún error, las explicaciones al hecho de que las magnitudes presentadas no guardan relación son de lo más variopinto:

- "Una persona mayor corre poco, un bebé corre poco, pero un joven corre mucho. No tiene nada que ver" (A41).

- “Todo depende de la forma física” (A50).

- "No están relacionadas porque si esto fuera verdad el más viejo correría más” (A19).

Dos alumnos (A11 y A44) responden que la edad de una persona no es una magnitud.

\section{Apartado c):}

En este caso las magnitudes presentadas podían suponerse inversamente proporcionales. Los errores cometidos por los alumnos en estos apartados se detallan a continuación:

\begin{tabular}{|c|c|c|c|c|c|c|}
\hline \multicolumn{2}{|c|}{} & A & C0 & CP1 & CP4 & P1 \\
\hline $\begin{array}{c}\text { Ejercicio 6 } \\
\text { Apartado c) }\end{array}$ & $\mathbf{N}^{\mathbf{0}}$ de resp. & 3 & 9 & 13 & 6 & 19 \\
\cline { 2 - 7 } & Porcentaje & $5^{\prime} 4 \%$ & $16^{\prime} 1 \%$ & $23{ }^{\prime} \% \%$ & $10{ }^{\prime} 7 \%$ & $333^{\prime} 9 \%$ \\
\hline
\end{tabular}

Estos resultados muestran claramente que la dificultad de este apartado ha sido mayor para los alumnos. 
En primer lugar, hay un número bastante elevado de alumnos que responde que las magnitudes son directamente proporcionales (error de tipo CP1). La mayoría de los alumnos que comenten este error piensan que es posible definir la razón entre las magnitudes presentadas (lo que no es cierto). Este error ya apareció en actividades anteriores y está relacionado con asociar la razón sólo con la idea de "tanto por uno” y no con la posibilidad de un "reparto”. Un ejemplo claro lo proporciona el alumno A13 al responder: "son directamente proporcionales porque la razón es el número de personas que se necesita para terminar la obra en un día o los días que necesita una persona para terminar la obra”.

También hay alumnos confunden la proporcionalidad directa entre magnitudes con la mera existencia de una relación entre las dos magnitudes (error de tipo CP4). Es el caso del alumno A46 cuando responde que "son directamente proporcionales porque si varía una varía la otra”.

Como en el apartado a), el error más común (por más que la conclusión pueda ser correcta) involucra la falsa idea de que basta con una relación funcional decreciente para hablar de proporcionalidad inversa (error de tipo P1). Por citar un ejemplo de los alumnos que así responden podemos presentar la respuesta de A35: “Es inversamente proporcional ya que cuanta más gente haya menos tardarán en acabar o por el contrario si hay poca gente habrá más tiempo de trabajo”.

Respecto a alumnos que no comprenden la situación (error de tipo C0) tenemos respuestas como la de A48: “depende de si van al mismo ritmo y hacen lo mismo en cada día” o la del alumno A20 que dice que "son dos magnitudes que al revés son igual de proporcionales".

En esta situación, son muy pocos (tan sólo 7) los alumnos que dan una respuesta relativamente satisfactoria. La mejor, posiblemente, sea la de los alumnos A17 y A37 que responden casi lo mismo (damos la respuesta de A17): "son inversamente proporcionales porque entre las magnitudes variables que son el número de obreros y el tiempo que tardan en terminar la obra no se puede definir la razón, pero sí que se puede si cogemos una tercera magnitud que es fija: el tamaño de la obra”. Esta respuesta no sólo muestra una comprensión de la caracterización de las magnitudes 
inversamente proporcionales, sino también de la situación, puesto que indica claramente qué magnitudes varían, cuál está fija, etc...

\section{Reflexiones sobre la prueba:}

1. Con respecto a la idea de razón y de condición de regularidad:

- Los alumnos parecen tener bastante clara la idea de razón como "tanto por uno”. De hecho, es posible que tiendan a utilizarla en situaciones inapropiadas obviando el hecho de que no sólo la idea de "tanto por uno" es sustancial, sino también el hecho de que se pueda "repartir" (en sentido amplio) una magnitud entre la otra.

- El papel de la existencia de la razón entre las magnitudes como definitorio del concepto de proporcionalidad directa queda bastante enmascarado por la influencia externa y la aparición del “a más, más”.

- Los alumnos no mencionan explícitamente la condición de regularidad a menos que se les pregunte por ella.

- Lo mismo sucede con el significado de la razón, aunque sí que utilizan operativamente dicho significado a la hora de resolver problemas de búsqueda de cantidades desconocidas en situaciones de proporcionalidad inversa.

2. Con respecto a los porcentajes:

- Los alumnos no perciben el porcentaje como poseedor de un significado similar al de la razón. El significado está completamente enmascarado por el manejo de los algoritmos que ya conocen desde la primaria.

- Los problemas de porcentajes no se perciben como problemas relacionados con la proporcionalidad y así no hay mención alguna ni sobre la idea de razón ni sobre las condiciones de regularidad.

3. Con respecto a las situaciones de proporcionalidad:

- Resulta bastante sencillo para los alumnos detectar situaciones en las que las magnitudes no están relacionadas. De hecho, algunos hilan incluso demasiado fino y acaban por considerar que dos magnitudes no están relacionadas cuando sí que pueden estarlo asumiendo una condición de regularidad razonable. 
- Algunos alumnos han llegado a identificar la proporcionalidad directa con la existencia de una relación entre las magnitudes y la proporcionalidad inversa con que las magnitudes no guarden relación entre ellas.

- El reconocimiento de las situaciones de proporcionalidad inversa es, con mucho, la mayor fuente de problemas para los alumnos.

4. Con respecto a la resolución de problemas:

Los alumnos resuelven bastante bien los problemas relacionados directamente con la proporcionalidad. Ahora bien, el uso de la razón es más bien implícito y las condiciones de regularidad apenas se verbalizan. De hecho, muchos alumnos que reconocen mal las situaciones de proporcionalidad directa, inversa o de no proporcionalidad resuelven correctamente problemas de búsqueda de cantidades desconocidas.

5. Con respecto a la influencia externa:

- La influencia externa recibida por los alumnos se pone de manifiesto en dos aspectos fundamentales:

o El uso de la Regla de Tres.

o La caracterización de la proporcionalidad directa en términos de crecimiento o decrecimiento.

- El recurso de los alumnos (incluso de aquellos que durante la propuesta no utilizaron dichas ideas, pero comprendían y resolvían bien las tareas), posiblemente se explica por la presión familiar y/o social a sacar una buena nota. Las técnicas recibidas desde el exterior, pese a su incorrección, resultan más sencillas de memorizar y de aplicar por parte del alumno que se preocupa más por resolver el ejercicio que por comprenderlo.

- En cualquier caso los resultados de la prueba muestran que existen alumnos que han sido capaces de asimilar y aplicar perfectamente las ideas presentadas durante la propuesta. 


\section{CAPÍtUlo VII:}

\section{CONCLUSIONES.}

\section{VII.1. INTRODUCCIÓN}

En la presente memoria se ha dado cuenta del desarrollo de una investigación centrada en la búsqueda de alternativas a la enseñanza habitual de los aspectos relacionados con la Proporcionalidad Aritmética. En particular, nos hemos centrado en elaborar una propuesta didáctica novedosa a partir de un profundo análisis fenomenológico histórico y didáctico. Esta propuesta gira en torno a los siguientes aspectos:

1. La razón como "tanto por uno".

2. La condición de regularidad como elemento clave para identificar las situaciones de proporcionalidad.

3. La separación entre las situaciones de proporcionalidad directa e inversa.

4. La potenciación de la estructura multiplicativa de los números racionales positivos dando significado a las operaciones con cantidades de magnitud.

5. La justificación de las técnicas adecuadas adaptadas a las ideas de proporcionalidad puestas en juego.

Además, esta propuesta didáctica se ha adaptado parcialmente para ser llevada a la práctica con dos grupos de alumnos de primer curso de E.S.O.

En este capítulo final vamos a presentar las conclusiones de mayor relevancia que se han obtenido a lo largo de la investigación, tanto en lo relativo a la comprensión alcanzada por los alumnos como a la propia propuesta didáctica. También 
presentaremos algunas líneas de trabajo futuras que surgen de forma natural a partir de los resultados de esta memoria.

\section{VII.2. CONCLUSIONES SOBRE LA COMPRENSIÓN DE LOS CONTENIDOS}

En el Capítulo I, en concreto en el punto I.4.2., se presentaron los principales focos de investigación en los que se iba a centrar nuestro trabajo. A través de la propuesta didáctica diseñada e implementada se pretendía mejorar la comprensión de los alumnos en tres campos fundamentalmente:

1. En el uso significativo de las estructuras multiplicativas que se han estudiado con anterioridad.

2. En la aprehensión de los aspectos conceptuales relacionados con la proporcionalidad.

3. En la aplicación de dichos aspectos a la hora de resolver situaciones problemáticas relacionadas con la proporcionalidad.

Parece natural, por tanto, organizar nuestras conclusiones en torno a los tres puntos anteriores.

\section{VII.2.1. Uso significativo de las estructuras multiplicativas}

El primer paso en este sentido se daba ya en las primeras actividades propuestas a los alumnos. En la Actividad de aula 1 y en la Tarea de casa 1 se presentaban a los alumnos situaciones de intercambio concretas en las que se conocía la cantidad de pajitas obtenidas a cambio de 4 tarjetas y se le preguntaba por la cantidad de pajitas obtenidas a cambio de otras cantidades de tarjetas (o a la inversa). Ante este tipo de cuestiones las estrategias utilizadas por los alumnos, como ya se vio en el Capítulo VI, no son únicas y en la tabla siguiente se muestran las que se han descubierto.

\begin{tabular}{|c|c|c|c|}
\cline { 2 - 4 } \multicolumn{1}{c|}{} & Multiplicativa & Aditiva & Razón directa \\
\hline Sobre 1 & $82^{\prime} 6 \%$ & $0 \%$ & $17^{\prime} 4 \%$ \\
\hline Sobre 2 & $83^{\prime} 3 \%$ & $0 \%$ & $16^{\prime} 7 \%$ \\
\hline Sobre 3 & $19 \%$ & $28^{\prime} 6 \%$ & $52^{\prime} 4 \%$ \\
\hline Sobre 4 & $23{ }^{\prime} 8 \%$ & $23^{\prime} 8 \%$ & $52^{\prime} 4 \%$ \\
\hline Sobre 5 & $38^{\prime} 9 \%$ & $0 \%$ & $61^{\prime} 1 \%$ \\
\hline
\end{tabular}

Tabla VII.1. Estrategias en la Actividad de aula 1. 
En la tabla anterior se han presentado las estrategias elegidas por los alumnos al realizar libremente la actividad (para más detalles puede verse la sección VI.2.1.1.). Posteriormente, se puso en común el trabajo haciendo énfasis en la importancia e interés del uso de la razón directa. En la Tarea de casa 1, completamente análoga a la actividad realizada en el aula las estrategias elegidas fueron:

\begin{tabular}{|c|c|c|c|c|}
\hline & Multiplicativa & Aditiva & Razón directa & Razón inversa \\
\hline Apartado 1 & $76^{\prime} 2 \%$ & $0 \%$ & $7^{\prime} 1 \%$ & $16^{\prime} 7 \%$ \\
\hline Apartado 2 & $45^{\prime} 9 \%$ & $27 \%$ & $8^{\prime} 1 \%$ & $19 \%$ \\
\hline Apartado 3 & $19^{\prime} 2 \%$ & $0 \%$ & $53^{\prime} 8 \%$ & $27 \%$ \\
\hline Apartado 4 & $13^{\prime} 8 \%$ & $6{ }^{\prime} 9 \%$ & $58{ }^{\prime} 6 \%$ & $20{ }^{\prime} 7 \%$ \\
\hline Apartado 5 & $14^{\prime} 3 \%$ & $10^{\prime} 7 \%$ & $533^{\prime} 6 \%$ & $21^{\prime} 4 \%$ \\
\hline Apartado 6 & $13^{\prime} 3 \%$ & $1 \%$ & $53^{\prime} 3 \%$ & $23^{\prime} 4 \%$ \\
\hline
\end{tabular}

Tabla VII.2. Estrategias en la Tarea de casa 1.

Aunque debido posiblemente a la proximidad en el tiempo el cambio no es espectacular, sí que se observa un progresivo abandono de las estrategias aditivas y un aumento de las estrategias relacionadas con la razón que son, a nuestro juicio, las que indican una mejor comprensión por parte del alumno de las ideas de producto y cociente implicadas en el proceso de intercambio.

Si bien la aplicación a situaciones problemáticas recibirá una mayor atención más adelante, ésta merece una mención en este punto. Muchos de los problemas “de proporcionalidad” que se plantean en el aula pueden resolverse fácilmente haciendo uso de los significados apropiados de las operaciones "producto" y "cociente” en el contexto del problema. Pensamos que nuestra propuesta ha contribuido a que los alumnos aborden de ese modo los problemas dejando de lado las técnicas tradicionales de la Regla de tres que no muestran claramente el porqué de las cosas.

A modo de ejemplo, recordar que el Ejercicio 3 de la prueba final decía: "Pagando 75 euros al mes tardaré 11 meses en pagar la televisión que me acabo de comprar. ¿Cuánto tardaré en pagarla si pago 165 euros al mes?’. Las frecuencias de cada una de las estrategias elegidas por los alumnos se recogen en la tabla siguiente: 


\begin{tabular}{|c|c|c|c|c|}
\hline \multirow{2}{*}{ En blanco } & \multicolumn{2}{|c|}{ Regla de tres } & \multicolumn{2}{c|}{ Operaciones } \\
\cline { 2 - 5 } & Correcto & Incorrecto & Correcto & Incorrecto \\
\hline 4 & 5 & 5 & 37 & 5 \\
\hline
\end{tabular}

Tabla VII.3. Estrategias en el Ejercicio 3 de la prueba final.

No sólo salta a la vista el claro desequilibrio a favor de estrategias que tratan de hacer uso únicamente del significado de las operaciones, sino que además mientras que el la mitad de los alumnos que optan por la Regla de tres lo hace de forma incorrecta tan sólo el 11’9\% de los alumnos que recurren al significado de las operaciones comete errores.

Pensamos por todo lo anterior que la propuesta que hemos desarrollado, si bien es mejorable, contribuye a que los alumnos hagan mayor y mejor uso de sus conocimientos sobre el significado de las operaciones aritméticas a la hora de resolver problemas relacionados con la proporcionalidad, obteniendo así un aprendizaje más significativo. Además se evita el recurso a técnicas algorítmicas que, además de requerir una memorización, hacen que el alumno identifique la resolución de problemas con la clasificación de problemas.

\section{VII.2.2. Aprehensión de aspectos conceptuales}

Generalmente los aspectos conceptuales son los que suelen dar mayores problemas a los alumnos a la hora de enfrentarse a las matemáticas. Esto es así en parte por la dificultad inherente a algunos de ellos pero también, y no en menor medida, al poco entrenamiento -podríamos decir - que poseen los alumnos en cuanto al manejo de conceptos “puros”. En general los alumnos conciben la matemática como una disciplina numérica y no aceptan que la respuesta a una pregunta en esta asignatura sea verbal y no un número.

En el caso que nos ocupa los conceptos fundamentales que se querían presentar eran la idea de razón como "tanto por uno" (y el porcentaje como "tanto por ciento" de modo análogo) junto con la idea de condición de regularidad y los conceptos de magnitudes directa e inversamente proporcionales. En todos los casos se trata de objetos matemáticos muy alejados de aquello con lo que los alumnos están acostumbrados a trabajar y cada uno les plantea diversos problemas. 


\section{VII.2.2.1. Las ideas de 'razón' y 'condición de regularidad'}

La idea de razón como "tanto por uno", tal y como se ha introducido a los alumnos, posee una doble vertiente que es lo que causa mayores dificultades a los alumnos. Nos referimos a la dicotomía entre “qué es” y “cuánto vale”. Además hemos de añadir a todo esto la idea de condición de regularidad, íntimamente ligada a la de razón (como condición necesaria para su existencia).

Los alumnos, en general, han mostrado problemas a la hora de manejar simultáneamente todas estas ideas. El Ejercicio 1 de la prueba final planteaba a los alumnos lo siguiente:

1.- Indica para estas situaciones (si se puede) las razones que aparecen y su significado. Señala también las condiciones de regularidad necesarias para poder hacerlo. Cuando no sea posible hablar de razón explica por qué:
a) En 2 horas han pasado 5 autobuses.
b) A las 3 de la tarde he quedado con 5 amigos.
c) 2 personas han tardado 5 días en pintar la casa.
d) 3 cajas de leche cuestan 2 euros.

En cada uno de los apartados el alumno debía “preocuparse” de múltiples aspectos y lo cierto es que muy pocos de los estudiantes pudieron dar cuenta de todos ellos correcta y simultáneamente.

Otro aspecto reseñable es la distinta dificultad que encuentran los alumnos en función de la situación que se les presenta. Este hecho no debe resultar sorprendente por cuanto las situaciones de proporcionalidad directa (como ya se vio en el Capítulo II) resultan mucho más naturales. Por ejemplo, fijémonos en parte de los resultados de los apartados a) y d):

\begin{tabular}{|l|c|c|c|}
\cline { 2 - 4 } \multicolumn{1}{c|}{} & Valor numérico de la razón & Significado de la razón & C. de regularidad \\
\hline Apartado a) & $42^{\prime} 9 \%$ & $64^{\prime} 3 \%$ & $44^{\prime} 6 \%$ \\
\hline Apartado b) & $46^{\prime} 4 \%$ & $75 \%$ & $46^{\prime} 4 \%$ \\
\hline
\end{tabular}

Tabla VII.4. Aspectos conceptuales relacionados con la razón. 
Los resultados ${ }^{1}$ son mejores en el apartado d) posiblemente (como se indicó ya en el Capítulo VI) debido a la mayor proximidad de la situación al alumno. Resulta sorprendente que, pese que los alumnos están acostumbrados a trabajar "sólo con números”, el valor numérico de la razón es señalado por menos de la mitad de los alumnos. Quizás se deba a cierta inseguridad a la hora de saber cómo se calcula.

En el apartado b) por ejemplo, donde no había posibilidad de definir razón alguna, los resultados son abrumadoramente mejores:

\begin{tabular}{|c|c|c|}
\hline \multirow{2}{*}{ Error } & \multicolumn{2}{|c|}{ Acierto } \\
\cline { 2 - 3 } & Sin justificación & Con justificación \\
\hline 4 & 13 & 39 \\
\hline
\end{tabular}

Tabla VII. 5. Respuestas cuando no existe la razón.

Como se comprobará más delante de forma reiterada, los alumnos reconocen muy bien las situaciones en las que no hay relación entre las magnitudes consideradas.

Las situaciones de proporcionalidad inversa son las que más dificultades presentan para los alumnos. En concreto, en el apartado d) únicamente 7 alumnos dieron una respuesta correcta en algún sentido (indicando bien que no existe la razón entre las magnitudes presentadas o bien haciendo entrar en juego la constante de proporcionalidad) mientras que hasta 45 dan respuestas erróneas o sin sentido. El error más frecuente (cometido por un total de 15 alumnos) fue dar como significado de la razón “los días que tarda una persona en pintar la casa”.

En vistas de estos resultados podemos presentar las siguientes conclusiones respecto a las ideas de razón y condición de regularidad:

1. Un porcentaje relativamente alto de los alumnos comprende la razón como “tanto por uno” y es capaz de explicitar su significado en una situación concreta.

2. En el caso de la condición de regularidad el porcentaje de alumnos que la hace explícita es bastante menor que para la razón. El porcentaje es similar cuando se refiere a dar el valor numérico de la razón (aunque en este caso se esperaba que fuera mayor).

\footnotetext{
${ }^{1}$ En esta tabla se han contabilizado incluso aquellos alumnos que han indicado únicamente una de las razones existentes y que por tanto, bajo el esquema seguido en el capítulo anterior, no dieron una respuesta totalmente correcta.
} 
3. Son muy pocos los alumnos que manejan todas las facetas de la idea de razón simultáneamente (valor, significado, condición de regularidad).

4. Los alumnos distinguen bien las situaciones en las que no existe la razón. Sin embargo, un número significativo de ellos no encuentra necesario - o no puede dar una justificación.

5. Presentar la razón como "tanto por uno" parece llevar a que los alumnos se centran excesivamente en esa idea, frente al resto de matices del concepto. Esto hace que en situaciones de proporcionalidad inversa piensen que sí existe la razón entre las magnitudes y le asignen el valor unitario, sin observar que la situación no es “de intercambio”.

\section{VII.2.2.2. El porcentaje}

Aunque el concepto de porcentaje se presenta de una forma análoga al de razón existe una diferencia significativa entre ambos casos: los alumnos ya están familiarizados con el porcentaje (ver VII.3. más adelante). Sin embargo, no es con el concepto de porcentaje con lo que los alumnos están realmente familiarizados, sino con un algoritmo de cálculo.

Con el tiempo que se ha podido dedicar a la introducción del concepto y al trabajo con el mismo ha resultado completamente imposible conseguir que los alumnos se desprendieran de su experiencia anterior. Como apunte clarificador traemos aquí el resultado del apartado a) del ejercicio 4 de la prueba final, dónde tan sólo 3 alumnos de los 56 mencionaron y utilizaron el significado del porcentaje como “tanto por ciento”.

\section{VII.2.2.3. El concepto de magnitudes proporcionales}

En cuanto a las magnitudes proporcionales, ya sea inversa o directamente, las dificultades de los alumnos tienen, a nuestro juicio, un origen diferente. El principal obstáculo se encuentra en que el enunciado “ser ... proporcionales" (directa o inversamente) es una enunciado sobre una relación entre magnitudes. Para poder hacer una afirmación de tales características los alumnos no han de fijarse en una u otra de las magnitudes; ni siquiera en las dos simultáneamente. Los alumnos han de fijarse en cómo están relacionadas ambas magnitudes. 
En general, la observación anterior implica que los alumnos tienen más dificultades a la hora de evaluar si dos magnitudes son proporcionales, o no, cuando la situación se les presenta sin ningún tipo de referente numérico. Esto se observa claramente en situaciones como las del ejercicio 6 de la prueba final, que decía lo siguiente:

6.- Indica si las siguientes magnitudes están relacionadas. Si lo están señala si son directamente proporcionales o inversamente proporcionales. Justifícalo.

a) La cantidad de azúcar necesaria para hacer una tarta y el número de raciones de la tarta.

b) La edad de una persona y la velocidad a la que puede correr.

c) El número de personas que hay trabajando en una obra y el tiempo que tardan en terminarla.

Esta tarea obliga a los alumnos, como ya dijimos, a centrarse tan sólo en la relación existente entre las magnitudes. Las frecuencias de las respuestas dadas por los alumnos en este ejercicio fueron (como ya se presentaron en el Capítulo VI):

\begin{tabular}{|c|c|c|c|c|c|}
\hline & \multirow[b]{2}{*}{ En blanco } & \multirow[b]{2}{*}{ Incorrecto } & \multirow[b]{2}{*}{$\begin{array}{l}\text { “Correcto" } \\
\text { sin razonar }\end{array}$} & \multicolumn{2}{|c|}{ Correcto } \\
\hline & & & & $\begin{array}{c}\text { Aumentos y } \\
\text { disminuciones }\end{array}$ & $\begin{array}{c}\text { Buen } \\
\text { razonamiento }\end{array}$ \\
\hline Apartado a) & 1 & 31 & ( & 15 & 9 \\
\hline Apartado b) & 1 & 11 & 16 & - & 28 \\
\hline Apartado c) & 3 & 28 & 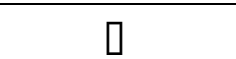 & 17 & 8 \\
\hline
\end{tabular}

Tabla VII.6. Distinguiendo magnitudes proporcionales en el Ejercicio final 6.

Analizando esta tabla se puede extraer varias conclusiones al respecto de lo que nos ocupa:

1. Los alumnos tienen ciertos problemas identificando la relación de proporcionalidad que existe entre dos magnitudes presentadas de forma genérica (sin datos numéricos concretos). Un 32\% aproximadamente no identificó correctamente la proporcionalidad directa y en torno al $29 \%$ en el caso de la inversa.

2. Los problemas son menores a la hora de decidir que dos magnitudes no guardan relación. En este caso tan sólo un 10\% apuntó una relación donde no la había. 
3. El porcentaje de alumnos que da una respuesta correcta, pero que no plasma su razonamiento (si es que existe) no es despreciable.

4. La dificultad que los alumnos perciben en este tipo de tarea es alta. Esto se muestra en el alto recurso a razonamientos “por aumento y disminución”, que no se mencionaron en el aula en ningún momento (volveremos sobre esto más adelante).

5. Pese a todo, hay un número razonable de alumnos que responden correctamente haciendo un uso adecuado de las herramientas que se les proporcionaron durante las sesiones.

A la vista de los datos anteriores, consideramos que la propuesta que hemos implementado muestra indicios suficientes de que permite a los alumnos comprender los conceptos de magnitudes directa e inversamente proporcionales y distinguir la relación existente entre dos magnitudes en una situación genérica. No obstante, el número de alumnos que presentan dificultades en este ámbito, así como el de respuestas indeseadas es elevado. Para subsanar esto es posible que debiera dedicarse más tiempo y esfuerzo a tratar estos aspectos.

\section{VII.2.2.4. Conclusiones sobre la propuesta.}

En los dos puntos anteriores se ha tratado sobre los dos aspectos conceptuales más importantes: la razón y condición de regularidad, y las magnitudes proporcionales. Algunos datos ya se han comentado y pensamos que a la luz de los resultados obtenidos deben extraerse algunas conclusiones sobre la propia propuesta didáctica diseñada:

1. El tiempo dedicado a afianzar aspectos conceptuales básicos como la razón, el porcentaje y la condición de regularidad ha de ser mayor.

2. Se debe hacer un mayor énfasis en la multiplicidad de aspectos que incluye el concepto de razón: valor numérico, significado, existencia; señalando la interdependencia de todos ellos.

3. Al presentar la razón como "tanto por uno" debe hacerse notar que la propia situación, el modo en que las magnitudes implicadas se relacionan, también es un ingrediente básico de la definición.

4. En relación con lo anterior, debe ampliarse el abanico de situaciones distintas que se presentan al alumno: magnitudes directa e inversamente proporcionales, 
magnitudes no relacionadas y también - y sobre todo - magnitudes relacionadas pero no de forma proporcional.

5. El concepto de porcentaje resulta muy difícil de introducir por el profundo obstáculo que suponen los conocimientos anteriores del alumno. Se hará necesario pensar en cómo luchar contra ellos.

Sin embargo, aunque los puntos anteriores suponen aspectos a mejorar o reforzar, pensamos que los resultados obtenidos indican que la propuesta diseñada permite una buena aprehensión de los aspectos conceptuales básicos relativos a la proporcionalidad por los alumnos.

\section{VII.2.3. Resolución de problemas}

La resolución de problemas es una de las facetas más importantes de la actividad matemática y, en consecuencia, es uno de los aspectos más importantes que han de tratarse en el aula. Es además el momento en que los alumnos han de poner en juego de forma directa los conceptos que han adquirido (Borasi, 1986).

En nuestro caso no entramos en consideraciones sobre tipos de problemas, sino que únicamente consideramos los dos tipos que hemos utilizado en nuestra investigación: problemas relativos a porcentajes y problemas relativos a búsqueda de cantidades desconocidas.

\section{VII.2.3.1. Problemas relativos a porcentajes.}

Como ya se ha apuntado con anterioridad el concepto de porcentaje como "tanto por ciento” no llegó a calar en los alumnos tras las sesiones de clase. La práctica totalidad se mantuvieron aferrados a los procedimientos aprendidos en el curso anterior.

Este apego al algoritmo se mostró claramente en los resultados obtenidos en el Ejercicio 4 de la prueba final. En el primer apartado, que planteaba un problema directo (calcular un porcentaje de una cierta cantidad), 40 alumnos (más de un 70\%) aplican un algoritmo y encuentran correctamente la cantidad buscada. Sin embargo, el apartado b) planteaba un problema inverso (calcular el total conociendo la cantidad correspondiente a un porcentaje dado). Este problema supone: bien haber memorizado otro algoritmo, 
bien saber manipular el utilizado en el apartado anterior. En consecuencia, 33 alumnos (casi un 60\%) dejan el apartado en blanco o lo resuelven mal.

Aunque podríamos decir que en lo relativo al concepto de porcentaje la implementación de la propuesta ha resultado fallida, cabe indicar como aspecto positivo que se ha demostrado que aquellos alumnos que han tratado de utilizar únicamente los algoritmos han fracasado mayoritariamente, mientras que aquellos (aunque pocos) que han recurrido al significado del porcentaje o al sentido de las operaciones han logrado resolver la tarea con éxito.

\section{VII.2.3.2. Búsqueda de cantidades desconocidas.}

Los problemas de búsqueda de cantidades desconocidas en situaciones de proporcionalidad tienen una importancia capital en la enseñanza de la Proporcionalidad aritmética. Para emitir las conclusiones relativas a la docencia reproducimos los resultados obtenidos en la prueba final. Los resultados sobre los tres ejercicios que se reproducen en el siguiente cuadro de texto se muestran en la tabla VII.7.

2.- Una fuente arroja 50 litros de agua en 6 horas. ¿Cuánto tardará en arrojar 35 litros de agua?

3.- Pagando 75 euros al mes tardaré 11 meses en pagar la televisión que me acabo de comprar. ¿Cuánto tardaré en pagarla si pago 165 euros al mes? 5.- Fernando tiene 13 años y pesa 47 kilos. ¿Cuánto pesará a los 40 años?

\begin{tabular}{|c|c|c|c|c|c|}
\cline { 2 - 6 } \multicolumn{1}{c|}{} & \multirow{2}{*}{$\begin{array}{c}\text { En } \\
\text { blanco }\end{array}$} & Incorrecto & $\begin{array}{c}\text { “Correcto” } \\
\text { sin razonar }\end{array}$ & Regla de tres & \begin{tabular}{c} 
Correcto \\
Bazonamiento \\
\cline { 4 - 6 }
\end{tabular} \\
\hline Ejercicio 2 & 3 & 13 & 0 & 12 & 28 \\
\hline Ejercicio 3 & 4 & 10 & - & 5 & 37 \\
\hline Ejercicio 5 & 2 & 8 & 0 & 0 & 46 \\
\hline
\end{tabular}

Tabla VII.7. Búsqueda de cantidades desconocidas.

Pensamos que estos resultados muestran que los alumnos han alcanzado un buen manejo de las situaciones de búsqueda de cantidades desconocidas. Especial mención merecen los datos de los ejercicios 3 (magnitudes inversamente proporcionales) y 5 
(magnitudes no relacionadas) por cuanto suponen generalmente mayores dificultades para los alumnos (en el primer caso por la mayor dificultad conceptual de la proporcionalidad inversa y en el segundo por la tendencia a razonar aditiva o proporcionalmente en una situación en la que ello carece de sentido).

\section{VII.3. HERENCIAS E INFLUENCIAS}

Generalmente, al hablar de un experimento científico, se entiende que éste tiene lugar en un entorno aislado y controlado. Desafortunadamente no es éste el caso cuando se experimenta en Ciencias Humanas. Cuando los sujetos del experimento son grupos humanos es absolutamente imposible evitar las preconcepciones que dichos sujetos tienen respecto a aquello que se les muestra así como las posibles influencias externas de su entorno, y el experimento no es reproducible.

Nuestra experimentación en el aula no podía ser una excepción y, de hecho, hemos detectado dos fenómenos que, aunque no eran inesperados, resultan interesantes:

1. Algunos alumnos habían recibido instrucción en algunos aspectos relativos a la Proporcionalidad en el último curso de Educación Primaria. En concreto, se detectaron algunos alumnos a los que se había presentado ya la técnica de la regla de tres y, por otro lado, a un gran número de los alumnos se les había instruido en el uso de algún algoritmo para calcular el porcentaje de una cantidad (lo que hemos llamado problema directo).

Esta instrucción previa supuso un gran obstáculo (Bachelard, 2007) para los alumnos a la hora de enfrentarse a las tareas propuestas, puesto que les resultó muy difícil dejar de lado aquello que ya habían interiorizado y que se les había presentado como el modo correcto de resolver dichas situaciones problemáticas. Por ejemplo, en la siguiente figura se muestra la respuesta de los alumnos A37 y A47 a una cuestión de la Actividad de clase 6, la primera en la que se presentaba el concepto de porcentaje como "tanto por cien” en analogía con el "tanto por uno” de la razón. La práctica totalidad de los alumnos (20 de los 25 grupos de trabajo que se constituyeron para las actividades de aula) calculó correctamente el 52\% de 725.000; sin embargo prácticamente todos lo hicieron 
algorítmicamente sin recurrir al significado. Esto sucedió así debido a que ya conocían un algoritmo para calcular porcentajes desde el curso anterior.

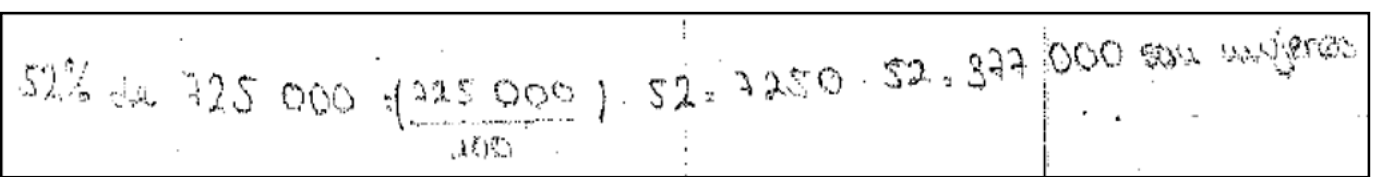

Figura VII.1. El algoritmo para calcular porcentajes en un momento temprano.

2. Una gran parte de los alumnos (34 en total) reconocieron (ver Sección VII.4) haber recibido algún tipo de ayuda a la hora de resolver las tareas de casa o de preparar la asignatura (aunque tenemos indicios que muestran que el número real es mayor). En concreto 28 alumnos reconocieron haber recibido ayuda de sus padres, 3 de sus hermanos y 2 de un profesor particular.

Estas ayudas externas suponen un problema por cuanto provienen de personas cuyos conocimientos se basan en la manera tradicional de presentar la Proporcionalidad aritmética. En consecuencia, al tratar de ayudar a sus hijos, hermanos o alumnos, las personas que prestan la ayuda presentan al estudiante ideas que chocan frontalmente con lo que se le ha presentado en clase.

En las imágenes siguientes se muestran dos respuestas del mismo alumno (A29). En la Figura VII.3. se muestra una respuesta dada en la Actividad de aula 5 mientras que la Figura VII.2. muestra una respuesta dada en la Tarea de casa 2. Las diferencias en la forma de pensar son significativas.

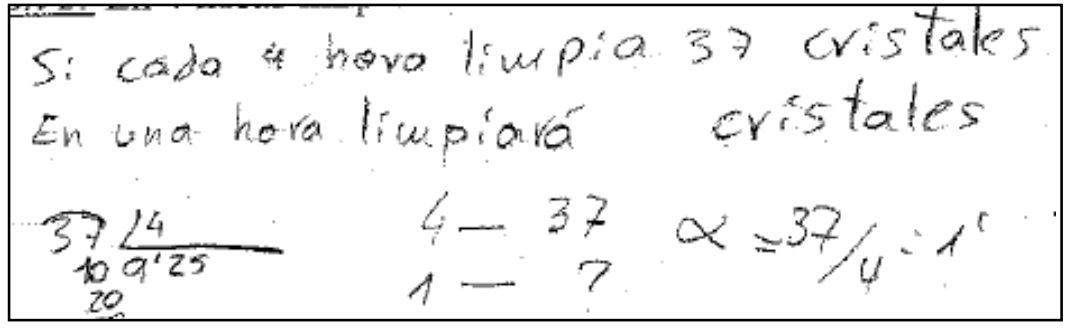

Figura VII. 2. Al alumno A29 en casa.

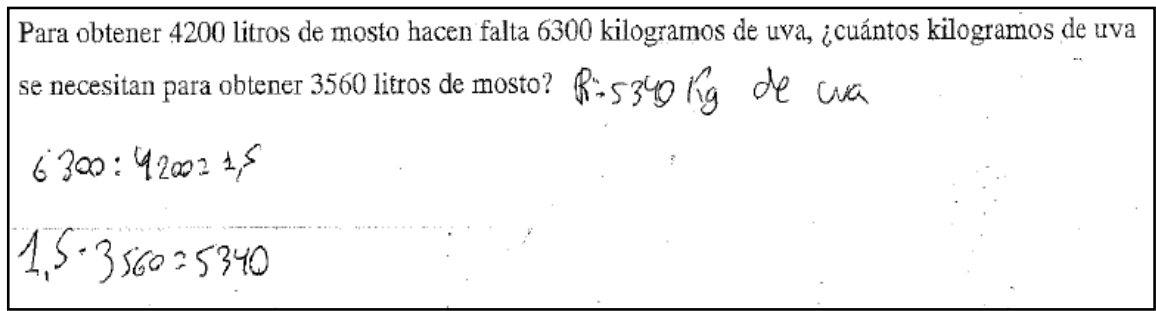

Figura VII. 3. El alumno A29 en clase. 
Además de las influencias que se han acaban de señalar y que tienen un origen muy claro, puede hablarse también de una influencia algo más difusa de origen cultural o social. Esta influencia se refleja es aspectos como que los alumnos preguntaran muy pronto en clase si iba a haber un examen o, de forma más notoria, en el hecho de que 31 de los 54 alumnos consideraran bastante o muy importante tener un cuadernillo que recogiera los contenidos presentados en clase.

Esta influencia se aprecia muy claramente también en la preocupación de los alumnos por la nota del examen y no sólo por su adquisición de conocimientos. Este hecho, relacionado con el punto 2 anterior, explica por qué algunos alumnos como A11, por ejemplo (ver figuras siguientes), que han seguido el desarrollo de las clases con normalidad; resolviendo las situaciones que se le planteaban haciendo uso tan sólo de las que se le habían ido proporcionando en clase, de repente utilizan en el examen ideas que sólo pueden haber conocido por influencias externas.

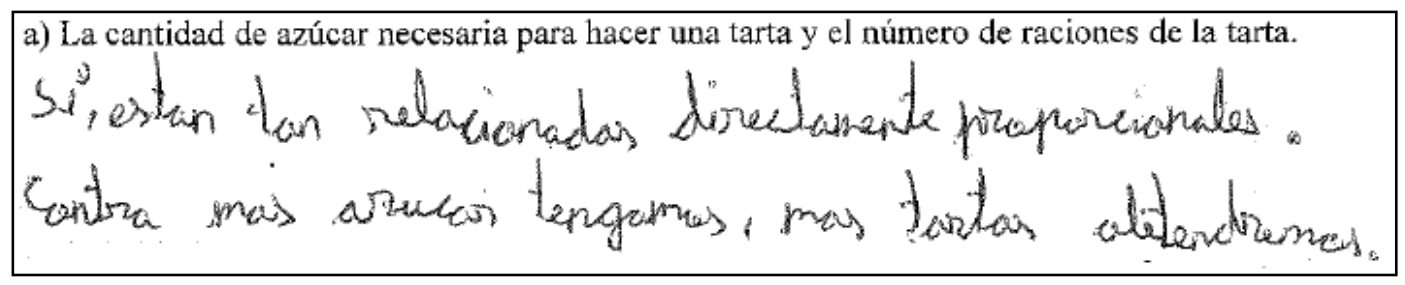

Figura VII.4. Aparición espontánea de la caracterización por aumentos y disminuciones en la producción de A11.

En la figura anterior se muestra una respuesta del alumno A11 en la prueba final. Este alumno no había utilizado en ninguna ocasión, ni en el aula ni en las Tareas de casa este tipo de razonamiento. De hecho, en otra pregunta en la que las magnitudes implicadas eran inversamente proporcionales la respuesta de este mismo alumno apunta el conflicto interno entre dos formas radicalmente distintas de razonar:

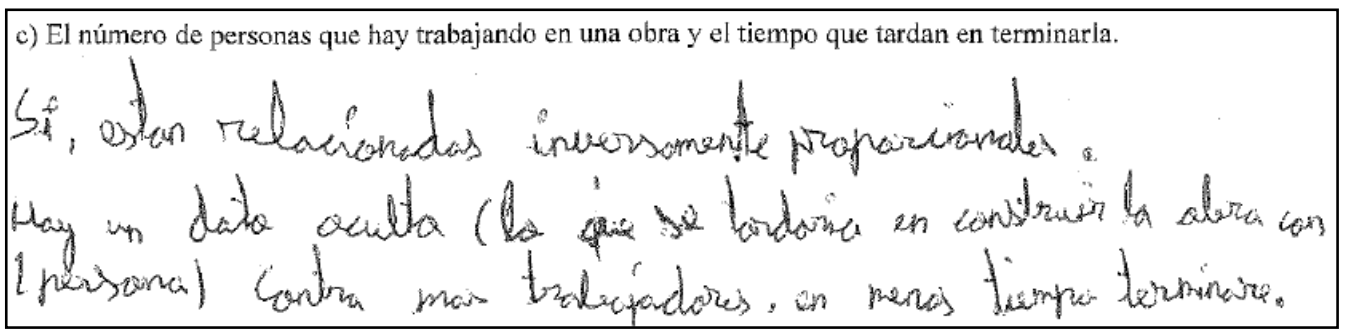

Figura VII.5. Lucha interna en A11. 
Se observa la mención (aunque imperfecta) a la constante de proporcionalidad, pero después el alumno recae en las explicaciones de tipo “a más,..., menos”. Es posible que este alumno haya percibido como más sencilla de memorizar esta forma de razonar y piense que le va a proporcionar mejores y más seguros resultados en el examen

\section{VII.4. ENCUESTA FINAL PLANTEADA A LOS ALUMNOS}

Una vez concluido el desarrollo de las sesiones y realizada la prueba final, se solicitó a los alumnos que completaran una encuesta. Mediante las preguntas que se plantearon se pretendía analizar principalmente los siguientes aspectos:

1. La opinión del alumno sobre el desarrollo de las clases y la forma de trabajar durante el tiempo en que el investigador actuó como profesor.

2. La opinión de los alumnos acerca del interés y la dificultad de los contenidos trabajados durante ese tiempo.

3. La actitud del alumno hacia la asignatura de matemáticas.

4. La ayuda externa que los alumnos pudieran haber recibido a lo largo del desarrollo de las sesiones.

En un principio se pretendía que la encuesta no fuera anónima por cuanto las respuestas que los alumnos pudieran dar no iban a tener influencia sobre ellos y, por lo tanto, la sinceridad de las respuestas no parecía quedar comprometida. Sin embargo, en uno de los grupos la profesora habitual de los alumnos les indicó que no debían poner el nombre. Debido a esto no siempre podemos cotejar las respuestas dadas por los alumnos con las impresiones (o certezas) del investigador al respecto de cada tema.

En el Anexo II se incluye la hoja que se entregó a los alumnos a modo de encuesta final. Observando las preguntas que se realizaron a los alumnos se aprecian claramente los cuatro aspectos que ya hemos señalado que se pretendían estudiar. Así, existen:

1. Preguntas orientadas a conocer la opinión del alumno sobre el desarrollo de las clases y la forma de trabajar:

- Las clases me han gustado / No me han gustado las clases.

- La forma de trabajar es aburrida / Las clases han sido amenas.

- El examen ha sido difícil / El examen era fácil. 
- El cuadernillo no hacía falta / Tener un cuadernillo me parece necesario.

- Los deberes eran muy largos / Había pocos deberes.

2. Preguntas orientadas a conocer la opinión de los alumnos acerca del interés y la dificultad de los contenidos trabajados:

- Lo que hemos dado me parece difícil / Esta parte me ha parecido fácil.

- Lo que hemos estudiado es útil / Lo que hemos dado no sirve para nada.

3. Preguntas orientadas a conocer la actitud del alumno hacia la asignatura de matemáticas:

- No me gusta que el profesor me pregunte en clase / Me gusta intervenir en clase.

- Tengo ganas de que llegue la clase de matemáticas / Tengo miedo de que llegue la hora de matemáticas.

- Me gusta la asignatura de matemáticas / Las matemáticas no me gustan.

4. Preguntas orientadas a descubrir la ayuda externa que los alumnos pudieran haber recibido:

- ¿Has recibido ayuda de alguien durante estos días?

- $\quad$ Si es que sí, ¿de quién?

A continuación vamos a analizar, superficialmente y desde un punto de vista cualitativo, las respuestas dadas por los alumnos.

\section{VII.4.1. Análisis de las preguntas orientadas a conocer la opinión del alumno sobre el desarrollo de las clases y la forma de trabajar:}

Ya hemos señalado con anterioridad las preguntas que se agrupan bajo este epígrafe. En la tabla siguiente se muestras las frecuencias de cada una de las posibles respuestas.

\begin{tabular}{|l|c|c|c|c|}
\cline { 2 - 5 } \multicolumn{1}{c|}{} & Mucho & Regular & Poco & Nada \\
\hline Las clases me han gustado & 3 & 26 & 17 & 8 \\
\hline
\end{tabular}




\begin{tabular}{|c|c|c|c|c|}
\hline La forma de trabajar es aburrida & 14 & 21 & 18 & 1 \\
\hline Las clases han sido amenas & 4 & 24 & 14 & 12 \\
\hline El examen ha sido difícil & 17 & 25 & 10 & 2 \\
\hline El cuadernillo no hacía falta & 17 & 9 & 7 & 21 \\
\hline Tener un cuadernillo me parece necesario & 27 & 14 & 7 & 6 \\
\hline Los deberes eran muy largos & 18 & 16 & 13 & 7 \\
\hline No me han gustado las clases & 9 & 27 & 9 & 9 \\
\hline El examen era fácil & 6 & 16 & 11 & 21 \\
\hline Había pocos deberes & 17 & 19 & 11 & 7 \\
\hline
\end{tabular}

A la hora de analizar un análisis cuantitativo, asignamos a cada una de las posibles respuestas un valor numérico: Nada (1), poco (2), regular (3), mucho (4). Con estas asignaciones se obtiene lo siguiente:

\begin{tabular}{|c|c|c|}
\cline { 2 - 3 } \multicolumn{1}{c|}{} & Media & D. Típica \\
\hline Las clases me han gustado & 2,44 & 1,57 \\
\hline Las clases han sido amenas & 2,89 & 1,12 \\
\hline El examen ha sido difícil & 2,37 & 1,64 \\
\hline El cuadernillo no hacía falta & 2,06 & 0,95 \\
\hline Tener un cuadernillo me parece necesario & 3,15 & 1,61 \\
\hline Los deberes eran muy largos & 2,83 & 1,18 \\
\hline No me han gustado las clases & 2,67 & 1,35 \\
\hline El examen era fácil & 2,13 & 1,89 \\
\hline Había pocos deberes & 2,85 & 1,16 \\
\hline
\end{tabular}

A la vista de los datos anteriores se observa que en casi todas las preguntas la media se encuentra muy centrada y que la desviación típica es bastante grande. Las dos únicas excepciones son las siguientes:

- Los alumnos consideran que el examen ha sido difícil. Esto no es de sorprender puesto que, a fin de cuentas, los alumnos siempre querrían que los exámenes fuesen más fáciles. Además, la tasa de aprobados en el examen fue satisfactoria tanto en términos absolutos como en comparación con el desempeño anterior de los grupos. 
- Los alumnos encuentran que el cuadernillo que se les entregó y que contenía los aspectos teóricos más relevantes, ejemplos y ejercicios era muy necesario. Esto ilustra que los alumnos están muy habituados a trabajar con material impreso, generalmente el libro de texto y les cuesta concebir una clase que no se fundamente en un manual o que no recurra a él para plantear ejercicios.

También se observa que, en general, no parece que los alumnos estén entusiasmados con el desarrollo de las clases. Esto se debe, fundamentalmente, a que el modo en que se organizó el trabajo rompía radicalmente con la dinámica habitual de sus clases de matemáticas. Esto, para ciertos alumnos, no supone un aliciente sino un problema.

VII.4.2. Análisis de las preguntas orientadas a conocer la opinión del alumno acerca del interés y la dificultad de los contenidos trabajados:

Ya hemos señalado con anterioridad las preguntas que se agrupan bajo este epígrafe. En la tabla siguiente se muestras las frecuencias de cada una de las posibles respuestas.

\begin{tabular}{|c|c|c|c|c|}
\cline { 2 - 5 } \multicolumn{1}{c|}{} & Mucho & Regular & Poco & Nada \\
\hline Lo que hemos dado me parece difícil & 19 & 24 & 5 & 6 \\
\hline Lo que hemos dado no sirve para nada & 6 & 18 & 9 & 21 \\
\hline Lo que hemos estudiado es útil & 20 & 24 & 7 & 3 \\
\hline Esta parte me ha parecido fácil & 3 & 22 & 13 & 16 \\
\hline
\end{tabular}

Con las mismas asignaciones que hemos realizado anteriormente, se obtiene lo siguiente:

\begin{tabular}{|c|c|c|}
\cline { 2 - 3 } \multicolumn{1}{c|}{} & Media & D. Típica \\
\hline Lo que hemos dado me parece difícil & 3,04 & 0,97 \\
\hline Lo que hemos estudiado es útil & 3,13 & 0,88 \\
\hline Esta parte me ha parecido fácil & 2,22 & 1,79 \\
\hline
\end{tabular}


Parece claro que, en general, los alumnos consideran que los contenidos trabajados han sido más bien difíciles, pero útiles. Este último aspecto nos parece destacable puesto que, en muchas ocasiones, los alumnos perciben las matemáticas como algo inútil y ajeno a la realidad y a su vida cotidiana.

VII.4.3. Análisis de las preguntas orientadas a conocer la actitud del alumno hacia la asignatura de matemáticas:

Ya hemos señalado con anterioridad las preguntas que se agrupan bajo este epígrafe. En la tabla siguiente se muestras las frecuencias de cada una de las posibles respuestas.

\begin{tabular}{|c|c|c|c|c|}
\cline { 2 - 5 } \multicolumn{1}{c|}{} & Mucho & Regular & Poco & Nada \\
\hline No me gusta que el profesor me pregunte en clase & 14 & 23 & 7 & 10 \\
\hline Tengo ganas de que llegue la clase de matemáticas & 17 & 11 & 10 & 16 \\
\hline Me gusta intervenir en clase & 9 & 16 & 18 & 11 \\
\hline Me gusta la asignatura de matemáticas & 17 & 24 & 7 & 6 \\
\hline Tengo miedo de que llegue la hora de matemáticas & 2 & 4 & 10 & 38 \\
\hline Las matemáticas no me gustan & 7 & 17 & 9 & 21 \\
\hline
\end{tabular}

Con las mismas asignaciones que hemos realizado anteriormente, se obtiene lo siguiente:

\begin{tabular}{|c|c|c|}
\cline { 2 - 3 } \multicolumn{1}{c|}{} & Media & D. Típica \\
\hline No me gusta que el profesor me pregunte en clase & 2,76 & 1,04 \\
\hline Tengo ganas de que llegue la clase de matemáticas & 2,54 & 1,22 \\
\hline Me gusta intervenir en clase & 2,43 & 1,00 \\
\hline Me gusta la asignatura de matemáticas & 2,96 & 0,95 \\
\hline Tengo miedo de que llegue la hora de matemáticas & 1,44 & 0,79 \\
\hline Las matemáticas no me gustan & 2,19 & 1,10 \\
\hline
\end{tabular}

Los resultados obtenidos muestran que los alumnos con los que se llevó a cabo el estudio no parecen sentir hacia las matemáticas especial atracción ni rechazo, si bien es cierto que las preguntas dedicadas al gusto de los alumnos por la asignatura la media aparece más inclinada a favor del gusto que del disgusto por las matemáticas. Respecto a la intervención en clase, tenemos una distribución casi simétrica y, como dato positivo 
indicar la muy baja media obtenida en el ítem "tengo miedo de que llegue la hora de matemáticas”. Todos estos datos coinciden con lo percibido por el investigador en el aula.

\section{VII.4.4. Análisis de las preguntas orientadas a descubrir la ayuda externa recibida por los alumnos:}

Bajo este epígrafe se situaban las dos últimas preguntas de la encuesta. La última de ellas, además, era la única cuya respuesta era abierta. Los alumnos dieron las siguientes respuestas:

\begin{tabular}{|c|c|c|c|c|c|}
\hline \multirow{2}{*}{ NO } & \multicolumn{5}{|c|}{ Sí } \\
\cline { 2 - 6 } & Hermanos & Padres & Compañeros & $\begin{array}{c}\text { Profesor } \\
\text { particular }\end{array}$ & El investigador \\
\hline 20 & 3 & 28 & 4 & 2 & 2 \\
\hline
\end{tabular}

Se observa que es mayor el número de alumnos que han recibido algún tipo de ayuda externa, mayoritariamente por parte de los padres. Dos alumnos dicen haber recibido ayuda del propio investigador, con ello se refieren a que, durante el desarrollo de las sesiones, se acercaron a preguntar dudas que les fueron resultas en privado como habría hecho su profesor habitual. Se ha detectado algún caso en que el alumno afirma no haber recibido ayuda externa, pero sin embargo se ha encontrado en sus respuestas a los ejercicios de la prueba final mención a ideas que sólo pueden provenir del exterior del aula (la caracterización de la proporcionalidad directa por aumentos y disminuciones, por ejemplo).

Ya se ha comentado en otro momento que esta influencia externa supone, y de hecho ha supuesto, una obstáculo bastante importante a la hora de conseguir que los alumnos se enfrenten a los problemas utilizando las ideas que pretendíamos transmitirles. Esta obstáculo se vuelve todavía más insalvable si tenemos en cuenta que, para muchos alumnos de esta edad la familia constituye el primer punto de apoyo ante las dificultades de la asignatura y, por supuesto, confían mucho más en los métodos e ideas provenientes de estos familiares que de las que el profesor pueda transmitirles en el aula. 


\section{VII.5. Perspectivas de FUTURo}

El trabajo que hemos realizado y que presentamos en esta memoria, en cierto modo, supone la compleción del proyecto que se presentó en el Capítulo I. Sin embargo, esto no quiere decir que consideremos que la línea de investigación iniciada esté agotada, sino todo lo contrario. Son múltiples las cuestiones en las que se podría profundizar, aspectos susceptibles de mejorar y también nuevas ideas que desarrollar. Algunas posibilidades son las siguientes:

1. Revisar críticamente nuestra propuesta didáctica a partir de los resultados de la implementación de la misma.

Pensamos que se ha comprobado que la propuesta didáctica diseñada e implementada permite a los alumnos una buena comprensión de los conceptos relacionados con la proporcionalidad y, sobre todo, el uso de técnicas adecuadas y con significado a la hora de resolver problemas. No obstante, nuestra propuesta es perfectible. Algunos aspectos mejorables, por ejemplo; podrían ser éstos:

- Revisar la temporalización y la extensión de las actividades de aula. Durante la puesta en práctica de la propuesta se observó que el tiempo previsto para cada uno de los aspectos a tratar, en ocasiones, resultaba insuficiente en dos sentidos:

- Las 11 sesiones planificadas inicialmente se revelaron, a juicio de los investigadores, insuficientes para poder presentar y desarrollar con el ritmo adecuado todos los contenidos seleccionados.

- La cantidad de apartados propuestos en las actividades de aula hacía que, en algunos casos, parte de los alumnos fueran incapaces de completarlas.

- Replantear el uso de materiales manipulativos en la introducción de la proporcionalidad directa. En la propuesta implementada en el aula se presentaba la proporcionalidad directa entre magnitudes a partir de las situaciones de intercambio y utilizando como materiales manipulativos pajitas y tarjetas de cartulina. Durante la experimentación se observó un 
escaso uso de dichos materiales por parte de los estudiantes, por lo que sería necesario abordar la problemática sobre el uso de esos u otros materiales o, incluso, sobre su no utilización en absoluto.

- Reflexionar sobre las situaciones problemáticas que se plantean a los alumnos y sobre las magnitudes que aparecen en dichas situaciones. Si bien es cierto que la variedad de situaciones que se plantean al alumno debe ser lo más rica posible, no es menos cierto que en el punto de su desarrollo cognitivo en el que se encuentran, hemos observado que muchos alumnos encuentran dificultades a la hora de manejar magnitudes provenientes de la física (velocidad, por ejemplo) sobre todo debido a que no tienen una noción clara del significado de dichas magnitudes.

- Revisar la metodología de trabajo utilizada. En la implementación realizada los alumnos trabajan por parejas en el aula y completaban individualmente las tareas de casa. Se debería reflexionar sobre esta metodología o, al menos, sobre la forma de llevarla a la práctica, por dos motivos:

- En el trabajo autónomo en casa se ha observado en parte de los alumnos una influencia externa disonante con el trabajo realizado en el aula.

- Trabajando en parejas o en grupos de tres alumnos se ha comprobado que, en algunos casos, todo el trabajo era realizado únicamente por uno de los miembros del grupo. Surge aquí la pregunta de cómo funcionaría la propuesta si los alumnos trabajaran en grupos colaborativos de nivel parecido.

2. Completar y perfeccionar la adaptación al aula de la propuesta didáctica presentada en el Capítulo 4 de esta memoria.

En el Capítulo 5 se ha presentado una adaptación de la propuesta didáctica diseñada a las condiciones concretas de la experimentación; a saber, 11 sesiones de 50 minutos y la necesidad de presentar los contenidos tradicionales de un curso de $1^{\circ}$ de E.S.O. En este sentido son varios los aspectos a trabajar: 
- Diseñar fichas de trabajo para el aula (y para casa, si se considerara oportuno) que desarrollen los contenidos no reflejados en la experimentación llevada a cabo (proporcionalidad compuesta, repartos,...). Esto permitirá completar la experimentación de la propuesta a lo largo de los cursos correspondientes.

- Concretar un modelo de aprendizaje apropiado para la introducción de la proporcionalidad inversa de modo que la idea de constante de proporcionalidad surja de modo natural. Al igual que en el caso de la proporcionalidad directa (y la idea de razón), pensamos que el modo en que se presenten dichos contenidos influirá de manera decisiva en la concepción que los alumnos tengan de los mismos.

- Reelaborar la secuenciación de los contenidos de forma que la nueva secuenciación refleje de forma clara la filosofía de la propuesta. Sin embargo, implementar en el aula una propuesta completa secuenciada de acuerdo a nuestra filosofía puede resultar complicado por cuanto supondría una ruptura muy grande con el currículo actual de Secundaria.

3. Extender la experimentación a otros centros. En nuestro caso la Fase de Acción se desarrolló únicamente en dos grupos del I.E.S. Avempace de Zaragoza. Sería interesante realizar una experimentación más amplia que nos permitiera:

- Disponer de una muestra mayor de alumnos que mejoraría nuestra capacidad de evaluar y mejorar la propuesta.

- Poder acceder a un mayor número de docentes y observar el modo en que acogen nuestra propuesta.

- Disponer de grupos de control para comparar los resultados obtenidos con nuestra propuesta frente a la enseñanza tradicional.

4. Trabajar con maestros de primaria y con profesores de secundaria, tanto en ejercicio como en formación.

Esta línea de trabajo es interesante por al menos dos motivos:

- Durante la experimentación que hemos realizado ha sido el propio investigador quién ha desempeñado las funciones de docente. Esto hace que los alumnos hayan percibido la situación como excepcional. Lograr la participación de los profesores supondría poder analizar la propuesta 
cuando se lleva a cabo en las condiciones naturales del aula y, además, permitirá estudiar cómo adaptan los profesores su práctica docente ante un cambio en la forma de introducir los contenidos.

- Uno de los objetivos más importantes, si no es el que más, de nuestra investigación ha sido ofrecer una alternativa a la enseñanza tradicional de la Proporcionalidad que permita a los alumnos una mejor comprensión de los conceptos y de las técnicas implicadas. Esta alternativa no podrá en ningún modo ser aceptada si la formación inicial de aquellos que deberán hacer uso de dicha propuesta se ha llevado a cabo de acuerdo al método tradicional que se desea modificar. Por ello, parece necesario trabajar en este sentido tanto con maestros de Primaria en formación (en las asignaturas correspondientes del Grado) como con futuros profesores de Secundaria (en las asignaturas del Máster).

Esperamos y deseamos que el trabajo realizado a lo largo de esta investigación ayude a incrementar la comprensión de los alumnos sobre la Proporcionalidad Aritmética. 


\section{REFERENCIAS BIBLIOGRÁFICAS}

ABRAHAMSON, D. (2004). Keeping Meaning in Proportion: The Multiplication Table as a Case of Pedagogical Bridging Tools. Tesis Doctoral, Northwestern University.

ABRAHAMSON, D. y CIGAN, C. (2003). A design for ratio and proportion instruction. Math. Teach. M. Sch., 8(9), pp. 493-501.

ADJIAGE, R. y PLUVINAGE, F. (2007). An experiment in teaching ratio and proportion. Educ. Stud. Math., 65, pp. 149-175.

ALATORRE, S. y FIGUERAS, O. (2005). A developmental model for proportional reasoning in ratio comparison tasks. En Proceedings of the $29^{\text {th }}$ Conference of the International Group for the Psychology of Mathematics Education, Vol. 2. Melbourne.

ALLARD, A. (1992). Le calcul indien (Algorismus). Librairie Scientifique et Technique Albert Blanchard, Paris.

ARISTÓTELES (1995). Física. Editorial Gredos. Madrid.

ARNAL, J., DEL RINCÓN, D. y LATORRE, A. (1992). Investigación educativa. Fundamentos y metodología. Labor, Barcelona.

BACHELARD, G. (2007). El Nuevo espíritu científico. Siglo XXI editores. México.

BAG, A.K. (1975). Al-Biruni on indian arithmetic. Indian J. History Sci., 10(2), pp. 174-184.

BEN-CHAIM, D., FEY, J.T., FITZGERALD, W.M., BENEDETTO, C. y MILLER, J. (1998). Proportional reasoning among $7^{\text {th }}$ grade students with different curricular experiences. Educ. Stud. Math., 36, pp. 247-273.

BENOIT, P.; CHEMLA, K. y RITTER, J. (Coords.) (1992). Histoire de fractions, fractions d'histoire. Birkhäuser Verlag. Basel, Boston, Berlin.

BISHOP, A.J. (1988). Mathematical enculturation. Kluwer Academic Publishers. Dordrecht. 
BOCHNER, S. (1966). The role of mathematics in the rise of science. Princeton University Press. New Jersey.

BORASI, R. (1986). On the nature of problems. Educational Studies of Mathematics, 17, pp. 125-141.

CANTORAL, R. (1997). Los textos de Cálculo: una visión de las reformas y contrarreformas. Revista EMA, 2(2), pp. 115-131.

CASSINET, J. (1999). Une arithmétique toscane en 1334 en Avignon dans la cité des papes et de leurs banquiers florentins. En Commerce et mathématiques du Moyen Age à la Renaissance, autour de la Meditérranée. Actes du Colloque international du Centre International d'Histoire des Sciences Occitanes. Editions du C.I.H.S.O., Toulouse.

CASTRO, E. (1994). Exploración de patrones numéricos mediante configuraciones puntuales. Estudio con escolares del primer ciclo de Secundaria. Tesis Doctoral, Universidad de Granada.

CAVEING, M. (1994). La proportionalité des grandeurs dans la doctrine de la nature d’Aristote. Rev. Histoire Sci., 47(2), pp. 163.188.

CLARK, M.R., BERENSON, S.B. Y CAVEY, L.O. (2003). A comparison of ratios and fractions and their roles as tools in proportional reasoning. J. Math. Beh., 22, pp. 297317.

COOK, T.D. y REICHARD, CH. S. (1982), Métodos cualitativos y cuantitativos en investigación evaluativa. Morata. Madrid.

CRESPO, C., FARFÁN, R.M. y LEZAMA, J. (2009). Algunas características de las argumentaciones y la matemática en escenarios sin influencia aristotélica. RELIME, 12(1), pp. 29-66.

CULLEN, C. (2004). The Suàn shù shū 'Writings on reckoning': A translation of a Chinese mathematical collection of the second century BC, with explanatory commentary. Needham Research Institute, Cambridge.

CULLEN, C. (2007). The Suàn shù shū, "Writings on reckoning'”: rewriting the history of early Chinese mathematics in the light of an excavated manuscript. Historia Math., 34(1), pp. 10-44. 
DAUBEN, J.W. (1998). Ancient Chinese mathematics: the Jiu Zhang Suan Shu vs Euclid's Elements. Aspects of proof and the linguistic limits of knowledge. Internat. J. Engrg. Sci., 36(12-14), pp. 1339-1359.

DJEBBAR, A. (1997). La rédaction de L'istikmal d'al-Mu'taman (XI ${ }^{\mathrm{e}}$ s.) par Ibn Sartaq, un mathématicien de XIII ${ }^{\mathrm{e}}-\mathrm{XIV}^{\mathrm{e}}$ siècles. Historia Math., 24(2), pp. 185-192.

DJEBBAR, A. (1999). Les transactions dans les mathématiques arabes: Classification, résolution et circulation. En Commerce et mathématiques du Moyen Age à la Renaissance, autour de la Meditérranée. Actes du Colloque international du Centre International d'Histoire des Sciences Occitanes. Editions du C.I.H.S.O., Toulouse.

DHOMBRES, J. (1984). French mathematical textbooks from Bézout to Cauchy. Historia Scientiarium, 28, pp. 91-137.

DORMOLEN, J. VAN (1986). Textual analysis. En Christiansen, B., Howson, A.G. y Otte, M. (Eds.). Perspectives on Mathematics Education. Reidel. Dordretch ELLIOT, J. (1990). La Investigación-Acción en Educación. Morata, Madrid. ESCOLANO, R. (2007). Enseñanza del número racional positivo en Educación Primaria: un estudio desde los modelos de medida y cociente. Tesis Doctoral, Universidad de Zaragoza.

EUCLIDES (1994). Elementos. Libros V-IX. Editorial Gredos. Madrid.

EVANS, G.W. (1927). The Greek idea of proportion. Amer. Math. Monthly., 34(7), pp. 354-357.

EYARALAR, J.M. (1933). Metodología de la Matemática. Editorial Reus. Madrid. FERNANDEZ, C. y LLINARES, S. (2010). Evolución de los perfiles de los estudiantes de primaria y secundaria cuando resuelven problemas lineales. En Investigación en Educación Matemática XIV. S.E.I.E.M. Lleida.

FERNÁNDEZ, A. y PUIG, L. (2002). Análisis fenomenológico de los conceptos de razón, proporción y proporcionalidad. Gac. R. Soc. Mat. Esp., 5(2), pp. 397-416.

FERNÁNDEZ, A. (2009). Razón y proporción. Un estudio en la escuela primaria. Departamento de Didáctica de la Matemática, Universidad de Valencia. Valencia. 
FILEP, L. (2003). Proportion theory in Greek mathematics. Acta Math. Acad. Paedagog. Hyházi., 19, pp. 167-174.

FINE, H.B. (1917). Ratio, proportion and measurement in the Elements of Euclid. Ann. of Math., 19(1), pp. 70-76.

FOWLER, D.H. (1979). Ratio in early Greek mathematics. Bull. amer. Math. Soc., 1(6), pp. 807-846.

FOWLER, D.H. (1980). Book II of Euclid's Elements and a pre-Eudoxan theory of ratio. Arch. Hist. Exact Sci., 22(1-2), pp. 5-36.

FOWLER, D.H. (1981). Anthyphairetic ratio and Eudoxan proportion. Arch. Hist. Exact Sci., 24(2), pp. 69-72.

FOWLER, D.H. (1982). Book II of Euclid's Elements and a pre-Eudoxan theory of ratio. II. Sides and diameters. Arch. Hist. Exact Sci., 26(3), pp. 193-209.

FREUDENTHAL, H. (1973). Mathematics as an educational task. D. Reidel Publishing Company. Dordrecht.

FREUDENTHAL, H. (1983). Didactical phenomenology of mathematical structures. D. Reidel Publishing Company. Dordrecht.

GAIRÍN, J.M. (1999). Sistemas de representación de números racionales positivos. Un estudio con maestros en formación. Tesis Doctoral, Universidad de Zaragoza.

GAIRÍN, J.M. y ESCOLANO, R. (2009). Proporcionalidad aritmética: buscando alternativas a la enseñanza tradicional. Suma, 62, pp. 35-48.

GÓMEZ, B. (1999). Tendencias metodológicas en la enseñanza de la proporcionalidad derivadas del análisis de libros antiguos. El caso de los problemas de "compañías". RELIME, 2(3), pp. 19-29.

GÓMEZ, B. (2006). Los ritos en la enseñanza de la regla de tres. En José Mariano Vallejo, el matemático ilustrado. Una mirada desde la Educación Matemática. Publicaciones Universidad de Córdoba.

GÓMEZ, B. (2011). El análisis de manuales y la identificación de problemas de investigación en Didáctica de las Matemáticas. PNA, 5(2), pp. 49-65. 
GÓMEZ, P. (2002). Análisis didáctico y diseño curricular en matemáticas. Revista EMA, 7(3), pp. 251-193.

GÓMEZ, P. (2004). Análisis didáctico y uso de tecnología en el aula de matemáticas. En Peñas, M; Moreno, A.; Lupiáñez, J.L. (Eds.) Investigación en el aula de matemáticas: tecnologías de la información y la comunicación. SAEM Thales, Granada.

GONZÁLEZ, Ma .T. y SIERRA, M. (2004). Metodología de análisis de libros de texto de matemáticas. Los puntos críticos en la enseñanza secundaria en España durante el siglo XX. Enseñanza de las Ciencias, 22(3), pp. 389-408.

GRATTAN-GUINNESS, I. (1996). Numbers, magnitudes, ratios and proportions in Euclid's Elements: how did he handle them?. Historia Math., 23(4), pp. 355-375.

HADLEY, J. y SINGMASTER, D. (1992). Problems to sharpen the young. An annotated translation of 'Propositiones ad acuendos juvenes' the oldest mathematical problem collection in Latin attributed to Alcuin of York. Math. Gaz. 76, pp. 102-126.

HOWSON, G. (1995). Mathematics textbooks: a comparative study of grade 8 texts. Pacific Educational Press, Vancouver.

ITARD, J. (1961). Les livres arithmétiques d'Euclide. Hermann, París.

KANGSHEN, S.; CROSSLEY, J.N. y LUN, A.W.-C. (1999). The nine chapters on the mathematical art. Oxford University Press, Beijing.

KEMMIS, S y MCTAGGART (1992) Cómo planificar la investigación-acción. Laertes, Barcelona.

KILPATRICK, J, HOYLES, C. y SKOVSMOSE, O. (2005). Meaning in mathematics education. Springer. New York.

LAABID, E. (1990). Arithmétique et algèbre des problêmes d'héritage selon l'Islam. Deux exemples: Traité d'Al-Hububi ( $X^{e}-X I^{e}$ s.) et pratique actuelle au Maroc. Université du Quebec, Montréal.

LAABID, E. (1999). Le partage proportionnel dans la tradition methématique maghrébine. En Commerce et mathématiques du Moyen Age à la Renaissance, autour 
de la Meditérranée. Actes du Colloque international du Centre International d'Histoire des Sciences Occitanes. Editions du C.I.H.S.O., Toulouse.

LABARTHE, M.H. (1999). “Suma de la art de Arismetica” de Francesch Sanct Climent. En Commerce et mathématiques du Moyen Age à la Renaissance, autour de la Meditérranée. Actes du Colloque international du Centre International d'Histoire des Sciences Occitanes. Editions du C.I.H.S.O., Toulouse.

LAM, L.Y. (1994). Jiu zhang suanshu (Nine chapters on the mathematical art): an overview. Arch. Hist. Exact Sci., 47(1), pp. 1-51.

LAMASSÉ, S. (1999). Les exercises de compagnie entre commerce et mathématiques. En Commerce et mathématiques du Moyen Age à la Renaissance, autour de la Meditérranée. Actes du Colloque international du Centre International d'Histoire des Sciences Occitanes. Editions du C.I.H.S.O., Toulouse.

LAMON, S.J. (1993). Ratio and proportion: Connecting content and children's thinking. J. Res. Math. Educ., 24(1), pp. 41-61.

LÓPEZ, J.A. y MORENO, Mª.L. (1997). Resultados de Matemáticas. Tercer Estudio Internacional de Matemáticas y Ciencias (TIMSS). Ministerio de Educación y Ciencia, Madrid.

LUPIÁÑEZ, J.L. y RICO, L. (2008). Análisis didáctico y formación inicial de profesores: competencias y capacidades en el aprendizaje de los escolares. PNA,3(1), pp. 35-48.

MAZ, A. (2000). Tratamiento de los números negativos en textos de matemáticas publicados en España en los siglos XVIII y XIX. Memoria de Tercer Ciclo, Universidad de Granada

MCNIFF, J. (1992). Action Research: principles and practice. Routledge, Canadá.

MEAVILLA, V. (2005). La historia de las matemáticas y la resolución no algebraica de problemas: una propuesta didáctica. En La Historia de la Ciencia como recurso de aula y de Investigación Didáctica. Teruel.

MEUSNIER, N. (2007). Le Problème des partis peut-il être d'origine arabomusulmane?. J. Électron. Hist. Probab. Stat., 3(1). 
MIYAKAWA, T. y WINSLOW, C. (2009). Didactical design for students’ proportional reasoning: an “open approach” lesson and a “fundamental situation”. Educ. Stud. Math., 72, pp. 199-218.

MODESTOU, M., ELIA, I., GAGATSIS, A. y SPANOUDIS, G. (2008). Behind the scenes of pseudo-proportionality. Int. J. Math. Educ. Sci. Technol., 39(3), pp. 313-324.

NABORS, W.K. (2003). From fractions to proportional reasoning: a cognitive schemes of operation approach. J. Math. Beh., 22, pp. 133-179.

NATIONAL COUNCIL OF TEACHERS OF MATHEMATICS (N.C.T.M.) (2002). Making sense of fractions, ratios, and proportions. N.C.T.M. Reston.

NOELTING, G. (1980a). The development of proportional reasoning and the ratio concept. Part I - Differentiation of stages. Educ. Stud. Math., 11, pp. 217-253.

NOELTING, G. (1980b). The development of proportional reasoning and the ratio concept. Part II - Problem-structure at successive stages; problem-solving strategies and the mechanism of adaptative restructuring. Educ. Stud. Math., 11, pp. 331-363.

NORTON, S.J. (2006). The construction of proportional reasoning. En Proceedings of the $29^{\text {th }}$ Conference of the International Group for the Psychology of Mathematics Education, Vol. 4. Melbourne.

PATWARDAN, K.S.; NAIMPALLY, S.A. y SINGH, A.L. (2001) Lilavati of Bhaskaracarya. A treatise of mathematics of vedic tradition. Motilal Banarsidass Publishers. Delhi.

PEPIN, B.E. y HAGGARTY, L. (2001). Mathematics textbooks and their use in english, French and German classrooms: a way to understand. Zentralbl. Didakt. Math., 33(5), pp. 158-175.

PERSON, A.C., BERENSON, S.B. y GREENSPON, P.J. (2004). The role of number in proportional reasoning: a prospective teacher's understanding. En Proceedings of the $28^{\text {th }}$ Conference of the International Group for the Psychology of Mathematics Education, Vol. 4.

PICADO, M. y RICO, L. (2011). Análisis de contenido en textos históricos de matemáticas. PNA, 6(1), pp. 11-27. 
PSYCHARIS, G. y KYNIGOS, C. (2004). Normalising geometrical constructions: a context for the generation of meanings for ratio and proportion. En Proceedings of the $28^{\text {th }}$ Conference of the International Group for the Psychology of Mathematics Education, Vol. 4.

PUIG, L. (1997) Análisis fenomenológico. En Rico, L. (Coord.) La educación matemática en la enseñanza secundaria, pág. 61-94. Ice-Horsori. Barcelona

RAPETTI, M.V. (2003). Razones internas y externas. Suma, 44, pp. 65-70.

RASHED, R. y VAHABZADEH, B. (1999). Al-Khayyam mathématicien. Librairie Scientifique et Technique Albert Blanchard, Paris.

RICO, L. (1998). Errores en el aprendizaje de las matemáticas. En KILPATRICK, J; RICO, L. y GÓMEZ, P. (eds.), Educación Matemática. Errores y dificultades de los estudiantes. Resolución de problemas. Evaluación. Historia. Bogotá: una empresa docente.

RICO, L., MARÍN, A., LUPIÁÑEZ, J.L. y GÓMEZ, P. (2008). Planificación de las matemáticas escolares en Secundaria. El caso de los números naturales. Suma, 58, pp. 723.

ROBINS, G. y SHUTE, C. (1987). The Rhind mathematical papyrus. An ancient Egypcian text. British Museum Publications, London.

ROMERO, I.M. (1995). Introducción del número real en Educación Secundaria. Tesis Doctoral, Universidad de Granada.

ROMMEVAUX, S. (1999). La proportionalité numérique dans le Libre VII del Éléments de Campanus. Rev. Histoire Math. 5(1). pp. 83-126.

ROSEN, F. (1986). The algebra of Mohammed ben Musa. Georg Olms Verlag, Hildesheim-Zürich-New York.

RUSNOCK, P. y THAGARD, P. (1995). Strategies for conceptual change: ratio and proportion in classical Greek mathematics. Stud. Hist. Phil. Sci., 26(1), pp. 107-131.

SCHUBRING, G. (1987). On the methodology of analysing historical textbooks: Lacroix as textbook author. Learn. Math., 7(3), pp. 41-51. 
SIERRA, M., GONZÁLEZ, Mª.T. y LÓPEZ, C. (1999). Evolución histórica del concepto de límite funcional en los libros de texto de Bachillerato y C.O.U.: 1940-1995. Enseñanza de las Ciencias, 17(3), pp. 463-476.

SIERRA, M., GONZÁLEZ, Mª.T. y LÓPEZ, C. (2003). El concepto de continuidad en los manuales españoles del siglo XX. Educación Matemática, 15(1), pp. 21-51.

SIGLER, L.E. (2002). Fibonacci's Liber Abaci. A translation into modern English of Leonardo Pisano’s Book of Calculation. Springer Verlag, New York.

SINGH, P. (2000). Understanding the concepts of proportion and ratio constructed by two grade six students. Educ. Stud. Math., 43, pp. 271-292.

SMITH, D.E. (1953). History of Mathematics, vol. II. Dover Publications, New York.

SMITH, M. y GLASS, G.(1987) Research and evaluation and social sciences. Prentice Hall, New Jersey.

SOLAR, H. y ZAMORANO, A. (2005). Algebrización en la proporcionalidad de magnitudes. Comunicación en el I Congreso Internacional sobre la Teoría antropológica de lo Didáctico.

SOPHIAN, C. (2000). Perceptions of proportionality in young children: matching spatial ratios. Cognition, 75, pp. 145-170.

SOUISSI, M. (1999). Applications des proportions - partages proportionnels problèmes d'arithmétique commerciale - règles de societé méthode de double fausse supposition. En Commerce et mathématiques du Moyen Age à la Renaissance, autour de la Meditérranée. Actes du Colloque international du Centre International d'Histoire des Sciences Occitanes. Editions du C.I.H.S.O., Toulouse.

SPIESSER, M. (1999). Le Compendy de la praticque des nombres, une arithmétique du $\mathrm{XV}^{\mathrm{e}}$ siècle à mi-chemin entre théorie et pratique comerciale. En Commerce et mathématiques du Moyen Age à la Renaissance, autour de la Meditérranée. Actes du Colloque international du Centre International d'Histoire des Sciences Occitanes. Editions du C.I.H.S.O., Toulouse.

STAKE, R. (1994). Case studies. En Denzin, N. y Lincoln, Y. (Eds.): Handbook of Qualitative Research. Sage Publications, California. 
STEINTHORSDOTTIR, O.B. (2006). Proportional reasoning: variable influencing the problems difficulty level and one's use of problem solving strategies. En Proceedings of the $30^{\text {th }}$ Conference of the International Group for the Psychology of Mathematics Education, Vol. 5. Praga.

TAYLOR, S.J. y BOGDAM, R. (1990). Introducción a los métodos cualitativos de investigación. Piados, Buenos Aires.

THORUP, A. (1992). A pre-Euclidean theory of proportions. Arch. Hist. Exact Sci., 45(1), pp. 1-16.

VALVERDE, A.G. y CASTRO, E. (2009). Razonamiento proporcional: un análisis de las actuaciones de maestros en formación. Indivisa, Boletín de Estudios e Investigación, Monografía XII, pp. 121-137.

VAN DOOREN, W., DE BOCK, D., EVERS, M. y VERSCHAFFEL, L. (2006). Pupils' over-use of proportionality on missing-value problems: how numbers may change solutions. En Proceedings of the $30^{\text {th }}$ Conference of the International Group for the Psychology of Mathematics Education, Vol. 5. Praga.

VAN DOOREN, W., DE BOCK, D., HESSELS, A., JANSSENS, D. y VERSCHAFFEL, L. (2004). Remedying secondary school students' illusion of linearity: a teaching experiment aiming at conceptual change. Learn. Inst., 14, pp. 485501.

WILLIAMS, J. (1995). Mathematics and the alloying of coinage 1202-1700: Part I. Annals of Science., 52(3), pp. 213-234.

YOUSCHKEVITCH, A.P. (1976). Les mathématiques arabes (VIII ${ }^{e} X V^{e}$ siècles). Librairie Philosophique J. Vrin, Paris.

\section{LIBROS DE TEXTO Y MANUALES ESCOLARES CONSULTADOS}

\section{Comprendidos entre 1850 y 1900:}

DAlmÁU, J. (1898). Aritmética razonada y nociones de Álgebra. Hernando y Ca. Madrid. 
DOS PROFESORES DEL RAMO (1860). Tratado de Aritmética teórico-práctica con la explicación del Sistema Métrico Decimal para uso de las Escuelas de Primera Enseñanza. Imprenta y Librería de Lucas Polo. Huesca.

MOYA, A. (1897). Elementos de Matemáticas. Librería de Hernando y Cía. Madrid.

RODRÍGUEZ, A. (1893). Elementos de Matemáticas. Imprenta de Leonardo Miñon. Valladolid.

SANJURJO, R. (1884). Elementos de Aritmética y Álgebra. Imprenta y litografía de "La Guirnalda”. Madrid.

SÁNCHEZ, B. (1866). Lecciones de Aritmética. Imprenta de F. Martínez García. Madrid. SÁNCHEZ, M. (1890). Aritmética para niños. Tipografía de Julián Sanz y Navarro. Zaragoza.

\section{Comprendidos entre 1900 y 1950:}

BARATECH, B. (1939). Matemáticas. Cuarto curso de Bachillerato. Librería General. Zaragoza.

BARTRINA, J.M. (1910). Matemática para el segundo año de Bachillerato. Imprenta de Francisco J. Altés y Alabart. Barcelona.

BRUÑO, G.M. (1912). Elementos de Aritmética con algunas nociones de Álgebra.

CORREA, F. (1941). Elementos de Aritmética. Imprenta Heraldo de Aragón. Zaragoza.

CORREA, F. (1914). Nociones de Aritmética. Imprenta del Hospicio Provincial. Zaragoza.

CRUSAT, L. (1941). Tratado de Aritmética y Álgebra. Primera parte. Bosch. Barcelona.

Librería de la $\mathrm{V}^{\mathrm{da}}$ de C. Bouret. Paris.

CUESTA, M. (1910). Aritmética Vulgar. Escuelas Profesionales de Artes y Oficios. Sevilla.

DALMÁU, J. (1930). Enciclopedia Cíclico-Pedagógica. Grado Medio. Dalmáu Carles, Pla Editores. Gerona. 
HURTADO, F. (1932). Rudimentos de Aritmética. Labor. Barcelona.

PARELlADA, A. (1943). Curso práctico de Matemáticas. Tomo I. Dossat. Madrid.

REY PASTOR, J. y PUIG ADAM, P. (1935). Matemáticas $4^{\circ}$ curso. Primera parte. Unión Poligráfica. Madrid.

RUÍZ, A. (1928). Elementos de Aritmética. Establecimiento tipográfico de A. Medina. Toledo.

RUÍZ, A. (1931). Nociones y Ejercicios de Aritmética y Geometría. Imprenta Editorial Gambón. Zaragoza.

SALINAS, I. y BENÍTEZ, M. (1908). Aritmética. Imprenta de Eduardo Arias. Madrid. TUÑÓN DE LARA, M. (1908). Lecciones de Aritmética. Florentino Serrano Impresor. Madrid.

XIBERTA, M. (1928). Elementos de Aritmética. Ministerio de Instrucción Pública y Bellas Artes. Madrid.

\section{Comprendidos entre 1950 y 1970:}

BARATECH B. (1966a). Matemáticas. Primer curso de Bachillerato. Edición del autor. Zaragoza.

BARATECH B. (1966b). Matemáticas. Segundo curso de Bachillerato. Edición del autor. Zaragoza.

BRUÑO (1957a). Matemáticas. Primer curso de Bachillerato. Ediciones Bruño. Valencia.

BRUÑO (1957b). Matemáticas. Segundo curso de Bachillerato. Ediciones Bruño. Valencia.

BRUÑO (1962). Aritmética. Curso medio. Ediciones Bruño. Valencia.

EDELVIVES (1951). Aritmética Segundo Grado. Luis Vives. Zaragoza

ORTEGA, J.J. (1963). Haces de luz. Matemáticas. Curso de Perfeccionamiento. Prima Luce. Barcelona.

RODRÍGUEZ, R. (1965). Cifras. Primer curso de Matemáticas. Teide. Barcelona. 


\section{Comprendidos entre 1970 y 1980:}

GONZÁLEZ, R. y CAPPA, A. (1971) Nosotros y los números. Matemáticas 7. Luis Vives. Zaragoza.

MARTÍNEZ, J. (1979). Cálculo $7^{\circ}$ E.G.B. S.M. Madrid

RICO, L, CORPAS, A., FERNÁNDEZ, A., GONZÁlEZ, J, LÓPEZ, F., MESAS, T., SÁENZ, O. y VALENZUELA, J. (1977). Matemáticas 7. Anaya. Cádiz.

\section{Comprendidos entre 1980 y 1990:}

JANÉ, A., CAPELLA, Ma.T., GUITERAS, J.M. y VALLS, B. (1988). Matemáticas 7. Proyecto Pegaso. Edebé. Barcelona.

MANSILLA, S., BUJANDA, Mª.P. (1984). Pitágoras. Matemáticas $7^{\circ}$ E.G.B. S.M. Madrid

SIGNO (1983). Azimut. Matemáticas $7^{\circ}$ E.G.B. Anaya. Cádiz.

\section{Comprendidos entre 1990 y 2010:}

ALMODÓVAR, J.A., GARCÍA, P., GIL, J. y NORTES, A. (1997). Matemáticas $2^{\circ}$. Santillana. Madrid.

ÁLVAREZ, F., GARRIDO, L.M., RUIZ, A. (1999a). Fractal 1 Matemáticas. Vicens Vives. Barcelona.

ÁlVAREZ, F., GARRIDO, L.M., RUIZ, A. (1999b). Fractal 2 Matemáticas. Vicens Vives. Barcelona.

ÁlVAREZ, Ma.D., MIRANDA, A.Y., PARRA, S., REDONDO, R. y SANTOS T. (2003a). Matemáticas Serie práctica $1^{\circ}$ ESO. Santillana. Madrid.

ÁlVAREZ, Ma.D., MIRANDA, A.Y., PARRA, S., REDONDO, R. y SANTOS T. (2003b). Matemáticas Serie práctica $2^{\circ}$ ESO. Santillana. Madrid.

BECERRA, Ma.V., PANCORBO, L. MARTÍNEZ, R. y RODRÍGUEZ, R. (1997). Matemáticas 2. McGraw-Hill. Madrid.

CÓLERA, J. y GAZTELU, I. (2008a). Matemáticas 1. Toledo: Anaya. 
CÓLERA, J. y GAZTELU, I. (2008b). Matemáticas 2. Toledo: Anaya.

CÓLERA, J. y GAZTELU, I. (2008c). Matemáticas 4. Opción A. Toledo: Anaya.

HAZA, C., MARQUÉS, M. y NORTES, A. (2003). Matemáticas $4^{\circ}$ ESO Opción A. Santillana. Madrid.

SIGNO (1994). Azimut. Matemáticas $7^{\circ}$ E.G.B. Anaya. Cádiz.

S.M. (2009a). Esfera. Matemáticas $1^{\circ}$ E.S.O. S.M. Madrid.

S.M. (2009b). Esfera. Matemáticas $2^{\circ}$ E.S.O. S.M. Madrid. 


\section{ANEXO I:}

\section{DIARIO DE CLASE.}

En este anexo se muestra el diario de clase correspondiente a la fase de observación descrita en el Capítulo VI de la presente memoria. Cada una de las 10 sesiones de clase (la undécima se dedicó a la realización de la prueba final) se organiza atendiendo a los siguientes aspectos:

1. Plan previsto.

2. Ejecución.

3. Aspectos actitudinales y asistencia de los alumnos.

4. Aspectos relacionados con la comprensión.

5. Valoración.

6. Toma de decisiones.

Al final del anexo, una vez terminada la descripción de las 10 sesiones de trabajo, se incluyen algunas observaciones generales sobre el desarrollo de las clases y que se agrupan también según los aspectos anteriores.

\section{Día 9 de marzo de 2010 (Primera sesión)}

\section{Plan previsto:}

Se pretende realizar la Actividad de aula 1 (Introducción del concepto de razón). Los principales objetivos perseguidos en esta actividad son:

1. Hacer ver al alumno las ventajas del razonamiento multiplicativo en situaciones de intercambio

2. Presentar la idea de razón entre magnitudes de distinta naturaleza como "tanto por uno".

\section{Ejecución:}

En principio se había decidido ir entregando cada uno de los 6 sobres a cada pareja secuencialmente; es decir, cuando una pareja hubiera resuelto la tarea propuesta en un sobre, se le entregaba el siguiente. En uno de los grupos de clase (el grupo D) esta dinámica de trabajo no resultó satisfactoria puesto que los 
alumnos trabajaron a un ritmo muy bajo (sólo 4 parejas completaron los 6 sobres); sin embargo se decidió mantener dicha dinámica con el otro grupo (grupo E), lo que resultó un acierto pues el ritmo de trabajo fue mejor.

En cuanto al tiempo previsto, en el grupo D fue escaso y apenas dio tiempo a llevar a cabo la puesta en común. Mientras tanto, en el grupo E el tiempo fue suficiente y se pudo realizar el trabajo en gran grupo de una forma más sosegada. En este sentido podría decirse que los objetivos previstos se consiguieron de forma más clara en el grupo E, sobre todo en lo referente a la introducción de la idea de razón.

Respecto al uso de materiales, se proporcionaron a los alumnos una serie de tarjetas de cartulina y de pajitas con el ánimo de que los alumnos pudieran utilizarlas en apoyo de sus razonamientos. Desafortunadamente tan sólo unas pocas parejas del grupo E los utilizan, seguramente por la falta de costumbre en el uso de materiales manipulativos en el aula.

Al final de la clase se reparte la Tarea de casa 1 (Intercambio en la otra dirección) para que cada alumno la complete individualmente.

\section{Aspectos actitudinales:}

Los alumnos de ambos grupos mostraron una buena disposición al trabajo, sobre todo al indicarles que trabajaría por parejas durante las siguientes sesiones de clase.

Asistencia de los alumnos:

Un alumno del grupo D falta a clase (A8).

\section{Aspectos relacionados con la comprensión:}

Inicialmente los alumnos, sobre todo en el grupo D, no acaban de comprender totalmente en qué consiste la tarea que han de realizar. Tras una breve intervención del profesor, queda claro.

En los primeros sobres la mayoría de los alumnos se inclinan, como se esperaba, por las estrategias multiplicativas. Se observa que los alumnos son reacios a buscar estrategias diferentes cuando han encontrado una que les ha funcionado en los casos iniciales. En consecuencia los alumnos que se inclinan desde el principio por estrategias “de reducción a la unidad” lleven a cabo la tarea con una mayor rapidez y facilidad que los que se inclinan por otro tipo de estrategias (particularmente complicados resultan los argumentos dados por las parejas que utilizan estrategias aditivas.

Durante la puesta en común la mayor parte de los alumnos parece comprender relativamente bien la idea de "tanto por uno", el nombre de "razón” les supone a algunos ciertos problemas por cuanto lo identifican con su significado de motivo o causa.

\section{Valoración:}

Los alumnos comprenden bien la dinámica de una situación de intercambio y, cuando se les presenta, aceptan la idea de "tanto por uno" como natural y fácil de entender y calcular. Sin embargo aquellos 
alumnos que han resuelto satisfactoriamente la tarea mediante otras técnicas no aprecian su utilidad y se muestran reacios a utilizarla.

El uso del material manipulativo por parte de los alumnos es testimonial, quizás deba eliminarse o, preferiblemente, buscar otros materiales o situaciones que resulten menos abstractos.

Toma de decisiones:

Debido a la falta de tiempo se decide comenzar la siguiente sesión haciendo una intervención recordando la puesta en común y la idea de razón recalcando la idea de “tanto por uno”. Para ello se utilizará la Tarea de casa 1 que se da a los alumnos para que completen en casa individualmente.

\section{Día 10 de marzo de 2010 (Segunda sesión)}

\section{Plan previsto:}

Se pretende poner en común la Tarea de casa 1 (Intercambio en la otra dirección) así como llevar a cabo la Actividad de aula 2 (La condición de regularidad). Con ello se perseguían los siguientes objetivos principales:

1. Reforzar el concepto de razón entre magnitudes de distinta naturaleza.

2. Enfatizar el hecho de que la razón no es sólo un número.

3. Introducir la necesidad de una “condición de regularidad” para poder hablar de razón entre magnitudes de distinta naturaleza.

\section{Ejecución:}

La puesta en común del trabajo realizado por los alumnos se lleva a cabo sin problemas, se completa la tabla entre todos y poniendo en común diversas estrategias haciendo énfasis, eso sí, en el uso del "tanto por uno”. Al final se muestra la relación entre la razón obtenida en la Actividad de clase el día anterior y la obtenida en casa.

Al desarrollo de la Actividad 2 se le pudo dedicar menos tiempo del previsto. Nuevamente hay cierta diferencia en cuanto a ritmo de trabajo entre los dos grupos de clase (a favor del grupo E). El hecho de que la Actividad 2 conlleve una gran dosis de incertidumbre a la hora de ser realizada es un problema para los alumnos, que están muy acostumbrados a saber exactamente qué se espera de ellos.

\section{Aspectos actitudinales:}

Los alumnos de ambos grupos mostraron una buena disposición al trabajo. El hecho de trabajar en parejas parece inclinar a los alumnos hacia un cierto alboroto que, en todo caso, es fácil de controlar.

$\underline{\text { Asistencia de los alumnos: }}$

No hay ausencias en ninguno de los dos grupos.

Aspectos relacionados con la comprensión: 
Tras la puesta en común de la Tarea 1 y la recapitulación de la actividad del día anterior los alumnos parecen comprender bien la idea de razón como "tanto por uno". Sin embargo, el orden que juegan las magnitudes en la expresión "razón entre pajitas y tarjetas" les resulta un poco más confuso. Saben calcular las pajitas correspondientes a 1 tarjeta y efectúan la división en el orden adecuado, pero les resulta difícil saber si ese cálculo concreto corresponde con la razón entre tarjetas y pajitas o (como es el caso) con la razón entre pajitas y tarjetas.

Algunos alumnos (A5 en el grupo D y A35 y A43 del grupo E) han hecho mención a la Regla de tres al poner en común la tarea. Al preguntarles que de dónde habían sacado esa idea A5 responde que lo ha leído en el libro de texto, A35 que le han ayudado sus padres y A43 que la había estudiado en $6^{\circ}$ de Primaria.

La introducción de la necesidad y del sentido de la condición de regularidad ha resultado algo confusa para los alumnos. Algunos buscan una posible relación entre los tamaños de los dos tipos de objetos (grandes y pequeños) buscando una unidad de medida común, otros relacionan de manera natural las tarjetas grandes con las pajitas grandes (y las pequeñas con las pequeñas). En ambos casos parece que los alumnos asumen tácitamente la necesidad de que exista una única magnitud para poder trabajar con el intercambio, pero no parece que sean del todo conscientes de este hecho y, menos aún, son capaces de verbalizarlo.

\section{Valoración:}

Que en un punto tan temprano de la propuesta aparezca ya la influencia externa de la Regla de tres resulta bastante preocupante. Sin embargo es una variable imposible de controlar.

El desarrollo de la Actividad 2 ha sido confuso en general. Esto se ha debido a que los alumnos no han llegado a comprender el objetivo de la actividad, sobre todo, porque al poner en común el trabajo parecen aceptar como obvio lo que se les estaba diciendo: que para hablar de razón entre magnitudes en un intercambio es necesario que exista una condición de regularidad, que los objetos intercambiados sea (o se consideren) iguales.

Respecto al uso de materiales, vuelve a ser escaso.

Toma de decisiones:

Puesto que no está previsto que hoy los alumnos realicen ninguna tarea individual en casa y con el fin de aclarar todavía más las ideas presentadas en las dos primeras sesiones de trabajo, se decide comenzar la siguiente sesión recapitulando nuevamente la idea de razón en todas sus vertientes: significado, cálculo, condición de regularidad,...

\section{Día 11 de marzo de 2010 (Tercera sesión)}

Plan previsto:

Tras una recapitulación de todos los aspectos tratados los días anteriores sobre el concepto de razón se 
pretende llevar a cabo la Actividad de aula 3 (Comparar razones). Con esta actividad se pretende, además de reforzar el concepto de razón, que los alumnos:

1. Calculen razones.

2. Utilicen las razones como herramienta en la comparación de situaciones.

\section{Ejecución:}

Se inicia esta sesión de trabajo poniendo en claro todo lo trabajado hasta la fecha. Se utilizan dos ejemplos de repartos: repartir caramelos entre los alumnos de la clase y repartir pasteles entre los alumnos. Estos ejemplos les resultan más cercanos que las situaciones utilizadas en las sesiones anteriores.

Con el tiempo algo ajustado, se pasa a desarrollar la Actividad 3, que discurre sin mayores problemas, aunque de forma poco satisfactoria. En primer lugar, surgen discrepancias respecto a qué significa “cambiar pajitas por tarjetas”. Se discute sobre si eso significa que tienes pajitas y quieres obtener tarjetas a cambio o viceversa. Por otro lado, prácticamente la totalidad de los alumnos (sólo una pareja del grupo D es la excepción) piensa que la situación más ventajosa es aquella en la que los cálculos a efectuar son más sencillos y no aquella en la que nos dan más a cambio de lo mismo.

En la puesta en común se plantea a los alumnos si la respuesta sería la misma si en vez de tarjetas de cartulina fueran billetes de $50 €$ y entonces todo se aclara.

Al finalizar la clase se reparte la Tarea de casa 2 (Reconocimiento de condiciones de regularidad y razones) para que los alumnos la completen individualmente.

\section{$\underline{\text { Aspectos actitudinales: }}$}

Los alumnos de ambos grupos mostraron una buena disposición al trabajo, tan sólo A9 (del grupo D) ocasiona algunos pequeños problemas pues no tienes mucho interés por trabajar. Algunos alumnos preguntan si va a haber examen, cómo va a ser y cómo lo van a estudiar. Se sorprenden cuando descubren que sí habrá examen y sienten alivio cuando se les dice que tendrán un cuadernillo para estudiar.

Asistencia de los alumnos:

Un alumno del grupo E falta a clase (A35).

Aspectos relacionados con la comprensión:

Tras la recapitulación inicial parece que las ideas relacionadas con el concepto de razón quedan claras, pero los alumnos muestran dificultades a la hora de distinguir qué es la razón frente a cómo se calcula. Están muy pegados a los números y si no se les presenta la situación con datos numéricos muestran cierta extrañeza.

Respecto al uso de la razón como herramienta para comparar situaciones, hubo que esperar a la puesta en común para que los alumnos comprendieran realmente ese aspecto; pero pensamos que la idea quedó clara. 


\section{Valoración:}

En cuanto a la consecución de los objetivos prefijados, la Actividad 3 puede calificarse de prácticamente fallida. Los alumnos no calcularon la razón adecuada en cada una de las cuatro situaciones y, mucho menos, la usaron para comparar nada.

\section{Toma de decisiones:}

Se debe analizar el modo en que está planteada la Actividad 3. En primer lugar se debe comprobar si los enunciados son lo suficientemente claros y en segundo lugar ha de valorarse si merece la pena buscar un contexto más cercano al alumno.

Se decide esperar a observar los resultados que se obtengan en la Tarea de casa 3 (ver sesión 5) antes de decidir si volver sobre la comparación de razones nuevamente.

\section{Día 12 de marzo de 2010 (Cuarta sesión)}

\section{Plan previsto:}

Se pretende iniciar la clase poniendo en común el trabajo realizado por los alumnos individualmente al resolver la Tarea de casa 2 (Reconocimiento de condiciones de regularidad y razones).

A partir de la puesta en común se quiere definir el concepto de magnitudes directamente proporcionales como "aquellas en las que puede definirse la razón entre ellas", para pasar a completar la Actividad de aula 4 (Reconocer magnitudes directamente proporcionales) con los siguientes objetivos:

1. Reconocer magnitudes directamente proporcionales y magnitudes que no lo son

2. Reforzar la idea de condición de regularidad y recordar el significado de razón como "tanto por uno”.

\section{Ejecución:}

Se comienza la clase comentando en gran grupo las respuestas de los alumnos a las situaciones 2, 4, 8 y 9 de la Tarea 2:

Situación 2: En 4 horas limpió 37 cristales.

Situación 4: En la planta 5 hay ingresados 28 enfermos.

Situación 8: Para preparar naranjada se mezclan 3 litros de zumo de naranja con 5 litros de agua.

Situación 9: El 10 de junio cumplí 16 años.

En general no hay problemas, se definen y calculan bien las razones y (aunque con un poco más de problemas) las condiciones de regularidad. En la Situación 2 un alumno habla de "trabajar al mismo ritmo".

Tras la puesta en común se definen magnitudes directamente proporcionales y se pasa a realizar la 
Actividad 4. Muy pocos la terminan completamente y reina una cierta confusión respecto a cuál es el objetivo de la actividad.

Se concluye comentando en común el Ejercicio 1 de la actividad:

Ejercicio 1:

Velocidad en kilómetros por hora

Distancia, en kilómetros, recorrida por el móvil

Edad, en años, del conductor Tiempo, en horas, empleado en el recorrido

El número de la matrícula del coche El número de pasajeros

Y repartiendo la Tarea de casa 3 (Comparación de razones en situaciones cualesquiera) para que cada alumno la complete individualmente.

Aspectos actitudinales:

Los alumnos de ambos grupos mostraron en general una buena actitud y disposición al trabajo. En el grupo D la sesión se desarrollo en la última hora de clase de la semana, con el consecuente alboroto por terminar la semana. Hubo un pequeño incidente con el alumno A26 (afectado de Síndrome de Asperger) que fue solucionado sin problemas con la ayuda del mejor amigo de dicho alumno.

$\underline{\text { Asistencia de los alumnos: }}$

No hay ausencias en ninguno de los dos grupos.

Aspectos relacionados con la comprensión:

Tras la puesta en común de la Tarea 2 parece que las ideas relativas al concepto de razón están aceptablemente claras.

En cuanto a la Actividad 4, los alumnos muestran pocas dificultades a la hora de encontrar parejas de magnitudes que no están relacionadas. Sin embargo este hecho lleva a la confusión entre magnitudes directamente proporcionales y magnitudes que están relacionadas entre sí.

Aparecen problemas al manejar la pareja de magnitudes velocidad y tiempo. No tienen una comprensión clara de qué significado tienen dichas magnitudes y se llega a indicar que la razón entre velocidad y tiempo es la velocidad que lleva el coche en cada unidad de tiempo.

\section{Valoración:}

En líneas generales esta sesión transcurrió satisfactoriamente, aunque se arrastraron los problemas de tiempo habituales y la también habitual dificultad de ciertos alumnos a la hora de comprender qué se les pide en la actividad.

Toma de decisiones:

Parece poco conveniente la utilización de magnitudes provenientes de la física puesto que los alumnos no poseen una idea clara y precisa sobre su significado.

Ha de valorarse la posibilidad de modificar la Tarea 2 añadiendo más ejemplos de situaciones que involucren magnitudes relacionadas que no sean directamente proporcionales. 


\section{Día 16 de marzo de 2010 (Quinta sesión)}

\section{Plan previsto:}

Se pretende comenzar la clase poniendo en común el trabajo de los alumnos al completar la Tarea de casa 3 (Comparación de razones). En segundo lugar se desarrollará la Actividad de aula 5 (Búsqueda de cantidades desconocidas), con la que se pretende:

1. Reforzar el reconocimiento de magnitudes directamente proporcionales y de magnitudes que no lo son.

2. Recordar el significado de razón como "tanto por uno" y utilizar esta razón para resolver problemas de búsqueda de cantidades desconocidas.

\section{Ejecución:}

Se comienza la clase comentando en gran grupo las respuestas de los alumnos a los ejercicios 2 y 4 de la Tarea 3:

Ejercicio 2: El futbolista $\mathrm{N}$ ha marcado 18 goles en los 22 partidos que ha jugado; mientras que el futbolista $\mathrm{P}$ ha marcado 25 goles en los 38 partidos jugados, ¿qué futbolista ofrece mayor rendimiento goleador?

Ejercicio 4: En segundo curso aprobé 7 asignaturas y en tercer curso aprobé también 7 asignaturas. ¿En qué curso obtuve mejor rendimiento?

Tras la discusión de estos ejercicios, que resultó adecuada, se plantea a los alumnos la Actividad de aula 5 en la que deben utilizar el concepto de razón para resolver problemas de búsqueda de cantidades desconocidas.

Se comentan en gran grupo las respuestas de los alumnos a los ejercicios 1 y 5 :

Ejercicio 1: Para obtener 4200 litros de mosto hacen falta 6300 kilogramos de uva, ¿cuántos kilogramos de uva se necesitan para obtener 3560 litros de mosto?

Ejercicio 5: En una clase de 25 alumnos hay 14 teléfonos móviles, ¿¿cuántos teléfonos móviles habrá en una clase de 18 alumnos?

Algunos alumnos vuelven a recurrir de nuevo a la Regla de tres para resolver estos problemas (uno dice que le ayudó una amiga de su madre que "sabe de ciencias"). En la puesta en común se omite completamente cualquier referencia a esta técnica y se hace énfasis en cuáles son las razones que aparecen, sus significados y las condiciones que se deben cumplir para poder definirlas.

Se concluye la sesión repartiendo a los alumnos la Tarea de casa 4 para que los alumnos la completen individualmente.

\section{Aspectos actitudinales:}

Los alumnos de ambos grupos mostraron en general una buena actitud y disposición al trabajo. El alumno 
A11 pregunta si el trabajo que se hace en clase cuenta para nota.

Asistencia de los alumnos:

Un alumno del grupo D falta a clase (A14).

Aspectos relacionados con la comprensión:

Pese a que la Actividad 3 (en la que introducía la idea de comparar situaciones utilizando el concepto de razón) fue poco exitosa, lo cierto es que los alumnos resuelven la Tarea 3 de forma bastante satisfactoria y no surgen problemas más allá de que algunos alumnos tienen dificultadas (como ya resulta habitual) a la hora de manejar el orden entre las magnitudes.

La mayor parte de los alumnos encuentran natural utilizar la idea de "tanto por uno" para resolver estos problemas. Las mayores dificultades surgen en la identificación de las magnitudes y en decidir si son o no directamente proporcionales. En este sentido, vuelven a ocasionar problemas magnitudes físicas como las implicadas en el ejercicio 4:

Se tarda 9 minutos en aumentar 5 grados la temperatura de un recipiente de 12 litros, ¿qué tiempo se

tardará en aumentar 17 grados la temperatura de dicho recipiente?

Valoración:

El desarrollo de la sesión es especialmente satisfactorio en su primera parte puesto que se esperaban unos resultados mucho peores a la hora de completar la Tarea 3. En la segunda parte vuelven a surgir los problemas de escasez de tiempo al tratarse de sesiones de sólo 50 minutos de duración.

Toma de decisiones:

No se toma decisión alguna que afecte al contenido o al desarrollo de la propuesta.

\section{Día 17 de marzo de 2010 (Sexta sesión)}

\section{Plan previsto:}

Se planea comenzar la sesión recopilando parte del trabajo realizado por los alumnos en la Tarea 4 (Búsqueda de cantidades desconocidas). A partir de uno de los ejercicios puestos en común se introducirá el concepto de porcentaje como “tanto por ciento” y se procederá a completar la Actividad de aula 6 (Porcentajes), con los siguientes objetivos:

1. Presentar el concepto de porcentaje y resolver, utilizando el significado de "tanto por ciento" diversos problemas relacionados con porcentajes

2. Comprender la relación entre razón y porcentaje.

\section{Ejecución:}

Se comienza la clase comentando en gran grupo las respuestas de los alumnos a los ejercicios 2, 3 y 5 de la Tarea 4: 
Ejercicio 2: María tiene 13 años y recibe una propina semanal de 7 euros. ¿Qué propina recibirá a los 17 años?

Ejercicio 3: Un grupo de 3 obreros tarda 2 días en embaldosar una superficie de 200 metros cuadrados. ¿Cuántos días tardarán en embaldosar una superficie de 350 metros cuadrados?

Ejercicio 5: En las rebajas de una tienda una camisa que cuesta 20 euros tiene un descuento de 3 euros. ¿Cuánto descuento tendrá un abrigo que cuesta 100 euros?

A partir de las respuestas dadas en el Ejercicio 5 se introduce la idea de porcentaje como "tanto por ciento” por analogía con el "tanto por uno” de la razón.

Una vez introducida la idea de porcentaje se propone a los alumnos, por parejas, la realización de la Actividad de aula 6. Se dedica a dicha actividad todo el resto del tiempo de clase, sin hacer ninguna puesta en común por escasez de tiempo.

Finalmente se entrega a los alumnos la Tarea de casa 5 (porcentajes) para que la completen individualmente en casa.

Aspectos actitudinales:

Los alumnos de ambos grupos mostraron en general una buena actitud y disposición al trabajo. No obstante, en el grupo D los alumnos participan de un modo menos activo, seguramente por tratarse de la primera hora del día (8:15 a.m.).

Asistencia de los alumnos:

Faltan a clase un alumno del grupo D (A14) y otro del grupo E (A50).

Aspectos relacionados con la comprensión:

Respecto a la búsqueda de cantidades desconocidas en situaciones de proporcionalidad directa no hay comentarios a añadir a los ya hechos anteriormente.

En cuanto al porcentaje, se observa claramente en los alumnos la influencia de la instrucción recibida en el último curso de primaria. Prácticamente todos los alumnos saben calcular un determinado porcentaje de una cantidad, aunque muy pocos (casi ninguno) son capaces de dar cuenta del significado de las operaciones que realizan para calcularlo. En consecuencia surgen problemas casi insalvables cuando se trata de calcular el total a partir de un porcentaje o de relacionar razón y porcentaje.

\section{Valoración:}

El concepto de porcentaje no parece haber calado en los alumnos, que se sienten suficientemente preparados con los algoritmos aprendidos en el curso anterior. Nuevamente se produce la superposición entre 'qué es' el porcentaje y 'cómo se calcula'. Esta suplantación se hace especialmente clara cuando se pregunta a un alumno sobre un ejercicio concreto y responde, siempre, únicamente con un número.

Toma de decisiones: 
Dada la escasez de tiempo para concluir la actividad se decide dedicar la siguiente sesión de forma integra a la puesta en común del trabajo que hayan realizado los alumnos en la Tarea 5.

\section{Día 18 de marzo de 2010 (Séptima sesión)}

\section{Plan previsto:}

Esta sesión se dedicará completamente a recopilar y poner el común las respuestas de los alumnos a los ejercicios de porcentajes de la Tarea 5. Con esto se pretende clarificar el significado del porcentaje y hacer énfasis en dicho significado por encima de los métodos de cálculo.

\section{Ejecución:}

Se van comentando uno a uno los 5 ejercicios de esta tarea (se dedican unos 10 minutos a cada uno de ellos).

Al final de la clase se reparte el folleto con el que los alumnos pueden preparar el examen, así como las fichas de la Tarea de casa 6 para que los alumnos la completen individualmente.

$\underline{\text { Aspectos actitudinales: }}$

Los alumnos de ambos grupos mostraron en general una buena actitud y disposición al trabajo. Sin embargo, las intervenciones “en alto” son escasas.

Los alumnos informan de que al día siguiente tienen una excursión, por lo que no habrá clase.

Asistencia de los alumnos:

Un alumno del grupo D falta a clase (A14).

Aspectos relacionados con la comprensión:

Como ya se apuntó en la sesión anterior, los alumnos encuentran los mayores problemas a la hora de afrontar tareas con una mayor carga conceptual, cuando deben relacionar razón y porcentaje, cuando se les hacen preguntas “abiertas” como en el Ejercicio 3:

Ejercicio 3:

En una tienda de ropa ves el siguiente cartel:

¿Qué opinas?

\section{¡¡Rebajas del $20 \%$ !!} Antes: 170e

Ahora : $145 \varepsilon$

o, en general, cuando la resolución del ejercicio pasa por algo más que la aplicación de un algoritmo. Incluso en este último caso se encuentran alumnos con problemas, puesto que a la hora de calcular el total a partir de un porcentaje conocido, aplican un algoritmo incorrecto.

Valoración:

Resulta extremadamente complicado conseguir que los alumnos se desembaracen de sus conocimientos 
anteriores. Ya se observó este fenómeno en sesiones anteriores cuando los alumnos utilizaban la Regla de tres, sin embargo en este caso resulta aún más difícil puesto que todos los alumnos de ambos grupos habían aprendido a calcular porcentajes.

En consecuencia, los alumnos han resuelto correctamente las tareas más simples (cálculo del porcentaje de una cantidad) pero, en general, han fracasado en aquellas con mayor riqueza conceptual.

\section{Toma de decisiones:}

Puesto que resulta imposible ocupar una sesión más de clase se decide eliminar la Actividad de aula 7 (Reconocer magnitudes inversamente proporcionales) y sustituirla por la Actividad de aula 8 (Búsqueda de cantidades desconocidas en situaciones de proporcionalidad inversa).

\section{Día 23 de marzo de 2010 (Octava sesión)}

\section{Plan previsto:}

Se pretende comenzar la sesión poniendo en común parte del trabajo realizado por los alumnos individualmente al resolver la Tarea 6. Esta puesta en común debe servir de punto de partida para introducir las magnitudes inversamente proporcionales.

Una vez introducido el concepto de magnitudes inversamente proporcionales se pasará a desarrollar la Actividad de aula 8 (Búsqueda de cantidades desconocidas en situaciones de proporcionalidad inversa) con la que se pretende:

1. Reforzar el reconocimiento de magnitudes que no son inversamente proporcionales.

2. Buscar la constante de proporcionalidad en situaciones de proporcionalidad inversa.

3. Utilizar la constante, la razón como "tanto por uno" y el significado de las operaciones para resolver problemas de búsqueda de cantidades desconocidas.

\section{Ejecución:}

Se comienza recopilando las respuestas de los alumnos en las situaciones 1 y 2 de la Tarea 6:

Situación 1: Para pagar el autobús de una excursión de 350 kilómetros cada uno de los 34 pasajeros tiene que pagar 45 euros.

Situación 2: Con los bocadillos que se han preparado, cada uno de los 60 alumnos que van de excursión puede comer 5 bocadillos a lo largo del día.

De estas dos situaciones, la más complicada para los alumnos es la segunda, puesto que en la primera aparecen explícitamente 3 magnitudes y el análisis es más rico.

A continuación se procede a desarrolla, en parejas, la Actividad de aula 8 (Búsqueda de cantidades desconocidas). El ritmo de trabajo es bueno, pero no se hace puesta en común para evitar romperlo. 
Por último, al terminar la clase, se reparte la Tarea de casa 7, como ampliación de lo hecho en clase, para que los alumnos la completen individualmente en casa.

\section{Aspectos actitudinales:}

Los alumnos de ambos grupos mostraron en general una buena actitud y disposición al trabajo. En las puestas en común intervienen los alumnos “de siempre”.

Los alumnos A26 y A14 (éste último ha faltado a 3 sesiones) me preguntan dudas sobre aspectos que no comprenden. El alumno A17 me indica que ha "descubierto" que en las magnitudes directamente proporcionales el aumento de una de ellas implica el aumento de la otra y que en las inversamente proporcionales, el aumento de una provoca la disminución de la otra. Me pregunta si esto es así siempre y le respondo que no, tratando de desincentivar ese tipo de argumento.

\section{Asistencia de los alumnos:}

Faltan a clase dos alumnos del grupo D (A6 y A8).

Aspectos relacionados con la comprensión:

Como era de esperar el concepto de magnitudes inversamente proporcionales causa bastantes problemas a los alumnos. Sobre todo la búsqueda de la constante de proporcionalidad les supone un problema en aquellos casos en los que dicha constante no puede calcularse explícitamente, como en el Ejercicio 1:

Ejercicio 1: Tres pintores tardan 7 días en pintar una fachada. Si hubiesen trabajado 5 pintores, ¿¿uántos días habrían tardado en pintar esa fachada?

Sin embargo en situaciones en las que dicha constante tiene un significado claro y puede calcularse explícitamente, los problemas son menores. Tal es el caso del ejercicio 2, en el que pueden calcularse las pulsaciones totales necesarias:

Ejercicio 2: Una mecanógrafa, que hace 380 pulsaciones por minuto tarda 4 horas en escribir un informe. Si hiciese 450 pulsaciones por minuto, ¿cuánto tiempo tardará en escribir el informe?

\section{Valoración:}

La proporcionalidad inversa es un concepto complejo que requeriría de mucho más tiempo para su comprensión. Haber perdido un día completo de clase no contribuye a que los alumnos lo adquieran con toda su riqueza; sin embargo el desarrollo de la clase y los resultados que se han obtenido son razonablemente buenos.

\section{Toma de decisiones:}

Se decide dedicar íntegramente la décima y última sesión a la resolución de la Tarea 7 y a reforzar y afianzar el concepto de magnitudes inversamente proporcionales. 


\section{Día 24 de marzo de 2010 (Novena sesión)}

\section{Plan previsto:}

En esta novena sesión se pretende poner en común el trabajo realizado por los alumnos individualmente al completar la Tarea 7. El objetivo principal es dejar lo más clara posible la definición de magnitudes inversamente proporcionales, así como los métodos de resolución de problemas de cantidades desconocidas.

\section{Ejecución:}

Los 6 ejercicios de la tarea se fueron tratando uno a uno. Entre ellos había uno en el que las magnitudes implicadas no estaban relacionadas y otro en el que eran directamente proporcionales. Se aprovecharon estos ejemplos para puntualizar las diferencias entre las 3 posibles situaciones estudiadas.

\section{Aspectos actitudinales:}

Los alumnos de ambos grupos mostraron en general una buena actitud y disposición al trabajo. No participan en la puesta en común muchos alumnos, pero los que lo hacen lo hacen bastante bien.

\section{Asistencia de los alumnos:}

Falta a clase un alumno del grupo D (A6).

\section{Aspectos relacionados con la comprensión:}

Las dificultades de comprensión apreciadas en el transcurso de esta sesión son las mismas que en la sesión anterior.

\section{Valoración:}

Se ha tratado de dedicar el mayor tiempo posible a la proporcionalidad inversa, sin embargo nos quedamos con la sensación de que no ha sido suficiente y los alumnos no han llegado a asimilar completamente las ideas implicadas.

\section{Toma de decisiones:}

No se toma decisión alguna que afecte al contenido o al desarrollo de la propuesta.

\section{Día 25 de marzo de 2010 (Décima sesión)}

\section{Plan previsto:}

Esta sesión está dedicada a efectuar la prueba final diseñada a modo de evaluación.

\section{Ejecución:}

Todos los alumnos, excepto A21 del grupo D y A33, A42 y A44 del grupo E, completan el examen en menos de los 50 minutos disponibles. 
Aspectos actitudinales:

No hubo ningún problema durante el desarrollo de la prueba.

Asistencia de los alumnos:

Falta a clase un alumno del grupo E (A39).

Toma de decisiones:

Se decide preparar una prueba final diferente, aunque de idéntica dificultad y con preguntas del mismo tipo para que el alumno A39 lo efectúe a la vuelta de las vacaciones de Semana Santa.

\section{OBSERVACIONES GENERALES:}

Sobre el plan previsto:

- No pudo llevarse a cabo la planificación que se hizo de antemano puesto que, con sólo un día de adelanto, se supo que el viernes 19 de marzo los alumnos tenían programada una excursión. Además, dicho día no pudo recuperarse al existir una frontera temporal insalvable: las vacaciones de Semana Santa.

- El número de sesiones destinado al desarrollo de la propuesta ha resultado, en nuestra opinión, insuficiente. El número inicial de sesiones (11) ya era reducido, pero nos veíamos limitados por el tiempo que se dedicaba a este tema en los restantes grupos de clase y por la Semana Santa.

Sobre la ejecución:

- En general las clases de 50 minutos resultaron bastante cortas, sobre todo teniendo en cuenta que al sonar el timbre los alumnos aún tenían que colocarse en sus asientos para empezar a trabajar. Siempre se comenzaba con retraso, pero siempre se terminaba con puntualidad.

- Además es posible que algunas de las actividades de aula fueran demasiado largas y los ejercicios tuvieran demasiados apartados como para que pudieran completarse en el tiempo destinado a ello.

- Los alumnos no están acostumbrados al trabajo en parejas ni a las puestas en común. Les costó un poco adaptarse - si es que lo hicieron - a una dinámica de trabajo en la que el peso recaía sobre ellos.

$\underline{\text { Sobre aspectos actitudinales y de asistencia: }}$

- Salvo escasas excepciones los alumnos han mostrado una buena disposición para trabajar. Es sorprendente, sin embargo, la excesiva preocupación que muestran (a nuestro juicio) por el 
examen, por saber si lo que hacen "va para nota" y por tener un material escrito a modo de libro de texto.

- Tan sólo un alumno (A16) tuvo un número de ausencias excesivo para poder completar el tema con éxito. Faltó a tres sesiones de clase de un total de 8: más de un tercio.

Sobre aspectos relacionados con la comprensión:

- Los contenidos que se han tratado han sido bastante diferentes desde un punto de vista conceptual. No tiene la misma dificultad la idea de razón que el concepto magnitudes directamente proporcionales, ni este que el de magnitudes inversamente proporcionales. En general, la parte correspondiente a la proporcionalidad directa ha causado menos problemas que la correspondiente a la proporcionalidad inversa.

- Es difícil luchar contra las influencias externas que reciben los alumnos y contra los conocimientos, no siempre adecuados, que poseen de antemano.

- No obstante, teniendo en cuenta el tiempo que se ha podido dedicar (que no es todo el que hubiéramos deseado) y el tratamiento que hemos dado al material (que no ha podido ser consecuente del todo con la propuesta que hicimos en el Capítulo IV) creemos que los alumnos han asimilado aceptablemente bien las ideas y que, sobre todo, se ha mostrado que la propuesta diseñada podría ser viable si se llevara a cabo con todas sus consecuencias.

Toma de decisiones:

De algunas de las observaciones anteriores se desprenden consecuencias que deberían tenerse en cuenta en el futuro:

- Es necesario dedicar más tiempo (en número de sesiones) al desarrollo de la propuesta.

- Las actividades de aula deben de ser más cortas. Es preferible que los alumnos completen y piensen despacio un menor número de ejercicios antes que traten superficialmente un mayor número de ellos.

- Han de elegirse cuidadosamente las situaciones problemáticas que se presentan a los alumnos. A veces tendemos a asumir que los alumnos comprenden el significado de ciertas magnitudes y el modo en que se relacionan, cuando en realidad no es así. Esto sucede de forma especialmente clara con las magnitudes provenientes de la física (velocidad, tiempo, temperatura, etc...).

- Para poder plasmar las ideas de nuestra propuesta de un modo completo sería necesaria una revisión profunda de los currículos de Secundaria, es especial en lo relativo a la secuenciación de los contenidos relativos a la Proporcionalidad. 


\section{ANEXO II:}

\section{MATERIAL PARA LOS ALUMNOS.}

En este anexo se presentan los siguientes materiales:

- El material utilizado con los alumnos durante las sesiones de clase: tanto las fichas de trabajo que debía completar cada pareja, como los carteles informativos que se utilizaron en las actividades de aula números 1,2 y 3.

- Las fichas de trabajo individuales que los alumnos completaban individualmente a modo de tareas para casa.

- La encuesta final que se entregó a los alumnos al concluir el periodo de sesiones de clase.

- El cuadernillo que se elaboró y entregó a los alumnos a modo de texto de apoyo y preparación.

Los materiales correspondientes a los dos puntos anteriores se presentan en orden cronológico, según se fueron utilizando durante las sesiones. 
ACTIVIDAD DE AULA 1

Cartel informativo:

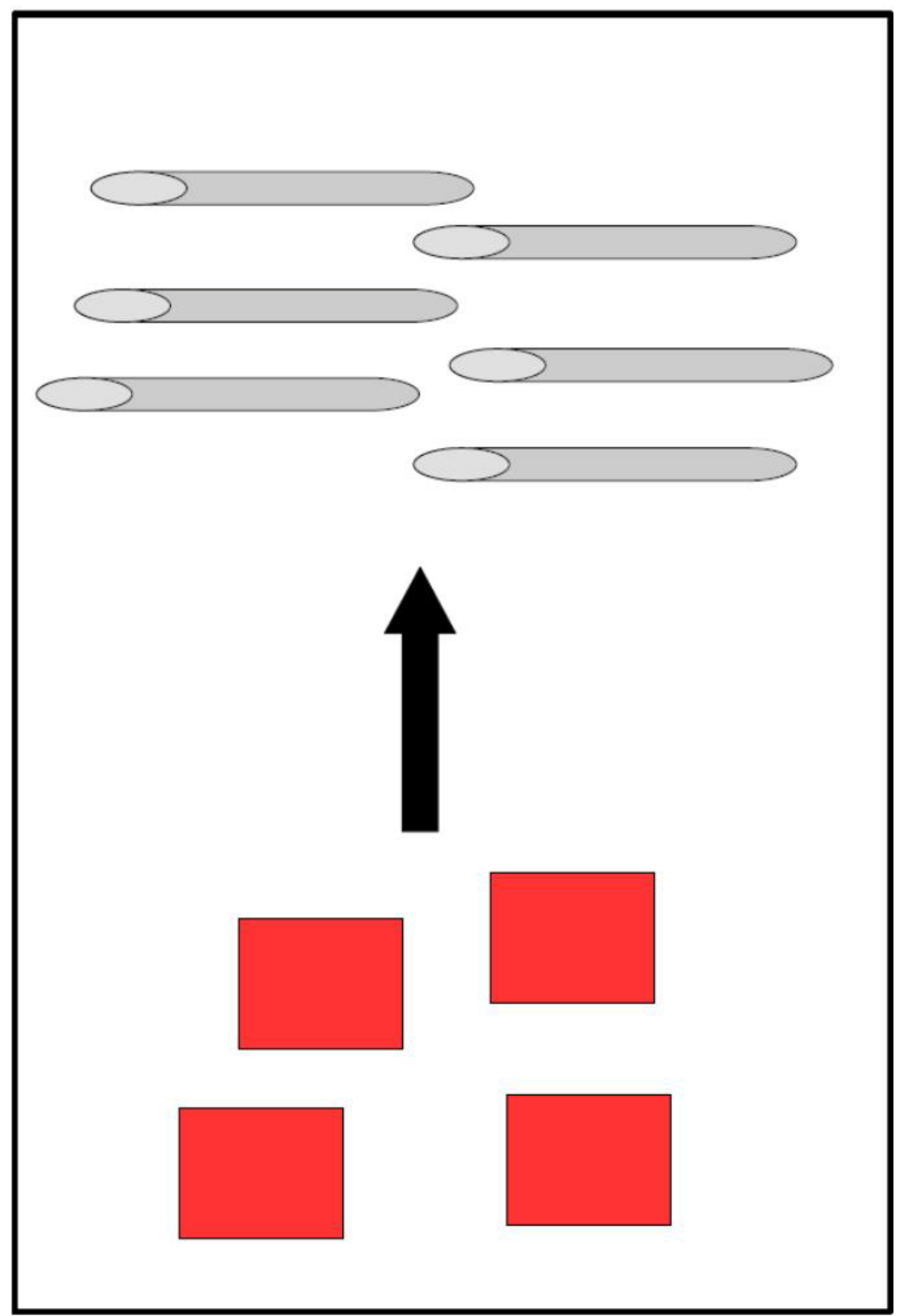


Ficha de trabajo de los alumnos (6 copias):

\section{Nombres:}

Tarjetas que hay en el sobre:

Pajitas entregadas a cambio de las tarjetas:

Razonamiento: 


\section{TAREA DE CASA 1}

Ficha de trabajo del alumno:

\section{Nombre:}

Observa el dibujo. En él se indica que por cada seis pajitas, podemos obtener a cambio cuatro tarjetas. Recuerda que ya has trabajado en clase una situación parecida.

\section{Actividad 1.}

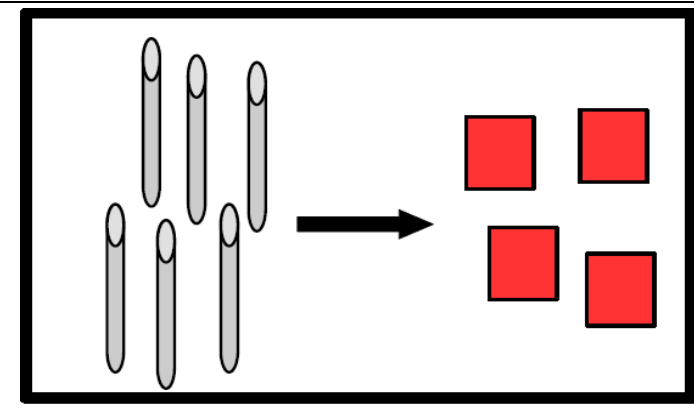

Completa la siguiente tabla, indicando cuántas tarjetas obtendrías a cambio de cada una de las cantidades de pajitas que se indican. Explica bien tu razonamiento en cada caso.

\begin{tabular}{|c|c|l|}
\hline Pajitas & Tarjetas & \\
\hline 6 & 4 & \\
\hline 3 & & \\
\hline 9 & & \\
\hline 1 & & \\
\hline 4 & & \\
\hline 5 & & \\
\hline 7 & & \\
\hline
\end{tabular}

Actividad 2.

¿Cuál es la razón entre tarjetas y pajitas? ¿Qué significado tiene esa razón en esta situación? 
ACTIVIDAD DE AULA 2

Cartel informativo:

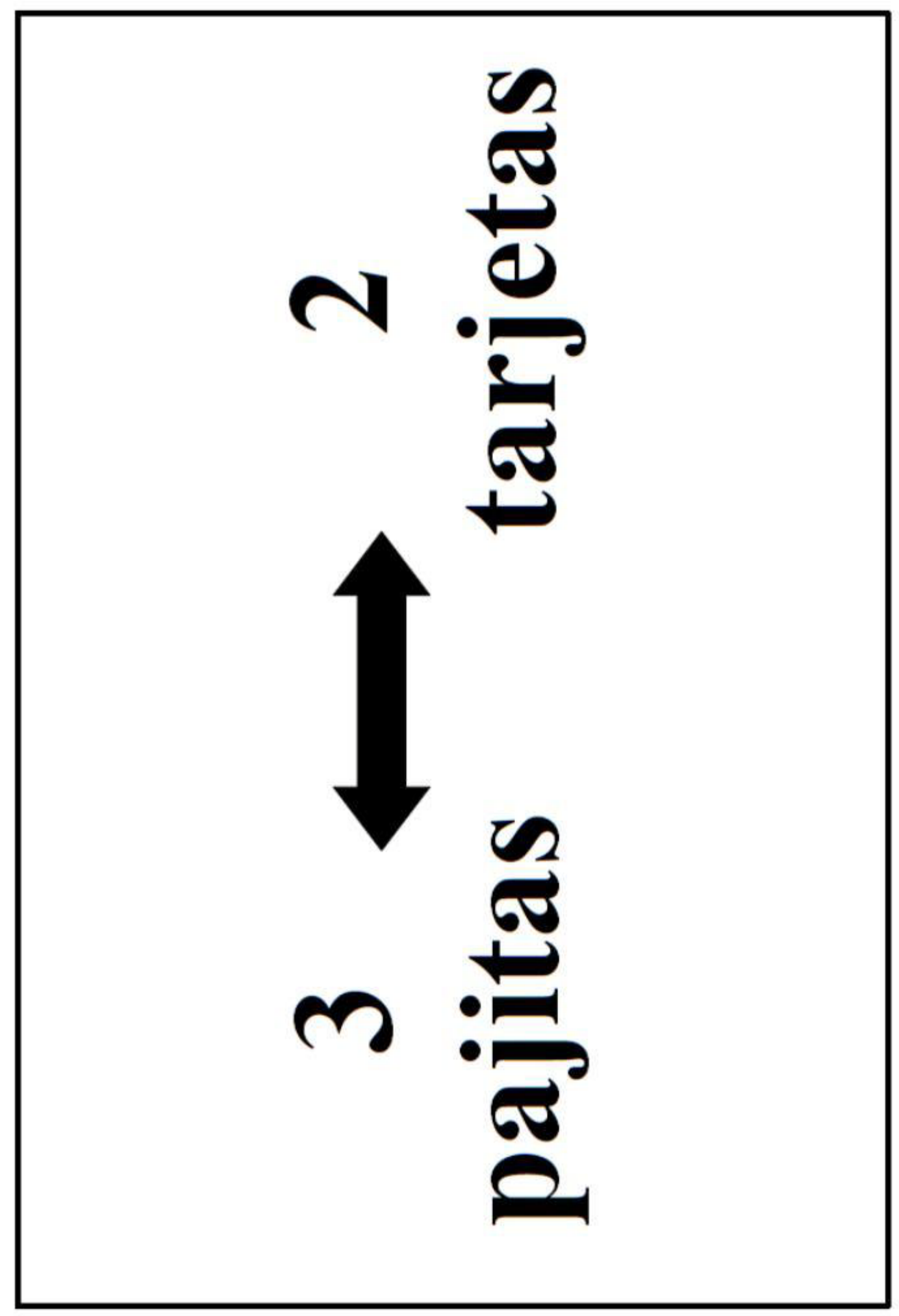


Ficha de trabajo de los alumnos (5 copias):

\section{Nombres:}

Contenido del sobre:

¿Qué se obtiene a cambio del contenido?:

Razonamiento: 
ACTIVIDAD DE AULA 3

Carteles informativos:

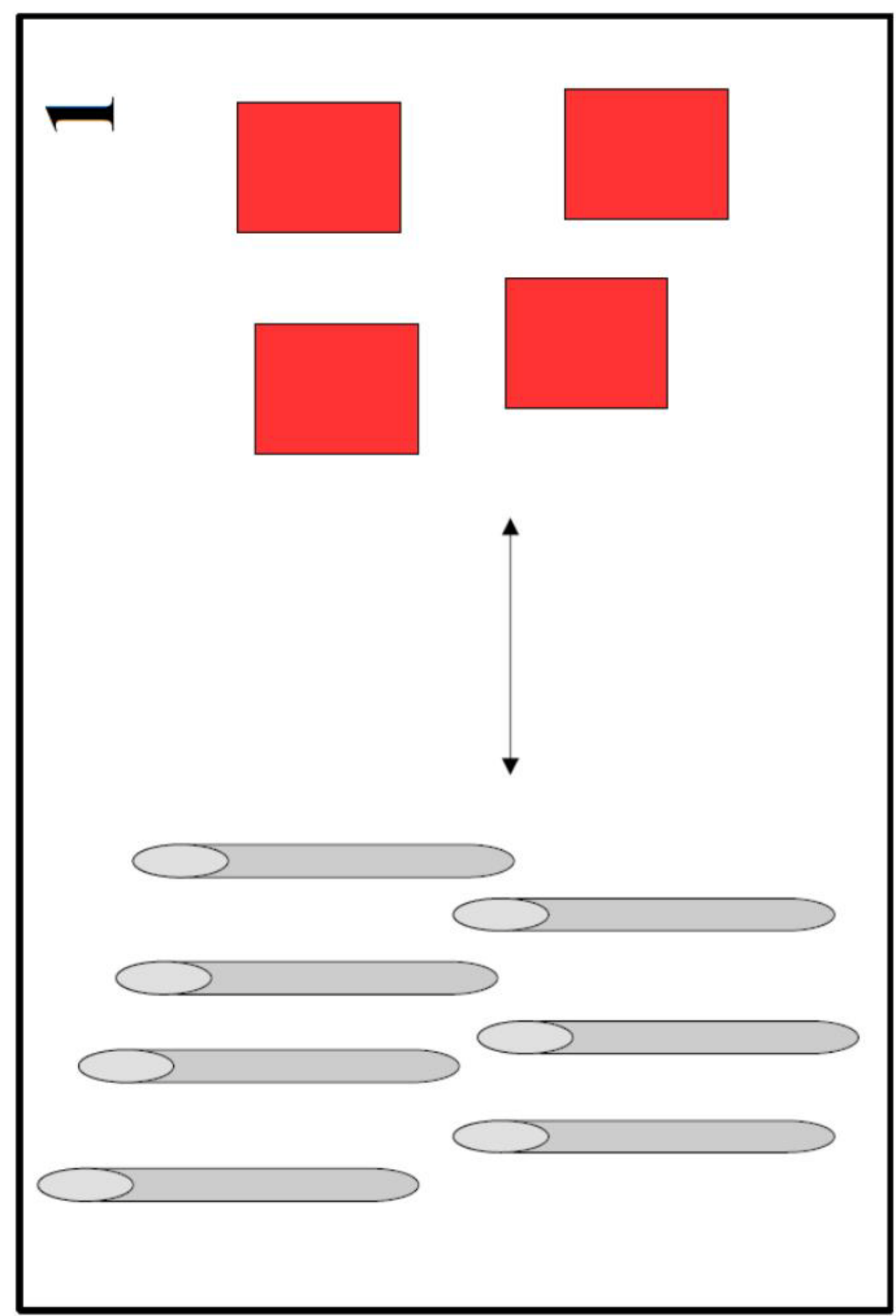




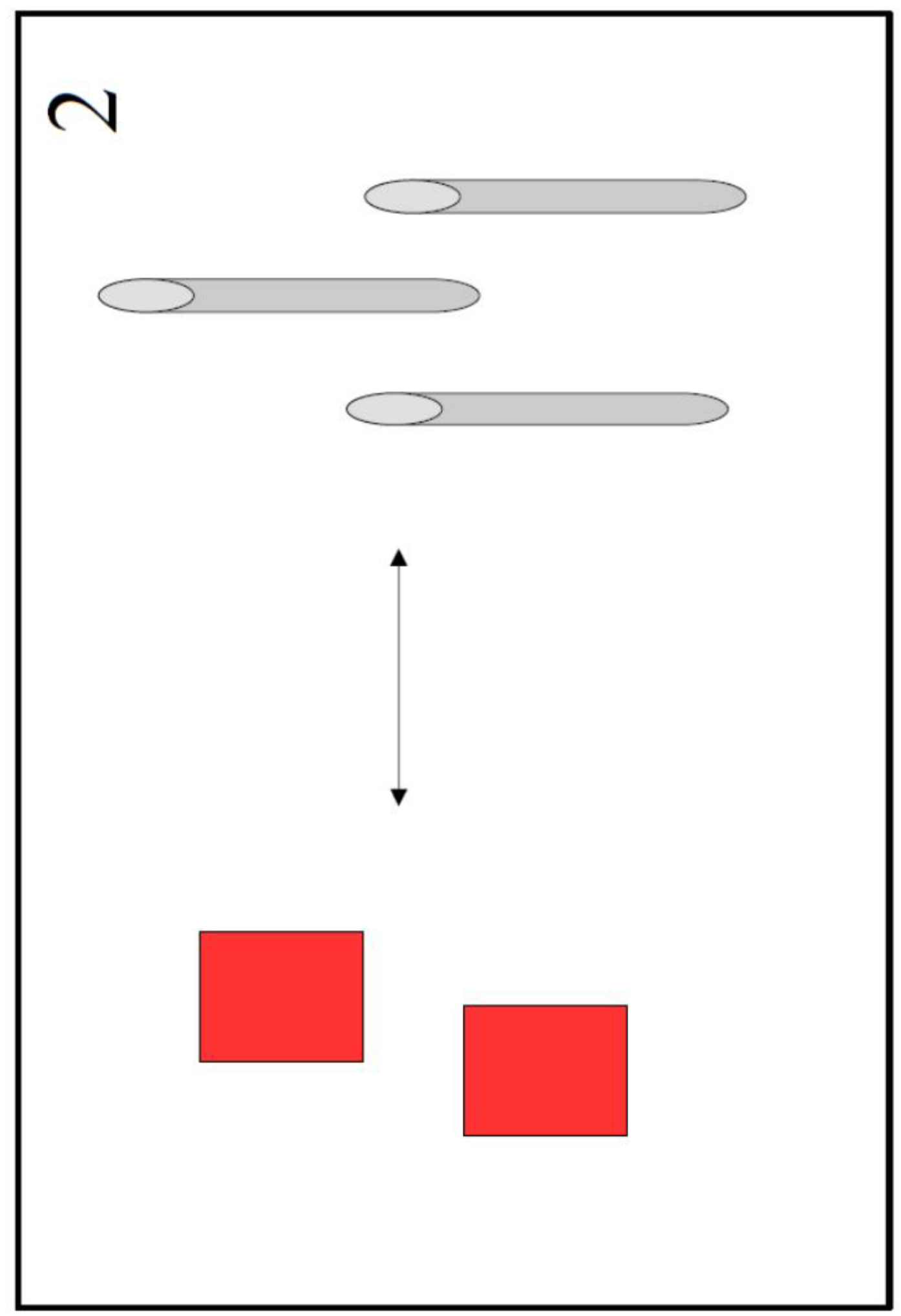




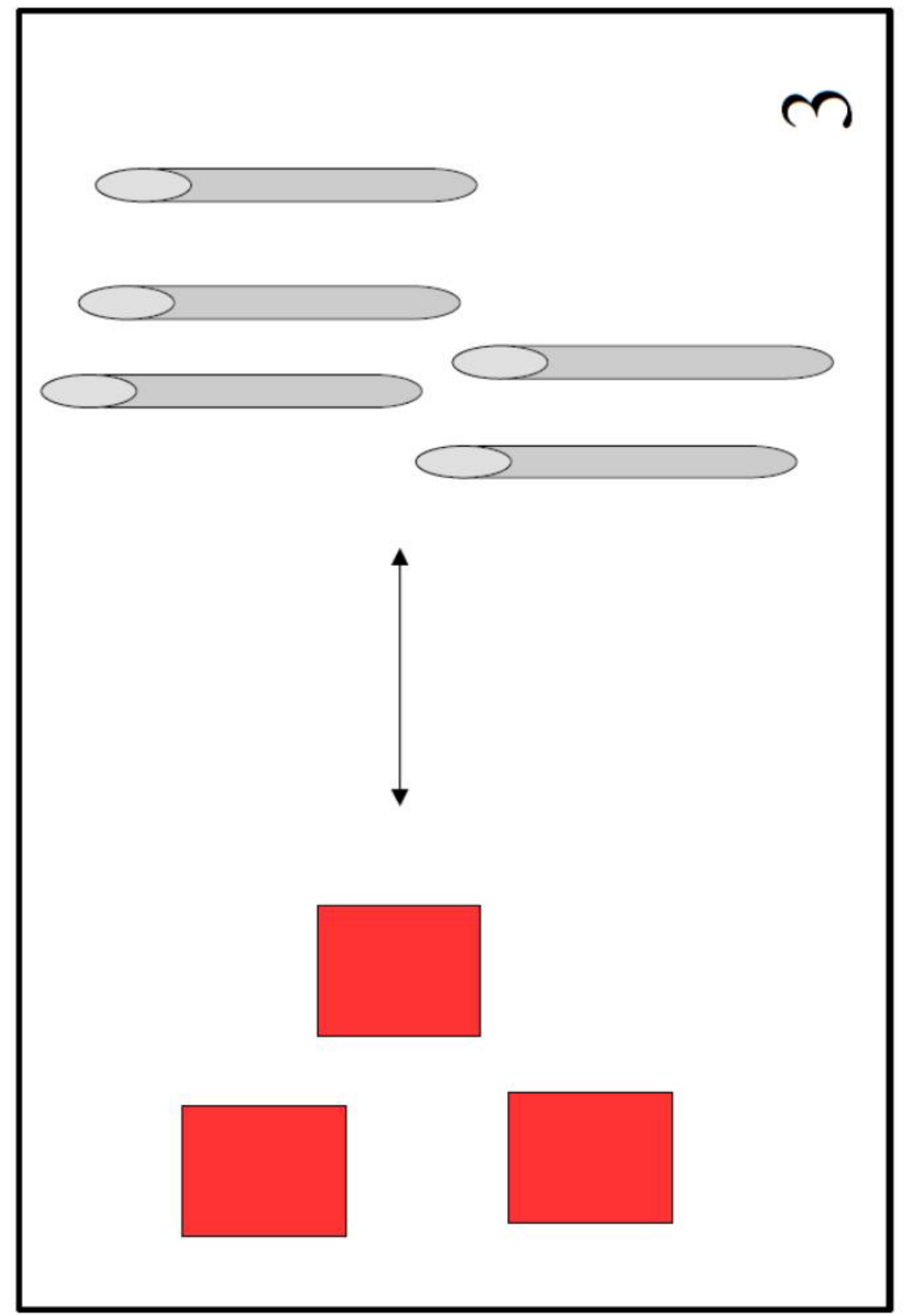




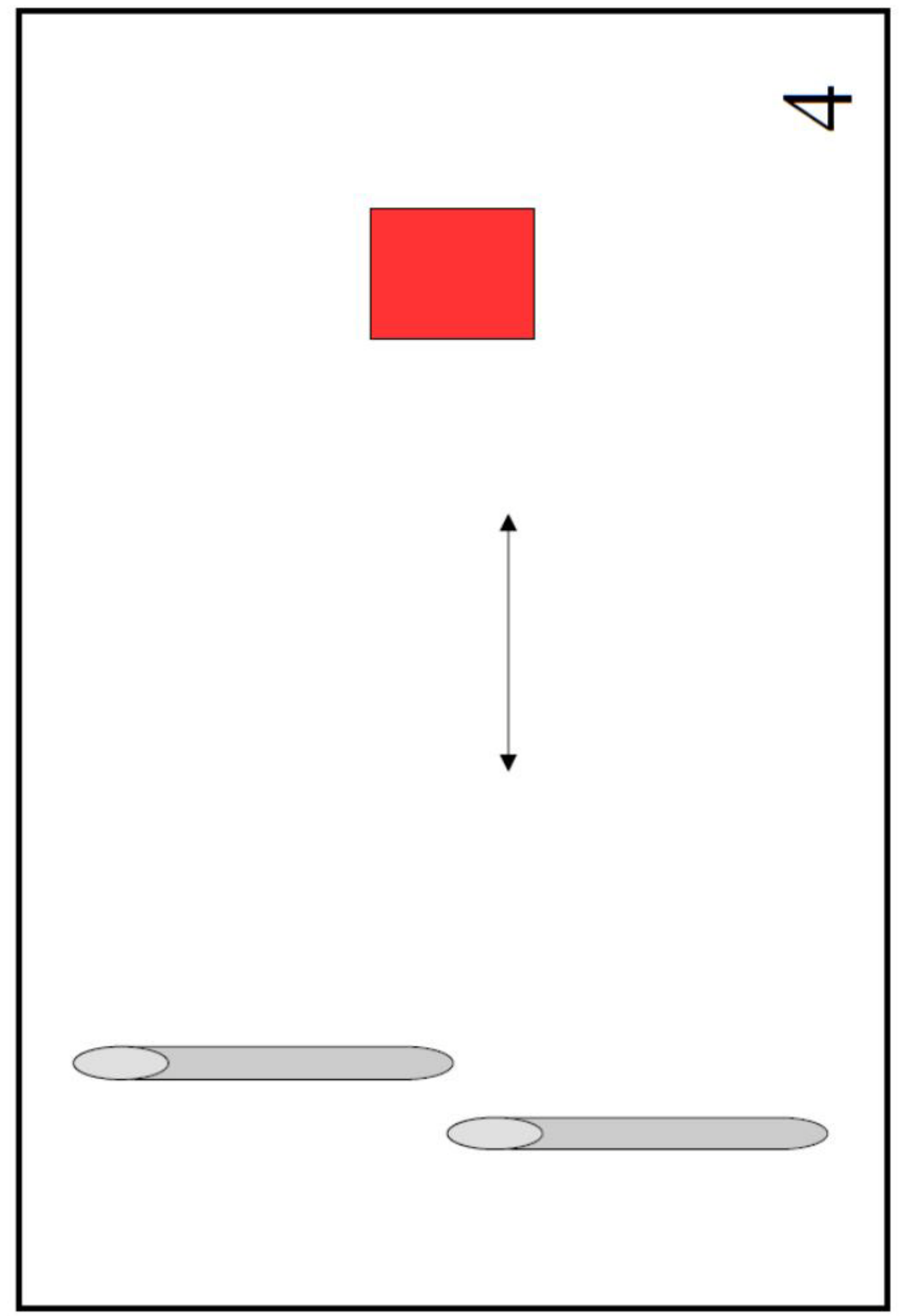


Ficha de trabajo de los alumnos:

Nombre:

A) Si tuvieras que cambiar pajitas por tarjetas, ¿qué cartel te resulta más ventajoso? Razónalo.

B) Si tuvieras que cambiar tarjetas por pajitas, ¿qué cartel te resulta más ventajoso? Razónalo.

¿Has utilizado material? 


\section{TAREA DE CASA 2}

\section{Ficha de trabajo del alumno:}

\section{Nombre:}

En clase hemos visto que para poder definir una razón entre dos magnitudes es necesario que se cumplan ciertas “condiciones de regularidad”. A continuación te presentamos varias situaciones. En cada una de ellas te pedimos que definas todas las razones que aparezcan, que digas lo que significan y que indiques cuáles son las "condiciones de regularidad” necesarias para poder definir dichas razones. Si en alguna de ellas no puedes definir ninguna razón entre las magnitudes que aparecen, indica el por qué.

Situación 1: En una tribu del Amazonas cambian 5 lanzas por 3 escudos.

Situación 2: En 4 horas limpió 37 cristales.

Situación 3: Laura tiene 10 años y tiene una estatura de 120 cm.

Situación 4: En la planta 5 hay ingresados 28 enfermos.

Situación 5: Al comprar 3 camisetas me regalaron 4 discos.

Situación 6: Mis 2 perros tardan 4 días en terminarse 1 saco de comida.

Situación 7: Por 125 dólares me han dado 155 euros

Situación 8: Para preparar naranjada se mezclan 3 litros de zumo de naranja con 5 litros de agua.

Situación 9: El 10 de junio cumplí 16 años.

Situación 10: Leyendo 2 horas al día tardo 7 días en terminar un libro de 426 páginas. 


\section{ACTIVIDAD DE AULA 4}

Ficha de trabajo de los alumnos:

\section{Nombres:}

Recuerda que dos magnitudes son directamente proporcionales cuando podemos definir una razón entre ellas (teniendo en cuenta que se deben cumplir ciertas condiciones de regularidad).

En cada uno de los ejercicios,

a) Busca una pareja de magnitudes que sean directamente proporcionales, señalando la condición de regularidad que deben cumplir. ¿Qué significado tiene la razón entre ellas?

b) Busca una pareja de magnitudes que no sean directamente proporcionales, indicando las razones por las que no lo son.

\section{Ejercicio 1:}

Velocidad en kilómetros por hora

Edad, en años, del conductor

El número de la matrícula del coche

Ejercicio 2:

Número de alumnos en el patio

Edad media de los alumnos

Anchura del patio

\section{Ejercicio 3:}

Número de libros

Precio de cada libro

El tamaño de la letra del texto
Distancia, en kilómetros, recorrida por el móvil

Tiempo, en horas, empleado en el recorrido

El número de pasajeros

Superficie, en metros cuadrados, del patio de recreo

Estatura media de los alumnos

Hora de comienzo de las clases

\section{Número de páginas}

Edad, en años, del comprador

Número de fotografías de cada libro 


\section{TAREA DE CASA 3}

\section{Ficha de trabajo del alumno:}

\section{Nombre:}

En clase hemos visto que en ciertas ocasiones la razón nos sirve para descubrir qué situación es más ventajosa para nosotros cuando tenemos varias opciones entre las que elegir. Con esta idea en la cabeza, trata de resolver los siguientes ejercicios. Pero, !cuidado i Recuerda que no siempre podemos definir la razón entre dos magnitudes.

\section{Ejercicio 1:}

En el banco A cambian 120 dólares por 170 euros, y en el banco B cambian 180 euros por 130 dólares. Si quieres cambiar euros a dólares, ¿̇a qué banco irías?

\section{Ejercicio 2:}

El futbolista $\mathrm{N}$ ha marcado 18 goles en los 22 partidos que ha jugado; mientras que el futbolista $\mathrm{P}$ ha marcado 25 goles en los 38 partidos jugados, ¿qué futbolista ofrece mayor rendimiento goleador?

\section{Ejercicio 3:}

Una receta de naranjada indica que hay que mezclar 0,5 litros de naranja con 1,5 litros de agua; otra receta dice que hay que mezclar 1,5 litros de naranja con 5 litros de agua, ¿cuál de las dos recetas proporciona un sabor de naranja más fuerte?

\section{Ejercicio 4:}

En segundo curso aprobé 7 asignaturas y en tercer curso aprobé también 7 asignaturas. ¿en qué curso obtuve mejor rendimiento?

\section{Ejercicio 5:}

En colegio A hay matriculados 450 alumnos, y en colegio B hay matriculados 320 alumnos. En el colegio A hay 35 profesores, mientras que en colegio B hay 25 profesores. ¿En cuál de los colegios los alumnos obtienen mejores calificaciones?

Ejercicio 6:

En una tienda si compras 3 discos te regalan 4 camisetas y en otra tienda te regalan 5 camisetas al comprar 4 discos, ¿en qué tienda es más rentable comprar?

Ejercicio 7:

Cuatro vacas negras dan tanta leche en cinco días como tres vacas marrones en seis días. ¿Qué clase de vaca es mejor lechera, la negra o la marrón? 


\section{ACTIVIDAD DE AULA 5}

Ficha de trabajo de los alumnos:

\section{Nombres:}

Recordad que dos magnitudes son directamente proporcionales si se puede definir una razón entre ellas. Además la razón entre dos magnitudes es la cantidad de la primera que se corresponde con una unidad de la segunda. Con esta idea, tratad de resolver los siguientes problemas.

\section{Ejercicio 1:}

Para obtener 4200 litros de mosto hacen falta 6300 kilogramos de uva, ¿cuántos kilogramos de uva se necesitan para obtener 3560 litros de mosto?

\section{Ejercicio 2:}

En un libro de 360 páginas hay 15 capítulos, ¿cuántos capítulos tendrá un libro de 288 páginas?

\section{Ejercicio 3:}

En una ciudad de 600000 habitantes se editan 4 periódicos, ¿cuántos periódicos se editarán en una ciudad de 1050000 habitantes

\section{Ejercicio 4:}

Se tardan 9 minutos para aumentar 5 grados la temperatura de un recipiente de 12 litros, ¿qué tiempo se tardará en aumentar 17 grados la temperatura de dicho recipiente?

\section{Ejercicio 5:}

En una clase de 25 alumnos hay 14 teléfonos móviles, ¿cuántos teléfonos móviles habrá en una clase de 18 alumnos? 


\section{TAREA DE CASA 4}

\section{Ficha de trabajo del alumno:}

\section{Nombre:}

En clase hemos comprobado cómo el uso de la razón nos permite resolver problemas en los que dos magnitudes son directamente proporcionales y queremos encontrar la cantidad de una de las magnitudes que se corresponde con una cantidad conocida de la otra. Estos ejercicios van en la misma dirección.

\section{Ejercicio 1:}

3 docenas de huevos cuestan 3,5 euros. ¿Cuánto costarán 25 huevos?

\section{Ejercicio 2:}

María tiene 13 años y recibe una propina semanal de 7 euros. ¿Qué propina recibirá a los 17 años?

\section{Ejercicio 3:}

Un grupo de 3 obreros tarda 2 días en embaldosar una superficie de 200 metros cuadrados. ¿Cuántos días tardarán en embaldosar una superficie de 350 metros cuadrados?

\section{Ejercicio 4:}

Con un saco de comida para perros los 2 perros de Luis pueden comer durante todo un mes, ¿cuánto tiempo les durará esa misma comida a los 3 perros de María?

\section{Ejercicio 5:}

En las rebajas de una tienda una camisa que cuesta 20 euros tiene un descuento de 3 euros. ¿Cuánto descuento tendrá un abrigo que cuesta 100 euros?

\section{Ejercicio 6:}

Para hacer hormigón un albañil junta 2 kilos de cemento con 4 kilos de arena. Si quiere fabricar 12 kilos de hormigón ¿cuántos kilos de cada material debe utilizar? ¿Y si quiere fabricar 100 kilos? 


\section{ACTIVIDAD DE AULA 6}

\section{Ficha de trabajo de los alumnos:}

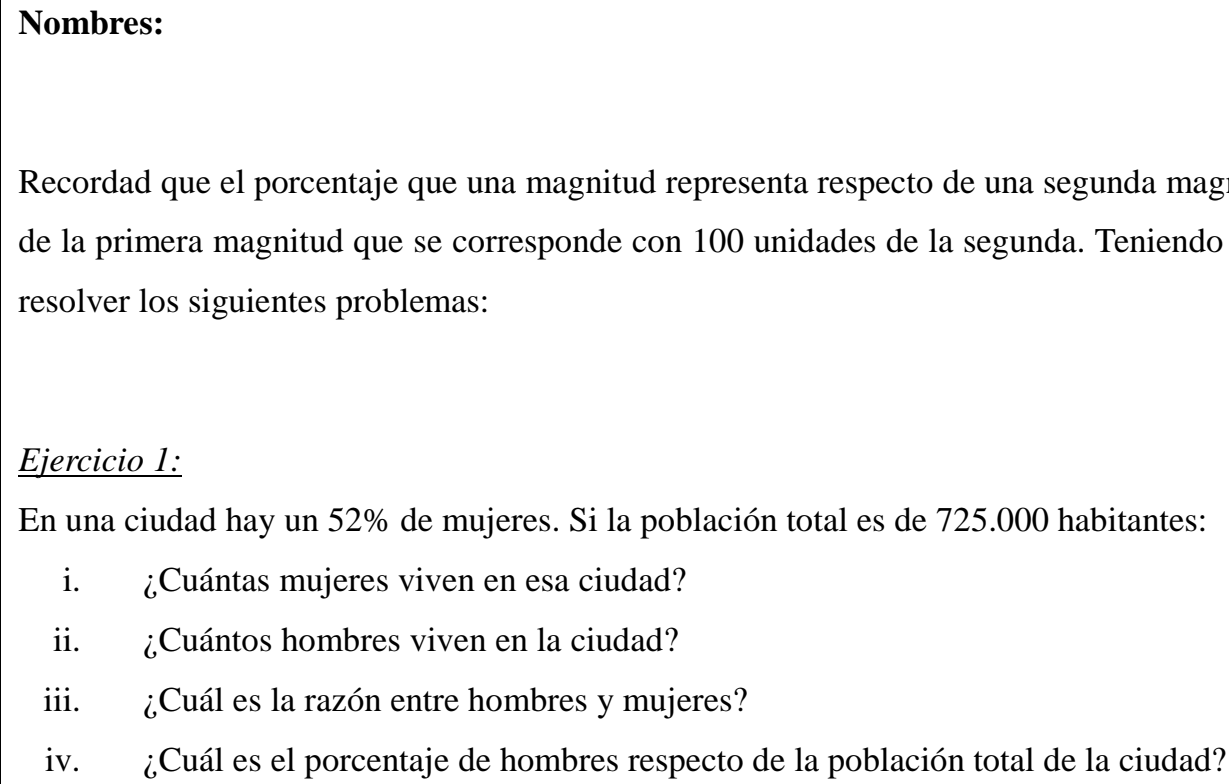

\section{Ejercicio 1:}

En una ciudad hay un 52\% de mujeres. Si la población total es de 725.000 habitantes:

i. ¿Cuántas mujeres viven en esa ciudad?

ii. ¿ ¿Cuántos hombres viven en la ciudad?

iii. ¿ ¿Cuál es la razón entre hombres y mujeres?

iv. ¿Cuál es el porcentaje de hombres respecto de la población total de la ciudad?

\section{Ejercicio 2:}

Se sabe que en un determinado pueblo sólo el 3\% de la gente es pelirroja. Si en ese pueblo hay exactamente 625 pelirrojos:

i. ¿ ¿Cuántas personas viven en ese pueblo?

ii. ¿ ¿Cuántas personas rubias viven allí?

iii. ¿ ¿Cuál es la razón entre el número de pelirrojos y el total de la población?

\section{Ejercicio 3:}

En una tienda de electrodomésticos un televisor LCD de 32 pulgadas cuesta 425 euros. Durante las rebajas el dueño decide hacer un descuento del $20 \%$.

i. ¿ ¿Cuál es el precio del televisor durante las rebajas?

ii. ¿ ¿Qué porcentaje representa el precio rebajado respecto del precio sin rebajar?

iii. Un DVD ha costado durante las rebajas 125 euros, ¿¿cuánto costaba antes de las rebajas?

\section{Ejercicio 4:}

Debido a la subida del precio de la gasolina, los billetes de autobús también van a subir de precio. En concreto la subida va a ser del $4,5 \%$.

i. Si un billete de autobús cuesta 1,10 euros, ¿¿cuánto costará después de la subida?

ii. Si un litro de gasolina ha pasado de costar 0,98 euros a costa 1,1 euros, ¿¿cuál es el porcentaje de subida del precio de la gasolina?

iii. ¿ ¿Es justa la subida del precio en el billete de autobús? 


\section{TAREA DE CASA 5}

\section{Ficha de trabajo del alumno:}

\section{Nombre:}

En clase hemos presentado lo que significa el porcentaje y has resuelto problemas en los que aparecía ese concepto. Recuérdalos y trata de resolver los siguientes.

\section{Ejercicio 1:}

En el Parque del Agua hay una gran variedad de árboles. El 7\% de ellos son olmos y el 11\% fresnos. Sabemos que hay 468 olmos.

i. ¿ ¿Cuántos árboles hay en total?

ii. ¿Cuántos de dichos árboles son fresnos?

iii. ¿ ¿Cuál es la razón entre fresnos y olmos?

iv. ¿Cuántos tilos hay en parque del agua?

\section{Ejercicio 2:}

En un anuncio de un coche nos dicen que el nuevo modelo consume un $15 \%$ menos de gasolina que el modelo antiguo. El modelo antiguo gasta 7 litros de gasolina cada 100 kilómetros.

i. ¿Cuántos litros de gasolina necesita el modelo antiguo para recorrer 175 kilómetros?

ii. Hacemos una prueba con el nuevo modelo y descubrimos que necesita 9 litros para recorrer 150 kilómetros. ¿Es engañosa la publicidad?

\section{Ejercicio 3:}

En una tienda de ropa ves el siguiente cartel:

¿Qué opinas?

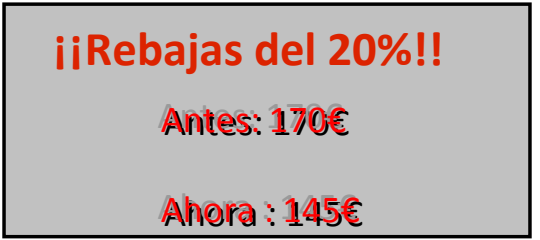

Ejercicio 4:

Para elaborar refresco de naranja se deben mezclar 400 mililitros de zumo de naranja con un litro de agua.

i. ¿Cuál es la razón entre el agua y el zumo?

ii. ¿ ¿Cuál es el porcentaje de zumo de naranja respecto del total de refresco?

iii. ¿Qué harías para elaborar 2 litros de refresco?

\section{Ejercicio 5:}

Ayer, en el Mercado Central, los tomates costaban 1,05 euros el kilo. Hoy, sin embargo, cuestan 1,35 euros el kilo. Ayer las naranjas costaban 0,68 euros el kilo y hoy cuestan 0,90 euros el kilo.

i. ¿ ¿Qué ha subido más de precio, el tomate o las naranjas?

ii. ¿ ¿Que porcentaje supone el precio de los tomates hoy respecto a ayer? 


\section{TAREA DE CASA 6}

\section{Ficha de trabajo del alumno:}

\section{Nombre:}

A continuación te presentamos diversas situaciones. En cada una de ellas debes indicar las magnitudes que varían, si alguna magnitud se mantiene constante y las razones que se puedan definir en cada situación (diciendo las condiciones de regularidad que se deben cumplir). Si entre dos magnitudes no se puede definir la razón indica los motivos.

Situación 1: Para pagar el autobús de una excursión de 350 kilómetros cada uno de los 34 pasajeros tiene que pagar 45 euros.

Situación 2: Con los bocadillos que se han preparado, cada uno de los 60 alumnos que van de excursión puede comer 5 bocadillos a lo largo del día.

Situación 3: En una caja caben 120 pelotas de tenis, tanto si son de color amarillo como si son de color verde.

Situación 4: Abriendo el grifo 8 minutos se llena una bañera de 225 litros.

Situación 5: Estudio 5 horas diarias para preparar los exámenes finales de las 7 asignaturas que hay en $4^{\circ}$ curso.

Situación 6: Los 120 kilogramos de café pesan, después de tostarlos, 96 kilogramos. 


\title{
ACTIVIDAD DE AULA 7
}

Ficha de trabajo de los alumnos:

\begin{abstract}
Nombres:
Recuerda que dos magnitudes son inversamente proporcionales, bajo ciertas condiciones de regularidad, cuando no se puede definir una razón entre ellas pero existe una tercera magnitud que permanece constante de manera que sí que se puede definir la razón entre dicha magnitud constante y cada una de las otras dos magnitudes.

En cada uno de los ejercicios,

i. Busca una pareja de magnitudes que sean inversamente proporcionales, señalando las condiciones de regularidad que se deben cumplir y la constante de proporcionalidad. ¿Qué significado tiene la razón entre la constante de proporcionalidad y cada una de las otras dos magnitudes?

c) Busca una pareja de magnitudes que no sean inversamente proporcionales, indicando las razones por las que no lo son.
\end{abstract}

\section{Ejercicio 1:}

Kilogramos de naranjas

Número de naranjas por kilogramo

Precio de cada naranja

Precio del kilogramo de naranjas

Peso de cada naranja

Diámetro de una naranja

\section{Ejercicio 2:}

Número de grifos

Capacidad de una piscina

Temperatura del agua

Tiempo de apertura de los grifos

Metros de profundidad de la piscina

Número de bañistas

\section{Ejercicio 3:}

Número de libros

Número de páginas

Precio de cada libro

Edad, en años, del comprador

El tamaño de la letra del texto

Número de fotografías de cada libro 


\section{ACTIVIDAD DE AULA 8}

Ficha de trabajo de los alumnos:

\section{Nombres:}

Recordad que dos magnitudes son inversamente proporcionales si no se puede definir una razón entre ellas, pero existe una magnitud constante de forma que sí que se puede definir la razón entre dicha constante y las magnitudes involucradas. Con esta idea, tratad de resolver los siguientes problemas.

\section{Ejercicio 1:}

Tres pintores tardan 7 días en pintar una fachada. Si hubiesen trabajado 5 pintores, ¿cuántos días habrían tardado en pintar esa fachada?

\section{Ejercicio 2:}

Una mecanógrafa, que hace 380 pulsaciones por minuto tarda 4 horas en escribir un informe. Si hiciese 450 pulsaciones por minuto, ¿¿cuánto tiempo tardará en escribir el informe?

\section{Ejercicio 3:}

De los 350 participantes en una maratón han terminado 260 atletas, ¿cuántos hubiesen finalizado la maratón si se presentan 200 atletas?

\section{Ejercicio 4:}

Un ganadero tiene pienso para alimentar a 300 terneros durante tres meses. Si tuviese 200 terneros, ¿durante cuántos días los podría alimentar?

\section{Ejercicio 5:}

Para trasladar la tierra producida al hacer un desmonte se necesitaron 100 camiones cada uno de los cuales transportó 12 metros cúbicos de tierra. ¿Cuántos viajes de camión se hubiese necesitado si la capacidad de los camiones fuese de 15 metros cúbicos? 


\section{TAREA DE CASA 7}

\section{Ficha de trabajo para el alumno:}

\section{Nombre:}

En clase hemos comprobado cómo el uso de la constante de proporcionalidad y de la razón nos permite resolver problemas en los que dos magnitudes son inversamente proporcionales y queremos encontrar la cantidad de una de las magnitudes que se corresponde con una cantidad conocida de la otra. Estos ejercicios van en la misma dirección.

\section{Ejercicio 1:}

Un grifo que vierte 18 litros por minuto emplea 28 horas en llenar un depósito, ¿qué tiempo emplearía si su caudal fuese de 42 litros por minuto?

\section{Ejercicio 2:}

Para atender un pedido de refrescos una fábrica tarda 8 horas utilizando 12 máquinas embotelladoras.

i. $\quad$ Si se estropean 4 máquinas, ¿cuántos tiempo tardará en hacerse el pedido?

ii. $\quad$ Si se quiere hacer el pedido en 3 horas, ¿¿cuántas máquinas harán falta?

\section{Ejercicio 3:}

En un campamento de 15 días de duración la edad media de los campistas es de 13 años, ¿¿cuál es la edad media de los campistas de otro campamento que va a durar 21 días?

\section{Ejercicio 4:}

Pedro paga 36 euros por las llamadas de teléfono realizadas durante un mes de 31 días, ¿cuánto pagará por las llamadas realizadas durante un mes de 28 días?

\section{Ejercicio 5:}

Veinte obreros realizan una obra; al cabo de quince días han hecho la mitad. ¿Cuantos obreros hay que agregar para terminar la obra en cuatro días?

\section{Ejercicio 6:}

Para limpiar los cristales de un edificio 15 personas tardan 6 horas. ¿Cuántas personas hay que añadir para limpiar los cristales en 5 horas? 


\section{ENCUESTA FINAL PARA LOS ALUMNOS}

\section{NOMBRE:}

\begin{tabular}{|l|l|l|l|l|}
\hline & Mucho & Regular & Poco & Nada \\
\hline Las clases me han gustado & & & & \\
\hline La forma de trabajar es aburrida & & & & \\
\hline Lo que hemos dado me parece difícil & & & & \\
\hline Las clases han sido amenas & & & & \\
\hline Lo que hemos estudiado es útil & & & & \\
\hline El examen ha sido difícil & & & & \\
\hline El cuadernillo no hacía falta & & & & \\
\hline Lo que hemos dado no sirve para nada & & & & \\
\hline Tener un cuadernillo me parece necesario & & & & \\
\hline Esta parte me ha parecido fácil & & & & \\
\hline Los deberes eran muy largos & & & & \\
\hline El examen era fácil & & & & \\
\hline Había pocos deberes & & & & \\
\hline No me han gustado las clases & & & & \\
\hline No me gusta que el profesor me pregunte en clase & & & & \\
\hline Tengo ganas de que llegue la clase de matemáticas & & & & \\
\hline Me gusta intervenir en clase & & & & \\
\hline Me gusta la asignatura de matemáticas & & & \\
\hline Tengo miedo de que llegue la hora de matemáticas & & & \\
\hline Las matemáticas no me gustan & & & \\
\hline
\end{tabular}

¿Has recibido ayuda de alguien durante estos días?

Si es que sí, ¿̇de quién? 
CUADERNILLO DE TEORÍA Y EJERCICIOS 